\title{
INHABITING THE MACHINE
}

by George Goodwin

A 120-point thesis submitted to the Victoria University of Wellington in partial

fulfillment of the requirements for the degree of Master of Architecture (Professional)

Victoria University of Wellington, 2015

School of Architecture

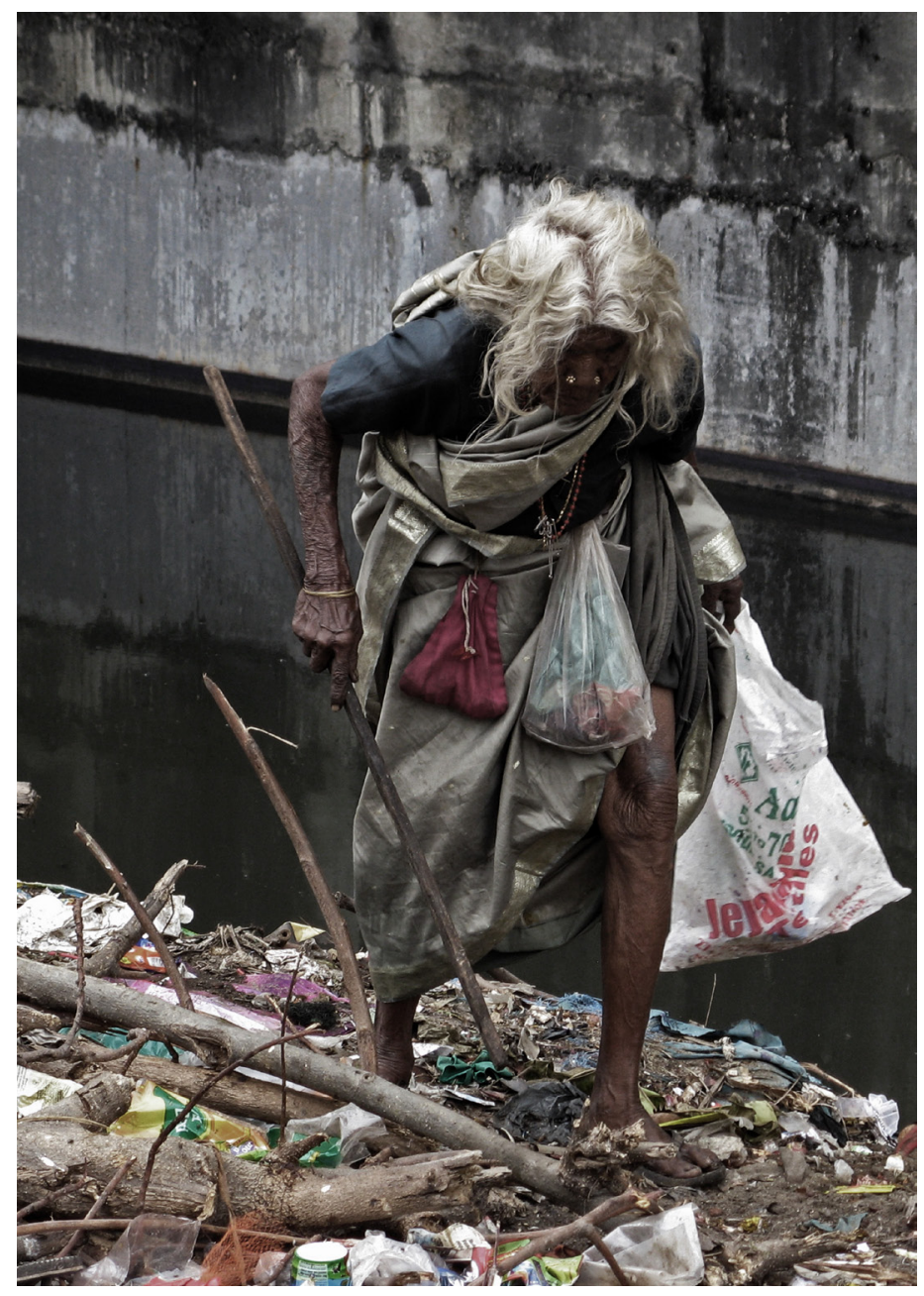





\section{INHABITING THE MACHINE}

by George Goodwin

A 120-point thesis submitted to the Victoria University of Wellington in partial fulfillment of the requirements for the degree of Master of Architecture (Professional)

Victoria University of Wellington, 2015

School of Architecture 
PREFACE 
In the month prior to commencing this thesis, I was granted the opportunity to travel to Chennai, India as part of a field research team to study how coastal slum conditions were further exacerbated by local pollution, basic lack of potable water, power and sanitation facilities, and vulnerability to environmental disasters. This was my first personal experience with extreme poverty; what touched me most was how welcome I was made to feel by the community. The human element was a huge awakening - real families, real struggles, real hopes, real lives. I was also touched by the severities of the site problems that defined the city's slums. I needed to feel I could make a difference; my profession could make a difference. I needed to believe that architecture could be a vehicle for social and economic improvements. Though this thesis is relegated to the theoretical, the research has allowed me to explore the most current opportunities for addressing these growing problems. And most importantly it has enhanced my understanding - my belief - in architecture's capability to effect change. 
ACKNOWLEDGMENTS 
First and foremost I would like to sincerely thank my supervisor, mentor and friend Daniel K. Brown for his dedication and support over the past 4 years. His enthusiasm, guidance and patience has been invaluable and a true inspiration throughout my studies.

I give thanks to Danielle Hrstich, Marco Duthie, Henry D'Ath, Hamish Beattie and Ben Allinson for their support, encouragement and friendship throughout our six years of study together.

Finally, a special acknowledgement needs to be made to my family. My parents David and Lianne, sister Sophie, grandparents Jeanette and Tony, aunt and uncle Bruce and Cath and girlfriend Monique. Thank you for supporting me throughout the entirety of my studies and providing me with encouragement and love.

Thank you 
ABSTRACT 
Like many cities across India, Chennai (capital of Tamil Nadu) has two tiers of slums - those with official government recognition and those without. Slums with official government recognition are then further categorised to either be objectionable or unobjectionable. Recognised slums receive government funding to provide new tenements and basic services on site. But recent studies have shown that $4.8 \mathrm{sq} \mathrm{km}$ of the Chennai metropolitan area are comprised of either unrecognised or objectionable slums. The current government strategy is to forcibly relocate families from unrecognised or objectionable slums to large-scale, high-rise settlement colonies on the distant outskirts of Chennai. Numerous civil society organisations, however, have documented that eviction and relocation results in extreme trauma for these families. The Transparent Chennai Project at the Institute for Financial Management and Research in Chennai argues that: "A far more reasonable strategy would be to once again implement the Tamil Nadu Slum Clearance Act in the spirit that it was written, and start to recognise slums and improve them in situ" (Raman and Narayan).

This thesis proposes that architectural design can improve conditions for Chennai's urban poor without resorting to forced relocation. It argues that a new framework for slum housing can be designed that is capable of: protecting slum dwellers from environmental disasters such as rising sea levels, storm surge, and tsunamis; mitigating environmental pollution to improve hygiene; and providing economic sources of fresh water and energy through sustainable means. It further argues that this framework can be achieved in a culturally sensitive manner by acknowledging traditional and historically significant regional architectural typologies. 


\section{CONTENTS}

PREFACE

ACKNOWLEDGMENTS

ABSTRACT

- $\quad$ 1.1 Research Problem

- $\quad 1.2$ Position

- $\quad 1.3$ Site Significance

- $\quad 1.4$ Approach

- $\quad$ 1.5 Research Question

- $\quad 2.1$ Site Introduction

- $\quad 2.2$ Climate | Tropical Storms | Tsunamis 20

- $\quad 2.3$ Storm Surge | Sea Level Rise | Flooding 24

- $\quad 2.4$ Srinivasa Puram Demographic 32

- $\quad 2.5$ Water Supply 38

- 2.6 Sanitation 44

- $\quad 2.7$ Waste Management 48

- $\quad 2.8$ Photographic Analysis $\quad 52$

- $\quad 2.9$ Slum Resettlement Schemes 66

- $\quad 2.10$ Site Placement 80

- $\quad 2.11$ Adyar River Mouth 86

$\begin{array}{lr}\text { 3.0 PROGRAM ANALYSIS } & 106\end{array}$

- $\quad$ 3.1 An Expanding Framework 110

- $\quad 3.2$ Water Supply 114

$\begin{array}{ll}\text { - } \quad 3.3 \text { Sewage Treatment } & 118\end{array}$ 
- $\quad$ 3.3 Garbage Treatment

- $\quad 3.4$ Energy Generation

\subsection{LITERATURE \& PROJECT REVIEW}

- $\quad$ 4.1 Water Harvesting

- $\quad$ 4.2 Passive Water Purification

- $\quad$ 4.3 Passive Energy Generation

- $\quad$ 4.4 Storm Surge \& Tsunami Barriers

- $\quad$ 4.5 Madurai: A Temple City

- $\quad 4.6$ Contemporary Indian Architecture

- $\quad 5.1$ Initial Design Experiments

- $\quad$ 5.2 Physical Modeling Experiments

- $\quad 5.3$ Conceptual Scheme One

- $\quad 5.4$ Conceptual Scheme Two

- $\quad 5.5$ Conceptual Scheme Three

\subsection{DEVELOPED DESIGN}

- $\quad$ 6.1 Mitigating The Storm

- $\quad$ 6.2 Cleansing The Environment 269

- $\quad 6.3$ Harvesting And Purifying 276

- $\quad$ 6.4 Retaining Livelihoods 282 


\subsection{INTRODUCTION}
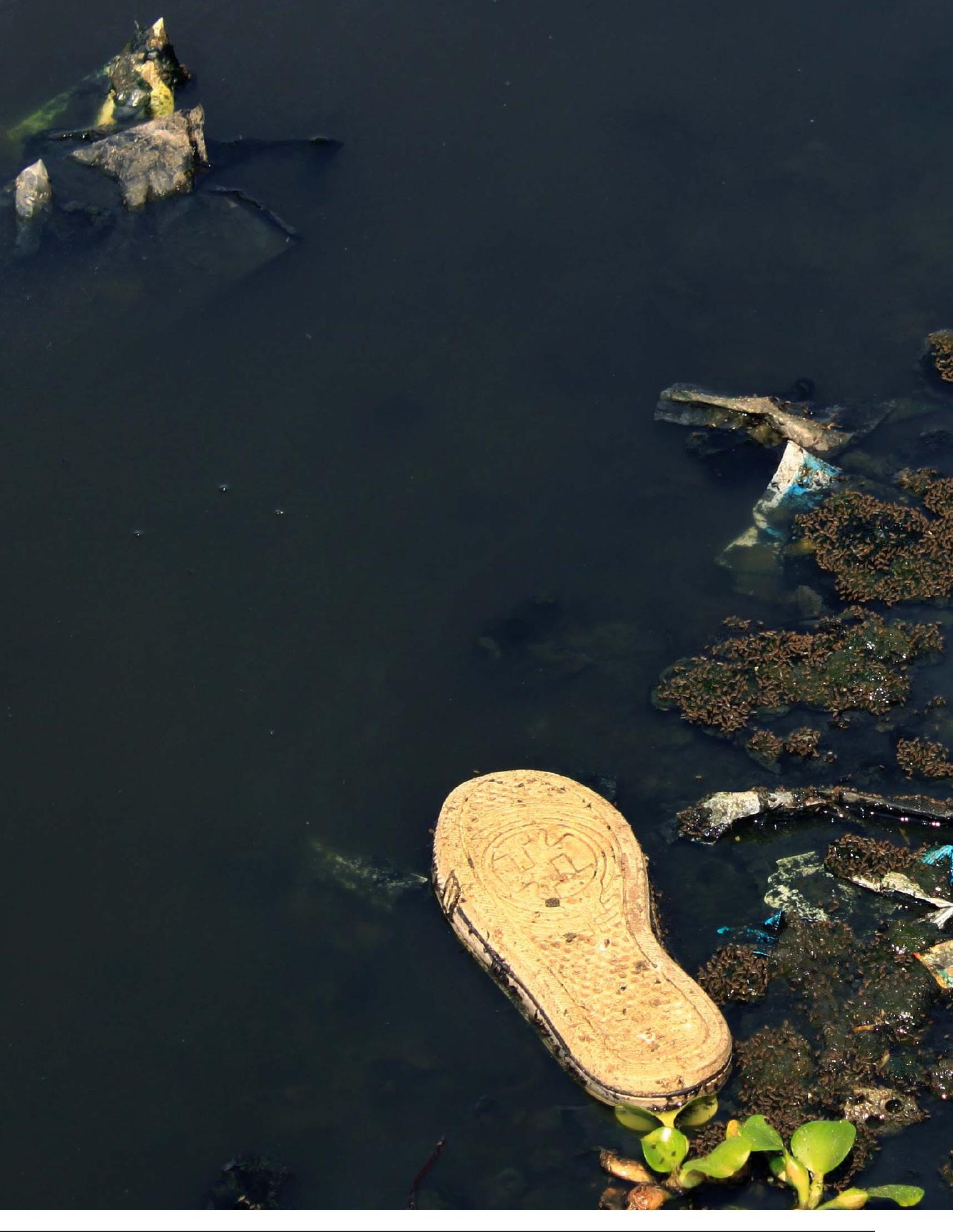

Fig. 01. Adyar Estuary, Srinivasa Puram. 


$$
\cos 2
$$
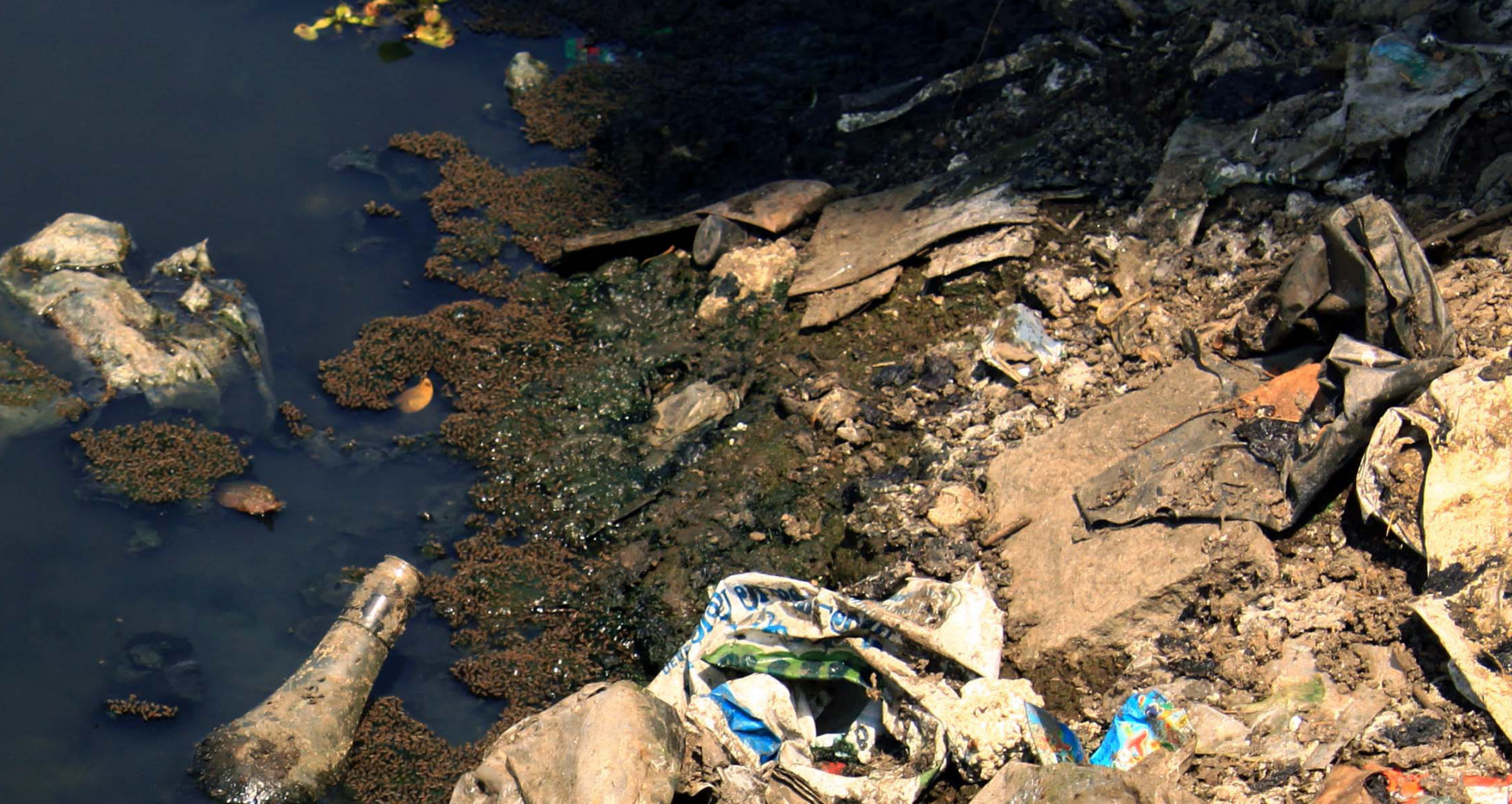

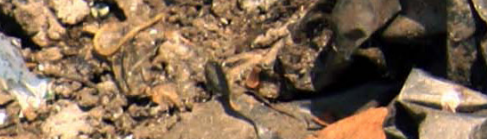
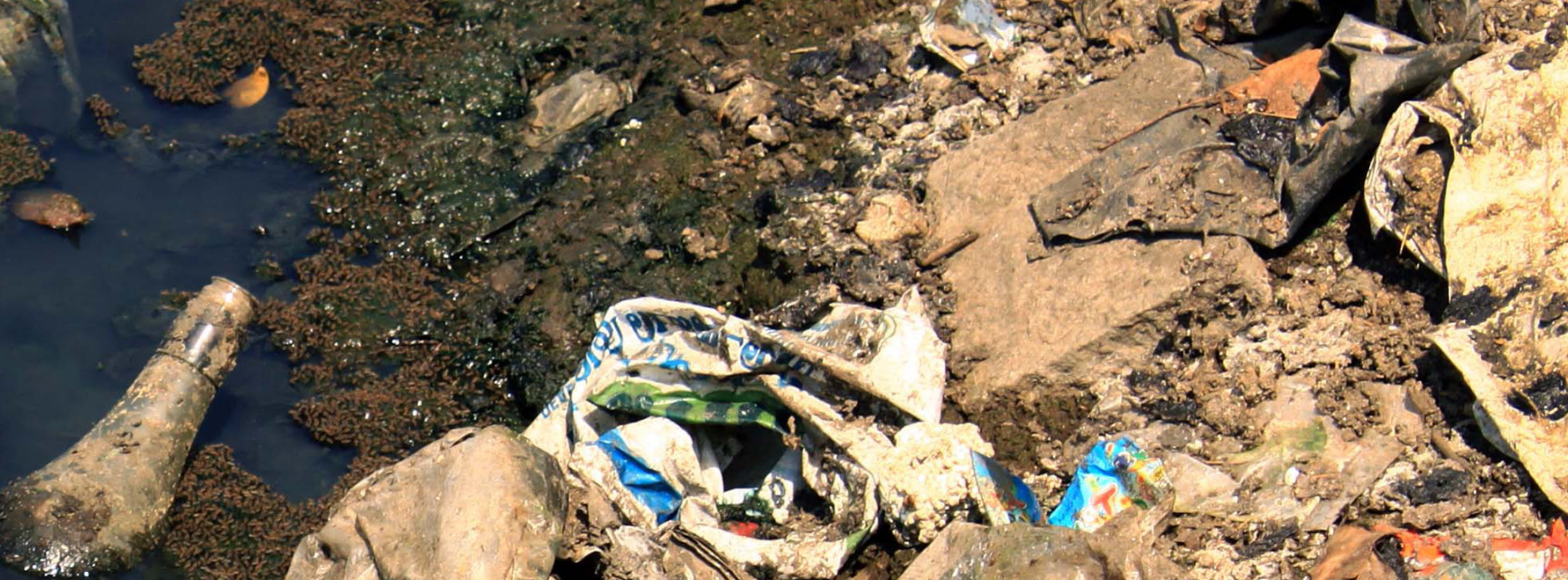

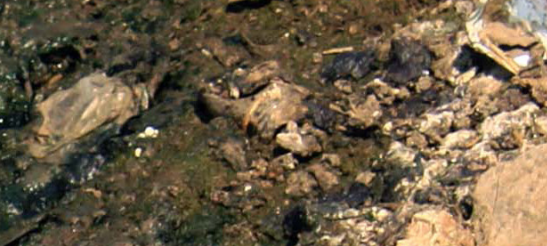
$3 x^{2}+x^{2}$

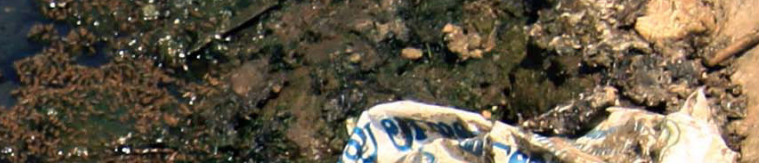

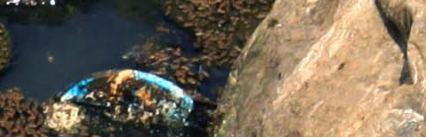

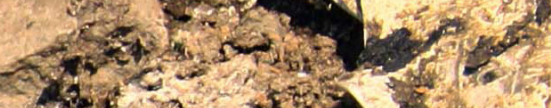
$12+10 x+5$

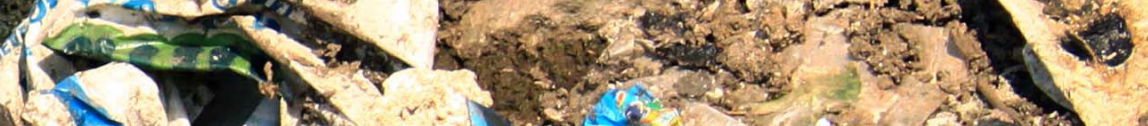

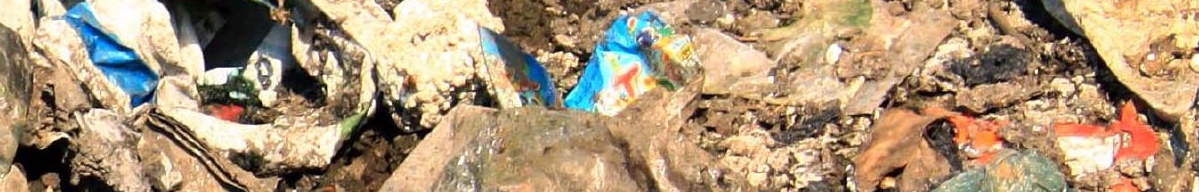

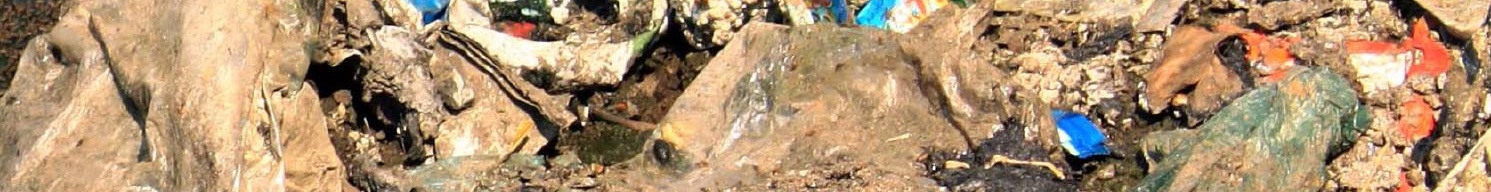

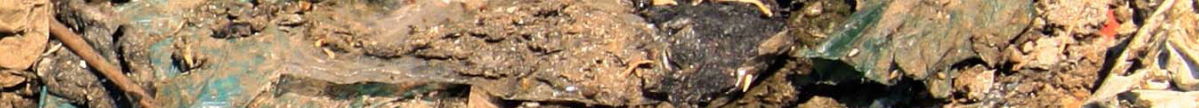

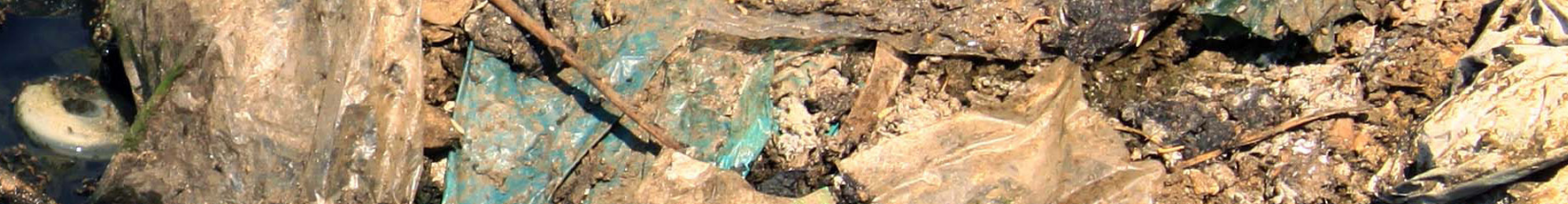

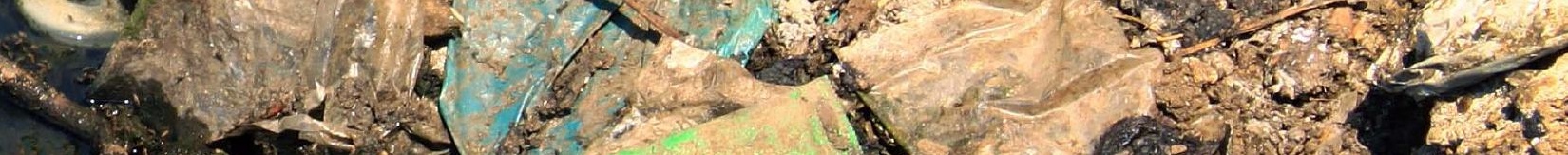

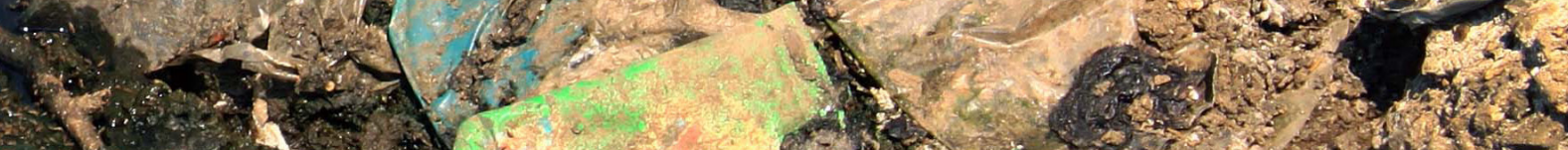

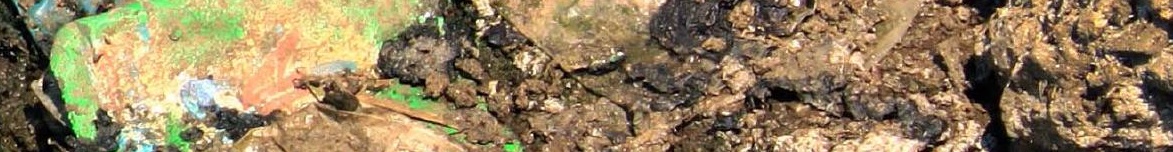

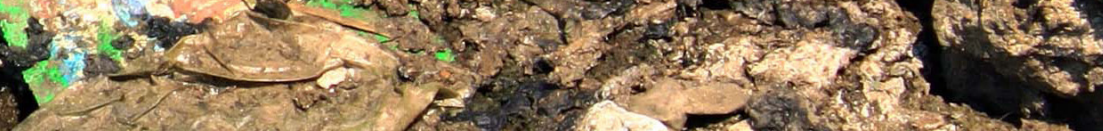

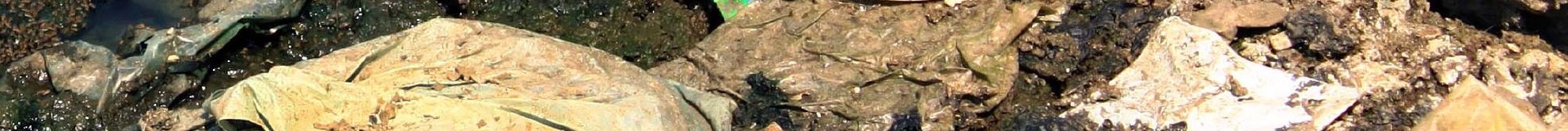

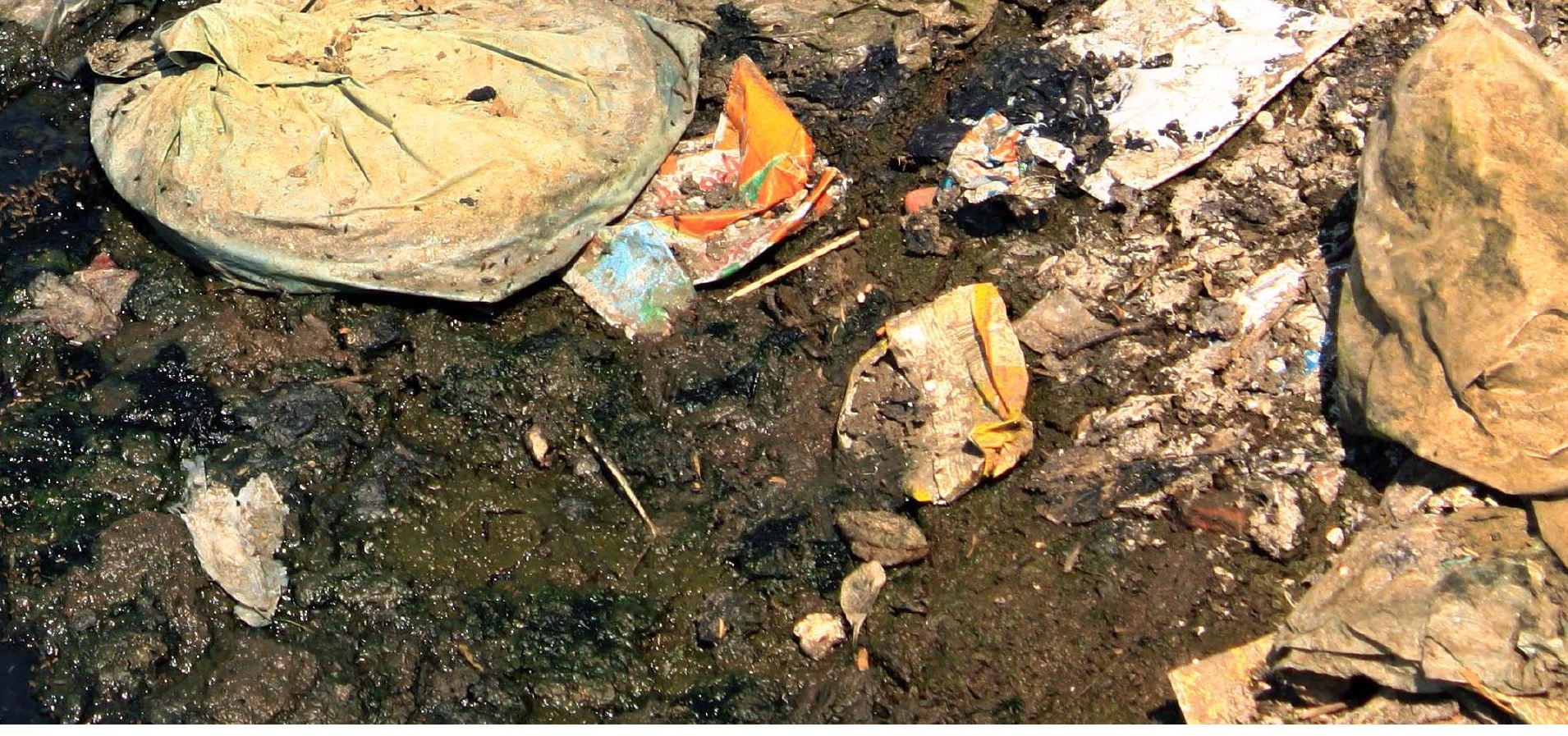




\subsection{RESEARCH PROBLEM}

The 20th Century saw a rapid development in both industrialisation and technological advancements within India which in turn resulted in urbanisation increasing from just $11 \%$ in 1901 to $32 \%$ in 2011; it is expected to reach $40 \%$ by 2050 . This mass scale urbanisation has had catastrophic effects on India's lower economic demographic.

In 2011 the national Indian census produced statistics surrounding informal settlements, typically labeled as slums. According to Government of India, the term 'slum' is defined as:

"Residential areas where dwellings are unfit for human habitation by reasons of dilapidation, overcrowding, faulty arrangements and design of such buildings, narrowness or faulty arrangement of street, lack of ventilation, light, or sanitation facilities or any combination of these factors which are detrimental to safety and health" (Selja).

In just one decade slum populations within India have grown from 52 million in 2001 to 65 million in 2011. More than a third of India's slum dwellers are living in unrecognised slums, meaning they receive no official government recognition, or access to legal protection and municipal services.

Chennai, the capital of Tamil Nadu, has the fourth largest metropolitan population in India, with the third highest proportion of slum households $(28.5 \%)$ in the country according to the 2011 census. The Tamil Nadu Slum Clearance Act of 1971 states that government is required to identify and officially recognise slums and improve them in situ. The introduction of the Act saw 1,202 slums recognised in Chennai immediately. In 1985 a further 17 slums were recognised within the city, all of which were improved in situ by means of providing both building tenements and basic services such as fresh water, sewage and electricity.
Since 1985 hundreds of new slums have developed throughout the Chennai Metropolitan area, though not one has been officially recognised by the government. A study in 2002 carried out by the Tamil Nadu Slum Clearance Board identified 444 unrecognised slums within Chennai, housing nearly half a million people at the time. This invisible population of slum dwellers relied on one public water source per 620 people on average.

In addition to the unrecognised slums of Chennai, there are also those with official government recognition that are sub-categorised to either be objectionable or unobjectionable. Objectionable slums are predominantly deemed to either be vulnerable to natural disasters such as flooding and tsunamis, or pose a major threat to the surrounding environment and ecosystem due to high levels of pollution. Typically these 'objectionable slums' reside along the banks of the city's three major water ways; the Adyar River, Cooum River and Buckingham Canal, which in turn becomes their waste management system.

Currently the government is providing an indirect response to the problem by forcibly evicting and relocating families from unrecognised or objectionable slums to large-scale, high-rise settlement colonies on the distant outskirts of Chennai. Numerous civil society organisations, however, have documented that eviction and relocation results in extreme trauma for these families. The Transparent Chennai Project at the Institute for Financial Management and Research in Chennai argues that: "A far more reasonable strategy would be to once again implement the Tamil Nadu Slum Clearance Act in the spirit that it was written, and start to recognise slums and improve them in situ." 


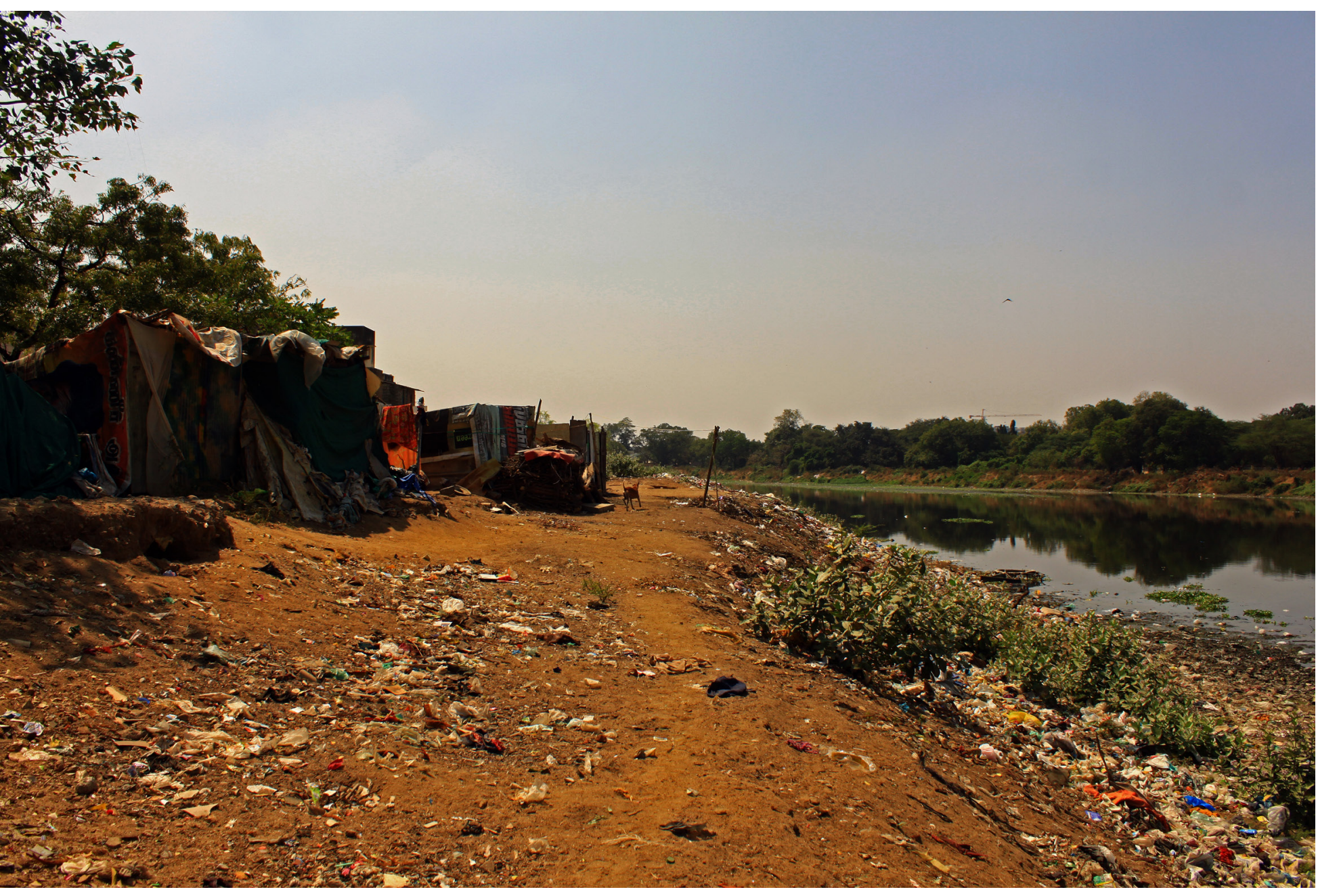

Fig. 02. Adyar Estuary, Chennai.

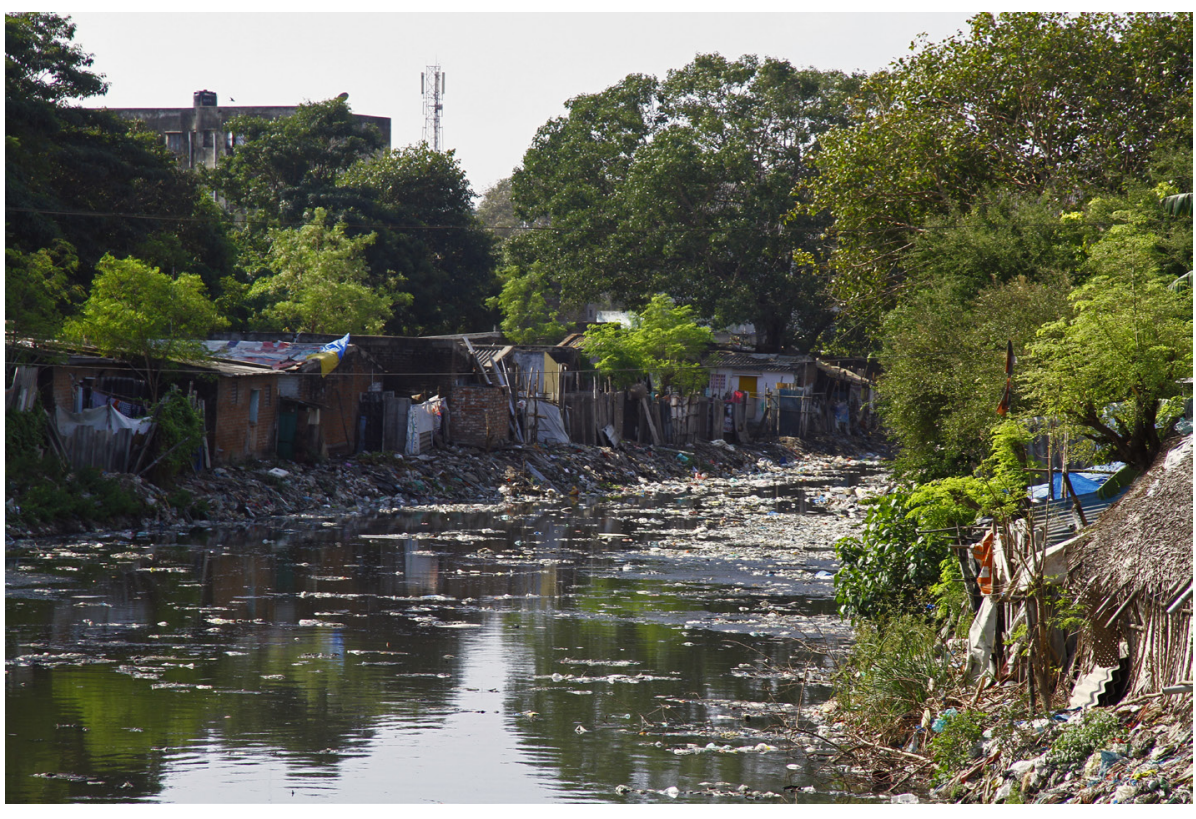

Fig. 03. Adyar River, Chennai. 


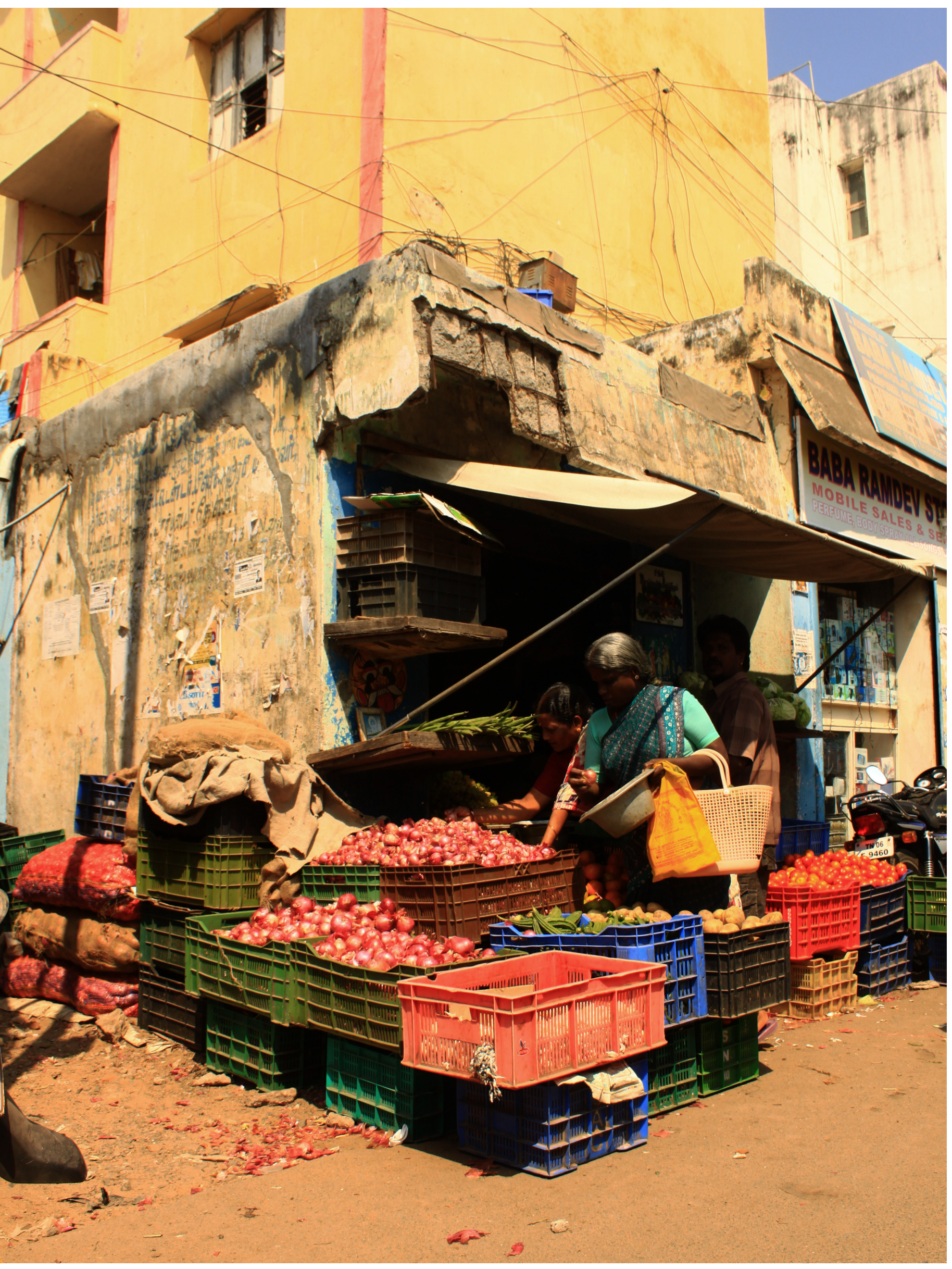

Fig. 04. Vegetable Market, Srinivasa Puram. 


\subsection{POSITION}

This thesis argues that the development of further high rise settlement colonies on the outskirts of Chennai essentially redirects the original problem to a distant site where environmental pollution, hygiene issues and slum dwellers become an invisible problem that remains unresolved. The thesis proposes to form a self-sustainable architectural framework that integrates an enhanced housing structure for the city's urban poor, with an environmental remediation scheme on a coastal site adjacent to an informal slum settlement that is vulnerable to government relocation, severe pollution, and potential environmental disasters such as cyclones, tsunamis and flooding.

This thesis proposes that architectural design can not only mediate these conditions, but also provide and reinstate a sense of self-worth, purpose and belonging to the city's slum dwellers while sustaining their current livelihood. 


\subsection{SITE SIGNIFICANCE}

The 2004 Boxing Day tsunami in the Indian Ocean caused wide spread devastation for many east coast communities in India, including thirteen districts along the Tamil Nadu coastline. Srinivasa Puram, a slum in Chennai, was one of the worst affected areas in the region with 54 lives lost and hundreds of families left homeless. Built upon a narrow stretch of land at the mouth of the Adyar River and surrounded by the relentless threat of natural disasters, Srinivasa Puram is one of the most vulnerable slum communities in Chennai. The slum settlement was again severely damaged in 2005 when the Adyar River flooded after a 100 -year rainfall of $40 \mathrm{~cm} /$ day.

\subsection{APPROACH}

Srinivasa Puram was selected as a vehicle for this design-led research in response to the government's recent approach of forcibly relocating families from unrecognised and objectionable slums. The thesis begins by examining the latest literature relating to innovative self-sustainable and environmental remediation technology.

The thesis title - Inhabiting the Machine - derives from the subsequent design experiments which test how these technological approaches can establish a framework upon or within which cost-effective, stormproof, sustainable modular housing can be sited. 


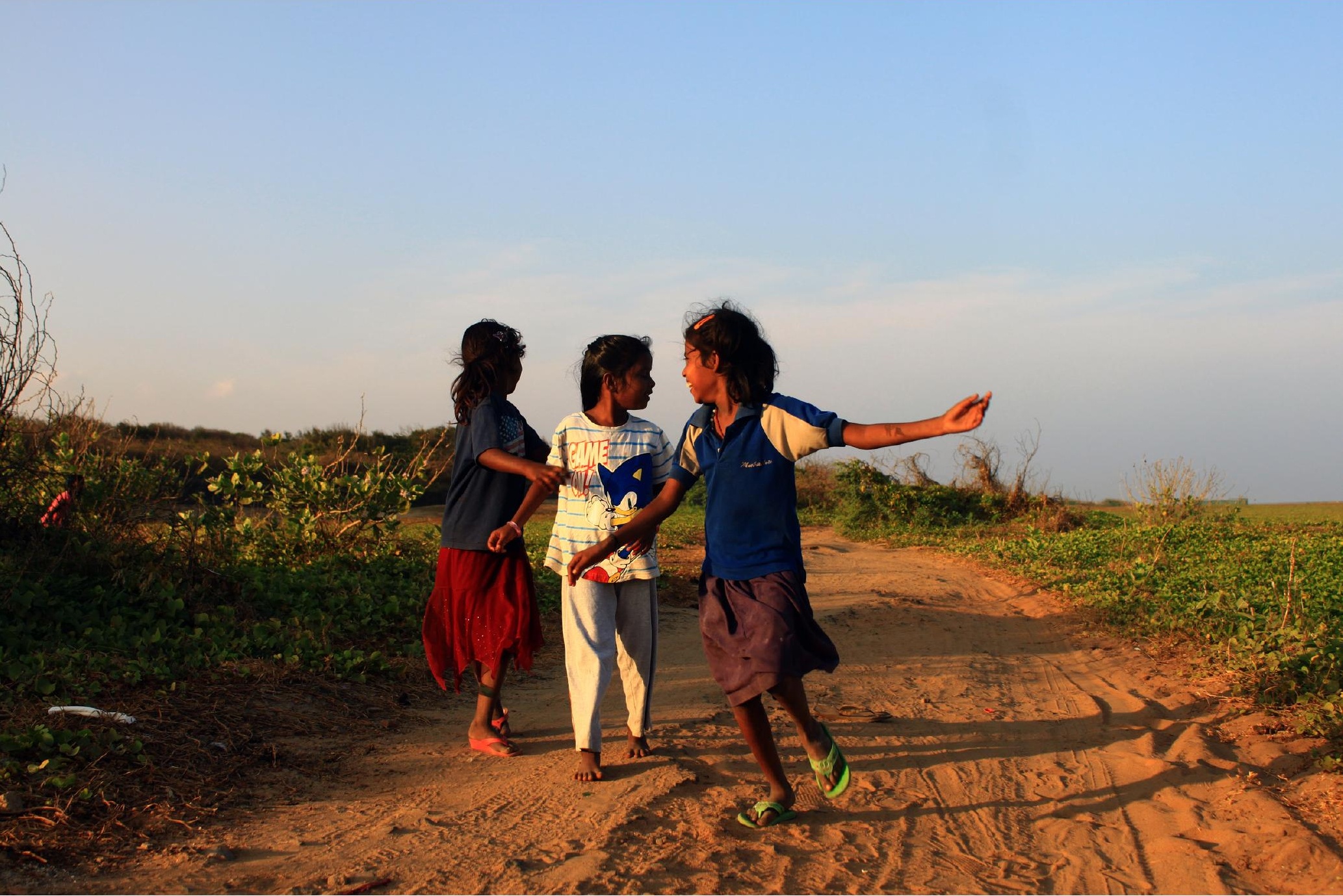

Fig. 05. Children playing along the beach, Srinivasa Puram. 


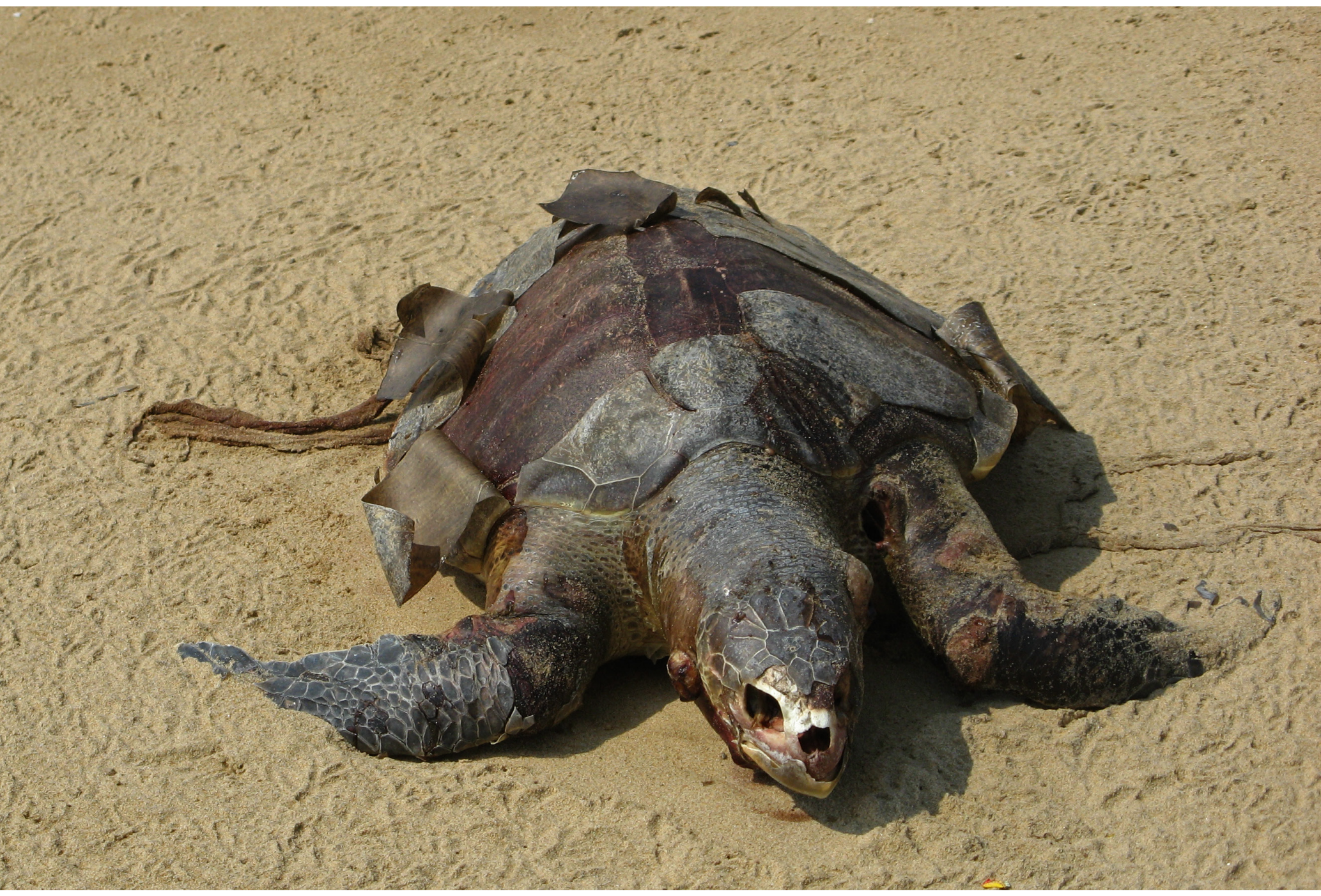

Fig. 06. Decomposing turtle along the beach front, Srinivasa Puram. 


\subsection{RESEARCH QUESTION}

RESEARCH QUESTION:

How can Chennai's urban slums be redeveloped to improve the lives of India's urban poor and enable them to become self-sustaining?

\section{RESEARCH AIM:}

To investigate ways that architectural design can be used to improve Chennai's urban slums, enabling them to become self-sustaining and enhancing the lives of slum dwellers without resorting to forced relocation.

\section{RESEARCH OBJECTIVES:}

— to provide enhanced housing for urban families in unrecognised slums;

- to protect slum dwellers from environmental disasters such as flooding, rising sea levels, storm surges, and tsunamis;

- to mitigate environmental pollution as an important means of improving hygiene;

- to provide economic sources of fresh water and energy through sustainable means;

- to establish an architectural framework that is culturally sensitive by acknowledging traditional and historically significant regional architectural typologies. 


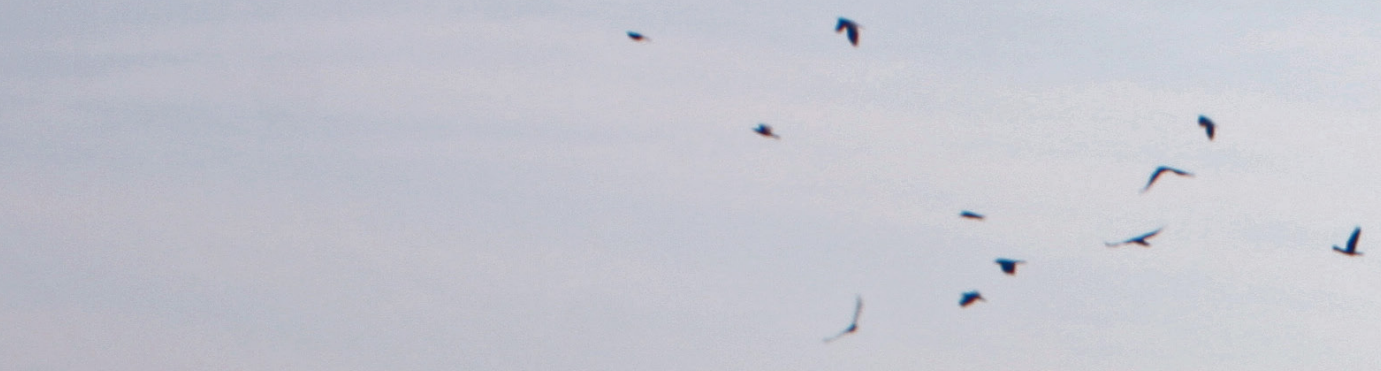

2.0 SITE ANALYSIS

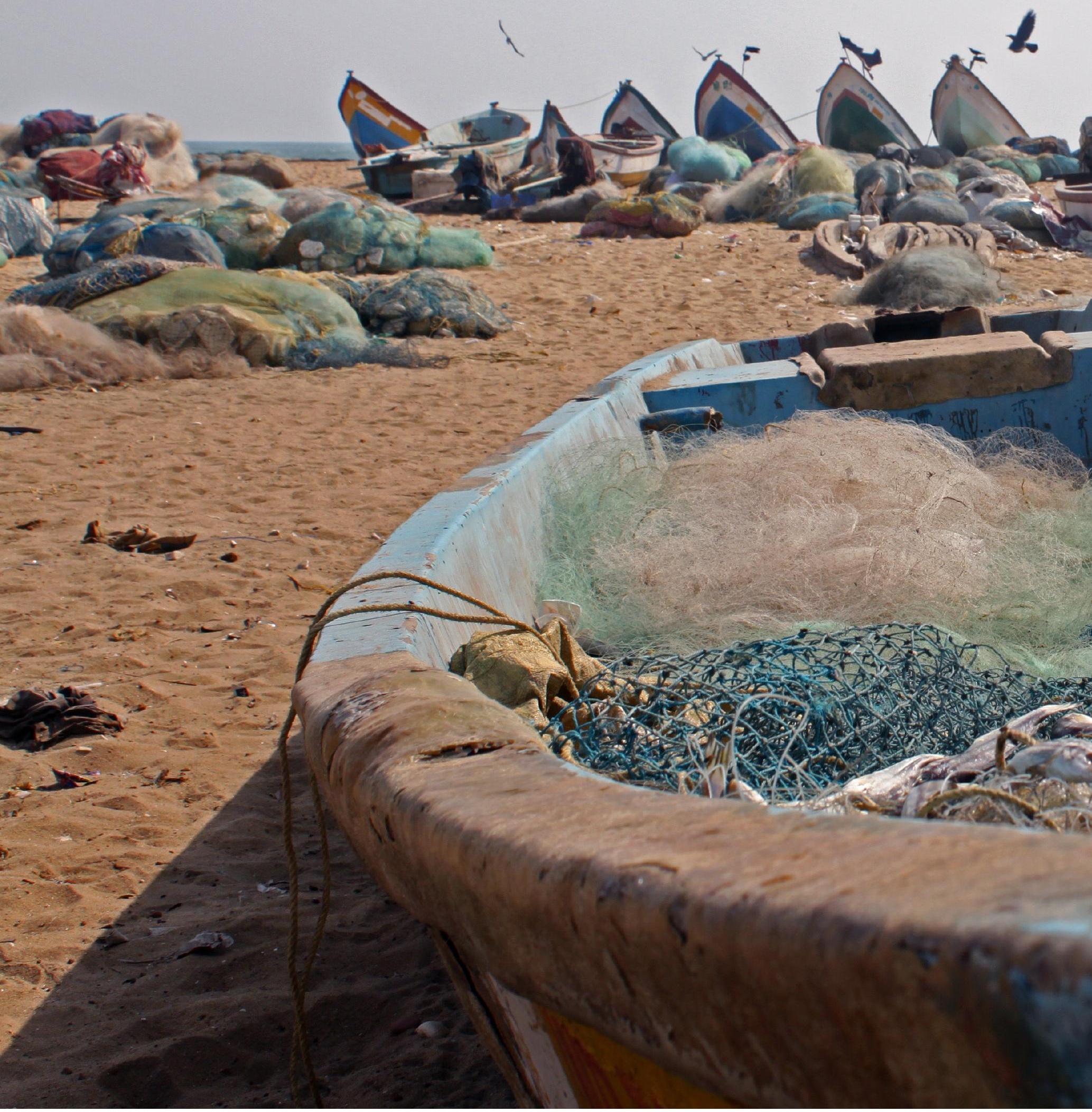




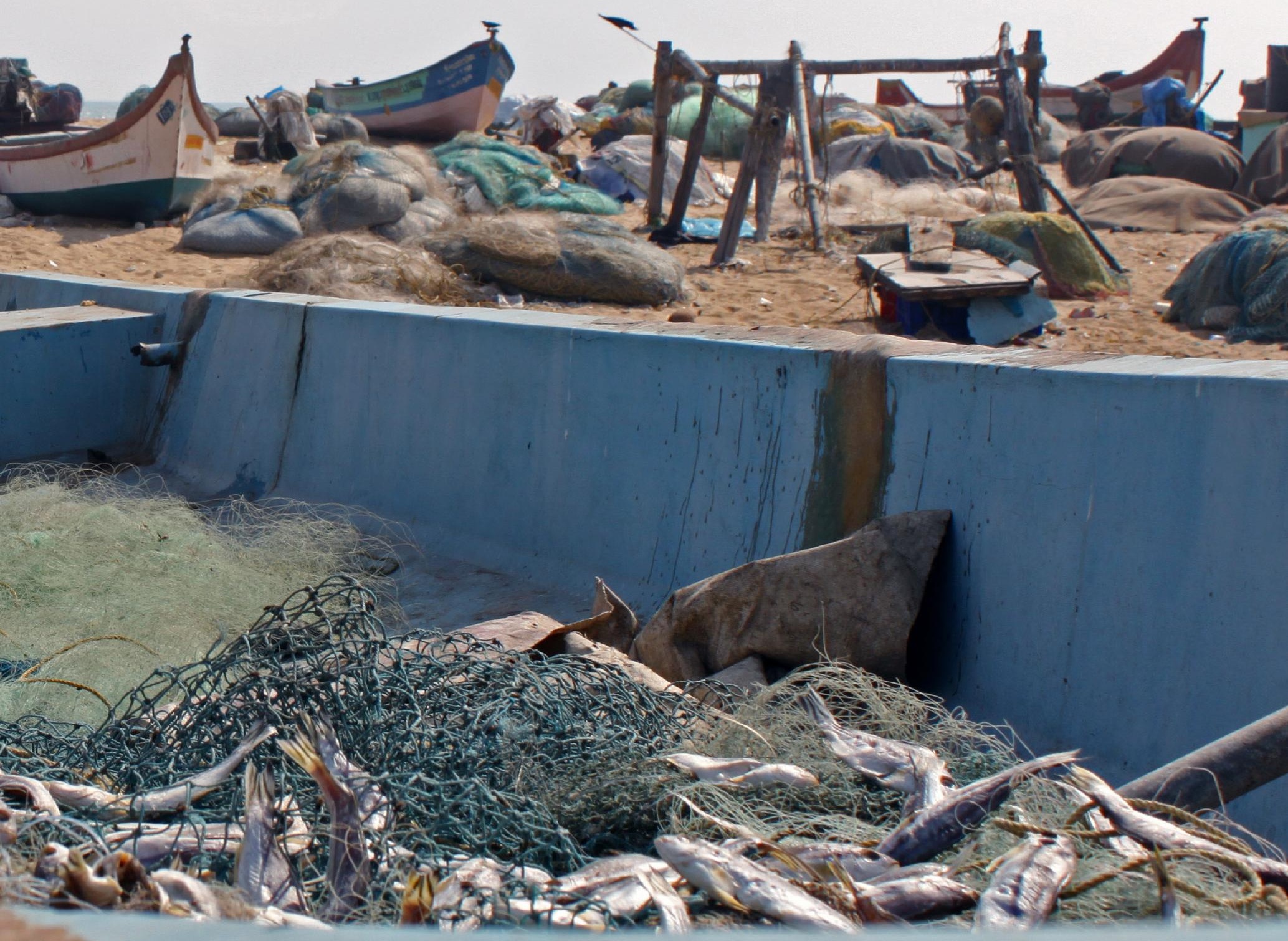




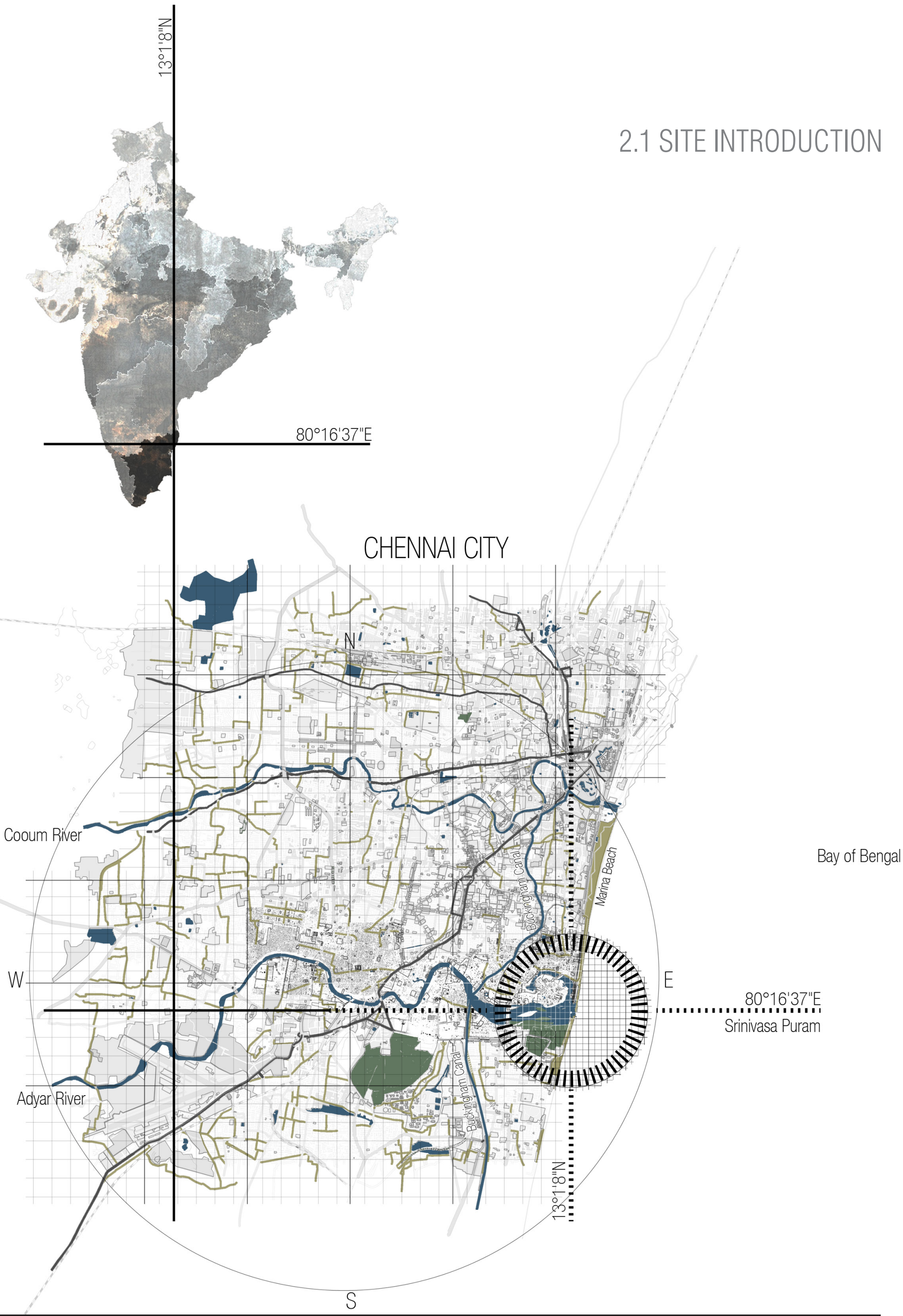

Fig. 08. Site Analysis. 
Chennai currently has hundreds of thousands of people residing in both unrecognised and objectionable slums predominantly along the city's three major water ways: the Adyar River, Cooum River and Buckingham Canal. Srinivasa Puram (Figure 08) is sited upon a narrow stretch of land south of Chennai's main Marina Beach at the mouth of the Adyar River.

The slum has a population of approximately 3086 families and a primarily fishing based economy. Srinivasa Puram has no sewage or waste management system in place and water is supplied daily via tankers. During the summer months water is provided on alternate days due to insufficient supply from the city's four water reservoirs (Lakshmi). The Adyar Estuary directly behind Srinivasa Puram is used as a direct outlet for sewage and garbage waste causing hygiene issues and destroying the surrounding ecosystem. The current government strategy is to forcibly relocate the families of unrecognised or objectionable slums throughout Chennai to one of three largescale, high-rise settlement colonies on the distant outskirts of Chennai: Kannagi Nagar, Semmencherry and Perumbakkam (Raman and Narayan).

Note: All photographs are of Srinivasa Puram and Author's own image 2014 unless noted otherwise. 


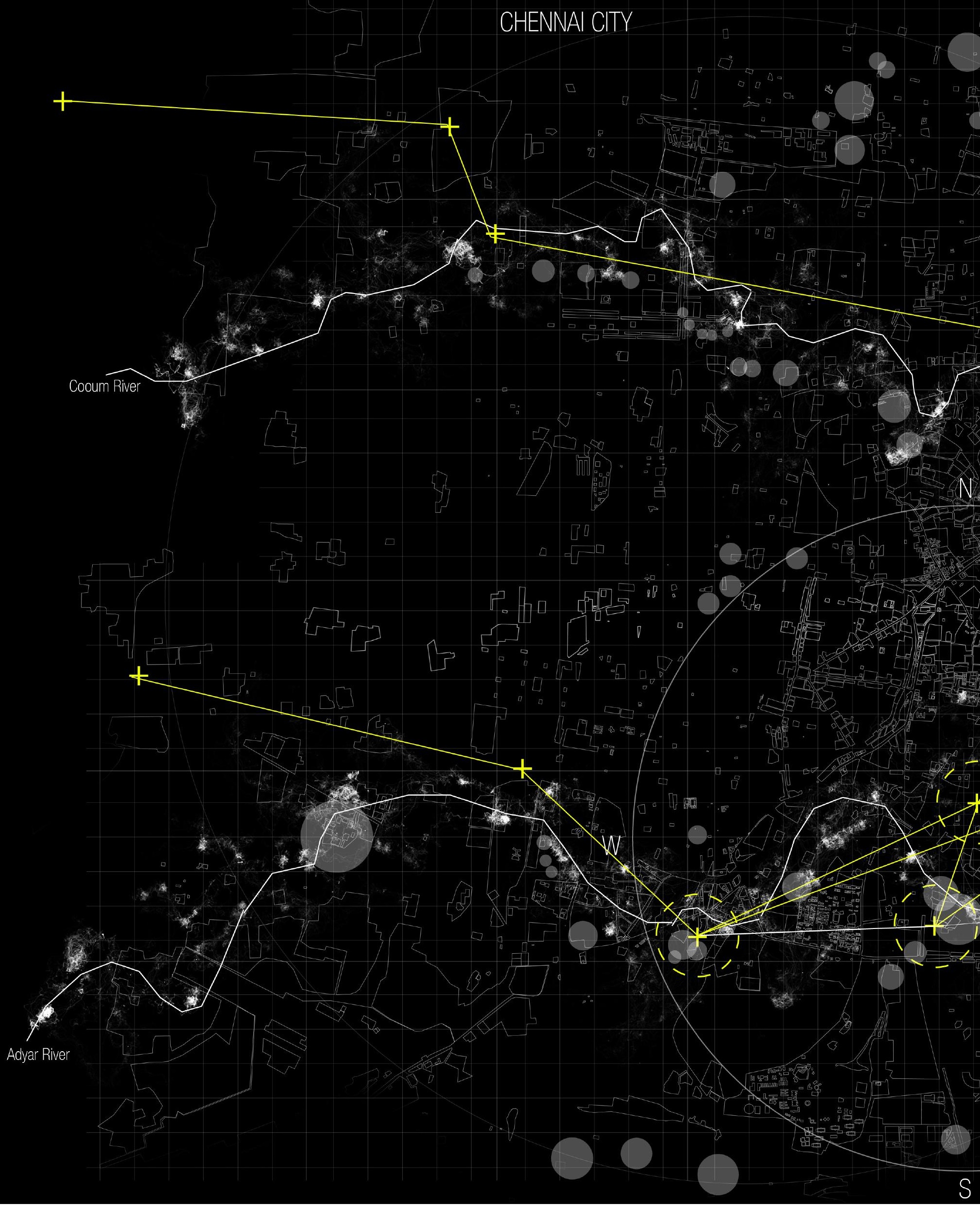




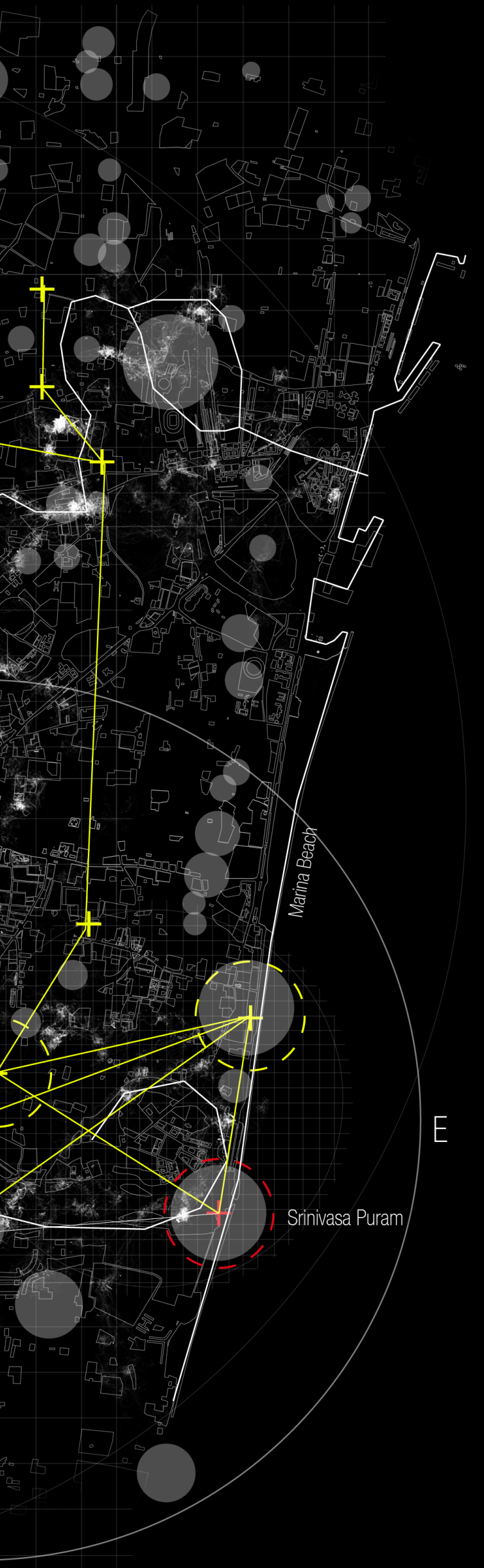

Bay of Bengal

Figure 09 shows a map of Chennai with plot points defining objectionable slums and slum eviction sites generated by the Institute for Financial Management and Research in Chennai. The diagram does not show unrecognised slum sites for the very reason that they are unrecognised. While Srinivasa Puram is shown as a slum eviction site, this is representative of only partial eviction. More than 3000 families still live in the objectionable coastal slum as highlighted by the plot point.

Objectionable Slums

(Population defined through scale of plot)

$+\quad$ Slum Eviction Sites

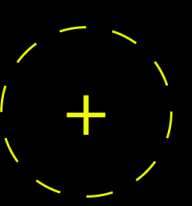

Slum Eviction Sites:

Cause - Natural Disasters 


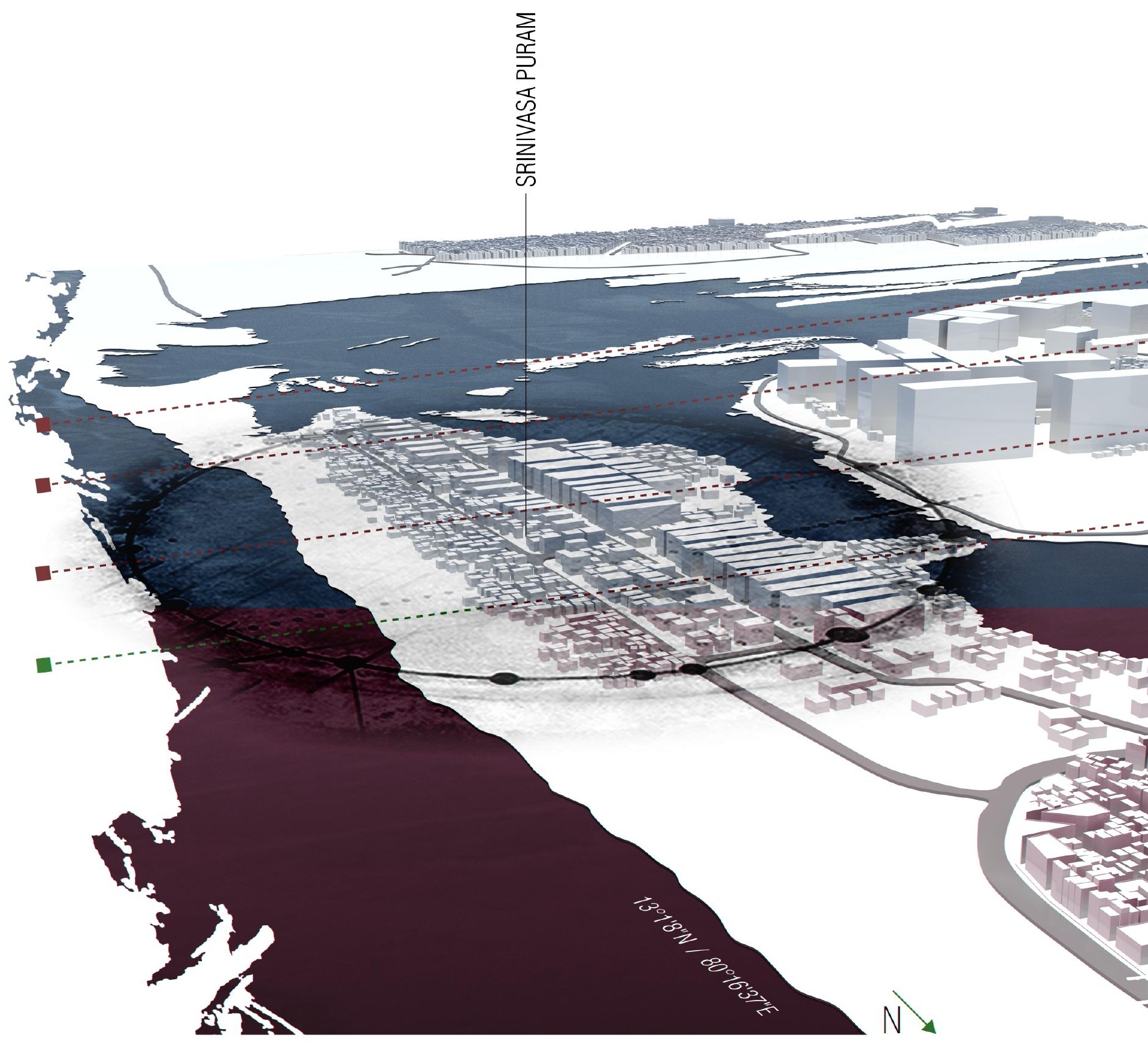




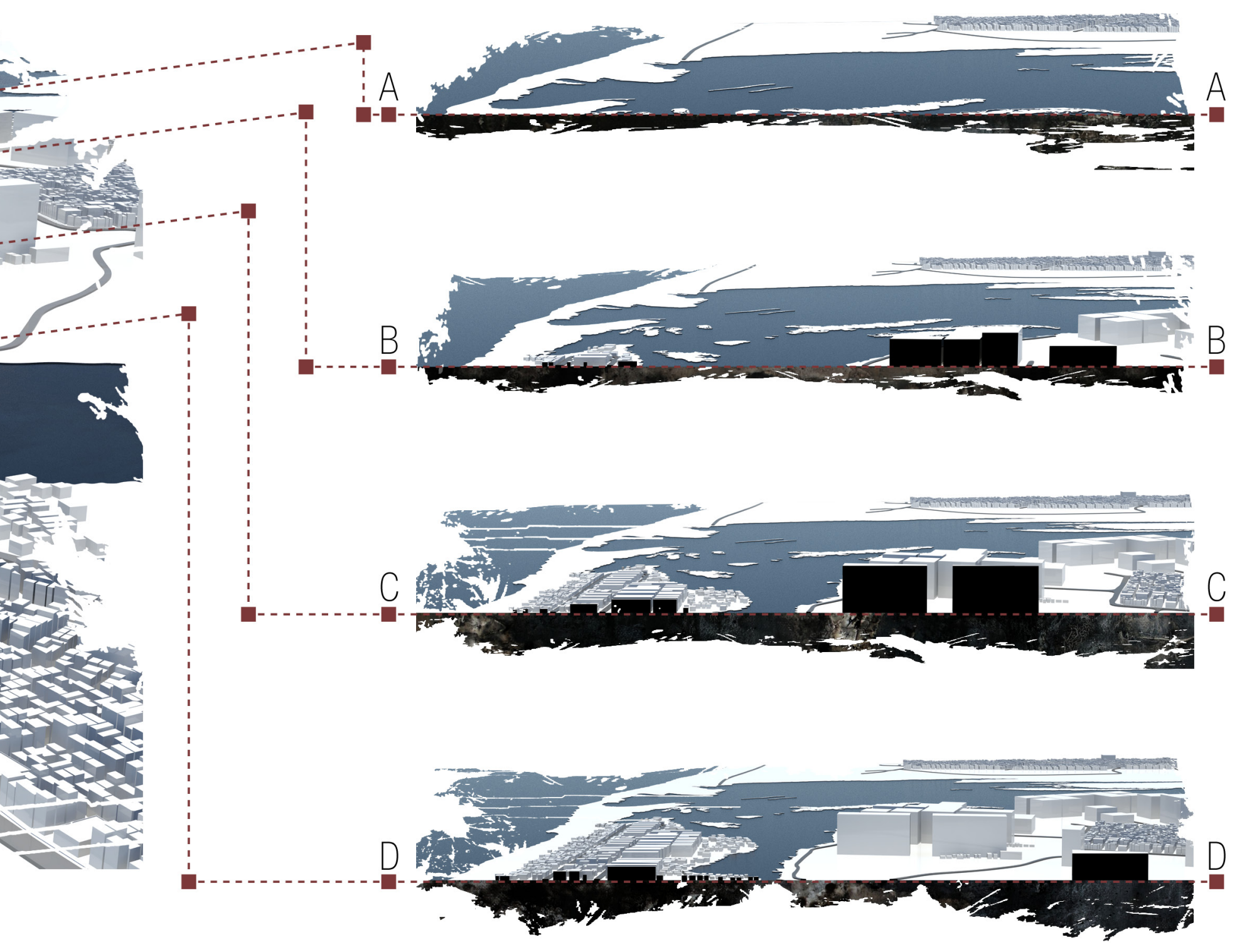


Figures 10-11 show relative building heights and densities of both Srinivasa Puram and the surrounding suburbs of Raja Annamalai Puram and Mylapore through section, plan and a three-dimensional site model in relation to Adyar River and coastline. The section cuts (Figure 10) show the relationship between Srinivasa Puram and newly constructed luxury high rise buildings on the island of Raja Annamalai Puram overlooking the slum. Visiting the site in January 2014, it was noted that severe damage from the 2004 tsunami was still evident. The most vulnerable slum buildings closest to the coastline were built from thatch and debris while structures further inland were constructed from masonry and concrete, better able to withstand storms. Although these inland buildings border the estuary and showed significant damage from Adyar flooding. 
2.2 CLIMATE | TROPICAL STORMS | TSUNAMIS

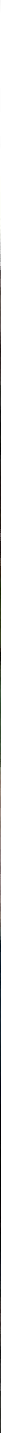



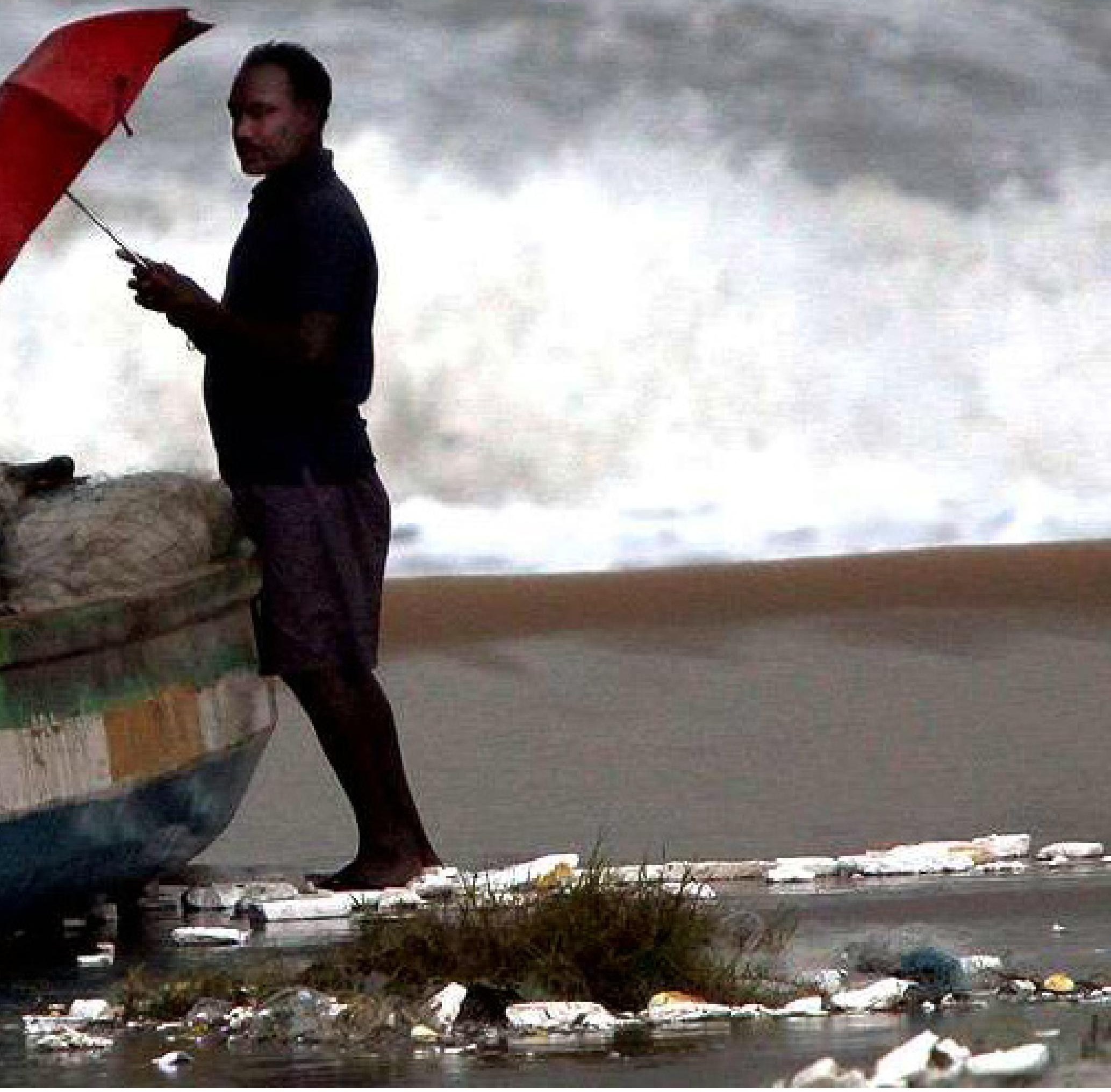


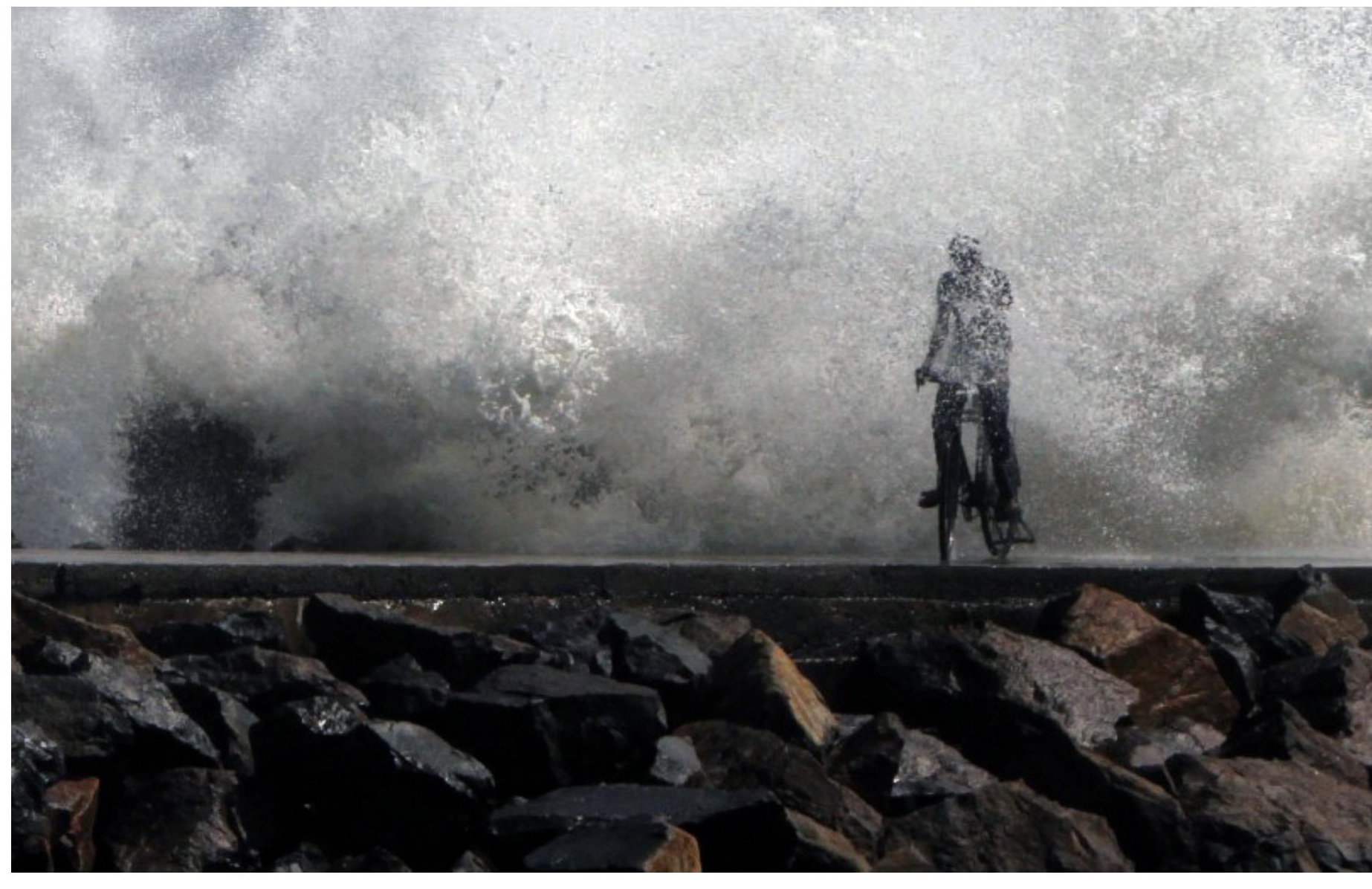

Fig. 13. Storm surge, Cyclone Thane (2011), Chennai.

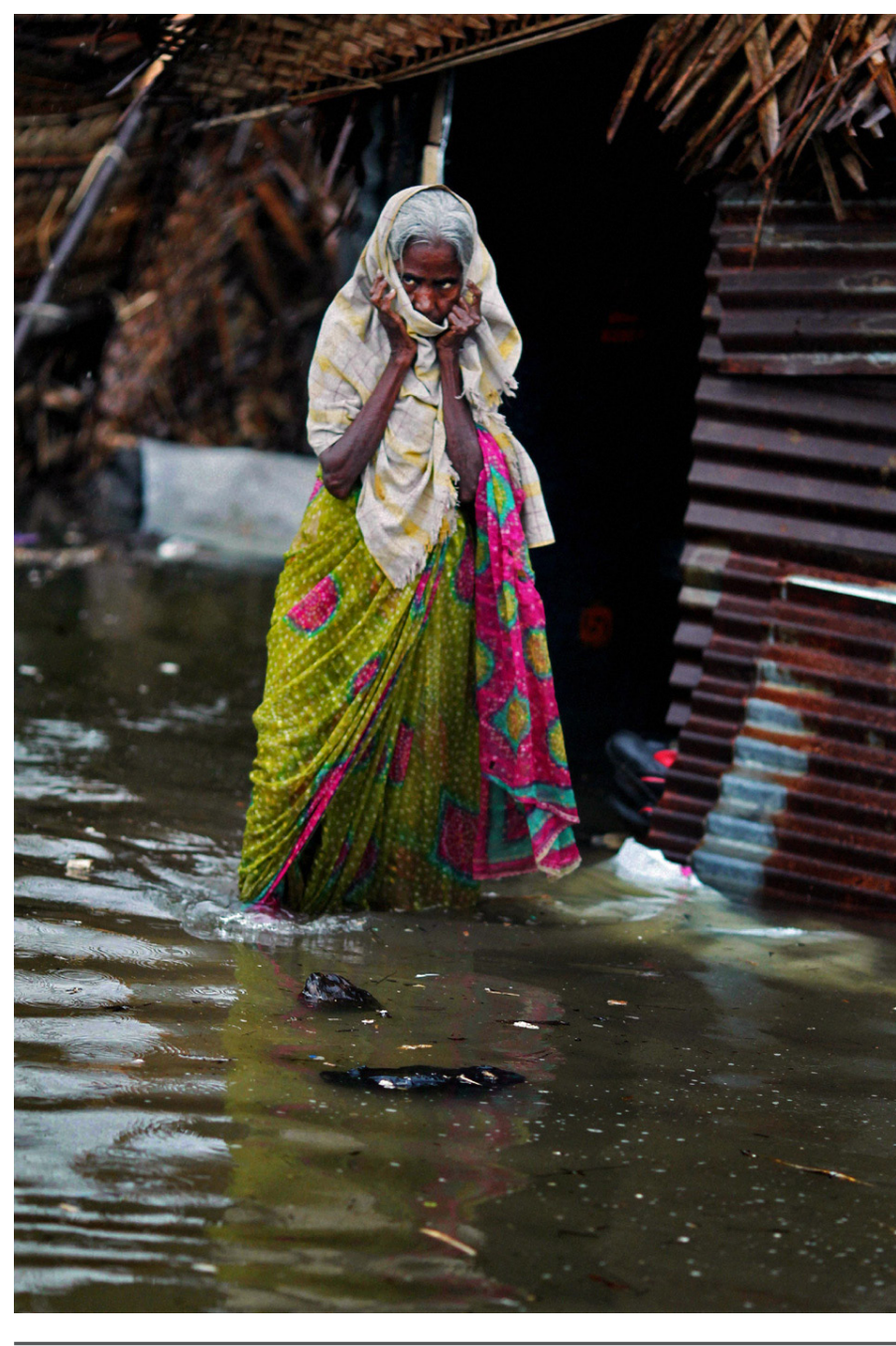

Fig. 14. Flooding, Cyclone Thane (2011), Srinivasa Puram 
Chennai's tropical climate has high temperatures and humidity that supplies the region with an annual rainfall of approximately $1200 \mathrm{~mm}$, though around $800 \mathrm{~mm}$ of this figure falls during the northeast monsoons between October and December (Gupta and Nair). The Bay of Bengal produces a number of tropical storms every year that cause widespread damage across much of India's eastern coastline. In 1967 a 2-3 meter wide bridge was constructed across the Adyar Estuary linking Srinivasa Puram to southern fishing communities. Ten years later in 1977 the bridge partly collapsed following heavy rains, destroying the transportation link (Figure 15) (Tejonmayam). In recent years there have been two significant cyclones that devastated Chennai's coastal habitats: Cyclone Thane (2011) and Cyclone Nilam (2012). Cyclone Nilam was a deadly tropical cyclone that delivered a storm surge travelling $100 \mathrm{~m}$ inland along Chennai's beach front. Thousands were evacuated and many made homeless. ("Severe Cyclones That Hit India")

The 2004 Boxing Day tsunami in the Indian Ocean caused widespread devastation for many east coast communities in India including thirteen districts along the Tamil Nadu coastline. Srinivasa Puram was one of the worst affected areas in the region with 54 lives lost and hundreds of families left homeless (Raju). 
2.3 STORM SURGE | SEA LEVEL RISE | FLOODING
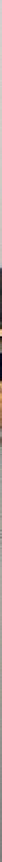


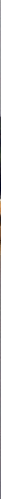


Chennai has an average elevation of only $6 \mathrm{~m}$ above sea level (Horrison and Rose 1). Figure 16 illustrates the coastal elevation risks and highlights the areas sea level rise would affect first. The comparative analysis drawings indicate the projected floodwater across Chennai ranging from current sea level to an extreme projection of a 3 meter sea level rise where both Srinivasa Puram and the Adyar river mouth would be severely affected. The Times of India reported predictions by a number of international scientists that sea level would rise between 0.5 to 1.4 meters within the $21^{\text {st }}$ century (Vasundara). For the purpose of this thesis, design experiments will anticipate a minimum sea level rise of 1 meter. 


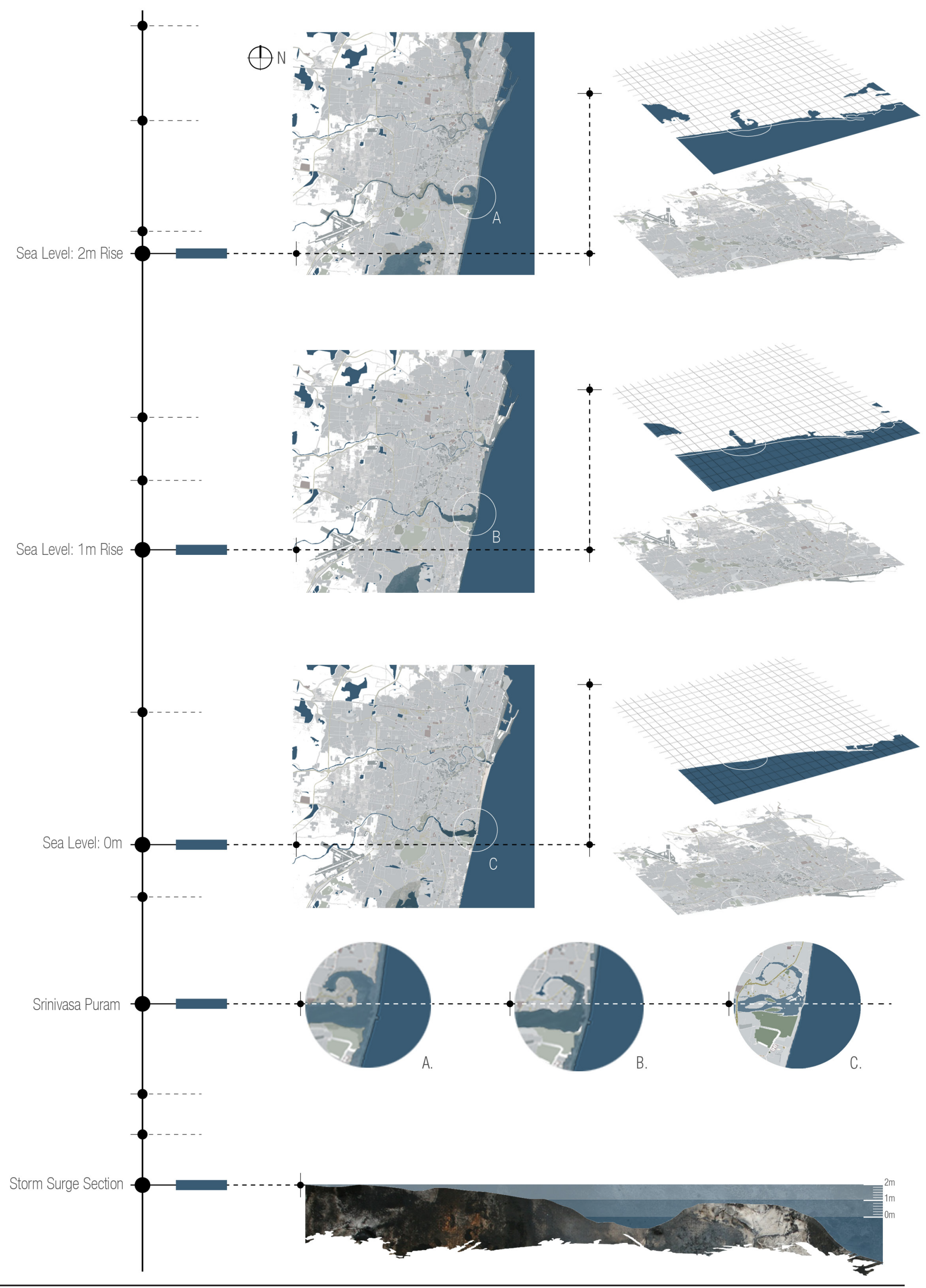

Fig. 16. Projected sea level rise due to global warming, Chennai. 


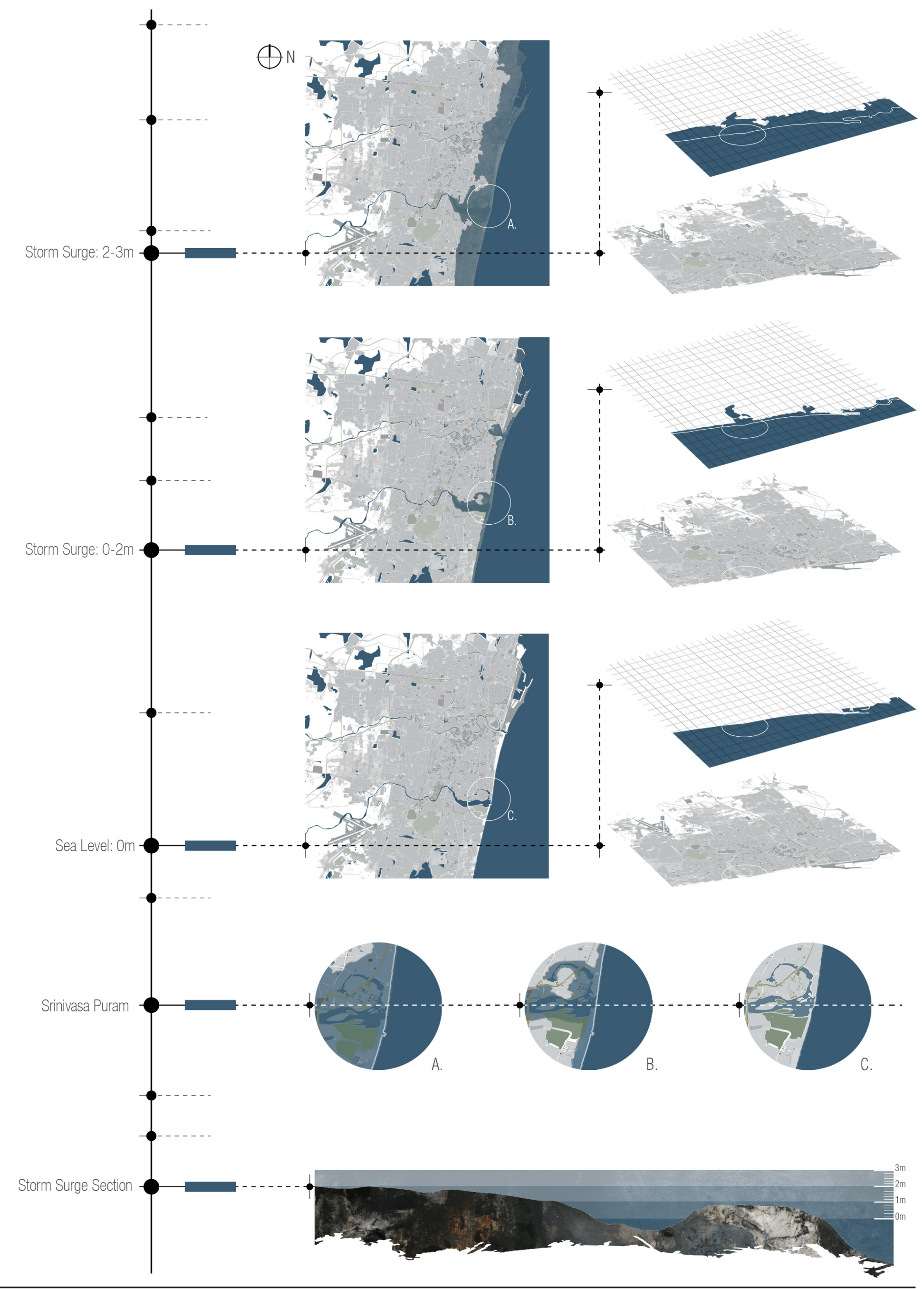

Fig. 17. Storm surge, Chennai. 
The projections for extreme storm surges (Figure 17) are subject to a number of variables including shoreline change rate, mean sea level change rate, regional elevation, bathymetry, mean tidal range, significant wave height and return periods (Kumar and Kunte 856, 857). Srinivasa Puram stands between 2-3m above sea level and can become inundated when severe storm surges meet a high tide. Storm surges generated from tropical cyclones have a long history within the state of Tamil Nadu and a number of breakwater strategies have been implemented in northern Chennai to mitigate damage to large scale fishing operations and coastal dwellings adjacent to Chennai's main port. 


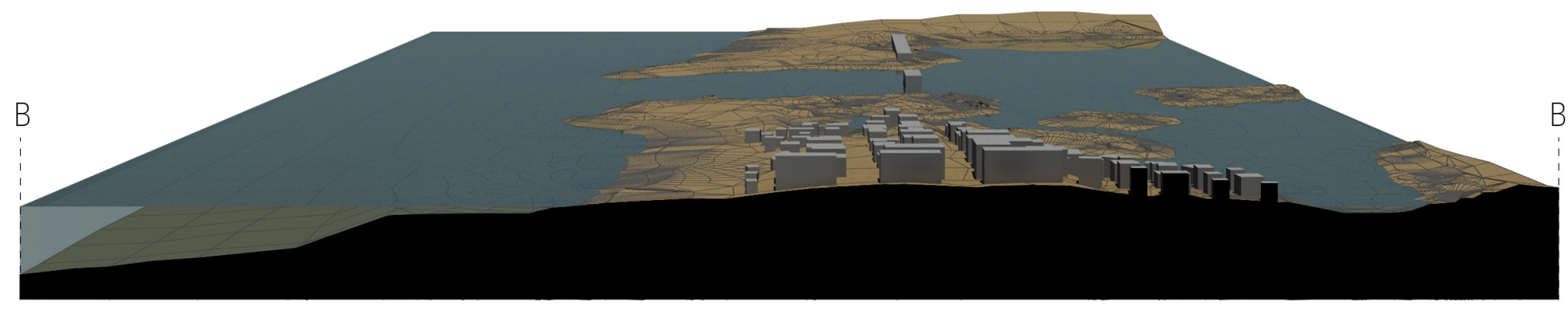

Transverse Section

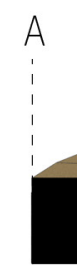

Longitudinal Section 
3

2.4 SRINIVASA PURAM DEMOGRAPHIC
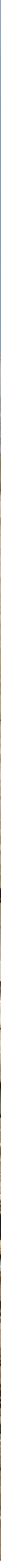


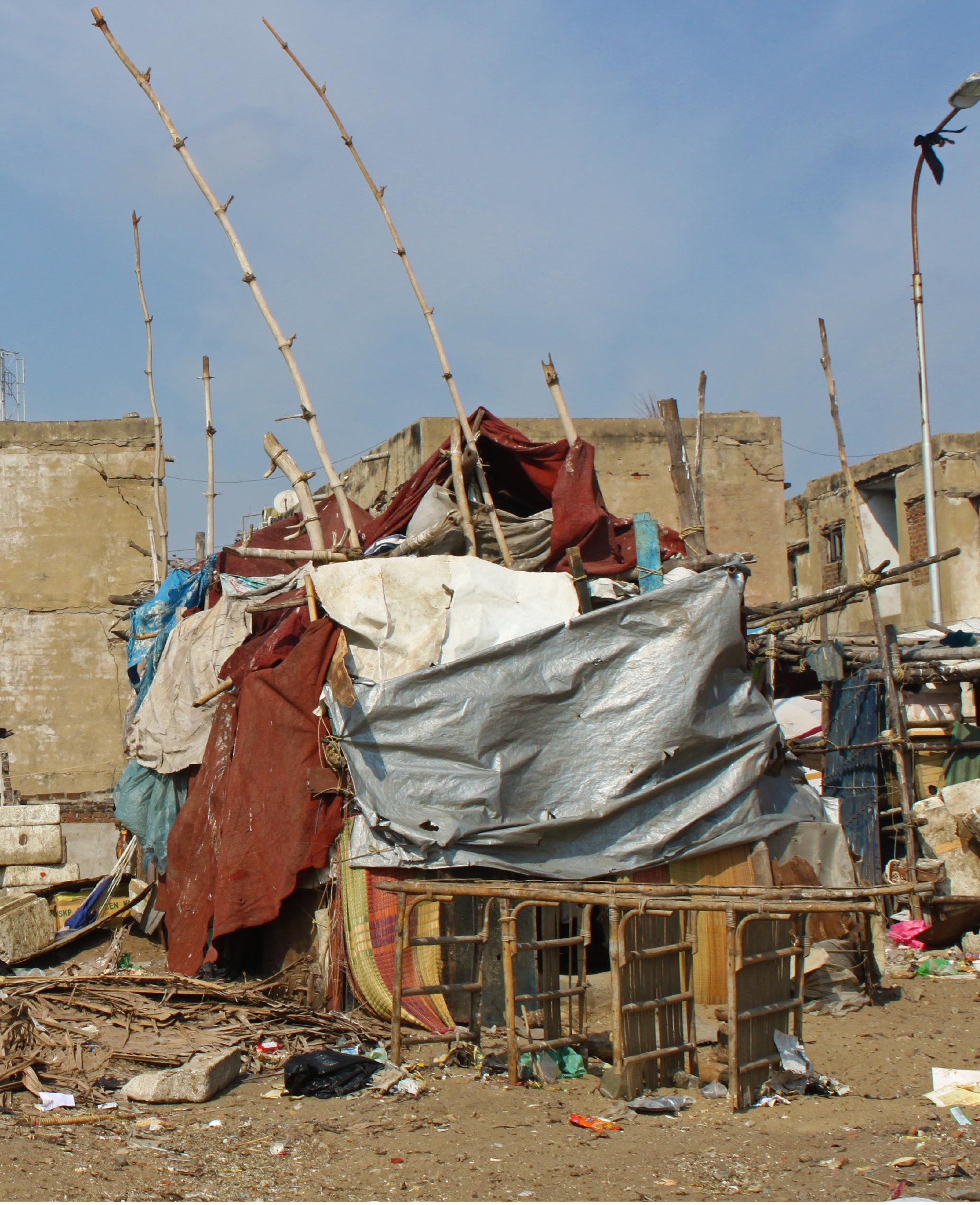


With approximately 27,000 people per $\mathrm{km}^{2}$, Chennai is one the most densely populated cities in the world. The 2011 national census recorded Chennai's population at 4.7 million with an additional 1 million slum dwellers estimated. Between 2001 and 2011, Chennai's population growth rate measured $7.8 \%$ (0.78\% per annum) (Umachandran).

With no accurate data surrounding Srinivasa Puram's current population, the national Indian census figure of 4.8 people per family ("A Tale of Two Emerging Economies") will be used to generate an estimated number of residents for the thesis design research experiments. The Tamil Nadu Slum Clearance Board has recorded 3086 families living in Srinivasa Puram (Raju), which suggests a current population of 14,813 , of which 769 families directly belong to the fishing community. 


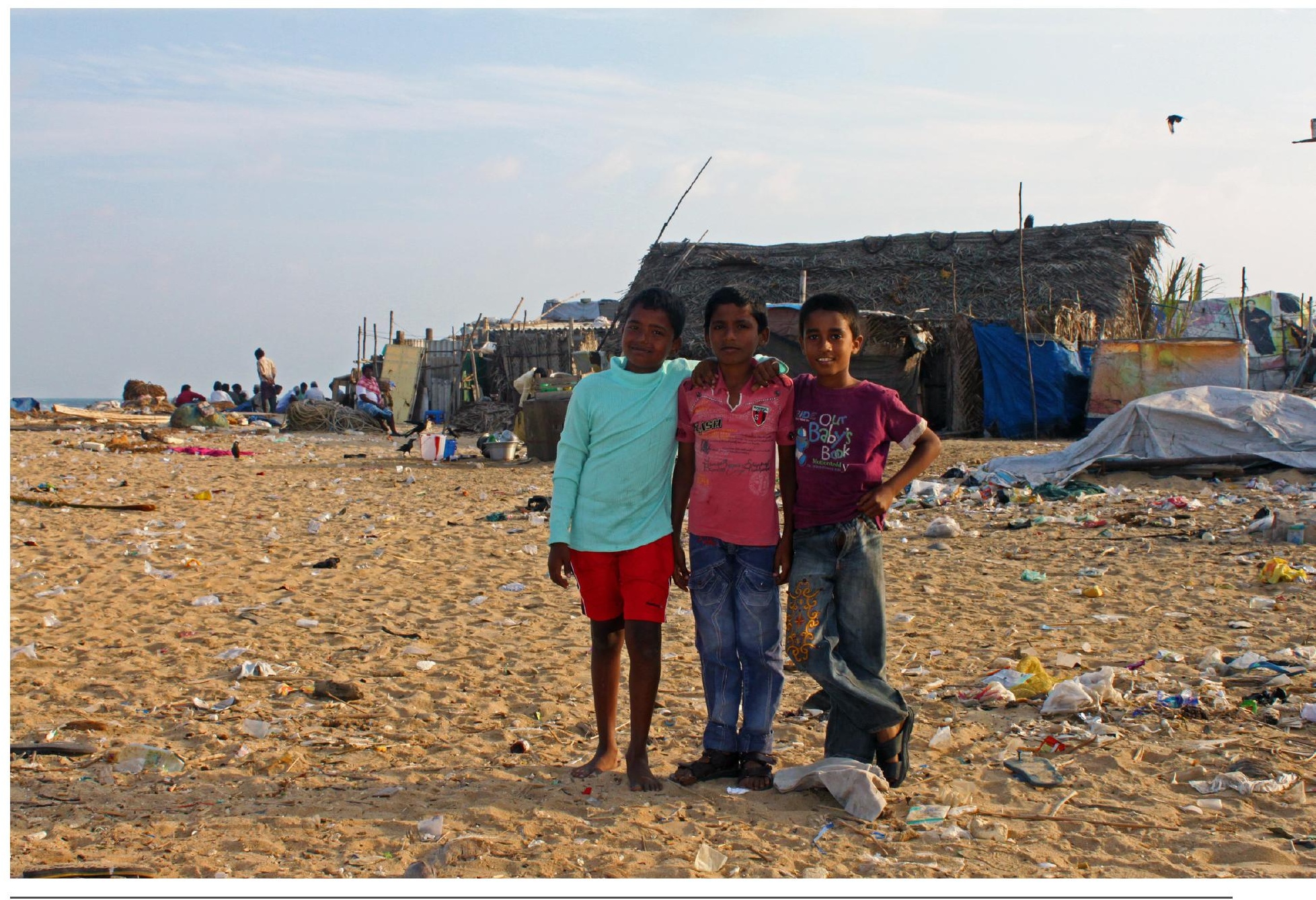

Fig. 20. Children of Srinivasa Puram.

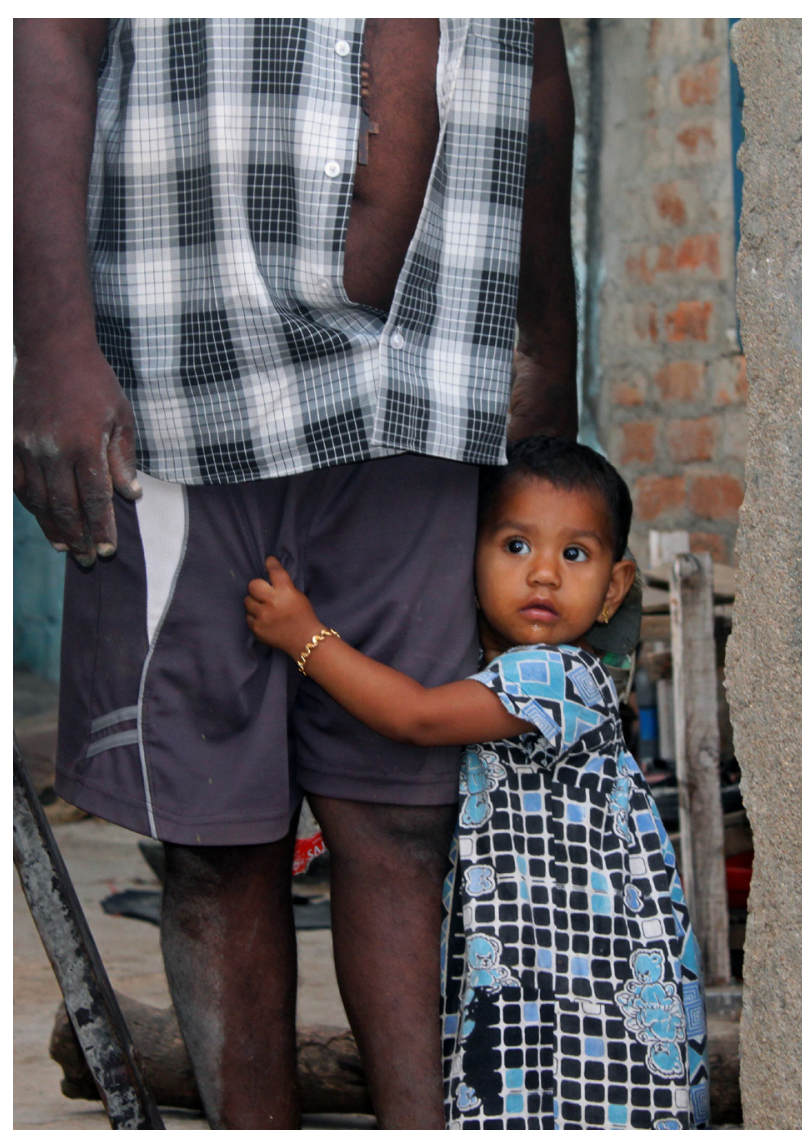

Fig. 21. The next generation. 


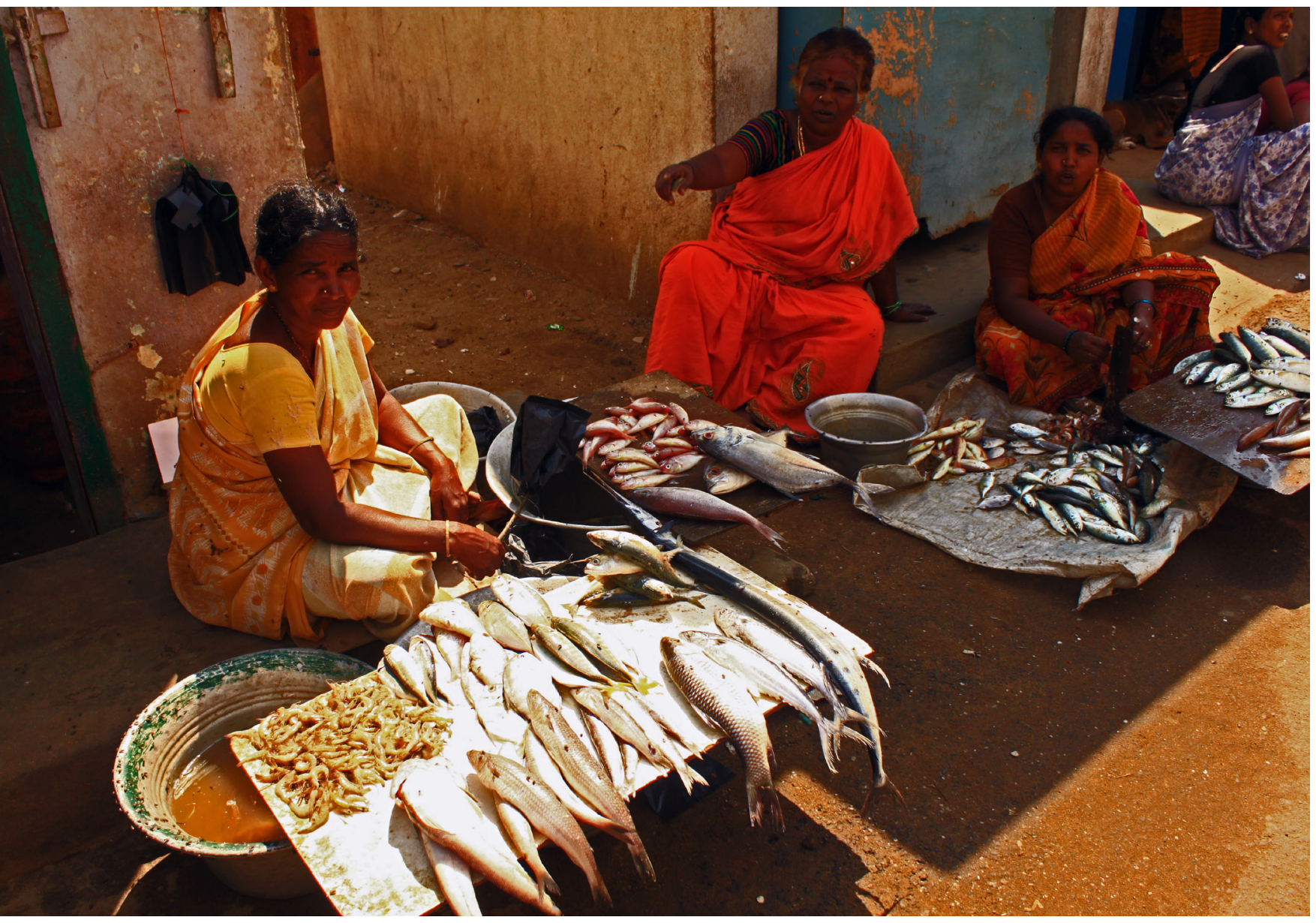

Fig. 22. Market space.

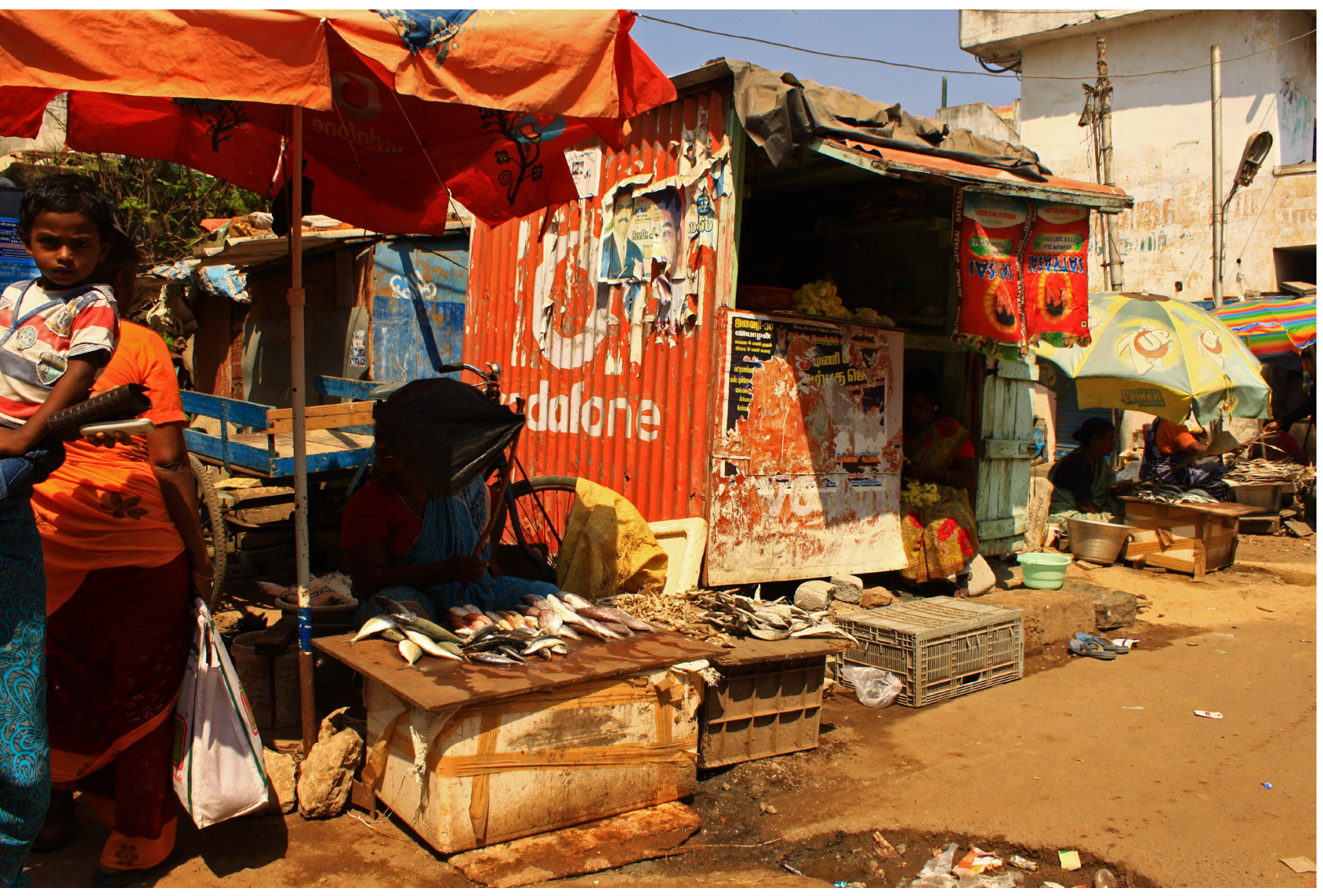

Fig. 23. Market space. 
"We use signs from the sea and the sky when deciding whether to venture out on a fishing trip (Raju)."
In his research article "Housing Reconstruction in Disaster Recovery: A Study of Fishing Communities Post-Tsunami in Chennai, India" Emmanuel Raju writes: "The majority of the fisher-folk expressed their 'belongingness to the sea' as an important cultural aspect of their life" (Raju). Mooring boats, fishing equipment storage and market space are all issues that pose concern if the residents of Srinivasa Puram are relocated more than 4 kilometers from the coast by government relocation schemes.

Srinivasa Puram has no mooring structures or shelter for its fishing vessels. Boats and equipment are pulled ashore beyond the hide tide line onto the beach. The formation of the sandbar at the Adyar River mouth prevents fishermen from storing boats in the more protected estuary behind the slum.

Visiting the site In January 2014 it was evident that the slum had a lack of dedicated public space for markets and leisure activities. Fruit, vegetable and fish were sold from temporary stands crammed between buildings (Firgure 22-23). Outdoor communal activities took place along the garbage-strewn beach amongst fishing boats and nets. 


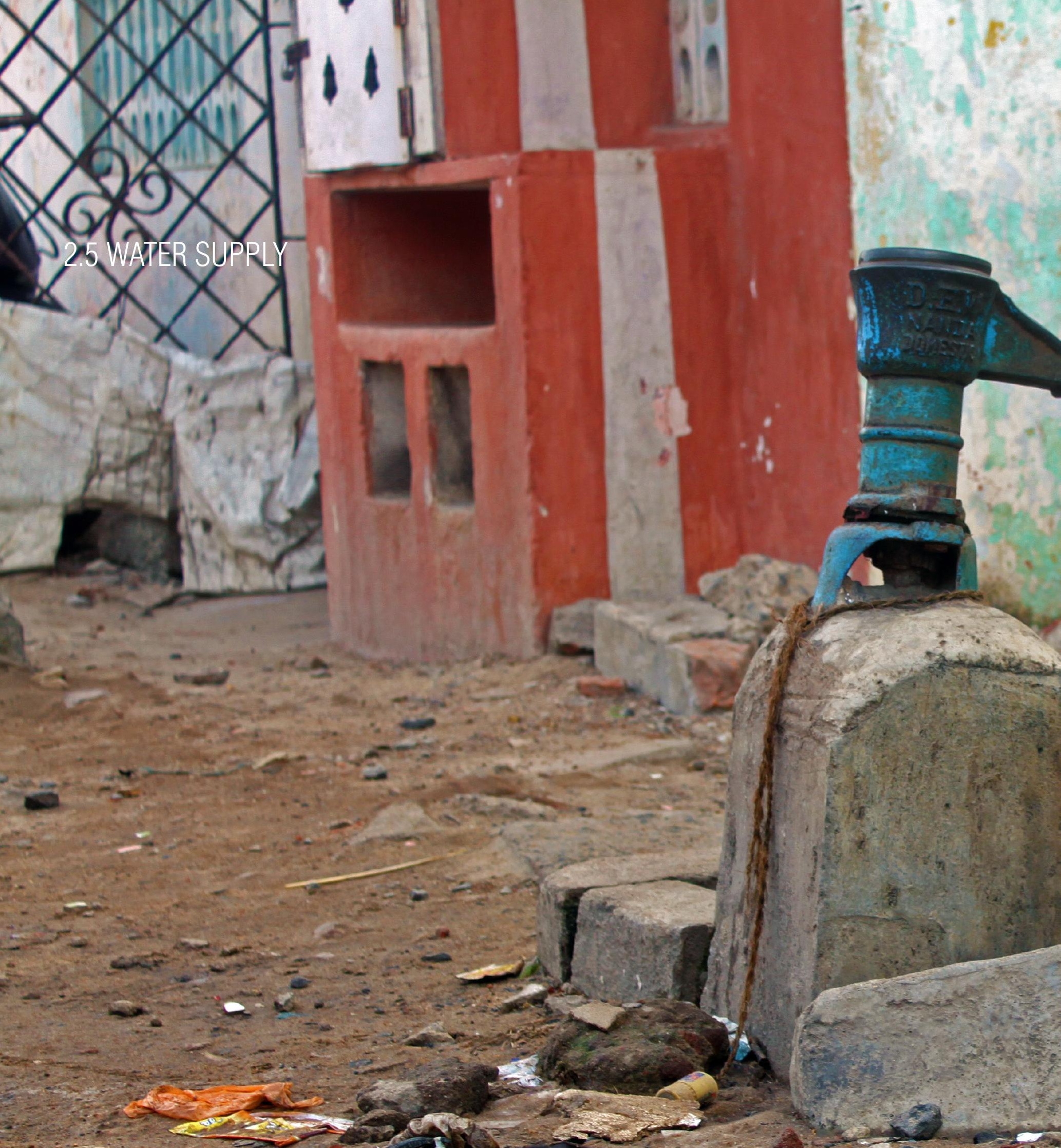

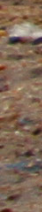

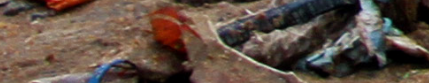

sesest

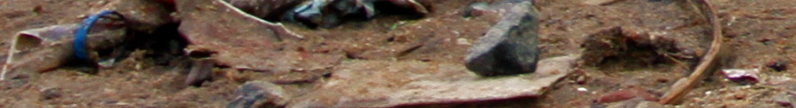

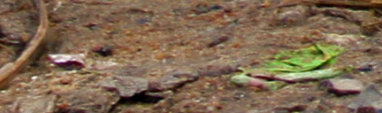

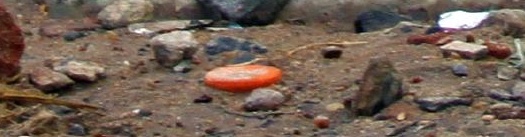

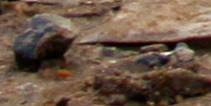
$+4 x^{2}=$ 
BMD

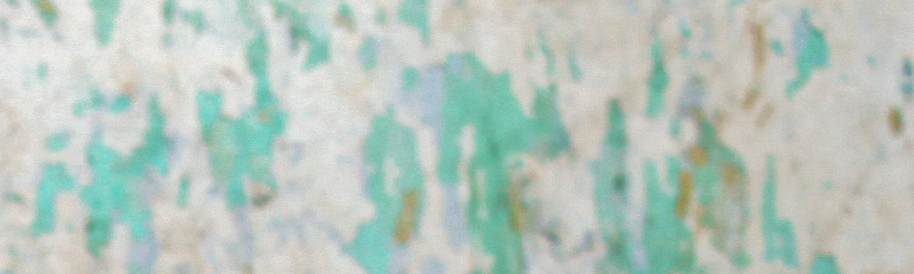

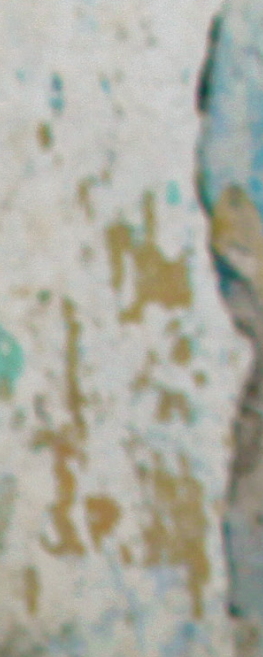

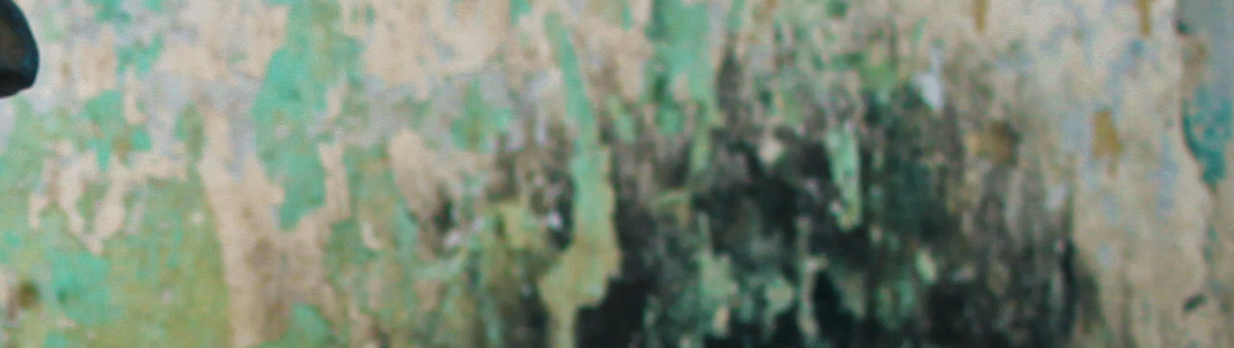

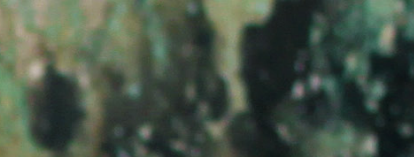

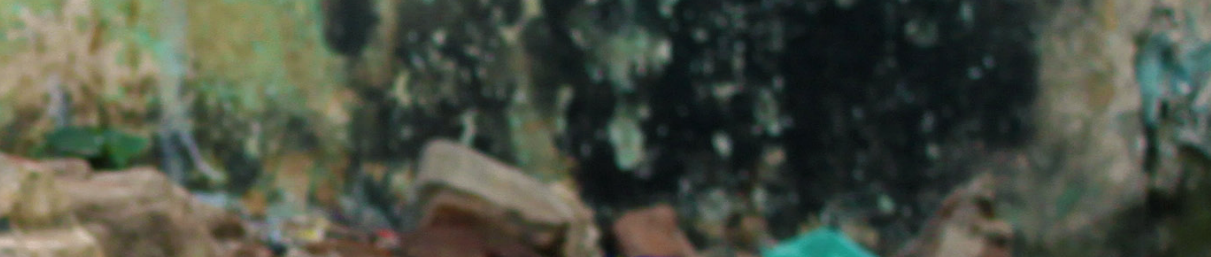

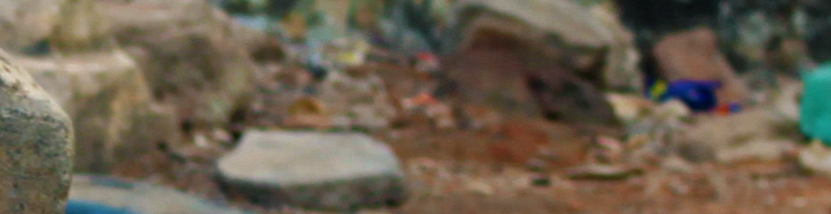
i.

\section{$\operatorname{lic}_{1}^{8}$} tet. 2,4
3

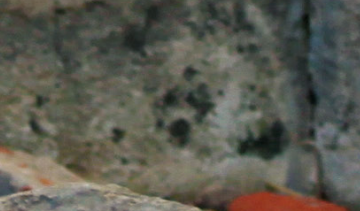

sing

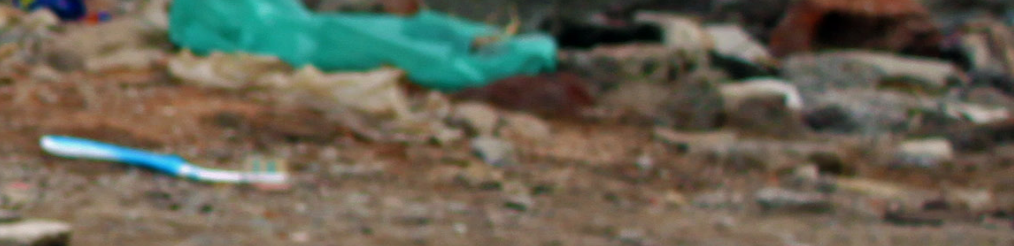
sin

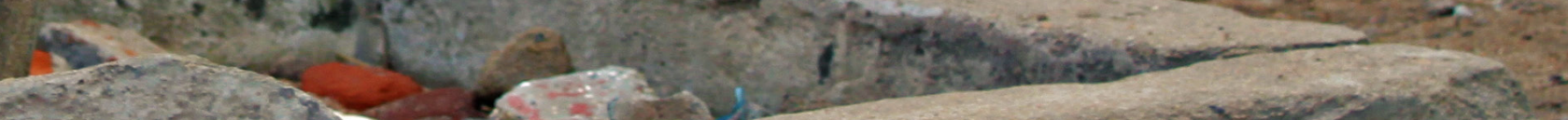
=.-. $3+2+4$ tincos

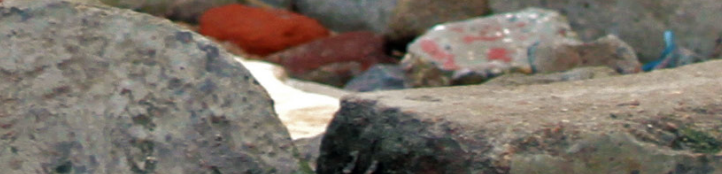

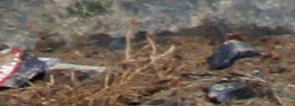

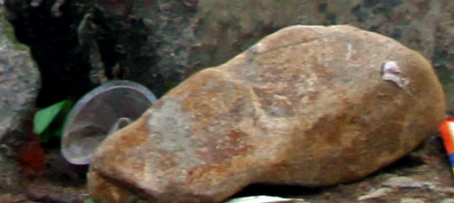

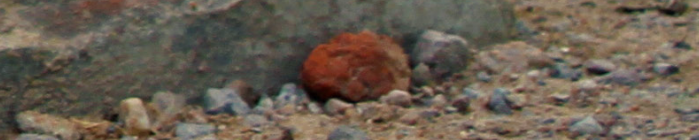

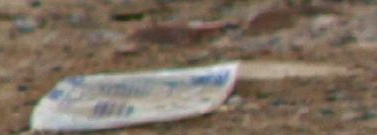

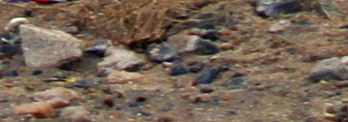

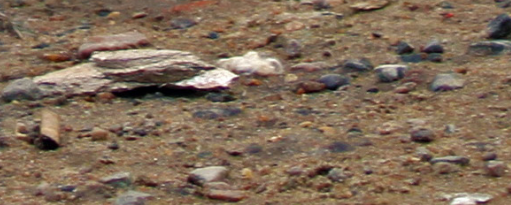

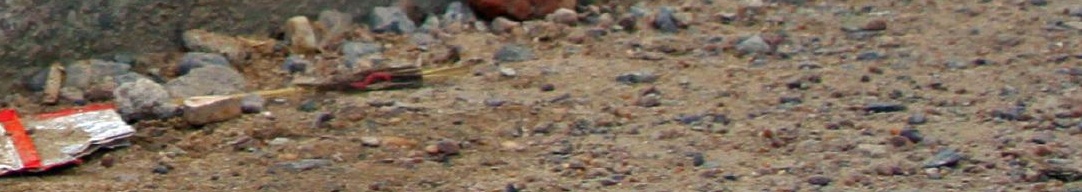

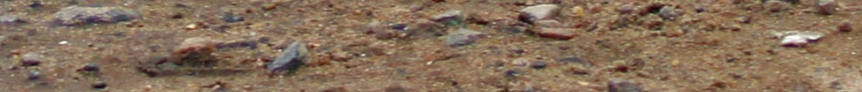

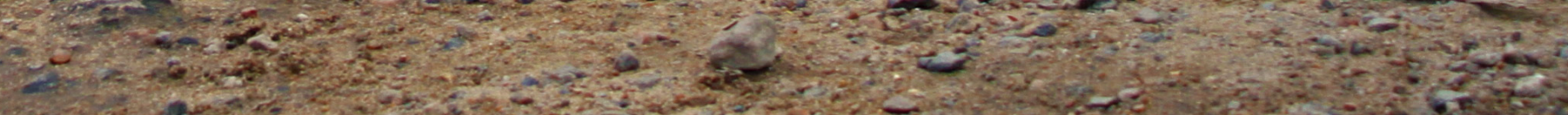

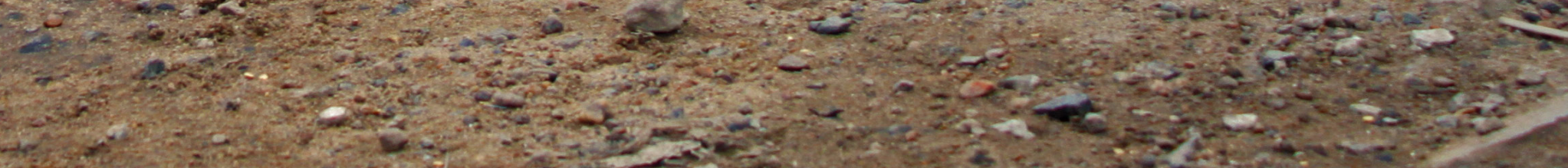


Chennai's current water supply of approximately 766 million liters per day falls drastically short of the city's 1.009 billion liter per day demand (Srivathsan).The city's four reservoirs deliver an average per capita water supply of 114 liters per day to much of the city through pipelines and tankers. Unfortunately it has become the norm for many slum communities to survive on 20-40 liters per capita daily for much of the year. During the dry months there is a severe water shortage throughout Chennai and many bore wells dry up. The first to be restricted are the slum communities and the already minimal daily water supply can often be required to stretch two or even three days before tankers return (Lakshmi). 


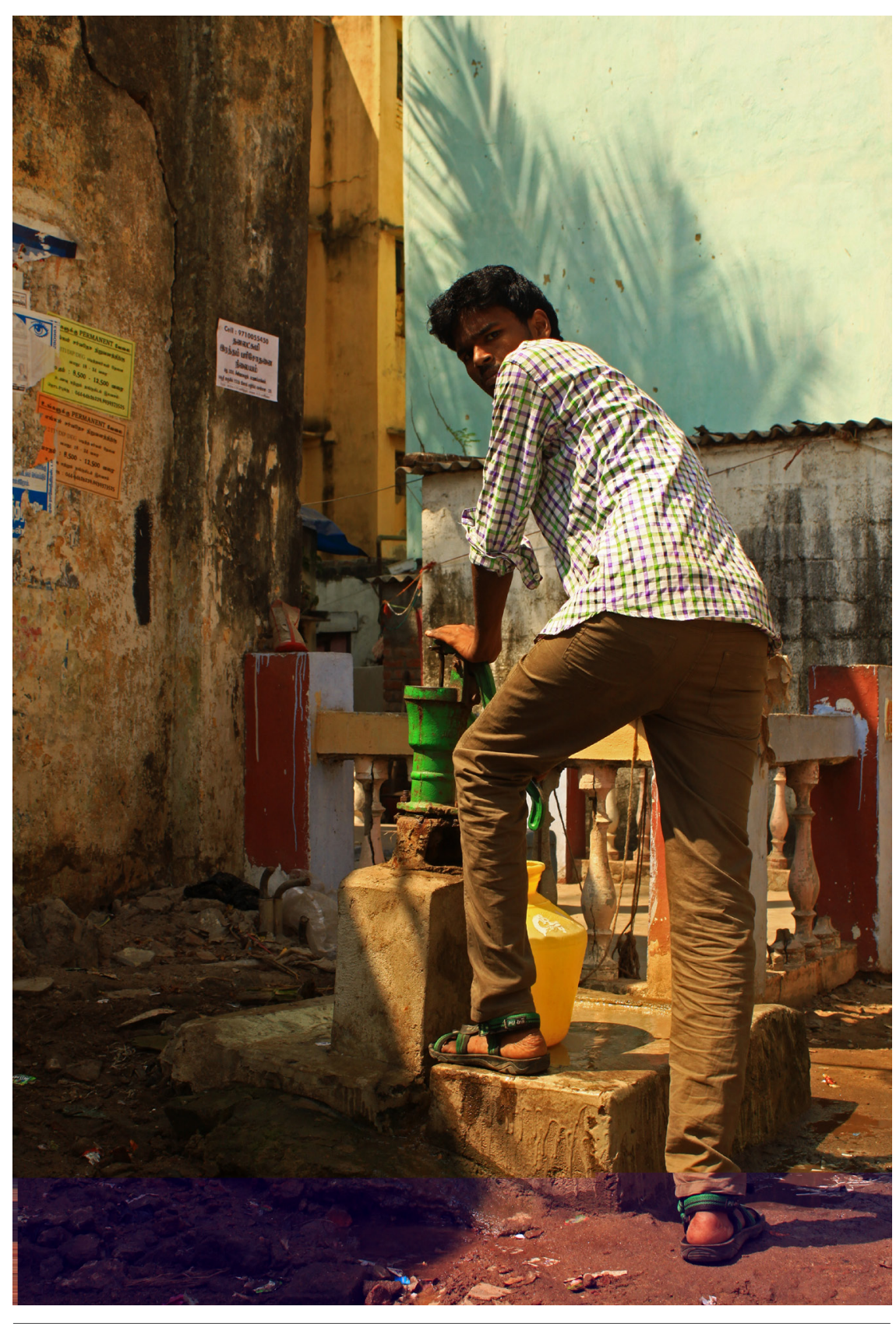

Fig. 25. Hand pump.

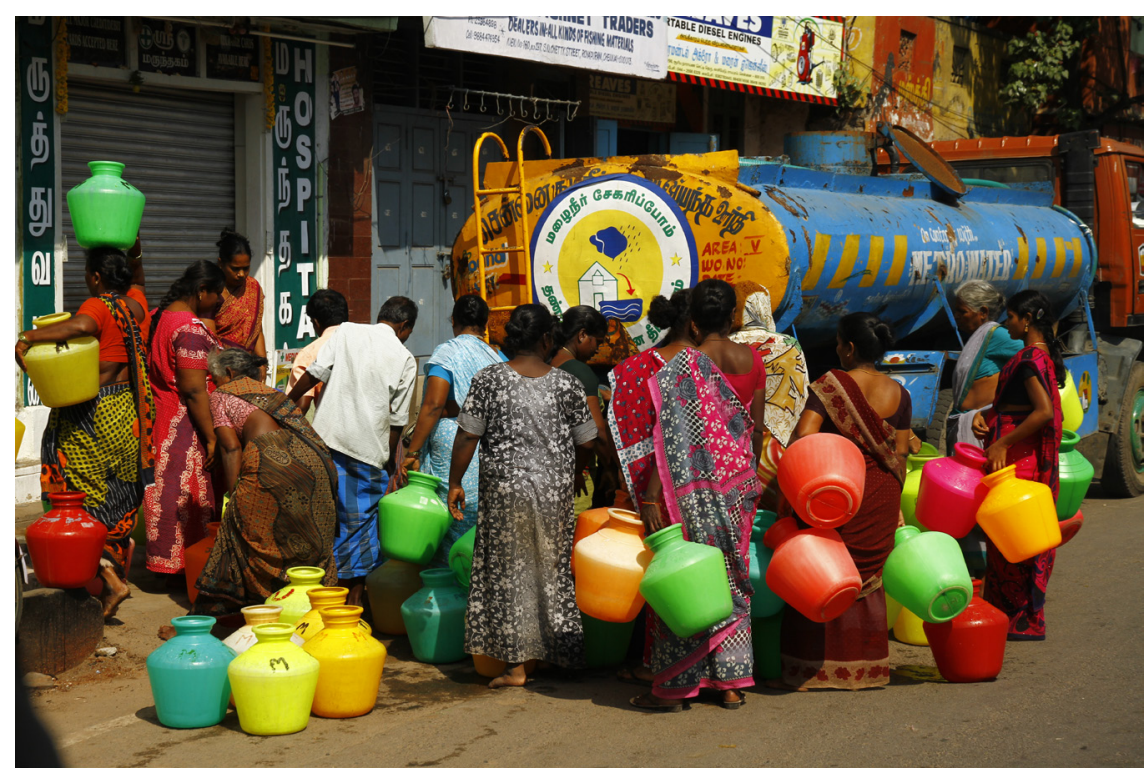

Fig. 26. Current water supply via tankers. 


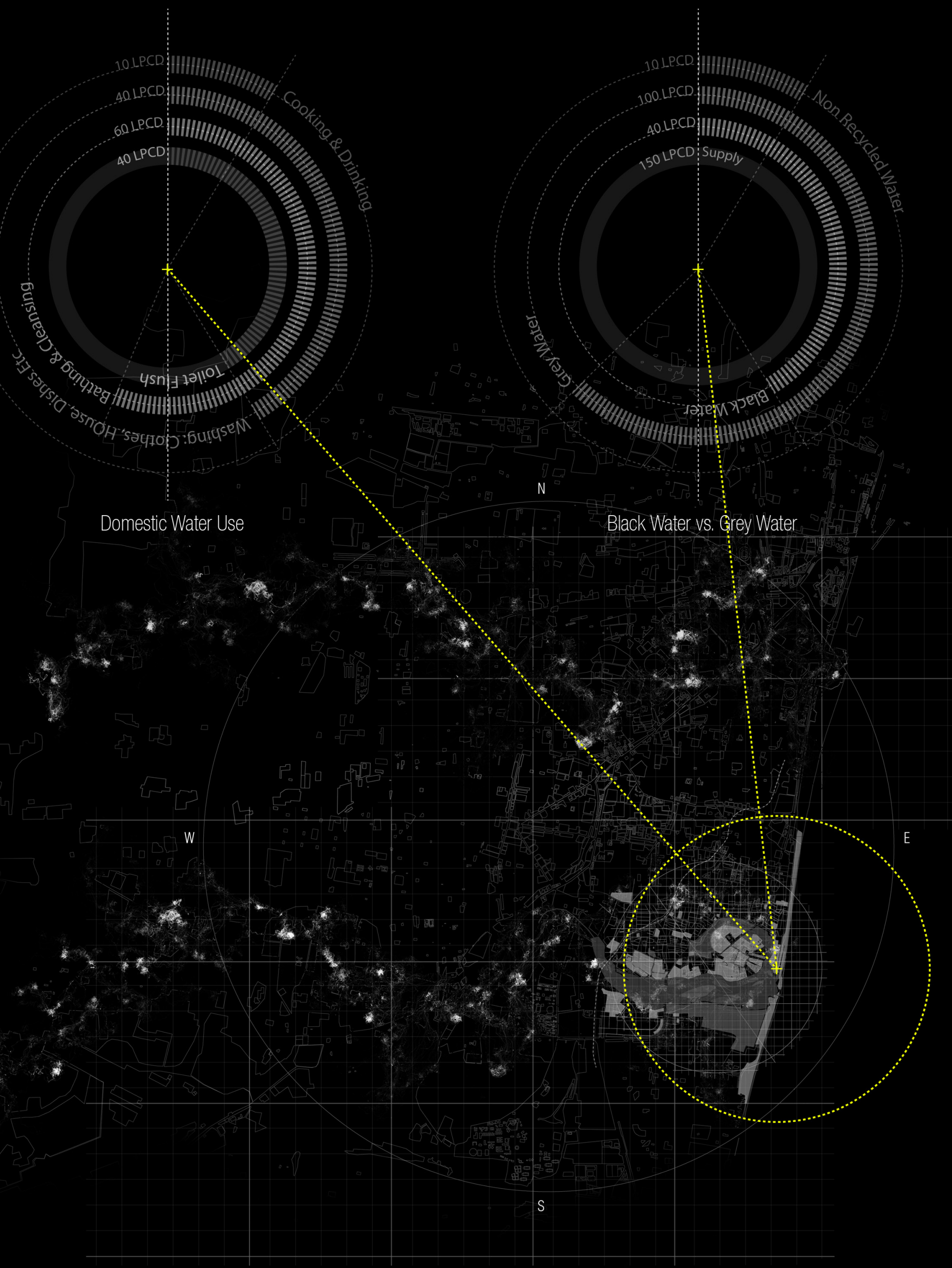


Figure 27 illustrates a typical per capita daily water use breakdown graphically illustrating: How much water does an urban citizen need? (Vishwanath) and representative of water demand for Srinivasa Puram. The current water supply is variable as tankers are their only source of fresh water. The black water vs. grey water diagram illustrates a breakdown of the potential recyclable water each person would produce if supplied 150 liters of fresh water per day. 


\subsection{SANITATION}
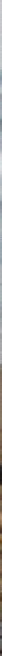

$$
\text { - } 5 \text { - }
$$

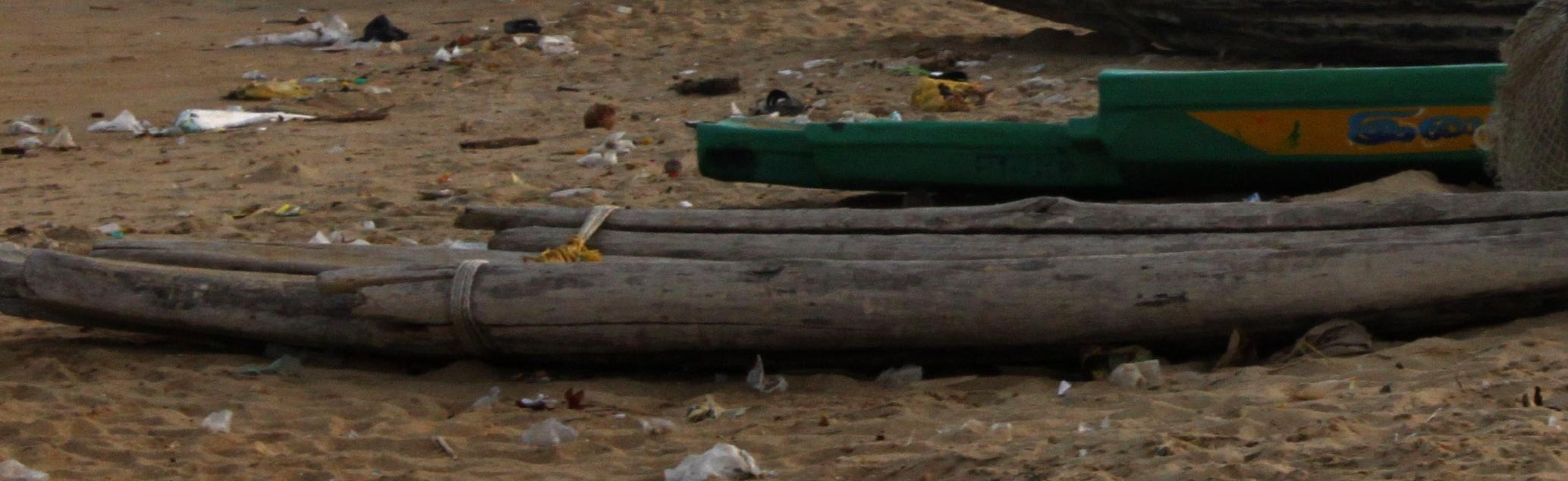
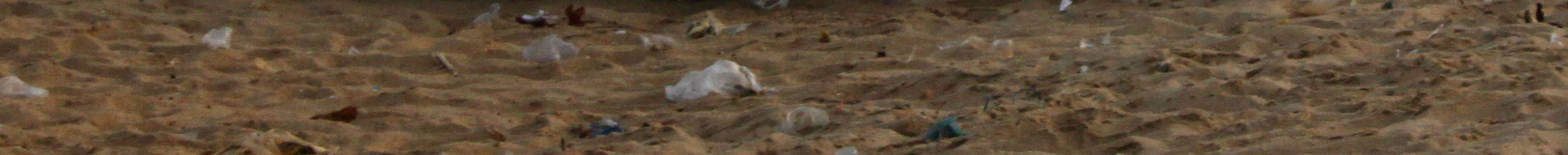

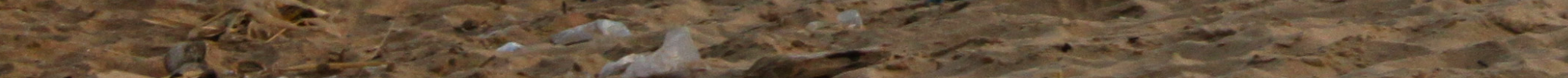

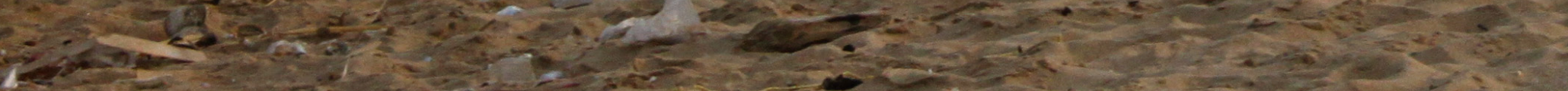

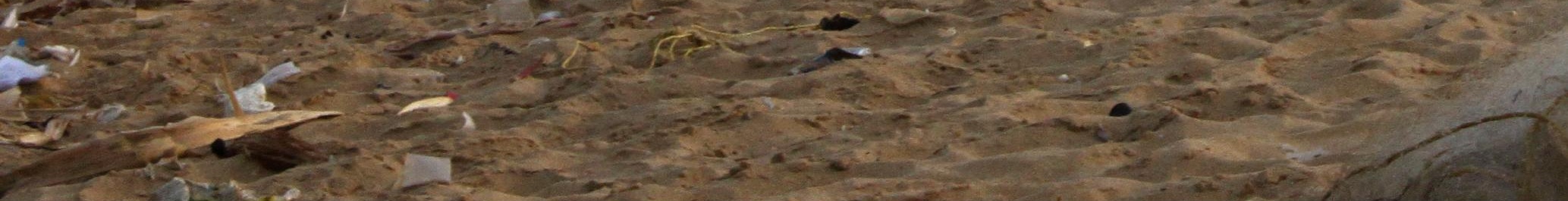




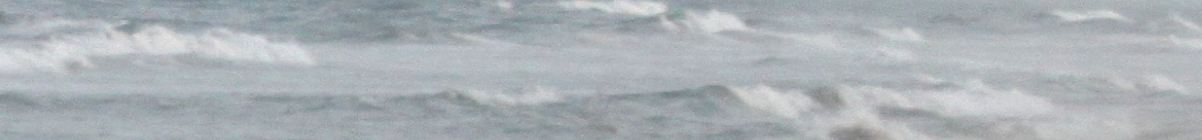

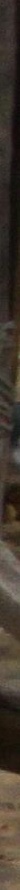

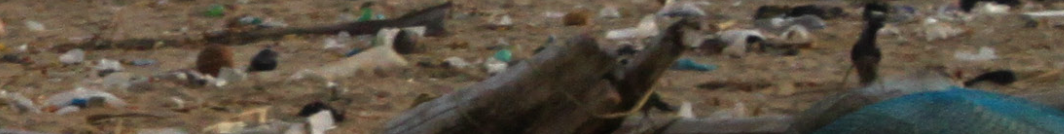

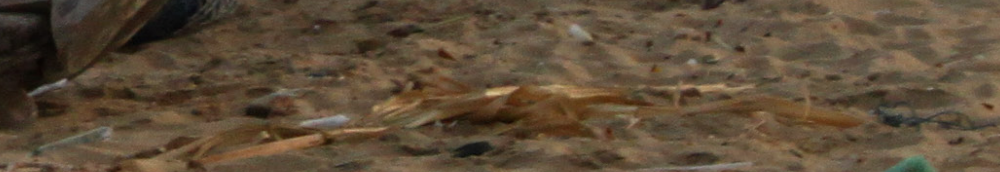

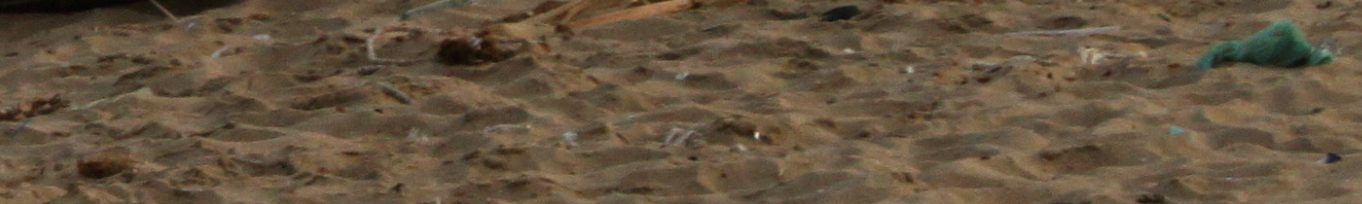

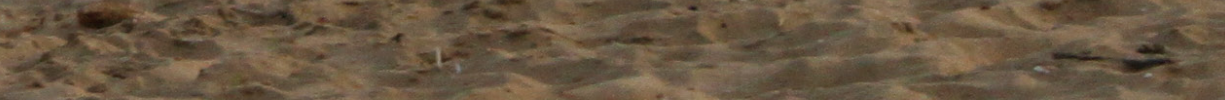

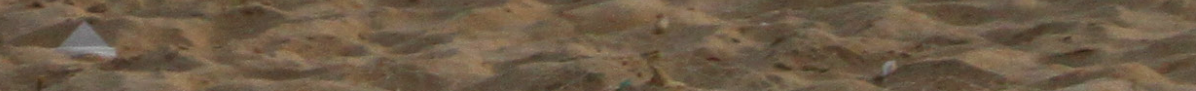

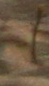

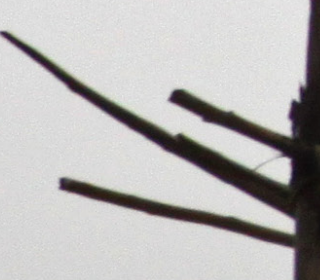




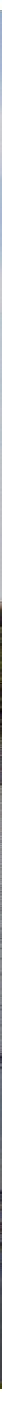

Fig. 29. Floating sludge in the Adyar Estuary behind Srinivasa Puram. 
The Chennai metropolitan area produces 580 million liters of sewage every day at a rate of 40 liters per capita daily, although the city only has the infrastructure to process a capacity of 558 million liters per day through its 10 treatment plants ("Meeting the Challenges in Water and Sanitation..."). The remaining surplus of solid waste often ends up in the city's waterways. A number of Chennai's sewage treatment plants are designed to generate renewable energy by converting the methane content in Bio-Gas to electricity and effectively enabling the treatment plants to be virtually self-sustainable.

Srinivasa Puram currently has no sewage system in place meaning that all human waste is deposited either on the beach littoral zone or in the Adyar Estuary behind the slum (Figures 28-29) causing hygiene issues and damaging the surrounding ecosystem. 


\subsection{WASTE MANAGEMENT}

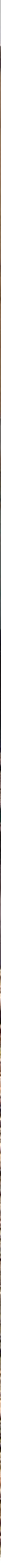




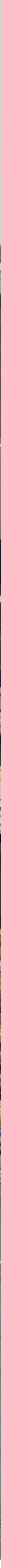



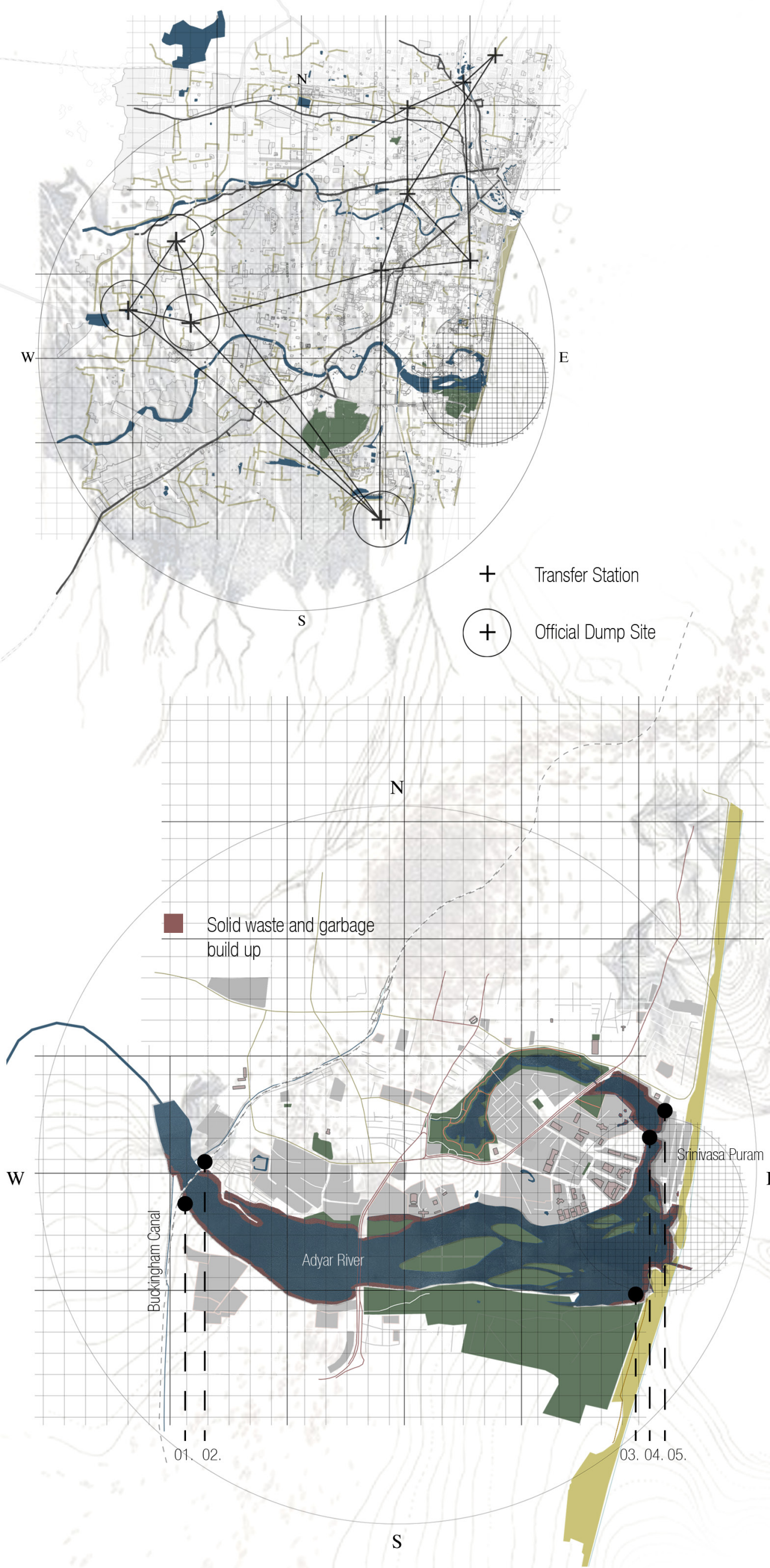

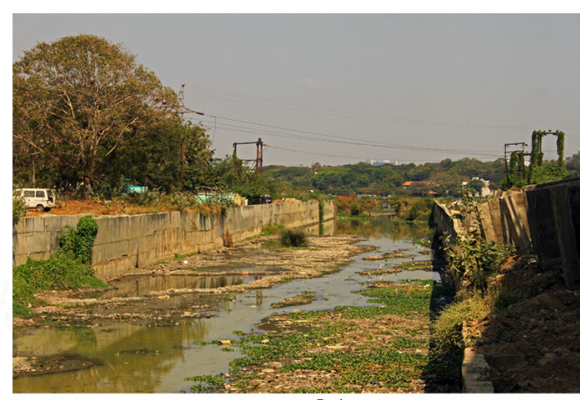

01. Buckingham Cana

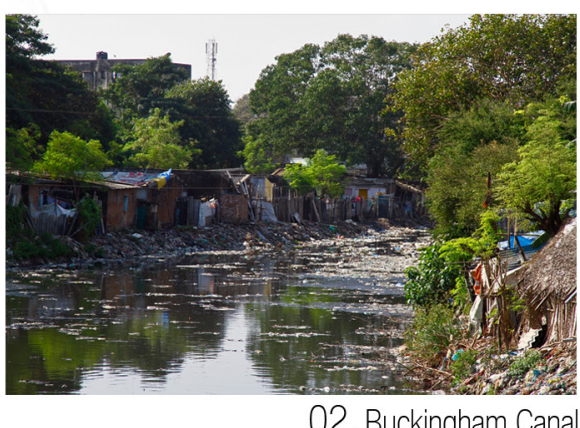

02. Buckingham Canal

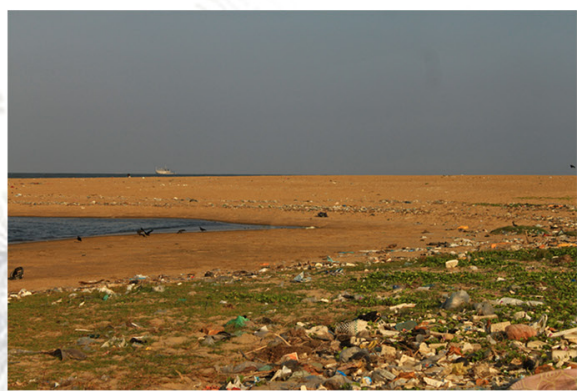

03. Adyar River Mouth

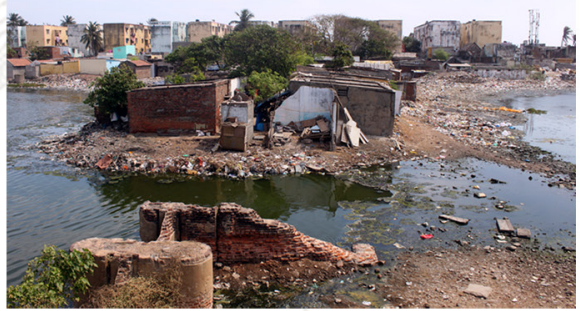

04. Srinivasa Puram

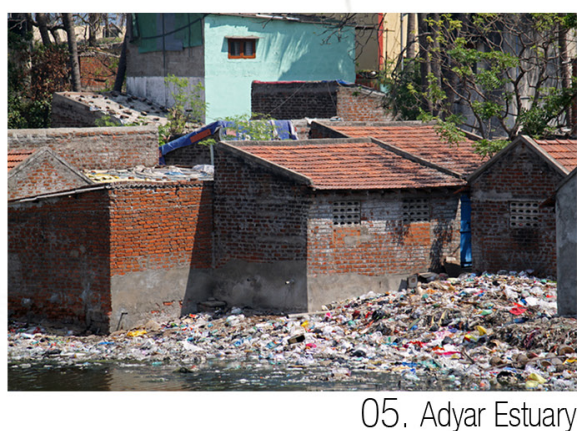


Upon visiting Chennai in January 2014, one of the more visually noticeable and horrific conditions of the city was the staggering amount of garbage that not only littered the beaches but predominantly the waterways. Areas of the Adyar River and Buckingham Canal from a distance appeared to be a garbage dump, though closer examination proved otherwise. Stagnant mosquito ridden waterways resided beneath thick layers of garbage and solid waste (Figure 31). These are the same waterways used for bathing, clothes washing, and fishing for thousands of slum dwellers along the river banks downstream. The article "Studies on the distribution of heavy metal concentrations in River Adyar, Chennai, Tamil Nadu" highlights the high levels of zinc, copper, cadmium, iron and lead found polluting the Adyar River as a result of rapid urbanisation and industrial development over the last decade (Silambarasan, Senthilkumaar, and Velmurugan). Due to the perennial sandbar formation at the river mouth and the low $1.2 \mathrm{~m}$ tidal range, the Adyar River is unable to naturally flush the toxic waste until the monsoon season (Gupta and Nair). To help ameliorate the stagnant nature of the waterway and facilitate flow, the local government employs two large scale excavators to dredge the river mouth at frequent intervals (Lakshmi).

The Waste to Energy Research and Technology Council in India highlighted that Chennai has the largest per capita waste volume in the country ("Chennai's per Capita Waste..."). Chennai currently produces 6,404 tonnes of waste every day at an average of $0.71 \mathrm{~kg}$ per capita daily. The article states that an average household in Chennai generates $60 \%$ organic waste, $30 \%$ recyclable waste and $10 \%$ hazardous waste. While the city has four official dump sites, Chennai's waste management system is failing to meet the demand which is having catastrophic effects on the surrounding environment. Figure 31 highlights a garbage dump site within 8 kilometers of Srinivasa Puram yet the slum receives no assistance in the form of a waste management system. Visiting the site in person, it was evident that the majority of their waste ended up in the Adyar Estuary directly behind Srinivasa Puram (Figure 31.04-05). 
2.8 PHOTOGRAPHIC ANALYSIS

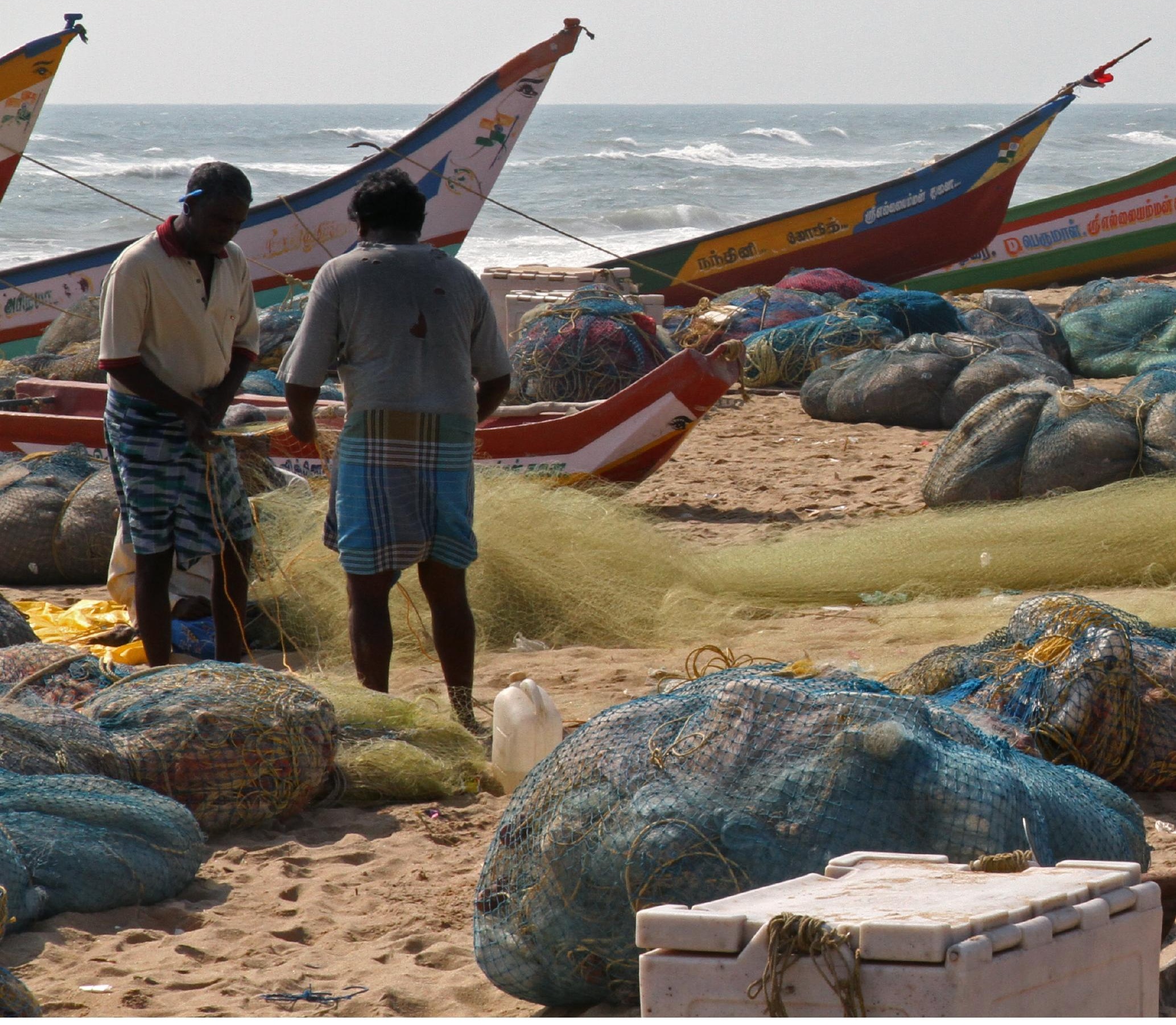




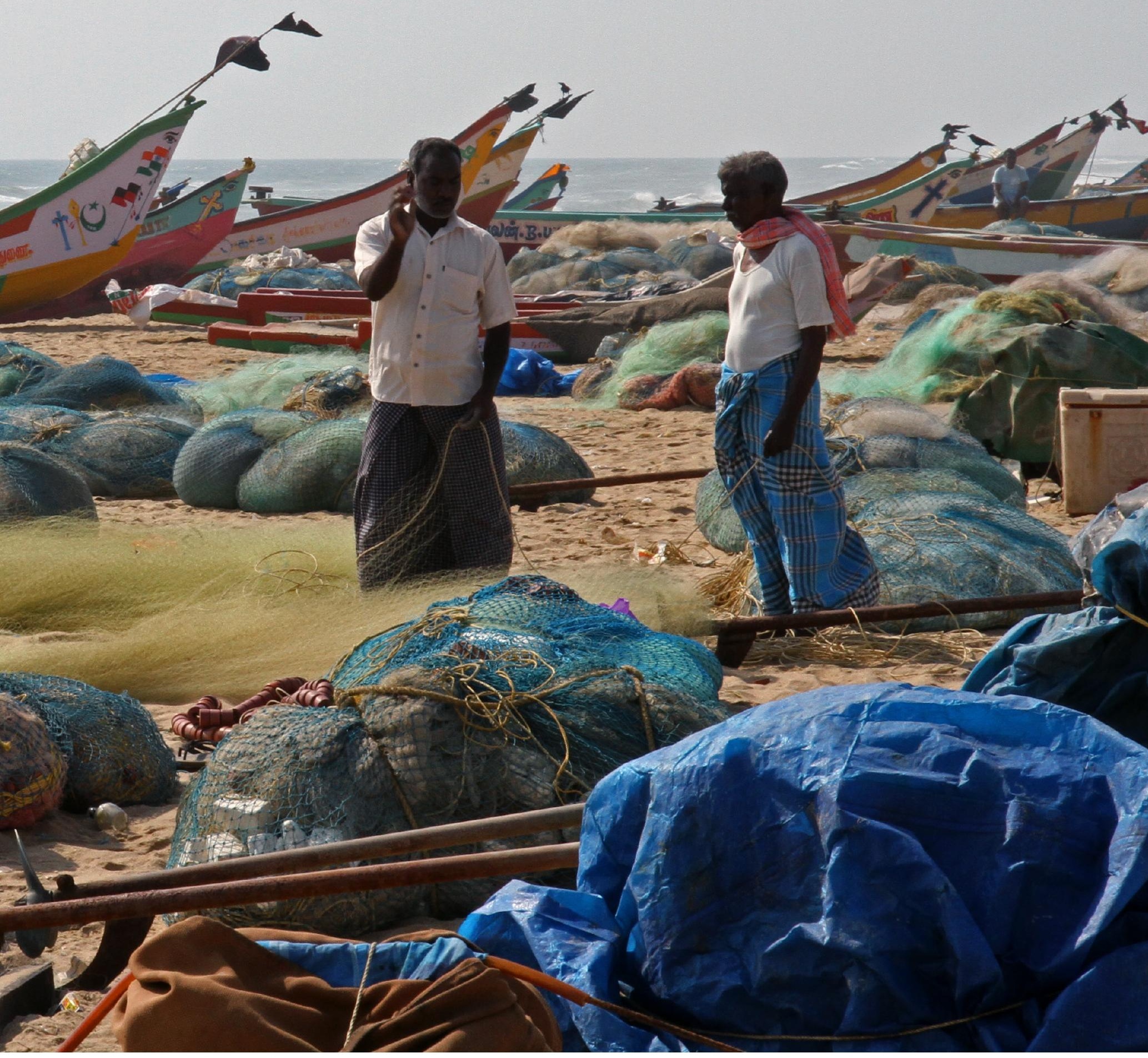




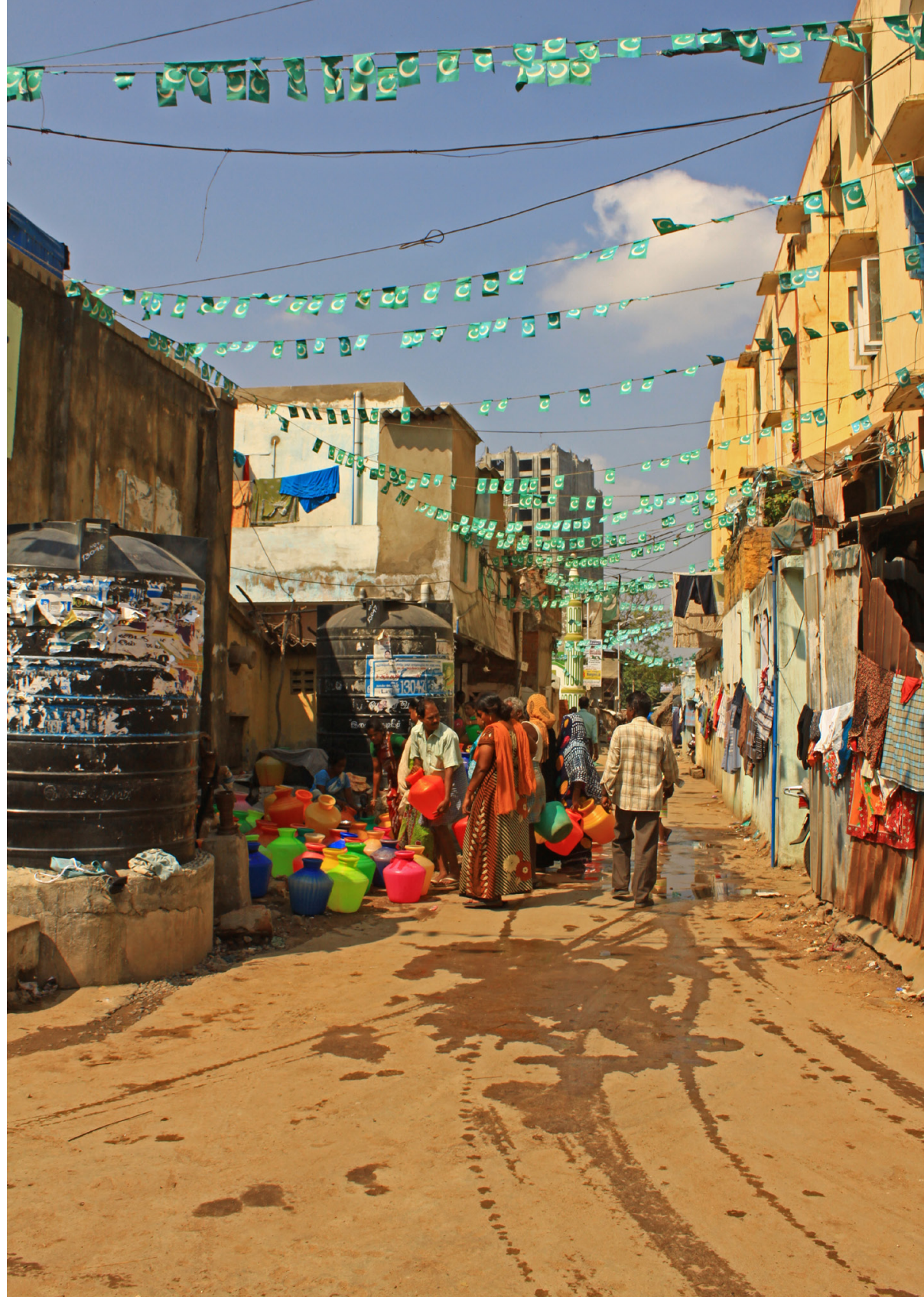

Fig. 34. Water supply: Water tanks filled via tankers.

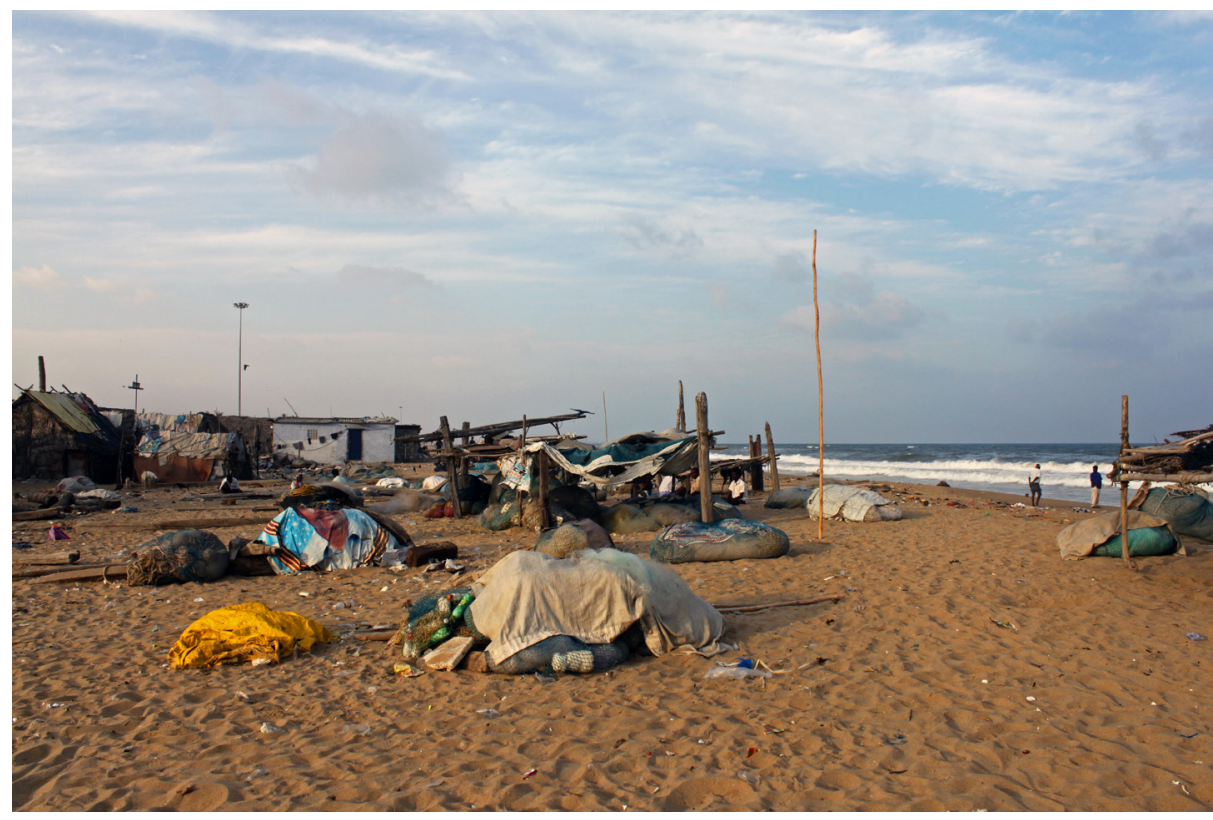

Fig. 33. Dwellings and fishing equipment. 


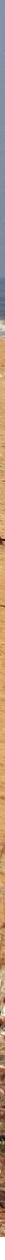

Fig. 35. Empty land after Boxing Day tsunami. 


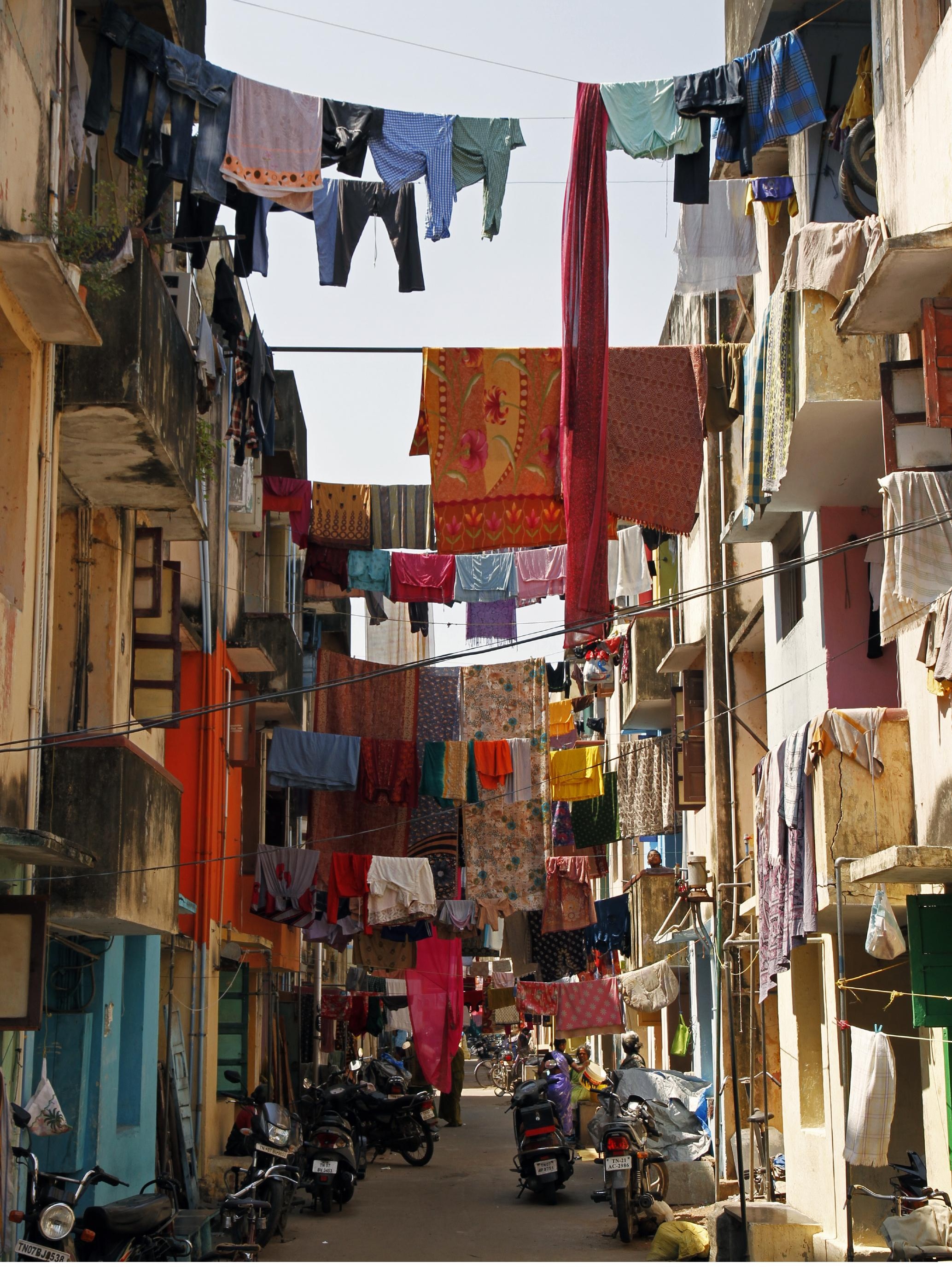




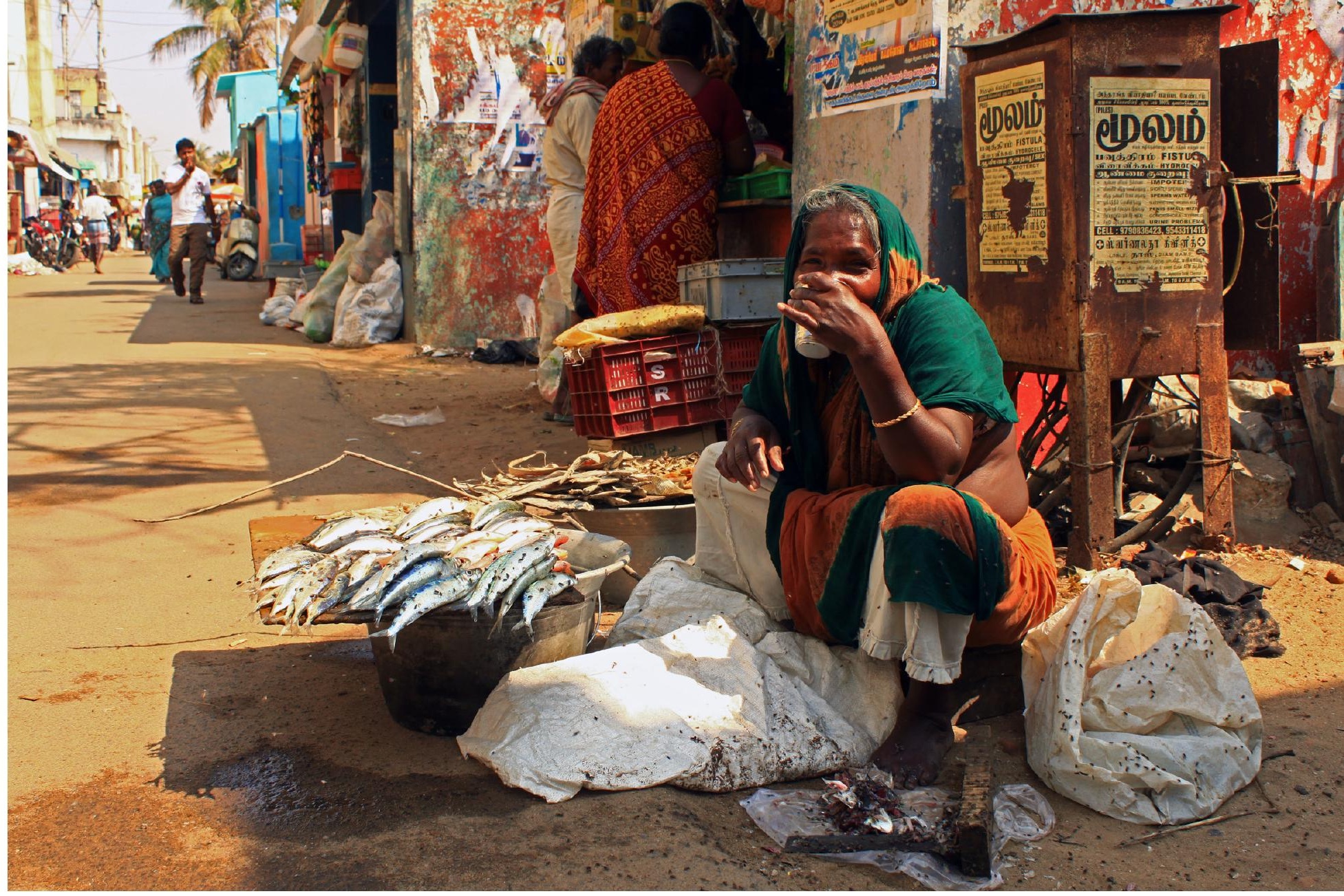

Fig. 37. Woman selling fish covered in flies.

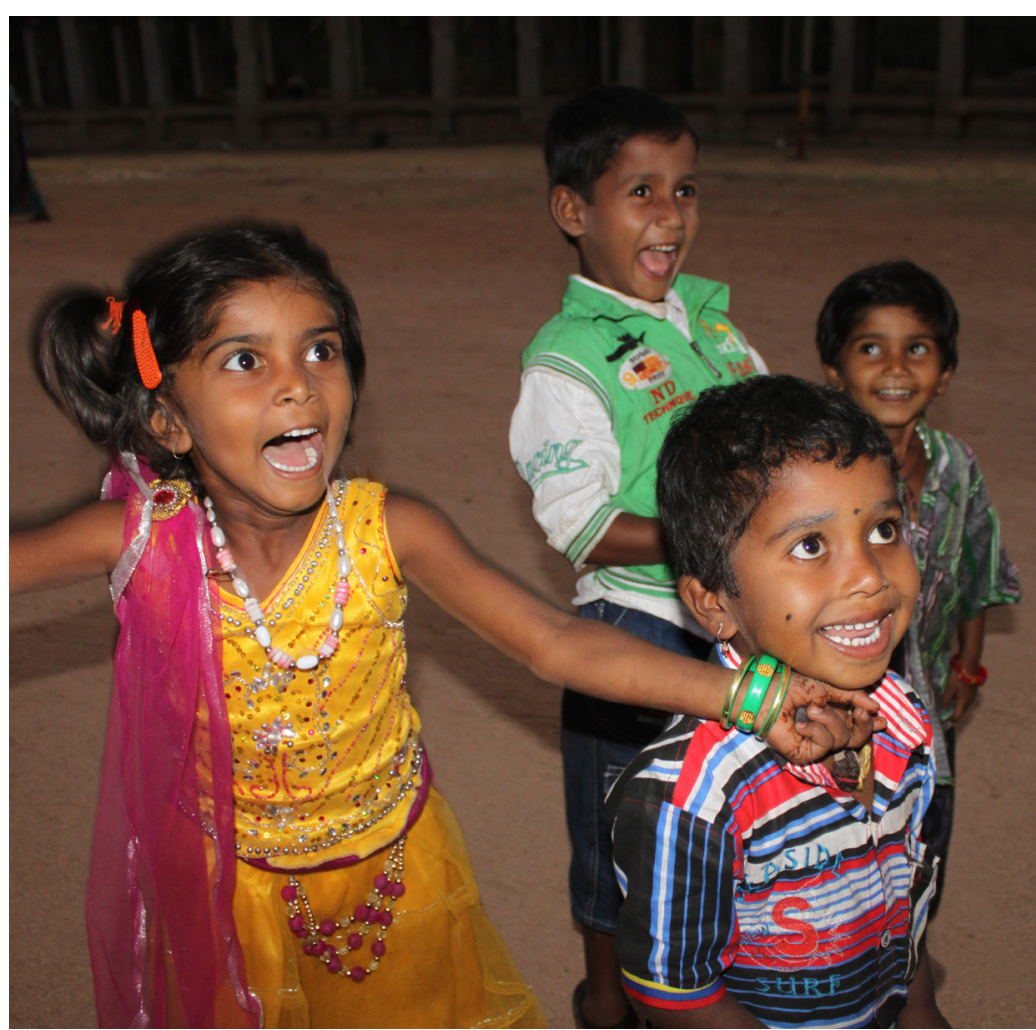

Fig. 38. Children playing in the streets. 


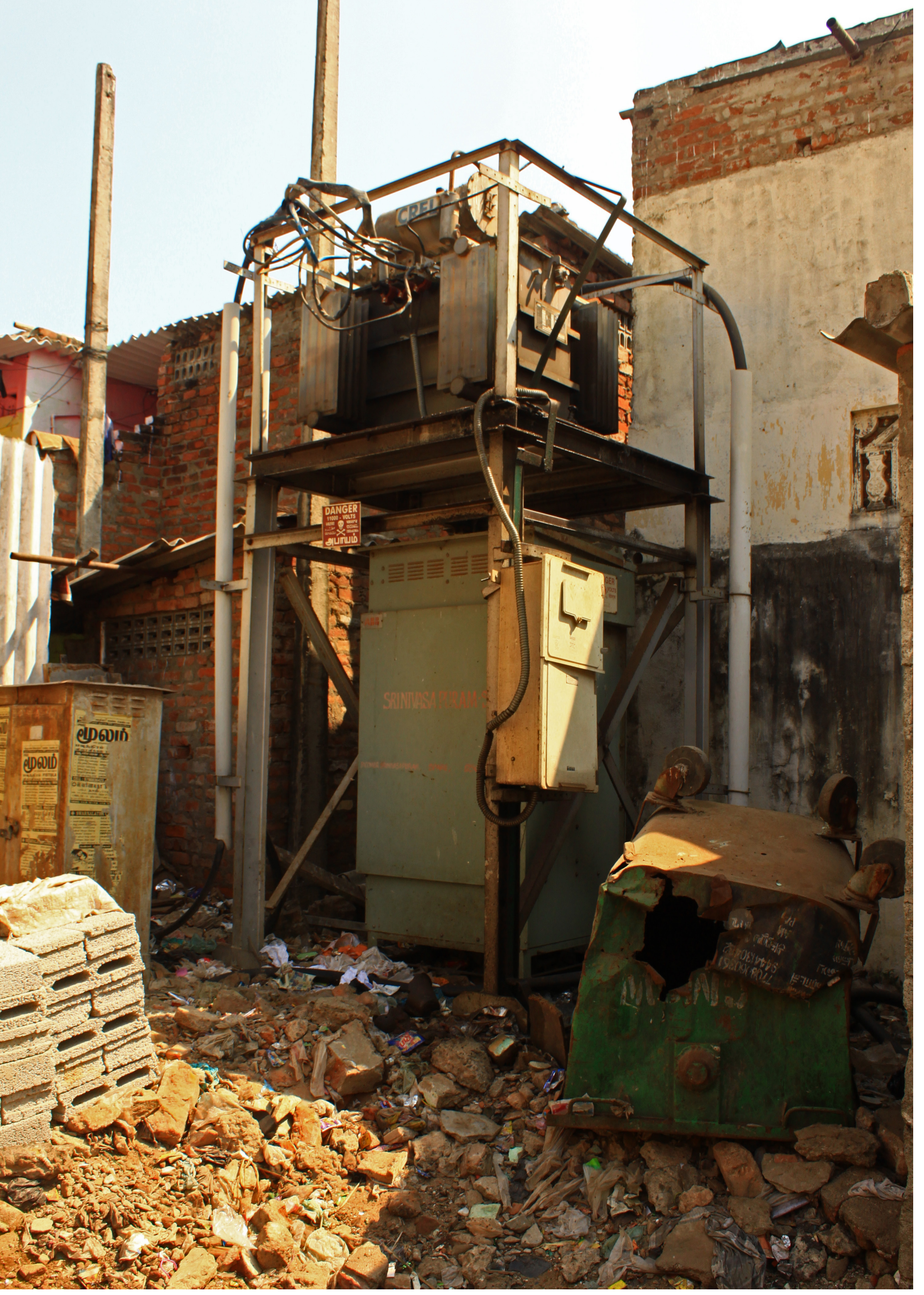




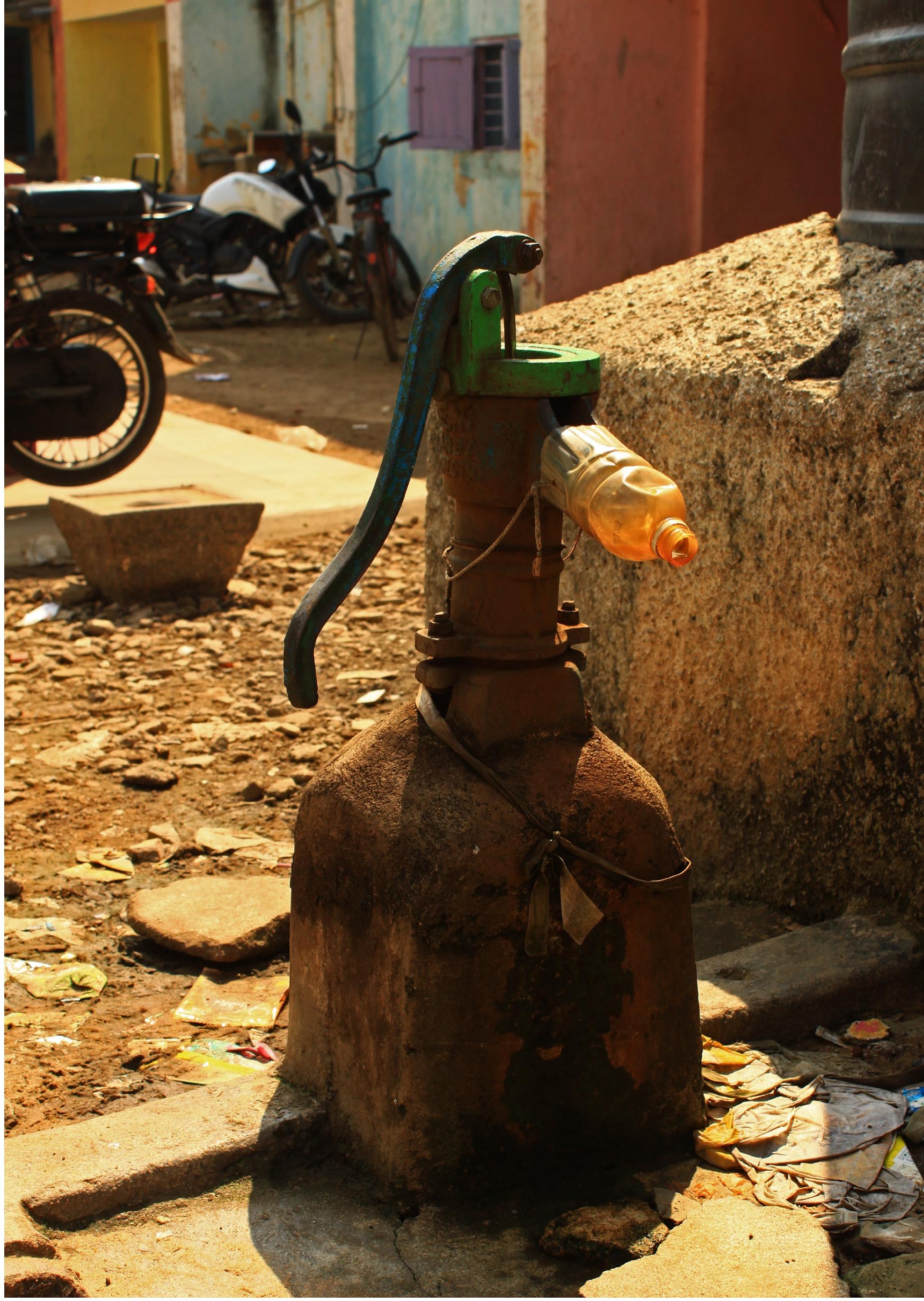




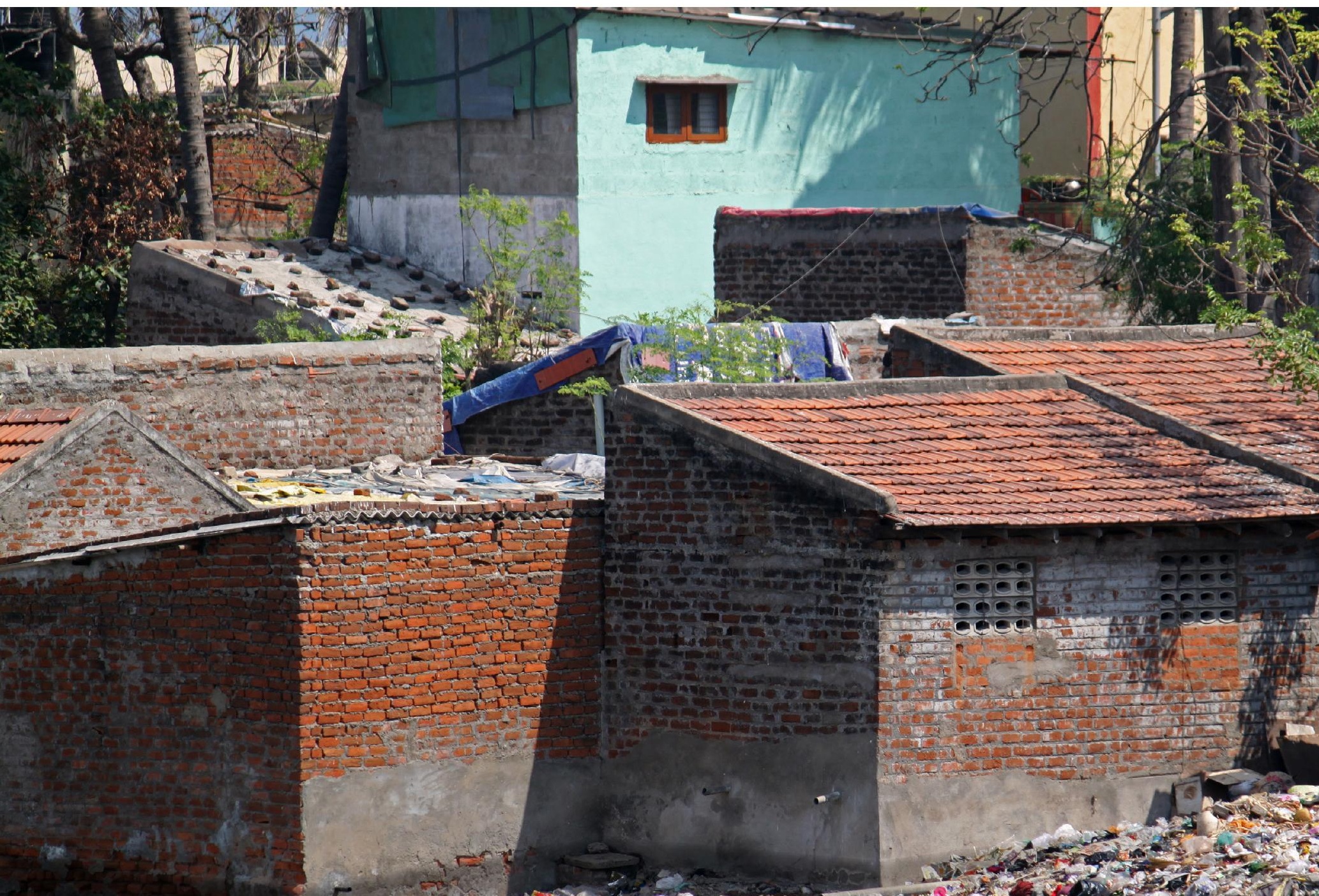

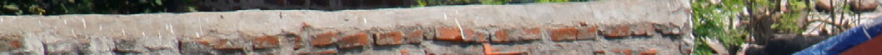
$-5 x=60$

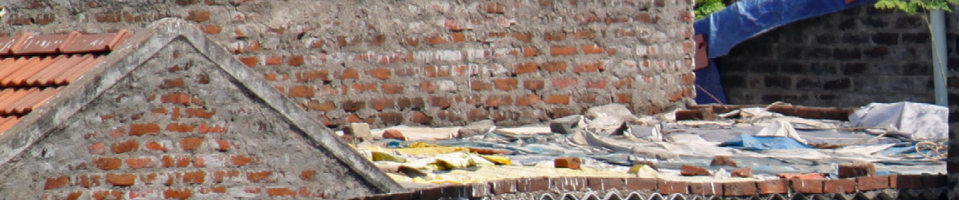

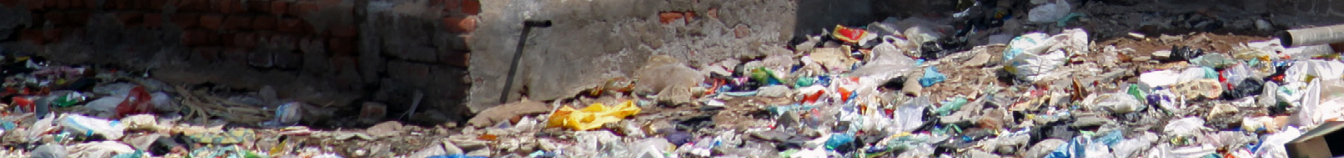

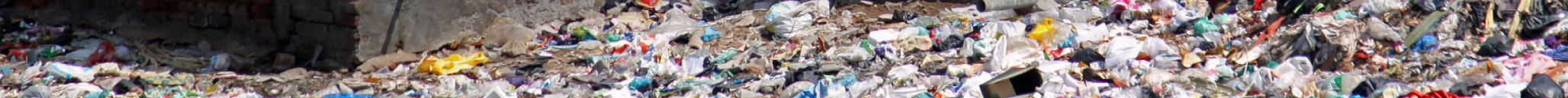
2.5.

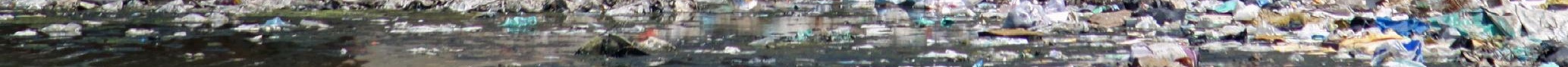

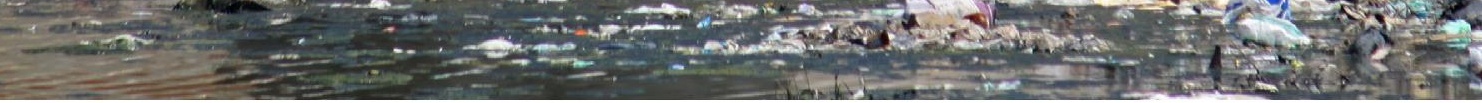



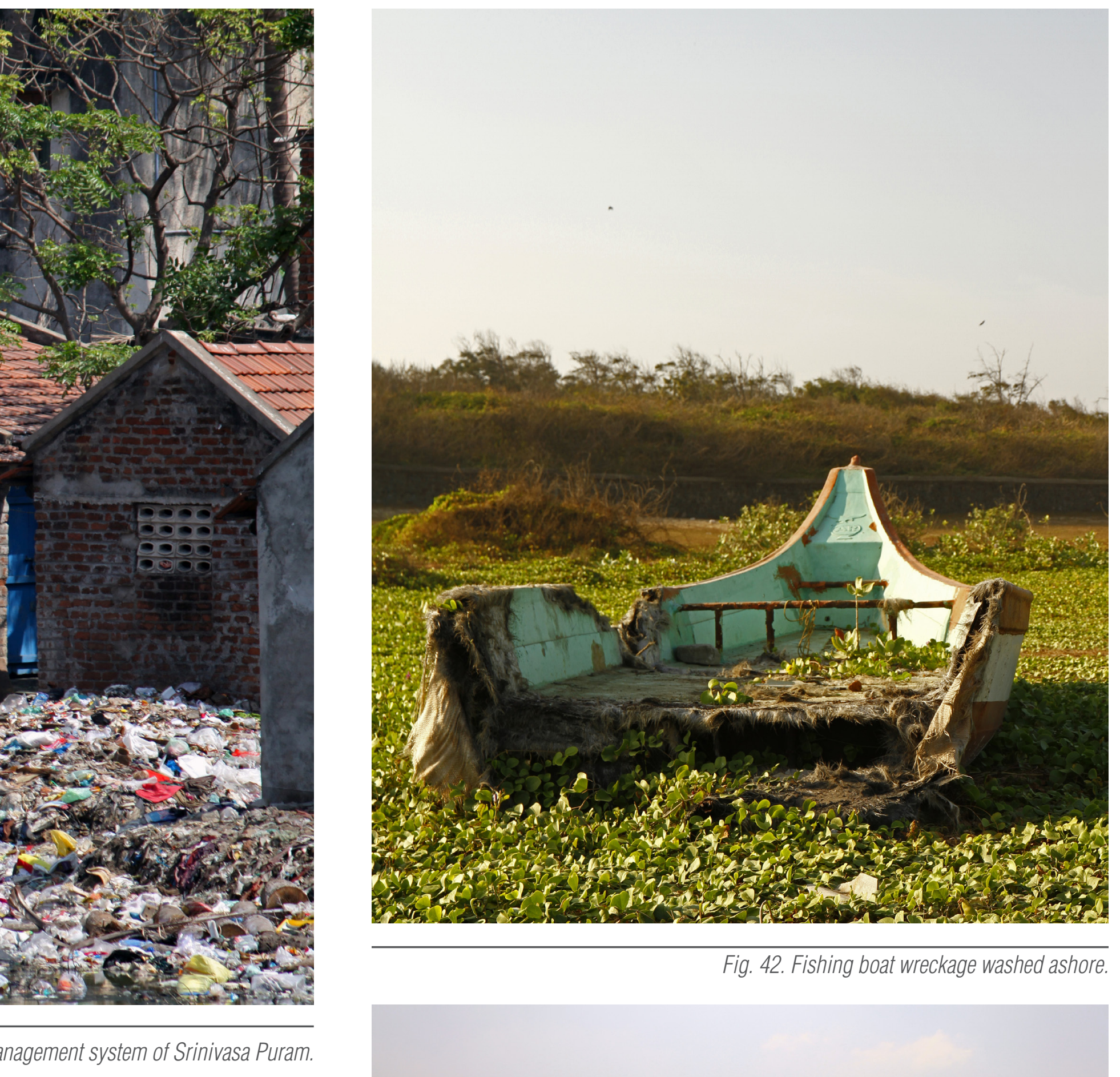

Fig. 42. Fishing boat wreckage washed ashore.

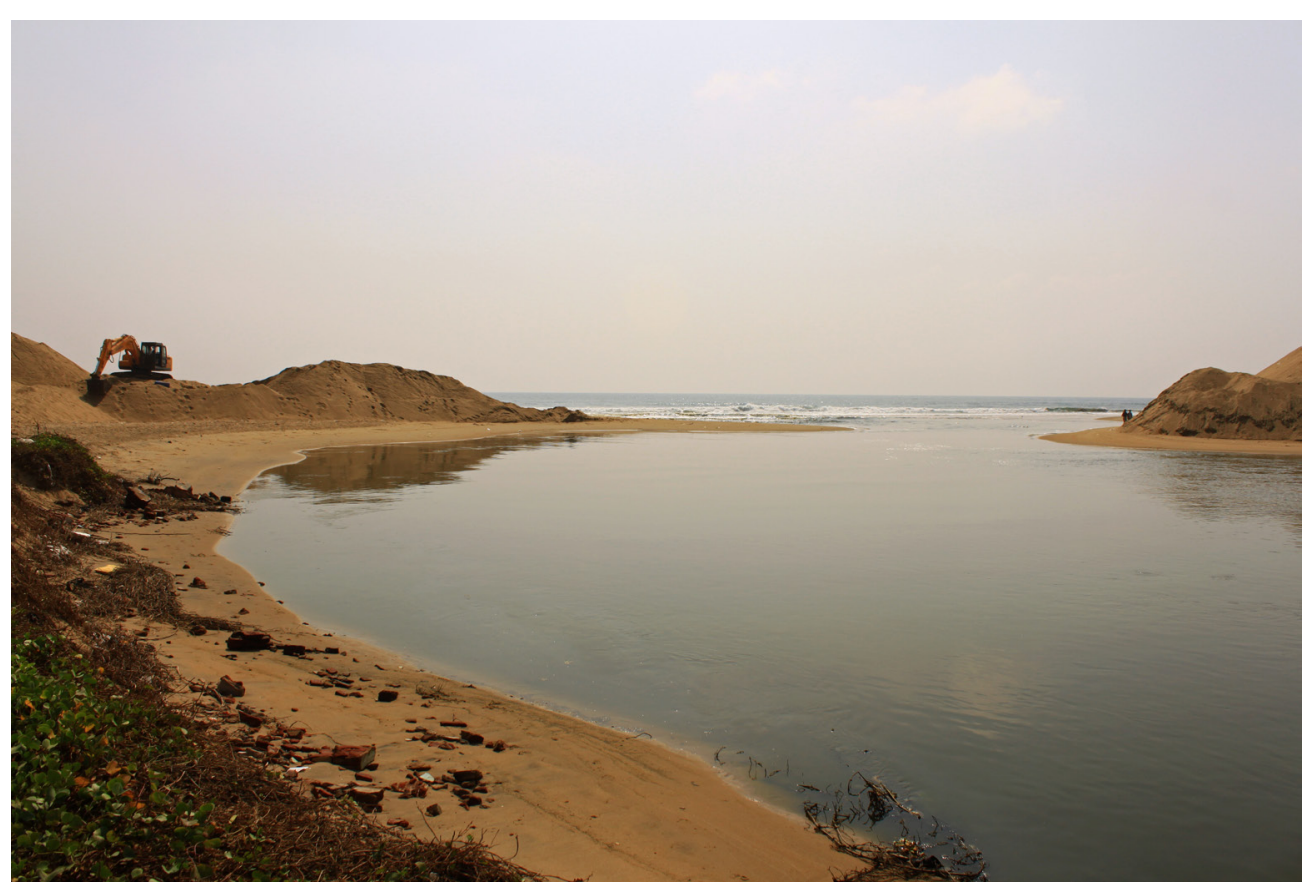

Fig. 43. Adyar River mouth requires constant dredging. 


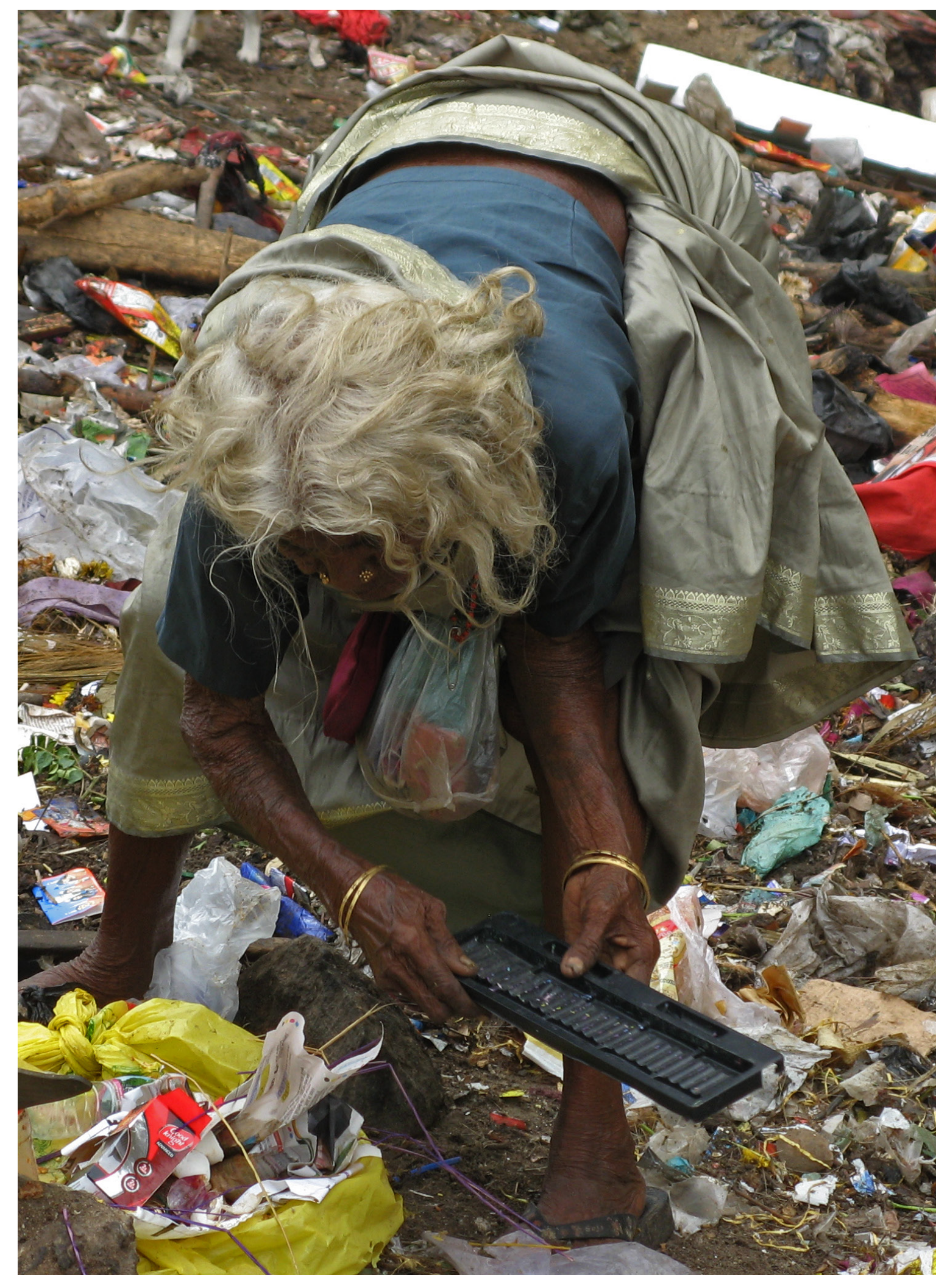

Fig. 44. Woman rummaging through garbage piles. 


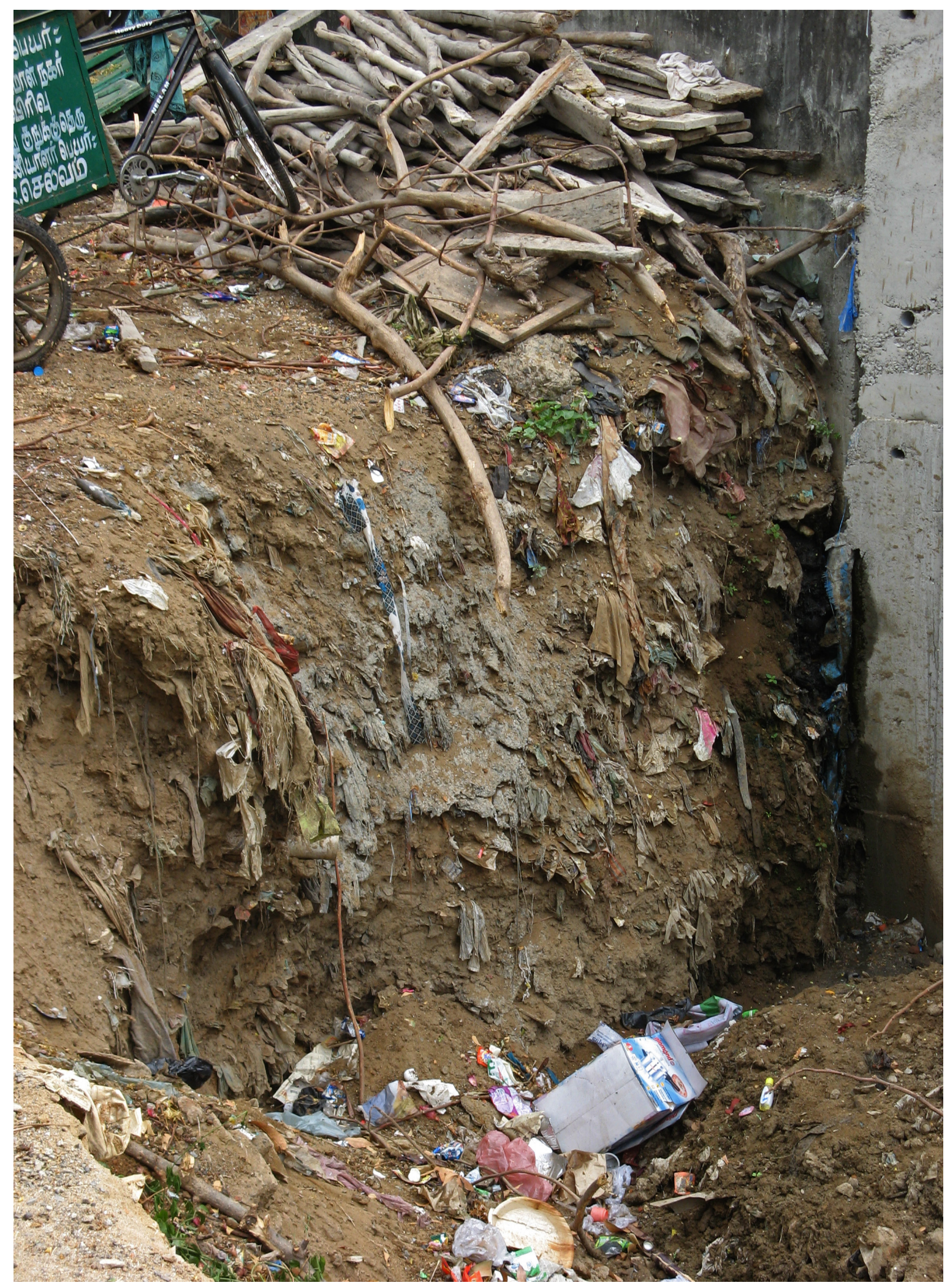

Fig. 45. Layers of garbage. 


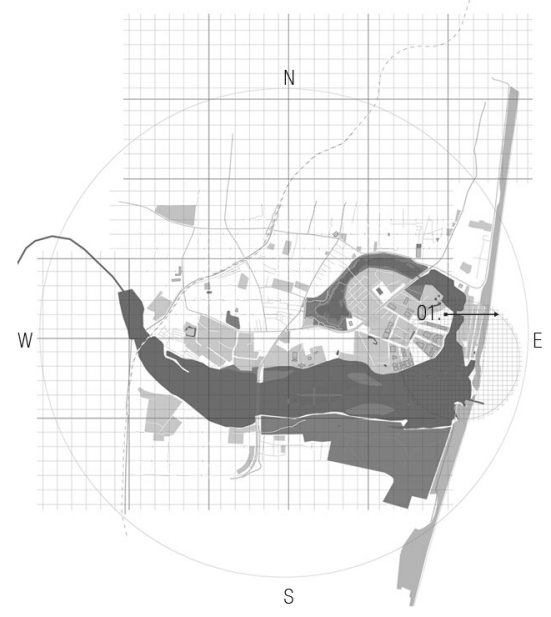

01.

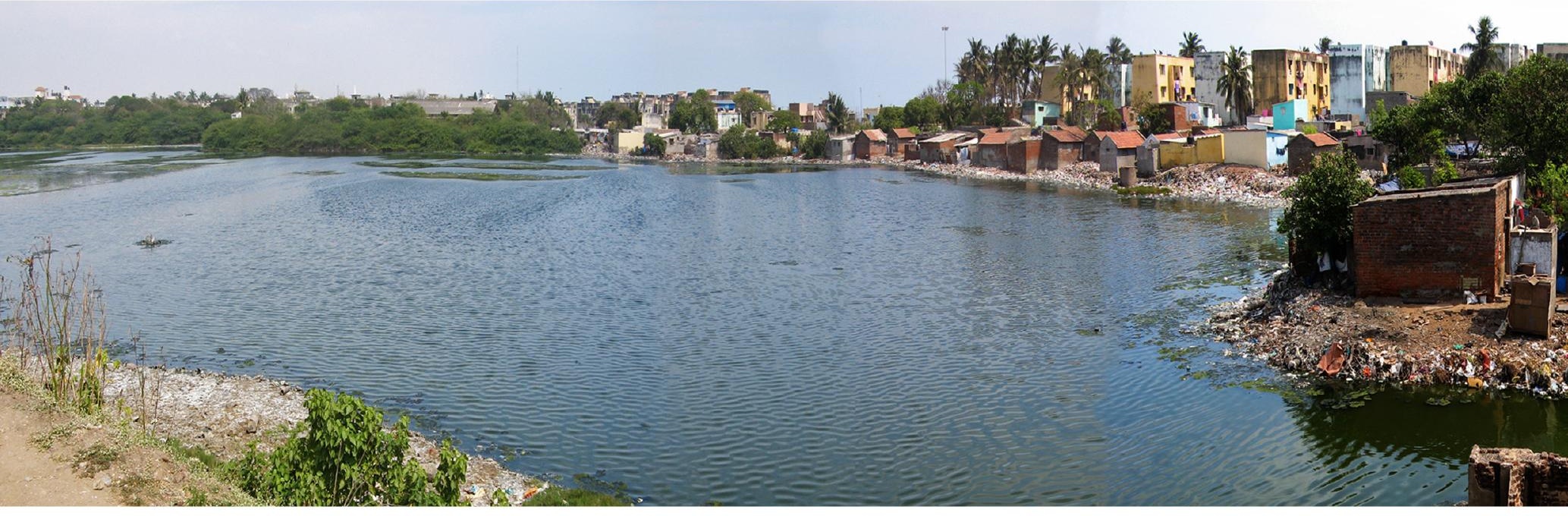

Fig. 46. Adyar Estuary behind Srinivasa Puram. 


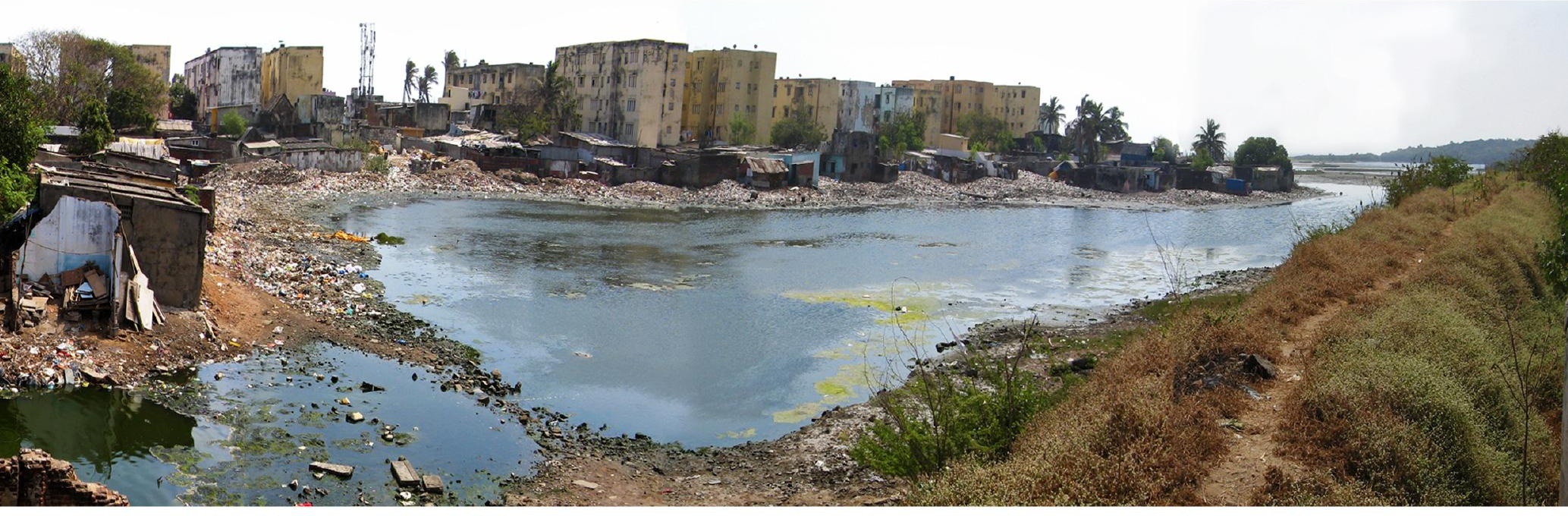


2.9 SLUM RESETTLEMENT SCHEMES

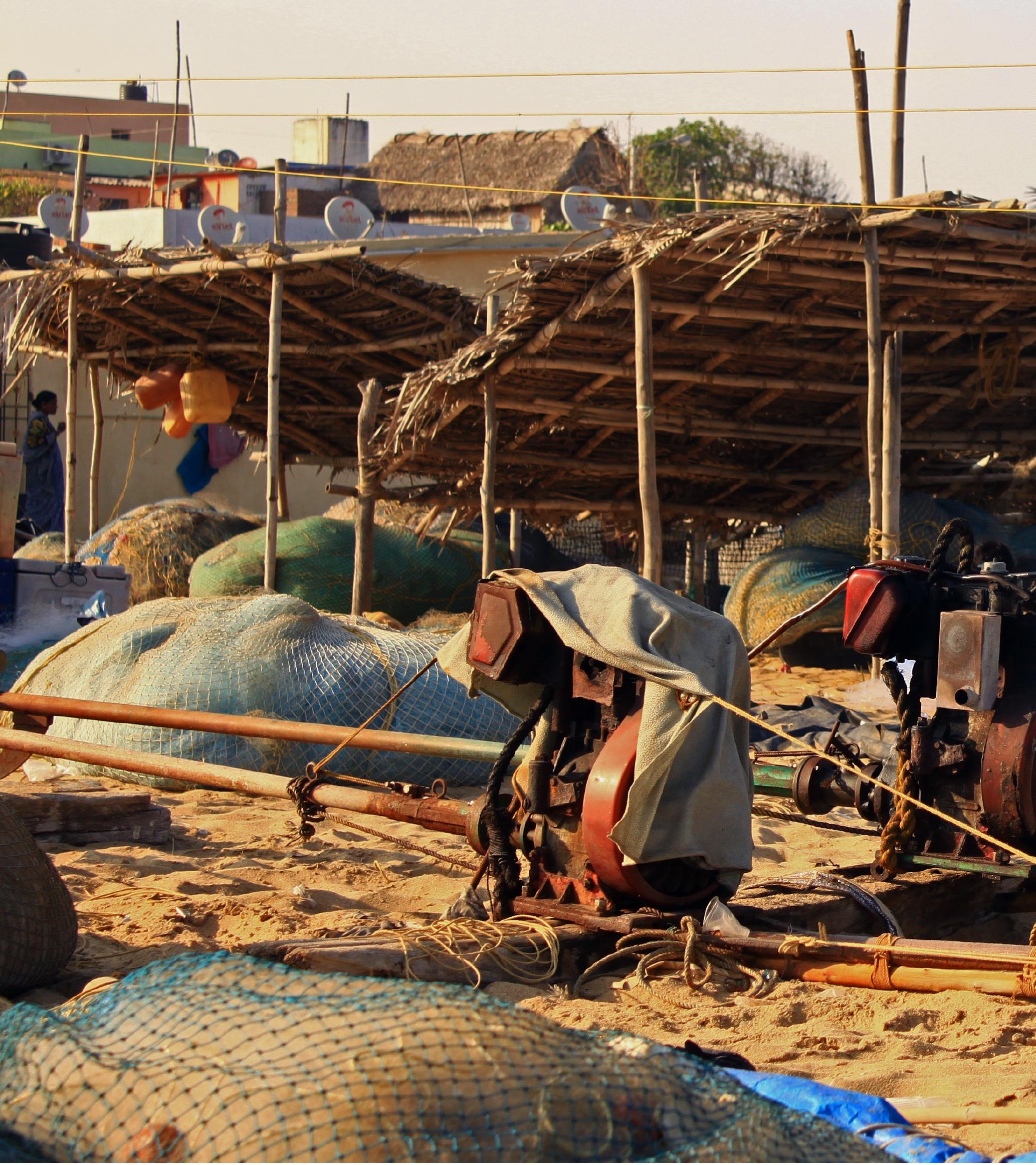









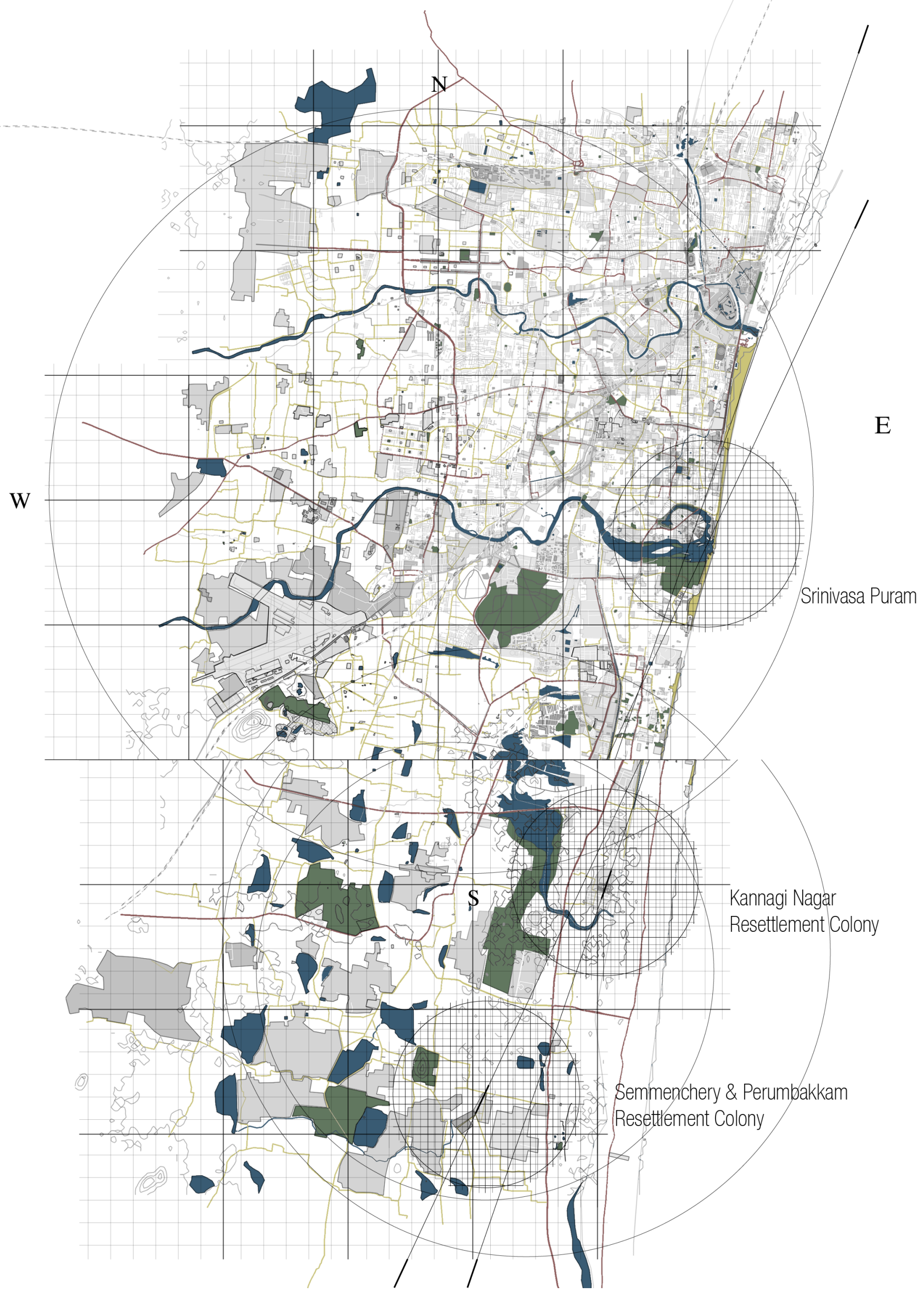

Fig. 48. Slum Resettlement Colonies. 
CHENNAI'S SLUM RESETTLEMENT SCHEMES

LOCATION: KANNAGI NAGAR SEMMENCHERRY
PERUMBAKKAM

Following the 2004 Boxing Day Tsunami, the Indian government's disaster recovery proposal for Srinivasa Puram received a large amount of criticism, not only in relation to the Tamil Nadu Slum Clearance Act of 1971 regarding in situ improvements, but also their approach to aiding the livelihoods of those who rely on coastal dwelling. The conflict began when the residents of Srinivasa Puram were offered tenements at the government funded tsunami resettlement program in Semmenchery, 22 kilometers away and more than 4 kilometers inland (Figure 48) (Raju).

Both the Flood Alleviation Program and Chennai Metropolitan Area Infrastructure Development Plan were introduced to relocate and provide housing for slum dwellers currently residing along river margins. Together these two programs have seen more than 100,000 slum dwellers forcibly evicted from more than 80 locations throughout Chennai and shipped to one of three high rise resettlement colonies (Kannagi Nagar, Semmenchery and Perumbakkam) on the outskirts of the city ("Information for the Fact Finding...").

Perhaps one of the more horrific and traumatic cases of slum eviction recently in Chennai involved an area along the banks of the Cooum River, where approximately 430 families were forcibly evicted by over 200 police officers and demolition bulldozers. The area was cleared ahead of a proposed elevated highway project. According to the United Nations Summary of Communications document "the families had not been issued an appropriate advance notice of the eviction. Reportedly, 150 families had not been offered alternative housing and had been left homeless by the evictions" (Human Rights Council 21). 
The current living conditions in all three government funded resettlement colonies include mass overcrowding, little or no ventilation and natural light, as well as lack of sanitation and irregular fresh water (Ashok and Lavanya). Not only are the living conditions unfit for human habitation but the eviction process and resettlement on the outskirts of the city often destroy their entire livelihood resulting in high numbers of suicides and families abandoning their tenements due to serve trauma.

Figure 49 shows the current tenement designs allocating an average of $14-15 \mathrm{~m}^{2}$ per family. "Some of the apartments hold families of 12 or more people, spanning three and four generations" (Rajagopalan). The proposed thesis investigation design scheme will enhance living conditions by providing a minimum of $28 \mathrm{~m}^{2}$ per tenement.

We are being shifted to Kannagi Nagar in Corporation Lorries just like how garbage is disposed in the dumping yards, we are viewed as garbage and hence they shift us using these corporation lorries. ("Information for the Fact Finding...") 


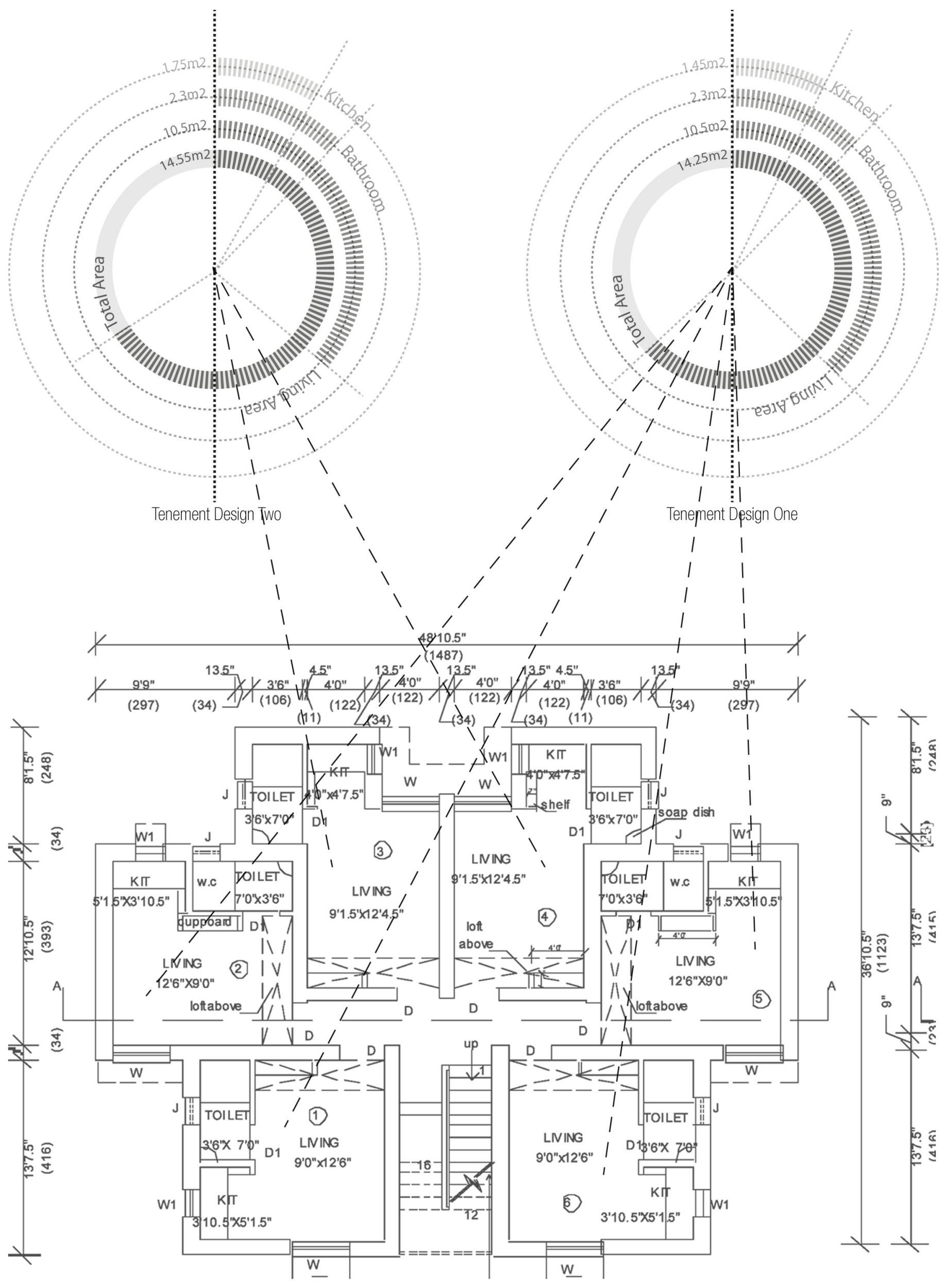


KANNAGI NAGAR

RESETTLEMENT COLONY

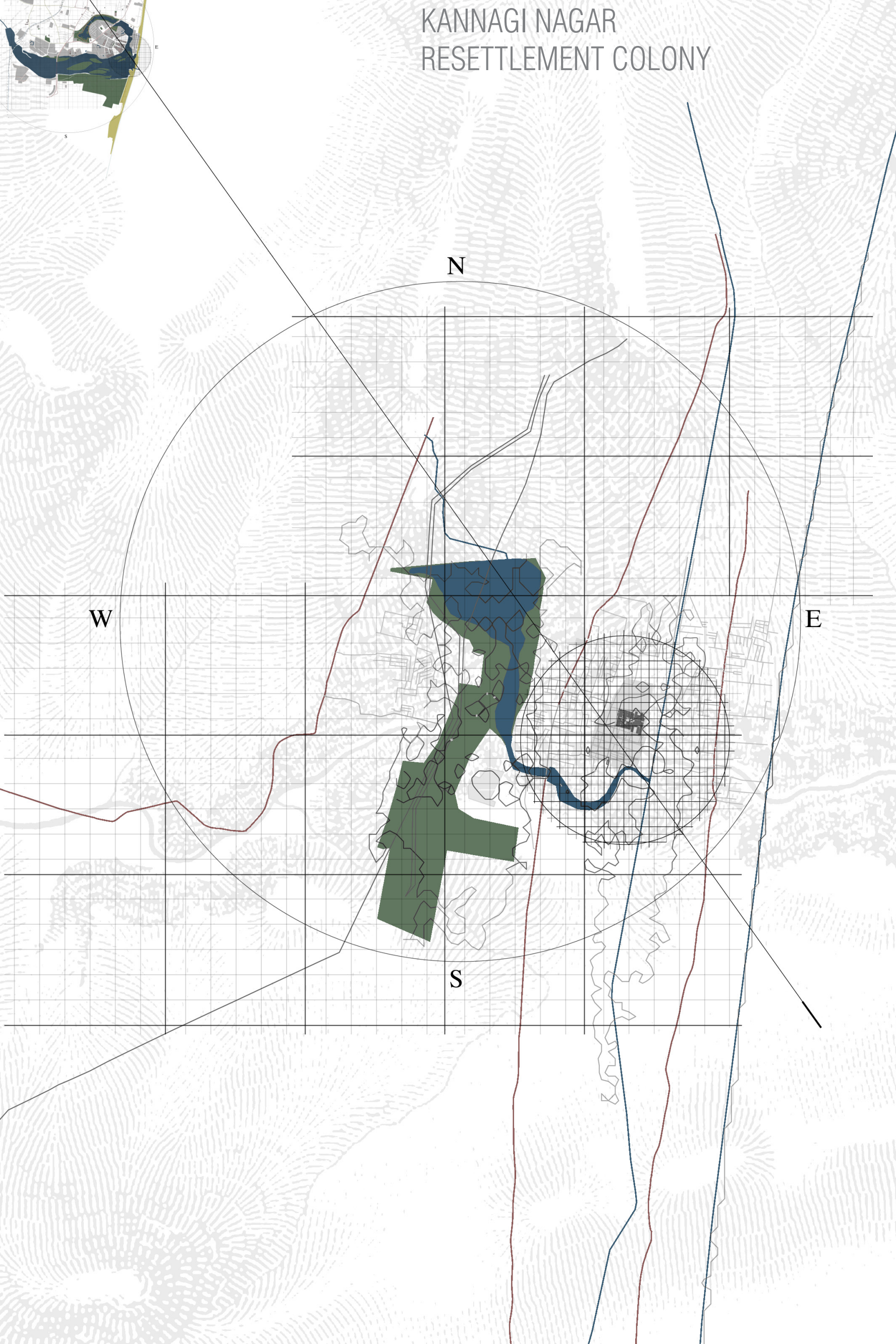




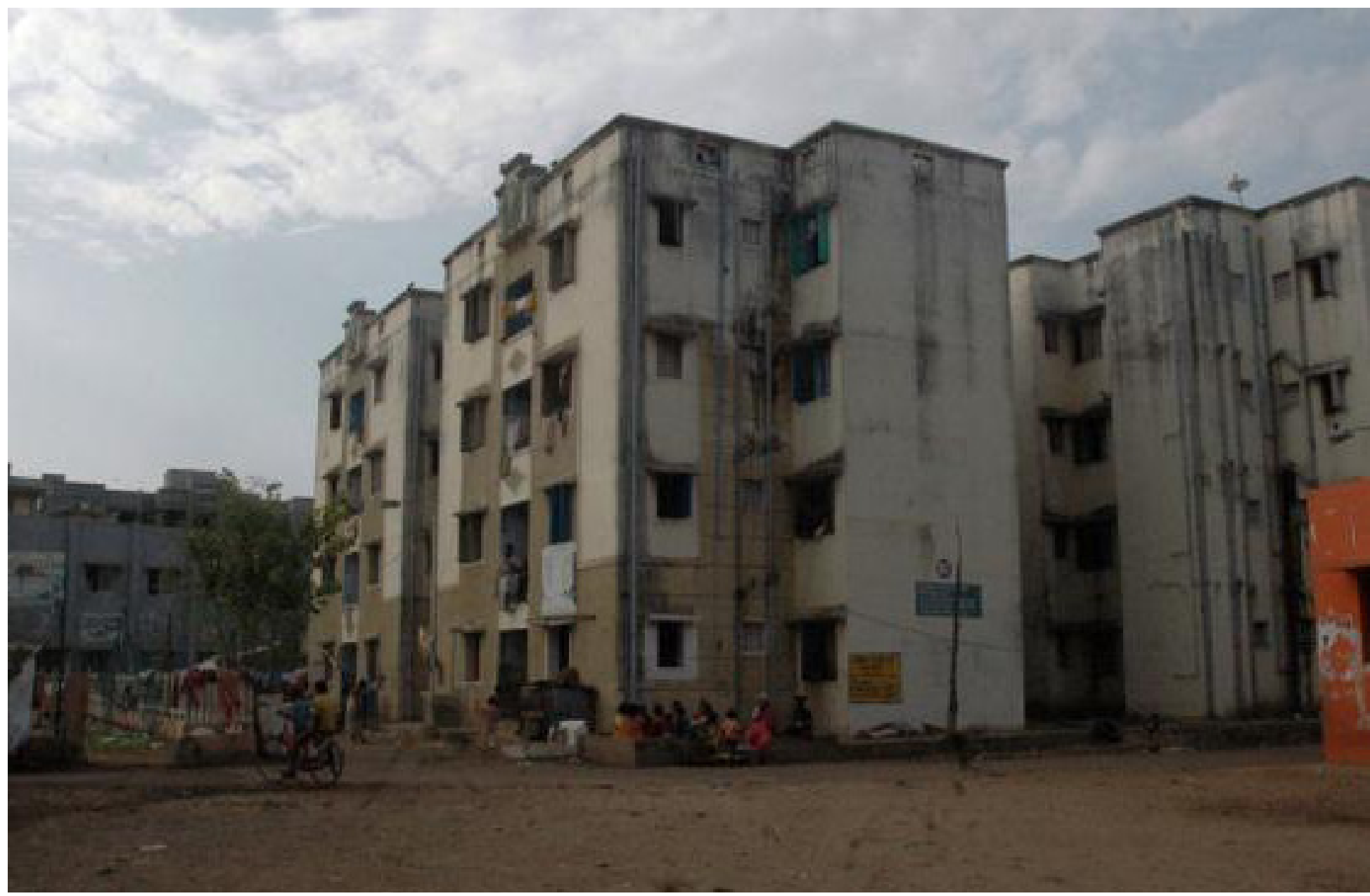

Fig. 50. Kannagi Nagar resettlement housing.

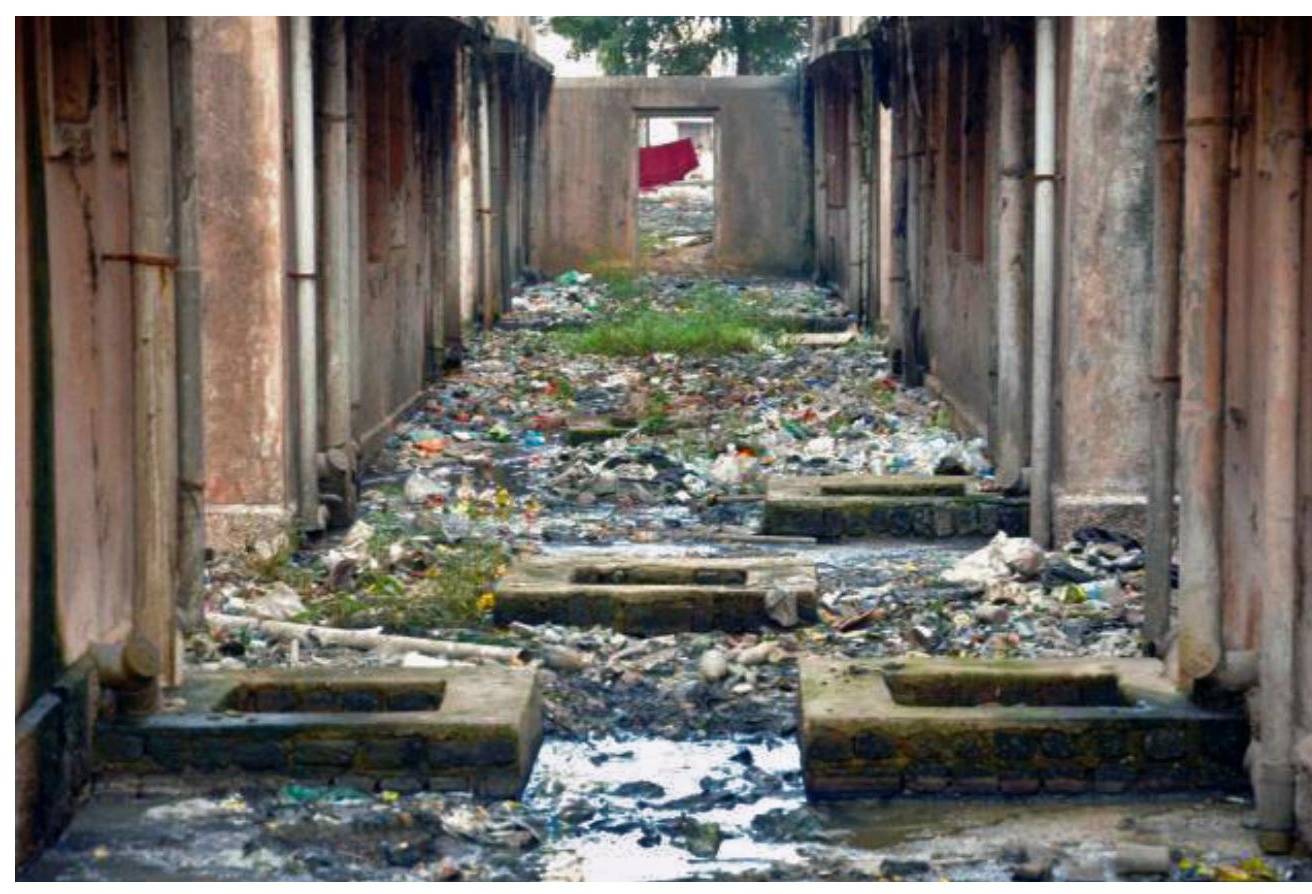

Fig. 51. Kannagi Nagar blocked drainage systems. 


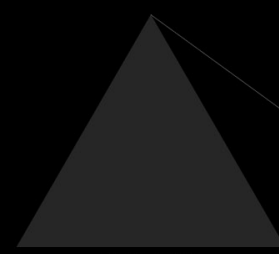

150 LPCD

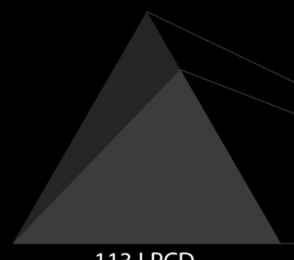

113 LPCD

LPCD - (Liters per capita daily)

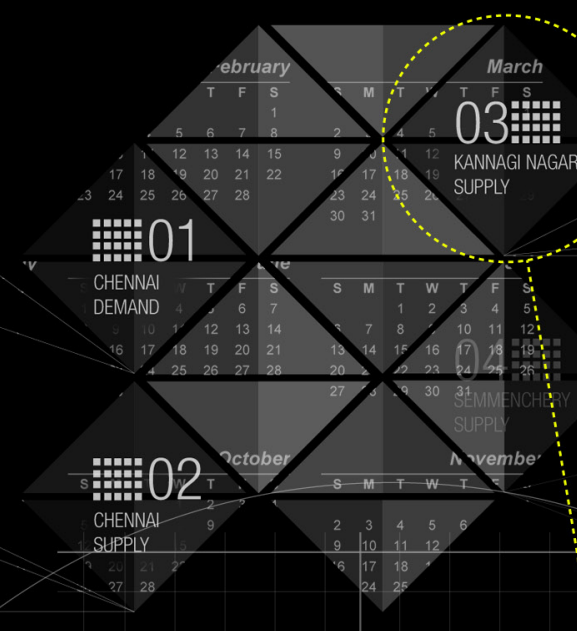

Water Supply vs. Demand 
It could be a scene from a holocaust movie. Blocks of identical buildings stand tiredly in the distance along broken, deserted roads. Heaps of garbage and puddles of dirty brown water break the monotony. Stray dogs lap from open sewers. This is Kannagi Nagar, where over 10,000 families displaced by Chennai's development projects have been stacked into unkempt rows. You could call it a forgotten filing cabinet for displaced people (Menon). 


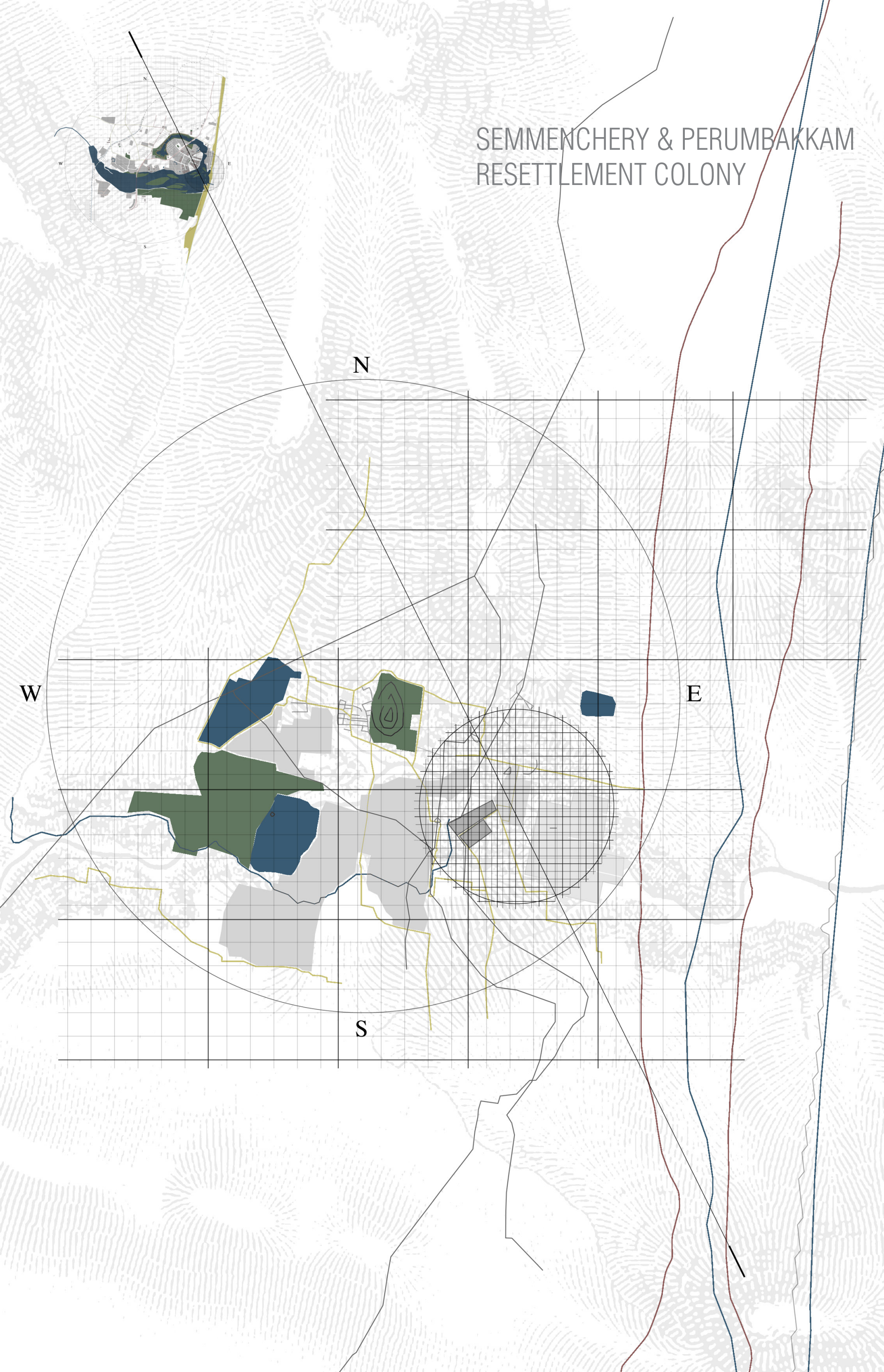




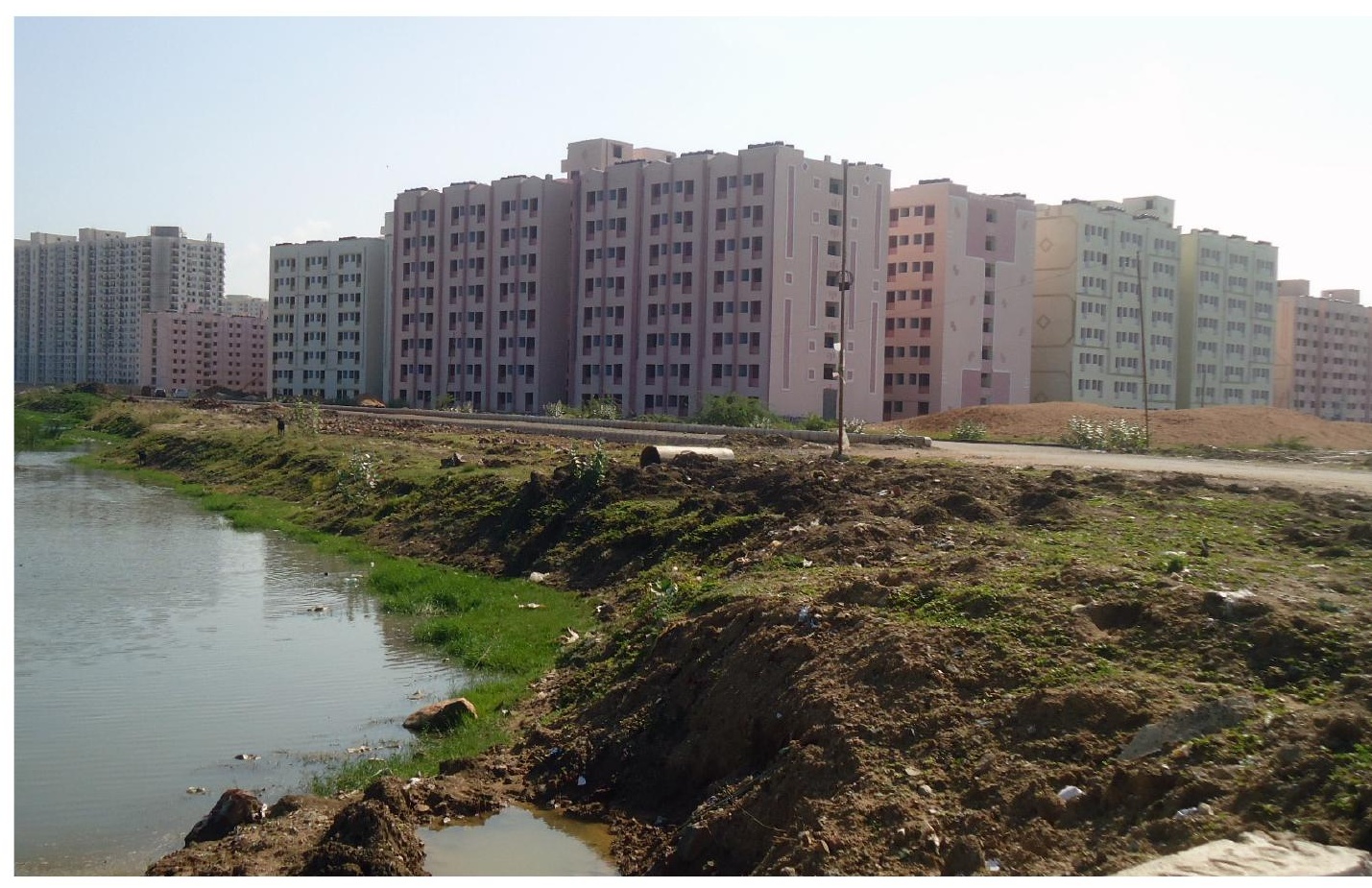

Fig. 53. Perumbakkam resettlement housing.

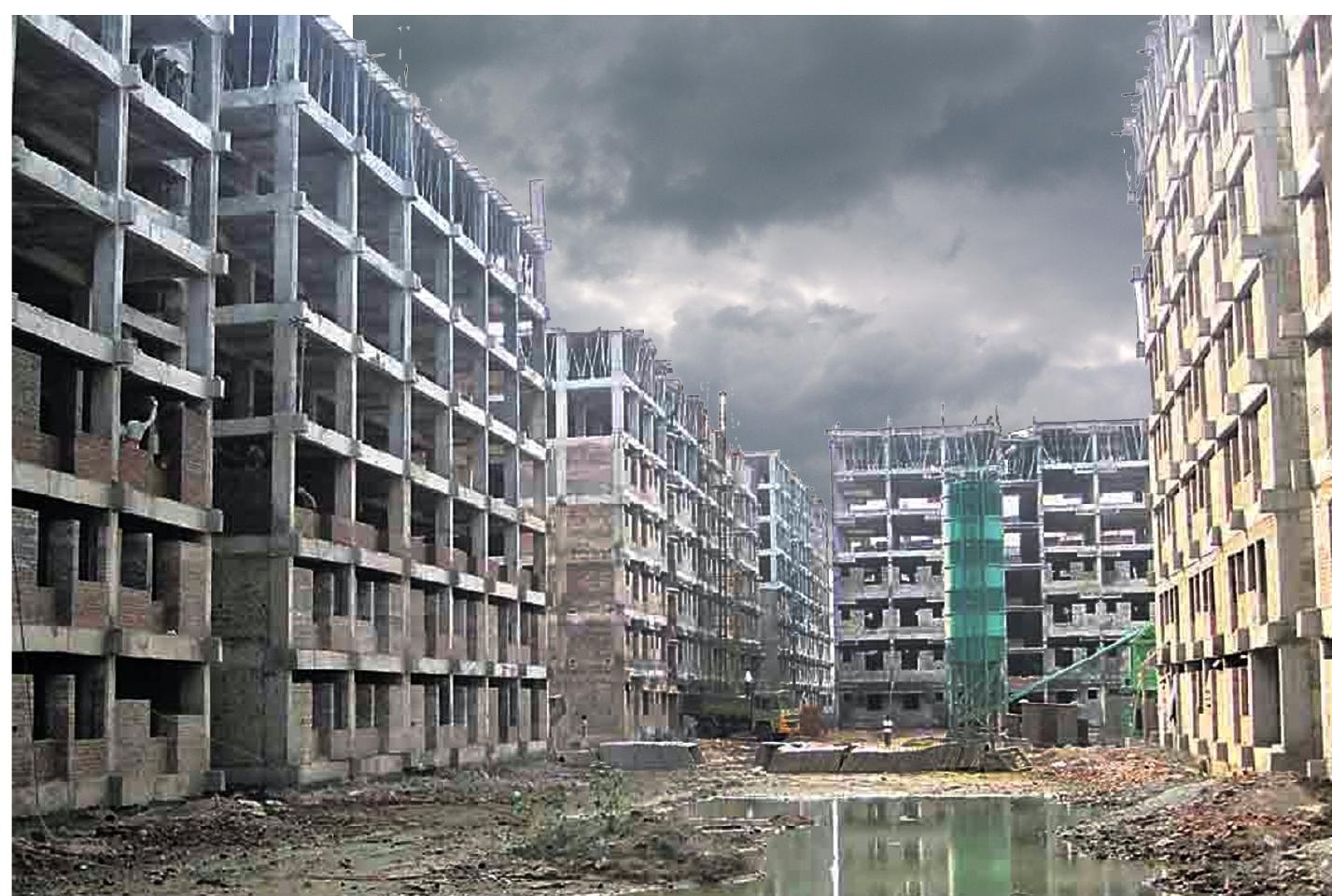

Fig. 54. Perumbakkam project under construction. 


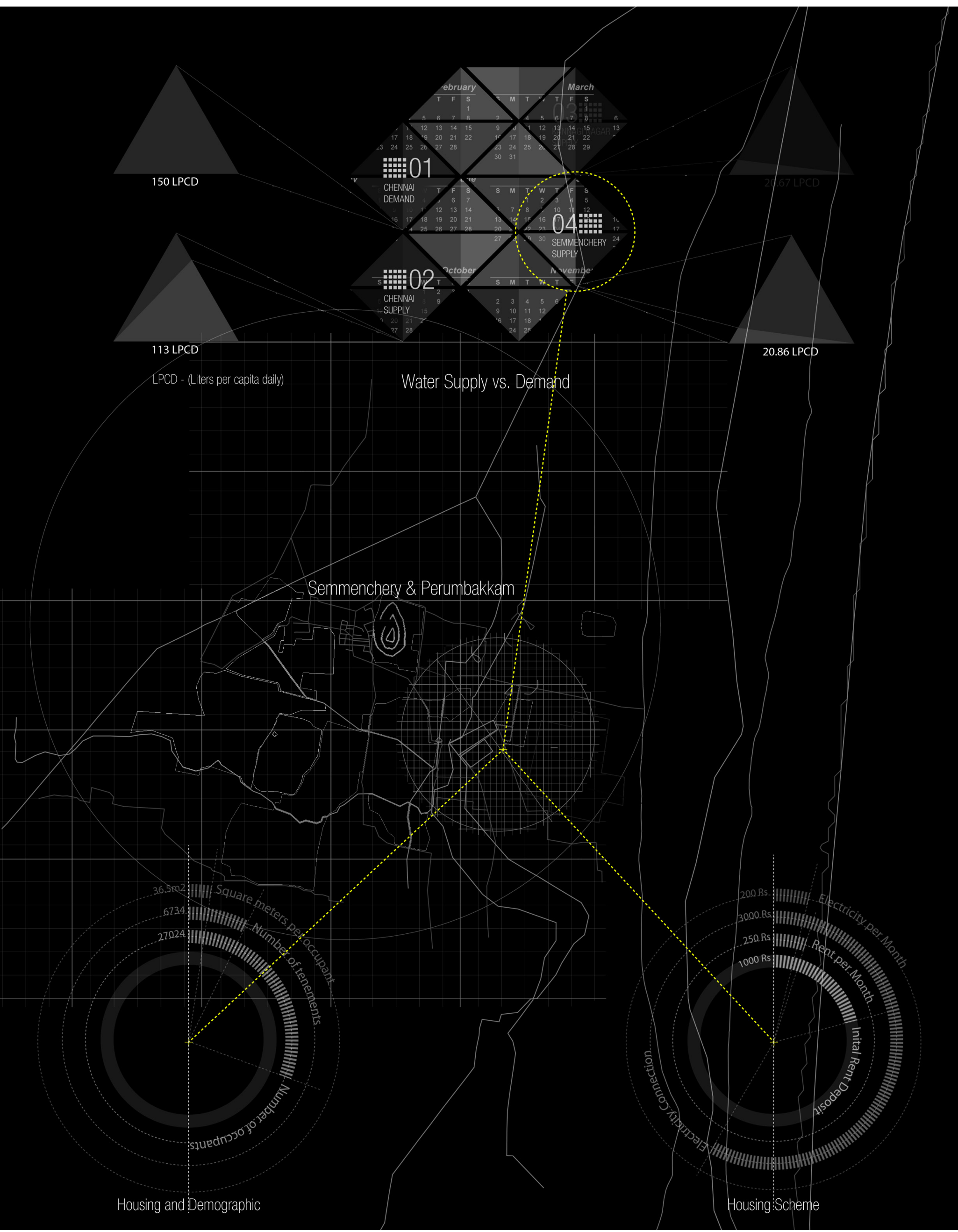


"The streets are unlit and clouds of mosquitoes infest the waterlogged roads" (Menon).
Two years after families were relocated to Semmencherry, running water was finally made available in their allocated tenements. It took a further three years for electricity to be supplied and a staggering six years after they were first relocated the city provided waste collectors (Rajagopalan). 


\subsection{SITE PLACEMENT}

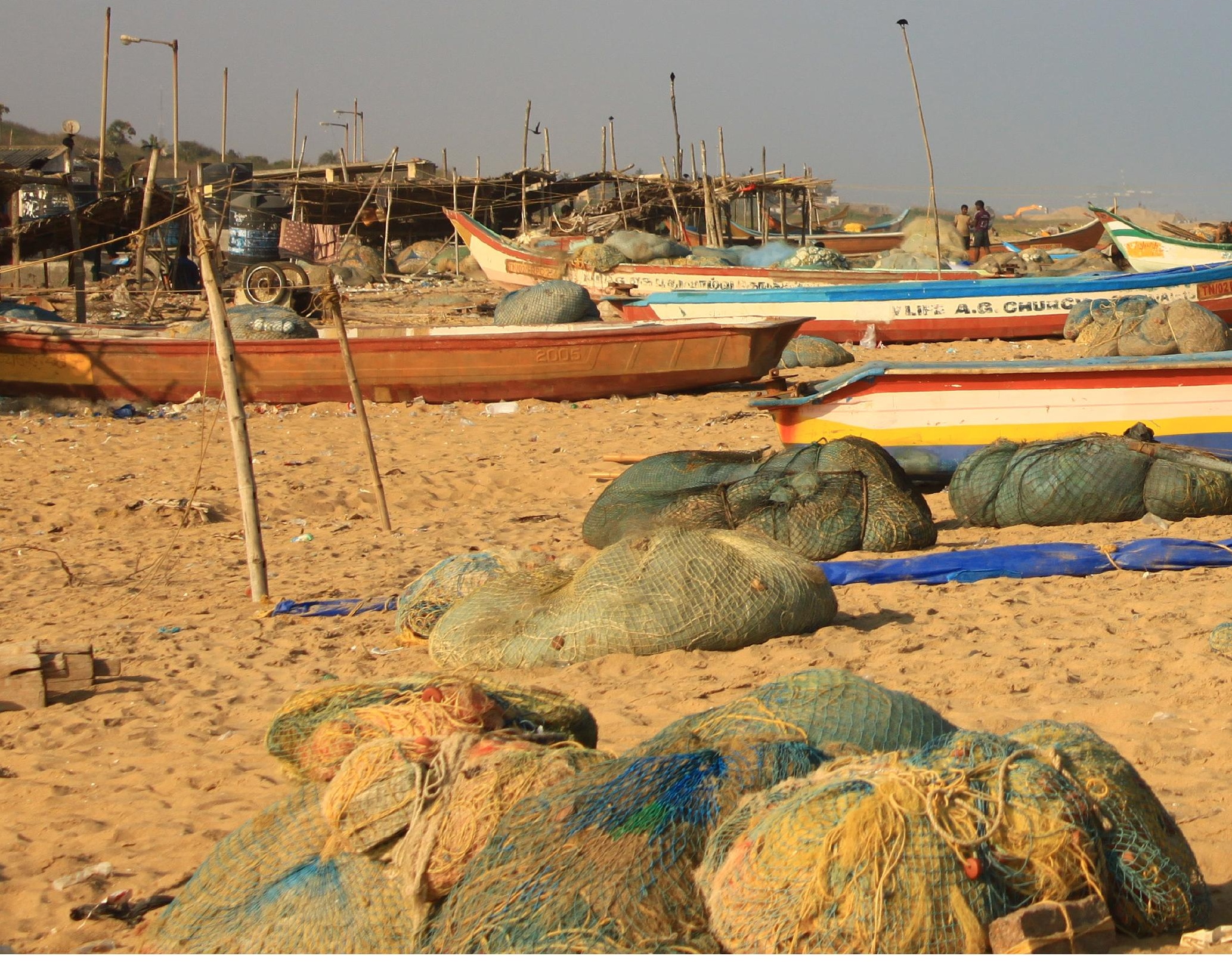




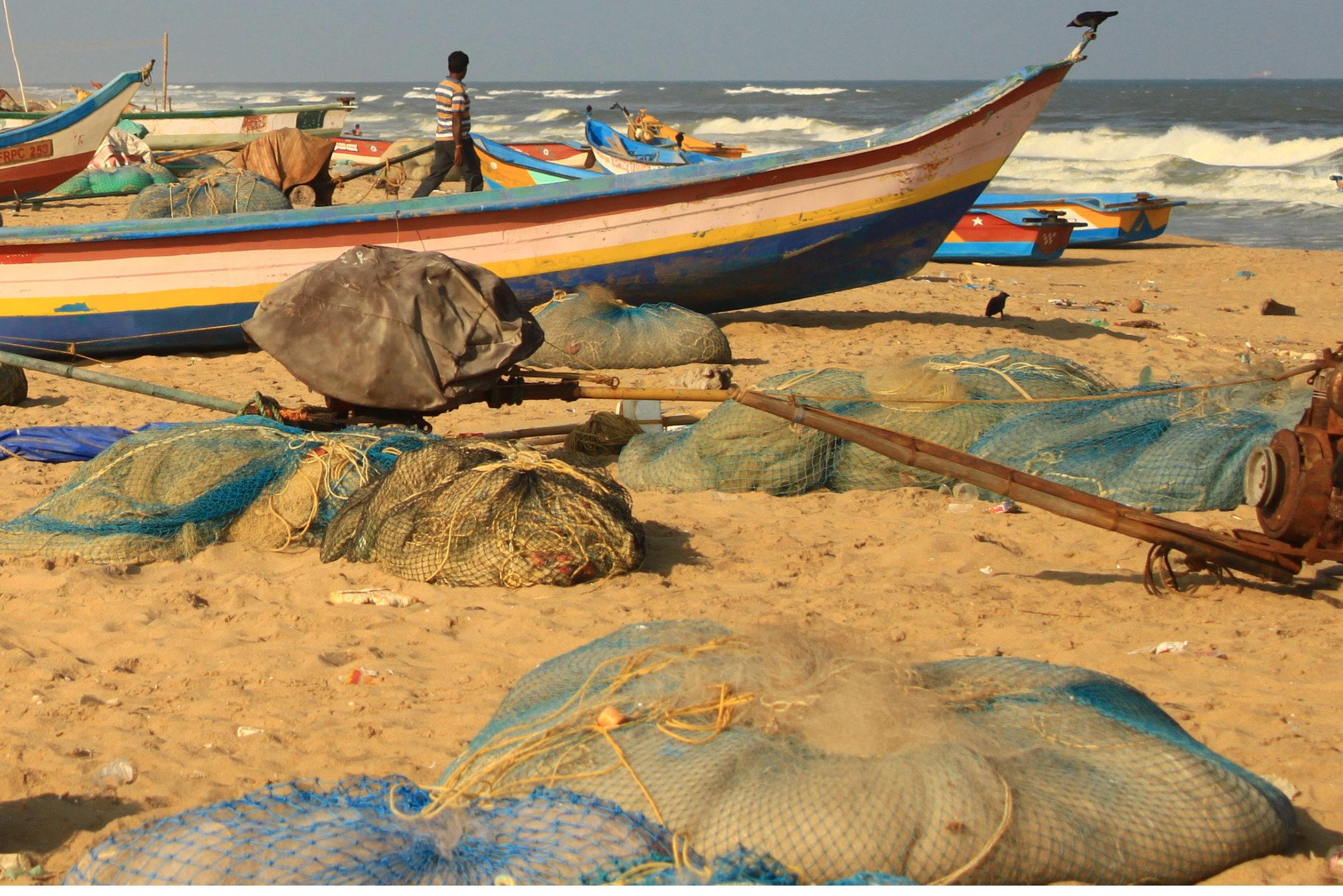




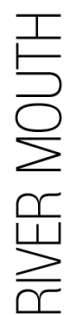

Fig. 57. Site placement. 


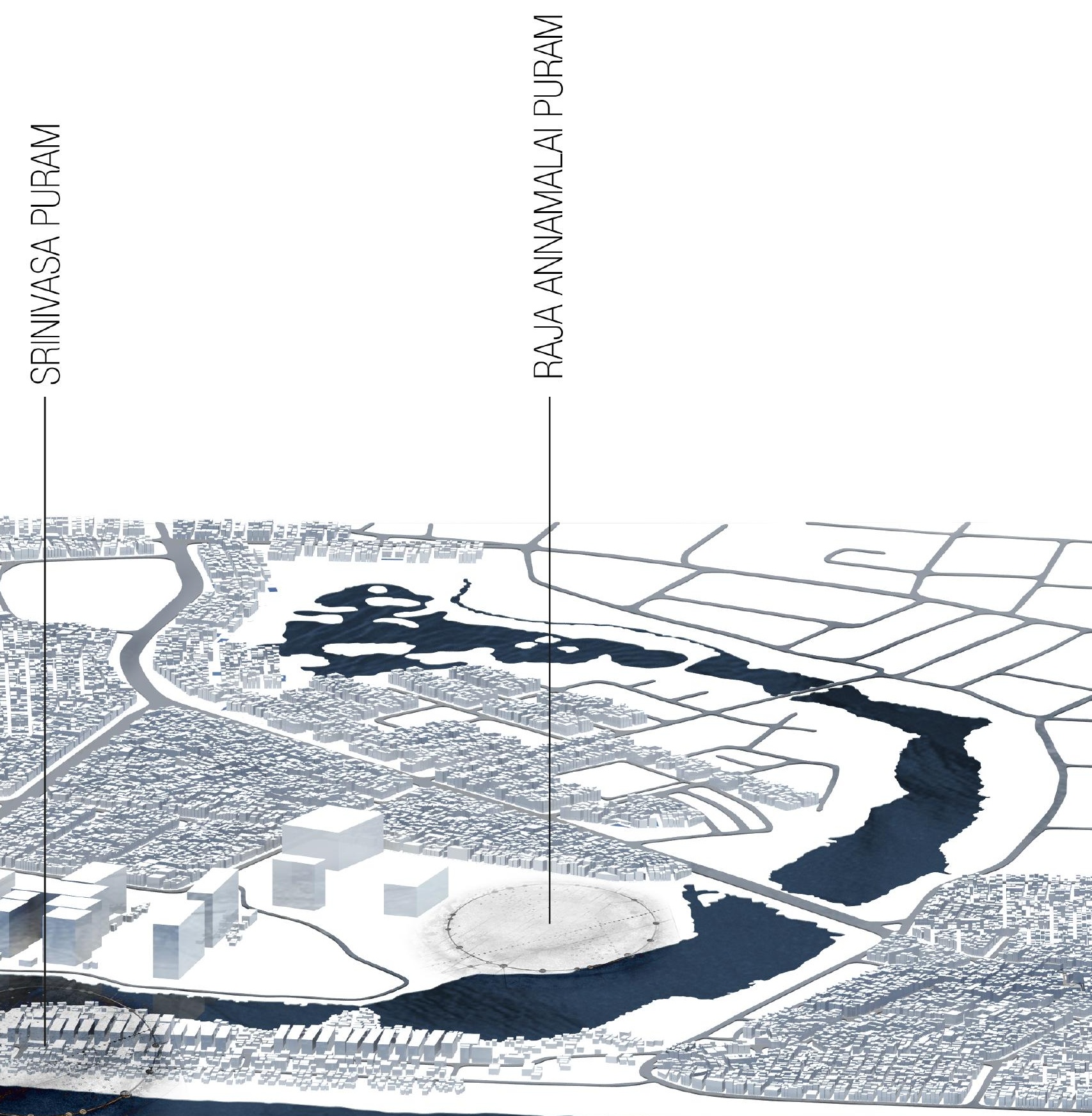


Though this is a theoretical design research study, building an intervention directly in place of the current site would exacerbate the problem as it would require displacement of the inhabitants. A more viable solution would be to create a framework adjacent to Srinivasa Puram that allows the community to expand or progressively relocate. Figures $57-58$ show the slum's current site and two adjacent sites: Raja Annamalai Puram and the Adyar River mouth. The Adyar River mouth was selected as the site of the research investigation due to its adjacency to Srinivasa Puram, its suitability for future expansion, and the opportunity to also mediate the surrounding adverse environmental conditions. 


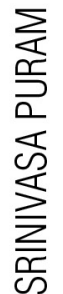
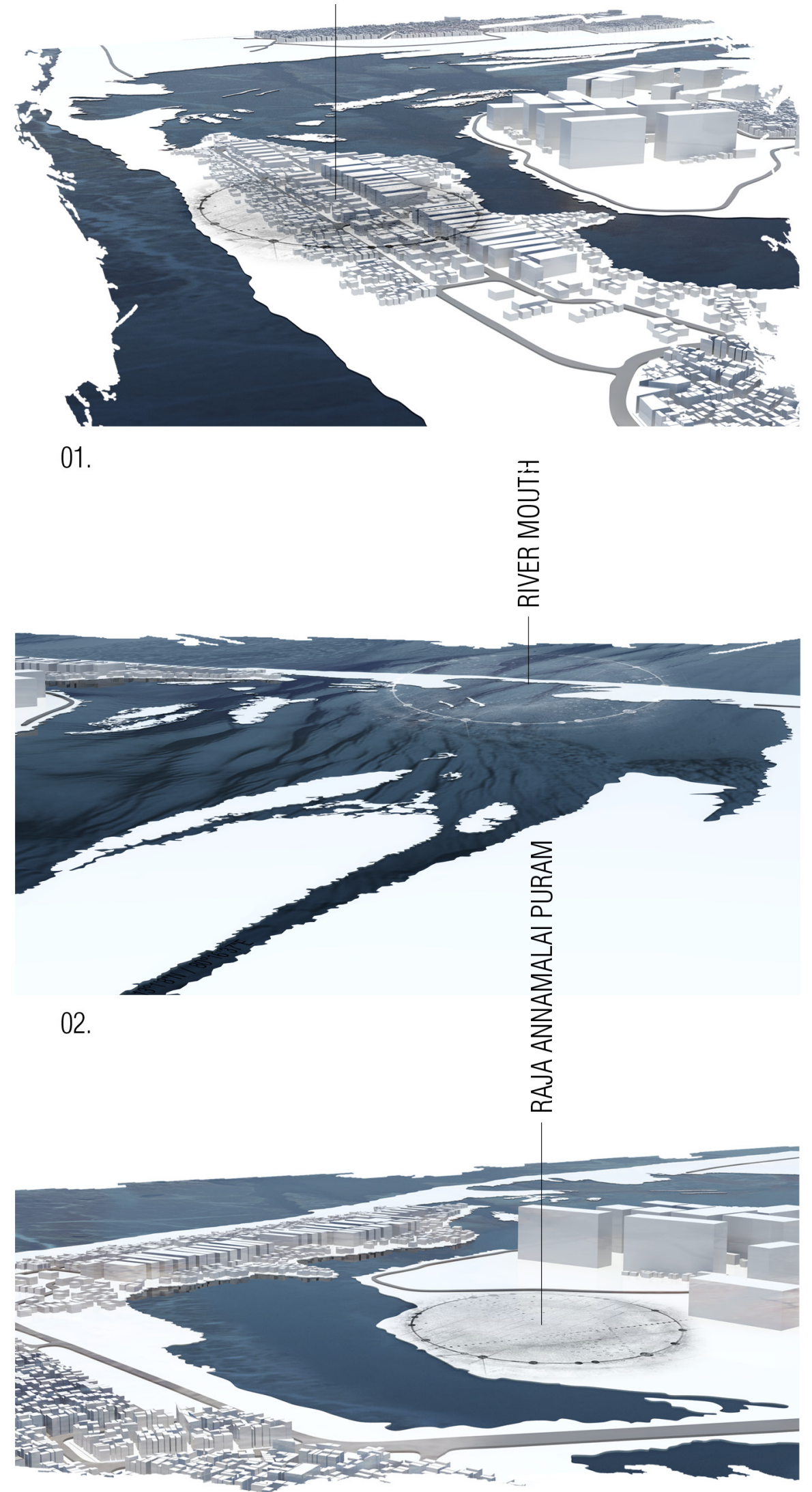

03. 


\subsection{ADYAR RIVER MOUTH}

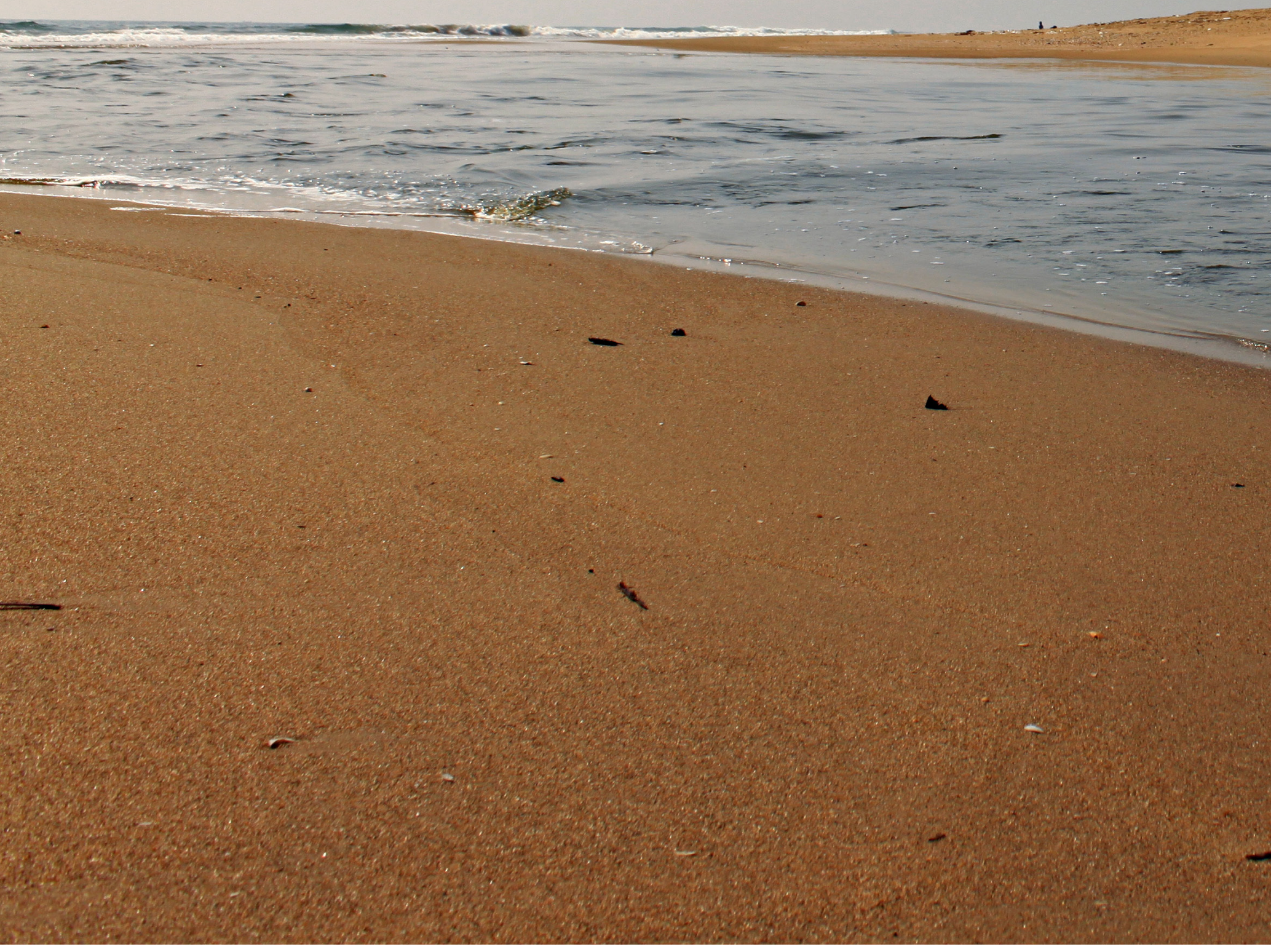




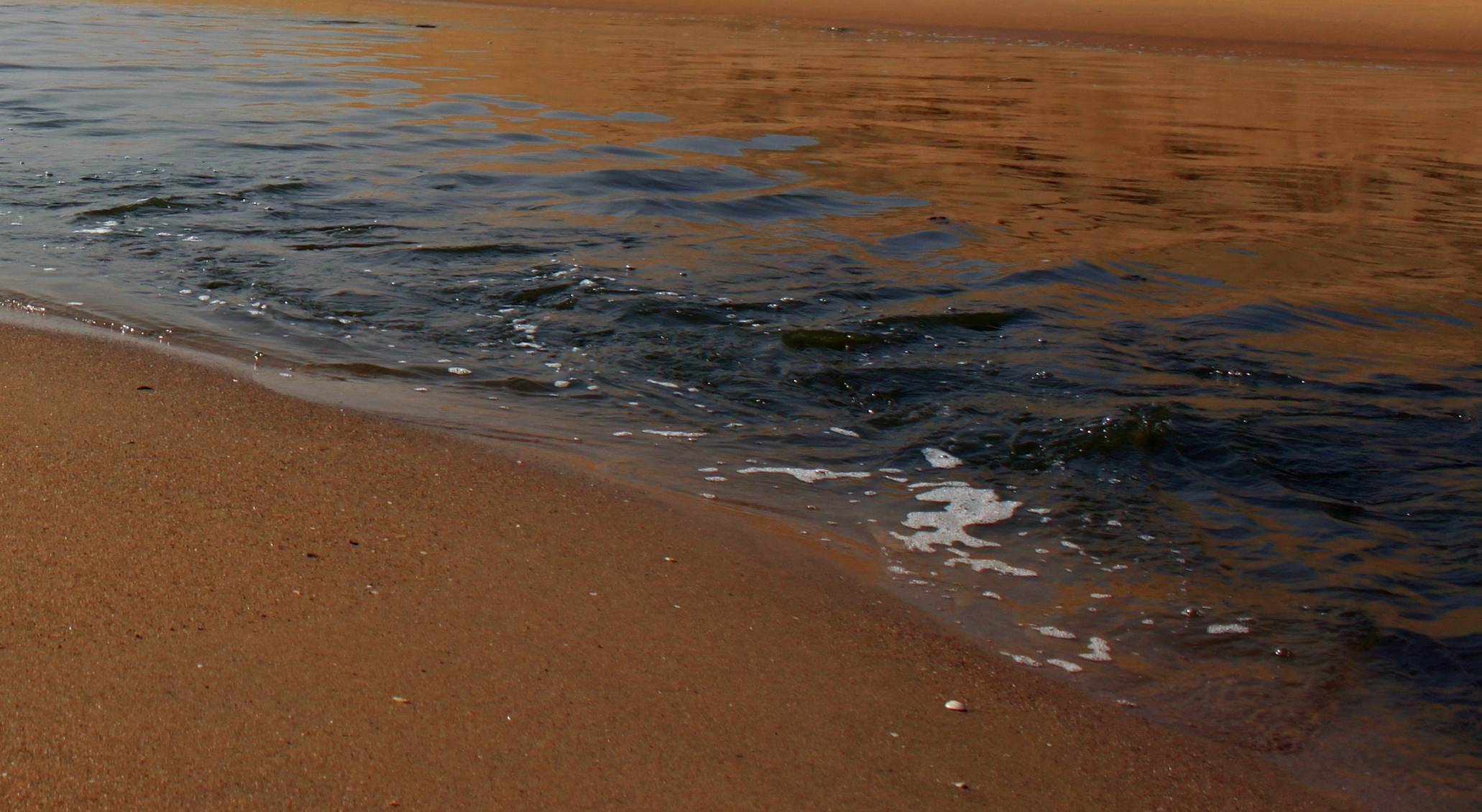


In 1884 the Adyar River mouth was situated at the northern end of the estuary (Figure 60), which aided in its usefulness as a major port for southeastern India. As development throughout the city expanded and water bodies such as the 'Long Tank' (Figure 60) were filled and built upon, Chennai's natural catchment systems began to deliver less water to its rivers ("Structure of Chennai" 6). The declining flow rate allowed the formation of an encroaching sandbar to close the river mouth.

In 1924 a new river mouth was forced open parallel to its directional flow (Figure 60). The continual destruction of natural catchments and drainage systems within Chennai's landscape over the past decades has slowly suffocated the flow rate of the Adyar River to a point where it is unable to compete with the relentless formation of annual sandbars generated by the northeast currents of the Indian Ocean (Gupta and Nair). 

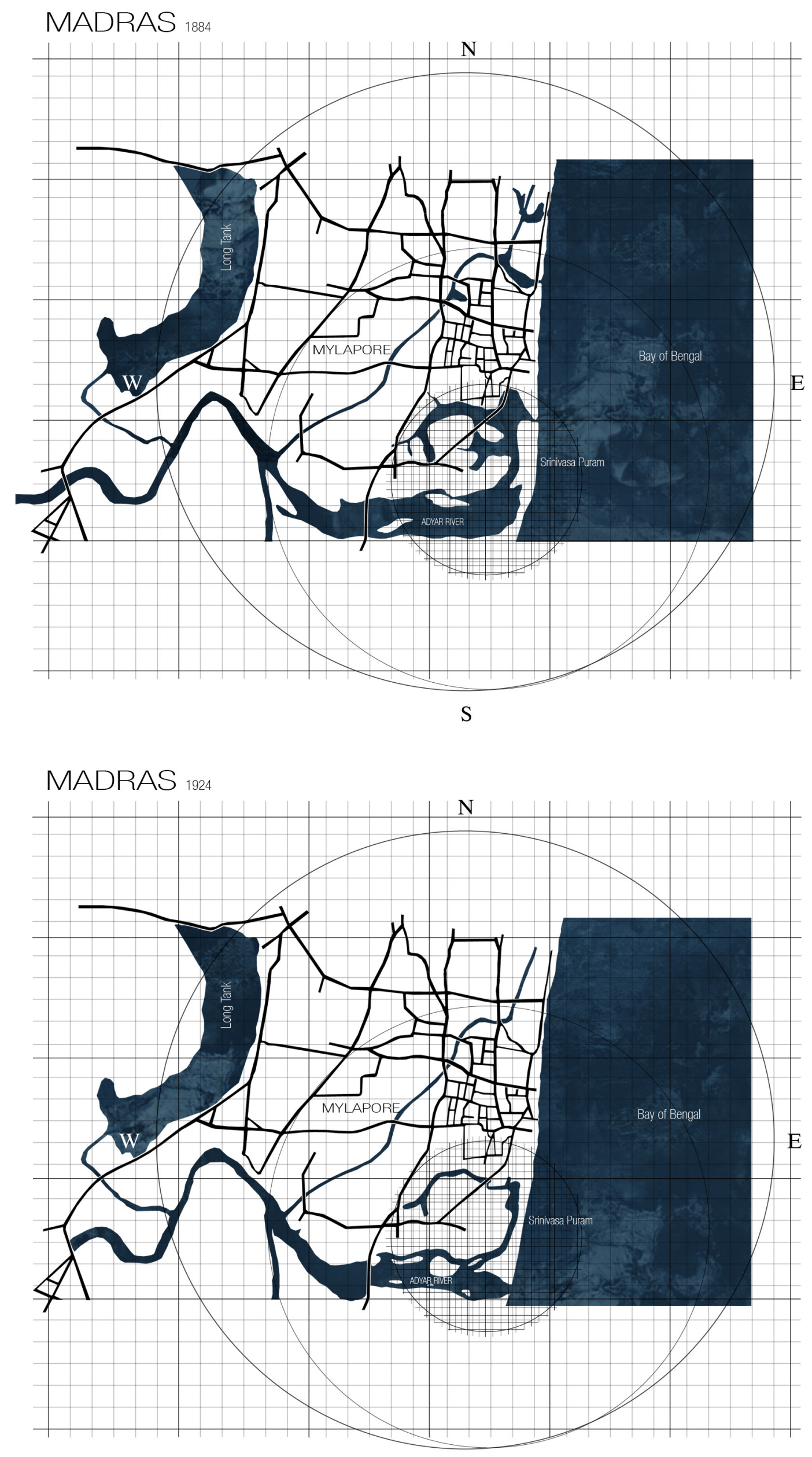


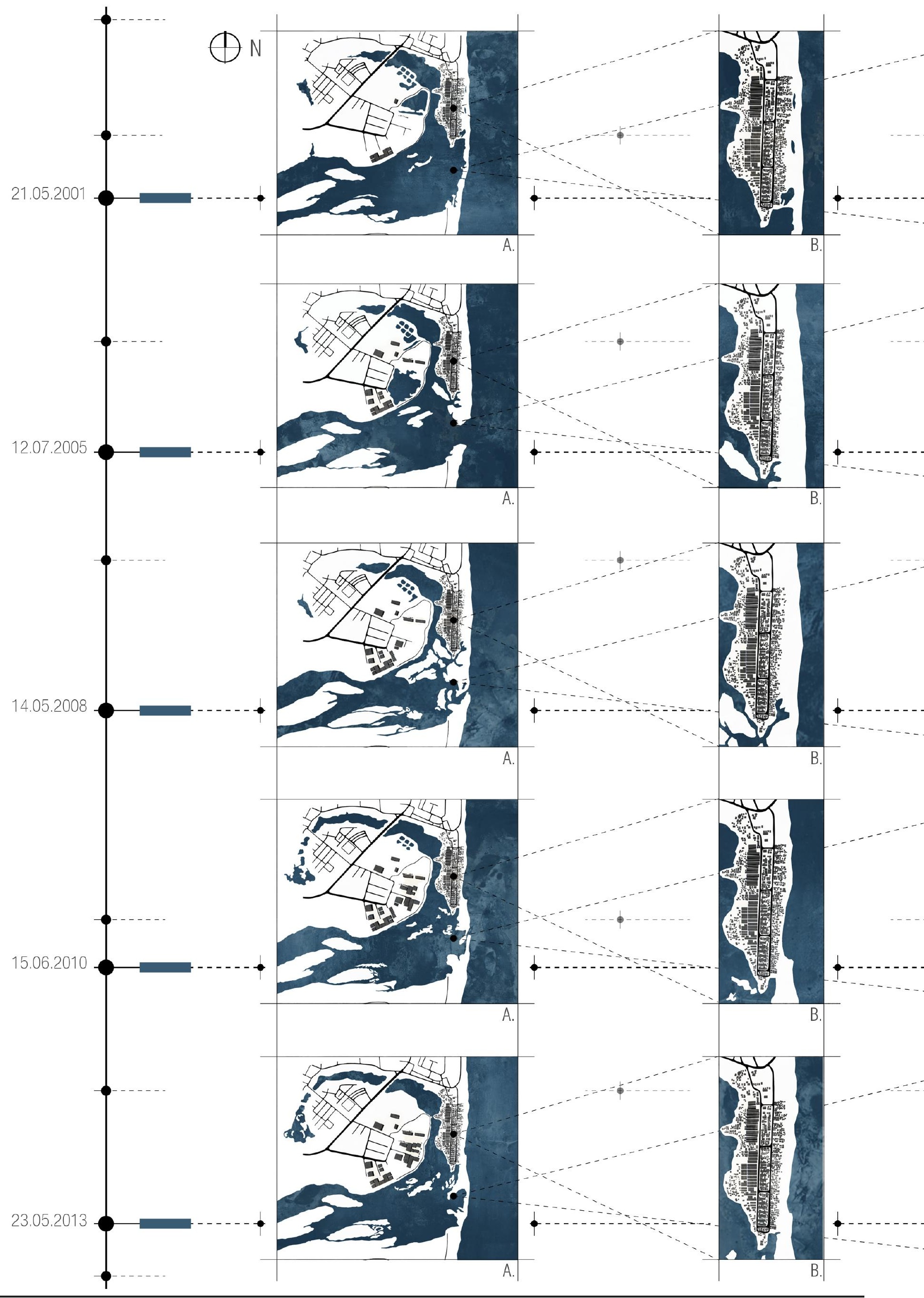

Fig. 61. Site development 2001-2013 generated by author from Google Earth satellite imagery. 


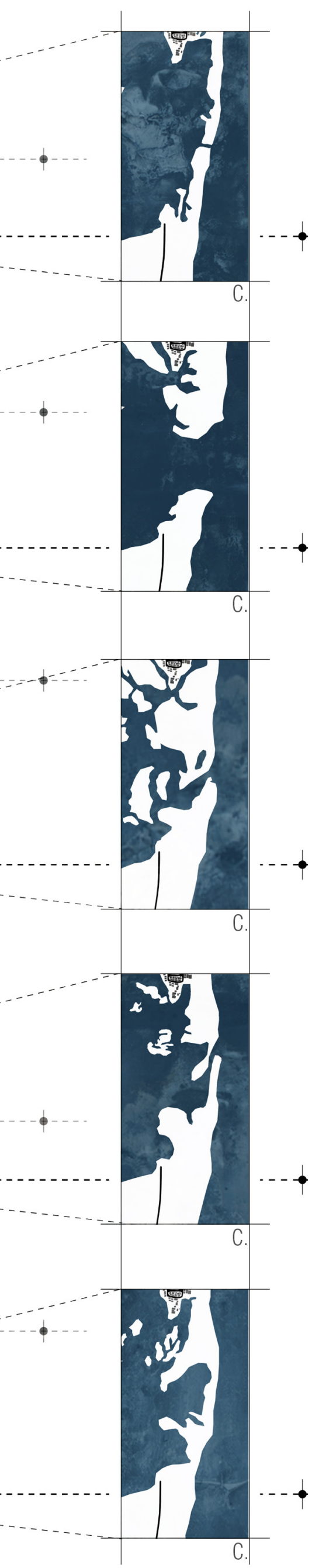

Figure 61 illustrates the vulnerable and ever-changing landscape of the Adyar River mouth and Srinivasa Puram's building densities from 2001 to 2013 as it is inundated by monsoon flooding, storm surges and tsunamis. Visiting the site it was evident that masonry dwellings and three-four story concrete apartment blocks were all that stood the test of time. Temporary thatch shelters are most vulnerable as they are built closest to the shoreline. 

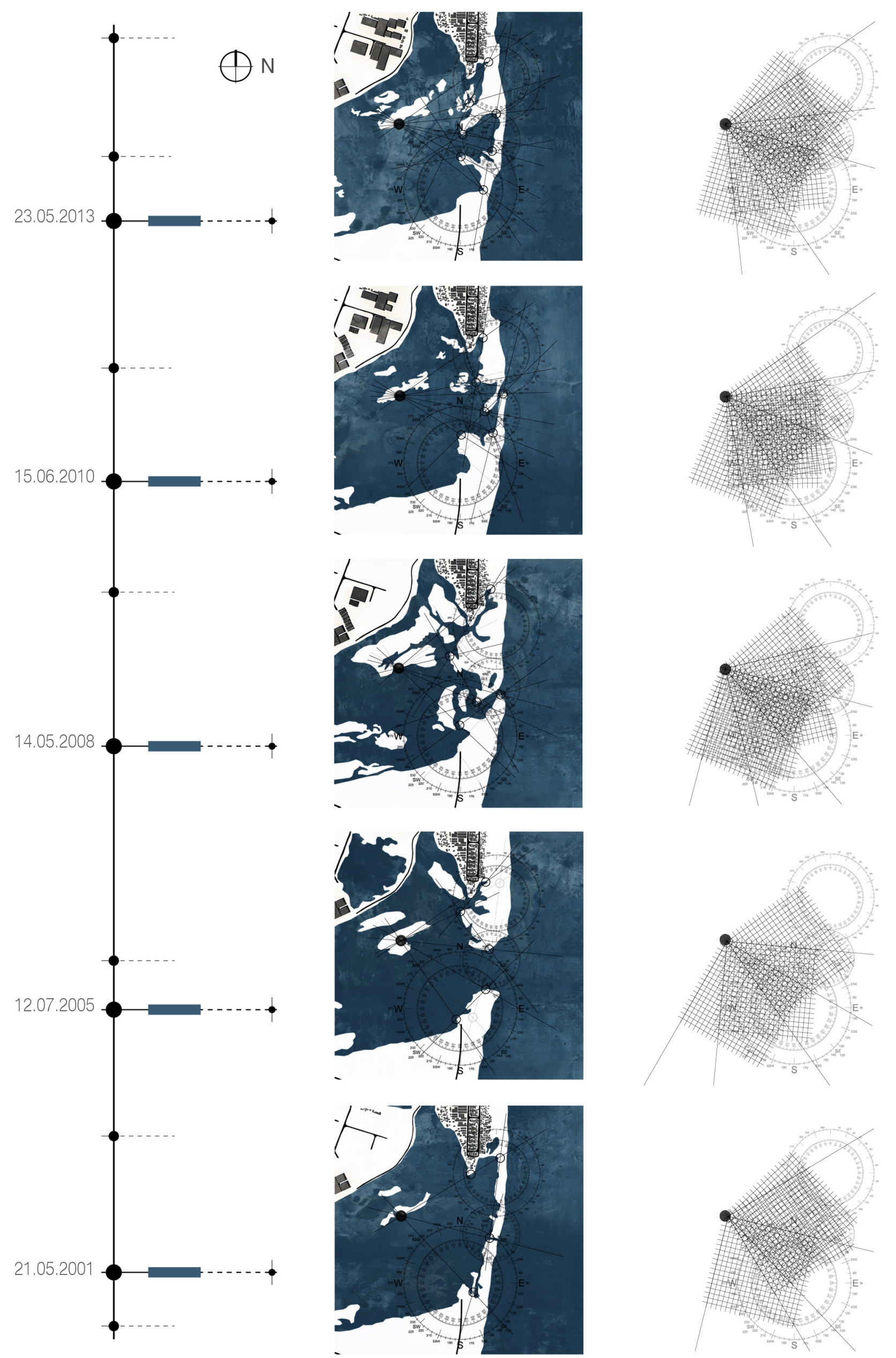

Fig. 62. Site development grid analysis. 


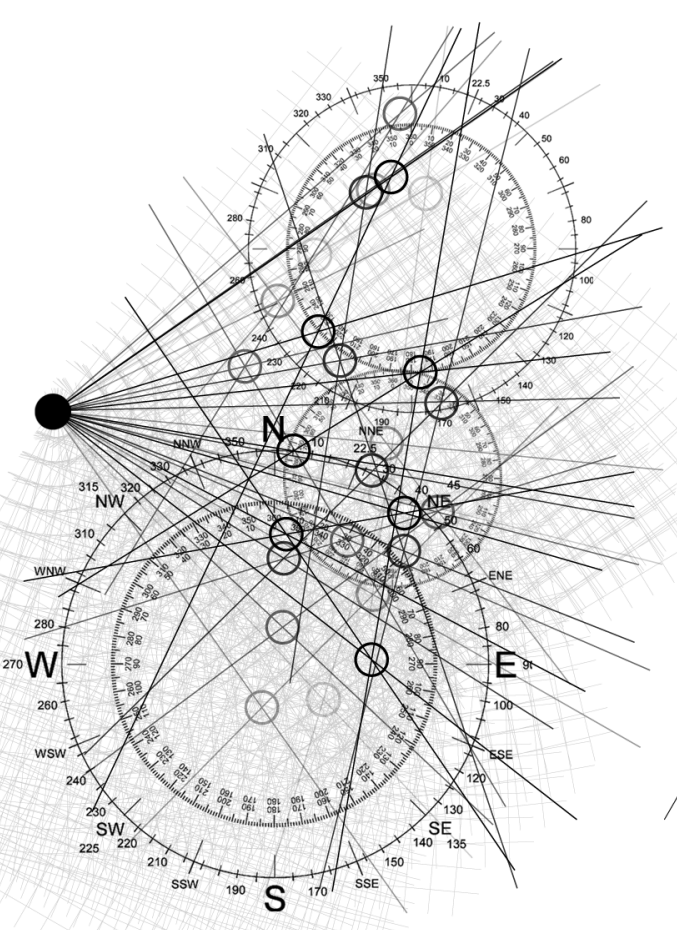

Overlaid site plot points \& angle shifts

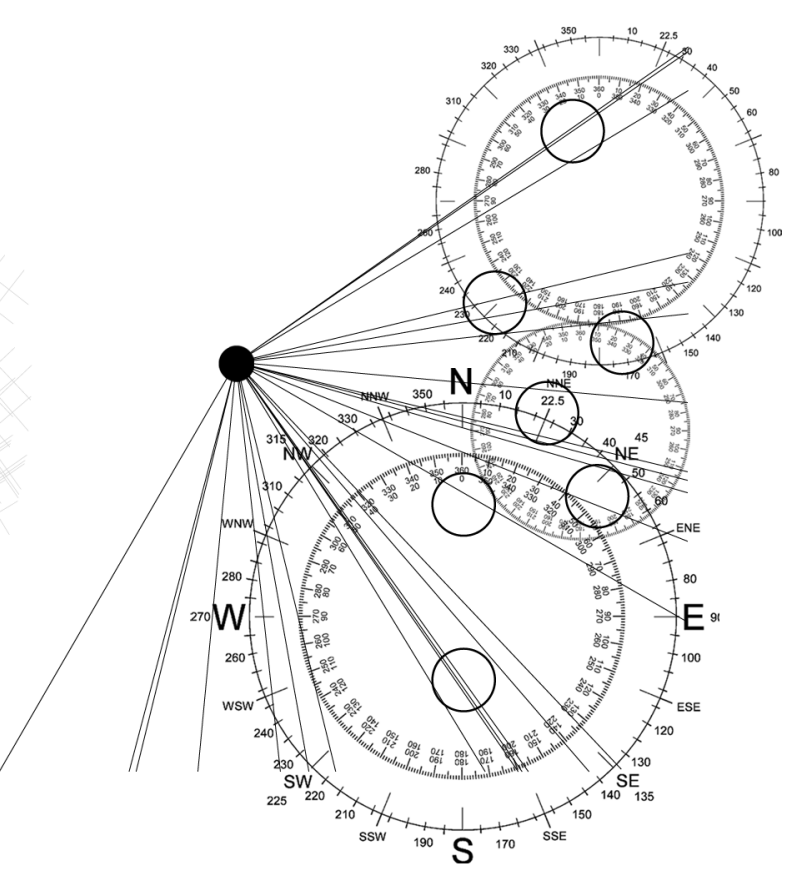

Simplified plot points \& site angles

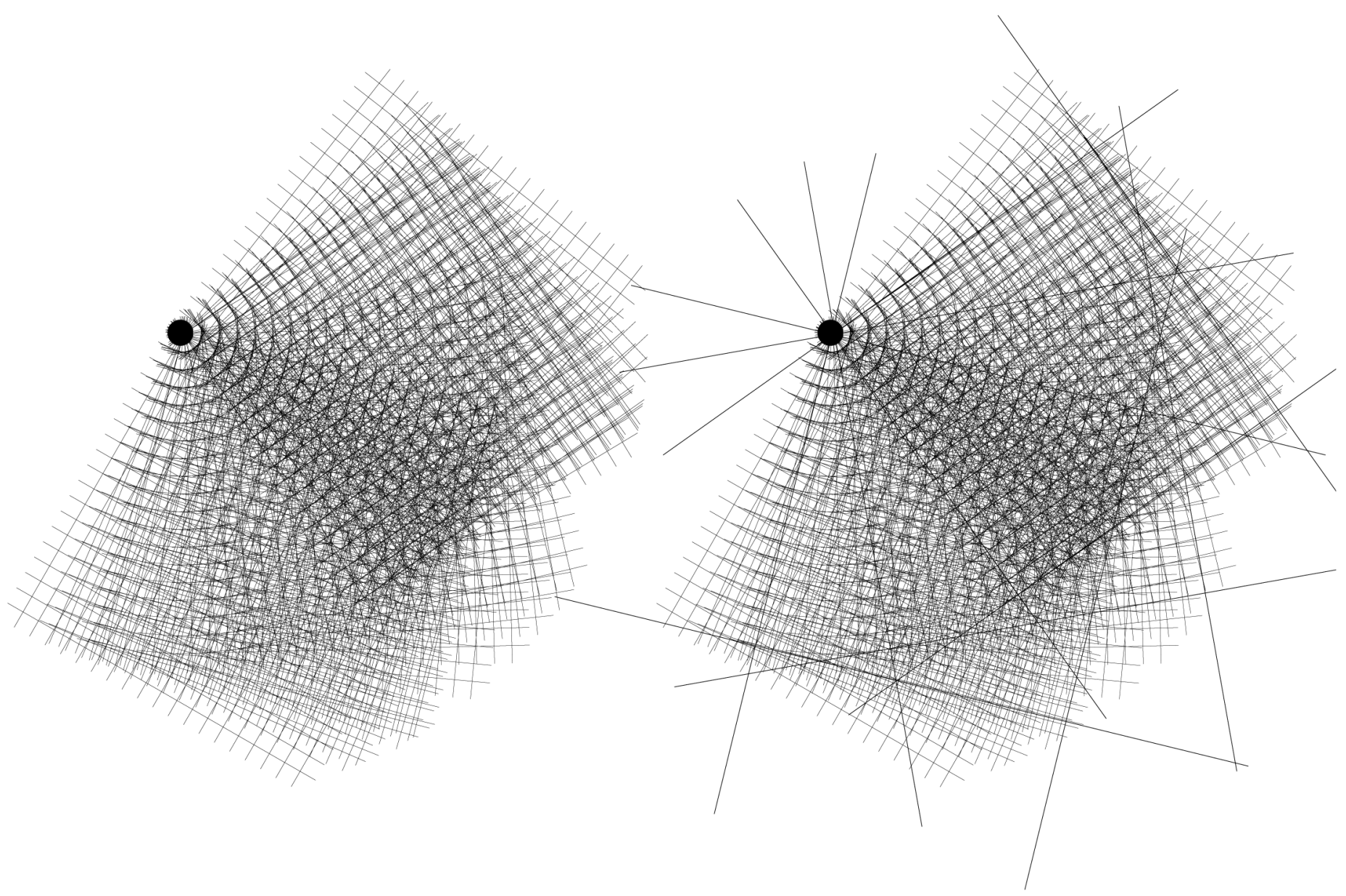

Overlaid grids generated from site angle shifts

Prominent grids generated from the analysis 
A comparative analysis study (Figures 61-63) illustrates the natural variations to the site over the last decade. Generated from Google Earth's satellite imagery it is observed that one particular point within the Adyar Estuary has remained the same from 2001 until present. This was selected as an anchor point to drive the study. Plot points of changes in the landscape were referenced back to the anchor generating angles that would form meaningful grid relations across the river mouth. The study produced three prominent and reoccurring grids that will be tested to orientate design responses. 


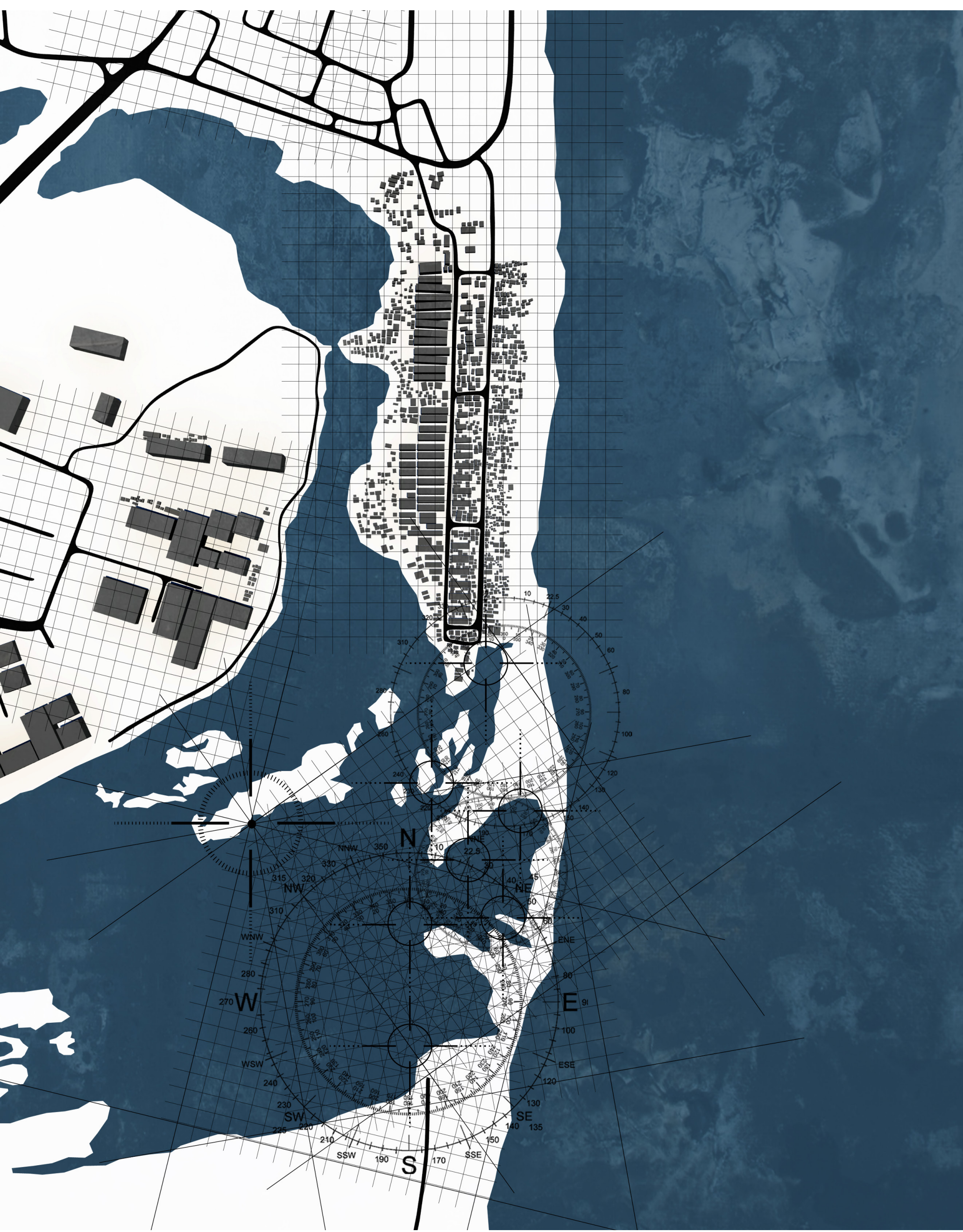




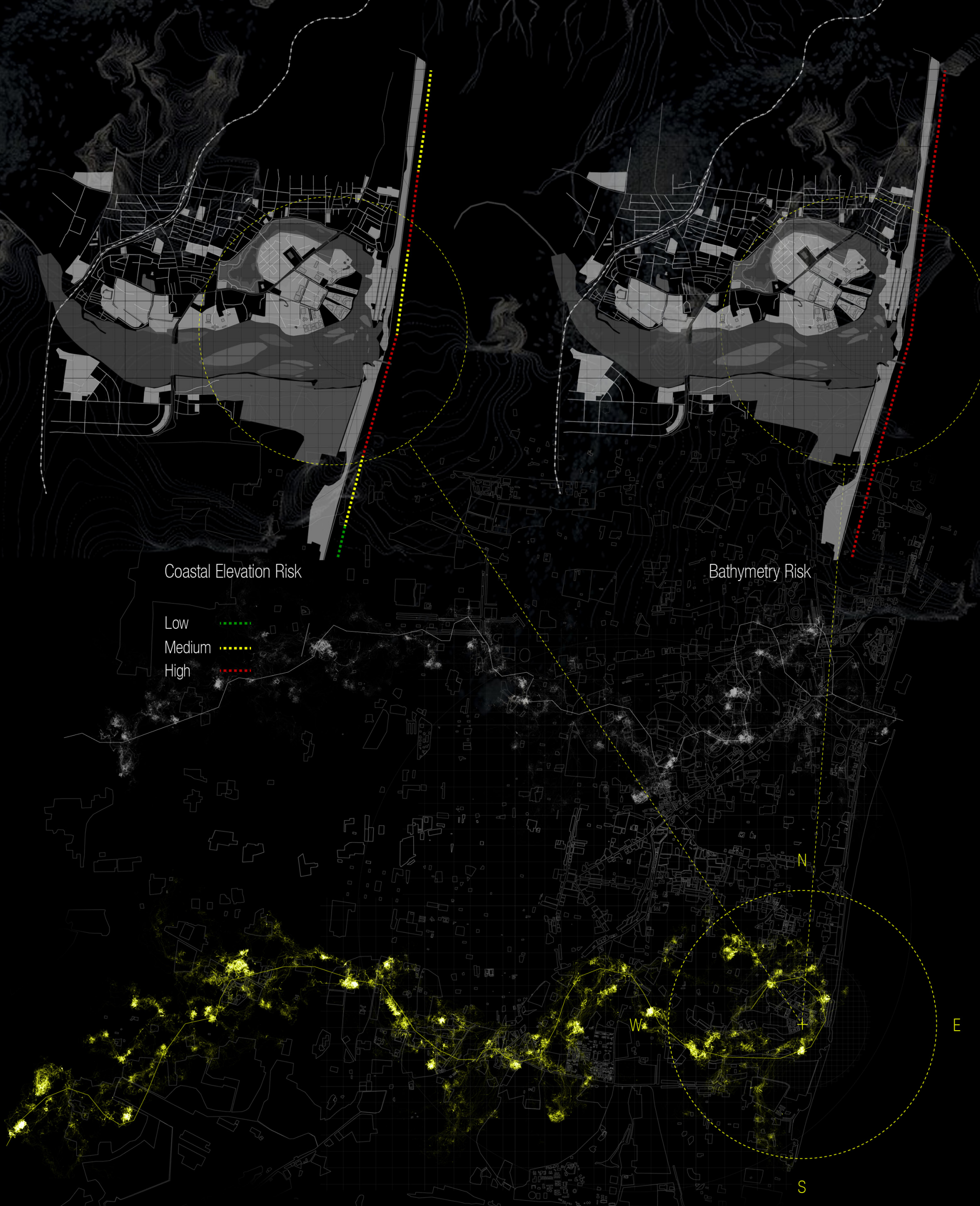

Adyar River Flood Risk 
Though the Adyar River has a catchment area of approximately $850 \mathrm{~km}^{2}$, the flow rate is insufficient to cleanse itself (Childambaram 20). The formation of the sandbar at the foot of the Adyar River mouth requires dredging at regular intervals to flush the water and buildup of pollution in an attempt to rejuvenate the ecosystems it supports (Lakshmi). Significant increases in river water levels during the monsoon season provide the only means of natural cleansing the river receives. The Adyar River has now become a stagnant breeding ground for mosquitos and diseases with millions of liters of raw sewage and heavy metal pollutants being dumped into it every day (Gowri et al.). The closed river mouth has devastating effects upon thousands of slum dwellers upstream who reside along the low lying river banks. For some, the river is their only means of drinking, cleansing and ablution water available.

Srinivasa Puram is one of the most vulnerable slum communities in Chennai. Nature's defense mechanisms such as natural reefs and mangrove plantations no longer exist along the coastline due to heavy pollution and Chennai's demand for expanding development (Shivakumar). This means dwellings closest to the coastline are often temporary means of shelter built from thatch, serving a purpose until the next storm arrives. When disasters strike, thousands of families are displaced and left homeless having to rebuild upon return.

Both Srinivasa Puram and the Adyar River mouth have high coastal elevation and bathymetry risks (Figure 64). The Adyar River flood risk map highlights low lying areas susceptible to flood damage during the monsoon seasons. 
Twenty-five percent of India's population lives within 50 kilometers of the coastline and depend on the ocean for their livelihood (Gupta 132). Adapted to brackish intertidal zones, mangroves are the most productive and bio-diverse forests on the planet supporting the livelihoods of millions of people around the world. Over the last 50 years over a third of the world's mangrove forests have been harvested to provide a source of foods, medicines, fuels and building materials while creating land for development and agricultural purposes (Alongi). The rejuvenation of mangrove plantations on site will be implemented into the design to restore coastal ecology systems, natural defense structures that mitigate storm surges and tsunamis as well as repopulate marine species. 


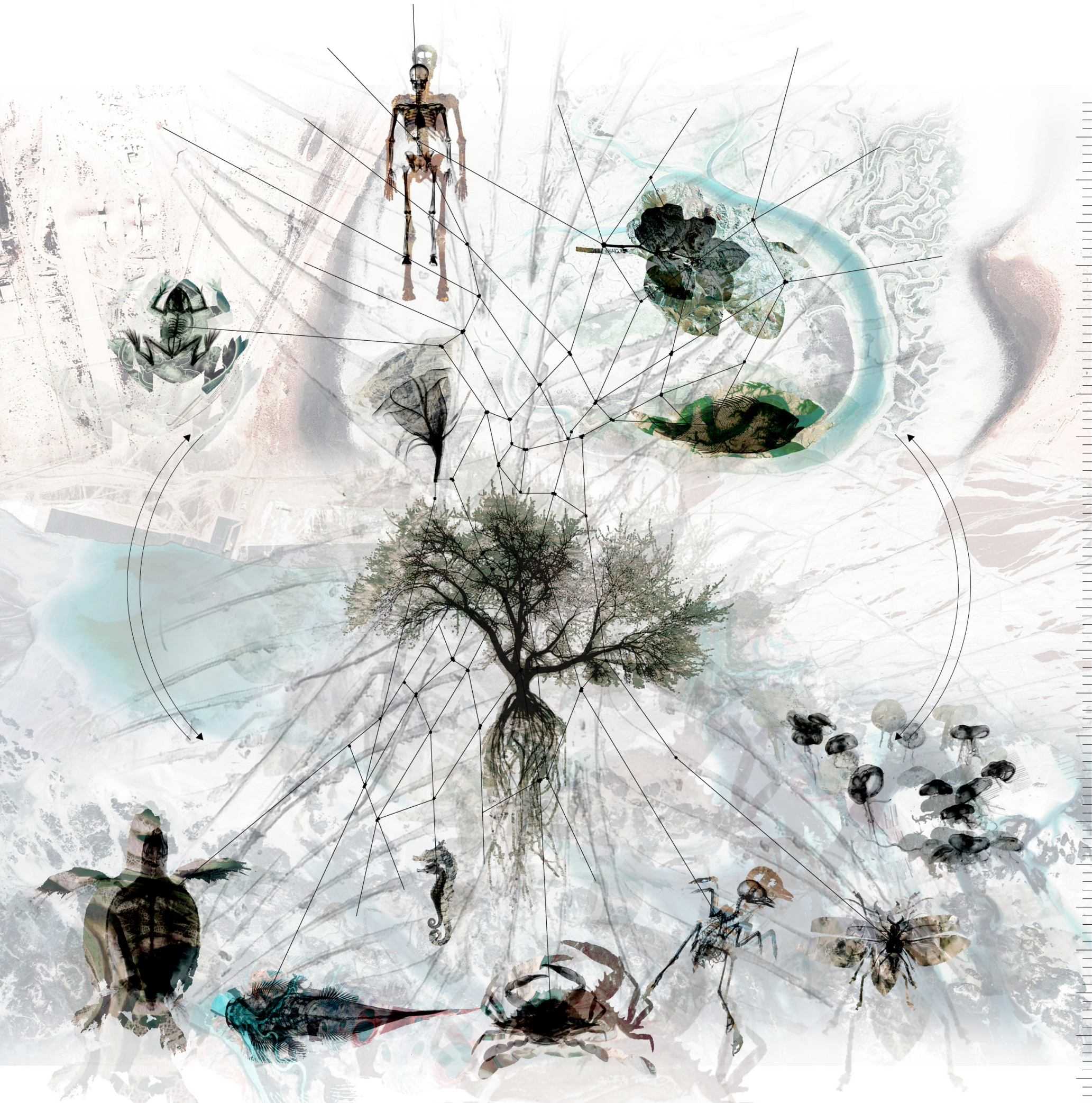




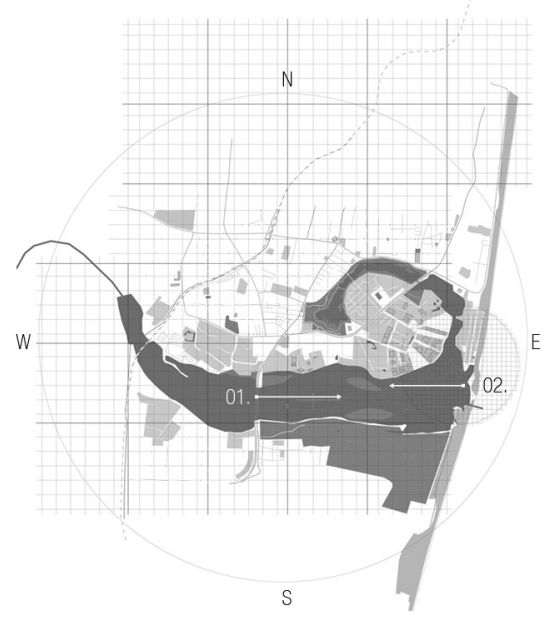

01.

Fig. 66. Adyar River.

02. Low Tide

,

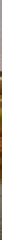

Fig. 67. Adyar River mouth. 


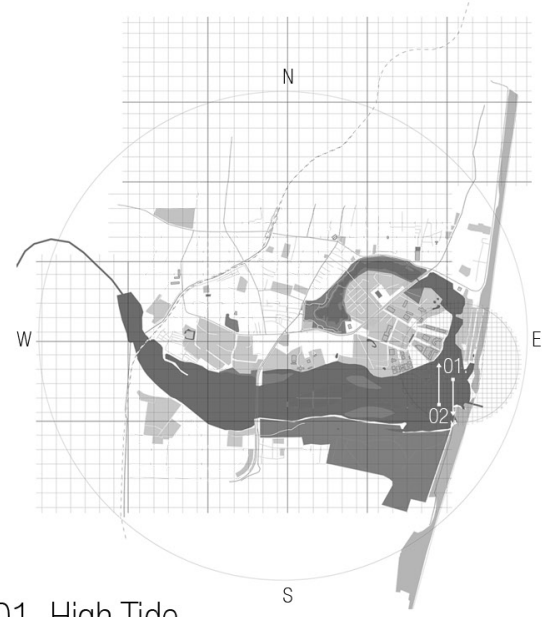

01. High Tide

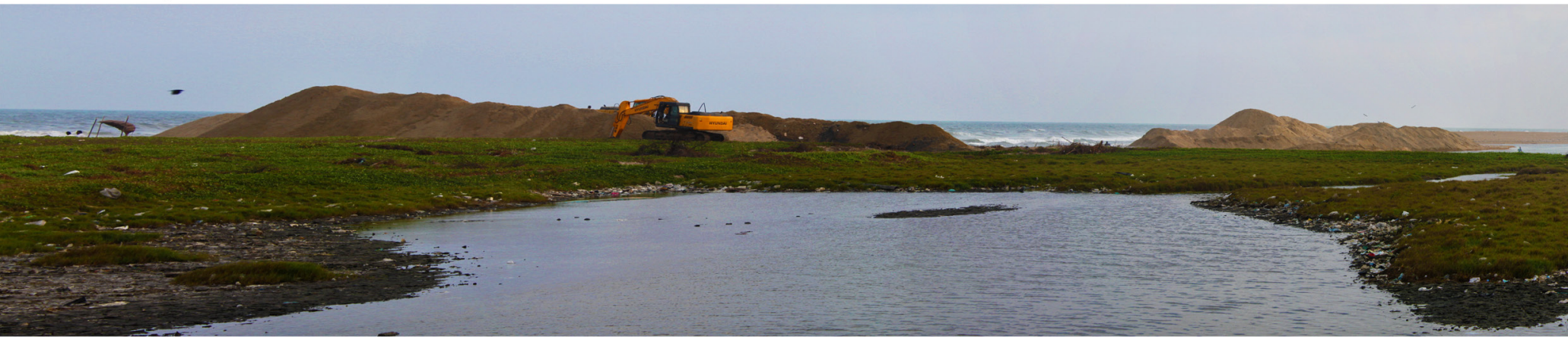

Fig. 68. Adyar River mouth looking south.

02. High Tide

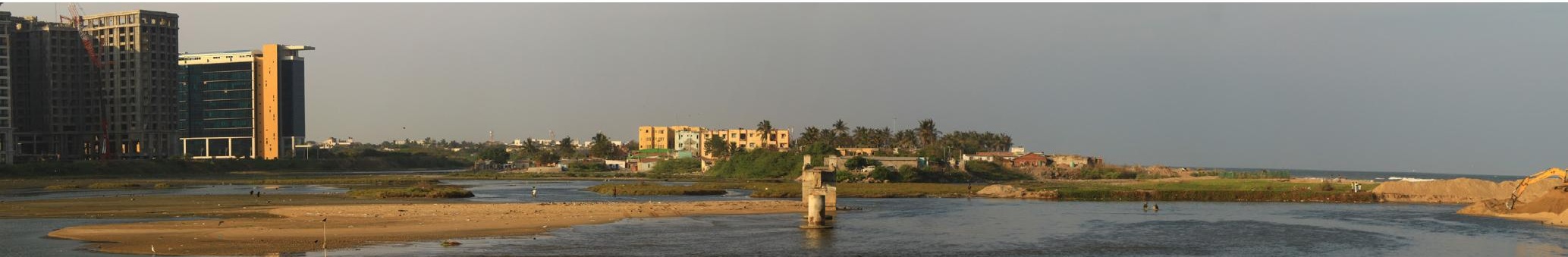

Fig. 69. Adyar River mouth looking north. 


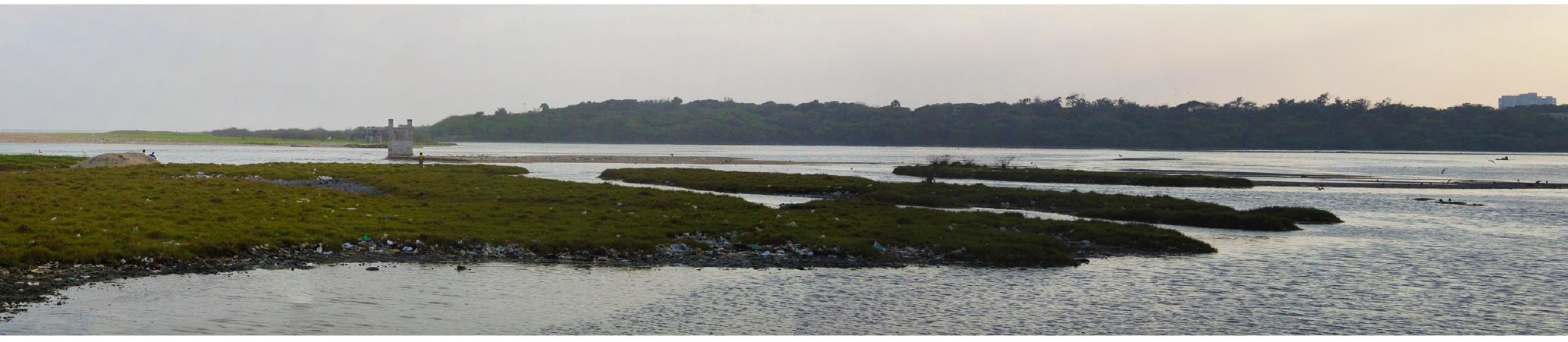


$4 x^{2}-y^{2}$

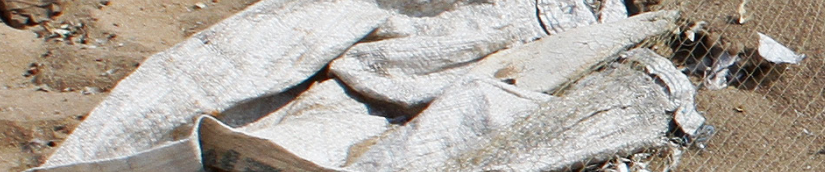

Notistis
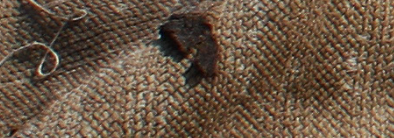

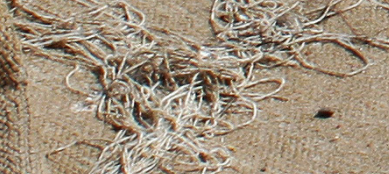
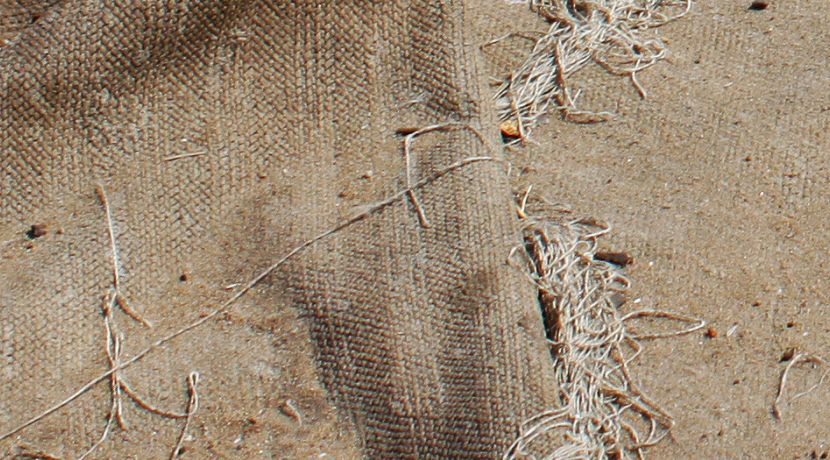

Q.
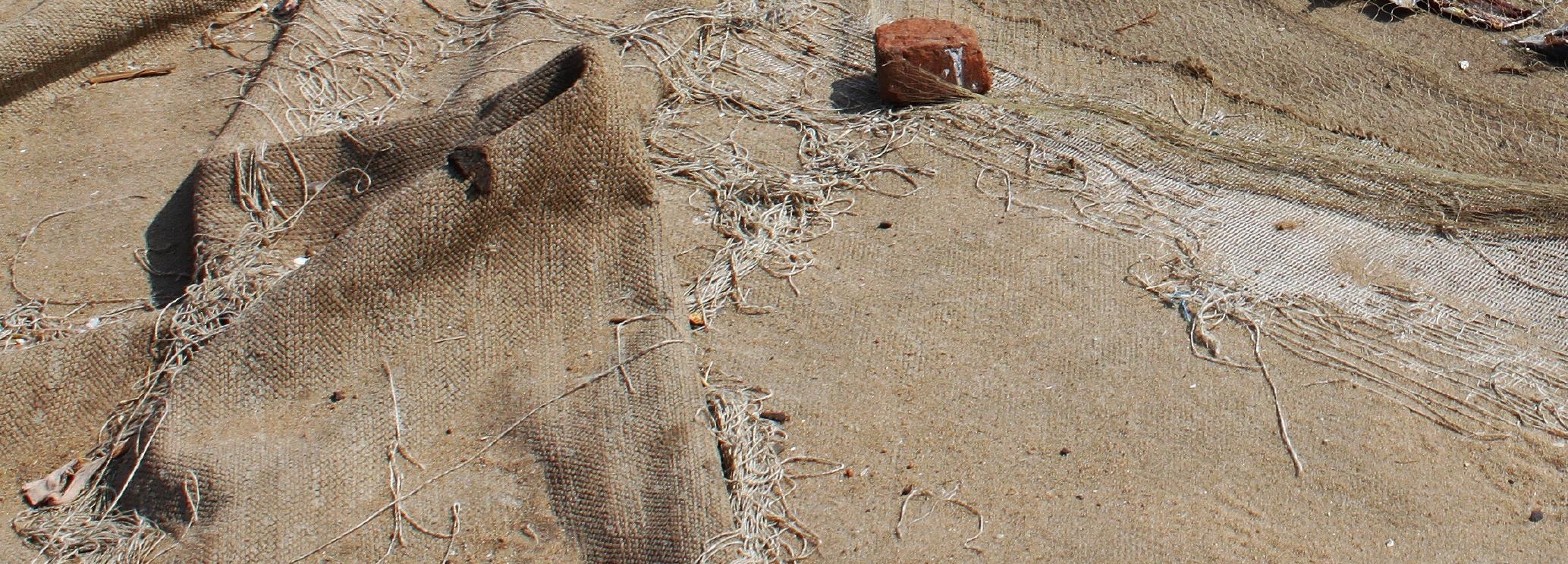

(t)

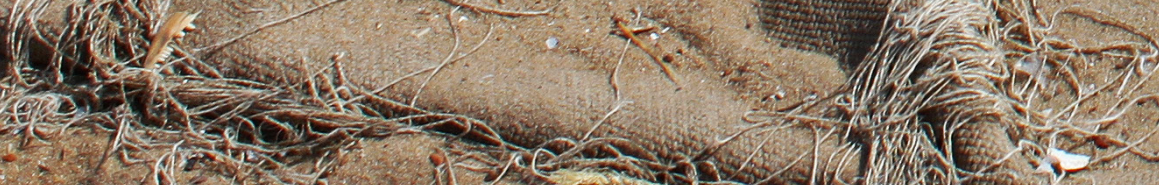

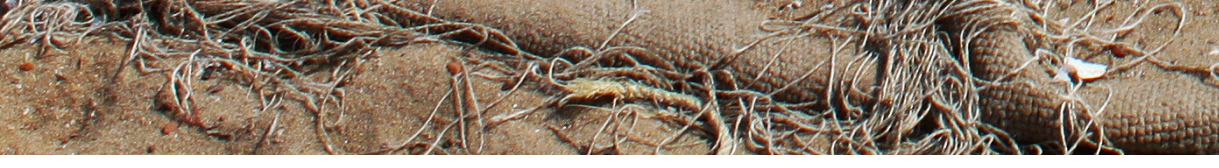



The site analysis chapter highlighted a number of immediate and extended site problems for both Srinivasa Puram and the Adyar River that are having drastic implications on both the slum dwellers' livelihoods and the surrounding ecosystems. This chapter outlines a set of programmatic requirements to form a self-sustainable framework capable of mitigating environmental disasters and pollution while allowing the residents of Srinivasa Puram to maintain and expand their livelihoods near the mouth of the Adyar estuary. 


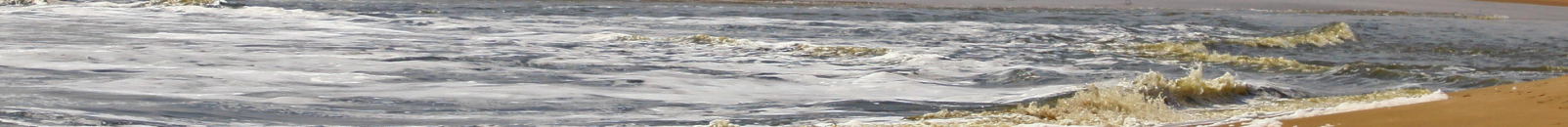

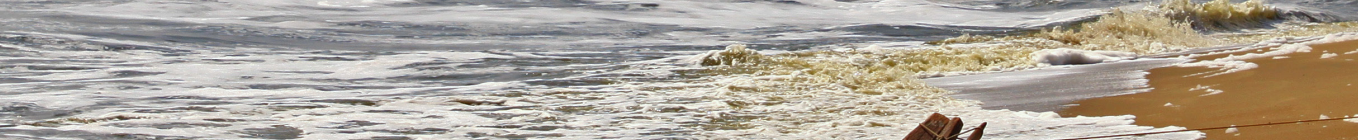
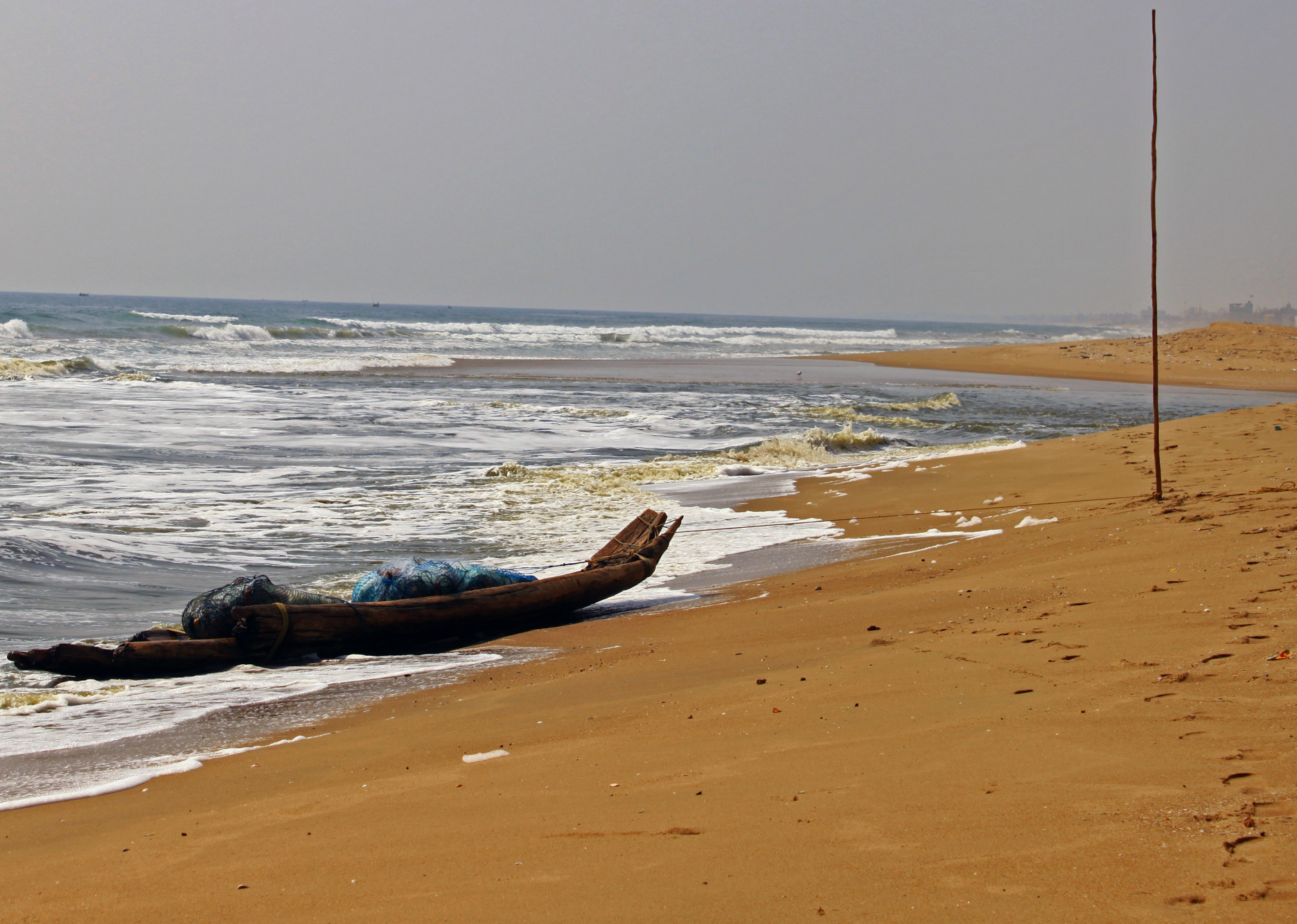

Fig. 73. Fishing boat pulled ashore. 


\subsection{AN EXPANDING FRAMEWORK}

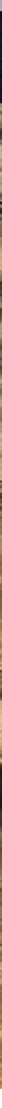




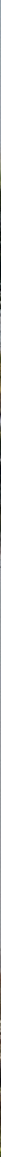




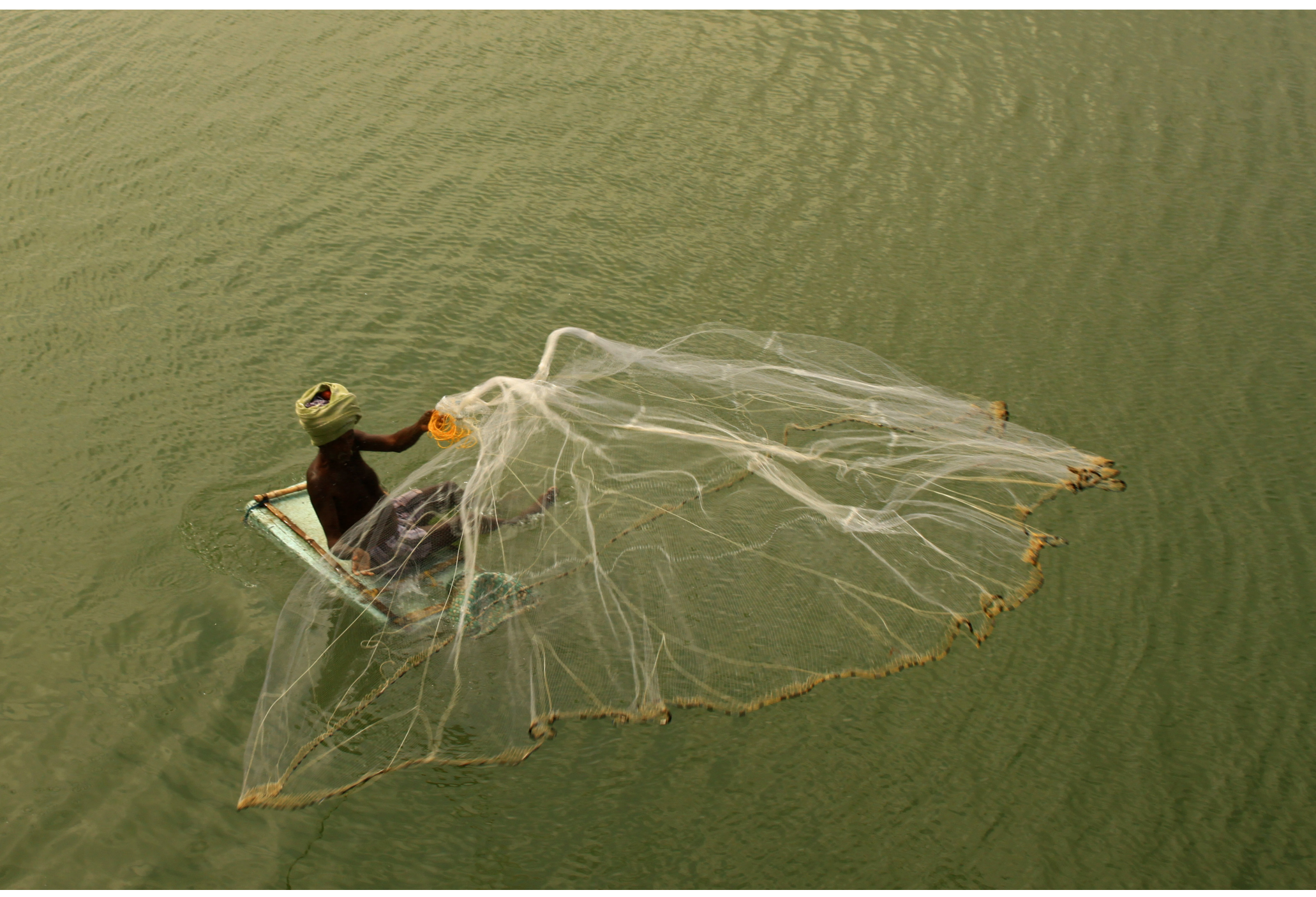

Fig. 75. Fishing on the Adyar River. 
The population of Srinivasa Puram is estimated to increase from 3086 families in 2011 to 3208 families by 2016, an increase of 122 families above the current population. Based on the Kanngi Nagar, Semmenchery and Perumbakkam case studies which limited tenement family dwellings to 14$15 \mathrm{~m}^{2}$ each, the thesis design research investigation proposes to provide $28 \mathrm{~m}^{2}$ per tenement in an effort to improve living conditions. The design scheme will therefore require a total housing area of $3170 \mathrm{~m}^{2}$.

Srinivasa Puram does not have any defense infrastructure in place to provide shelter from storm surges, tsunamis or rising sea levels. It also lacks any viable public space to accommodate events such as fresh produce markets, communal activities and rituals. The programme for the proposed design scheme therefore will provide housing for a minimum of 122 families, secure shelter for fishing vessel mooring during storm surges and cyclones, public market space for fruit, vegetables, fish and communal activities, as well as facilities for fishing equipment storage and maintenance. 
3.2 WATER SUPPLY

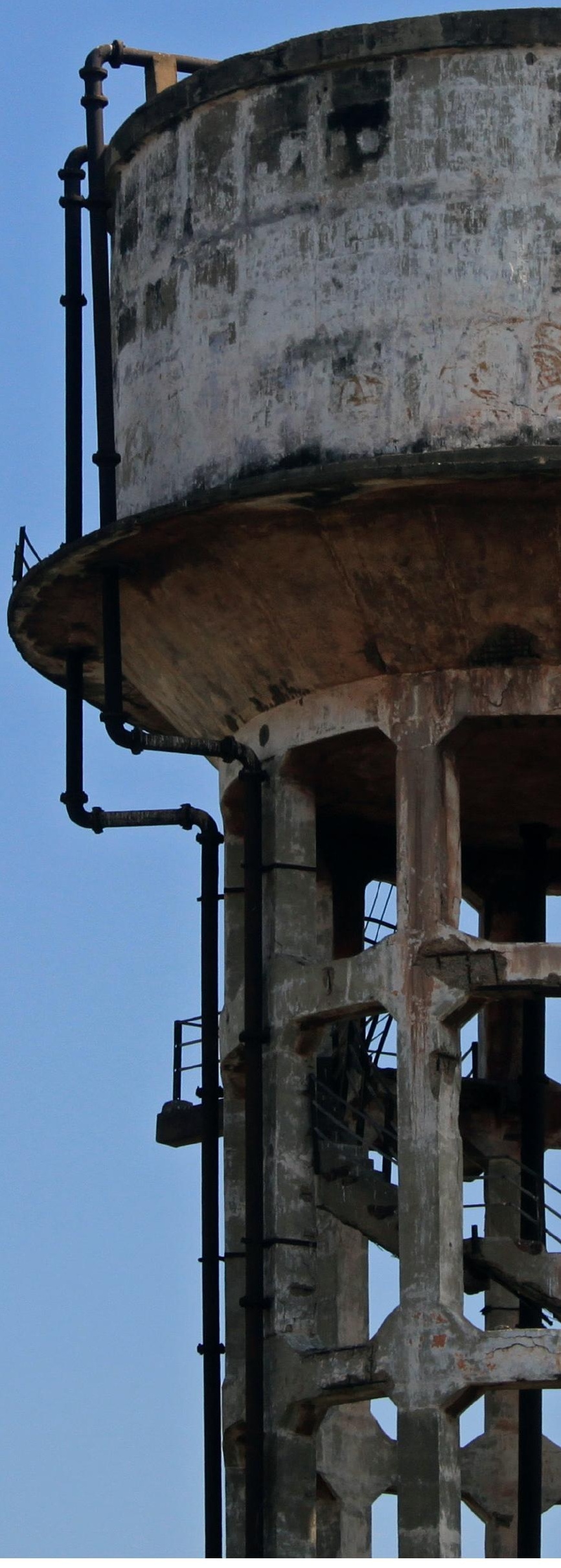




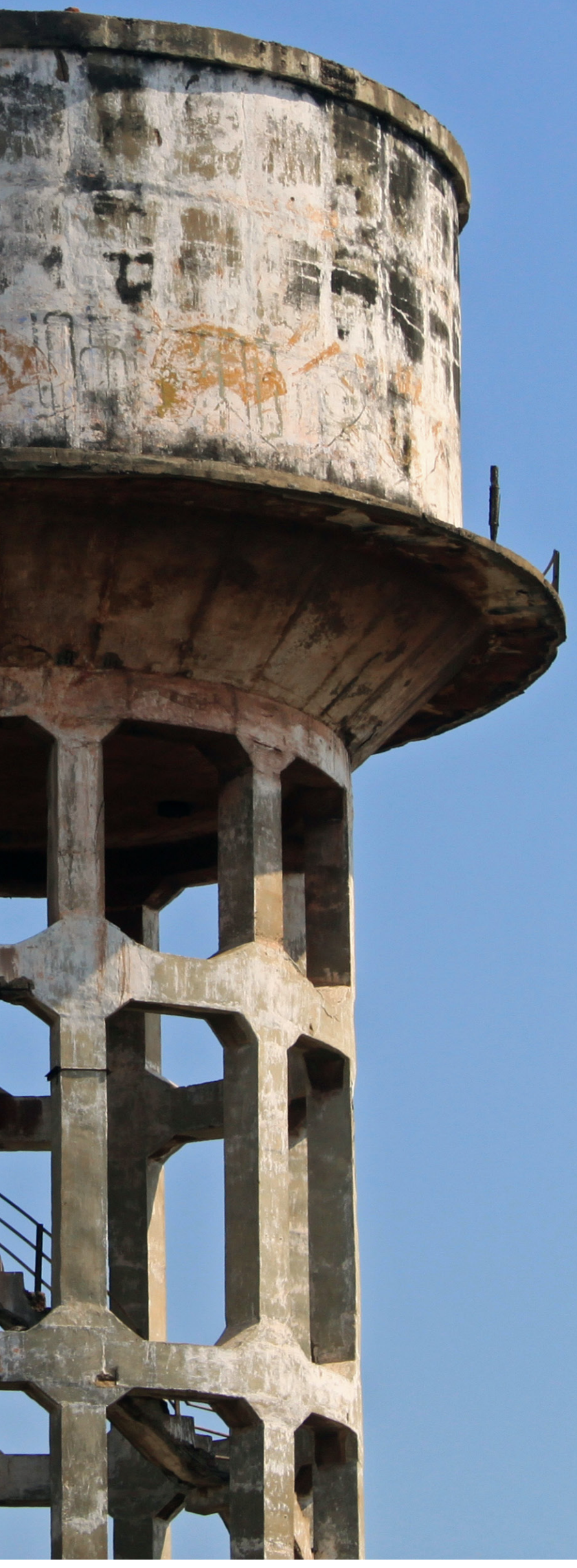




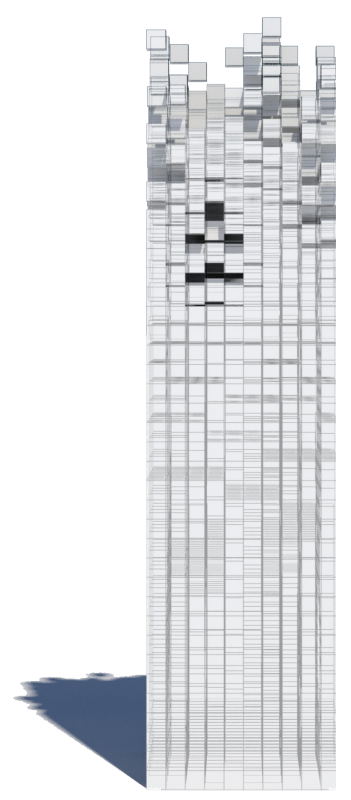

While the local government of Chennai is desperately trying to close the increasing gap between Chennai's fresh water supply and the demand, those who are in need most remain an invisible priority (Lakshmi). As the proposed design scheme looks to implement a self-sustainable framework that helps mitigate severe environmental disasters, a logical and feasible answer for providing a reliable fresh water system to the Srinivasa Puram would be to respond directly to the one resource in surplus; sea water.

With an estimated population of 15,400 by 2016 , Srinivasa Puram will require 2.31 million liters of potable water per day at a rate of 150 liters per capita daily. To mitigate the threat of a water supply failure due to natural disasters, the design will include a fresh water storage capacity of a 2 week water supply $\left(32340 \mathrm{~m}^{3}\right)$.

Stepped structures and freestanding columns are common throughout South India and represent traditional Hindu architecture. Stepped ghats and stepped water tank structures (Figures 77-78) also common throughout South India and still widely used as traditional architectural forms relating to water. Ancient ghats still occur widely along river and lake edges, symbolising mountains (ghats) reaching the water. Much public interaction is traditionally centered around ghats.

Passive river water collection and purification is unfeasible for this site due to the high levels of toxic pollutants found in the water and the lack of elevation needed for terraced bio-filtration wetland systems. The design will implement both active and passive means of water harvesting and recyclable purification methods. 


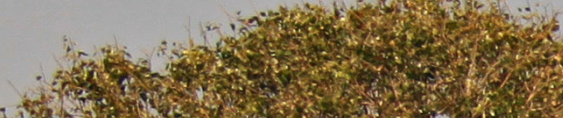

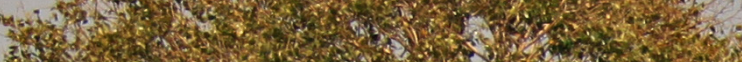

4.

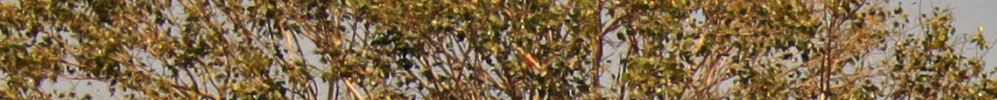

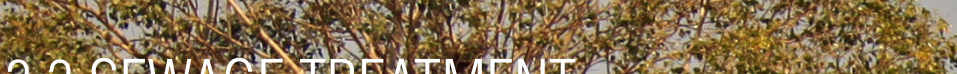

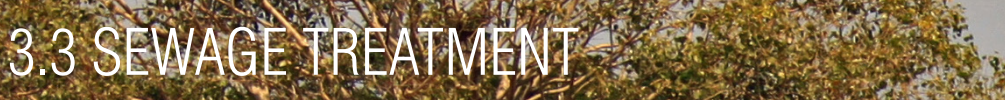

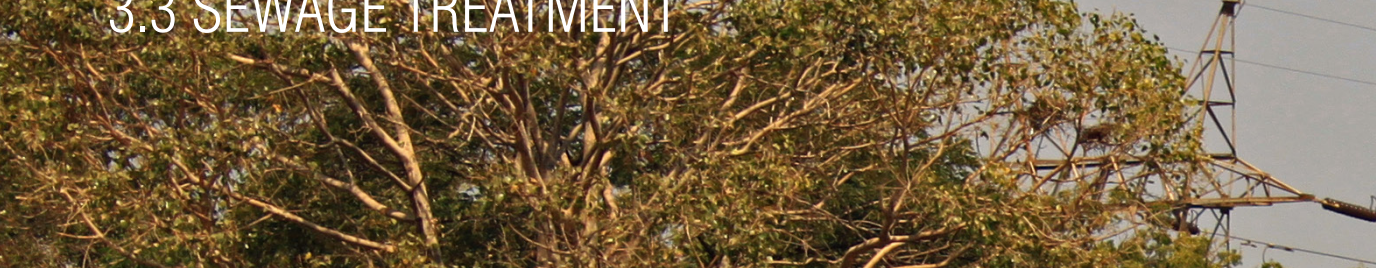

I.

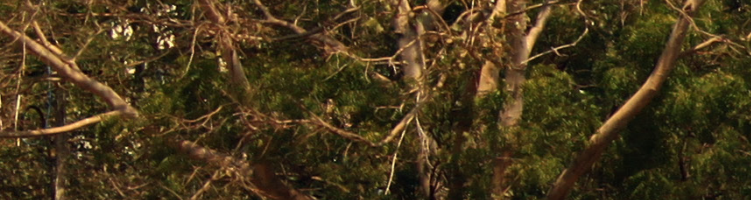

$\lim ^{2}$

.

Pit

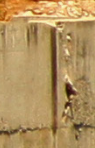

$4 x^{2}(x)$

mint

monting

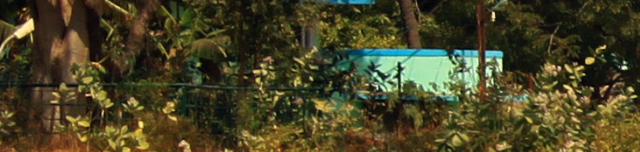

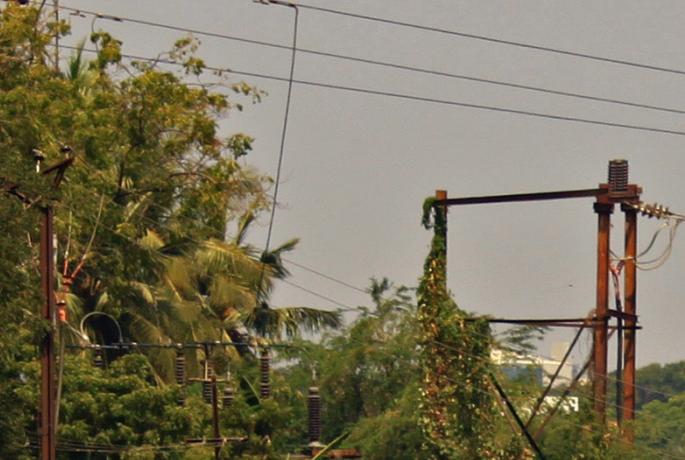

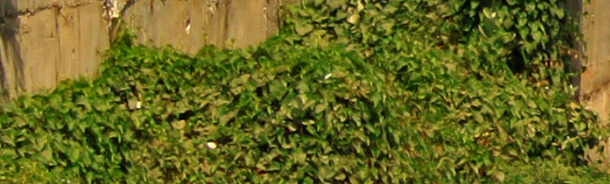

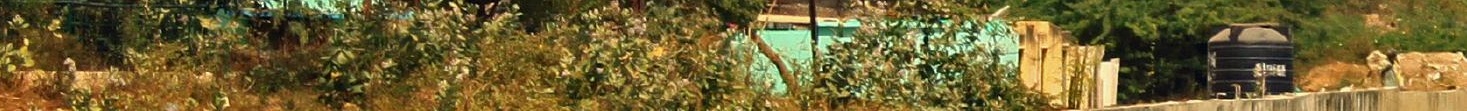
$4+2$

(3)

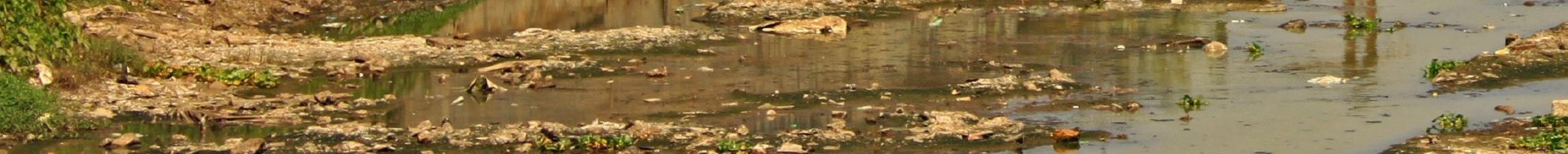

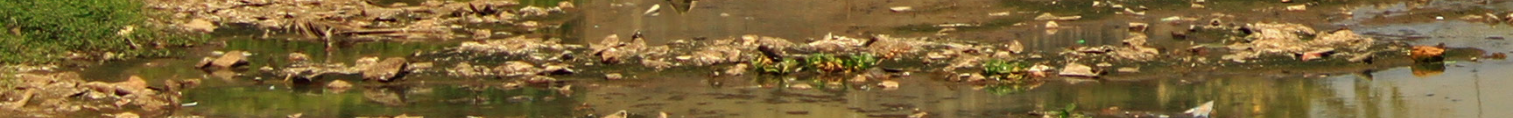

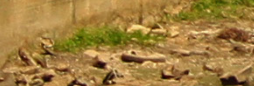

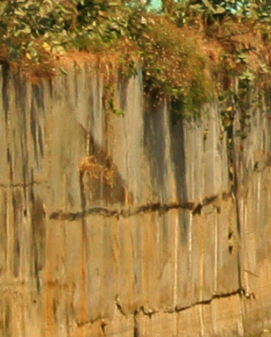




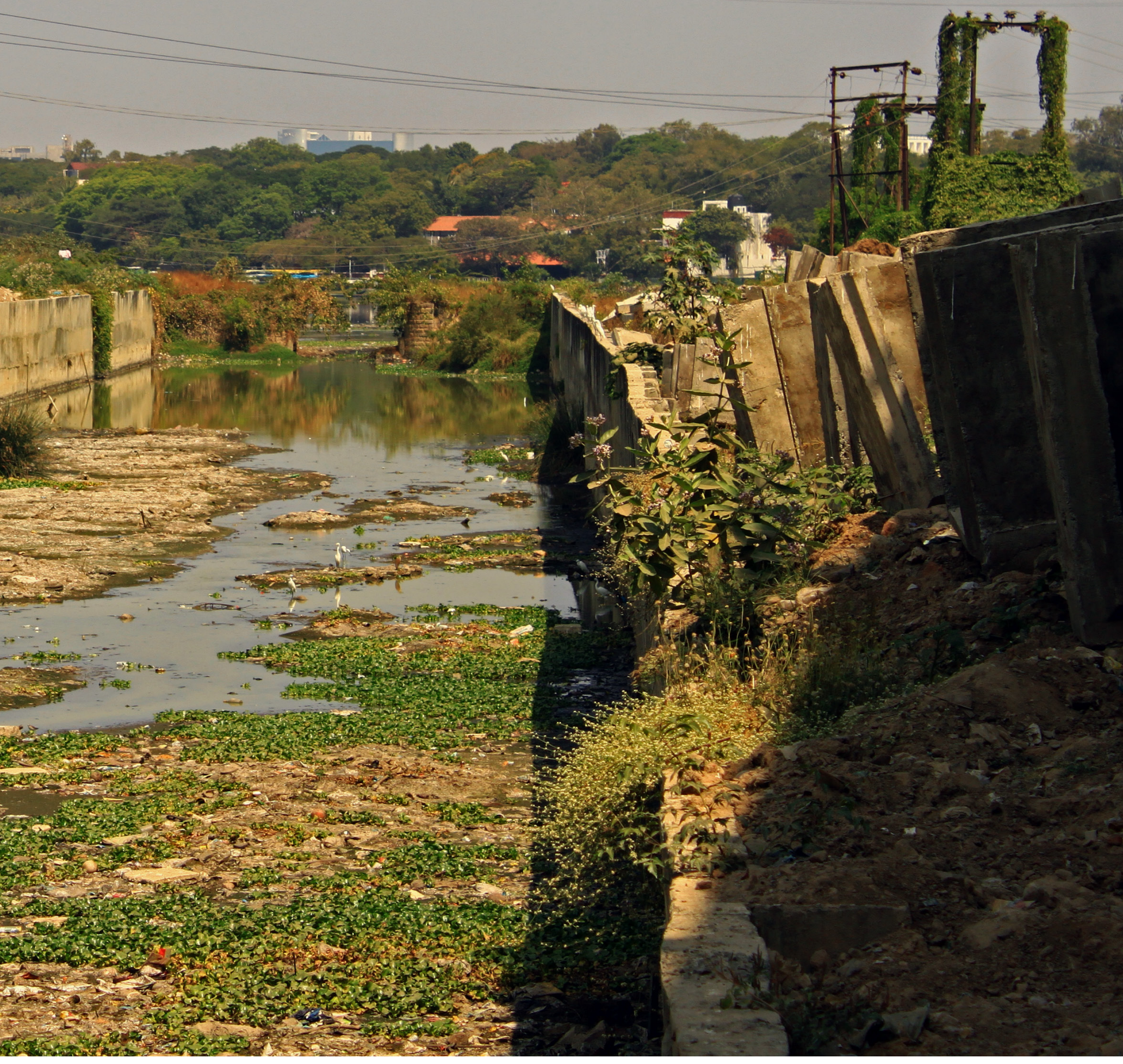

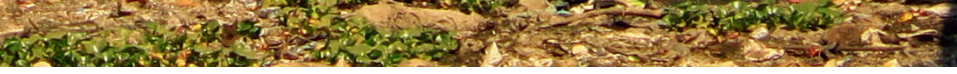


Outlined in the site analysis chapter Srinivasa Puram does not have any municipal sewerage system. This means Srinivasa Puram will produce 616,000 liters of untreated sewage daily by 2016. The design scheme will be required to process and treat this daily capacity on site and allow for a maximum two week storage capacity of $8624 \mathrm{~m}^{3}$.

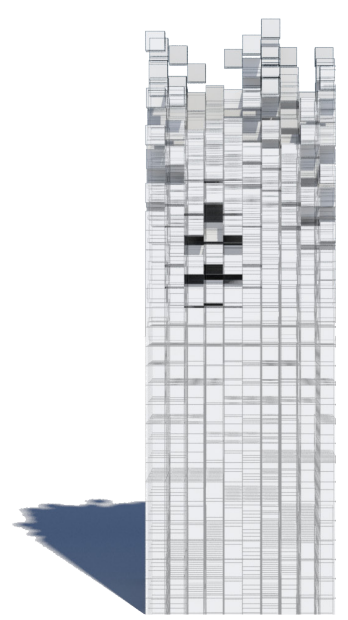




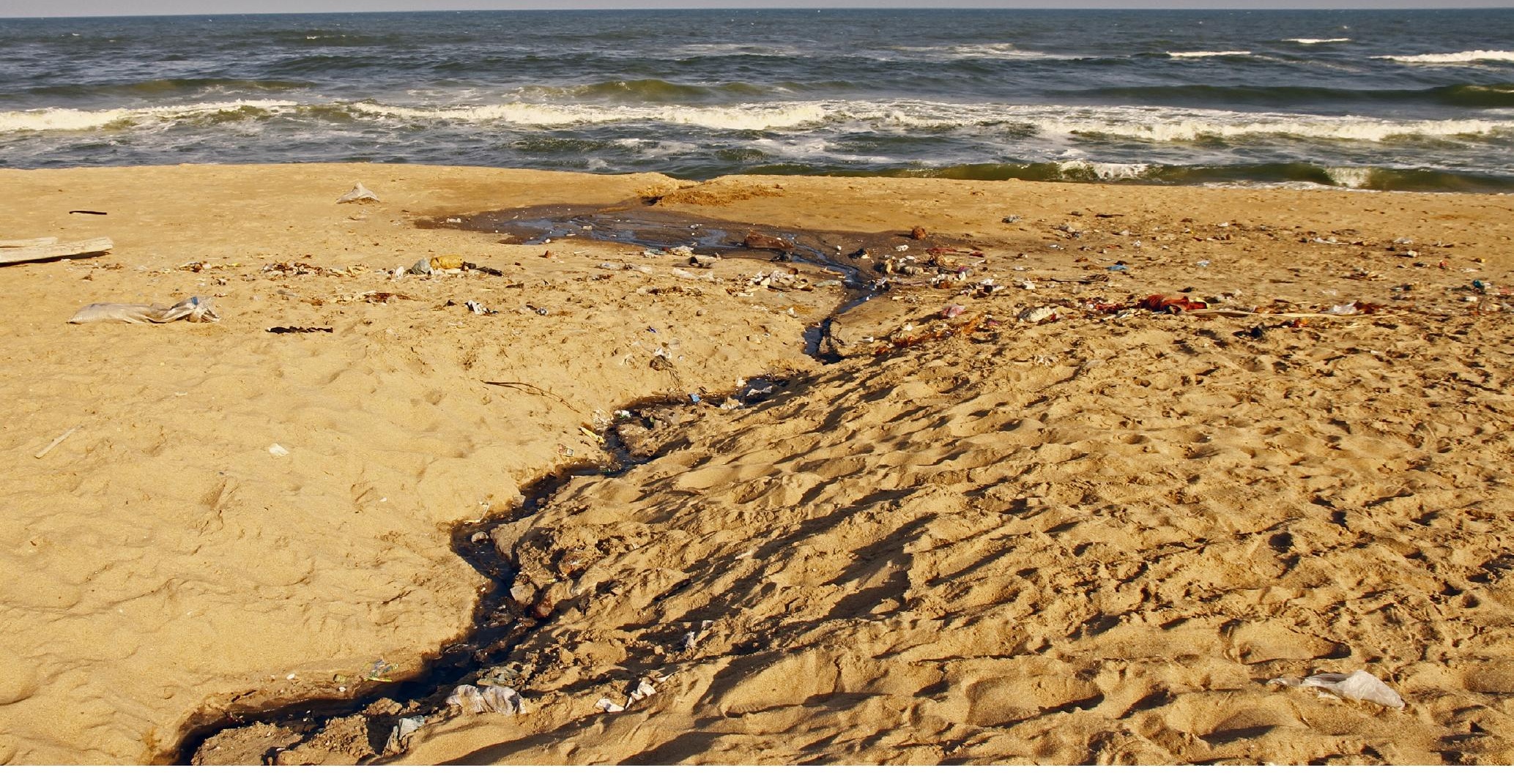

Fig. 80. Untreated sewage flowing out to sea. 


\subsection{GARBAGE TREATMENT}

\section{$-1-2-6$

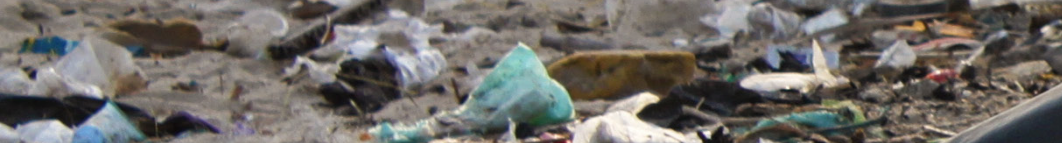 -

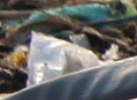

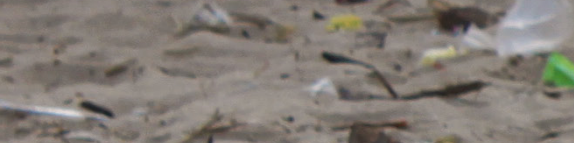

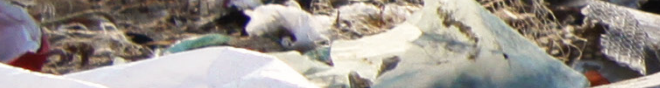

tis

$-5$

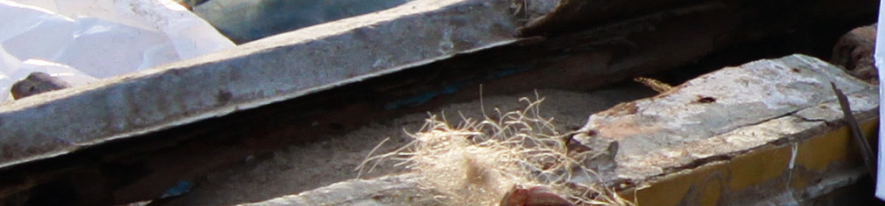

2
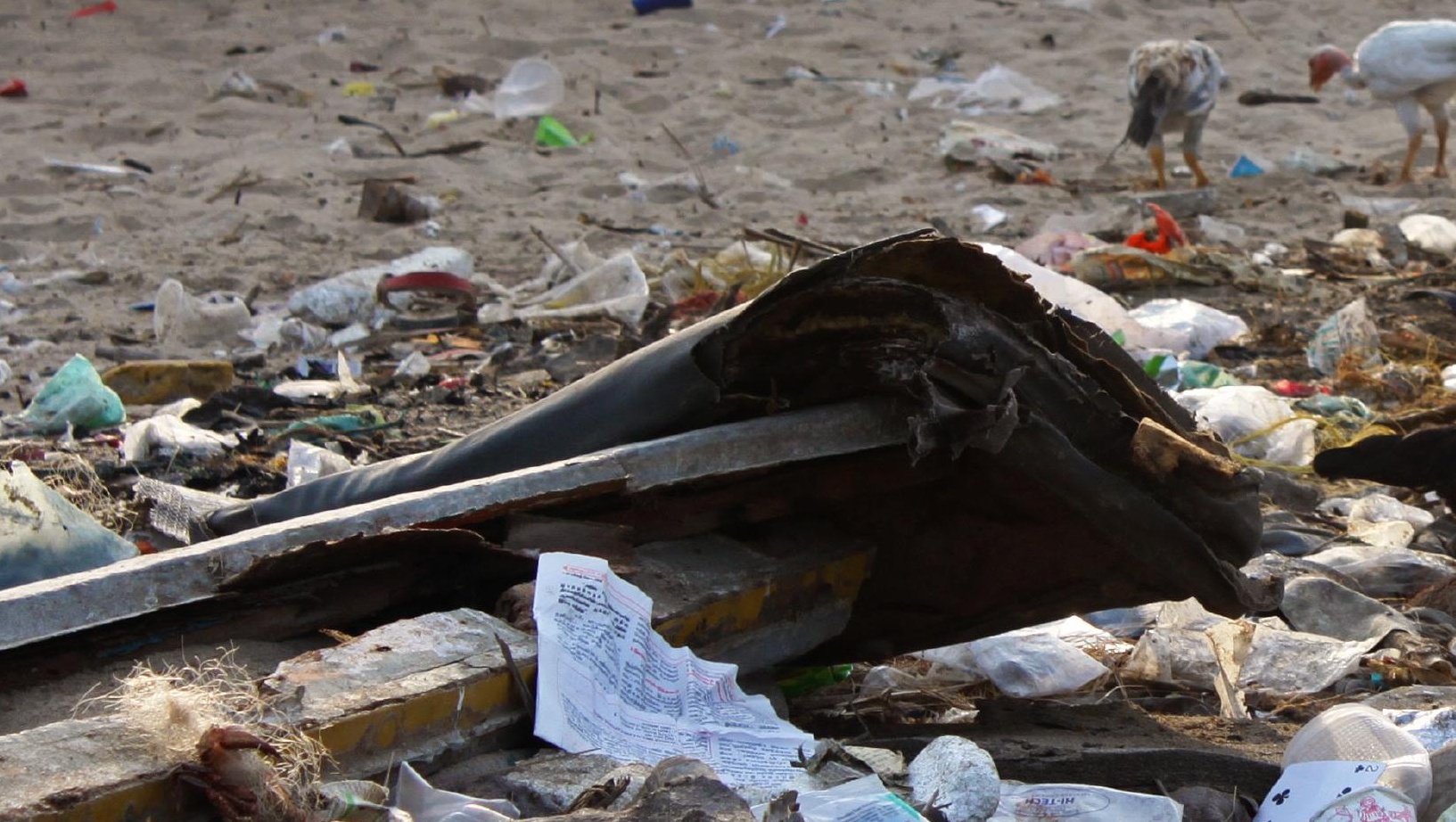

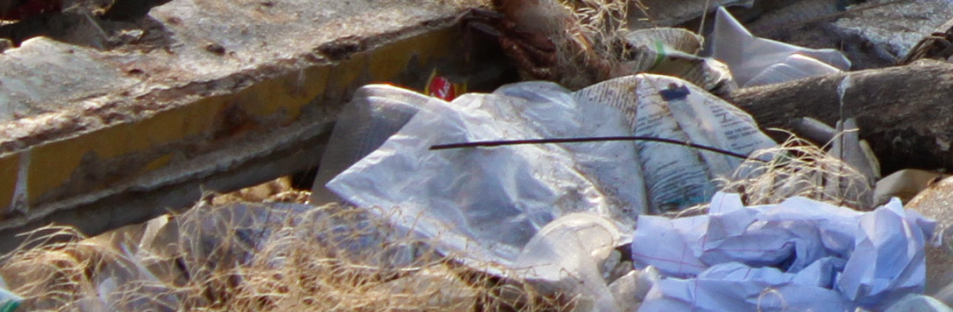

(2) S. $\cos _{-2}^{2}+20$ 36 2. Lastones

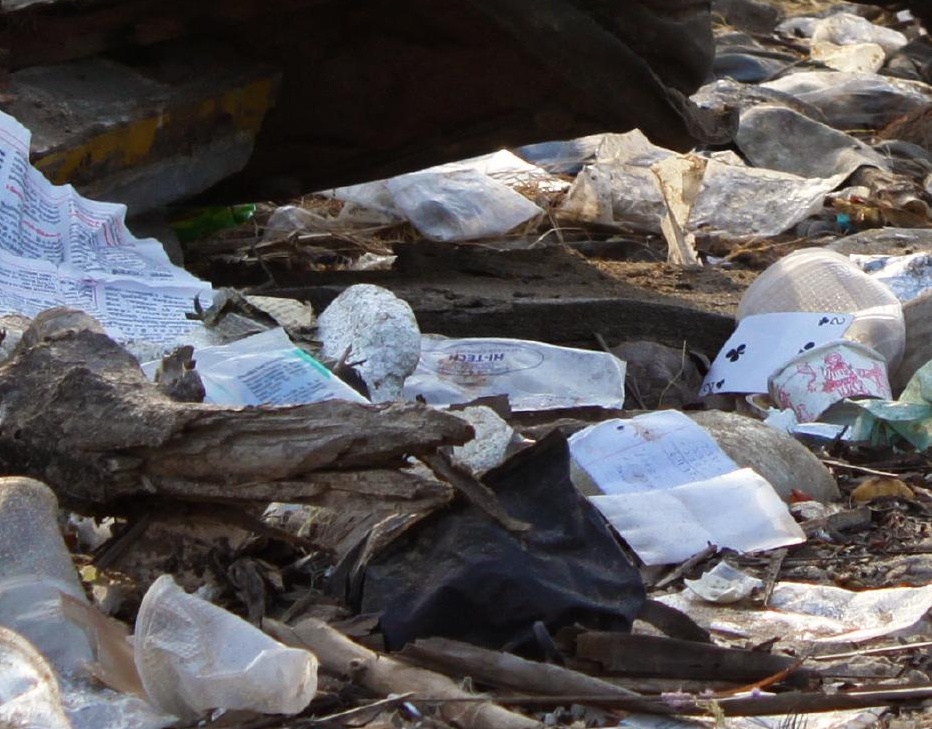

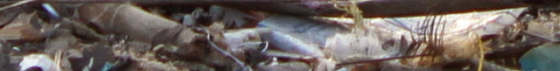

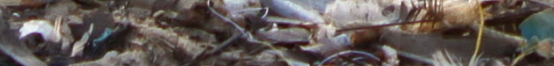

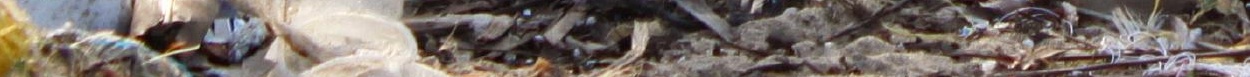

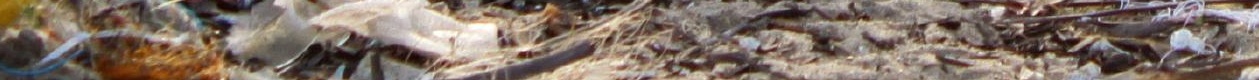

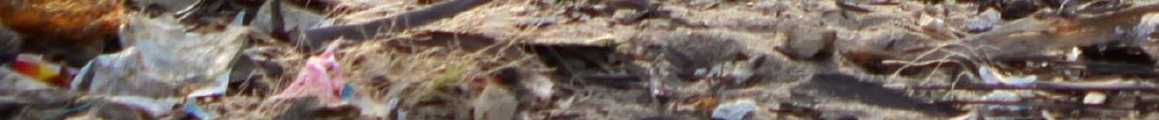

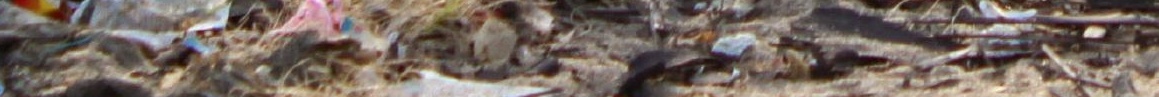

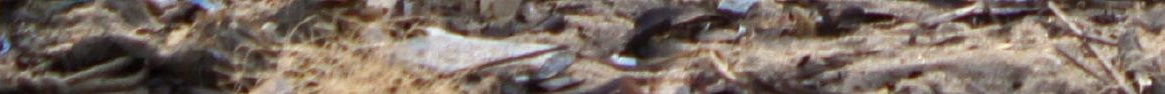

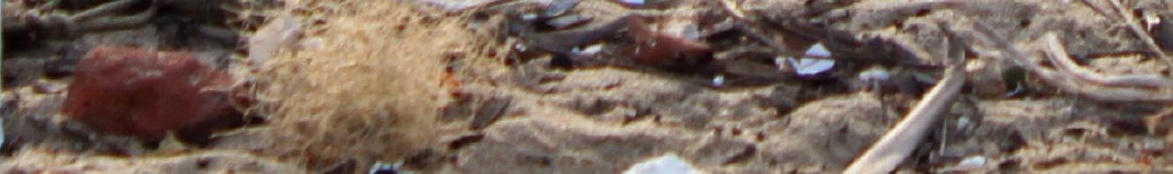




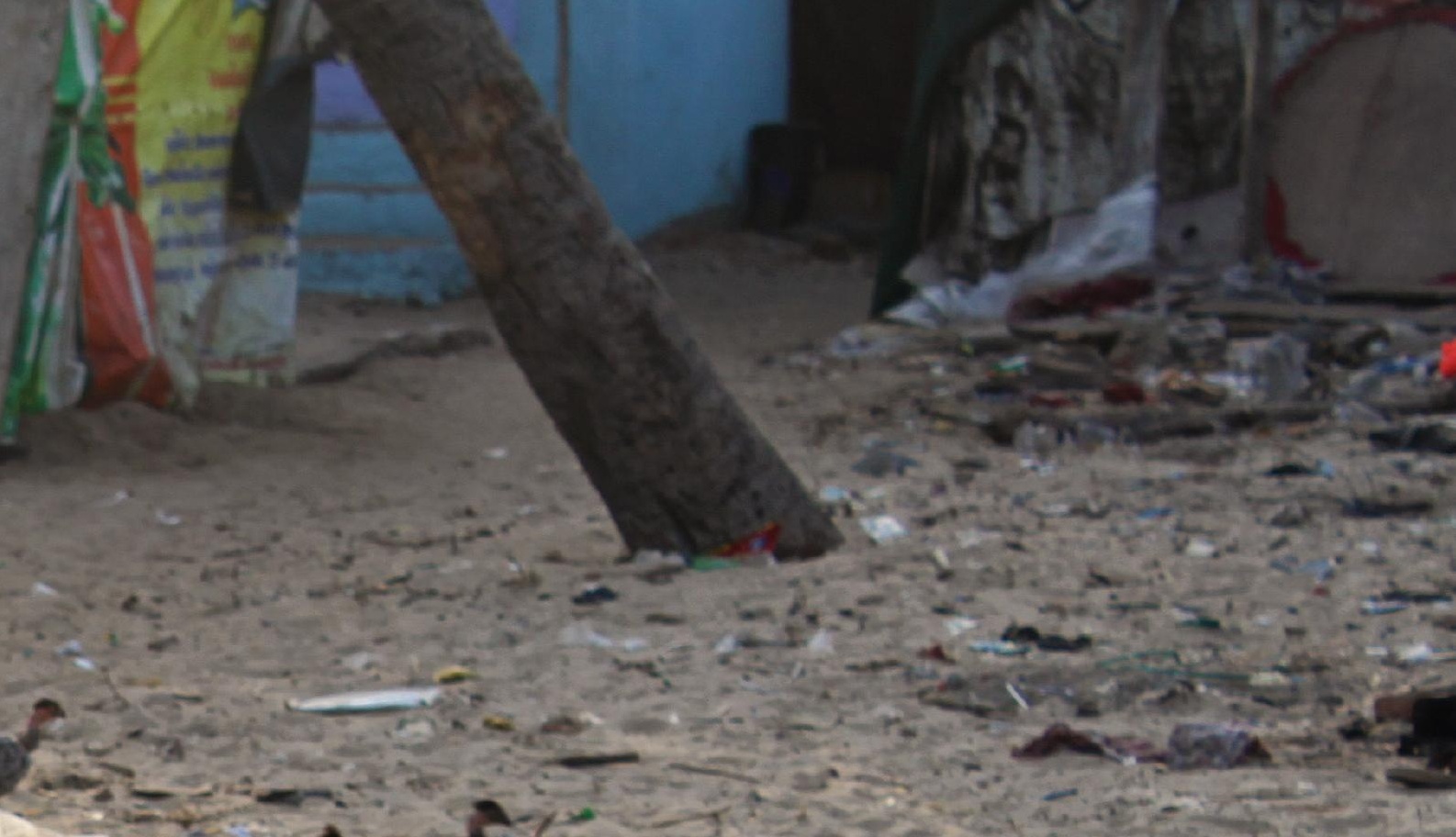

\section{$320+22^{2}$}

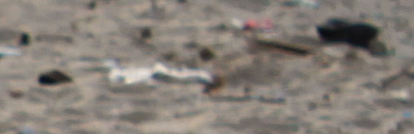

........

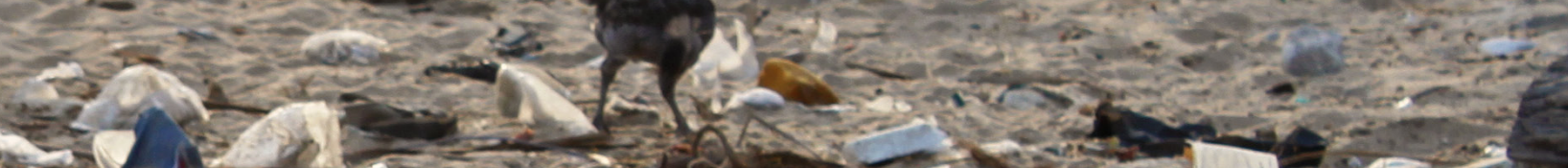

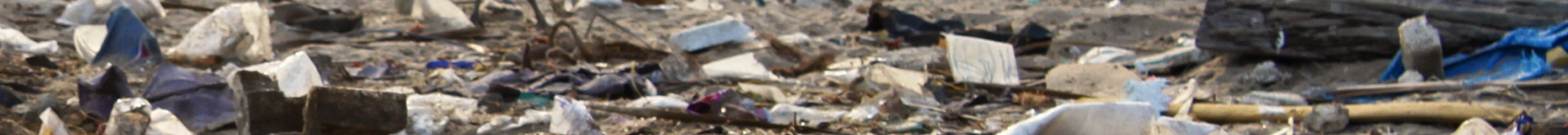

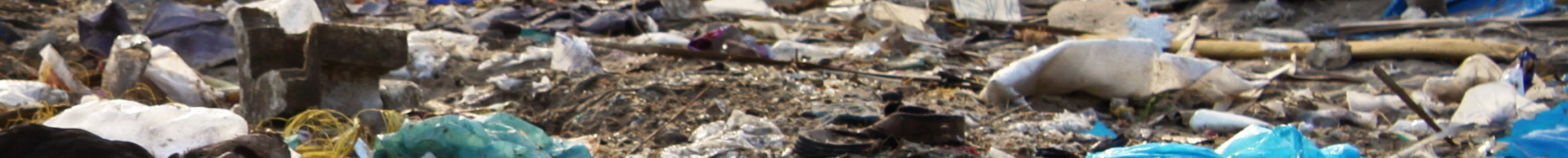

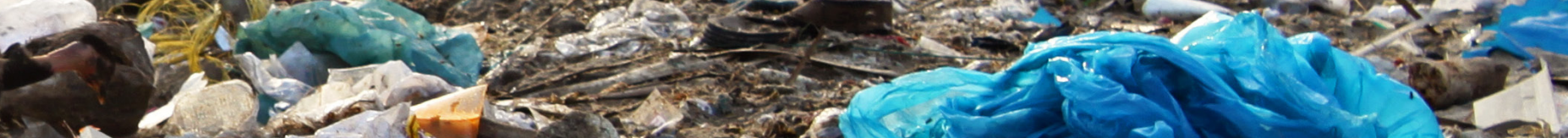

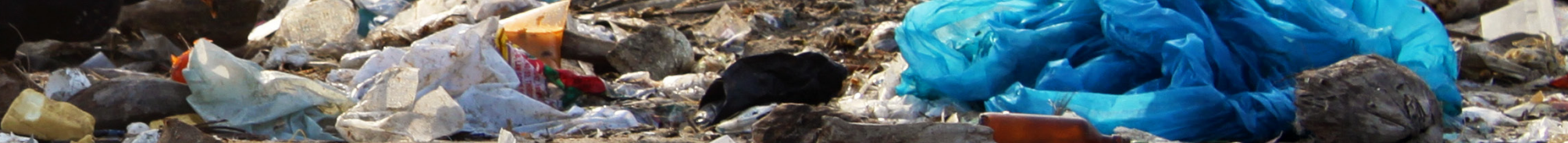

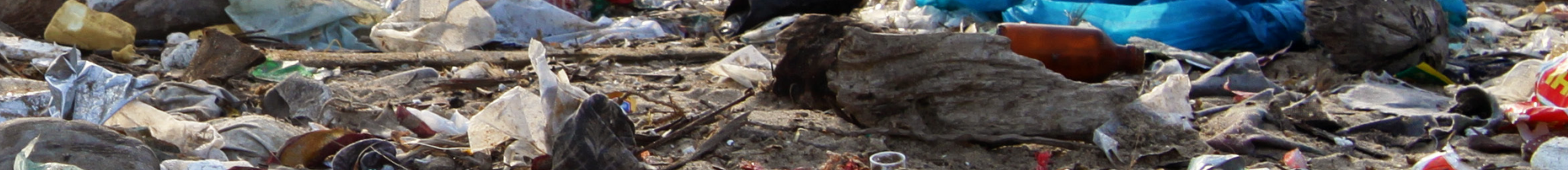

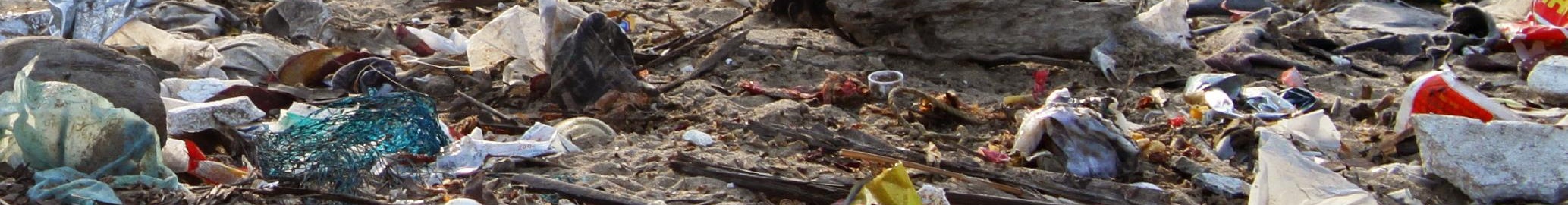

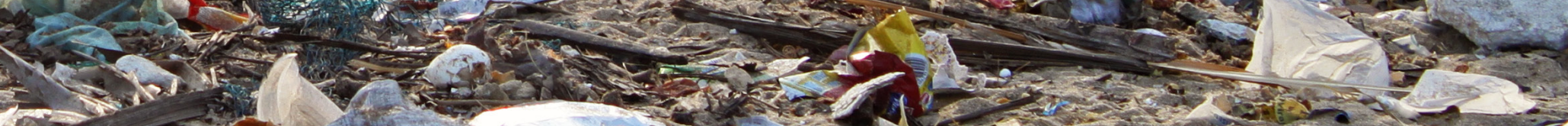

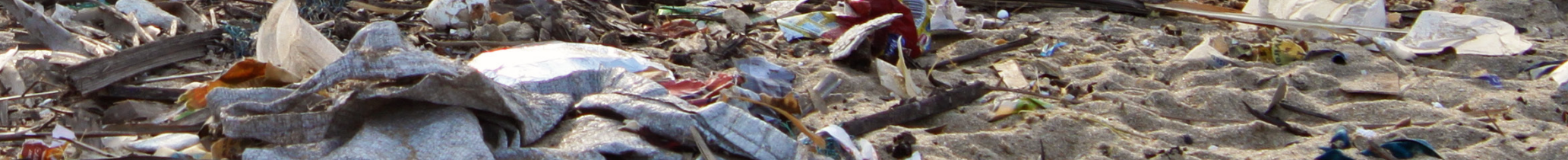

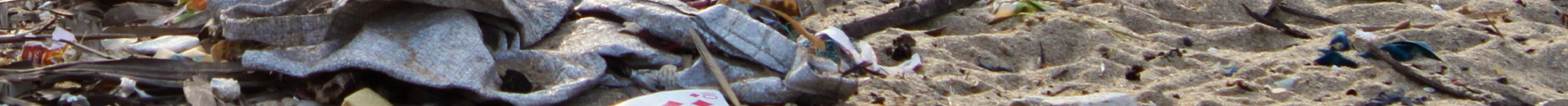

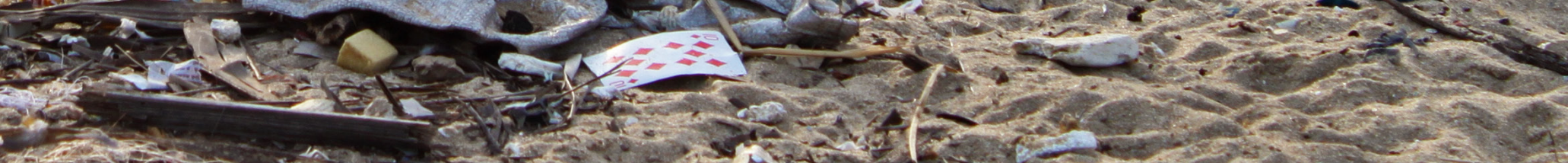

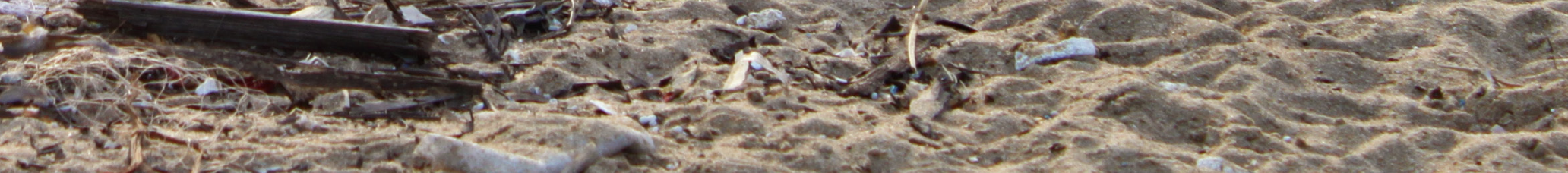

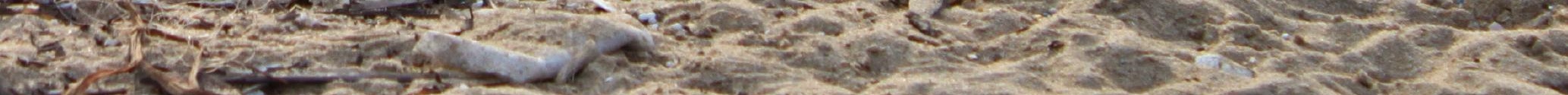

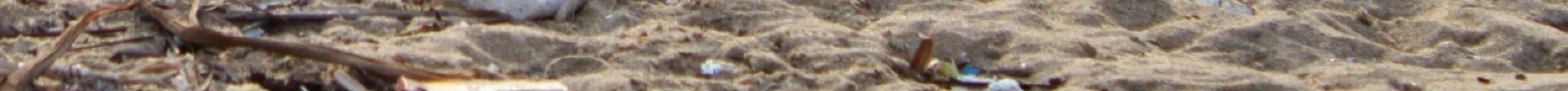

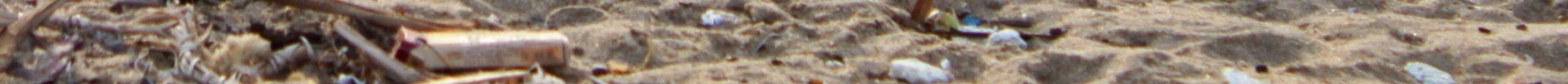




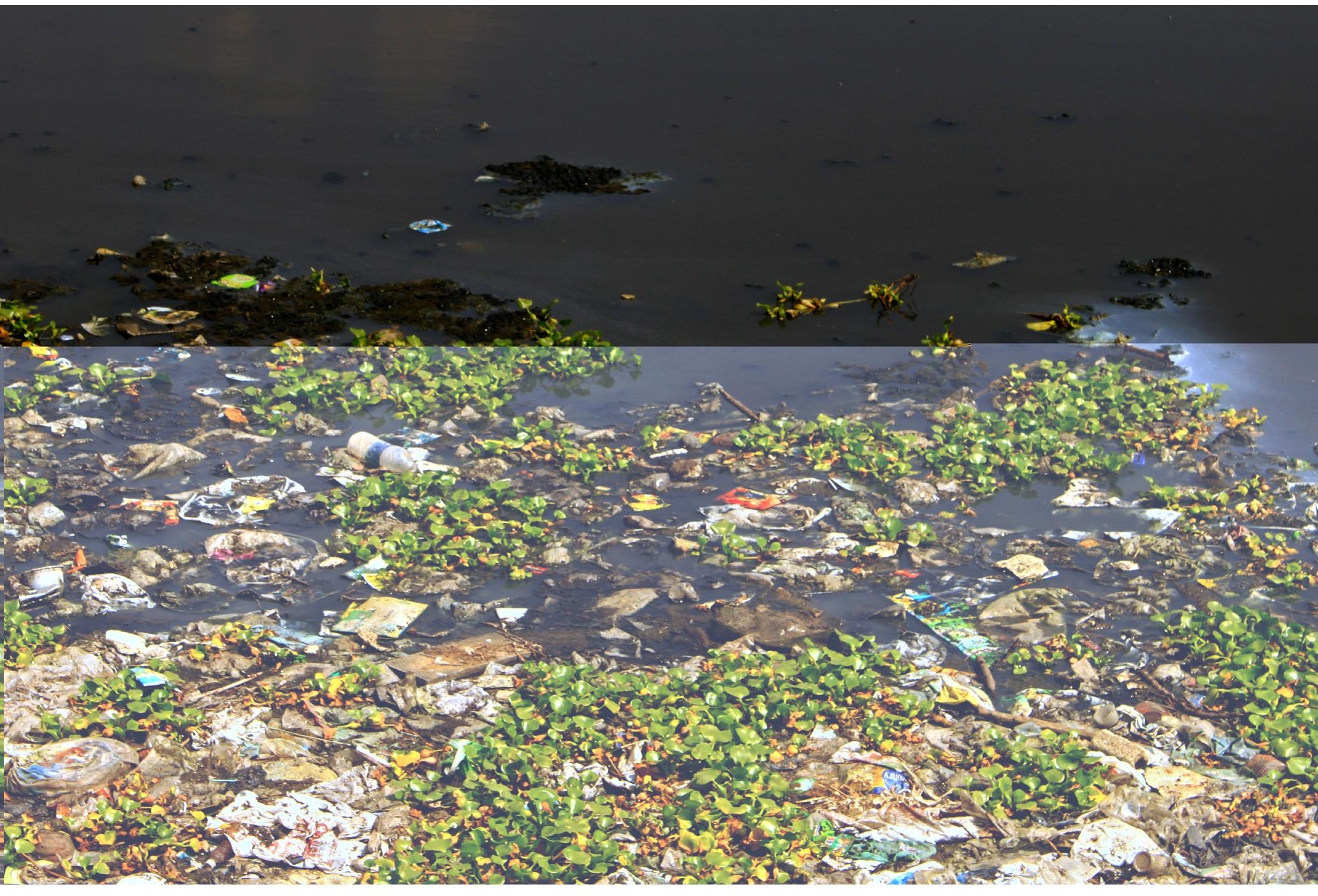

Fig. 82. Garbage buildup on the Adyar River. 
Chennai's daily waste of $0.71 \mathrm{~kg}$ 's per capita is the highest in India ("Chennai's per Capita Waste..."). and composed of $60 \%$ organic waste, $30 \%$ recyclable waste and $10 \%$ hazardous waste. Using these figures as a guide, Srinivasa Puram will produce the following by 2016:

- $10934 \mathrm{~kg}$ total waste per day

- $6560.4 \mathrm{~kg}$ organic waste per day

- $3280.2 \mathrm{~kg}$ recyclable waste per day

- $1093.4 \mathrm{~kg}$ hazardous waste per day

The design research experiment will be required to treat these capacities on site every day using sustainable technology to process the organic waste. All hazardous waste will be transferred to landfill while recyclable material will be sold, generating an income. The design will also implement an integrated river mouth garbage collection system to help mitigate the hygiene and pollution problems of the Adyar River in an effort to rejuvenate the surrounding ecosystem. 
3.4 ENERGY GENERATION 


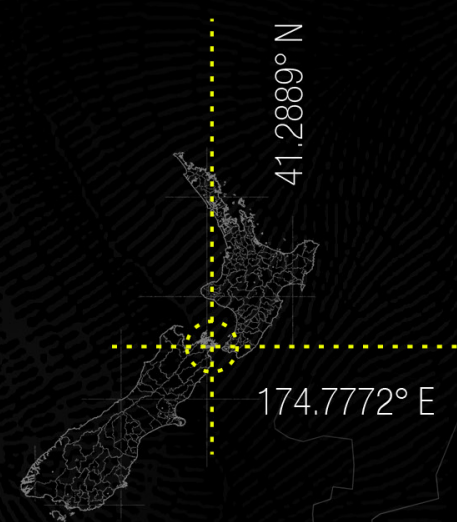

New Zealand household annual power consumption: $11,400 \mathrm{~kW}$

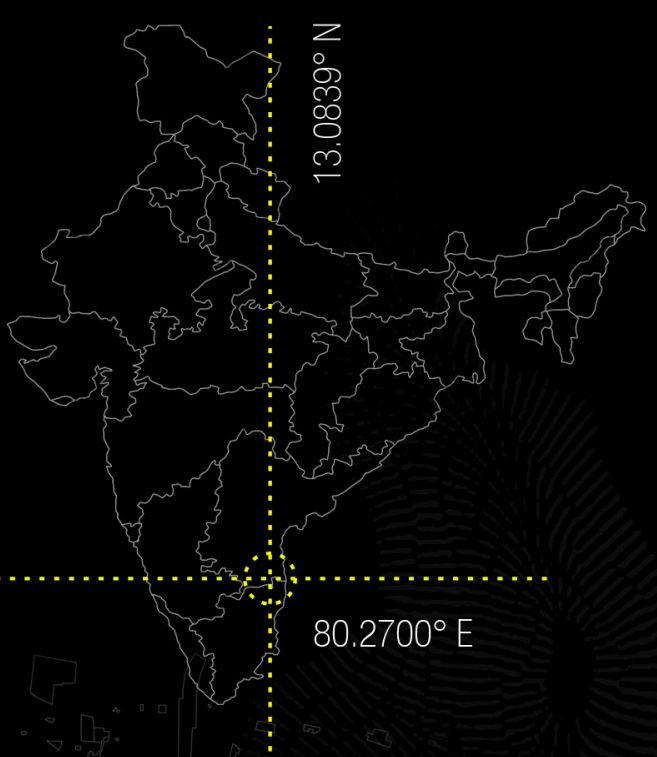

Tamil Nádu's household annual power consumption: 
According to National Geographic, India is the fourth largest producer of greenhouse gas emissions with $59 \%$ of its electricity generated from coal (Ravindran). This is a substantial figure given that the World Bank states only $75 \%$ of India's population has access to electricity ("Access to Electricity").

A comparative analysis surrounding electricity consumption between New Zealand and the state of Tamil Nadu showed that on average New Zealanders use around 11,400kw per household annually (Kemp), while Tamil Nadu uses approximately 1000kw per household annually ("Energy - State Power Scenario"). Chennai makes up less than $10 \%$ of the population of Tamil Nadu, although consumes around $18 \%$ of the state's electrical energy (Srivathsan). The estimated population for the design scheme of 15,400 will require approximately $3,080,000 \mathrm{kw}$ per annum. This figure will require an average of $8438 \mathrm{kw}$ to be generated per day in order to supply all residential tenements within the framework.

As a sustainable solution to mitigate high electricity usage in Chennai and the global issue of environmentally damaging green house gases, the design framework will look to benefit from innovative methods of passive, renewable energy. 


\subsection{LITERATURE \& PROJECT REVIEW}

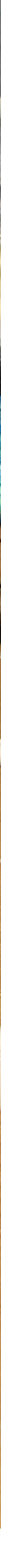




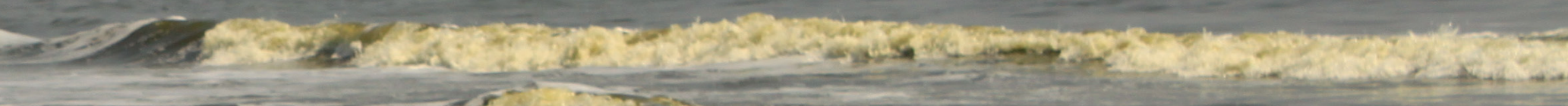
-

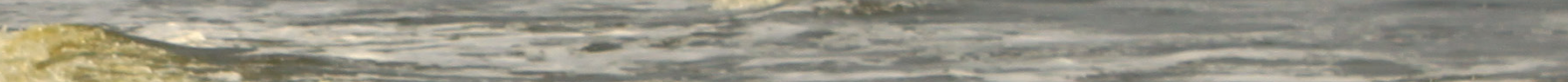

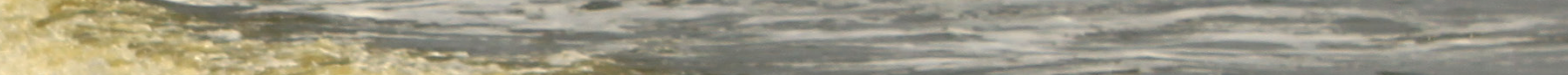

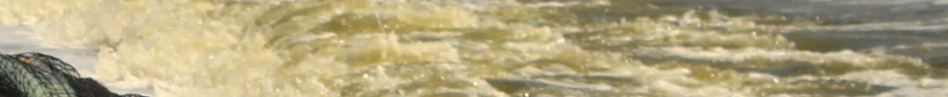

S.

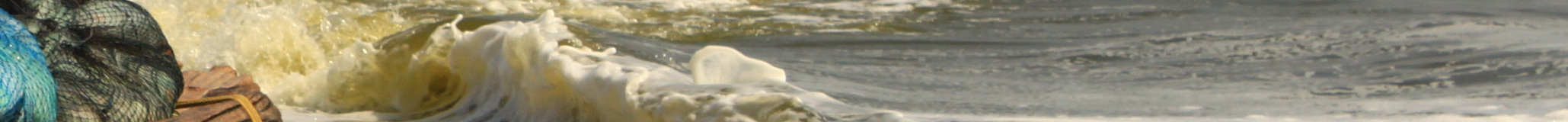

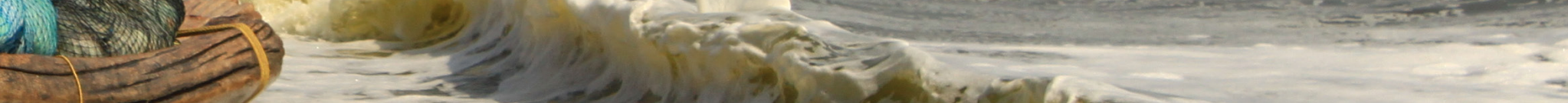
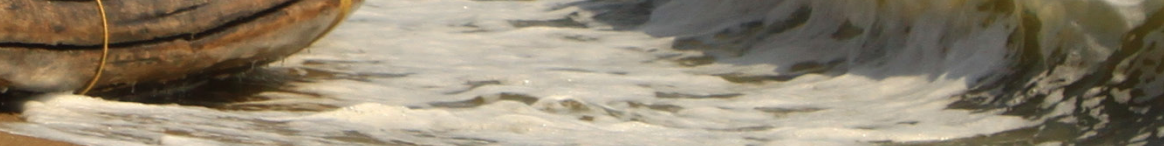

5
5

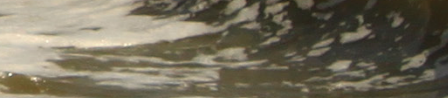
Sots
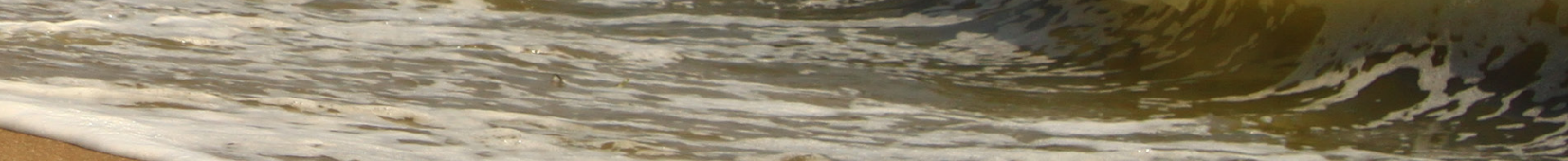

(1)

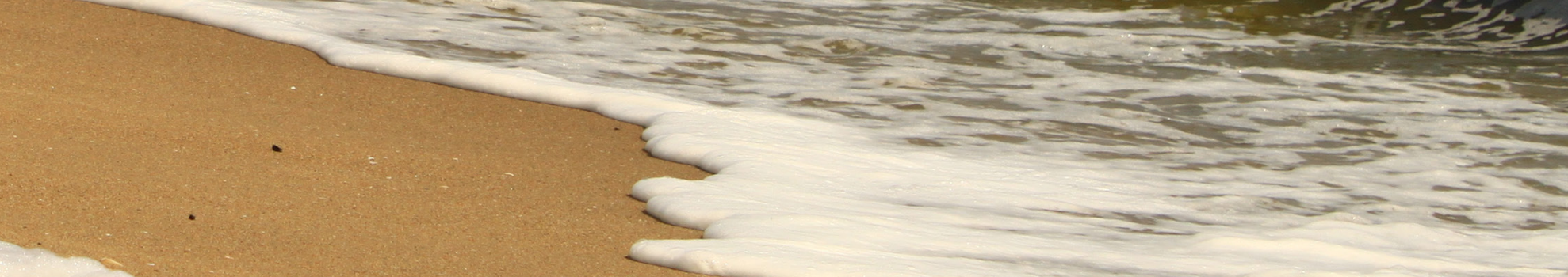

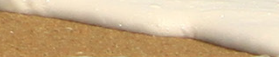

(a)
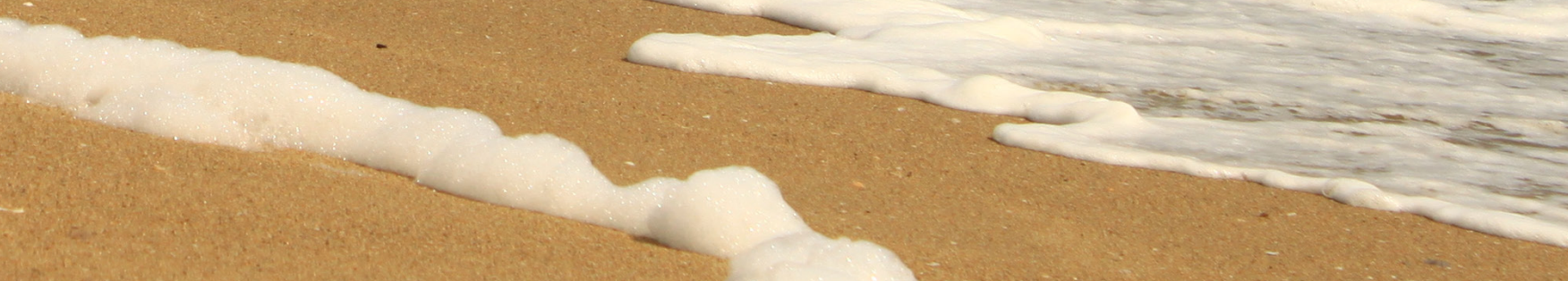

$+x$

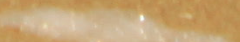


Clean water, sanitation and hygiene are fundamental to not only health and development but also survival. The lack of these basic amenities coupled with the vulnerability of the site can be a fatal combination. This chapter examines the latest literature relating to innovative approaches to: economic and sustainable means of fresh water collection and purification, passive methods of wastewater treatment, renewable energy sources from waste and wave energy, and severe flooding and storm surge mitigation systems to form a fully integrated, self-sustainable and culturally sensitive architectural framework that improves the living conditions of coastal slum dwellers. 


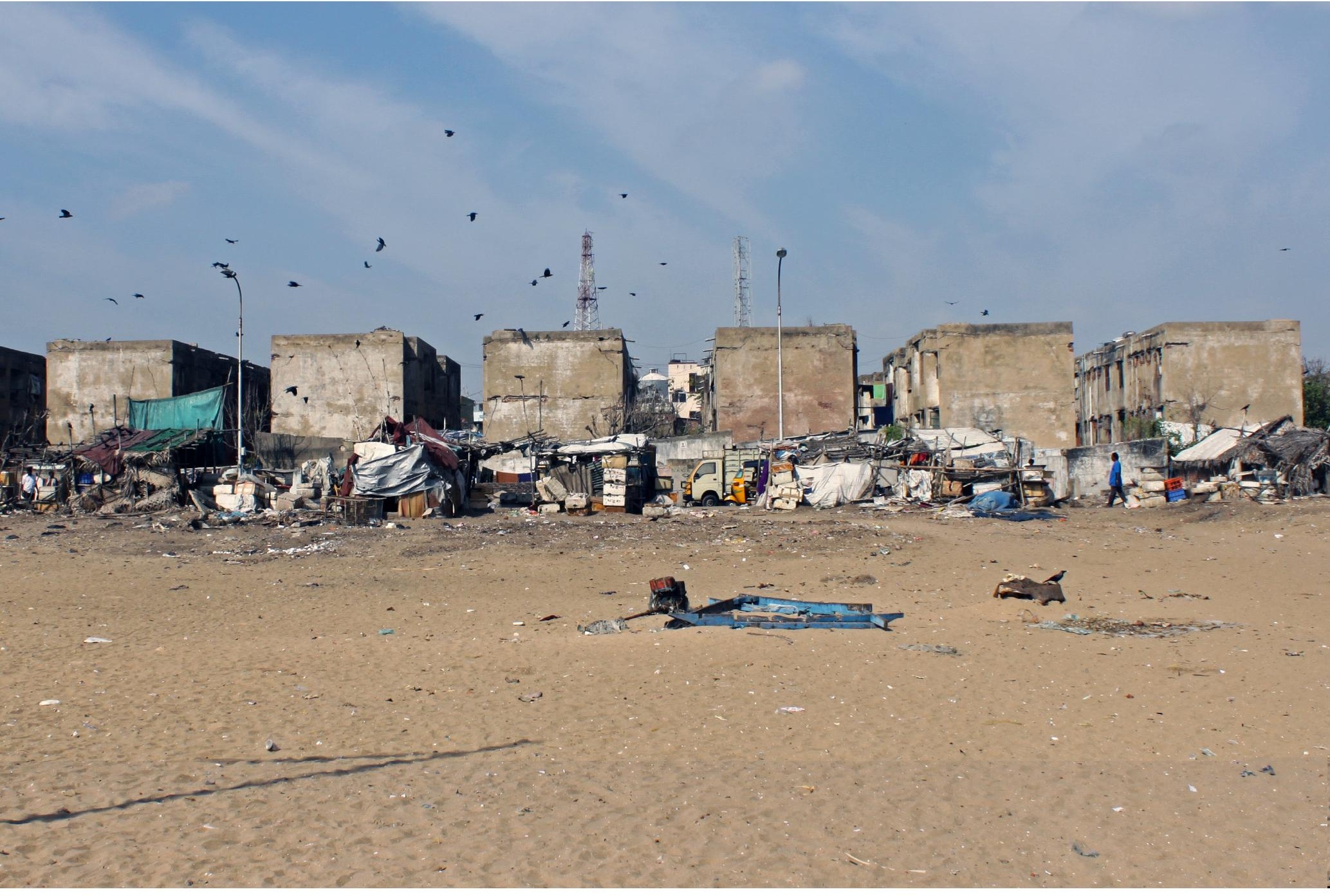

Fig. 86. Beach front housing. 


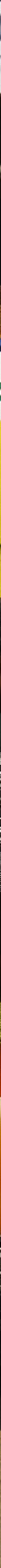




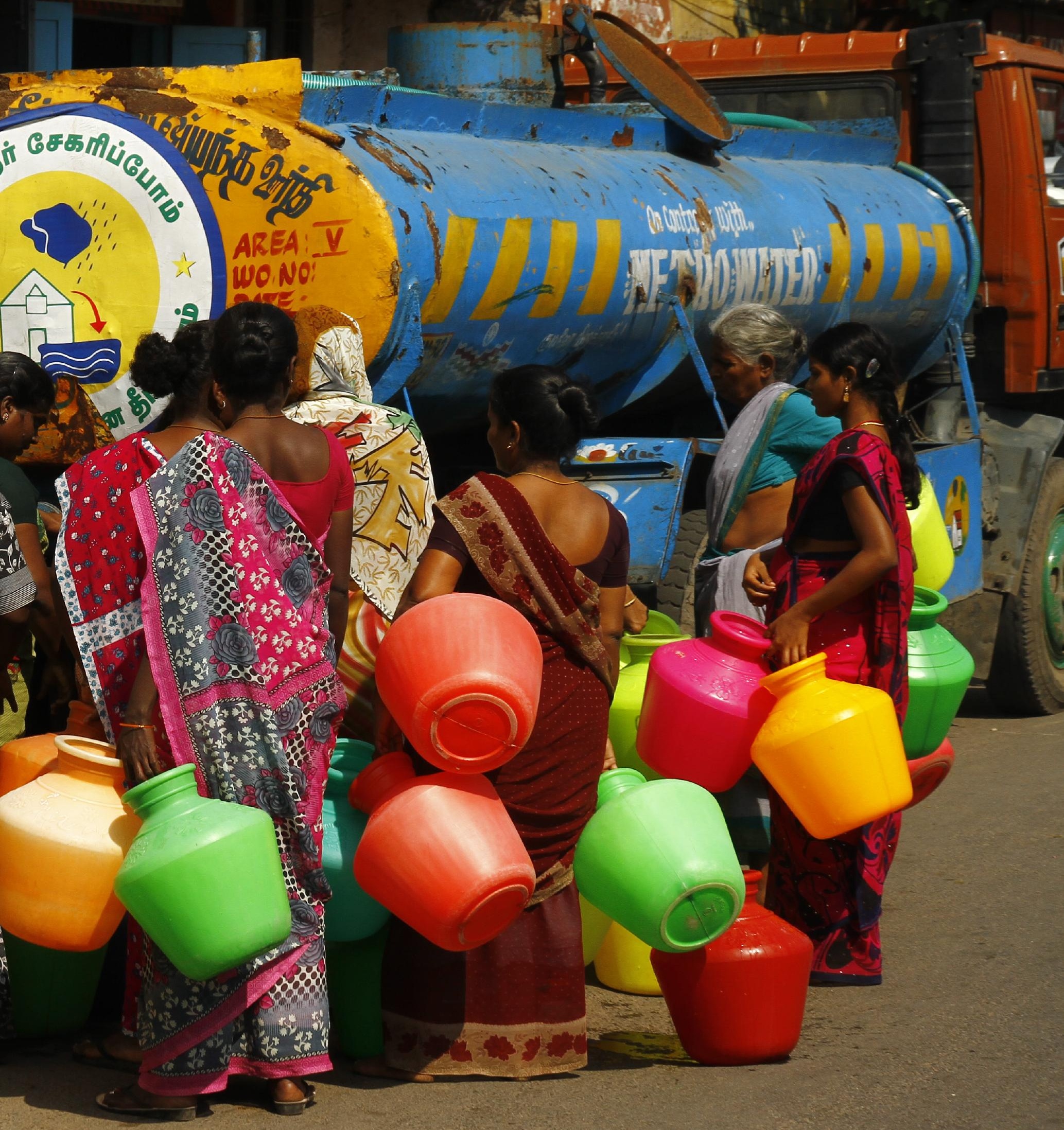


DESALINATION:

Fifty two percent of the world's population resides in arid and semi-arid areas and depends solely on rainwater harvesting to sustain their livelihoods (Water: A Shared Responsibility...). Elena Lopez-Gunn and Manuel Ramón Llamas investigate possibilities of brackish and salt water desalination in the article "Re-thinking water scarcity: Can science and technology solve the global water crisis?" Technological advances in chemical engineering and energy recovery systems are now allowing impoverished countries and communities to benefit from 'new' water sources as an economically viable solution (Lopez-Gunn and Llamas 234). Nikolay Voutchkov, an internationally recognised expert in the field of desalination and membrane application technology highlights in the article "California's plans for desalination" that while the cost of producing fresh water through seawater desalination has significantly fallen in recent decades, the cost of producing clean drinkable water from sources such as lakes, rivers and aquifers has increased by between $50-100 \%$ due to availability, pollution levels and increased water regulations (Voutchkov). High levels of zinc, copper, cadmium, iron, lead and raw sewage found polluting the Adyar River (Silambarasan, Senthilkumaar, and Velmurugan) suggests any form of brackish water desalination is an unfeasible option for the proposed framework.

In 2010 India's first seawater desalination plant began supplying Chennai with 100 million liters of fresh water per day ("India's First and Largest Sea..."). While this is a considerable improvement in fresh water supply for the city there still remains a substantial gap between supply and demand. In a city where drinking water is scarce and much of the ground water is saline, the local government of Tamil Nadu has recently announced that two additional seawater desalination plants will be built as a feasible option to assist Chennai's growing water demand ("Two More Desalination Plants..."). 
SEAWATER DESALINATION PLANT

LOCATON: MINDELO

CAPE VERDE, WEST AFRICA

Mindelo in Cape Verde, West Africa relies solely on seawater desalination to supply its population of 50,000 people ("Containerized Reverse Osmosis..."). The design is a pre-assembled, pre-wired, and pre-piped reverse osmosis system compacted into containerized modules allowing for a capacity of $4250 \mathrm{~m}^{3}$ per day. The reverse osmosis system incorporates an energy recovery process that reduces energy requirements by up to $40 \%$ (Gilau and Small). The design requires 3 kilowatts of energy to produce one cubic meter of fresh water. Using these figures to influence a sustainable framework, the design would require approximately 6930 kilowatts per day to generate a constant fresh water supply of 150 liters per capita daily to Srinivasa Puram. Constructed as modules, the system allows for an expandable framework as the population of Srinivasa Puram develops.

\section{RAINWATER:}

Perhaps the most sustainable and economically viable method of water collection is rainwater harvesting. Recent amendments to both the Tamil Nadu District Municipalities Act, 1920 and Building Rules 1973, have made it compulsory to provide rainwater collecting systems in all new buildings ("Rain Water Harvesting"). While Chennai benefits from an average annual rainfall of $1200 \mathrm{~mm}$, the high levels of atmospheric pollution means rainwater must still be filtered before consumed. Passive means of bio-filtration in the form of integrated terraced wetlands is a viable option to treat rainwater. 


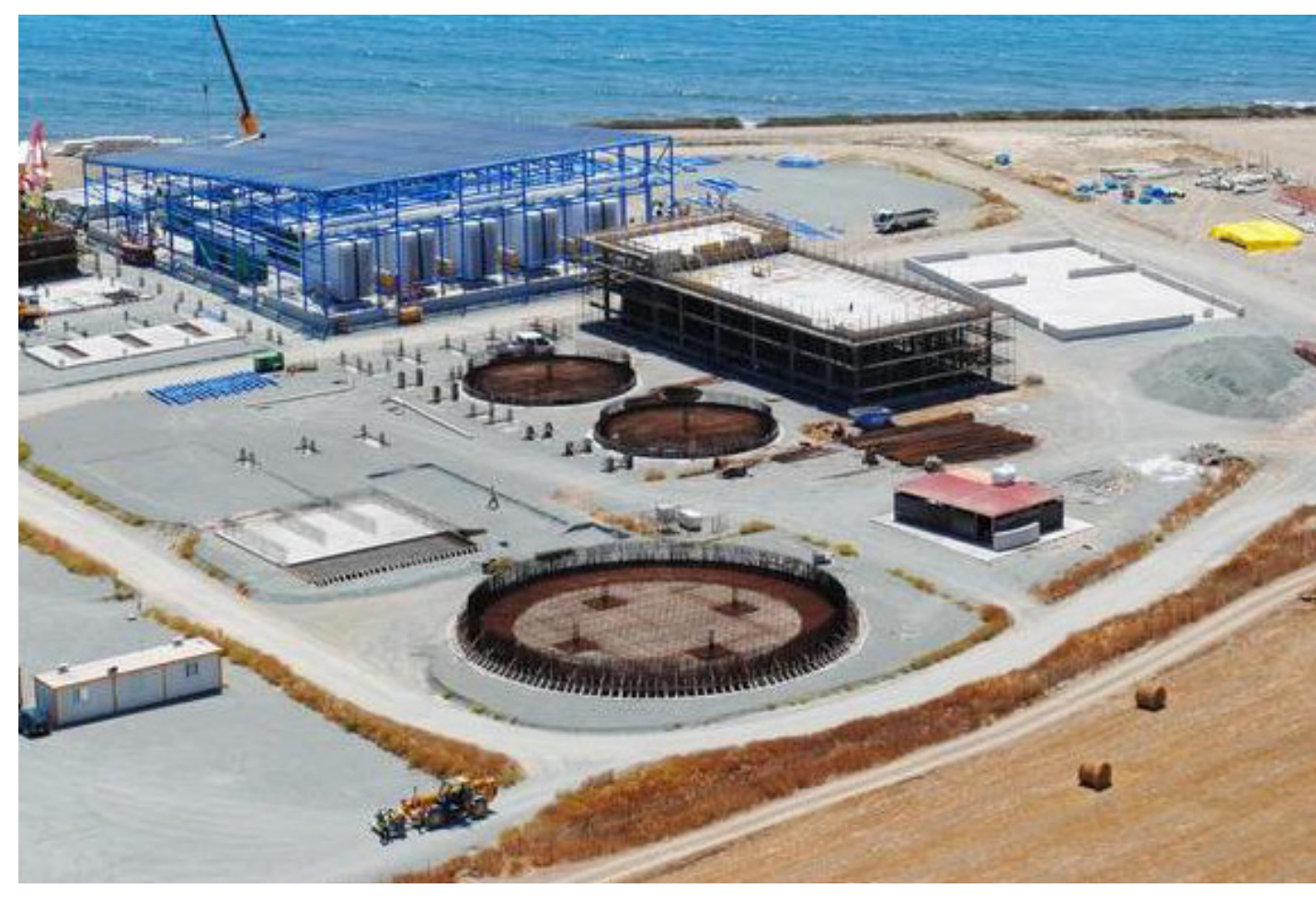

Fig. 89. Seawater desalination plant, Mindelo, Cape Verde. 


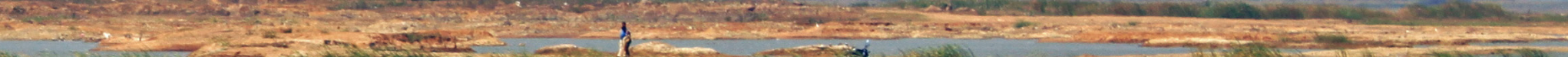

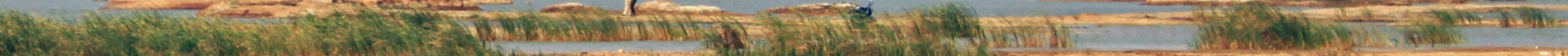

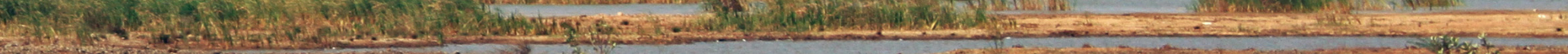

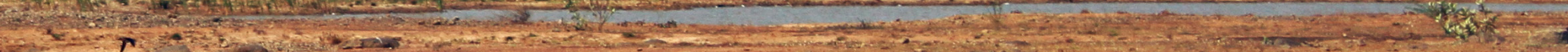
D.x. 1 .

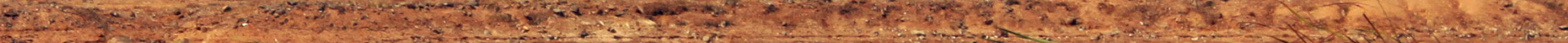

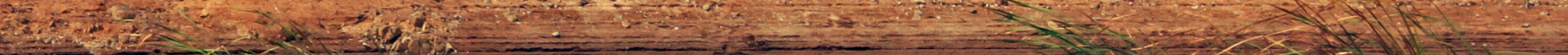

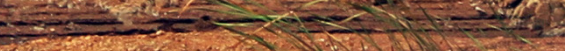

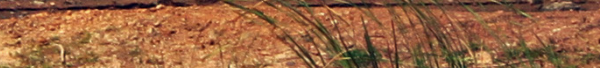

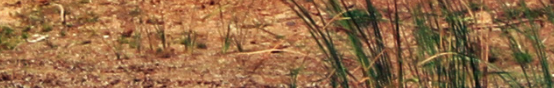
S

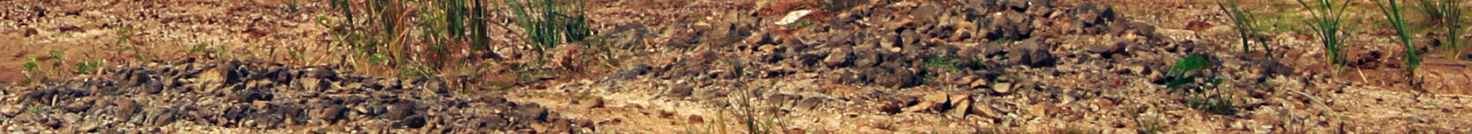

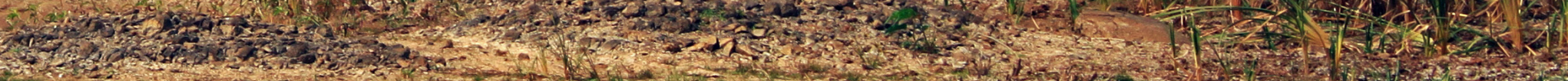

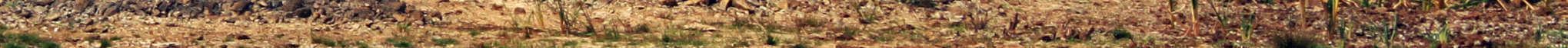
ransor

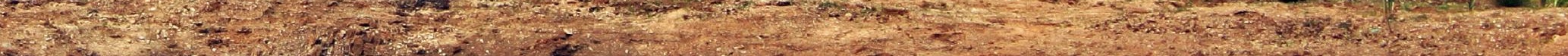

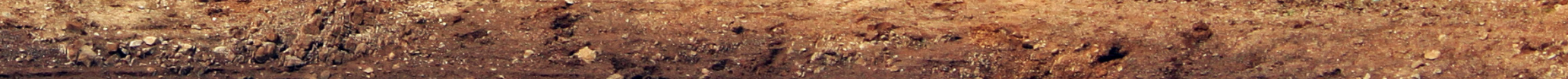

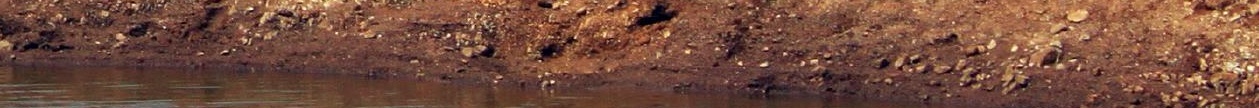

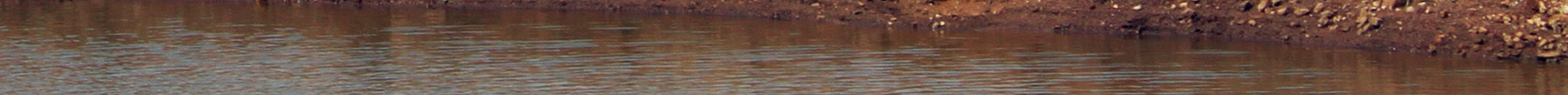
T. - 


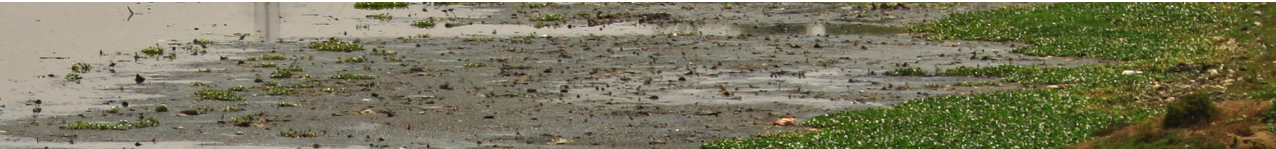
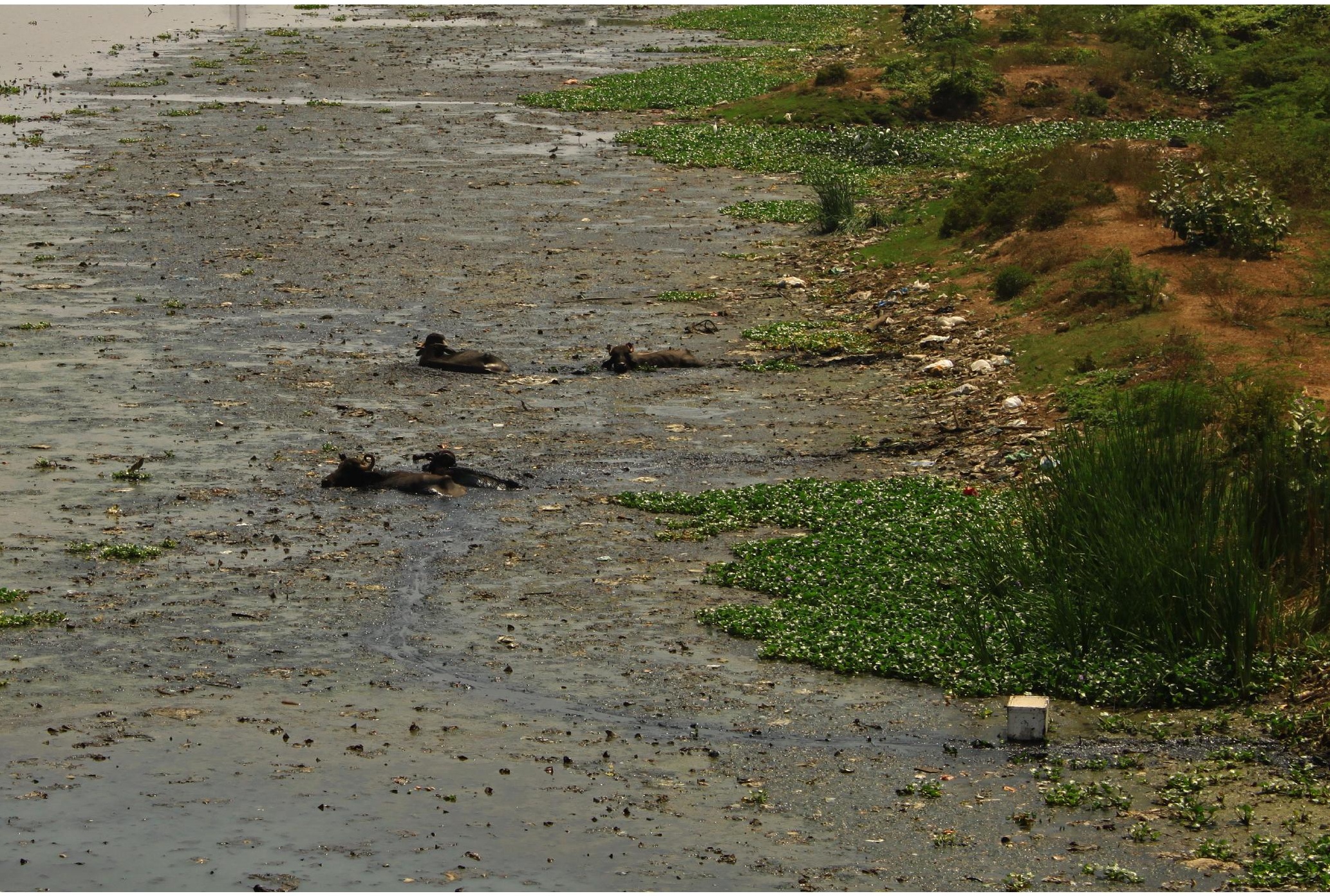

Fig. 91. Garbage build up in Adyar River wetlands. 
Wetlands play a crucial role in the structure of many ecosystems providing diverse functions such as natural water filtration, mitigating floods, storm surges and coastal erosion as well as providing habitats for wildlife. Applying this concept to artificially integrated wetland systems within urban conditions is proving to be a low-cost and sustainable solution to water purification and sanitation methods, not only for impoverished communities but also treating polluted storm water from urban hardscapes. Günter Langergraber outlines in the article "Modeling of Processes in Subsurface Flow Constructed Wetlands..." that modern constructed wetlands are "engineered to optimize the treatment conditions found in natural wetlands by using a complex mixture of water, substrate, plants, litter (fallen plant material), and a variety of microorganisms (especially bacteria)" (Langergraber).

Articles including "The Role of Integrated Constructed Wetland for Wastewater Treatment" in the Asian Journal of Applied Sciences have concluded that integrated constructed wetland systems that are engineered correctly are an effective method of wastewater treatment not only for domestic and commercial purposes but also at an urban scale as a means of river water purification (Mirunalini et al.). Passive means of river filtration such as Hyderabad's wetland remediation plan ("Ayala Water and Ecology...") is an emerging method used for cleansing river water and its related ecosystems. Wetland interventions strategically placed along the length of the Adyar River are outside the scope of this thesis. But the proposed design scheme will look to implement other feasible and innovative methods of cleansing the Adyar River through garbage and sludge collection before it enters the Bay of Bengal to help rejuvenate the surrounding estuarine ecosystem. 
SIDWELL FRIENDS SCHOOL TERRACED WETLANDS

LOCATON: TENLEYTOWN

In 2007 Sidwell Friends School outside Washington, D.C. expanded its middle school building to include an integrated rain, storm and wastewater terraced wetland system. The building and surrounding landscape now function as a single living machine with the entire system harvesting, filtering and recycling over 11,000 liters of water per day. The cleaned water is then reused throughout the building's toilets, cooling tower and landscape irrigation, reducing the school's water consumption by $93 \%$ ("Designing Our Future: Sustainable Landscapes...").

If 150 liters of fresh water is supplied per capita daily in the thesis design experiment, 100 liters of the total supplied water could be collected as grey water from bathing and cleaning while 40 liters of the total supplied water would be produced as black water from toilets and the remaining balance consumed through drinking and cooking.

The proposed design scheme for Srinivasa Puram will require three separate terraced wetland systems:

- Black water wetland treatment system filtering wastewater before returning it into the waterways.

- Grey water wetland treatment system with the ability to produce up to 100 liters per capita daily of clean recycled and reusable water.

- Rain and storm water wetland treatment system as a means of purifying harvested water throughout the year.

By integrating these passive means of constructed wetland systems into the proposed architectural framework for Srinivasa Puram, the total requirement of desalinized seawater and its energy consumption can be reduced by up to $66 \%$ (Figure 93). 


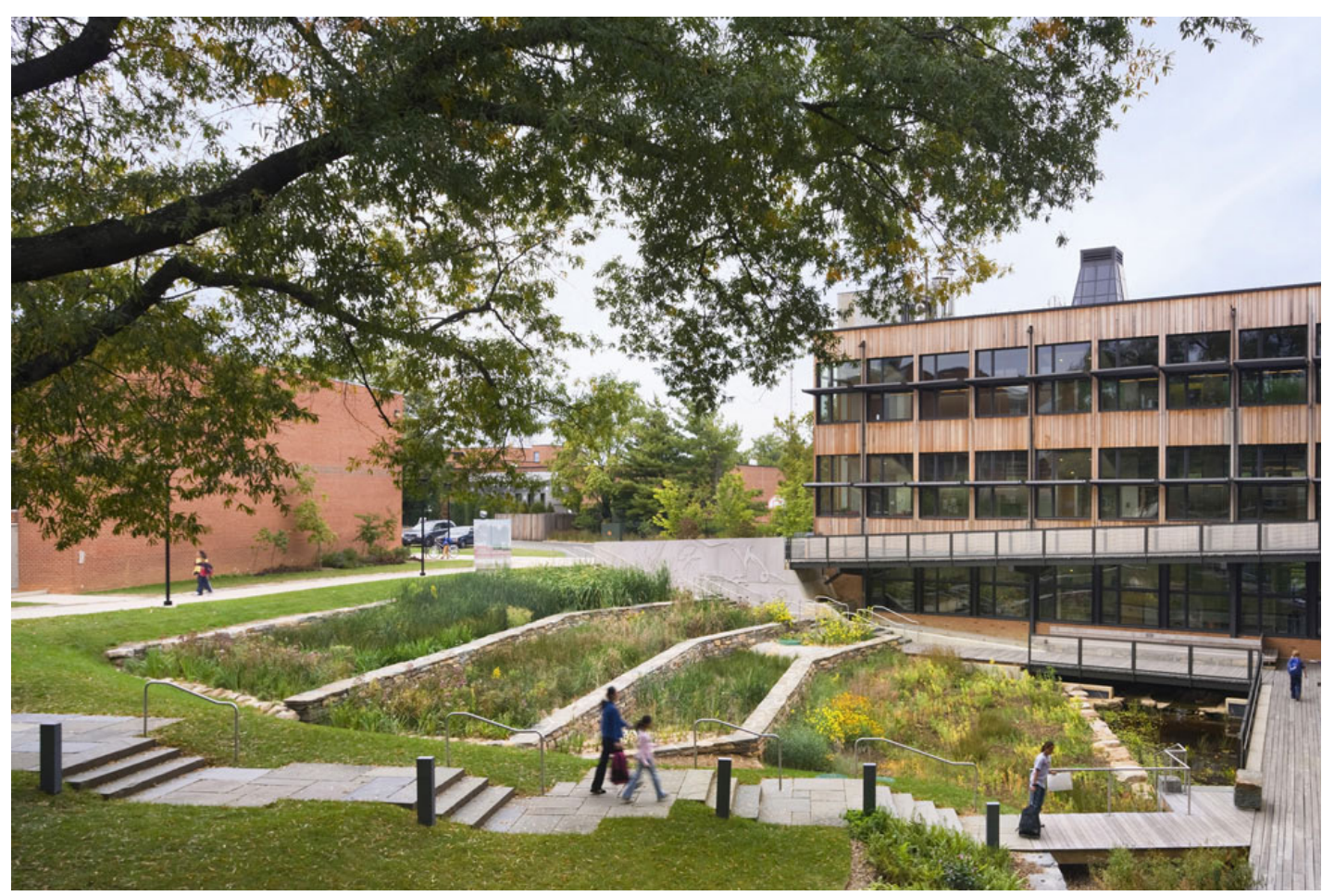

Fig. 92. Sidwell terraced wetlands system.

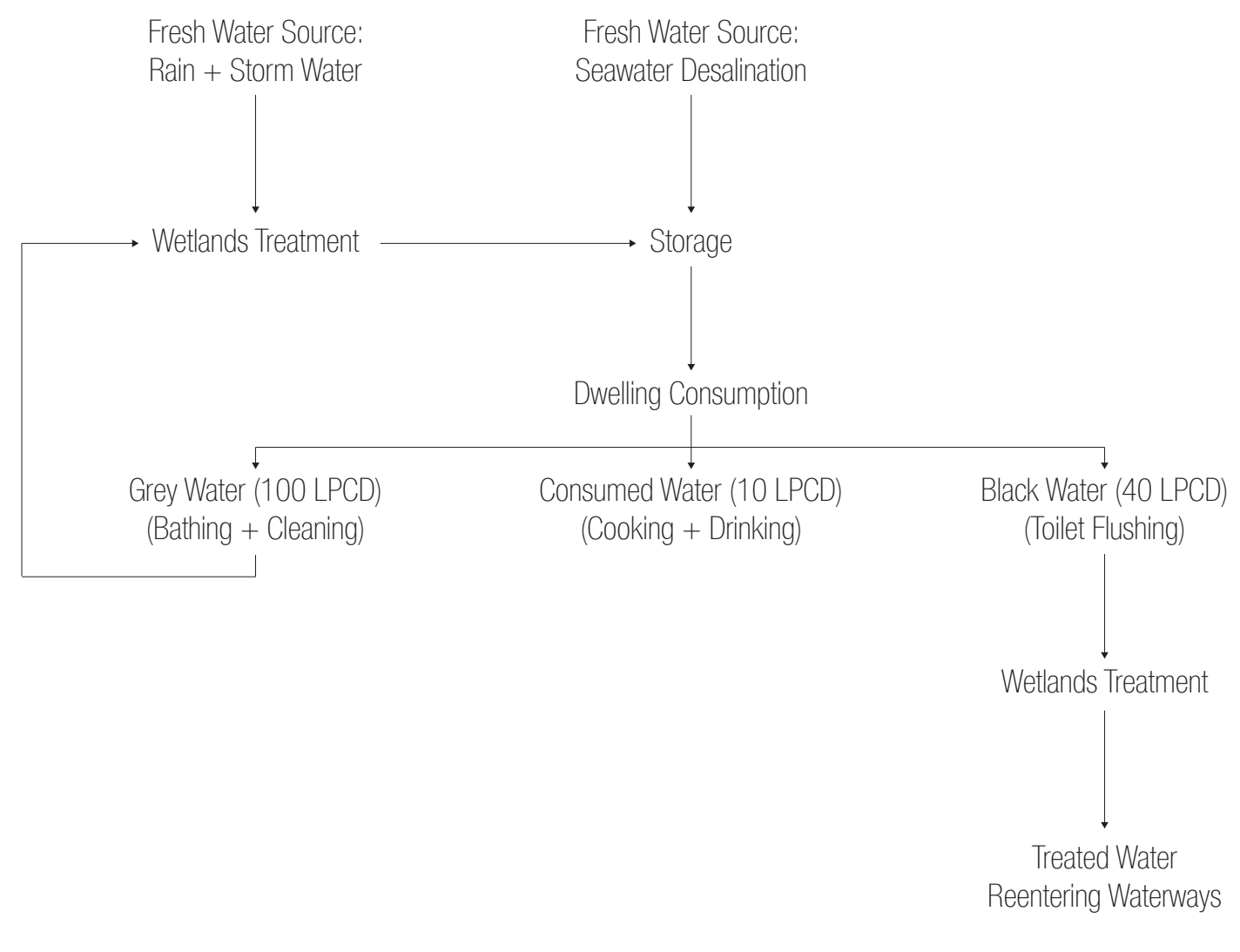

Fig. 93. Water production and consumption diagram. 


\section{PASSIVE GARBAGE COLLECTION}

LOCATION: $\quad$ BALTIMORE

The high levels of zinc, copper, cadmium, iron, lead and raw sewage found polluting the Adyar River (Silambarasan, Senthilkumaar, and Velmurugan) means any form of wetlands system is an unfeasible option for river water collection and purification.

An innovative solution to river pollution in Baltimore, Maryland designed by John Kellett and Daniel Chase of Clearwater Mills has the ability to remove more than 22 tonnes of garbage from the Jones Falls River every day (Wang). The design is powered by both solar panels and the river's current, producing 2,500 watts of electricity per day. Collected waste is then transferred to garbage treatment facilities with the opportunity of creating further energy from waste-to-energy technology.

The proposed architectural framework for Srinivasa Puram will implement similar river purification methods to the Baltimore Solar-Powered Water Wheel as a solution to garbage and sludge removal from the Adyar River. 


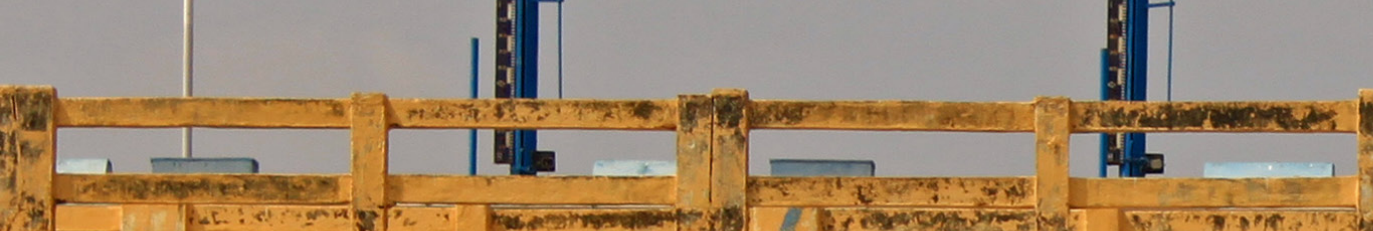

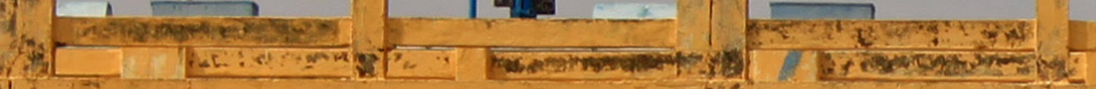

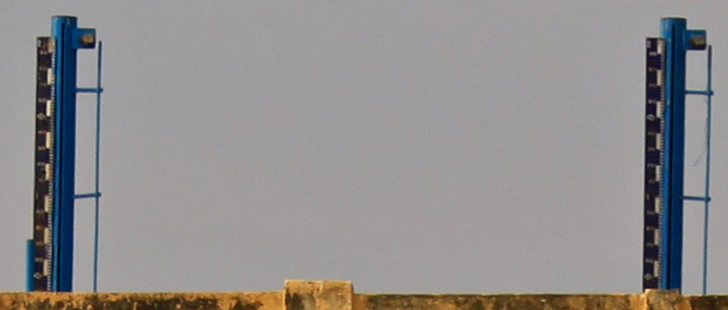
His

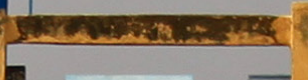

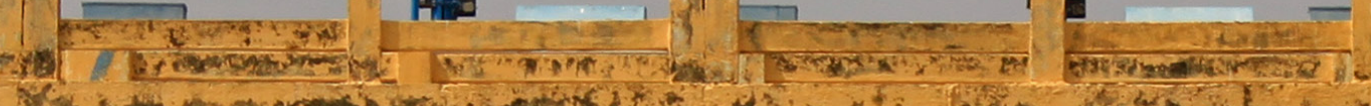

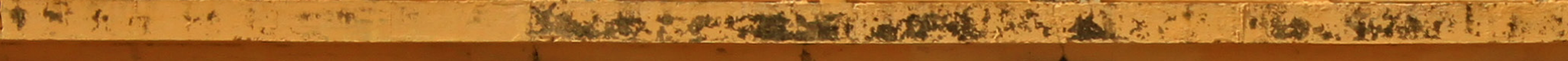
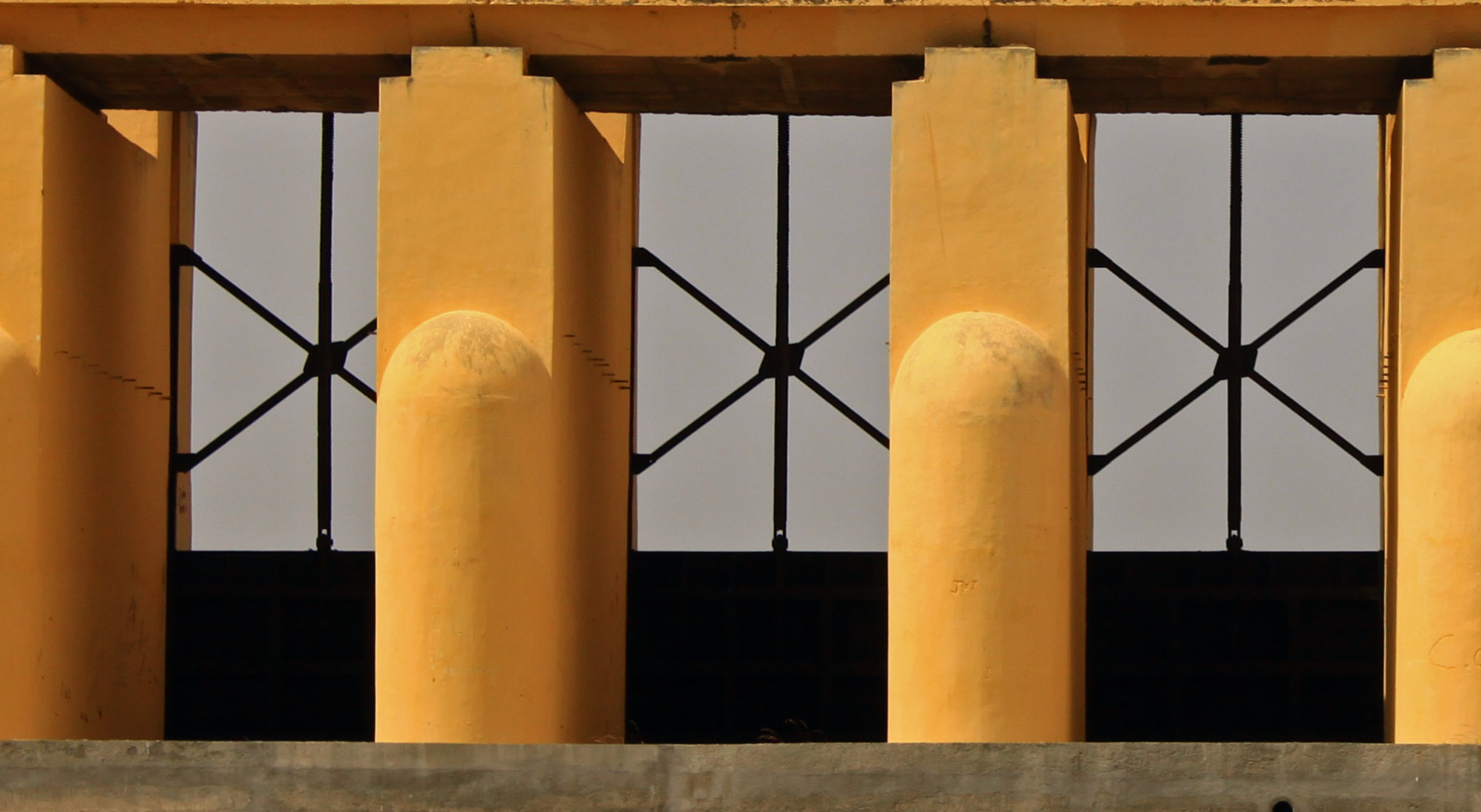

$:$ 
WASTE TO ENERGY:

With the technological advancements in recent years there is an opportunity to mitigate sanitation and hygiene problems while producing renewable energy. Organic food waste and sewage sludge can bypass landfill and be used to produce energy through a process called anaerobic digestion. The method primarily produces methane, a biogas that can be converted to electricity, and a nutrient rich bio-fertiliser used by the agricultural industry ("Anaerobic Digester Plant"). Hugh Tan, Associate Professor of Biological Sciences at the National University of Singapore writes that "If developed fully this biofuel could simultaneously meet part of the world's energy needs, while also combating carbon emissions and fossil fuel dependency" (Tan). Sewage wastewater process is filtered through terraced wetland systems, after all solid waste and sludge has been removed, separated and transferred to an onsite garbage and sewage treatment plant.

Garbage collected from both Srinivasa Puram and the Adyar River will be processed through a sorting facility with organic waste transferred to the same garbage and sewage treatment plant as an important means of improving hygiene while producing renewable energy. The following case studies highlight the feasibility of these technologies with a number of treatment plants already in use throughout Chennai. 


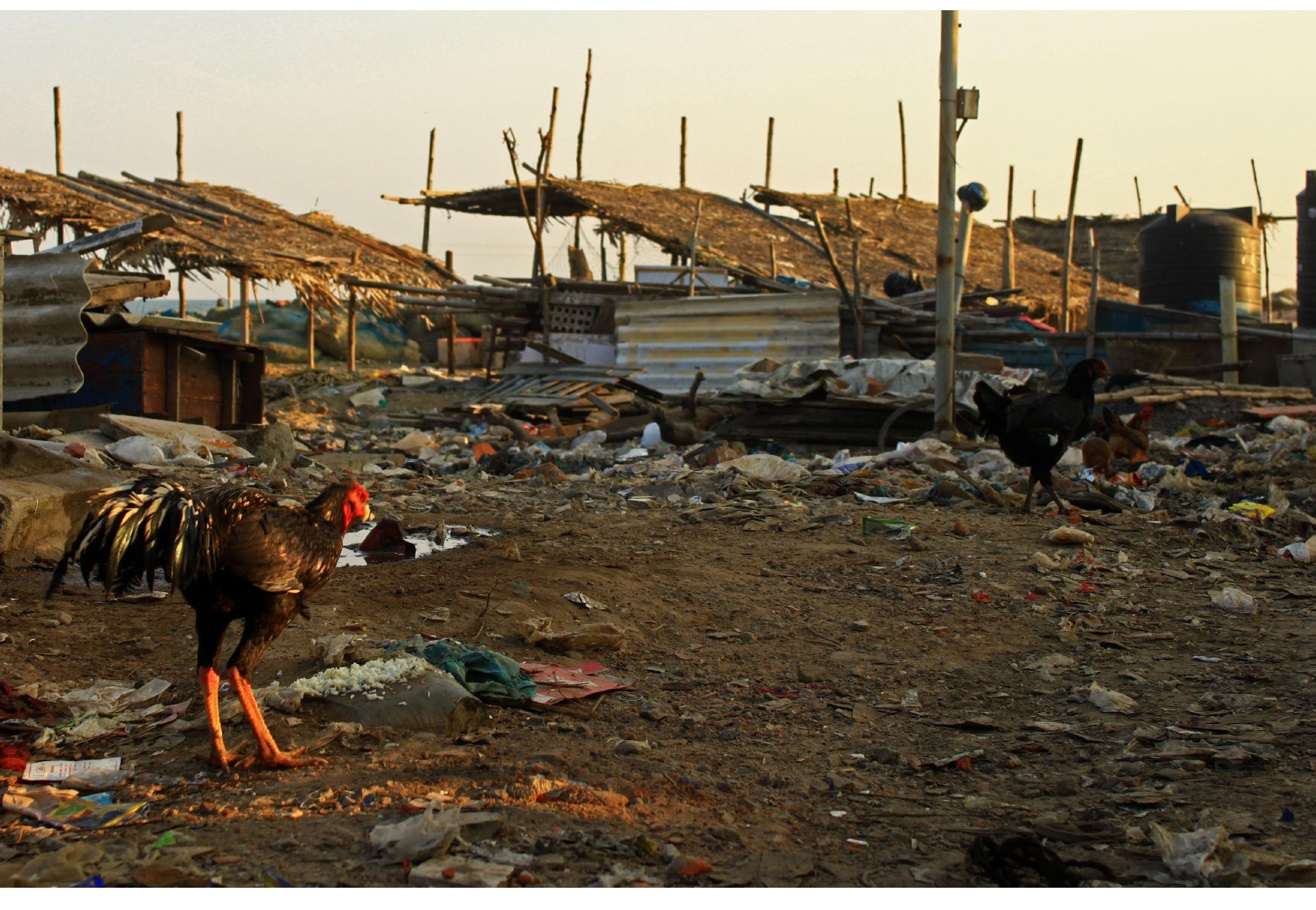

Fig. 96. Beach front garbage build up. 

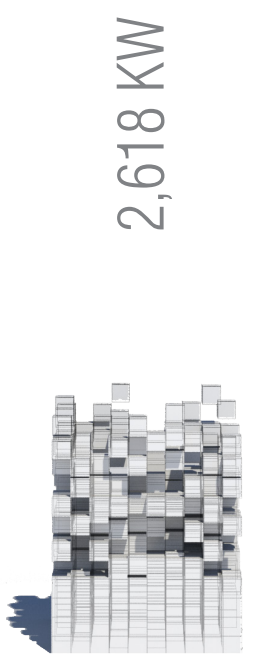
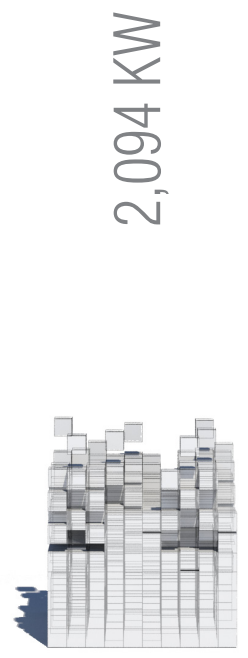

\section{KOYAMBEDU SEWAGE TREATMENT PLANT}

The Koyambedu Sewage Treatment Plant in Chennai has the capacity to currently process 120 million liters of sewage per day. For every $0.00425 \mathrm{kw}$ of power required to process one liter of sewage, $0.0034 \mathrm{kw}$ of renewable energy is generated by converting the methane content in bio-gas to electricity ("Koyambedu Sewage Treatment Power Plant"). The treatment plant essentially produces $80 \%$ of the energy that it requires to operate. Secondary treated sludge has also recently become a part of the sustainable process and even generates revenue for the plant as corporations such as Madras Fertilizer Ltd recycle the waste content for reuse in the agricultural industry ("Sewage Treatment Plant").

Using these figures as a guideline for the proposed scheme, Srinivasa Puram will produce approximately 616,000 liters of sewage per day requiring $2,618 \mathrm{kw}$ of power each day to operate. The system will generate a total of $2094 \mathrm{kw}$ per day through the conversion of bio-gas to electricity.

\section{$\underset{\substack{\text { WOCATOON } \\ \text { WASTE TO ENENAI }}}{\text { ENERGY TREATMENT PLANTS }}$}

Chennai Petroleum Corporation Ltd has recently announced the introduction of a number of 'waste to energy` projects set for Chennai (Philip). Each biomethanol plant will generate $360 \mathrm{kw}$ of power per tonne of biodegradable waste supplied. Chennai produces $0.71 \mathrm{~kg}$ of garbage per capita daily. In a country where poverty is mushrooming at an exponential rate it is horrifying to note $60 \%$ of this figure is made up of food waste. Using these figures as a basis for the design, the thesis experiment will produce 6.5 tonnes of organic waste per day with the opportunity of generating approximately $2340 \mathrm{kw}$ of power every day ("Chennai's per Capita Waste..."). All other waste produced will be transferred to either recycling centers or landfill within Chennai. 


\section{WAVE ENERGY:}

Wave energy is a predictable, daily and dependable source of renewable energy. Wave power has the potential to be generated $90 \%$ of the time, while other sources of renewable energy such as solar and wind tend to be available between $20-30 \%$ of the time (Pelc and Fujita). Constructed either onshore or partially offshore with the ability to be integrated into breakwater systems this renewable energy source may prove to be a viable option for the proposed framework.

\section{LIMPET 500 WAVE TO ENERGY GENERATOR

$$
\begin{aligned}
& \text { ISLAY } \\
& \text { SCOTLAND }
\end{aligned}
$$

The Land Installed Marine Powered Energy Transformer (LIMPET) highlights opportunities of ocean basedpower plants harnessing energy from tidal movements and waves to generate electricity ("Islay Limpet Wave Power Plant"). The design was first installed in 2000 on the Hebridean island off Islay on the western coast of Scotland. The design harnesses the kinetic movement of wave motion inside an air-tight chamber to compress air, turning a turbine and producing electricity (Figure 99). As a sustainable source of renewable energy the LIMPET 500 will produce approximately 1800MW of power per annum per system (Isaly LIMPET Wave Power Plant). 


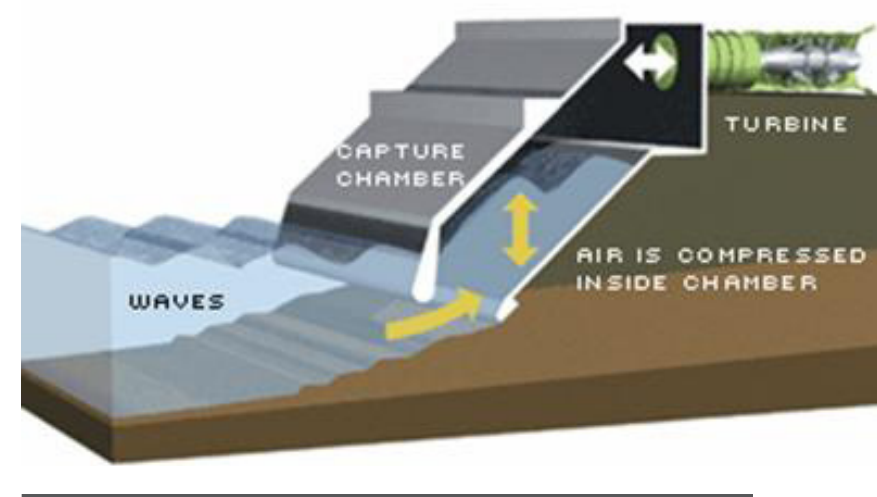

Fig. 99. Schematics of LIMPET 500 system.

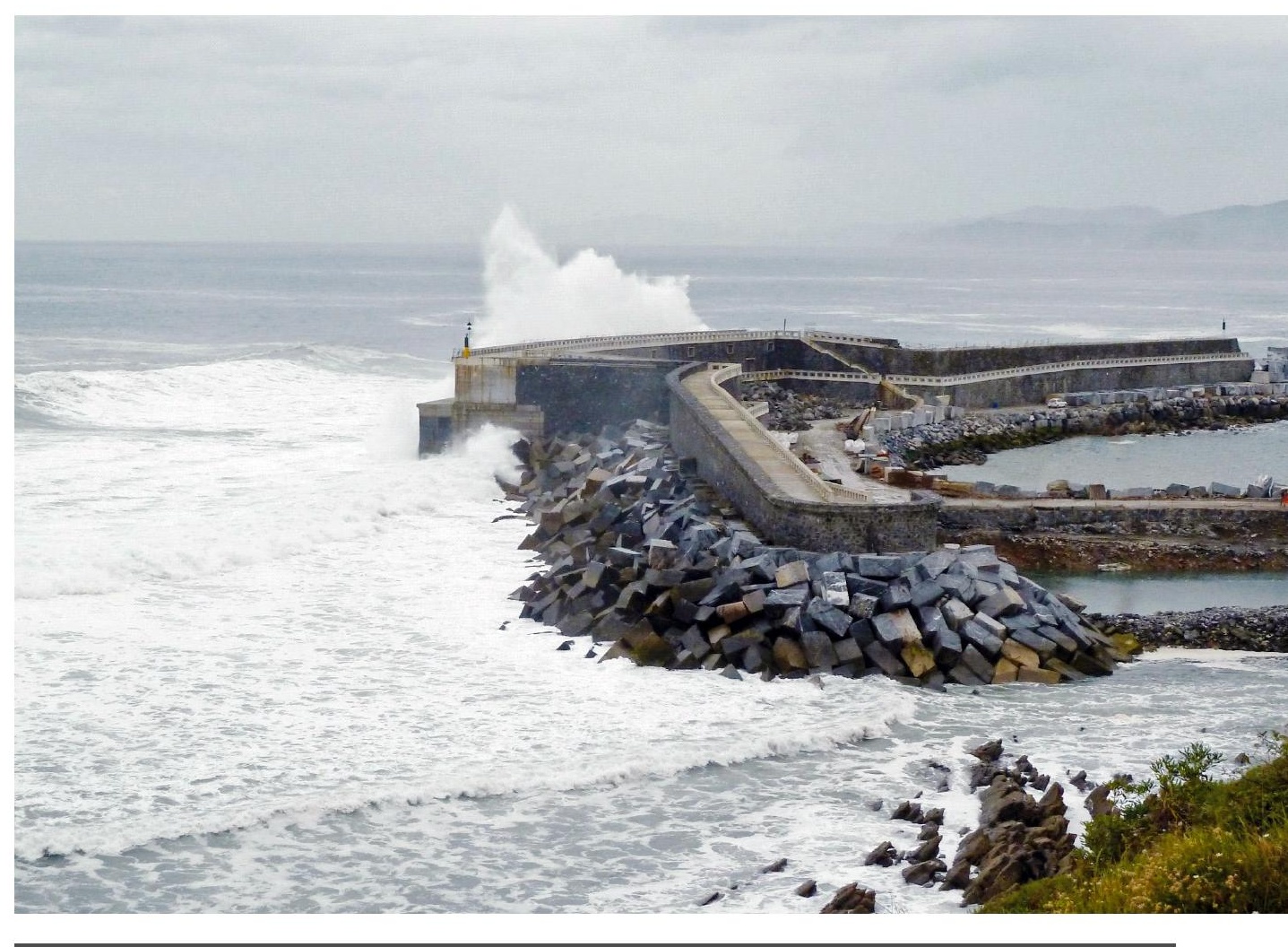

Fig. 98. Land Installed Marine Powered Energy Transformer. 


\subsection{STORM SURGE \& TSUNAMI BARRIERS}

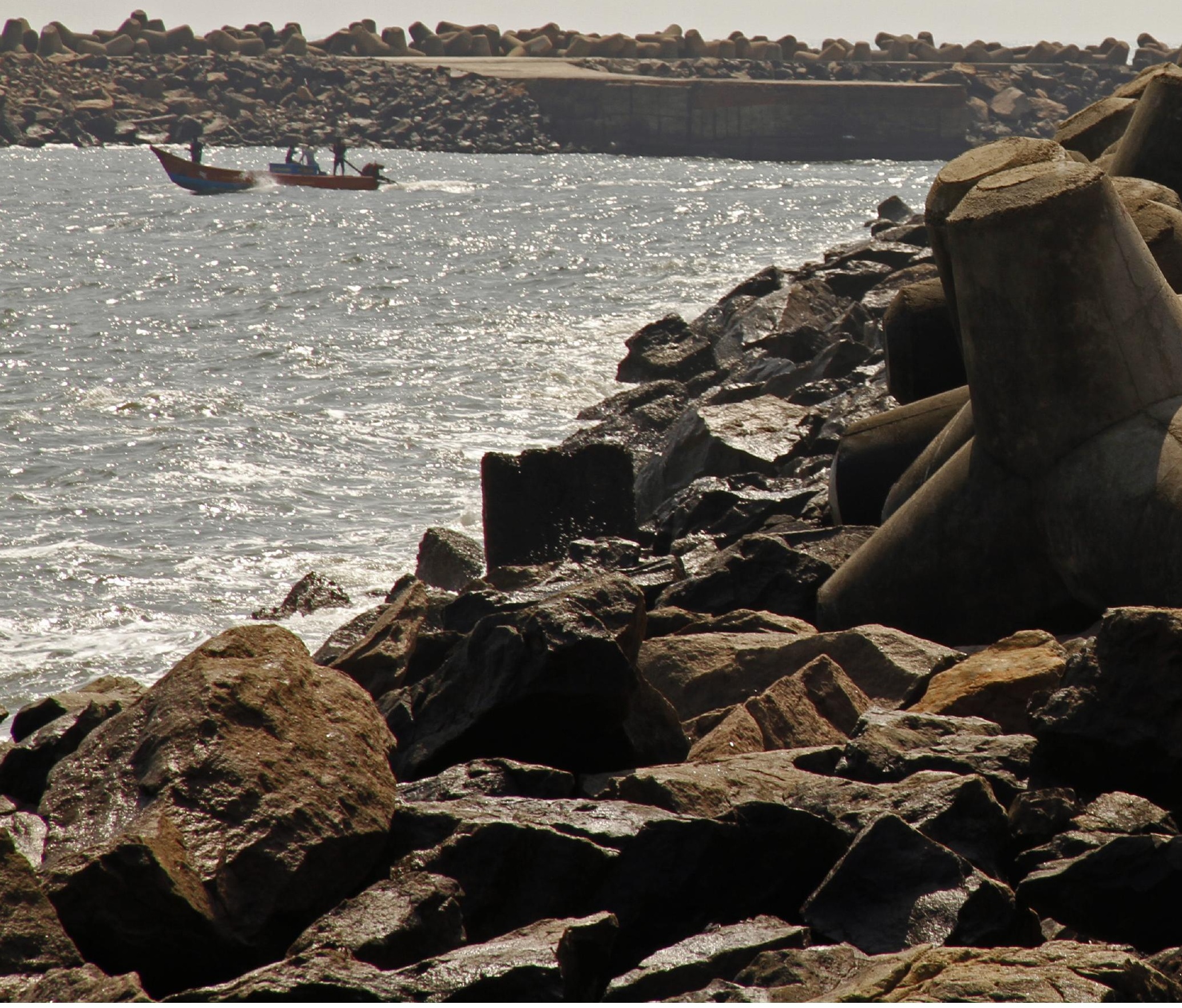




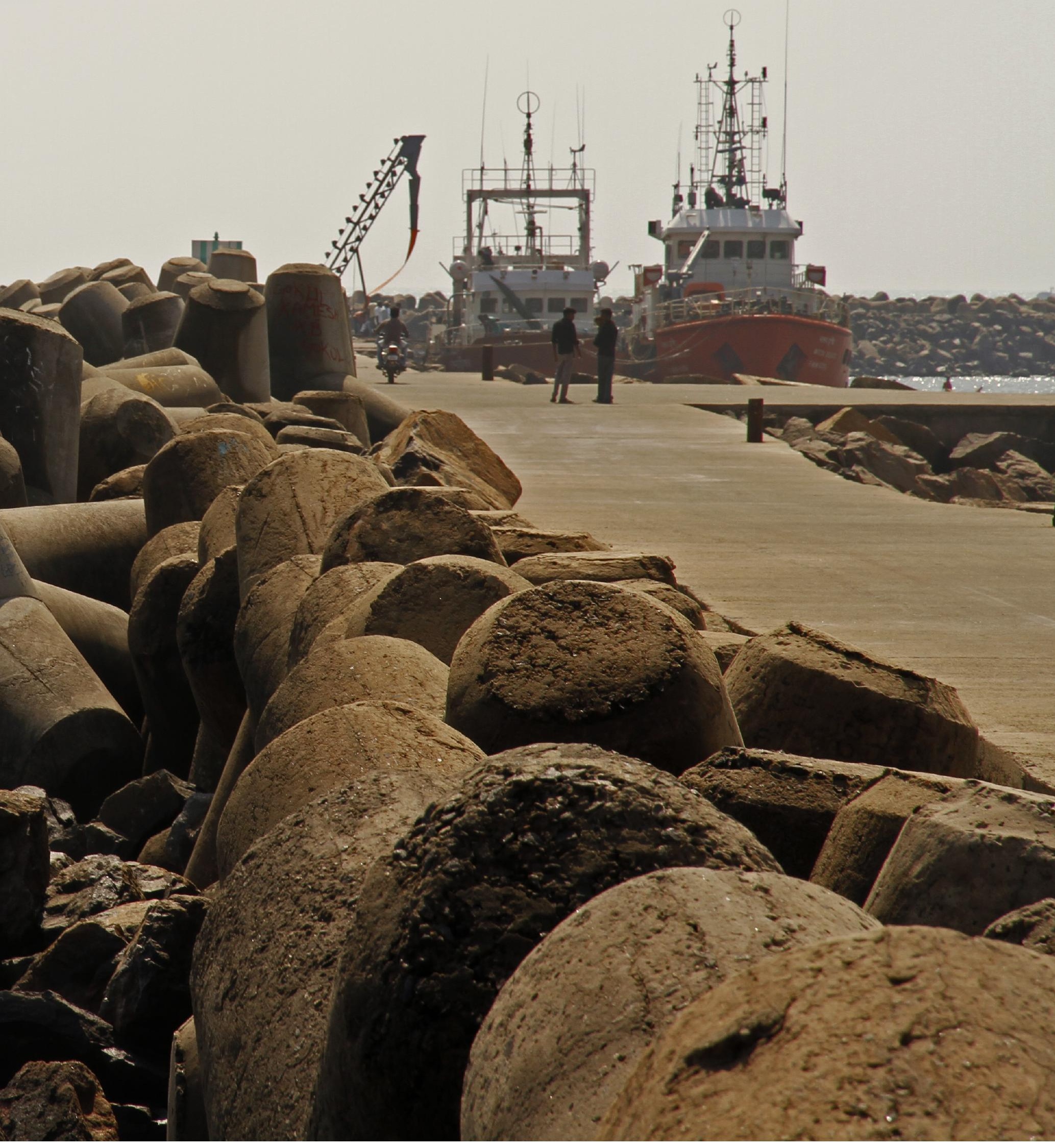




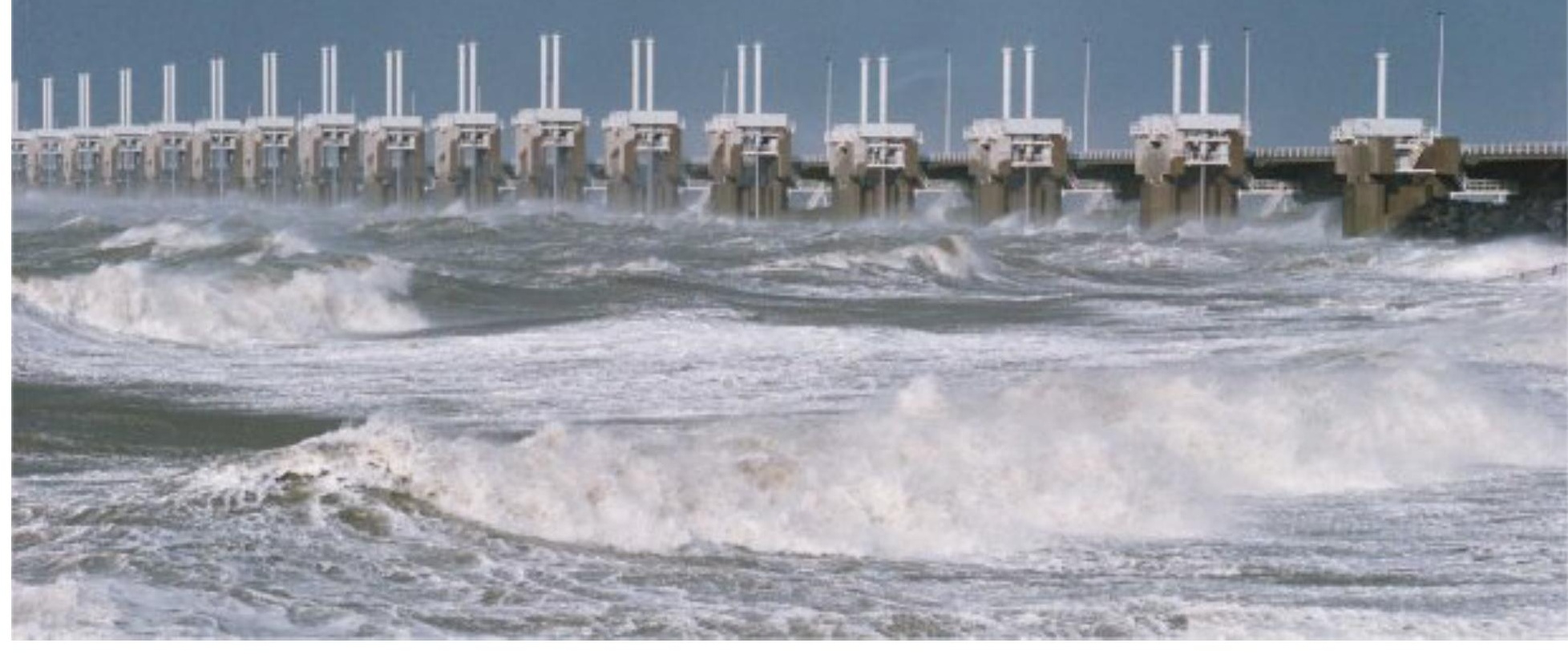

Fig. 101. Eastern Scheldt Flood Barrier in Oosterschelde, Netherlands

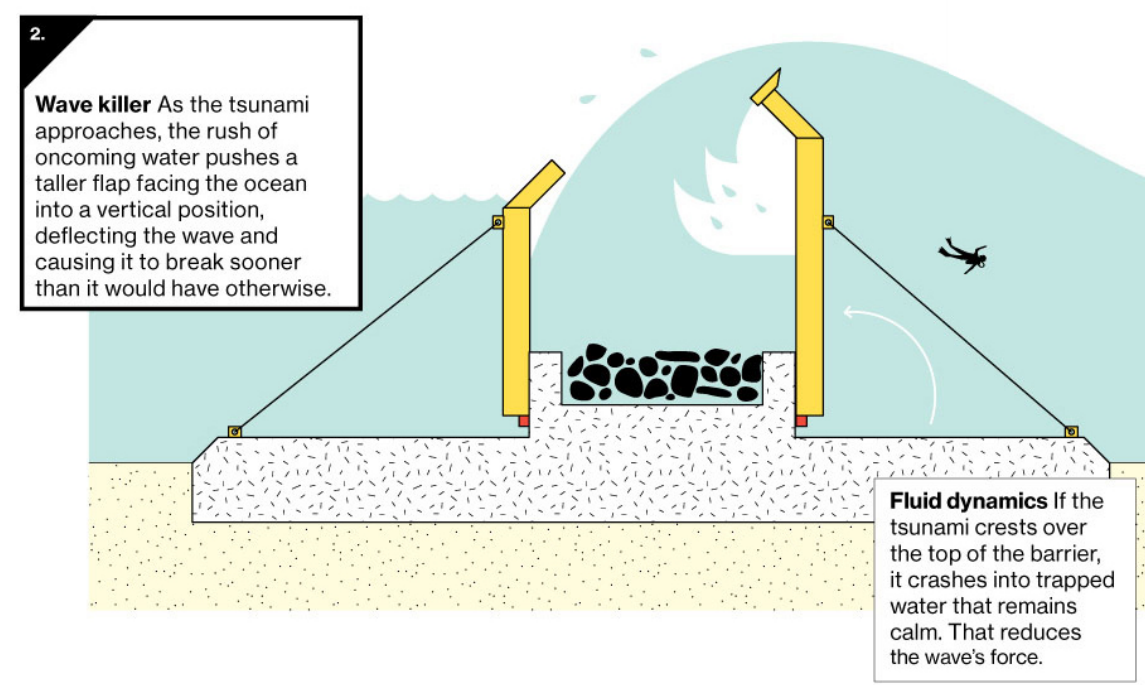

Fig. 102. Twin Wing Tsunami Barrier. 


\section{STORM SURGE BARRIERS}

Traditionally walls and levees were the only means of mitigating threats from storm surges, tsunamis and flooding, though in recent decades innovative new technologies have been developed to control adverse effects of the environment. Designed to span small bays, harbor openings and rivers, the Eastern Scheldt Flood Barrier in Oosterschelde, Netherlands has produced successful results to date. Costing billions of dollars to construct, however (Rockaway Shoreline Protection) it would be an unfeasible proposal to protect the slum community of Srinivasa Puram.

The US National Tsunami Hazard Mitigation Program's publication Designing for Tsunamis highlights a number of important planning strategies to reduce the risk of tsunami including: Slowing water through means of plantations and elevation changes, Steering water by integrating strategically placed angled barriers, and Blocking water by using systems such as walls and terraced hardscapes ("Designing for Tsunamis"). The devastation caused by recent tsunamis has prompted engineers to begin developing and testing innovative conceptual systems such as the Twin Wing Tsunami Barrier, designed to interrupt and neutralize both the positive and negative energy of tsunamis ("TwinWing-Tsunami Barrier"). The design is currently not in use and the requirement to form a sealed negative tsunami wave means the structure would be best used to span small bays or harbor openings as opposed to a wide estuary opening along the coastline of Chennai. 


\section{$\underset{\text { LOCATON }}{\text { ROYAPURAM FISHING HARBOUR }}$}

This case study provides an insight into a similar fishing community in northern Chennai and the local government's response to coastal protection through the construction of large-scale breakwater systems.

Constructed in 1975, the Royapuram fishing harbour north of Chennai's port has the capacity to moor over one thousand fishing vessels ranging from homemade catamarans to 45 foot deep sea trawlers. The design consists of a $200 \mathrm{~m}$ inner wharf flanked by a $300 \mathrm{~m}$ outer wharf, both of which are strengthened by a concrete tetrapod breakwater system (Figure 104). While the 2004 Boxing Day Tsunami caused extensive damage to the $300 \mathrm{~m}$ outer wharf as well as a number of trawlers moored to the structure, the vast majority of fishing vessels within the harbor survived the natural disaster with only minor damage. ("Two Major Projects in Fisheries Sanctioned in Chennai")

Thousands of slum dwellers reside along Chennai's coastal fringes to the north of the Royapuram fishing harbor. To mitigate the threat of coastal erosion and the destruction of natural disasters the local government has implemented a series of large scale breakwater systems. Stretching for kilometers, the structure provides a first line of defense for thousands of coastal dwellings. This design proves a feasible case study for the proposed scheme at the mouth of the Adyar River.

With approximately a quarter of Srinivasa Puram being directly invested in the fishing community, the design will look to adopt similar design principles to the Royapuram fishing harbor with the aim of mitigating potential damages caused by future storm surges and tsunamis.
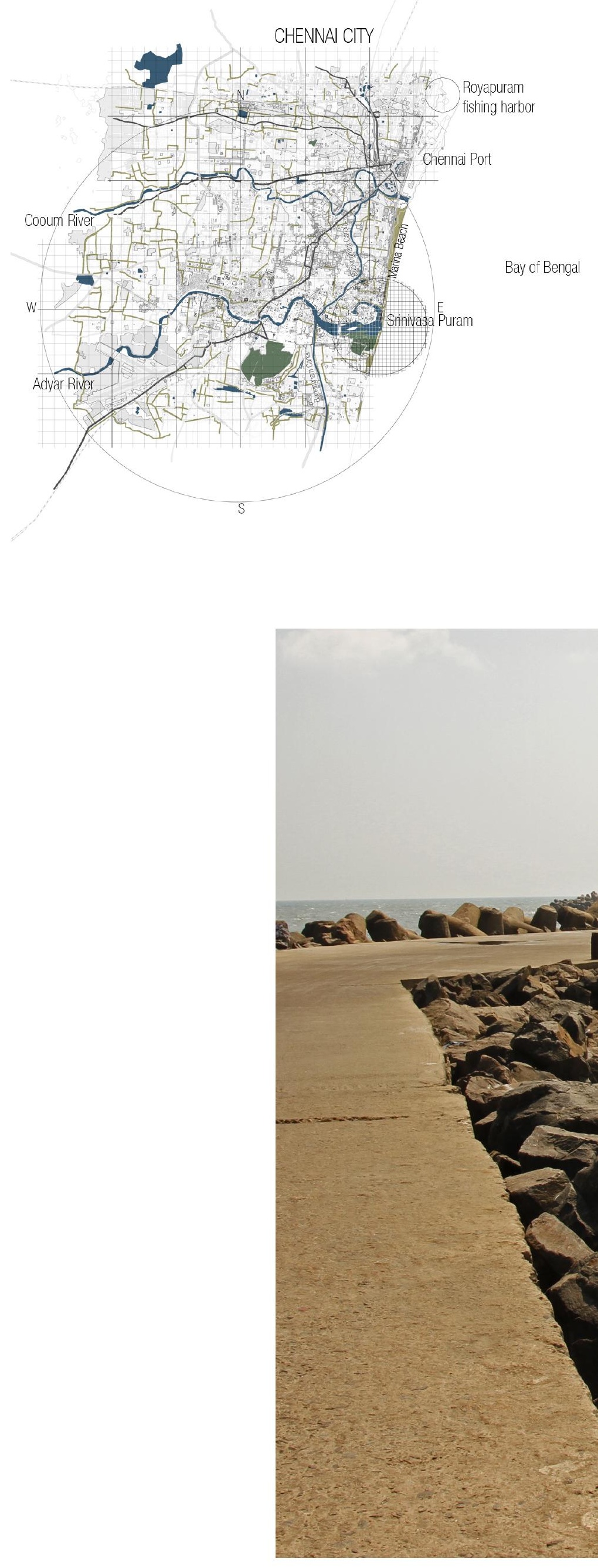


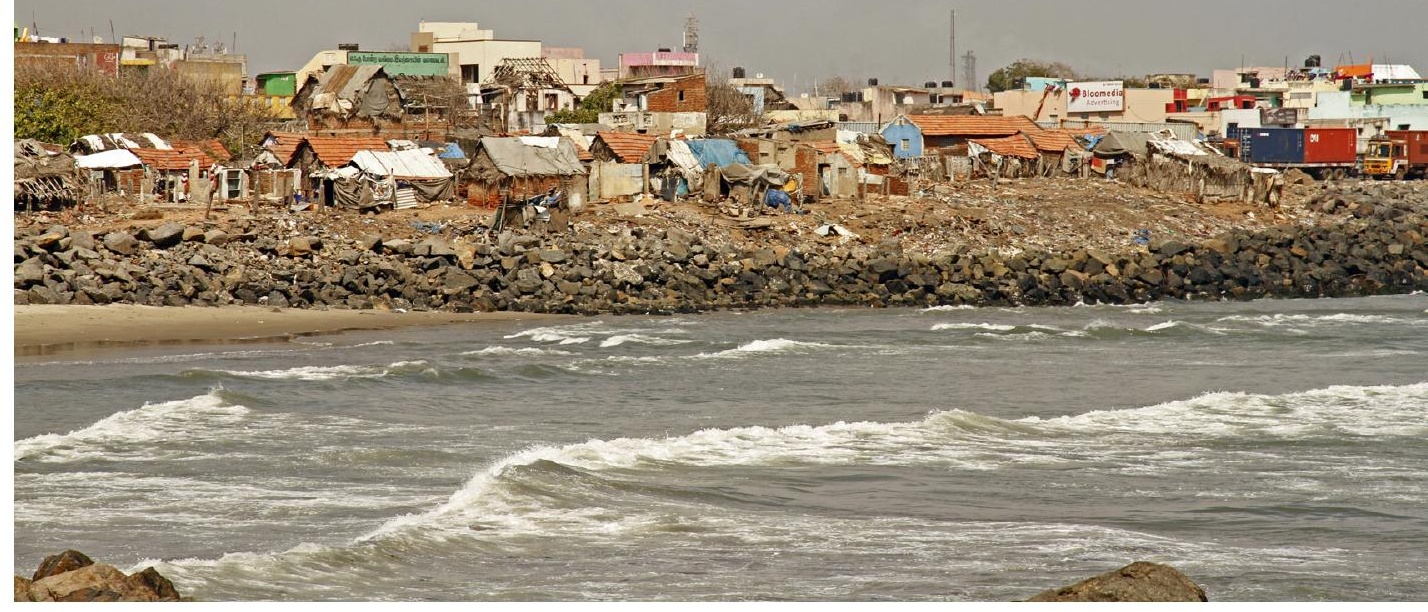

Fig. 103. Informal settlement outside the Royapuram fishing harbour, Chennai.

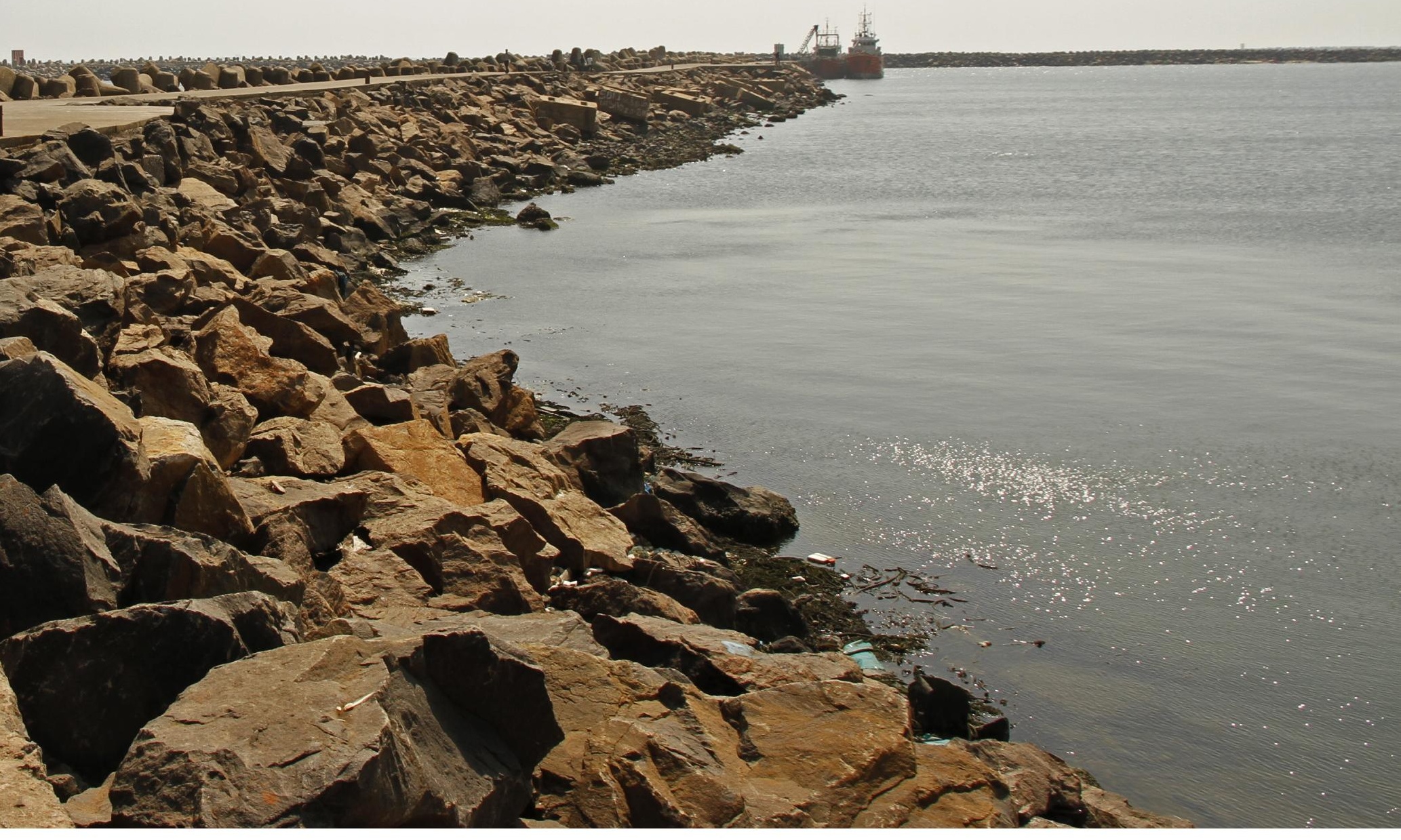

Fig. 104. Royapuram fishing harbour breakwater system, Chennai. 


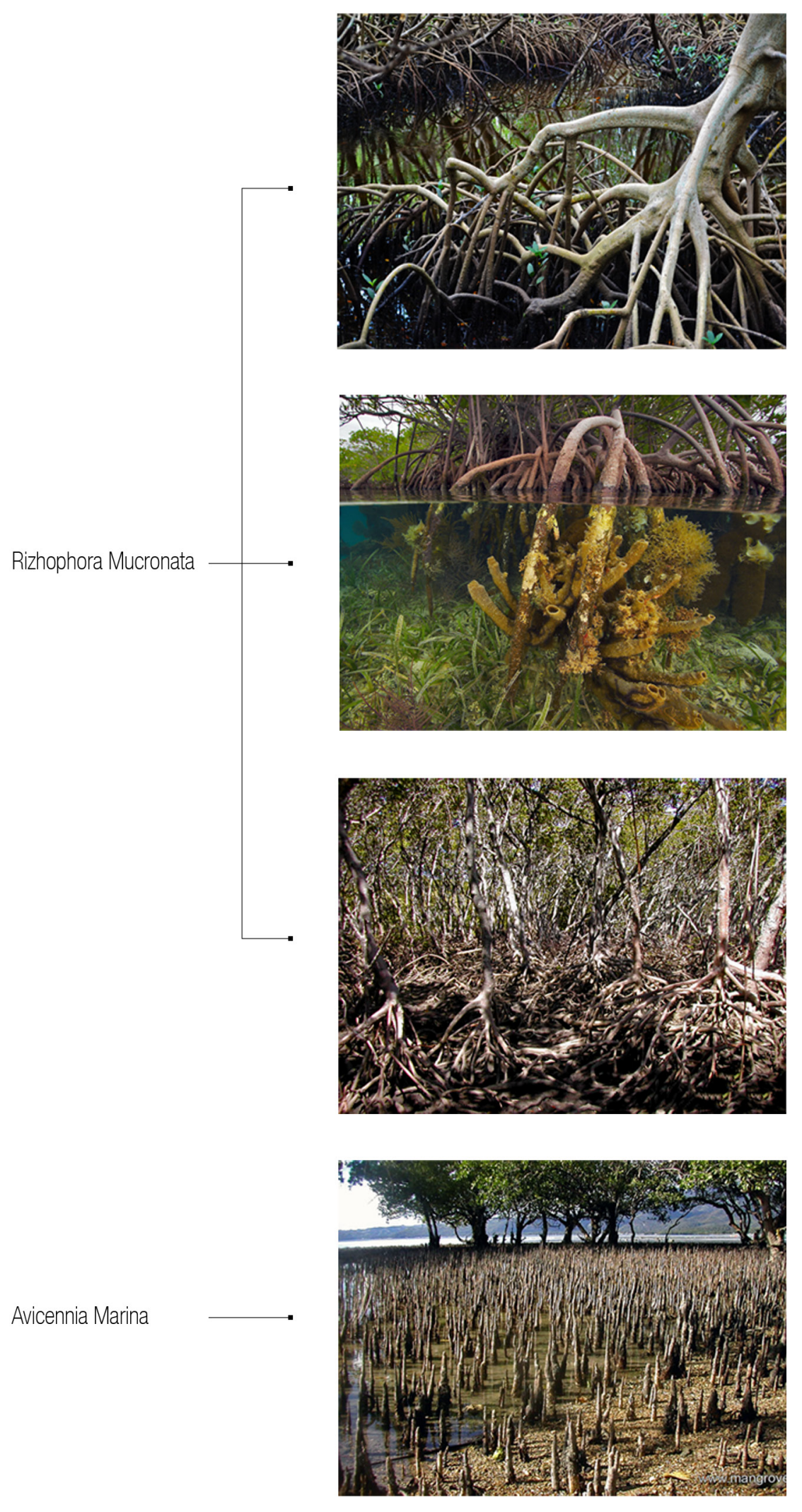


Coastal reefs and mangrove plantations are nature's natural defense systems against disastrous wave action events and flooding, and they are disappearing at a horrific rate due to pollutants entering waterways and mangrove forests being harvested to provide a source of foods, medicines, fuels and building materials while creating land for development and agricultural purposes (Alongi). The absence of these natural ecosystems is having devastating effects when disasters such as storm surges and tsunamis occur. Mangrove plantations and coastal reefs create a dissipation and dampening of both wave and wind energy through the resistance and interference provided by vegetation (Pardue).

Storm surge barriers such as the Eastern Scheldt Flood Barrier in Oosterschelde, Netherlands, the Eider Barrage Barrier in Toning, Germany, the Thames Barrier in London, England and innovative tsunami barriers such as the Twin Wing Tsunami Barrier are too costly for mitigating both storm surges and tsunamis for Srinivasa Puram. A more cost-effective alternative option would be to implement a breakwater system similar to the Royapuram fishing harbor integrated with mangrove plantations to not only dissipate wave and wind energy generated through storm surges and tsunamis but to also reduce coastal erosion and rejuvenate the surrounding ecosystem. 


\section{$\underset{\substack{\text { LOCGRON } \\ \text { TEMPLE }} \text { MADURAI }}{\text { CITY }}$}

This section reflects upon the important role architecture plays within traditional Indian values, rituals and environmental aesthetics, as well as highlighting the importance of underlying narrative in ancient Indian temple complexes and cities.

For example, the 17th century urban plan of the ancient temple city of Madurai is based upon the mandala, a symbolic representation of the microcosm of the universe. The entire city plan of Madurai is designed as a sequence of concentric square rings ultimately leading to the Sundareshvara shrine symbolising Mount Meru, the home of the gods at the center of the city (Smith and Reynolds 5). Madurai continued to expand throughout the rise and fall of a number of empires, each adding to the series of concentric rings. While this was influenced by the need to create more defensive structures in relation to urban expansion, each addition followed the same principles of the mandala. Everything within the outer perimeter wall is symbolic of the cosmic world; the spaces contained within each concentric ring represent progressively more sacred inhabitants, from plants in the outermost ring, to animals in the next, then to lower caste inhabitants, and ultimately to the highest cast inhabitants followed by the priests and gods. While the temple complex at the centre of the urban mandala was a sacred place of the gods used for worship, it is flanked by large Mandapa pillar halls were used for shops and stores giving a sense of communal participation to the inhabitants - "an intimate responsiveness to the architectural environment that creates a vital sense of belonging, of interaction" (Brown 6). 
The concentric outer rings of a mandala symbolise alternating bands of earth and water making up the cosmic world, beyond which lies the cosmic sea. The temple spires (gopuram) symbolise mountains, and the four eaves of the gopuram symbolise the four rivers of the sacred world flowing down the mountainside. Inside the central mountain of the gods lies the womb chamber (garbhagriha) of mother earth. From the womb chamber sacred liquids flow out and into a large outdoor water tank surrounded by stone steps (ghats). The word 'ghat' translates as 'mountain' leading down to the waters in the tank, which are used for sacred cleansing. Also within a temple complex is a hall of columns (mandapa) which symbolises a forest within which pilgrims find shade and shelter (Brown 5).

The temple city of Madurai is a prime example of architecture as landscape responding to site dynamics. The architecture represents translations of the mountains, rivers and trees displayed through architectural elements such as Gopuram, Ghats and Mandapas. These symbolic architectural components are understood by all South Indians as a fundamental part of their heritage, and they were used to inform the preliminary design experiments (Figure 109). This series of free standing columns and flat vs. stepped design experiments portray the traditional architectural symbolism exemplified in Madurai and similar ancient Hindu architecture structures, exploring a contemporary translation of these architectural elements for the designs of the thesis wetland systems, storm surge barriers and housing frameworks for Srinivasa Puram. 


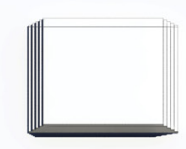

13

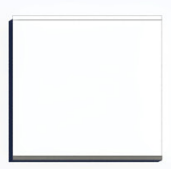

07

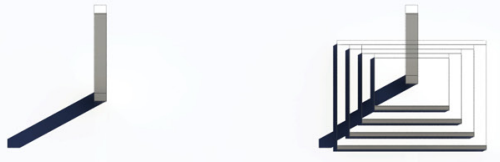

01

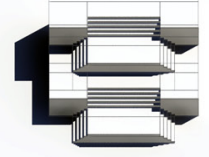

14.

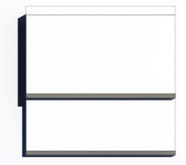

08.

02.

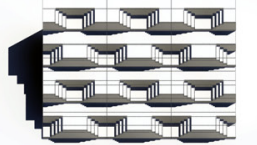

15

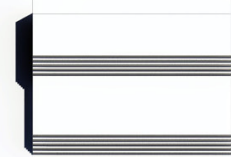

09

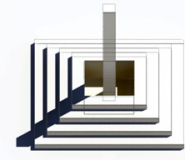

03.

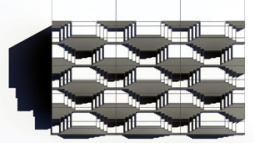

16.

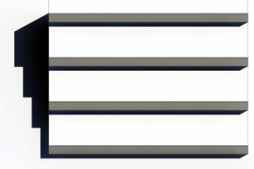

10.

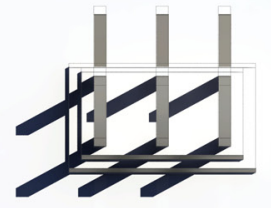

04.

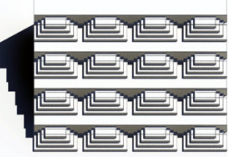

17.

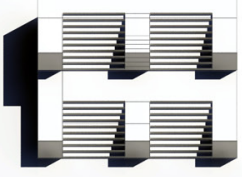

11.

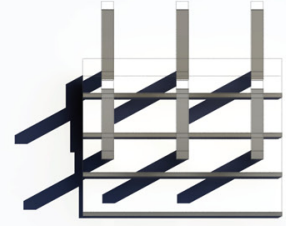

05.

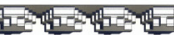

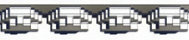

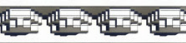

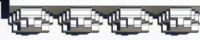

18

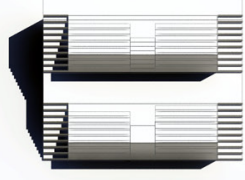

12

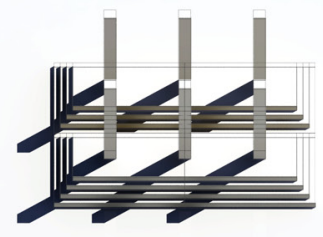

06. 


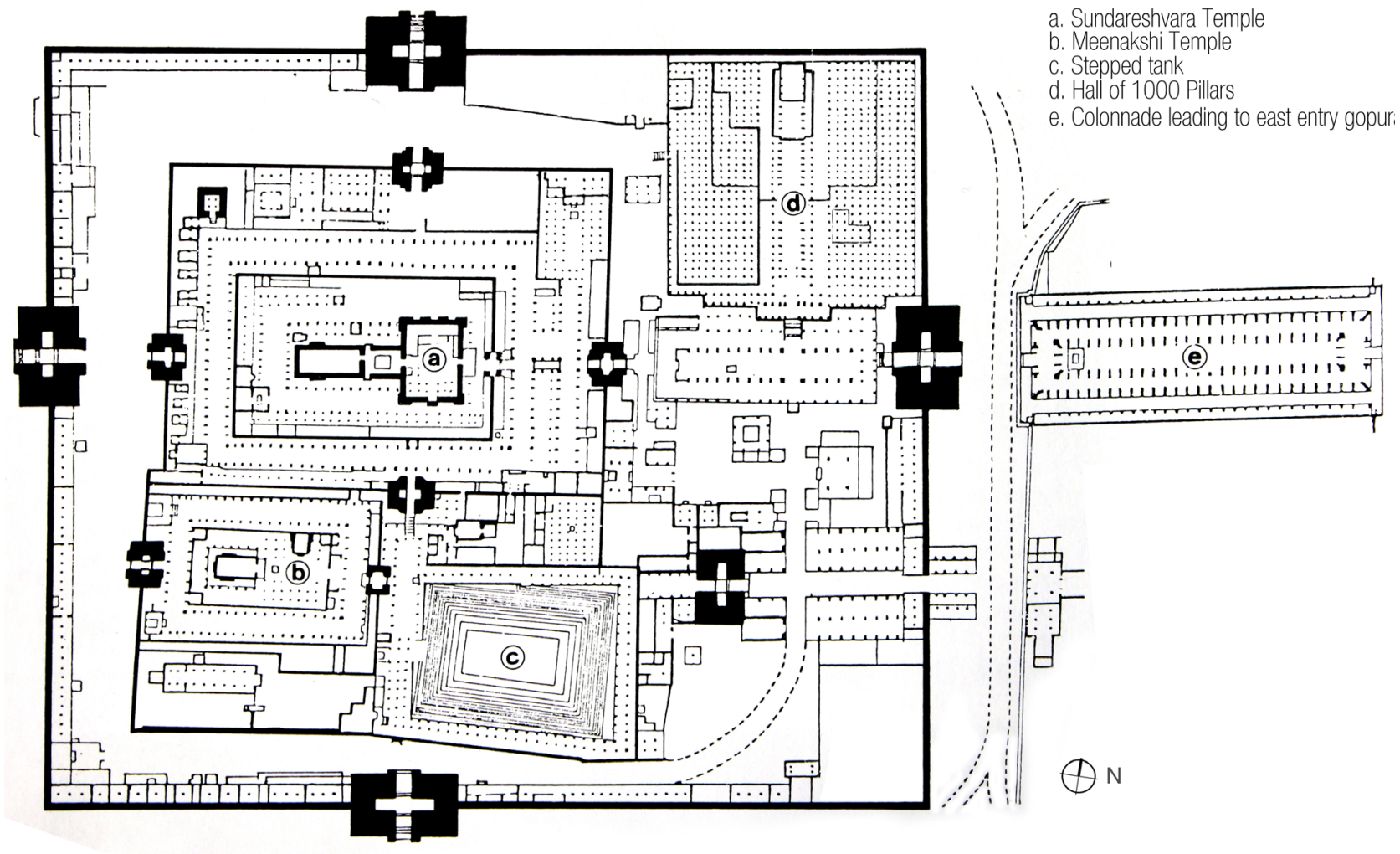

Fig. 110. Minakshi-Sundareshvara temple plan, Madurai. 
The mythology of time is an important aspect of Hindu culture. Temples are traditionally designed to be experienced in a clockwise direction with the entry and exit to a temple always positioned to the east symbolising re-birth while south symbolises life and fertility, west symbolises death and north enlightenment. In the northeast corner between enlightenment and re-birth typically lies a sacred tank, for cleansing before the cycle of life reoccurs. (Brown 3) 
This narrative of time is evident on a much greater scale in the submerged temples of Bilaspur (Figure 111). Though the introduction of a manmade reservoir downstream has threatened the existence of these temples over the last 50 years, the temples were sited such that flood waters submerged them completely during the monsoons, as a symbolic act of ritual cleansing. (Brown 4).

Monsoon flooding, storm surges and tidal shifts could all be implicated as design tools in the thesis experiments, not only representative of the traditional Hindu ritual of sacred cleansing but also a pragmatic means of sustainable site purification systems. 


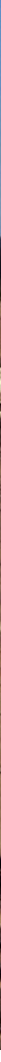

Fig. 111. Goel, Tarun. Submerged temple, Bilaspur, 2012. 


\subsection{CONTEMPORARY INOIAN ARCHITECTURE}
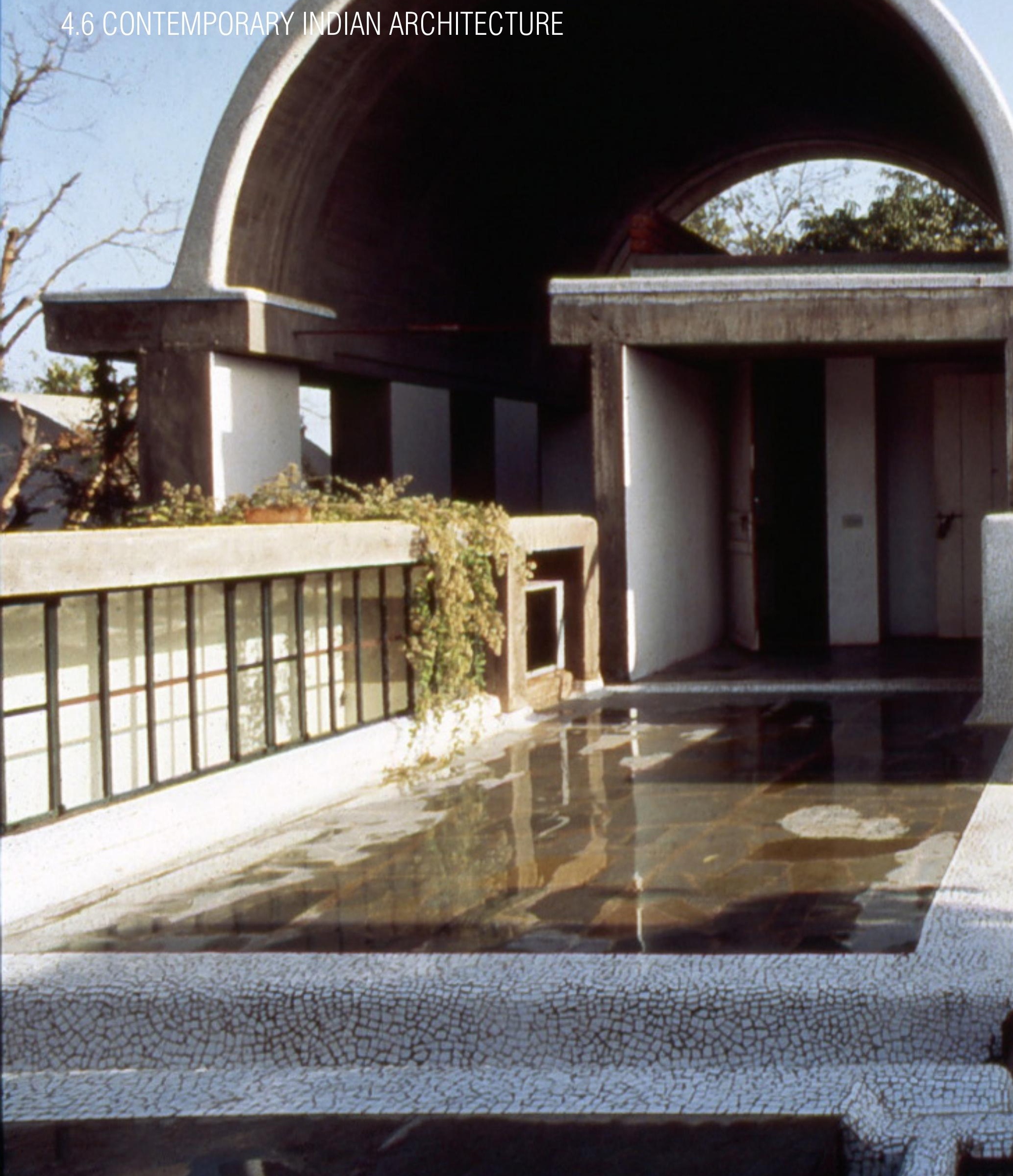


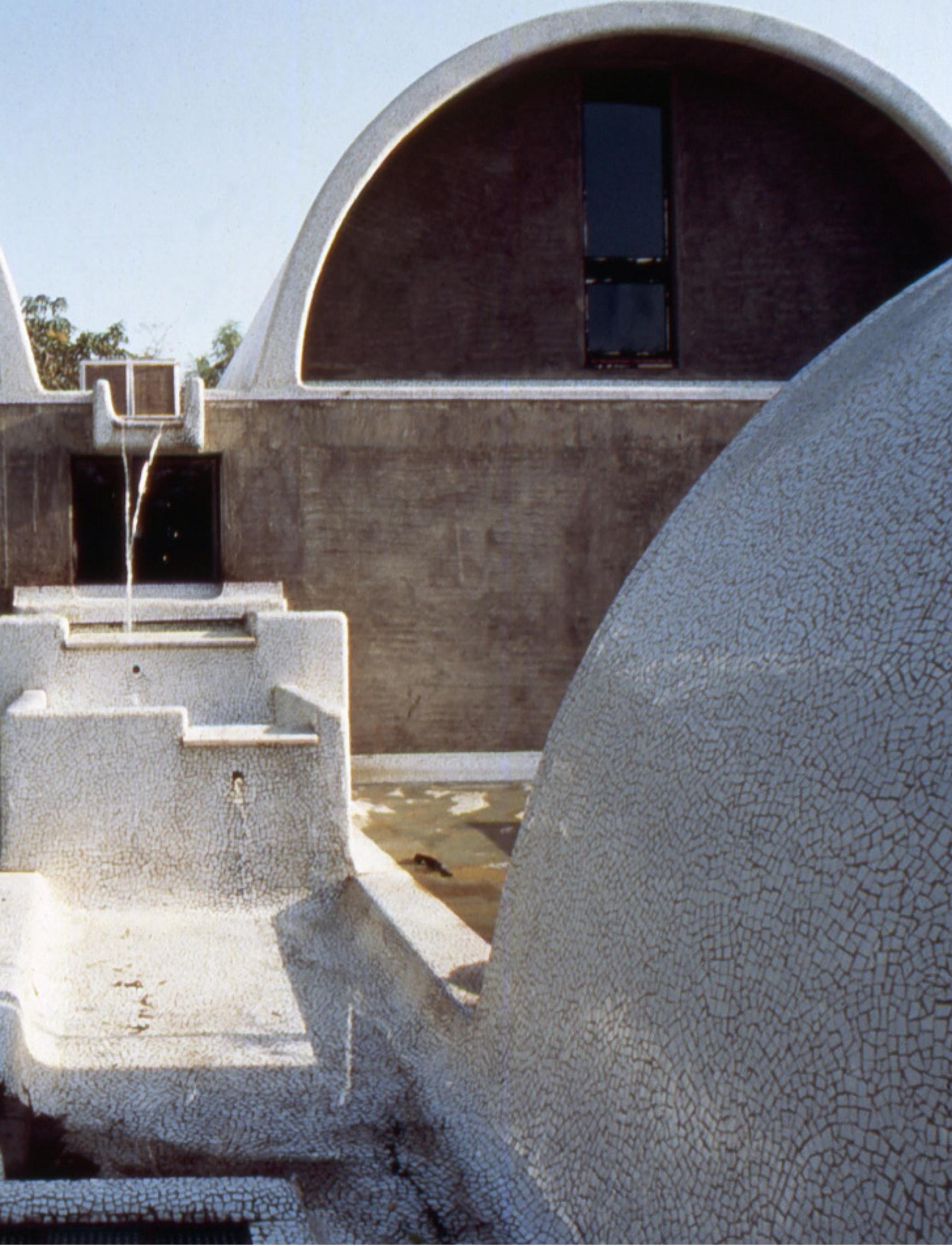

\section{Evis}




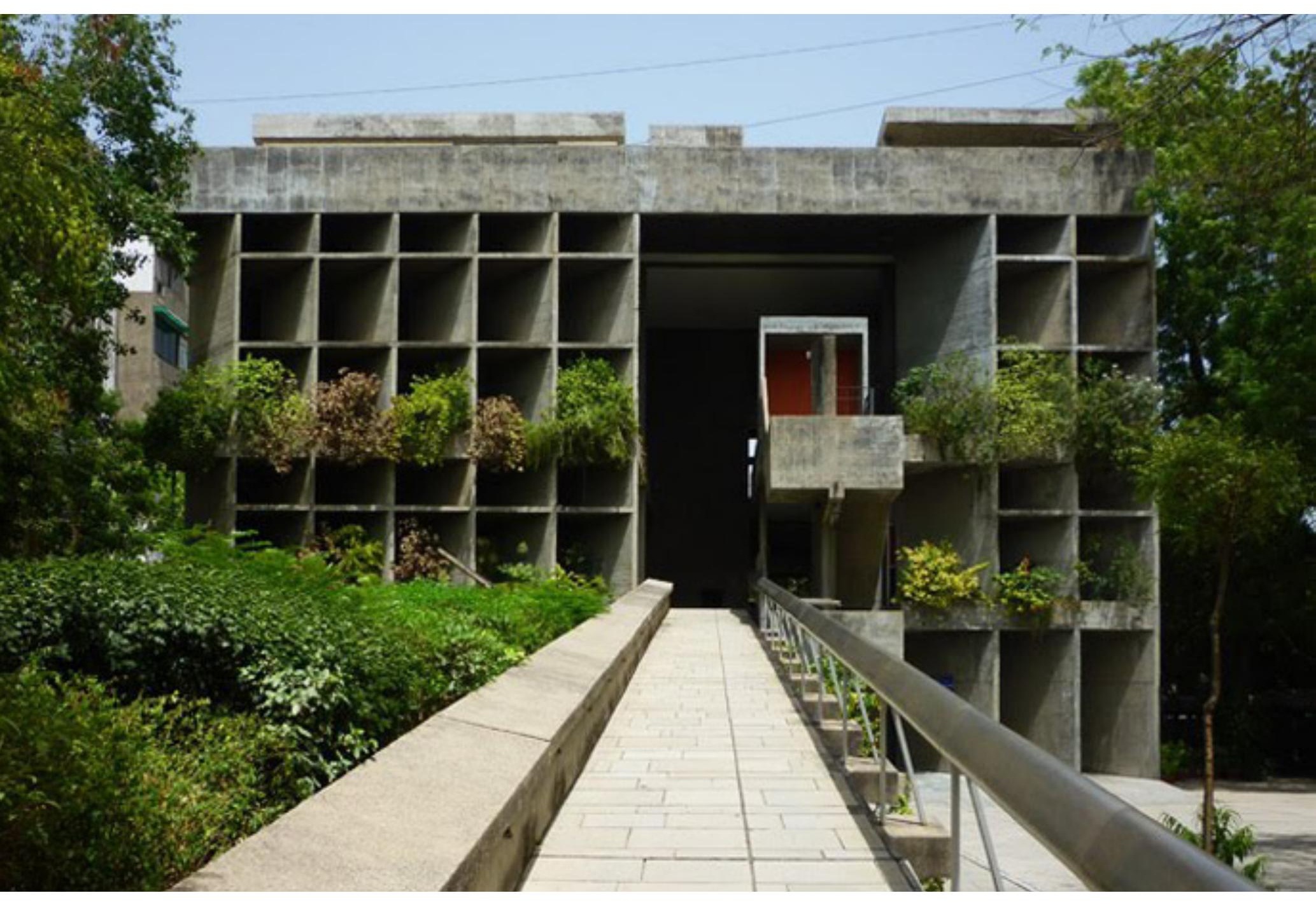

Fig. 113. Le Corbusier's Mill Owners' Association Building. 
The period following India's independence in 1947 saw contemporary Indian architects seeking solutions to house a rapidly growing population while searching for identity. Sustainable means of material choice, technology and energy became important, while architects such as Le Corbusier, Louis Kahn and Balakrishna Vittaldas Doshi stressed the importance of designing contemporary solutions reflecting traditional Indian values, rituals and architectural aesthetics. Corbusier's Mill Owners' Association Building and B.V. Doshi's Sangath House both situated in Ahmedabad were among early contemporary Indian designs; these designs evidence a strong tie to traditional Indian architectural vocabulary as well as the relationship they share with the surrounding landscape and climatic conditions (Kultermann). Doshi learned "to observe and react to climate, to tradition, to function, to structure, to economy and to the landscape around me" during his collaboration with Corbusier; he also built on this by applying his own culture to contemporary design that expressed public and social opened and enclosed spaces spanning a variety of scales and uses as an essential response to traditional Indian living ("Beyond Mere Aesthetics..."). Perhaps one of his greatest examples of this was the design of Aranya Community Housing in Indore, India: 
ARANYA LOW COST COMMUNITY HOUSING

BNDORE, INDIA

The objective of Doshi's Aranya Housing Project in Indore, India was to create an intimate community with a strong sense of belonging and interaction within a balanced matrix of socio-economic groups. Centered around a continual dialogue between designer, builder and inhabitants, the project was encouraged to be "considered as a living entity where incremental growth and personal changes were allowed and integrated as a part of the scheme" ("Beyond Mere Aesthetics..."). The urban plan is based around an offset grid system interlinking a variety of social and public sub-centers, open spaces and a hierarchy of street networks to discourage through-traffic as Doshi explains that "communication, behaviour pattern, cultural needs and rituals - all of these are interconnected"("Beyond Mere Aesthetics...") and are fundamental to sustaining the inhabitants' livelihoods within the settlement.

As the diverse structure of informal settlements is constantly growing, evolving and adapting to a variety of living and environmental conditions, Doshi's design for Aranya solely provided sanitary cores as the only architecture within each allotment (Figure 115) (Curtis). The concept allows for the community to maintain diversity through a flexible and personalised building typology as opposed to a dictated set of parameters.

The site analysis chapter highlighted Srinivasa Puram's lack of integrated public and social space that typically defines traditional Indian living within an intimate community. The proposed design scheme will adopt similar design strategies to those implemented by Doshi in his Aranya Housing project by creating a framework that encourages the inhabitants to grow, adapt, evolve and personalise their own building typology to suit their living condition. 


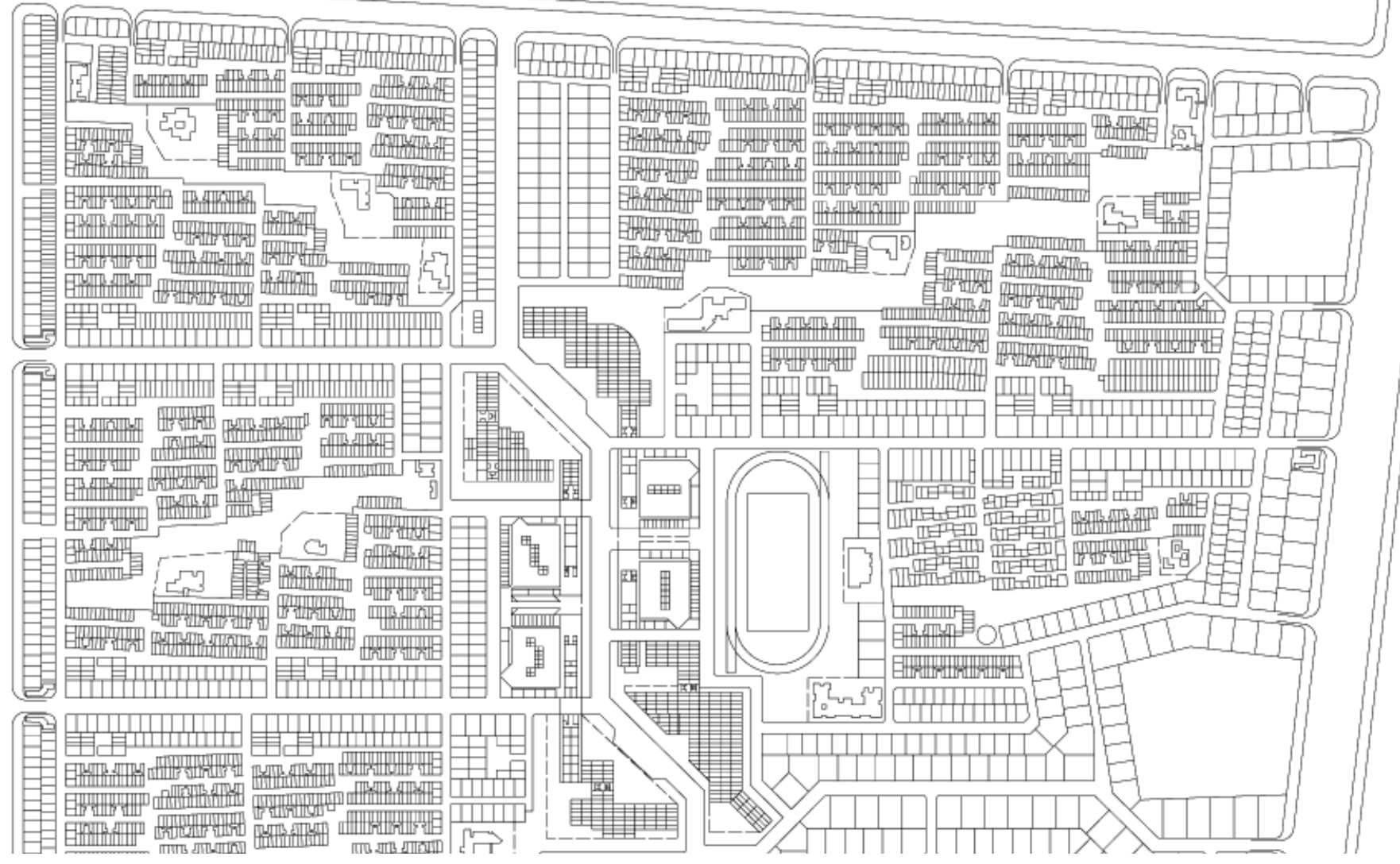

Fig. 114. Master plan of Aranya Housing Project.
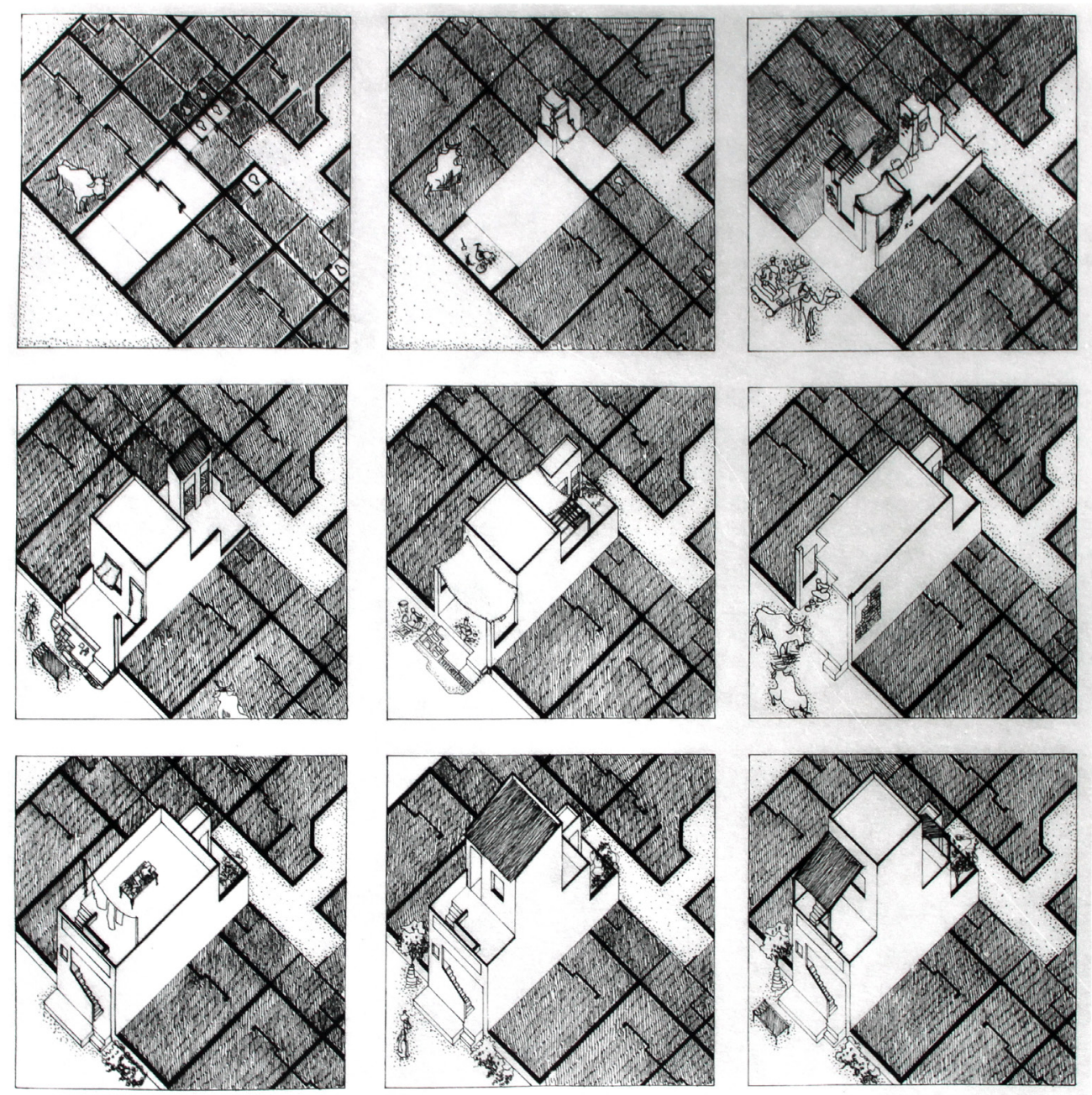

Fig. 115. Doshi, B. V. Gradual growth of house starting with bathroom core. 


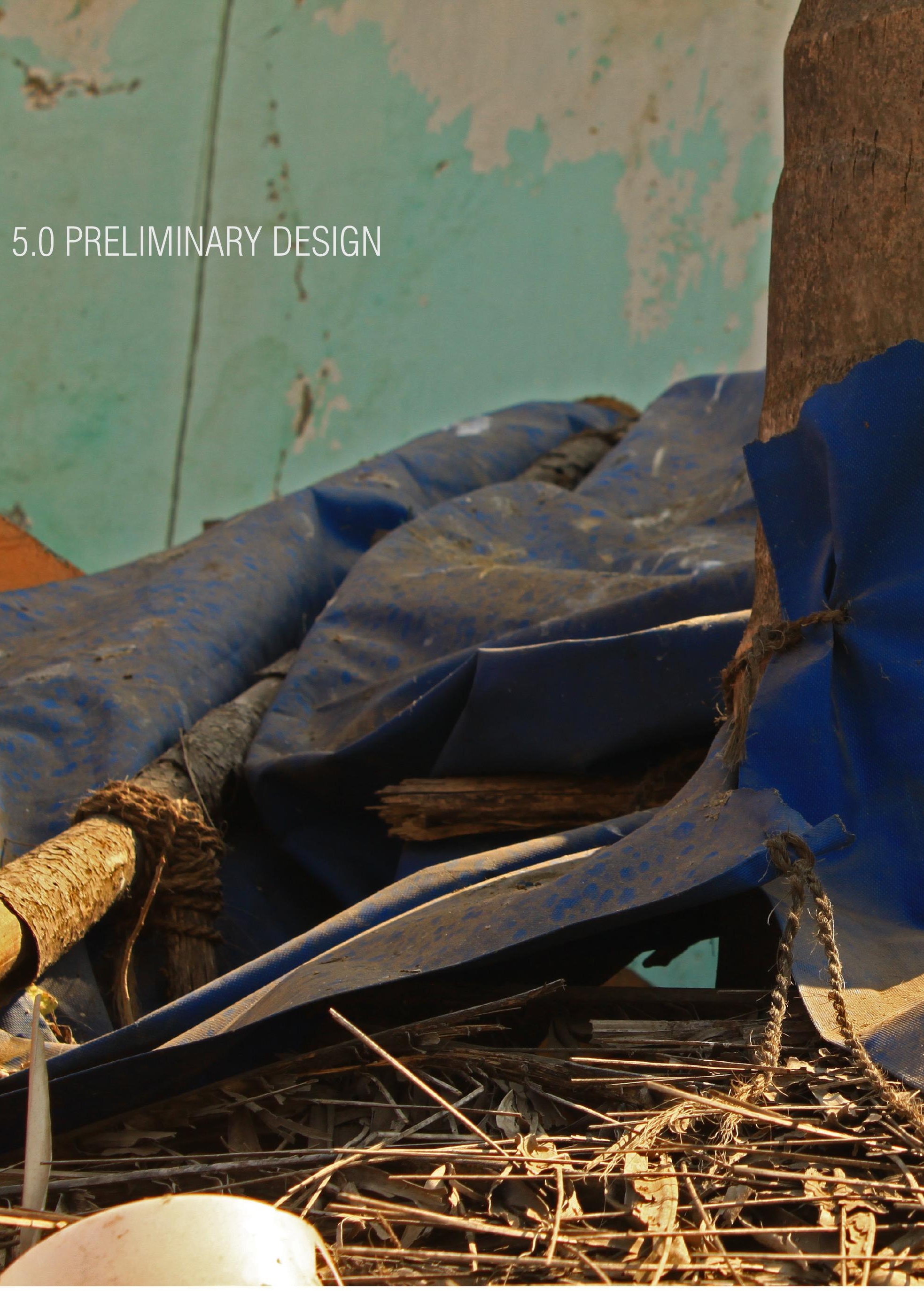

Fig. 116. Beach hut flashing detail, Srinivasa Puram. 


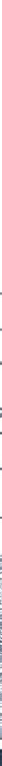

Fig. 117. Site placement. 
This chapter applies and tests design models directly responding to: severe environmental disasters such as a one meter sea level rise, tsunamis, storm surges and monsoon flooding through a series of storm surge barriers, breakwater systems and elevated structures; mitigation of environmental pollution including sewage and garbage treatment as a means of improving hygiene and generating renewable energy; and economic sources of fresh water through rainwater harvesting, wetland treatment systems and seawater desalination.

The chapter begins with a series of individual sketch experiments for storm surge protection, seawater desalination and fresh water storage that address site problems and capacity requirements highlighted in the site and program analysis chapter. It then develops and tests three integrated architectural frameworks that incorporate the researched approaches to innovative technology methods as well as traditional and contemporary Indian architectural typologies. 


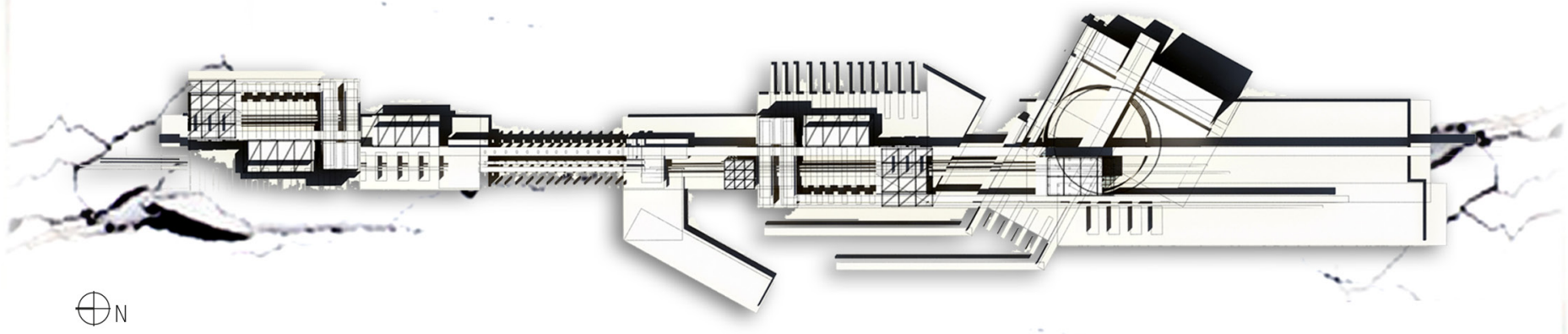

$\theta_{\mathrm{N}}$

Fig. 119. Storm surge and river mouth hardscape experiment plan.
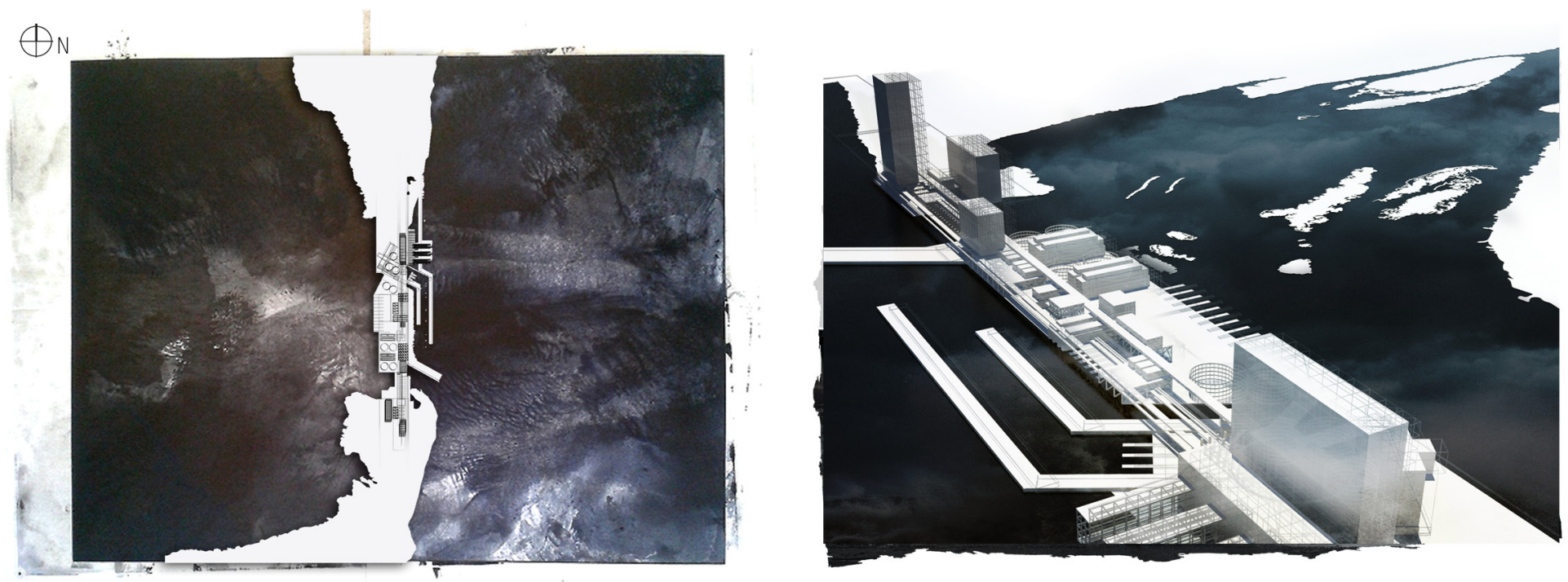

Fig. 120. River mouth hardscape experiment plan.

Fig. 121. River mouth hardscape experiment perspective. 
STORM SURGE + RIVER MOUTH HARDSCAPE

Figures 122-124 begin to separate masses allowing a larger river mouth opening parallel to the directional flow. Each design test begins to integrate a resilient housing structure as a means of protection from environmental disasters.
PERSONAL REFLECTION:

PROS:

- Allows the Adyar River to naturally cleanse itself

— Introducing a system of order and hierarchy

CONS:

- Though elevated, the designs have limited first line of defense from storm surges

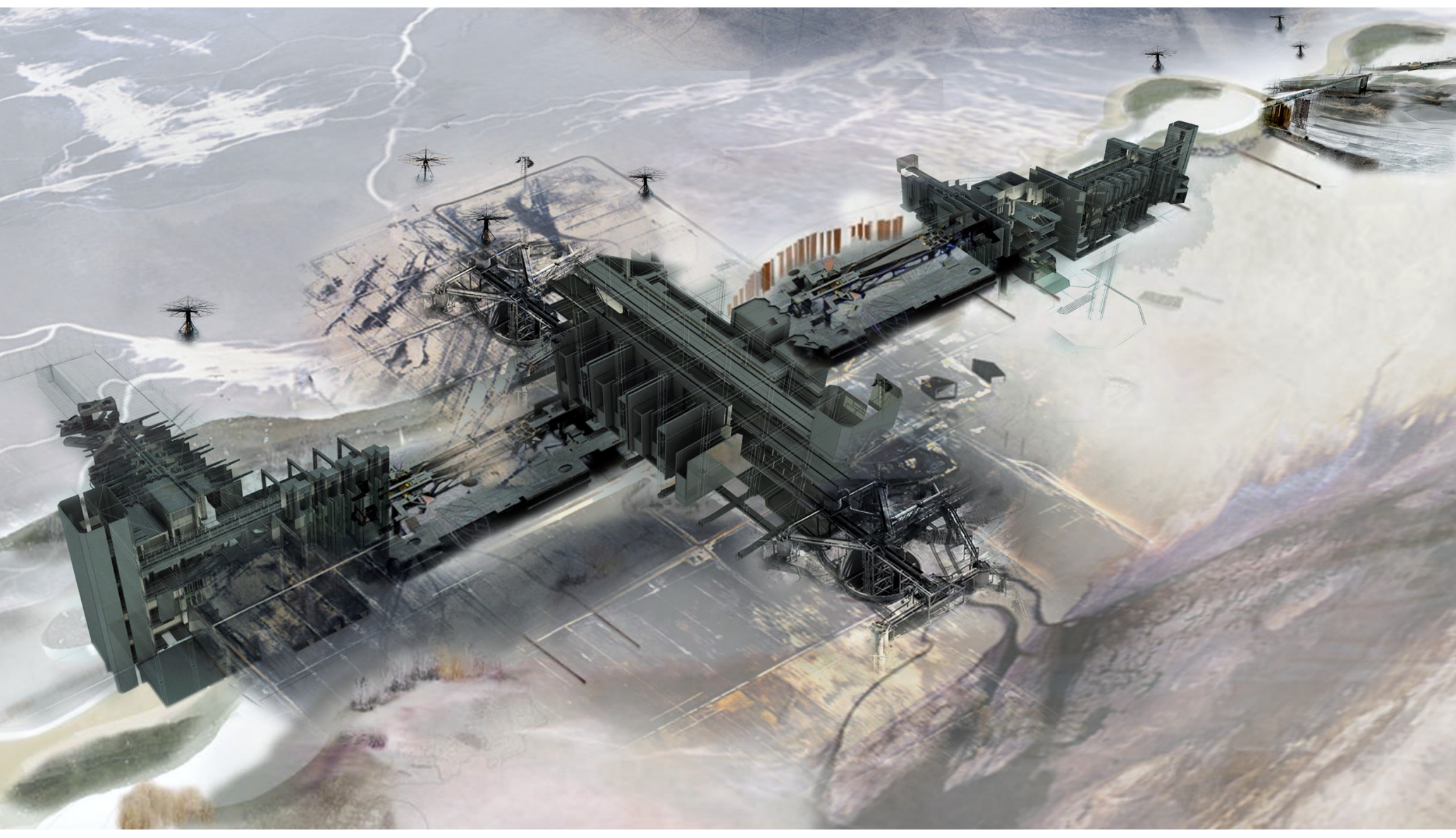

Fig. 122. Conceptual framework allowing the Adyar River mouth to remain open. 


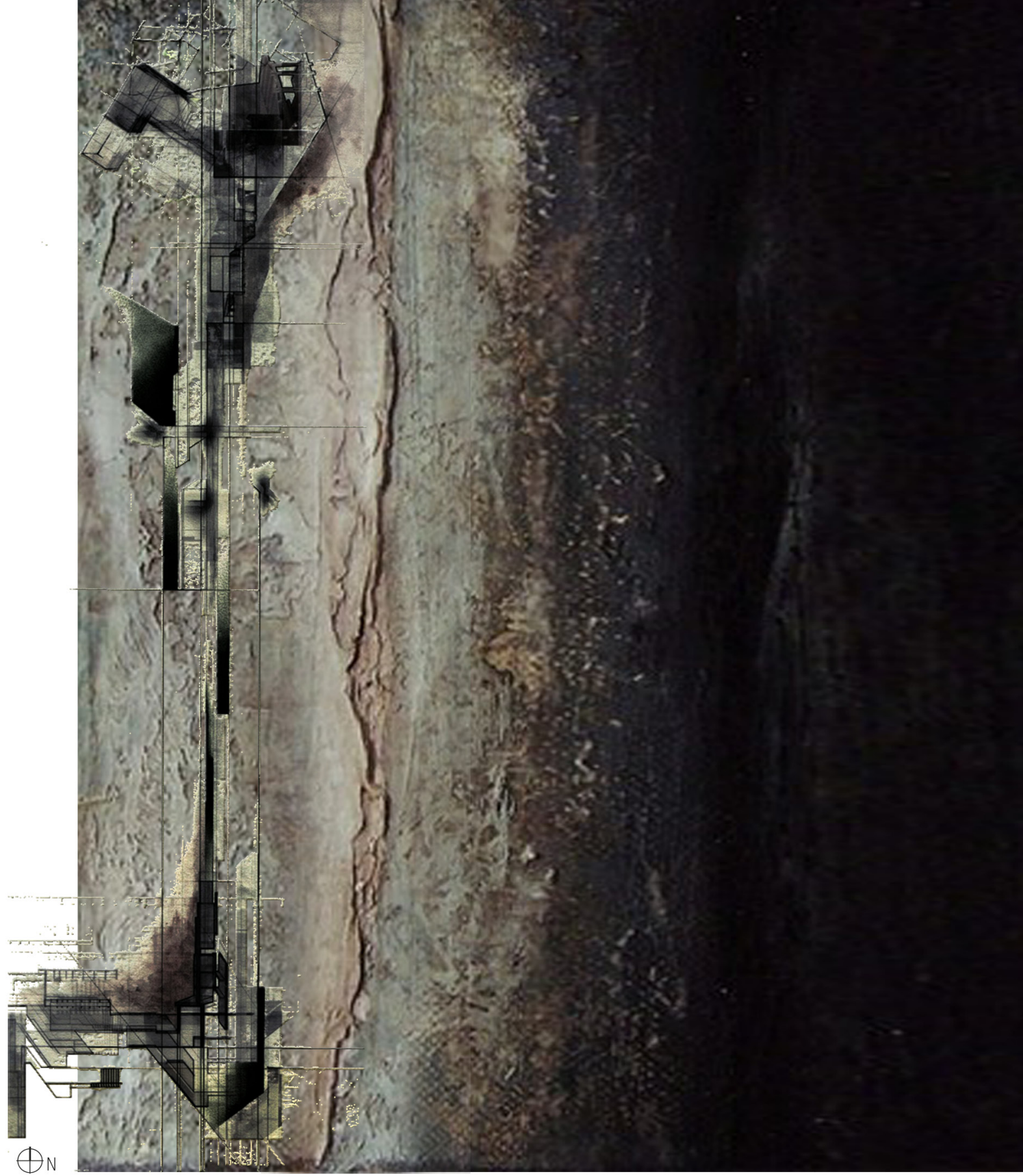

Fig. 123. Conceptual plan of framework.

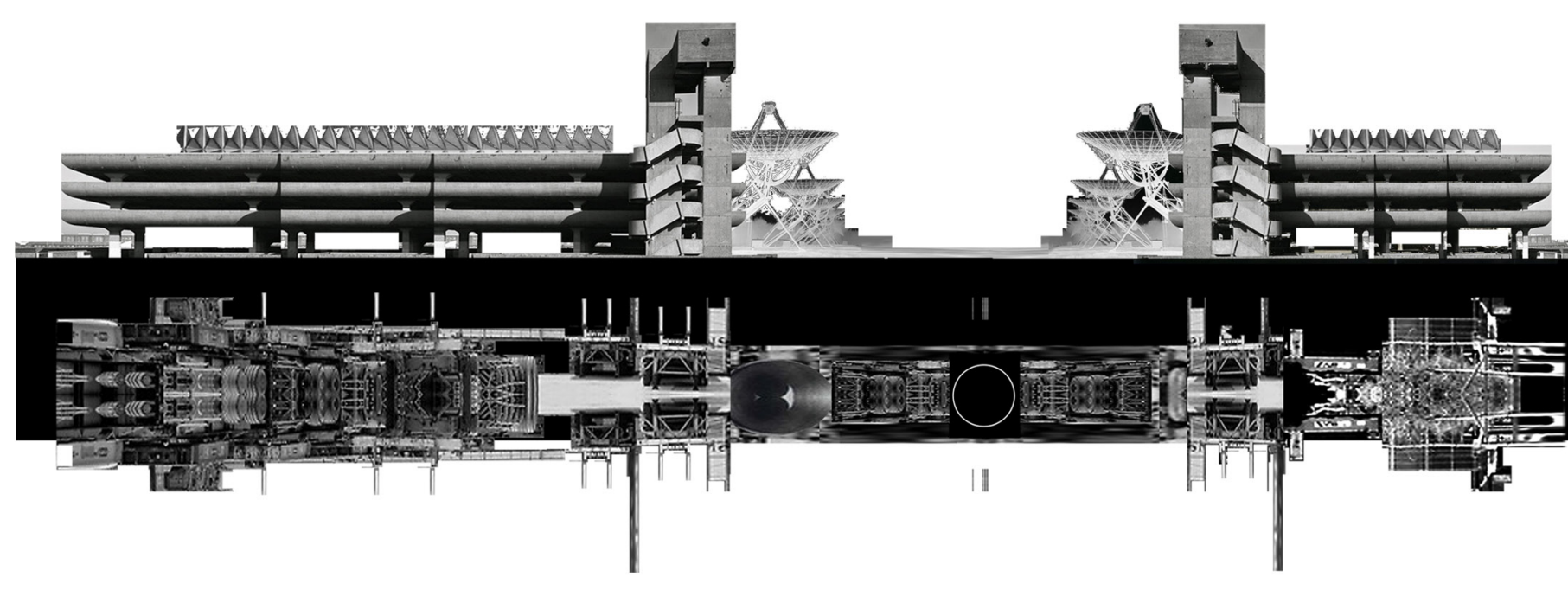

Fig. 124. Conceptual elevation (above), plan (below) illustrating a resilient structure providing shelter from environmental disasters. 


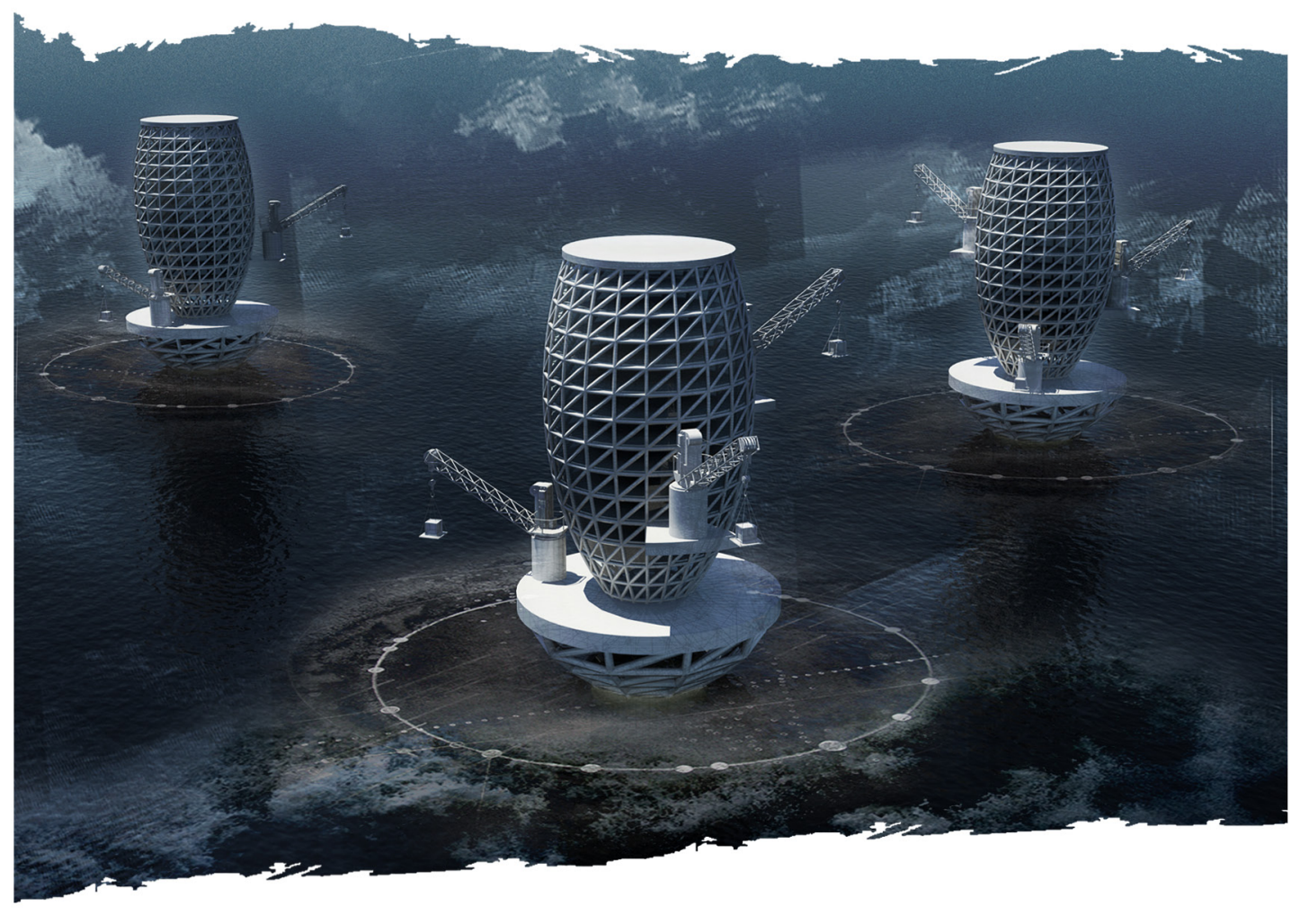

Fig. 125. Conceptual sketch responding to sea level rise off shore.

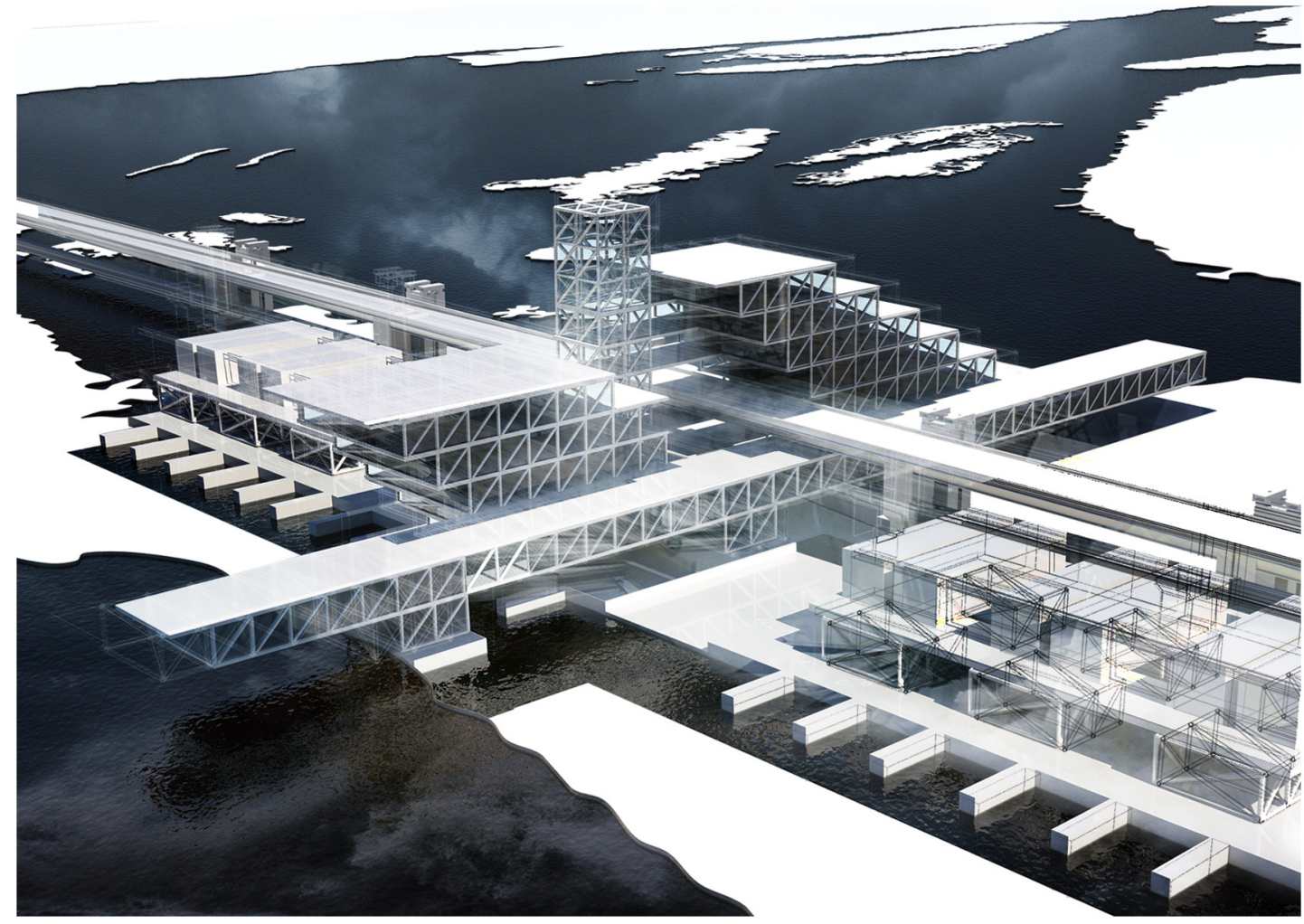

Fig. 126. Conceptual sketch responding to storm surge and sea level rise on shore.

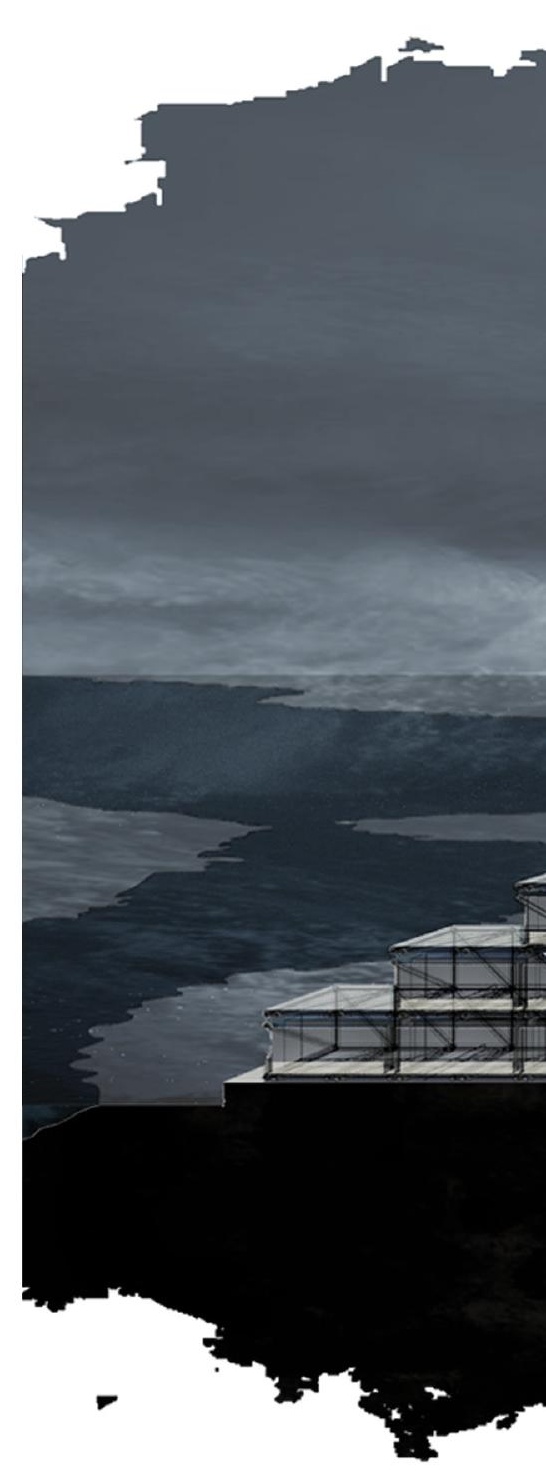




\section{STORM SURGE + SEA LEVEL RISE}

Figures 125-127 illustrate design responses to sea level rise and storm surges. The off shore towers (Figure 125) extend Srinivasa Puram as a hybrid of land and sea structures. Positioned at different intervals each tower creates a wave refraction node generating interference during storm surges and tsunamis. Figures 126-127 represents a terraced, elevated structure allowing wave energy to pass beneath it.
REFLECTION:

PROS:

- Ability to expand framework with population growth

- Terraced design creates the opportunity for passive water filtration via gravity-fed wetlands systems

CONS:

- Offshore tower would require advanced architectural technologies - unfeasible for slum dwelling

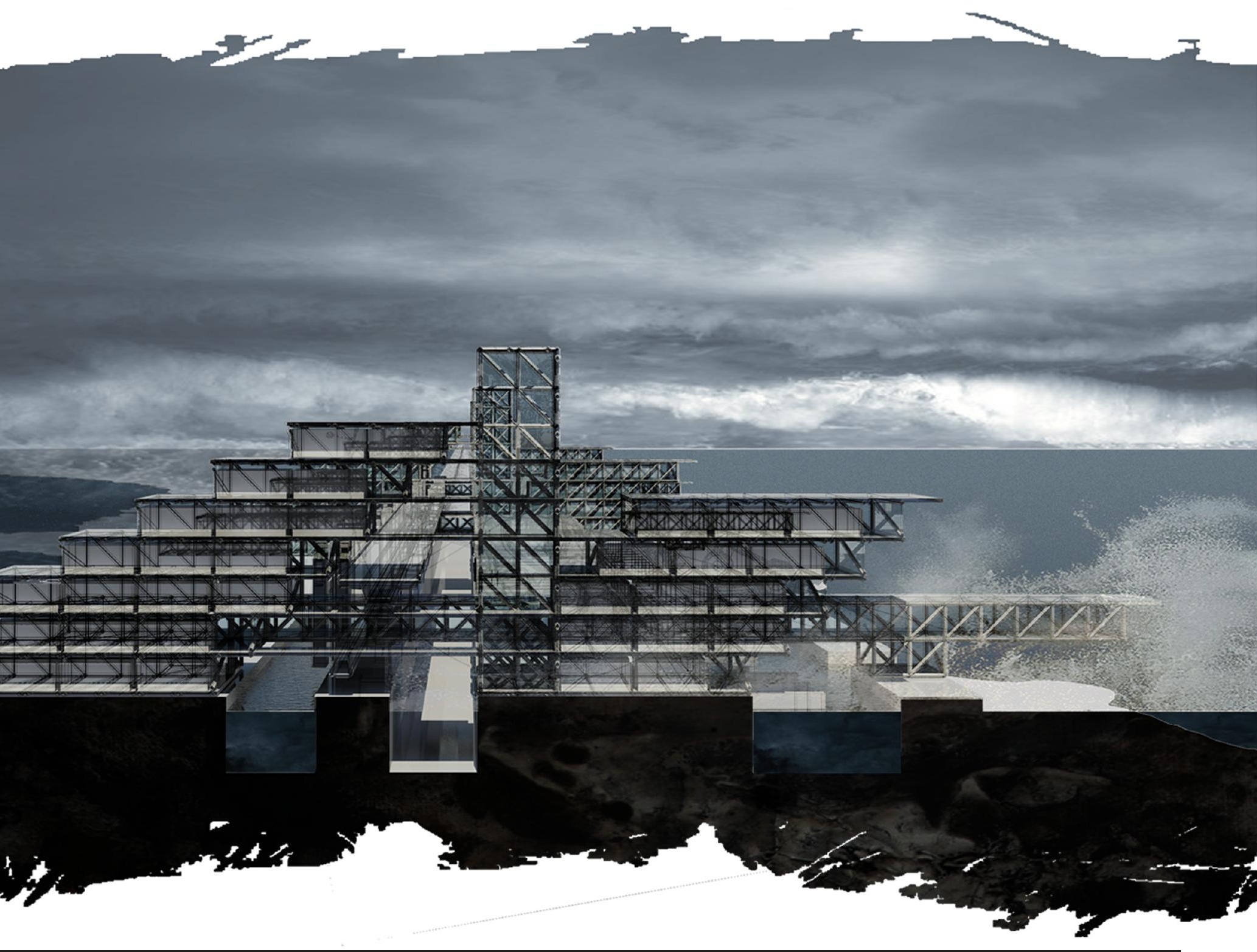

Fig. 127. Conceptual section responding to storm surge and sea level rise on shore. 
Fig. 128. Conceptual sketch of a seawater desalination plant. 


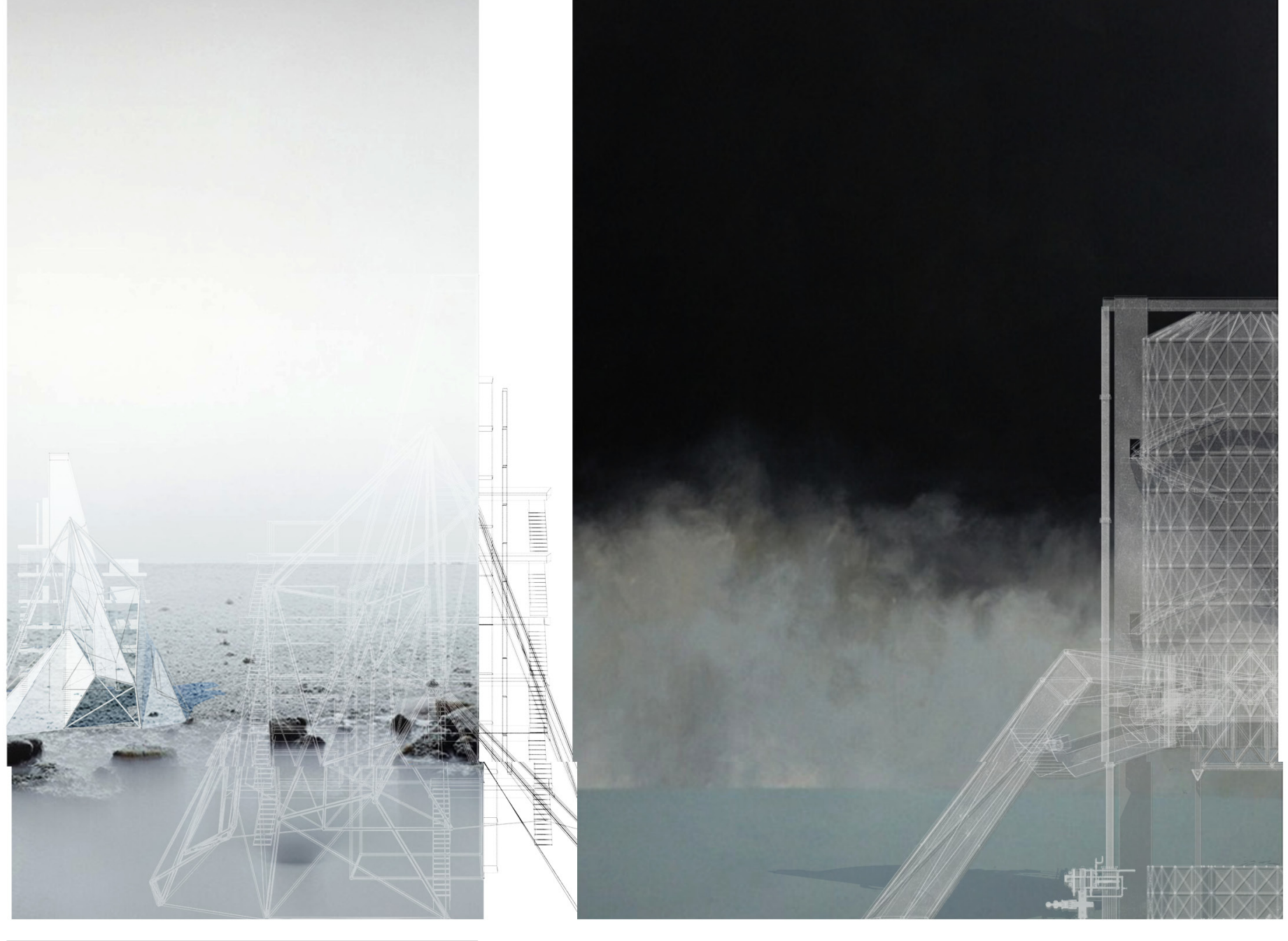

Fig. 129. Seawater desalination plant.

Fig. 130. Conceptual sketch of fresh water storage tank.

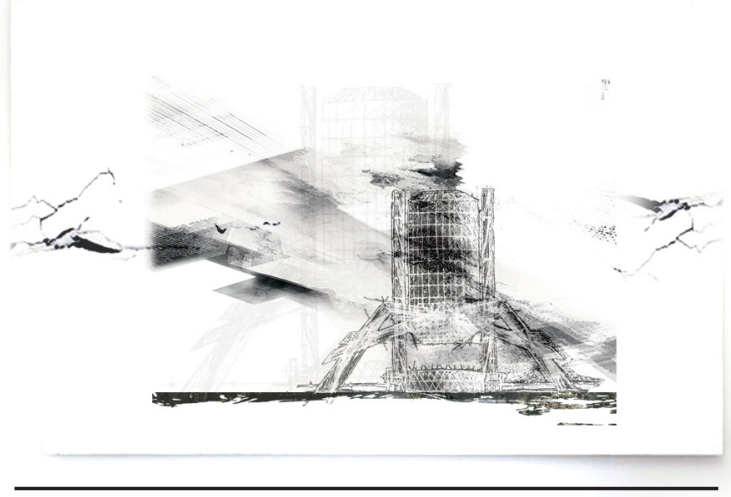

Fig. 131. Sketch of fresh water storage tank.

\section{STORM SURGE + SEA LEVEL RISE}

Figures 128-129 proposes an offshore seawater desalination concept allowing for the consumption of less toxic seawater to be treated. Figures 130-131 illustrate an elevated water storage tanks with the capacity to store approximately $11,000 m^{2}$ (1/3 total required capacity). 


\section{PERSONAL REFLECTION}

The images shown in Figures 132-133 illustrate a conceptual framework responding to initial design tests to address site conditions such storm surges, sea levels rise and flooding. While the elevated structure for both habitation and machine may mitigate the direct impact to the framework during the event of a natural disaster, the concept of wave energy passing beneath with no defense structure in place to dissipate and slow the forces of storm surges, tsunamis or flooding could have major implications for inland areas.

Future framework designs will test a significantly more grounded structure that has the ability to protect and mitigate the effects caused by natural disasters by means of large scale breakwater systems similar to the Royapuram fishing harbor case study north of Chennai's port. 


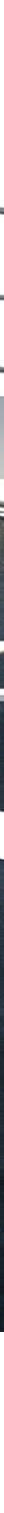

Fig. 133. Conceptual framework responding to initial sketch experiments. 


\subsection{PHYSICAL MODELING EXPERIMENTS}
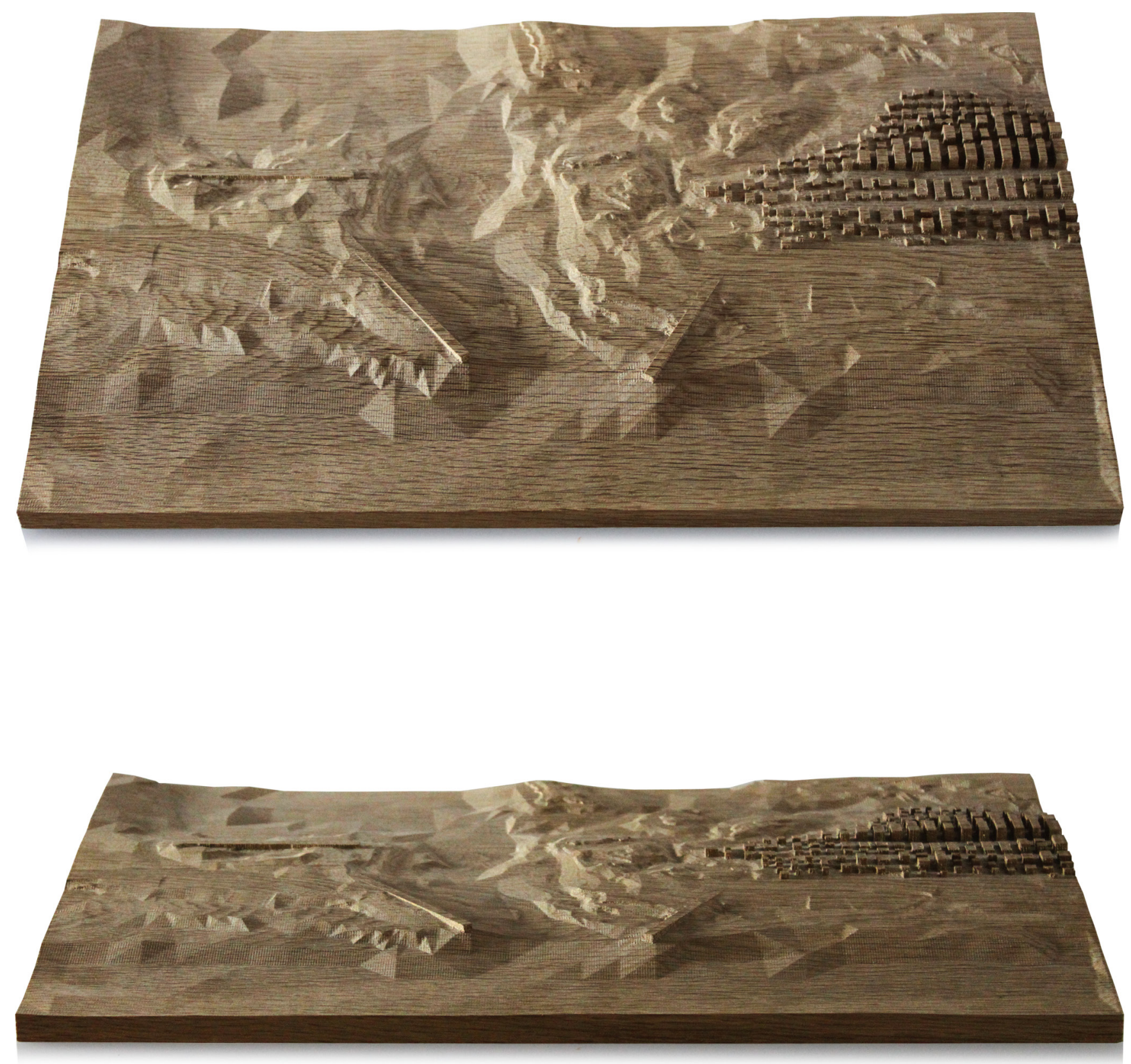
The physical modeling experiments (Figures 134136) test a series of mechanical forms used to generate an initial 'machine' structure, framework placement, orientation and the relationship between site topography and bathymetry. The results will then be tested throughout the following conceptual schemes. 


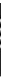

\section{Graphite Modeling Tools}

Freeform

Selection

\section{V}

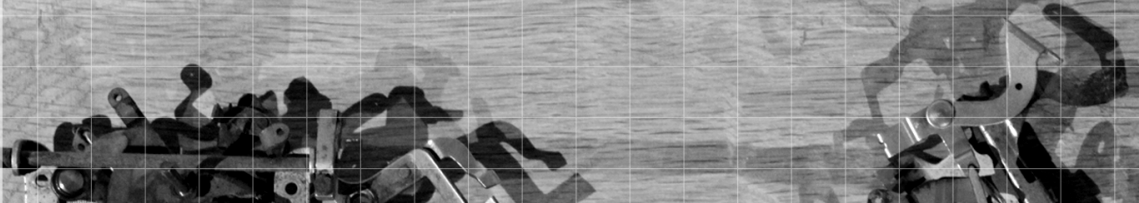

o.

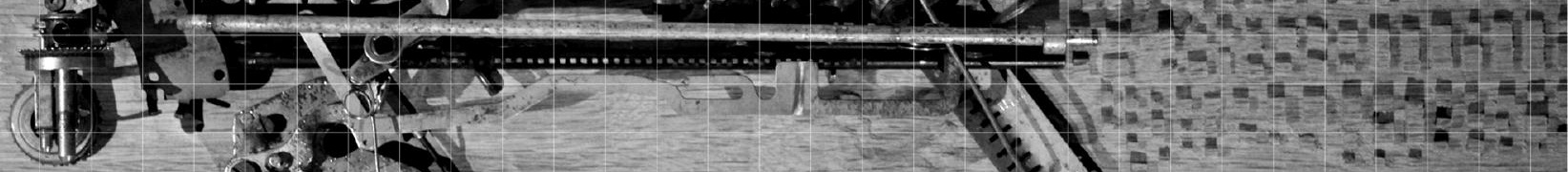
Q. (2)

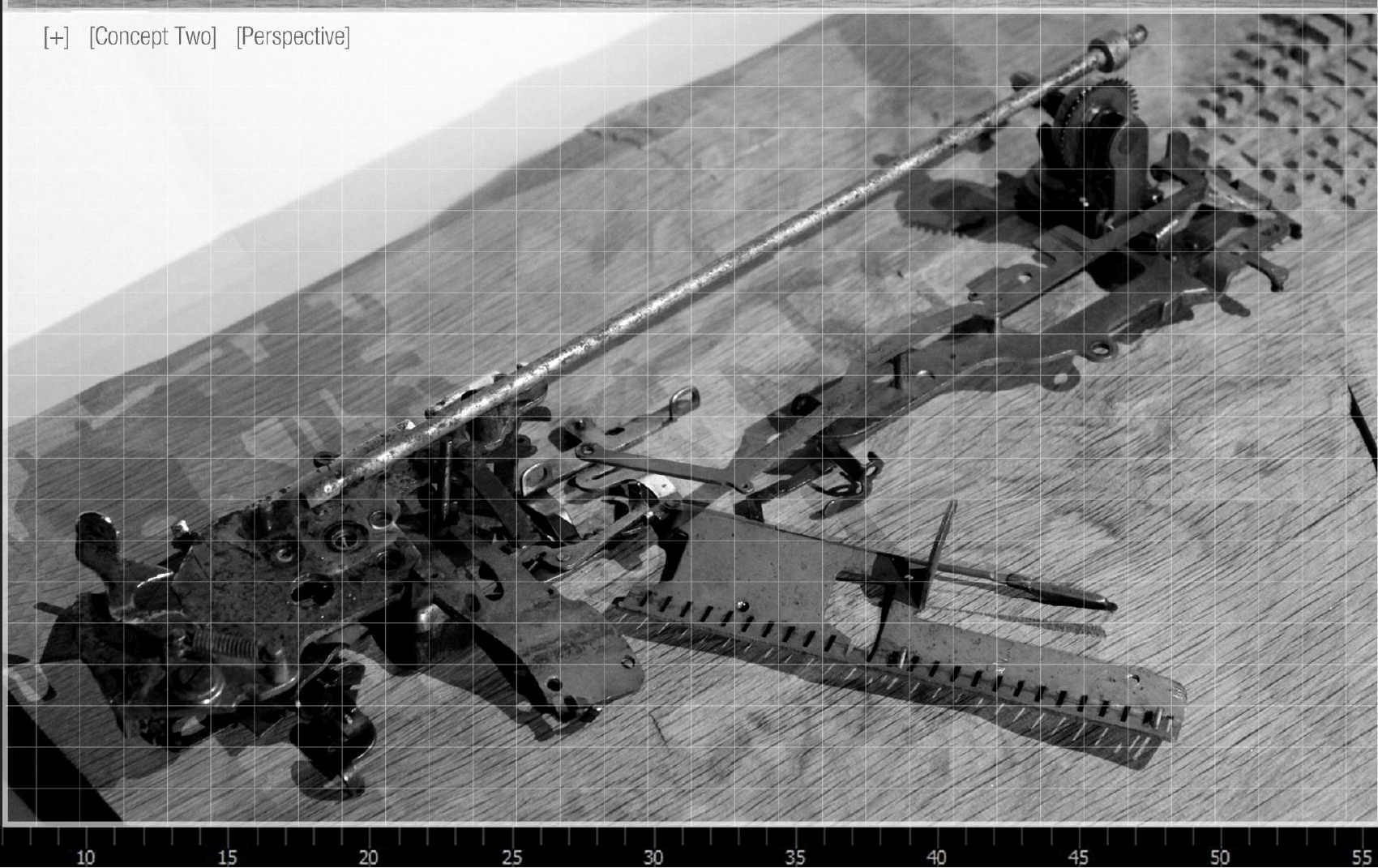


Q G G

Graphite Modeling Tools Freeform Selection

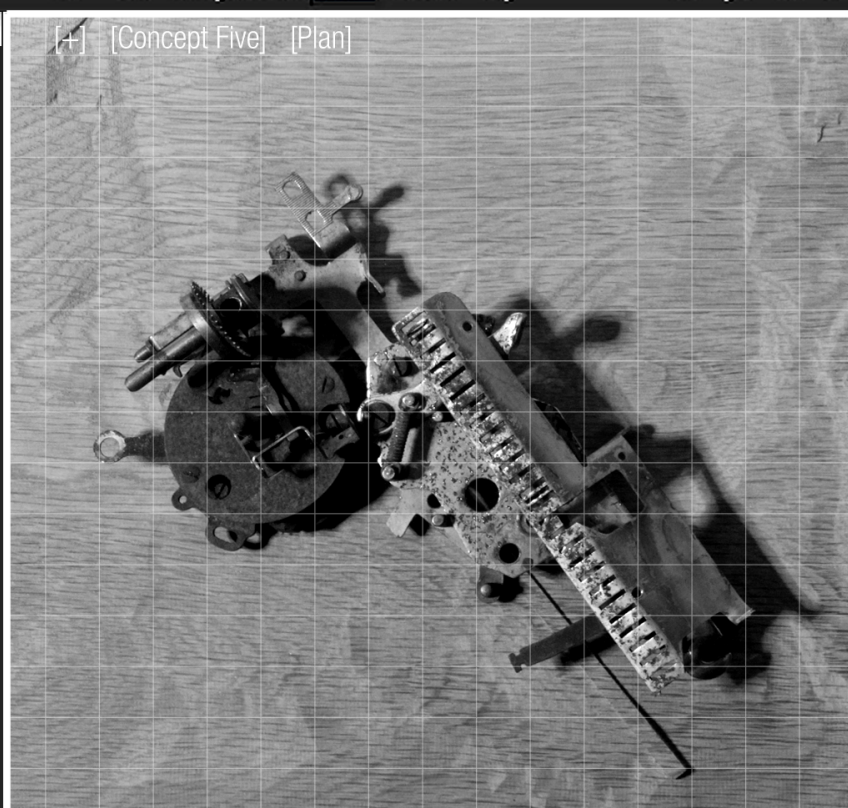

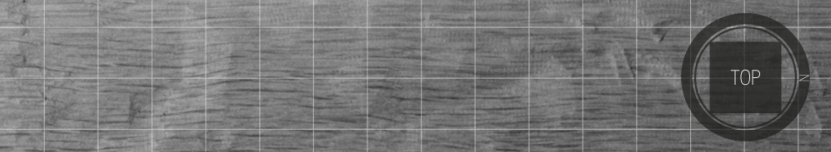

- $x^{2} n=2$

Jing yyen

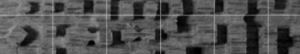

11:

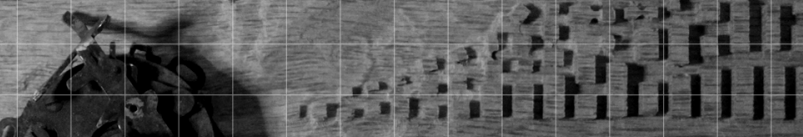

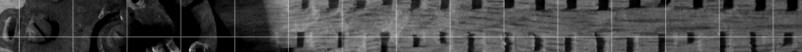

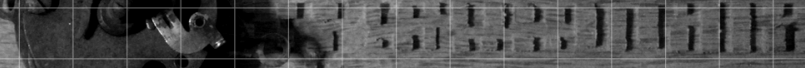

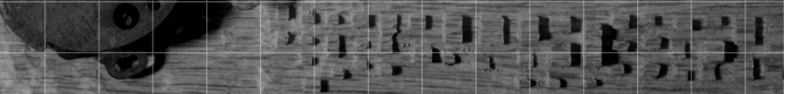

\section{\%}

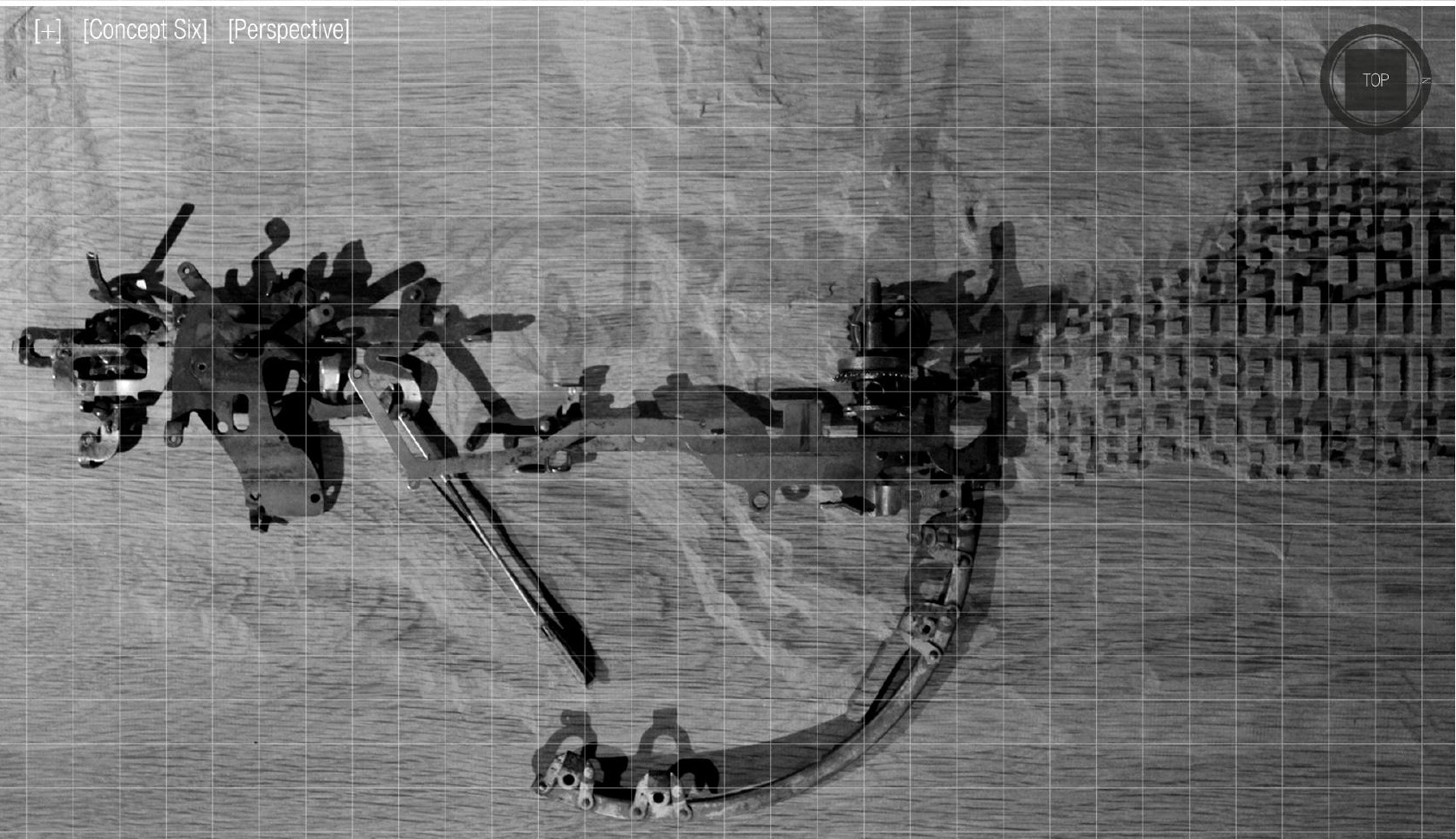




\begin{tabular}{|c|c|}
\hline \multicolumn{1}{|c|}{ Object Type } \\
\hline$\square$ Autorid \\
\hline Box & Cone \\
\hline Sphere & Geosphere \\
\hline Cylinder & Tube \\
\hline Torus & Pyramid \\
\hline Teapot & Plane \\
\hline
\end{tabular}


DEVELOPMENT STAGES

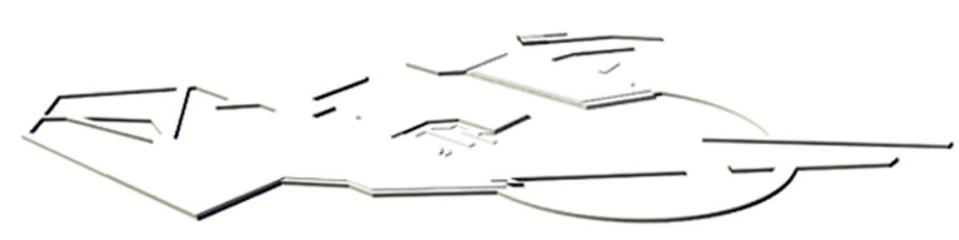

01. Initial Framework

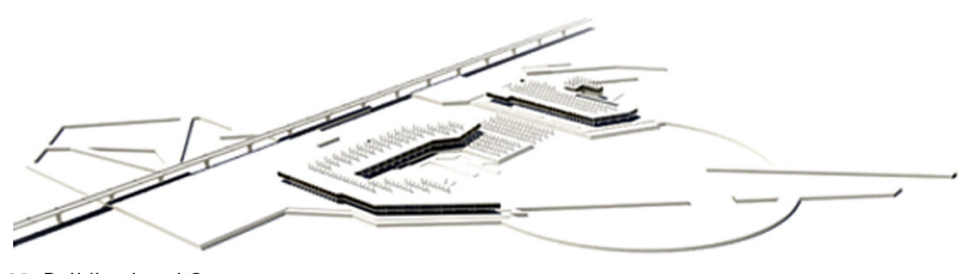

03. Building Level One

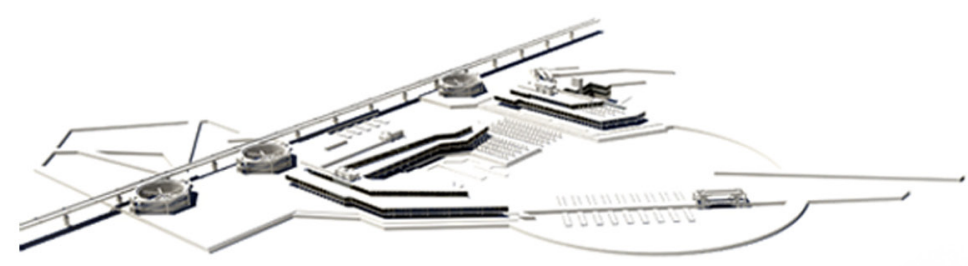

05. Water Storage Tanks

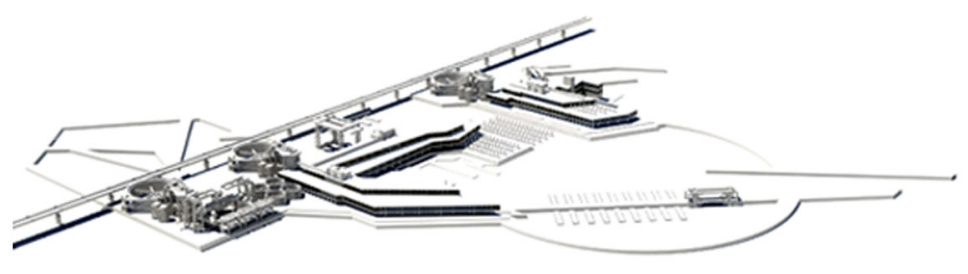

07. Sewage Treatment System

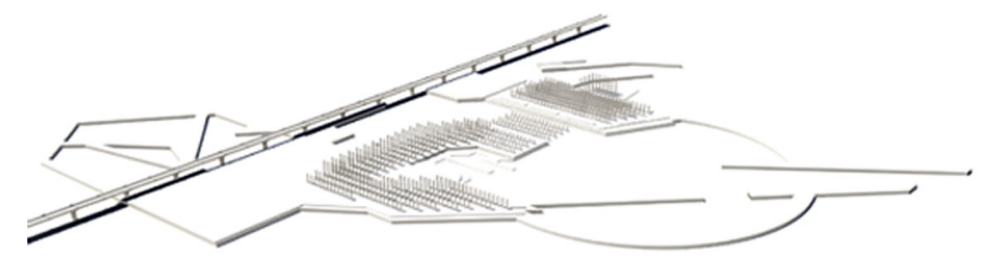

02. Column Structure + Elevated Bridge System

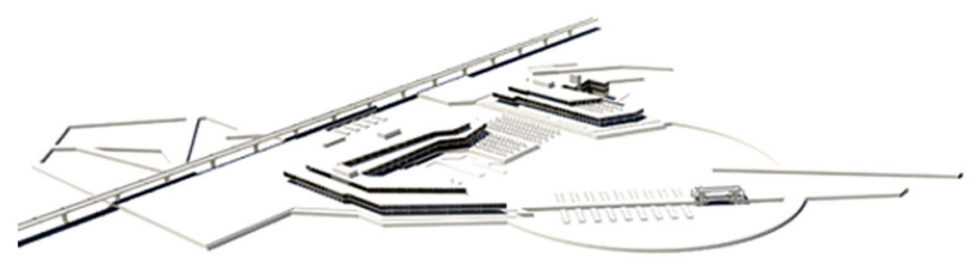

04. Building Level Two + Mooring Structures

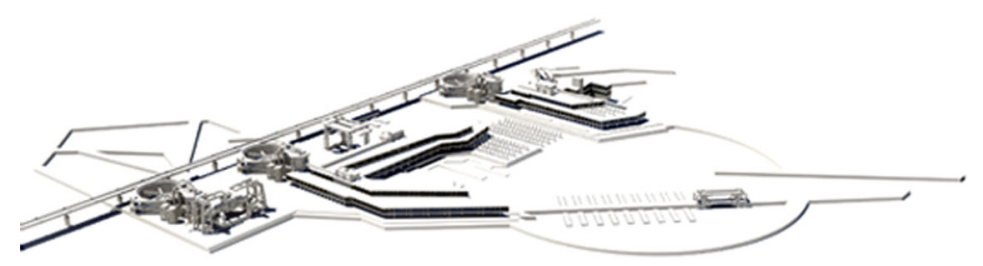

06. Garbage Treatment System

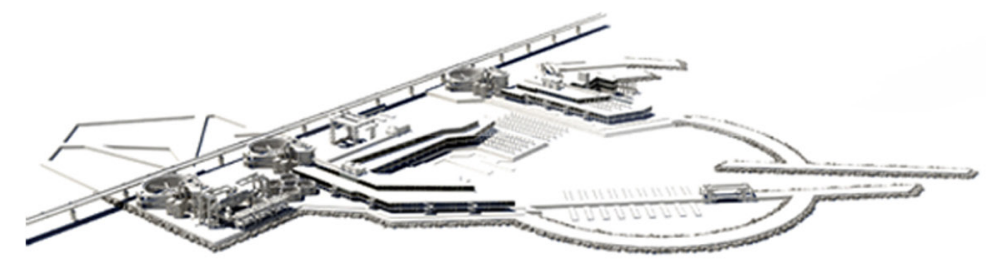

08. Breakwater System

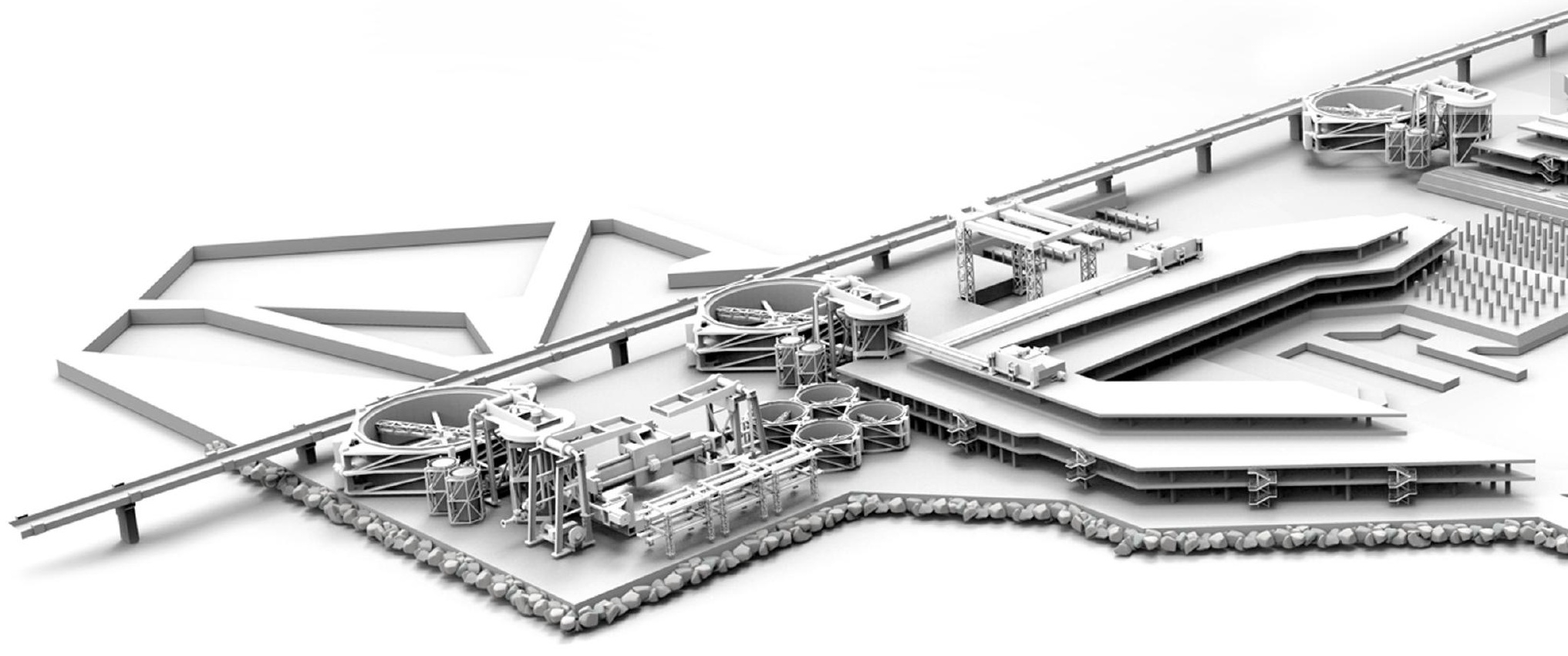




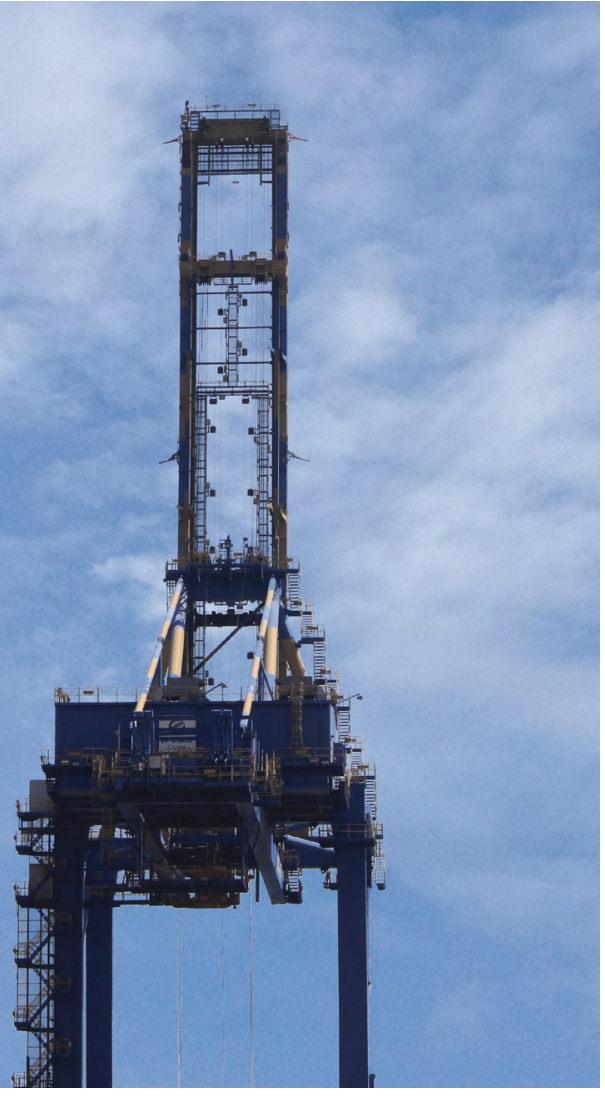

Fig. 138. Chennai port shipping derrick.

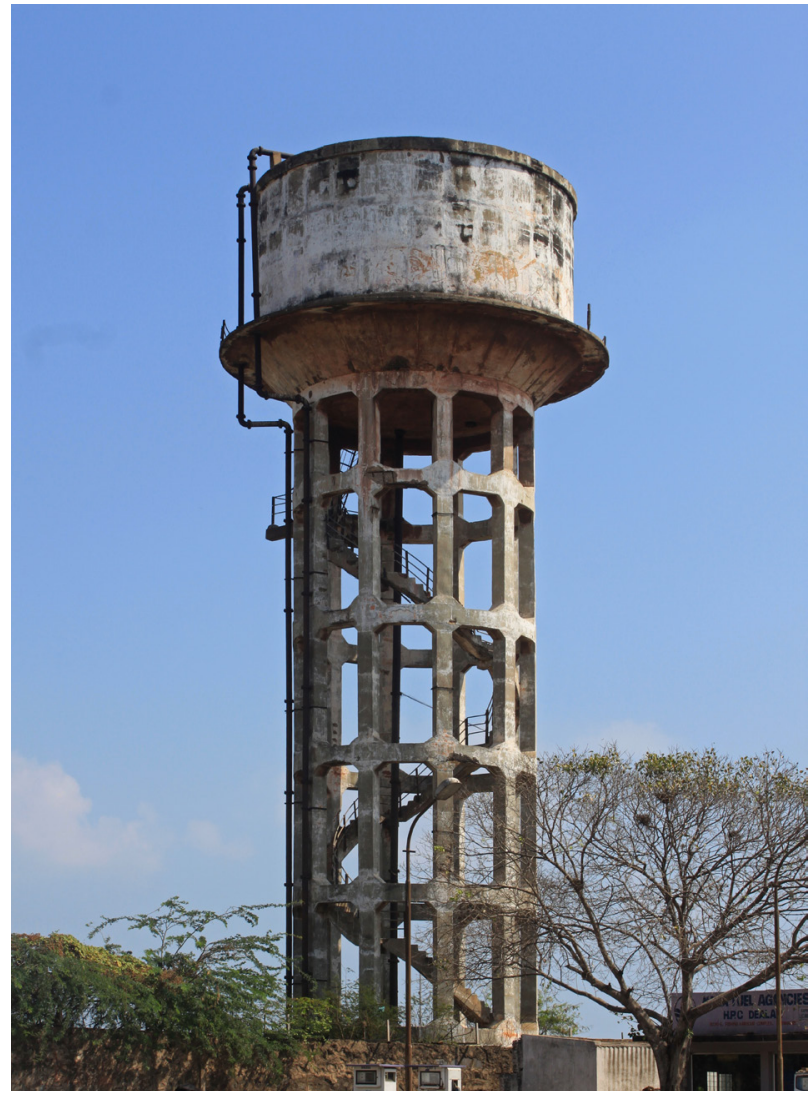

Fig. 139. Raised water tank, Royapuram fishing harbor.
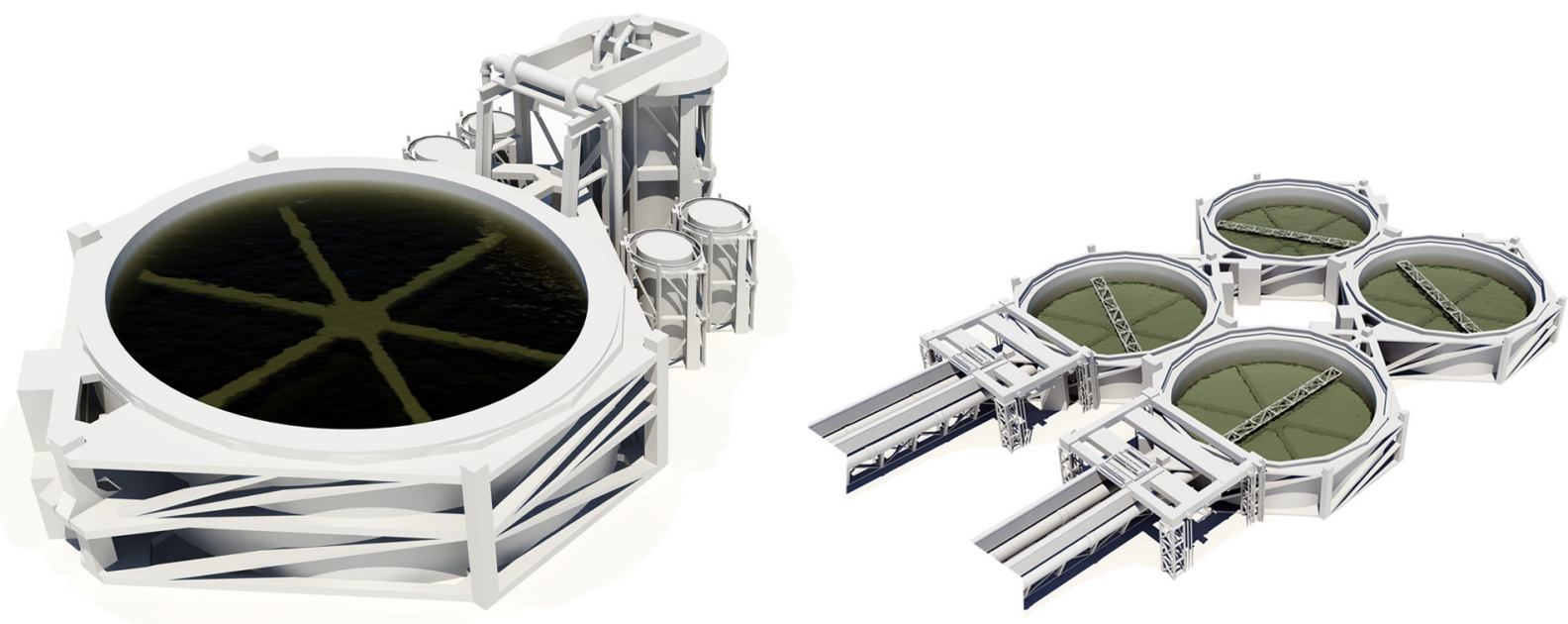

Fig. 140. Conceptual sketches of water storage and sewage treatment plant. 


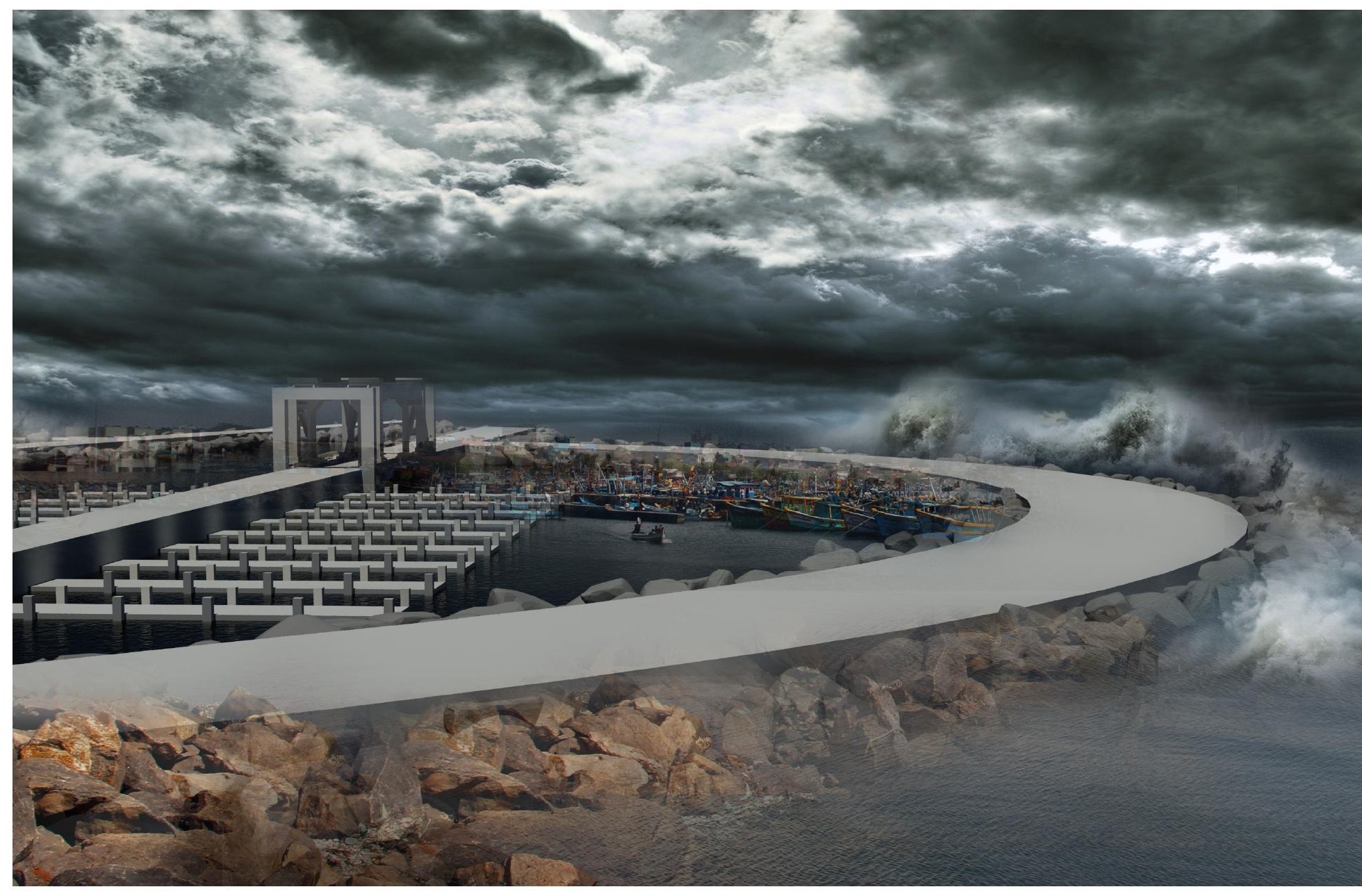

Fig. 141. Conceptual sketch of scheme one breakwater system.

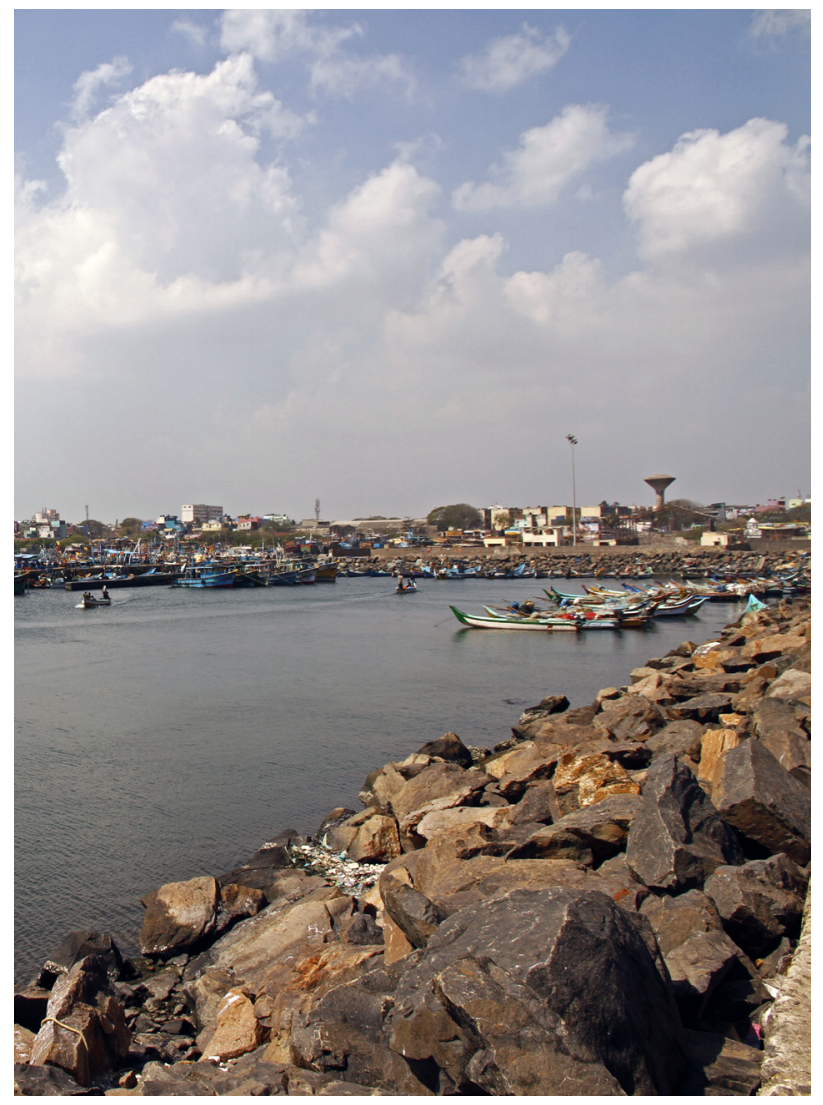

Figures 140-141 illustrate conceptual sketches responding to typical regional design precedents along Chennai's coastline. The Chennai port structures (Figure 138) as well as the Royapuram fishing harbor water tank and breakwater system (Figures 139 \& 142) have been used to influence design tests. The response is a hybrid of each system generating a machine aesthetic with the intention of strengthening infrastructure to mitigate the forces of natural disasters.

Fig. 142. Royapuram fishing harbor breakwater system. 


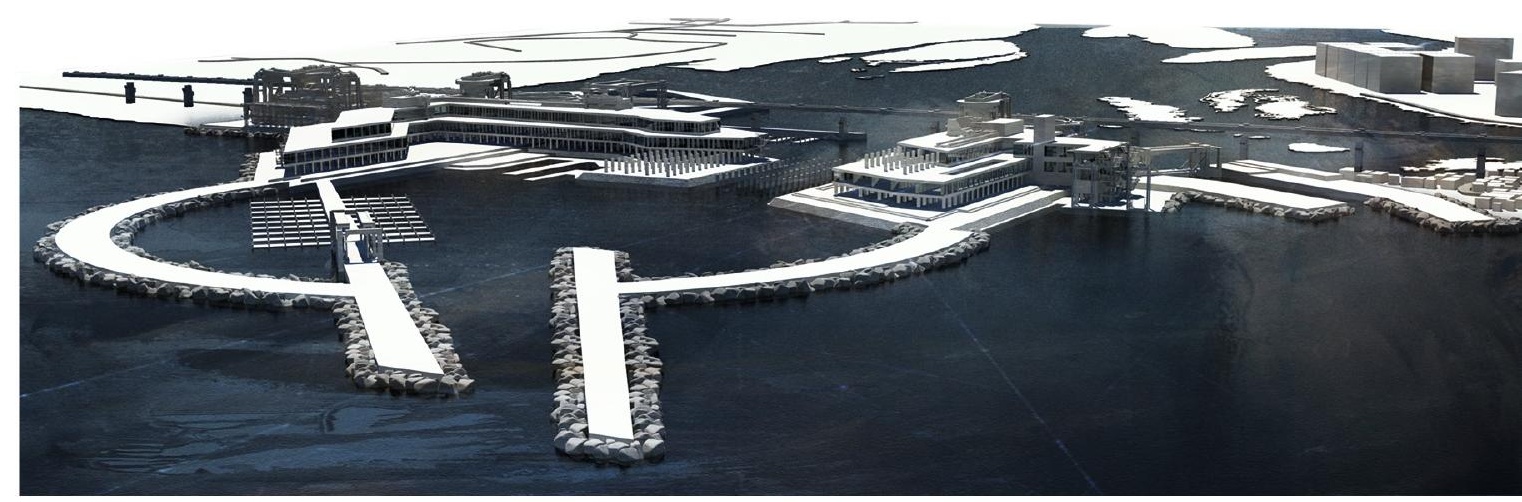

01. Perspective Sketch illustrating Rrver mouth integration

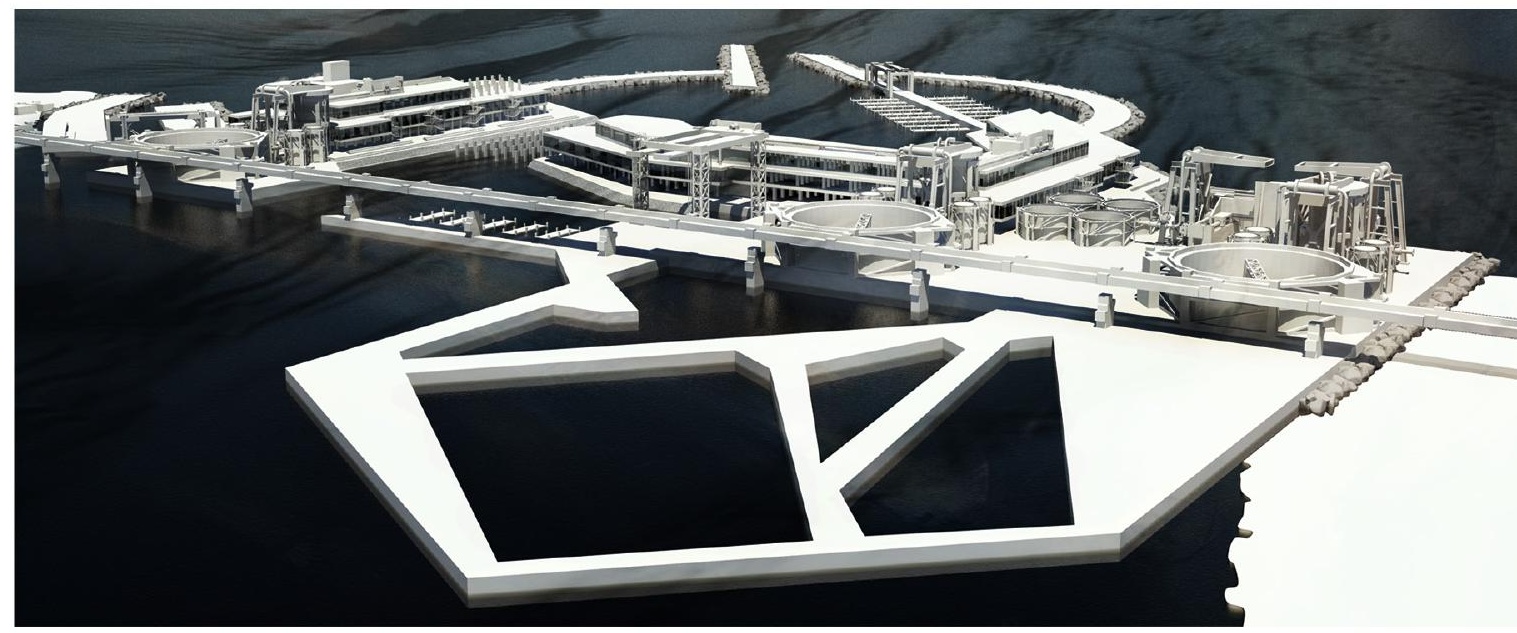

02. Sketch experiment for wetland tanks filtering wastewater and returning treated water into the Adyar Estuary

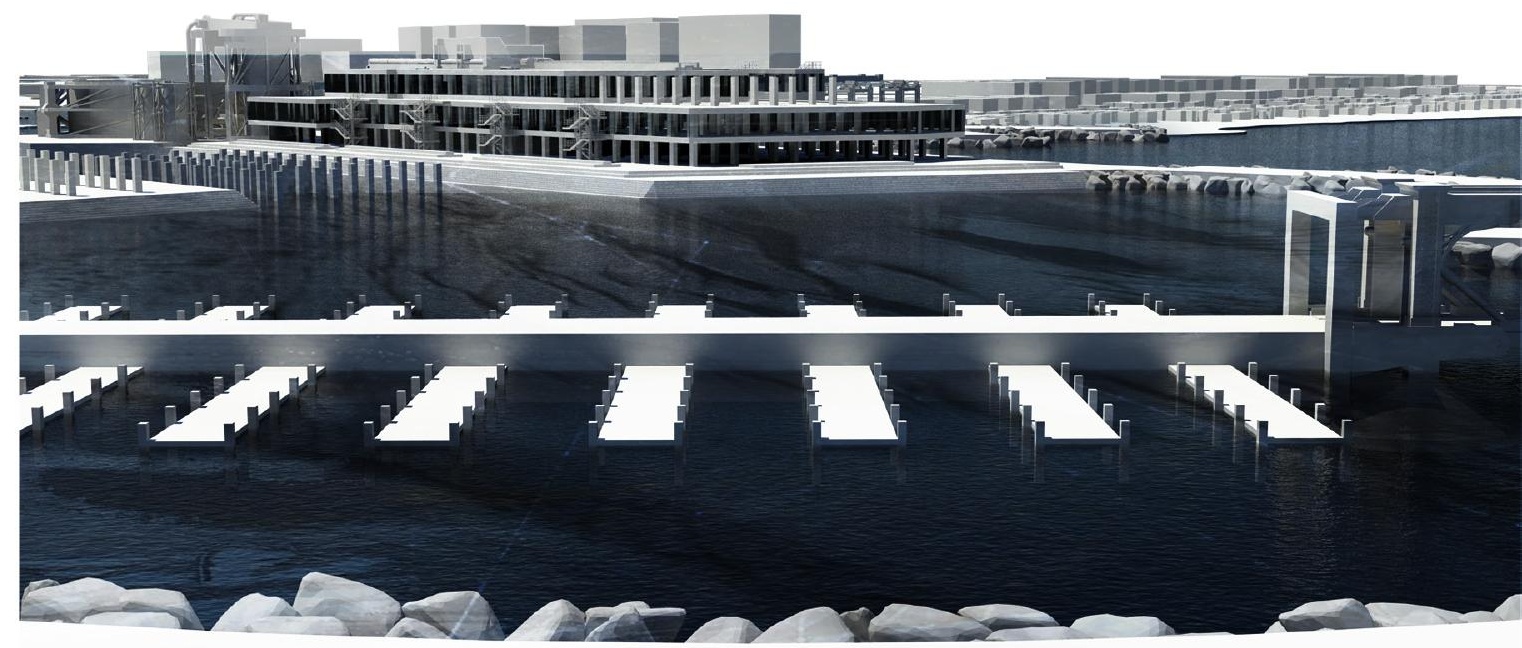

03. Mooring structures protected inside the breakwater system 

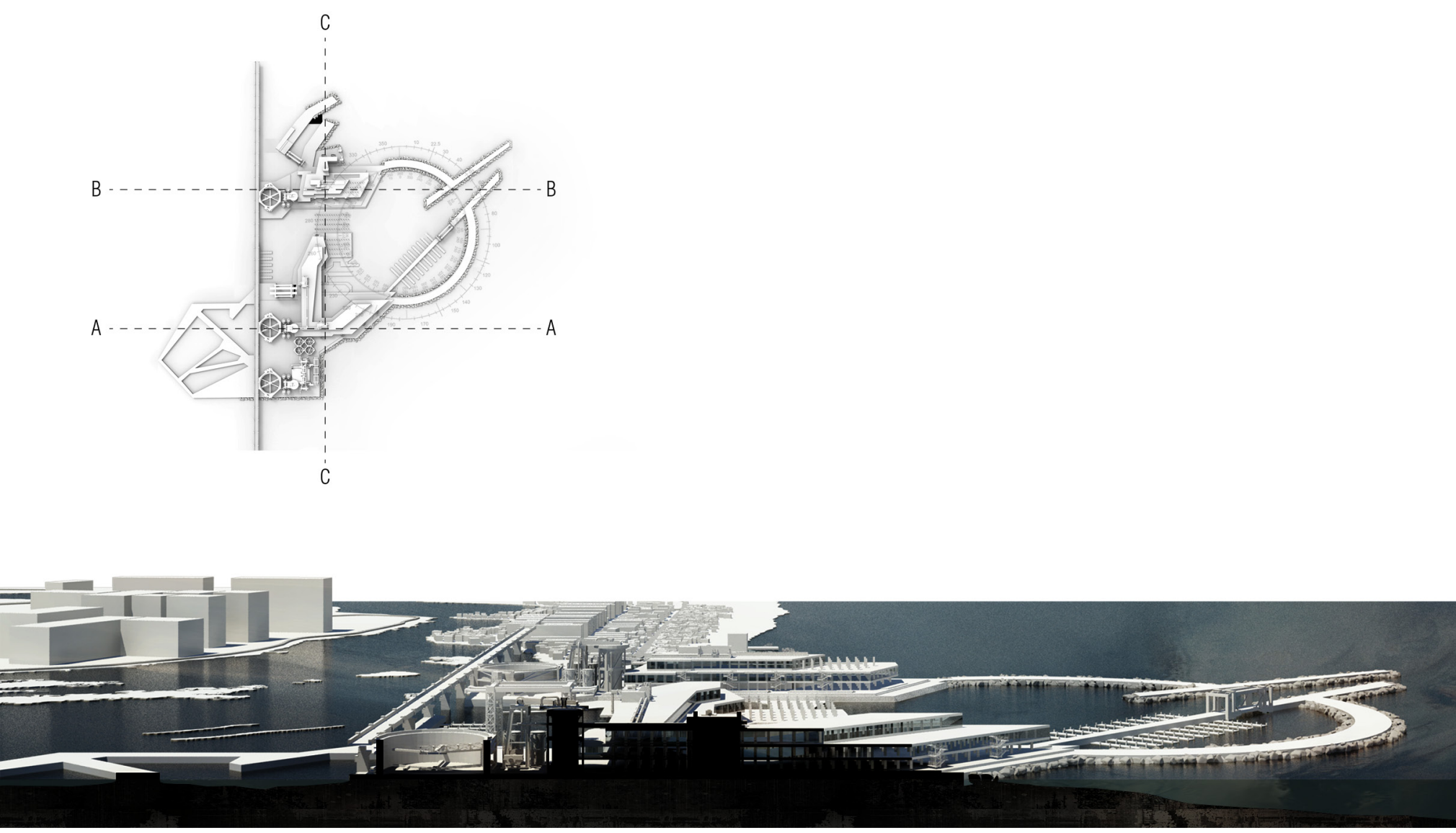

Section AA
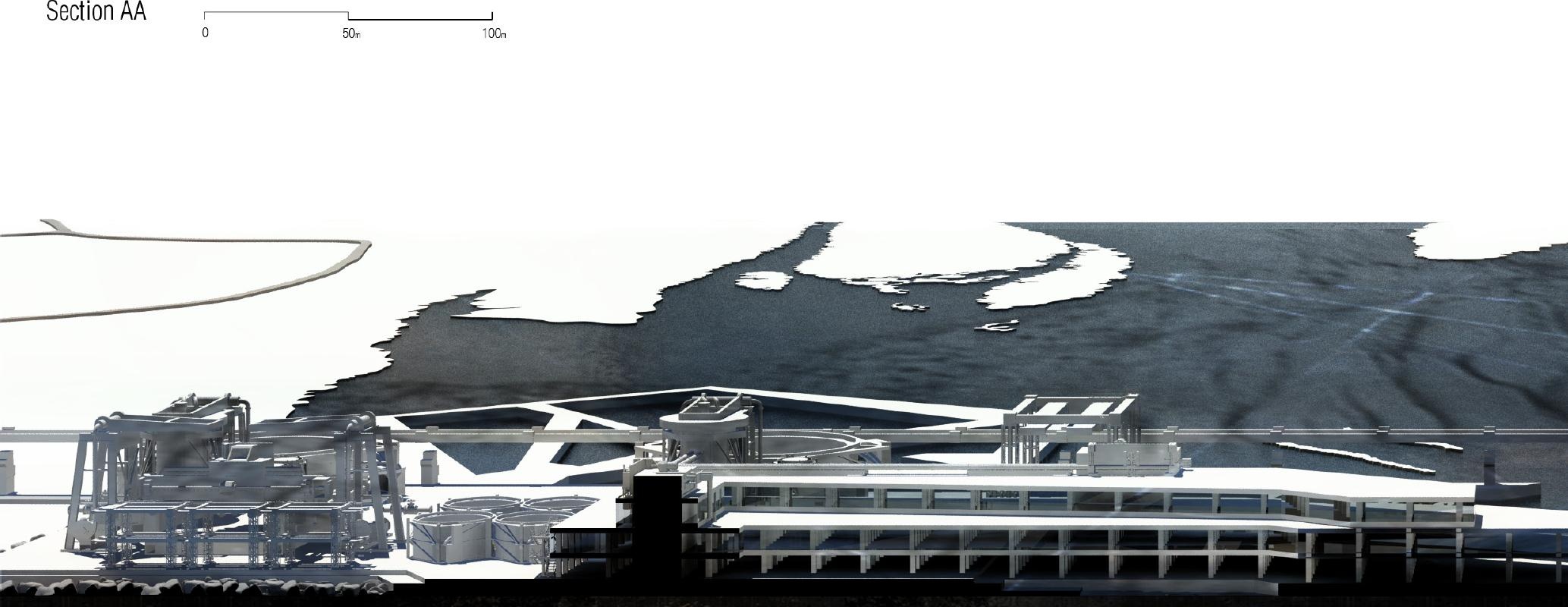

Section CC

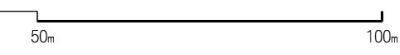




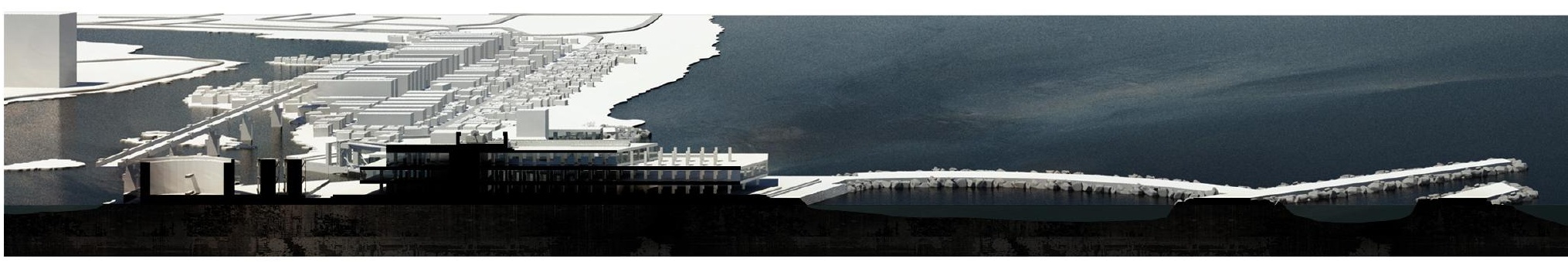

Section BB
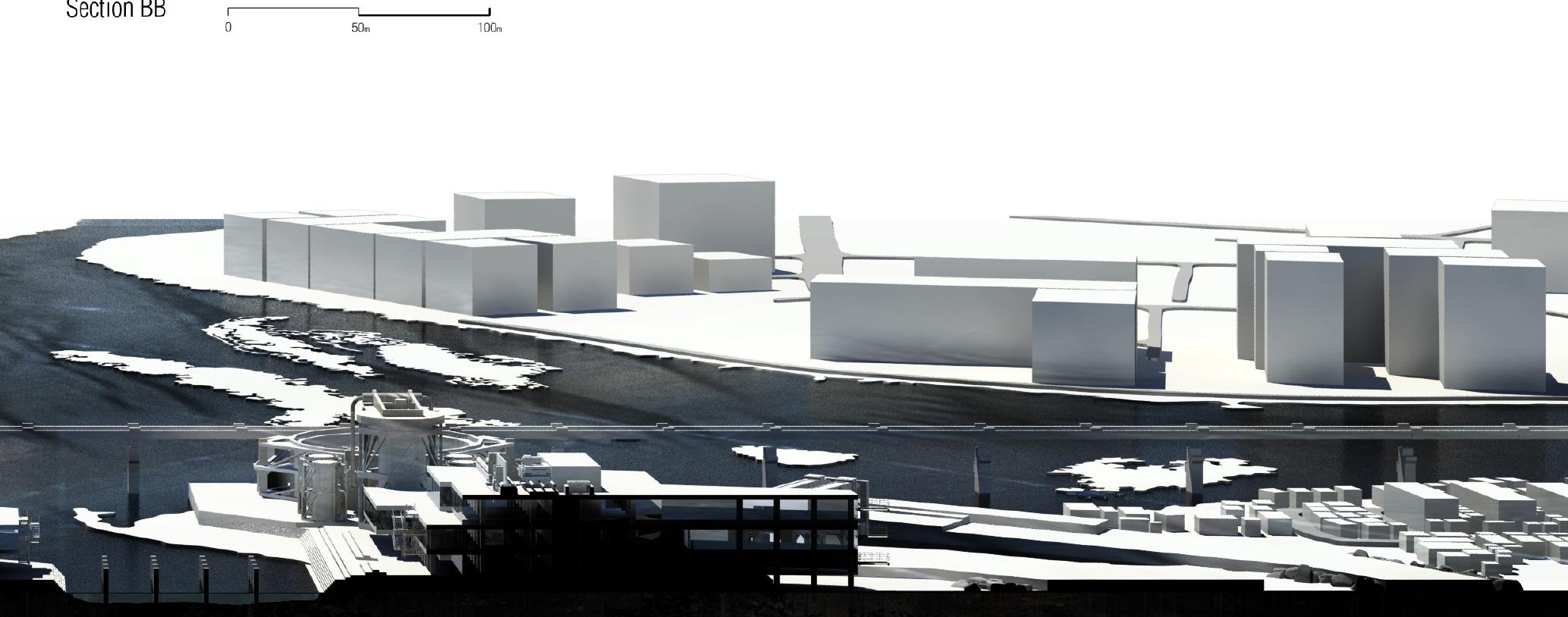

Fig. 145. Conceptual scheme one - Sections. 


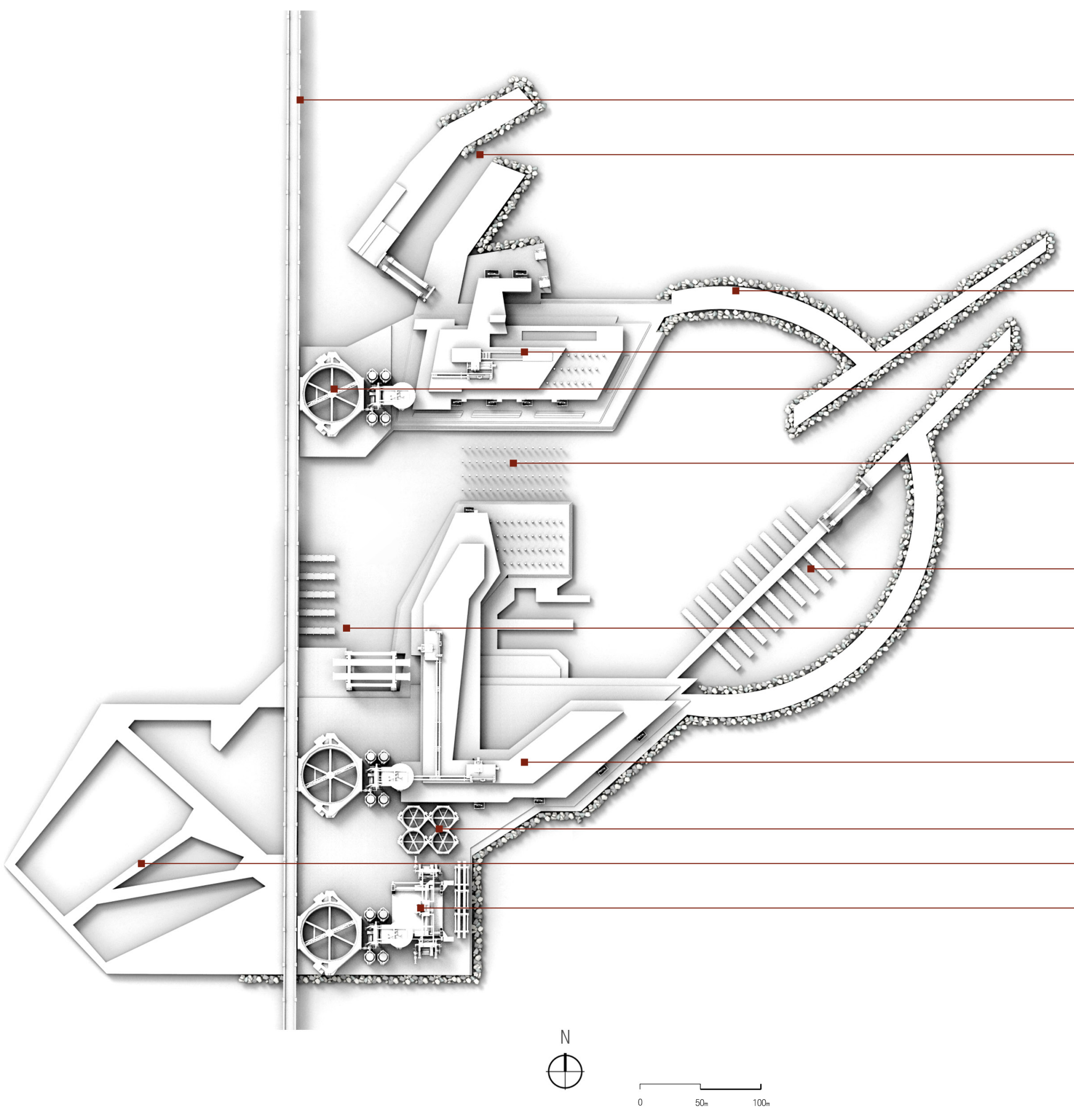


Elevated Bridge

Flood By-Pass Channel

Radial Breakwater System

Housing Framework

Water Storage

Rivermouth

Fishing Vessel Mooring

Fishing Vessel Mooring

Housing Framework

Sewage Treatment Plant

Terraced Wetlands

Garbage Treatment Plant 
PROS:

- Linear 'machine' infrastructure allows the framework to expand, evolve and grow with population growth while also supplying residents remaining in Srinivasa Puram with basic amenities

CONS:

- Design appears dystopian-like conditions in focusing on the mitigation of frequent major natural disasters

- Little dialogue between site dynamics and framework such as surrounding grids, axes and building placement with relation to topographical conditions

- Absence of a contemporary translation of traditional Indian architecture vocabulary and materials such as traditional terracing and stone aesthetic 


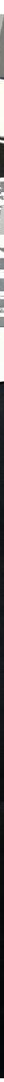

Fig. 147. Conceptual scheme one - Perspective. 


\subsection{CONCEPTUAL SCHEME TWO}

\section{HOUSING STRUCTURE DEVELOPMENT STAGES}
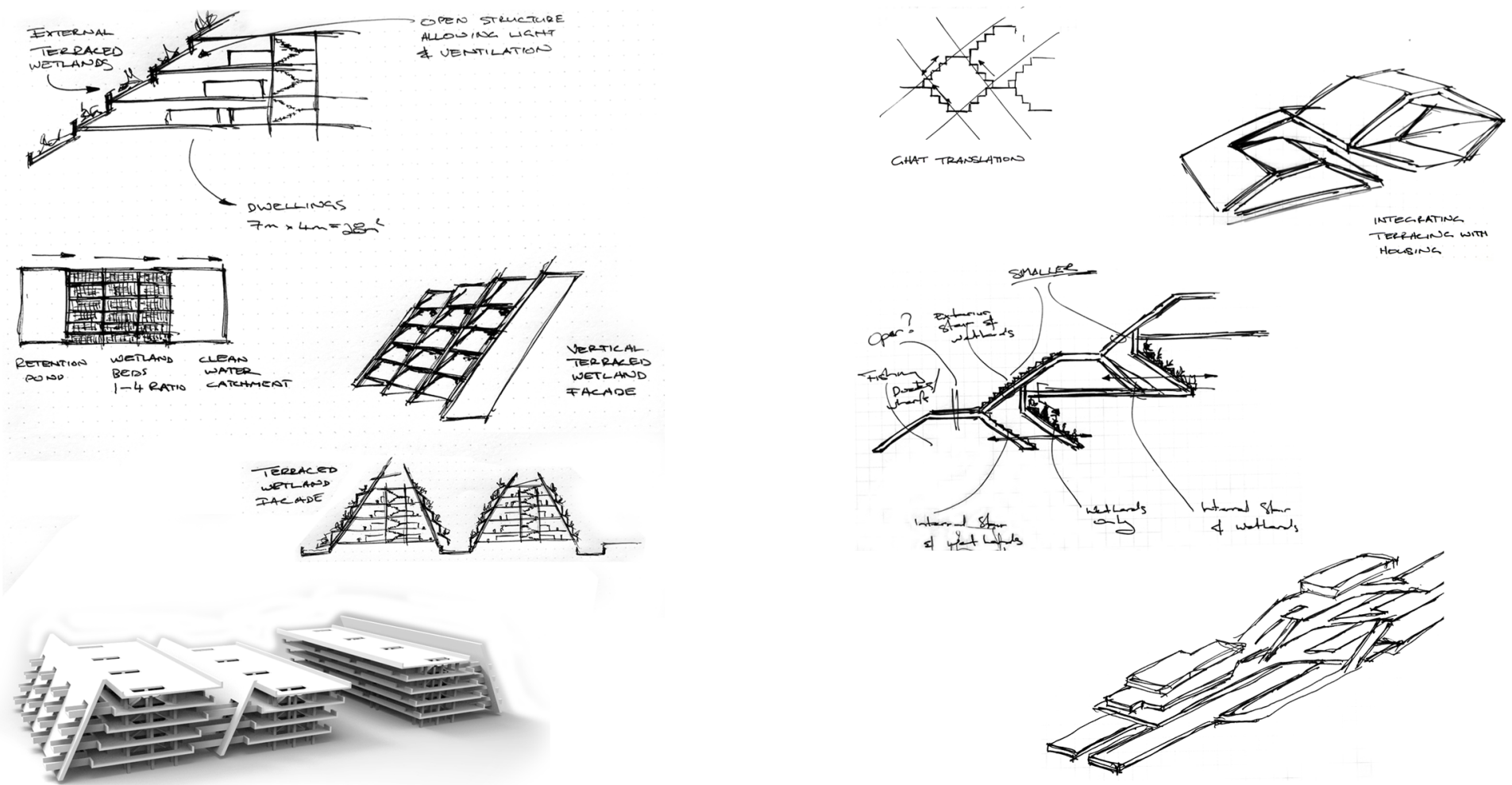

Terraced Facade Experiment

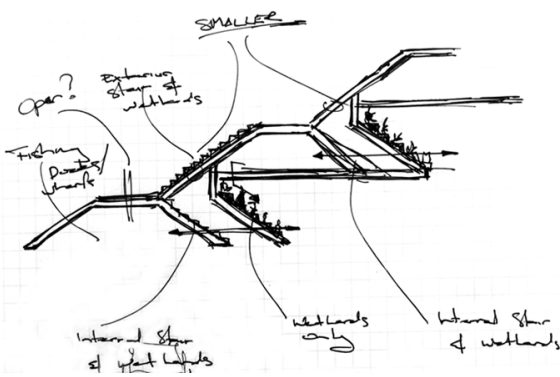

terratuma

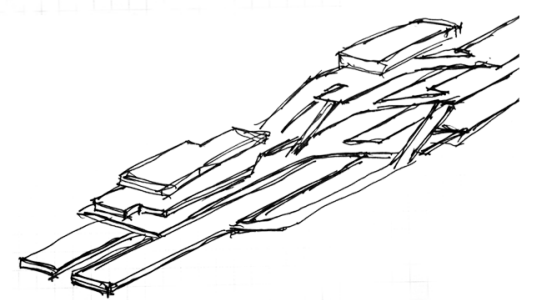

Ghat Translation Experiment

Ghat Translation: Building Development

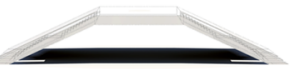

01.

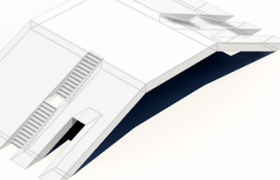

01.

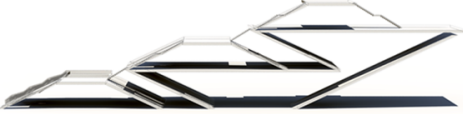

02.

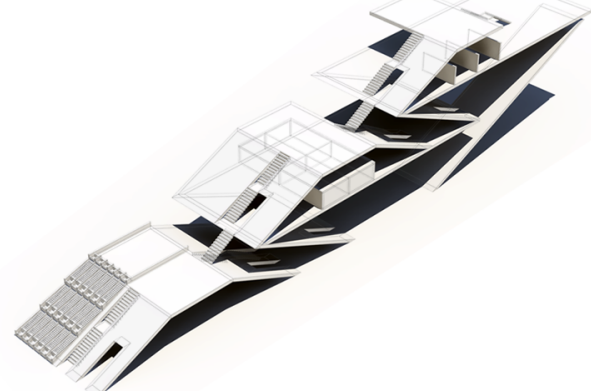

02

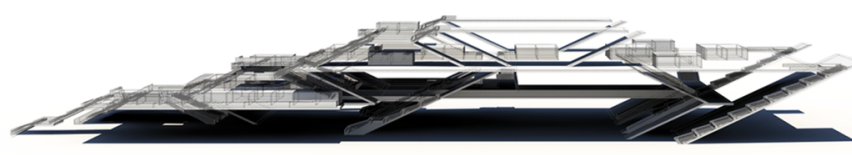

03.

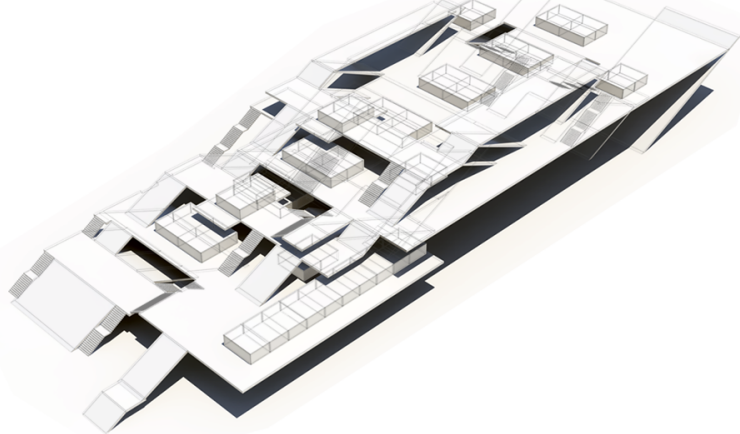

03 
Figure 148 illustrates a number of designs testing the contemporary translation of traditional Indian terraced ghat structures as both a grey water wetland treatment façade as well as the building structure evidencing a terracing vocabulary.

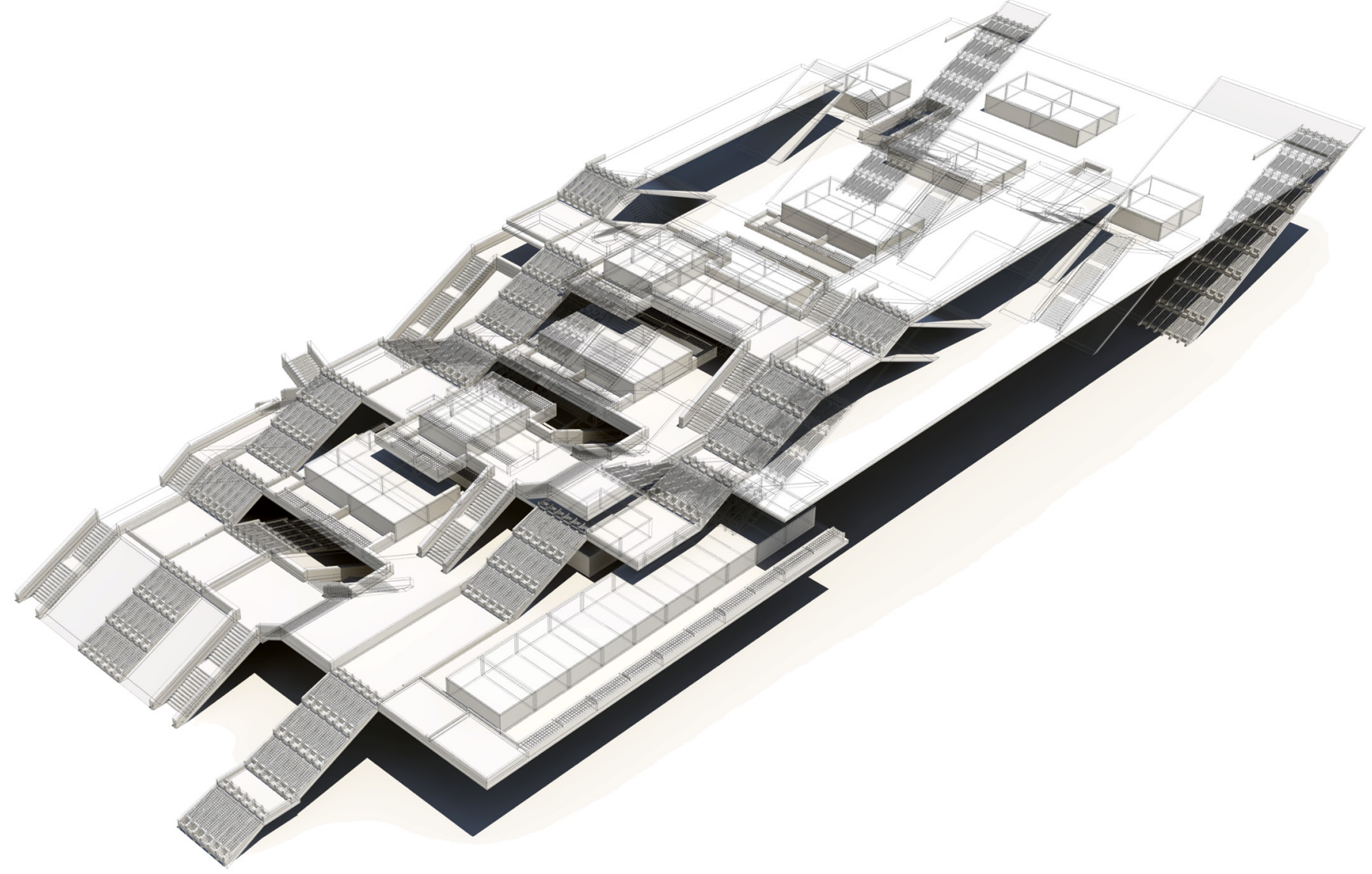




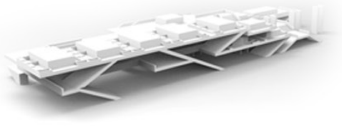

01. Housing

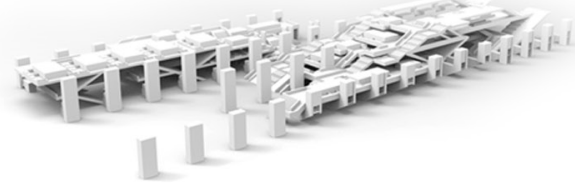

03. Service Cores

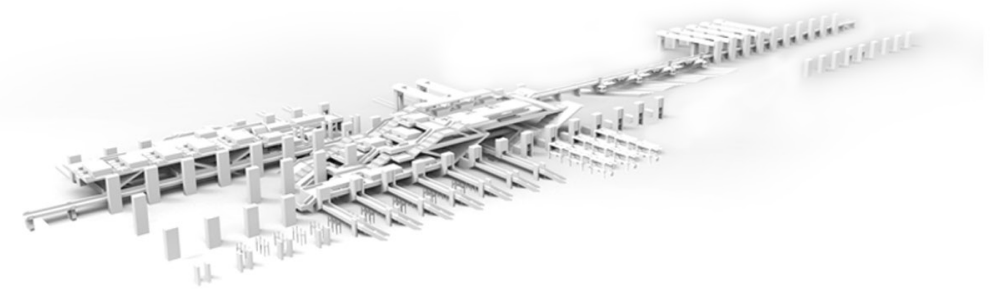

05.Garbage Treatment

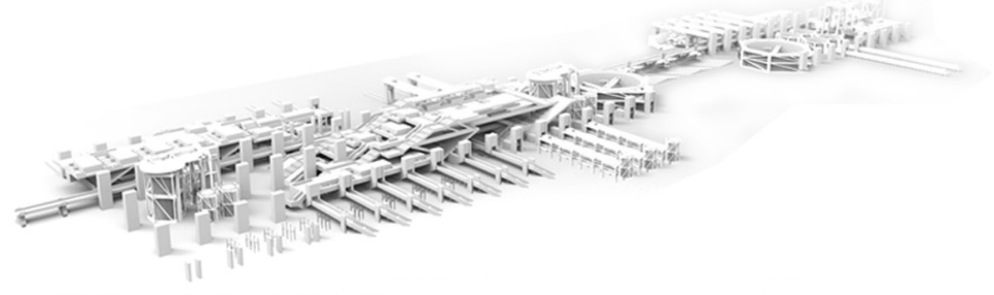

07. Sewage Treatment + Water Storage

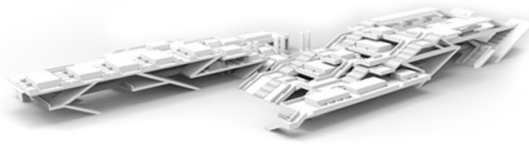

02. Housing

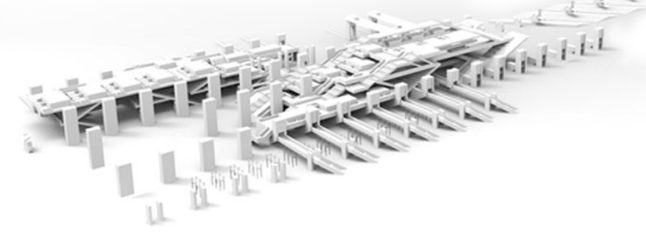

04. River Mouth Hardscape + Mooring Structures
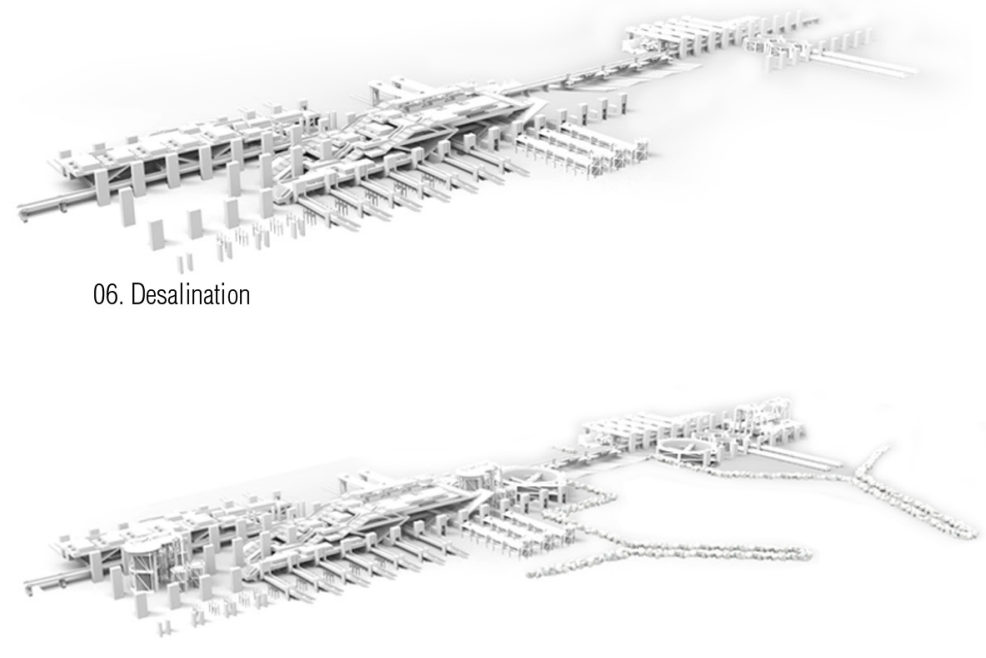

08. Breakwater System

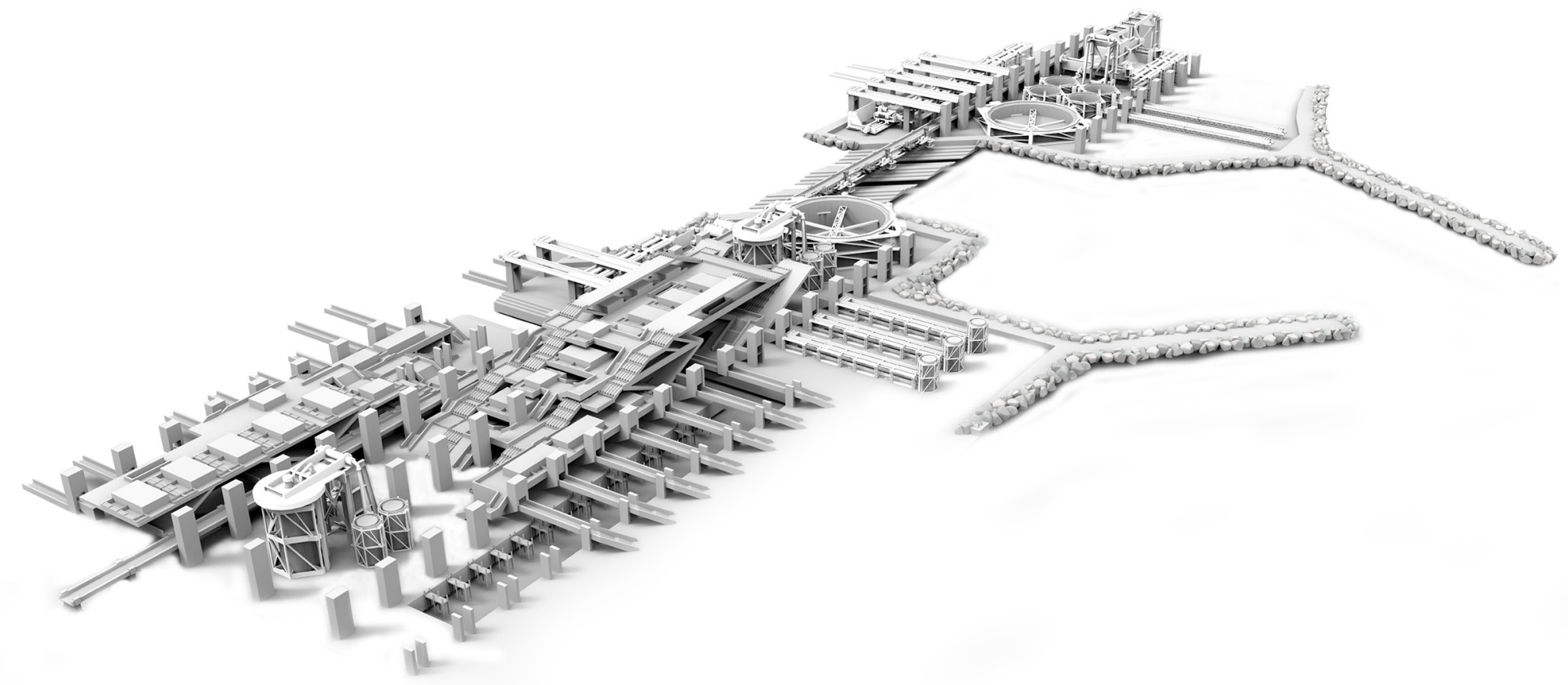


The Conceptual Design Scheme Two terraced housing framework aims to enhance living conditions by maximising natural light and ventilation with an open yet resilient structure that provides shelter from the threat of natural disaster by integrating vegetation into the reinforced concrete framework. The regular interval service cores and linear design of the self-sustainable machine infrastructure allow for the framework to expand with population growth. The design elevates housing platforms above a network of public and social spaces that surround a canal inlet, (Figure 150.03) essentially creating a series of community sub-centers built around the fishing community including market space, fishing vessel mooring and equipment storage. 
CRITICS' NOTES - REVIEW DATE 22.08.14

PROS:

- Integration of passive water purification systems though terracing appears too steep

- Partially open design allows the building to respond to climatic conditions while providing adequate shelter from natural disasters

- Beginning to develop a contemporary Indian architecture vocabulary

- Greater river mouth hardscape allows for increased flow rate during monsoon rains to minimise flooding both onsite and for communities upstream within a close proximity of the Adyar River

CONS:

- Architectural elements should respond to the importance of how they touche the earth or water evidencing a contemporary translation of traditional Ghat systems

- Terracing should become a framework where housing can naturally evolve

- Housing markers should not be visible as they read as architecture and influence the design image

- Public and social spaces require a better dialogue with housing

- Breakwater system appears inadequate 


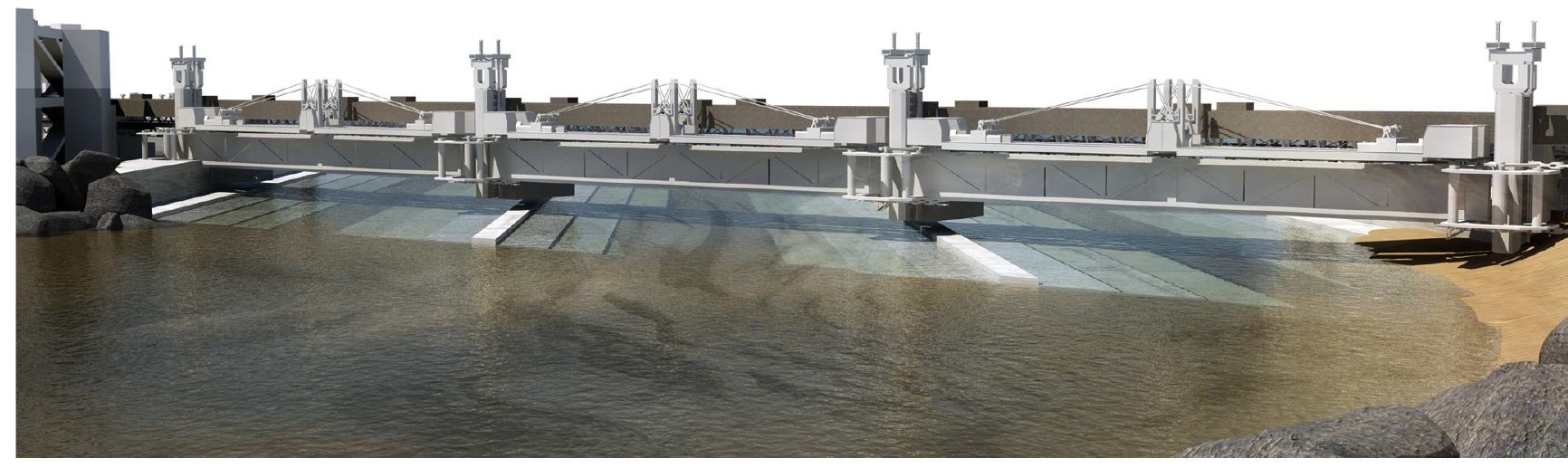

01. Terraced river mouth hardscape allowing river to have continuous flow

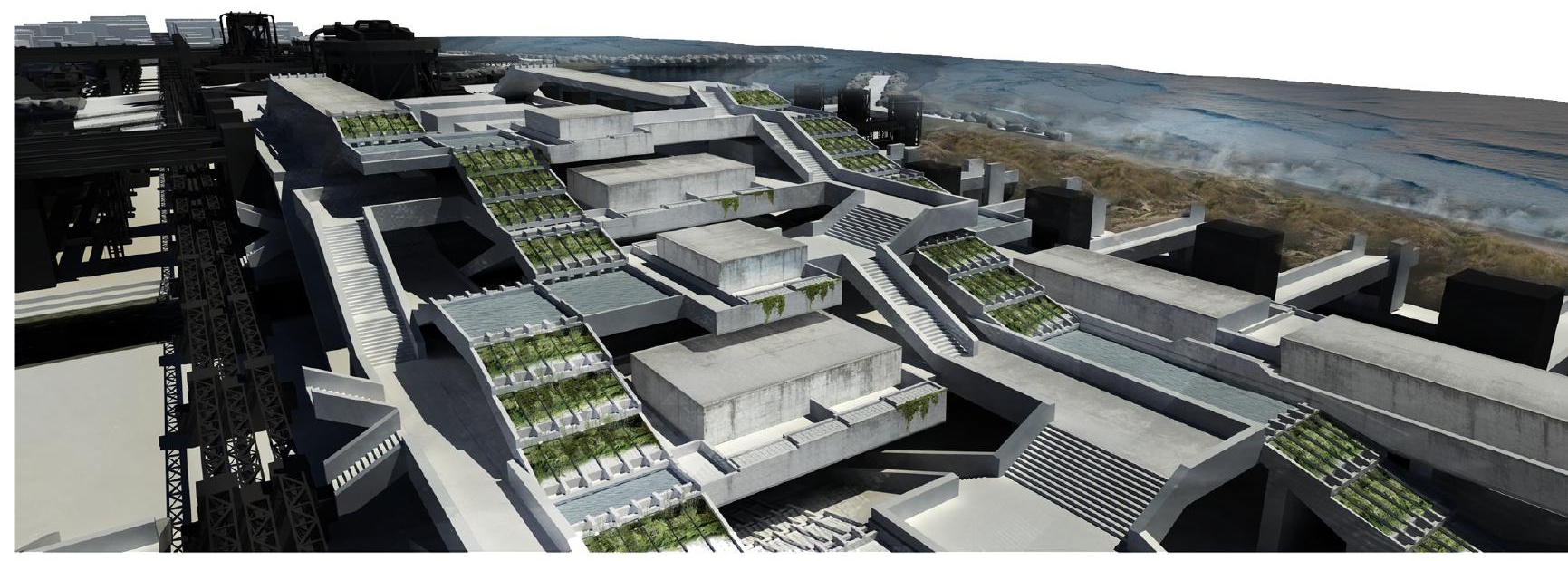

02. Terraced housing structure implementing a waste water wetlands system

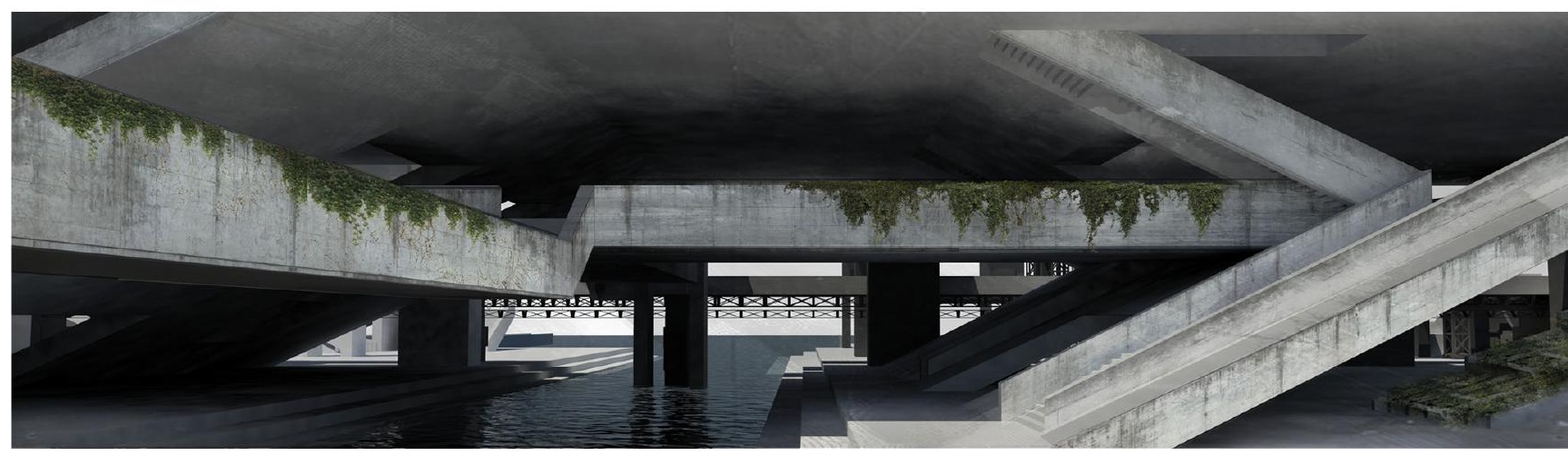

03. Integrated public space and canal system below housing structure 


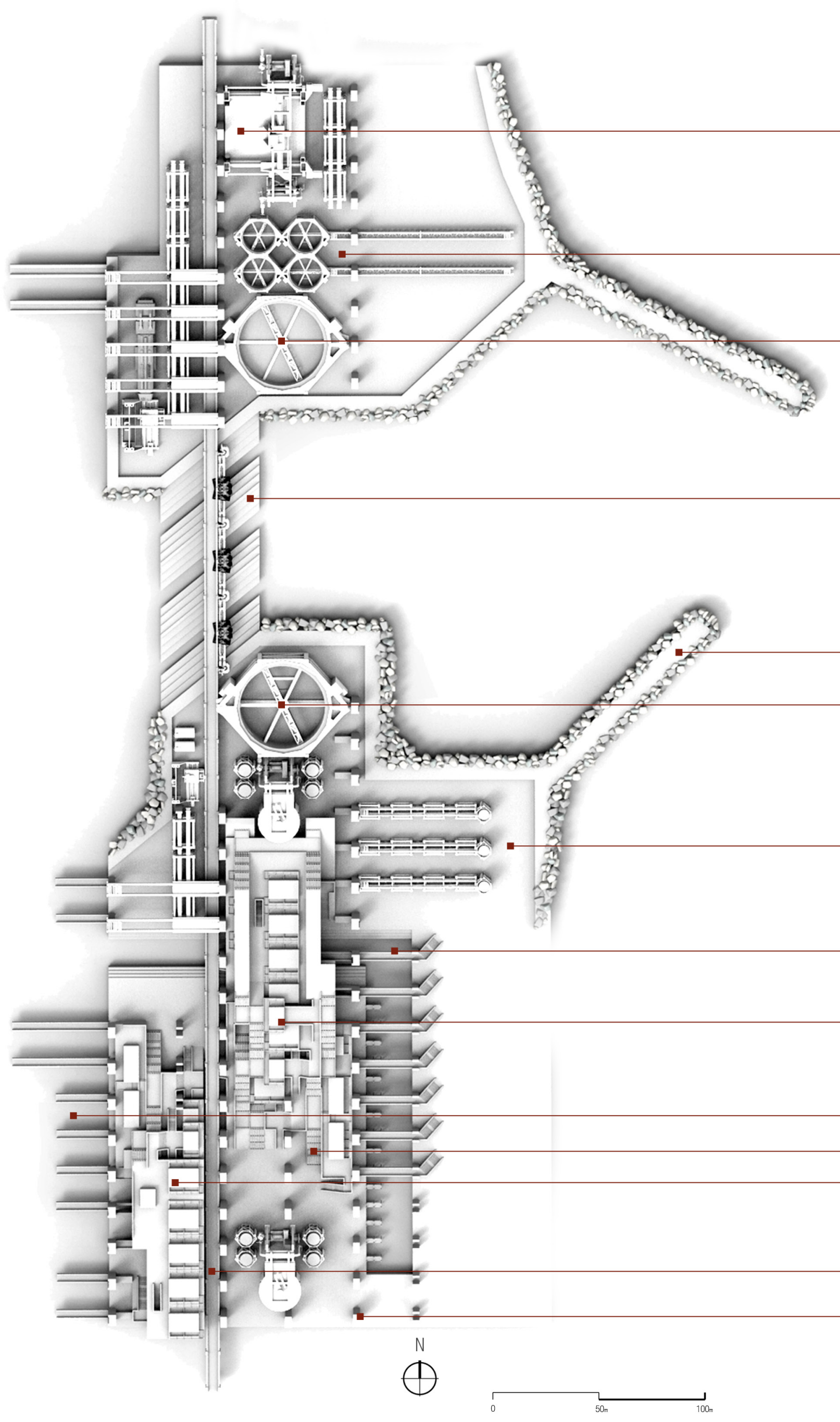

Fig. 151. Conceptual scheme two - Program plan. 
Garbage Treatment Plant

Sewage Treatment Plant

Water Storage

Terraced River Mouth Hardscape

Tetrapod Breakwater System

Water Storage

Seawater Desalination Plant

Canal

Terraced Housing Framework

Fishing Vessel Mooring

Terraced Grey Water Wetland System

Terraced Housing Framework

Elevated Bridge

Service Cores Allowing For Expansion 


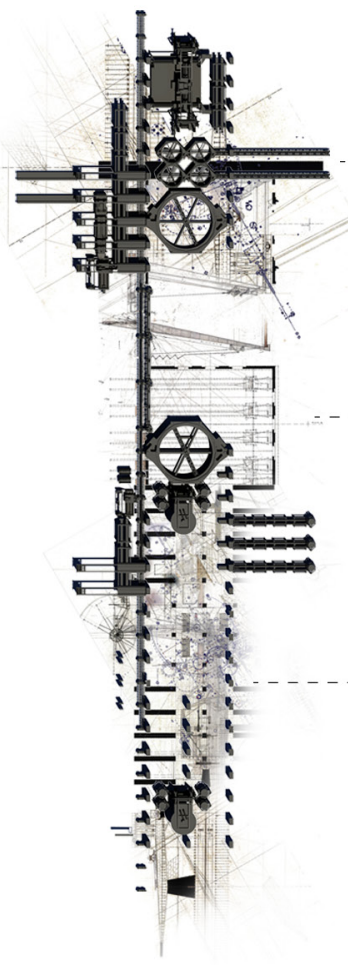

Machine

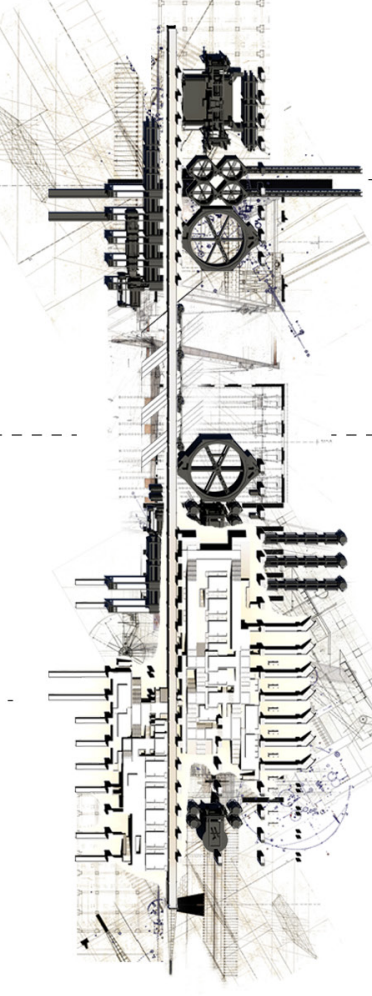

Framework

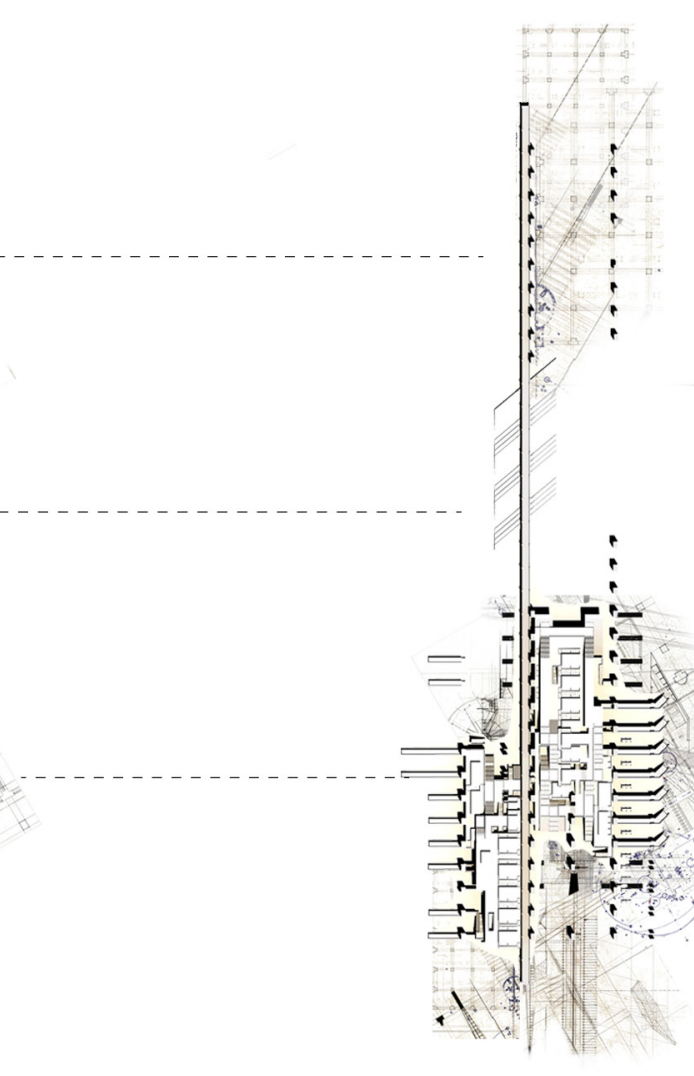

Housing 


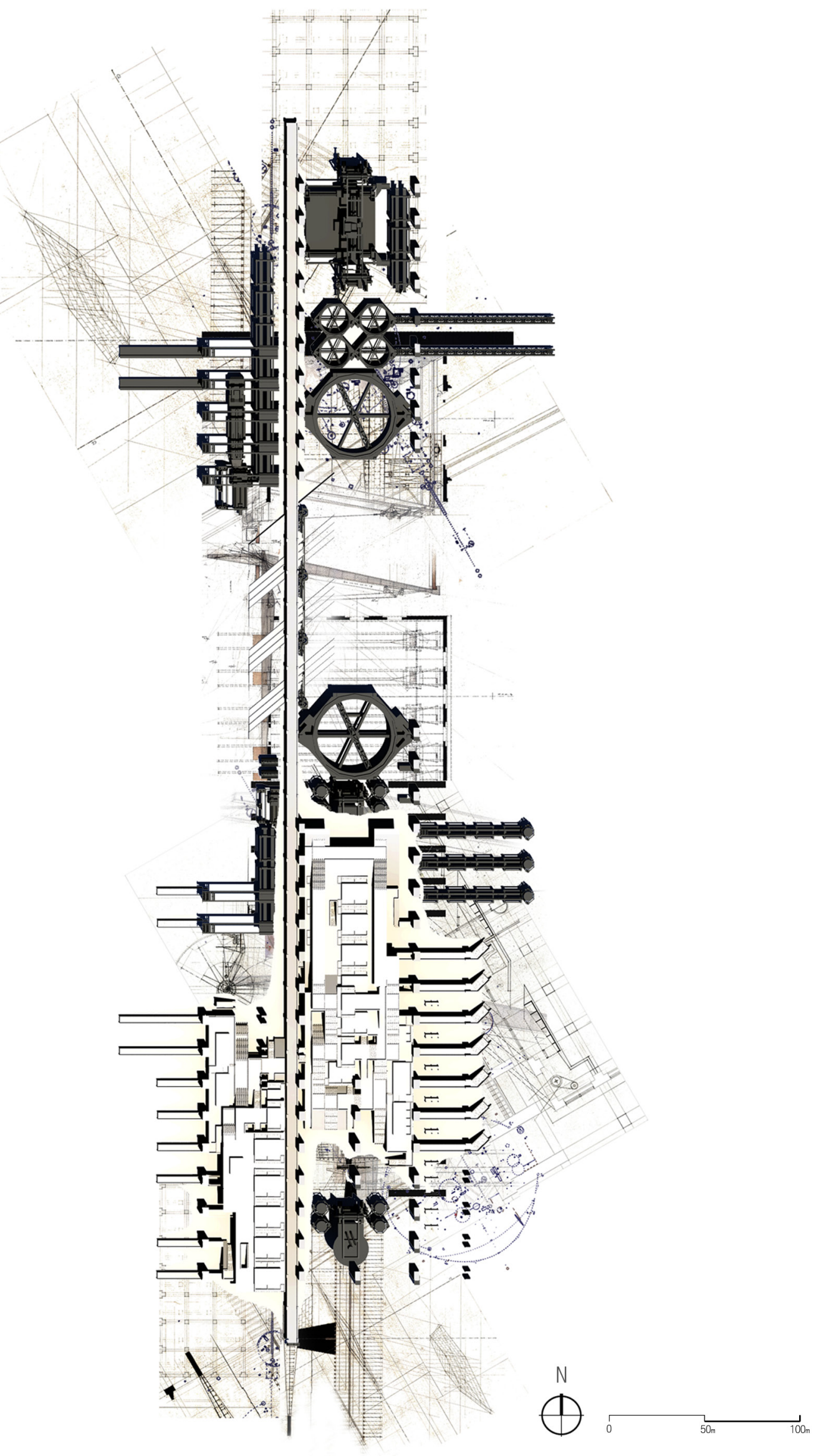




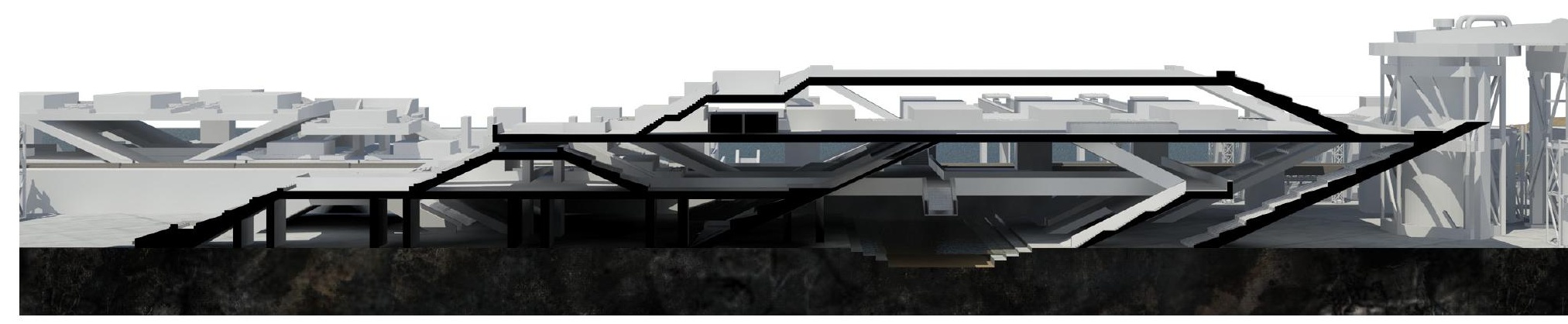

Section BB

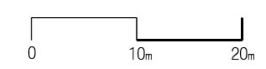

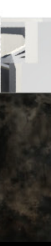

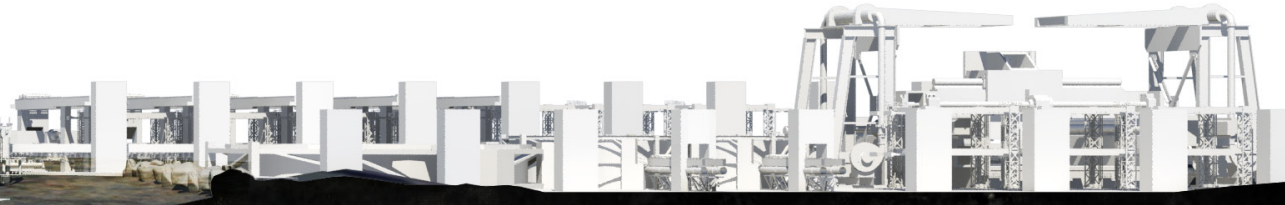

Fig. 153. Conceptual scheme two - Sections. 


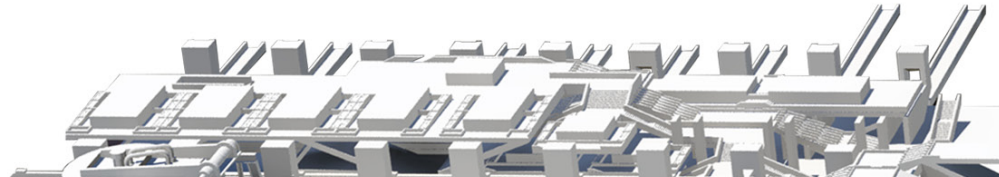

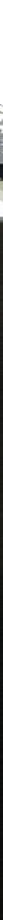




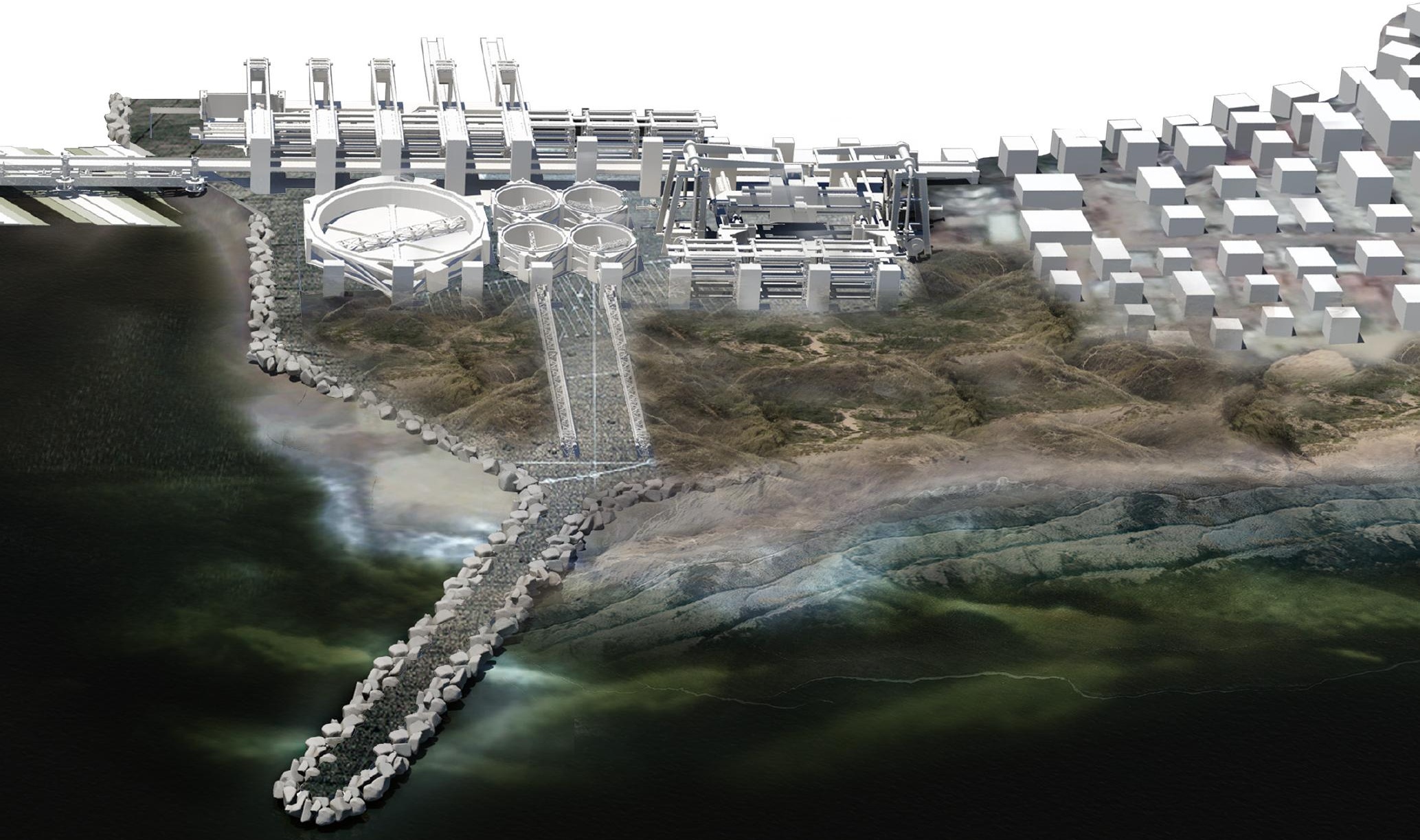

Fig. 154. Conceptual scheme two - Framework perspective. 


\subsection{CONCEPTUAL SCHEME THREE}

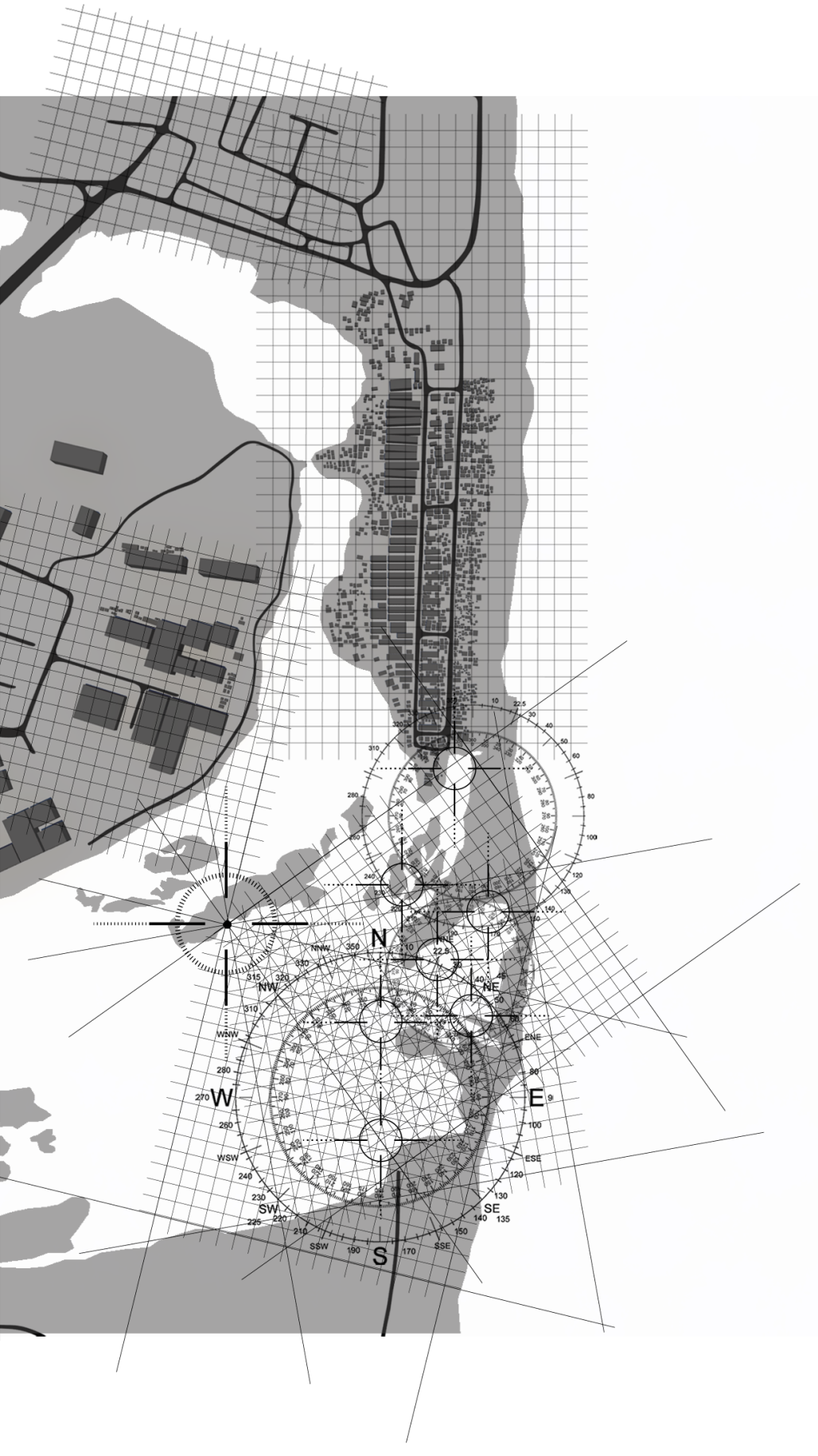

Fig. 155. Site dynamics - Emerging site axes and grid analyses.
Conceptual scheme three tests framework sketches (Figure 156) that respond to the site development study carried out in the site analysis chapter and again in Figure 155. The study highlighted a number of extreme variations in the structure of the river mouth from 2001 until present using Google Earth's satellite imagery. The variations in landscape formed a series of grids that will be used to inform design decisions such as housing, river mouth and breakwater orientation throughout conceptual scheme three. 

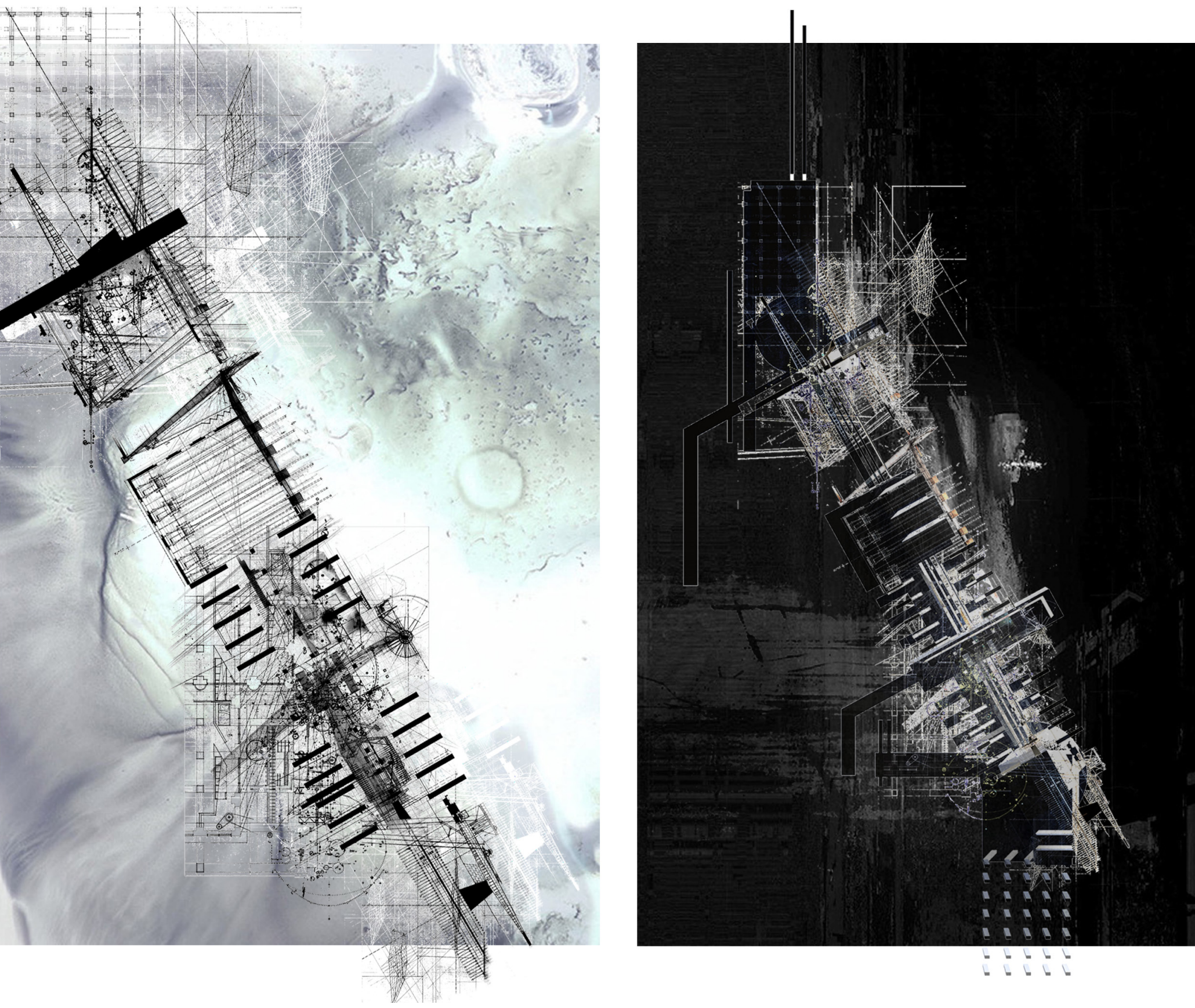

$-5=5$

Fig. 156. Conceptual plans responding to site grid analyses. 


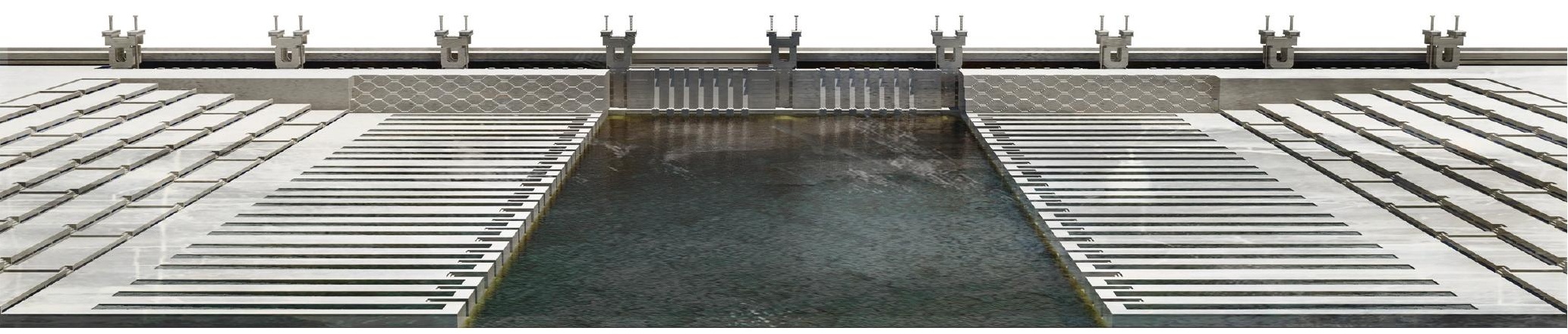

01. Wetland filtration terraces treating grey water to supply bathing tanks with clean water as a daily cleansing ritual

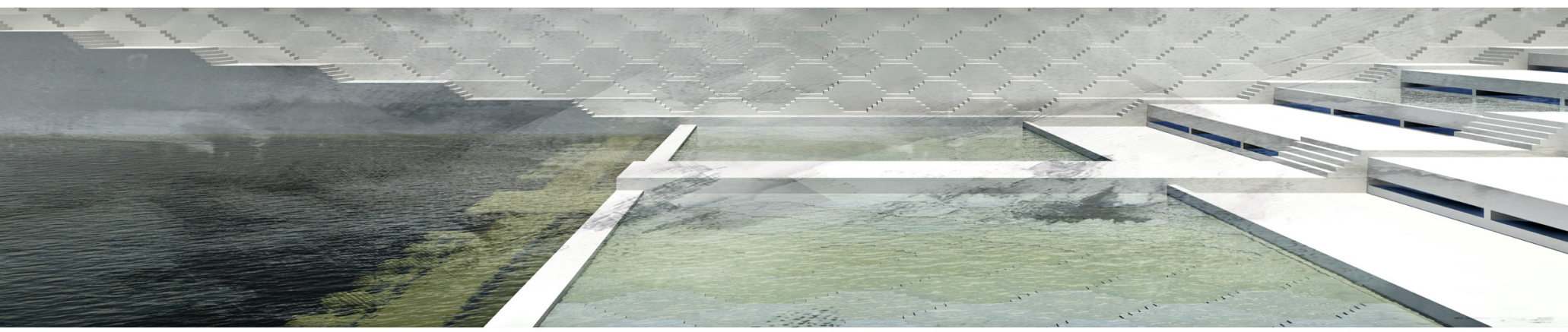

02. Fresh water bathing tanks used as a daily cleansing ritual

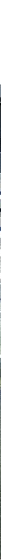

03. Terraced wetlands treating wastewater and returning filtered water back into the waterways 

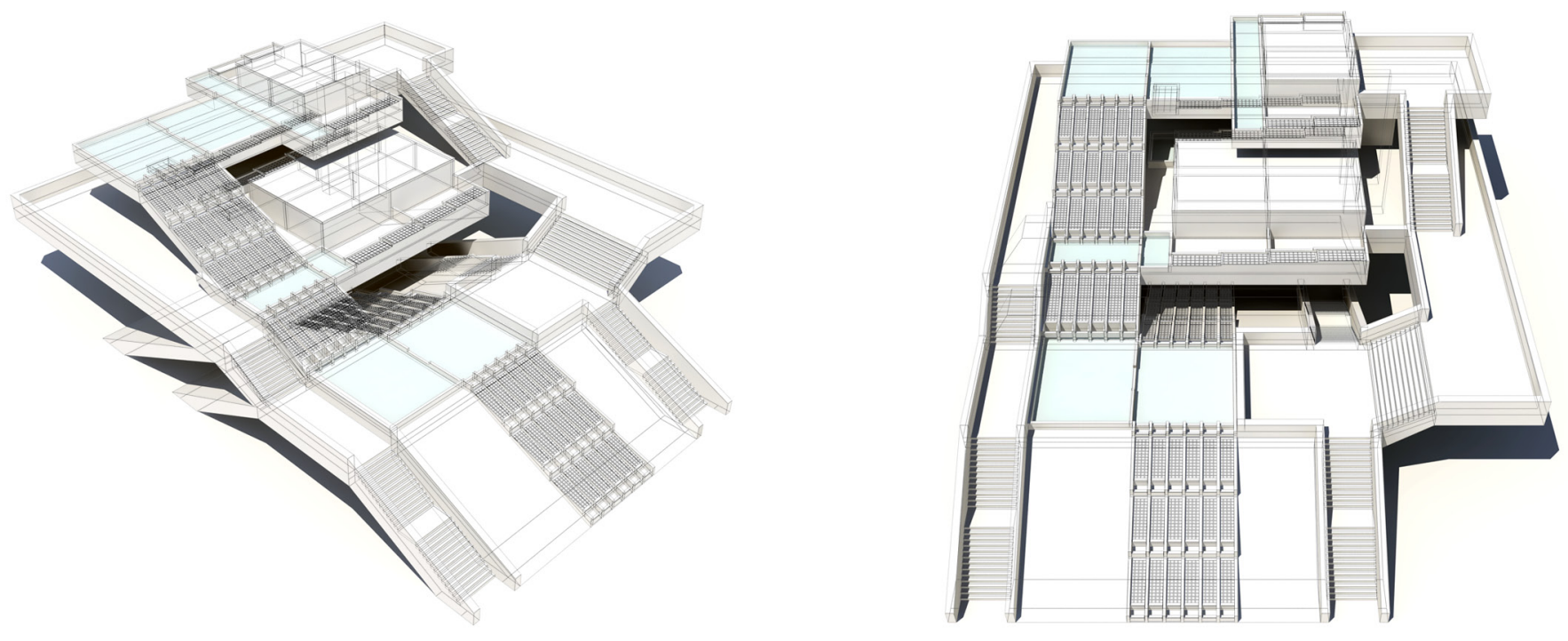

04. Terraced wetlands treating grey water integrated into housing structure test one
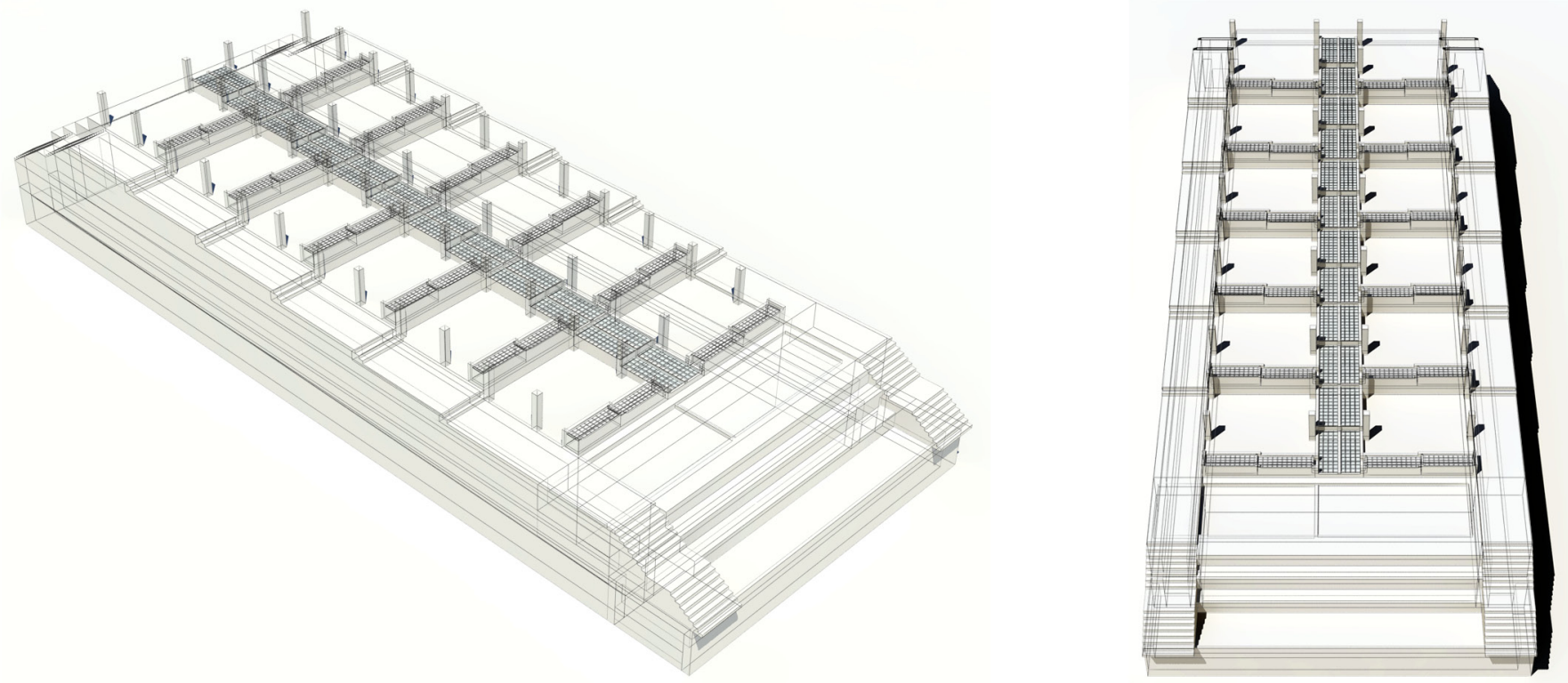

05. Terraced wetlands treating grey water integrated into housing structure test two 


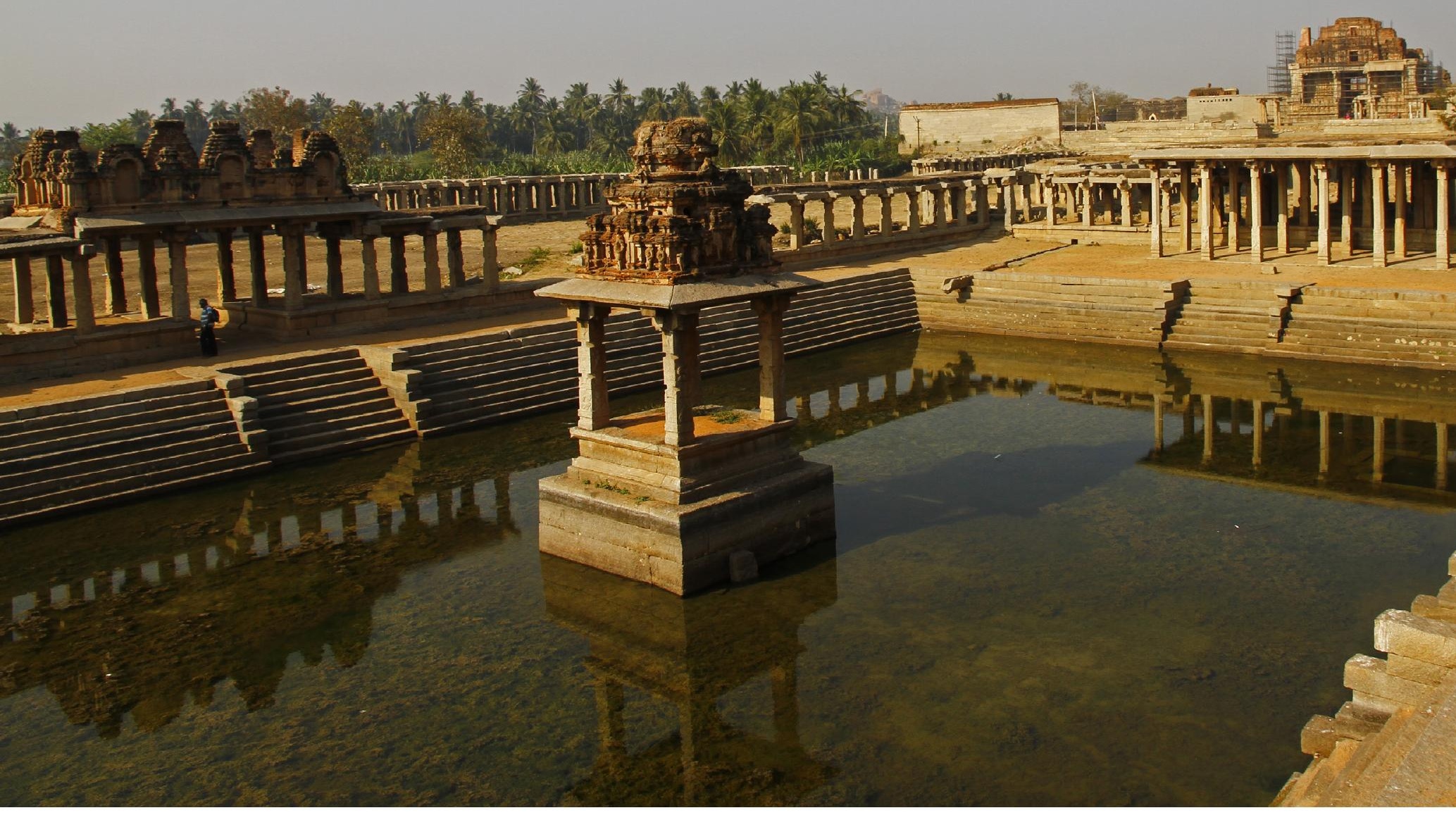

Fig. 158. Stepped water tank, Hampi.

Figures 158-159 show ancient Indian methods of water collection and storage tanks evident throughout South Indian. The structures were also used for the sacred ritual of cleansing. The contemporary translation (Figure 160) conceptual sketches allow access from wildlife and saltwater suggesting the structure would be better suited for bathing and cleansing rituals as opposed to a fresh water collection tank. 

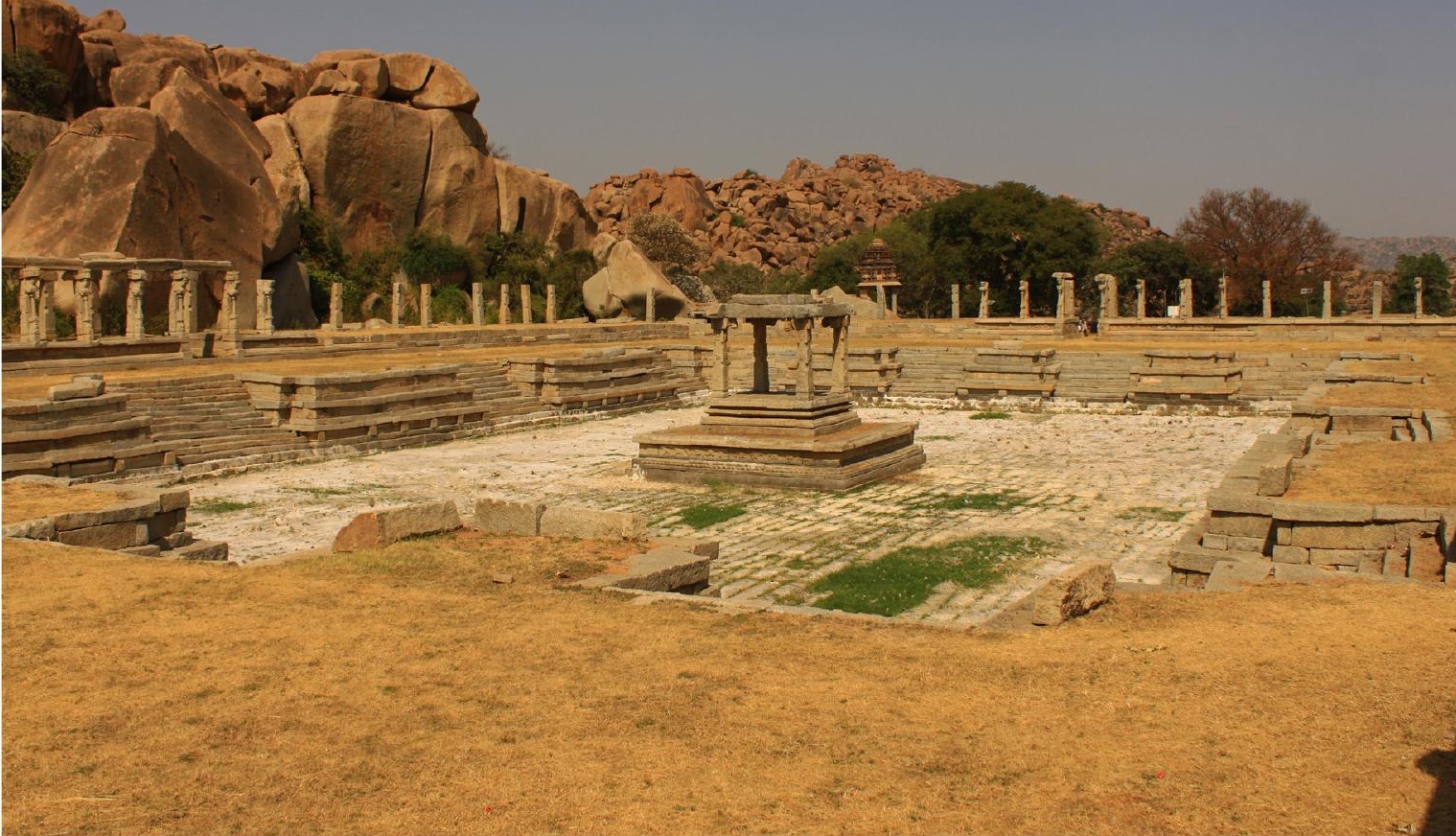

Fig. 159. Stepped water tank, Hampi.

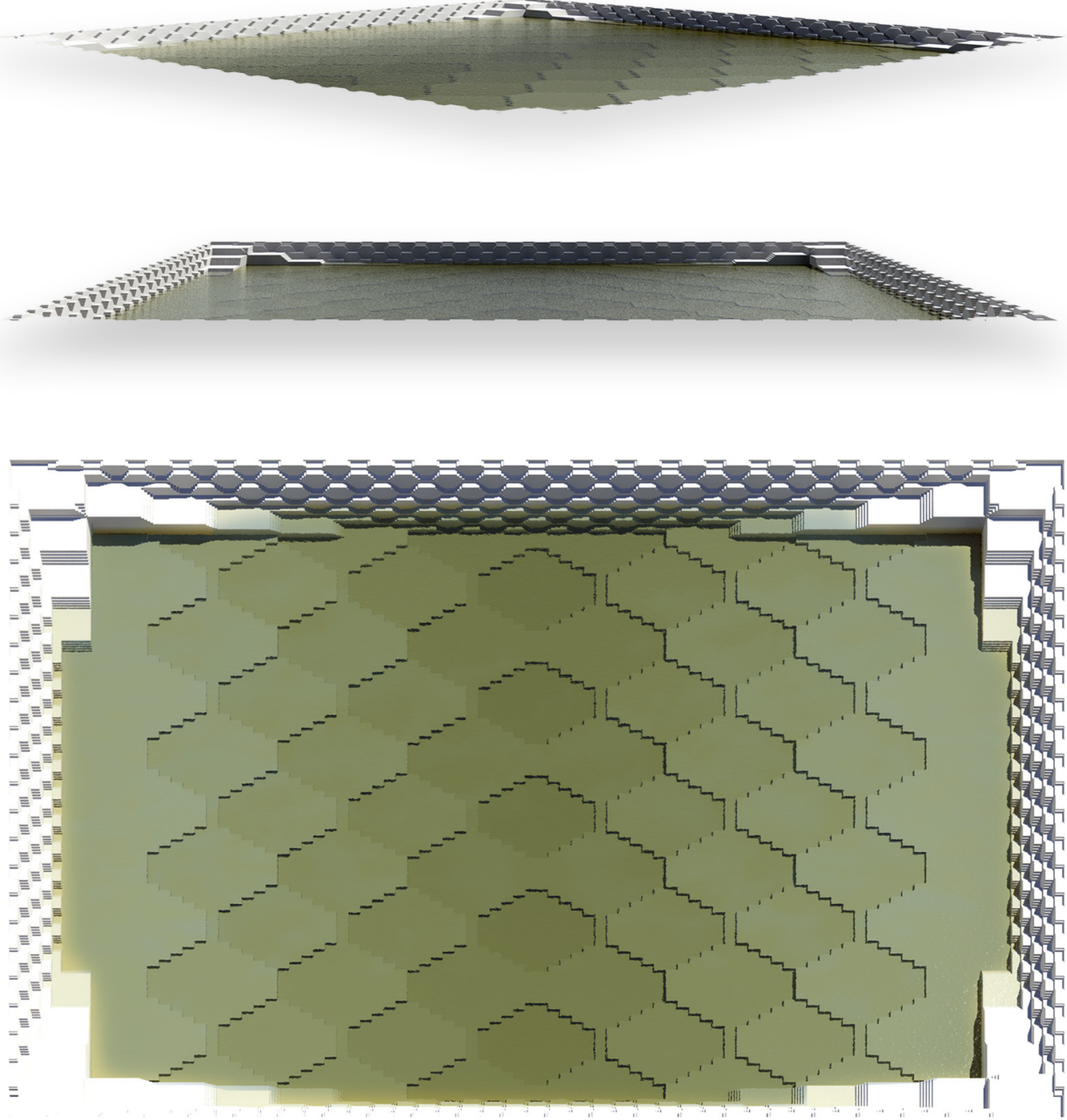



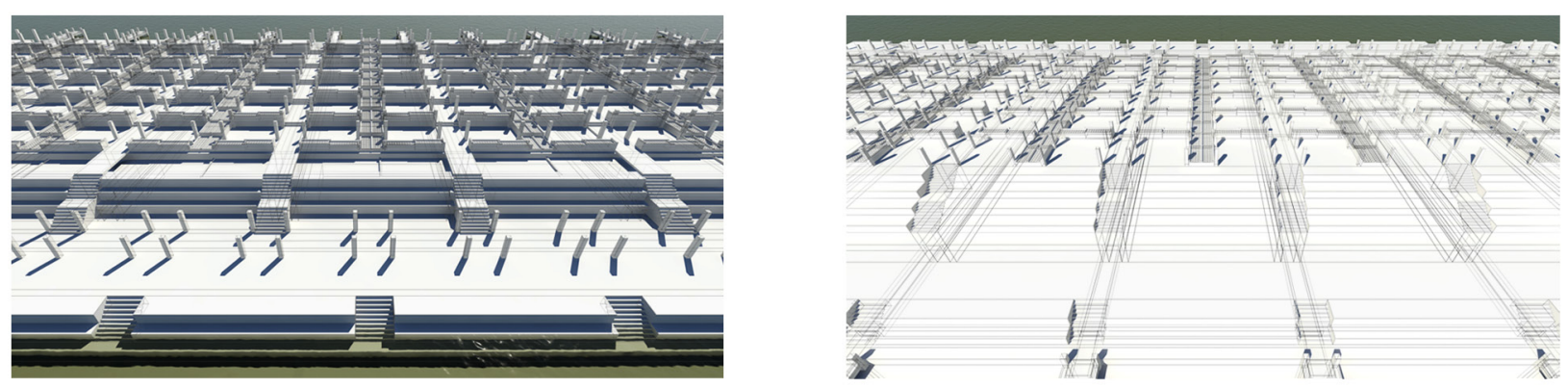

Housing Hardscape
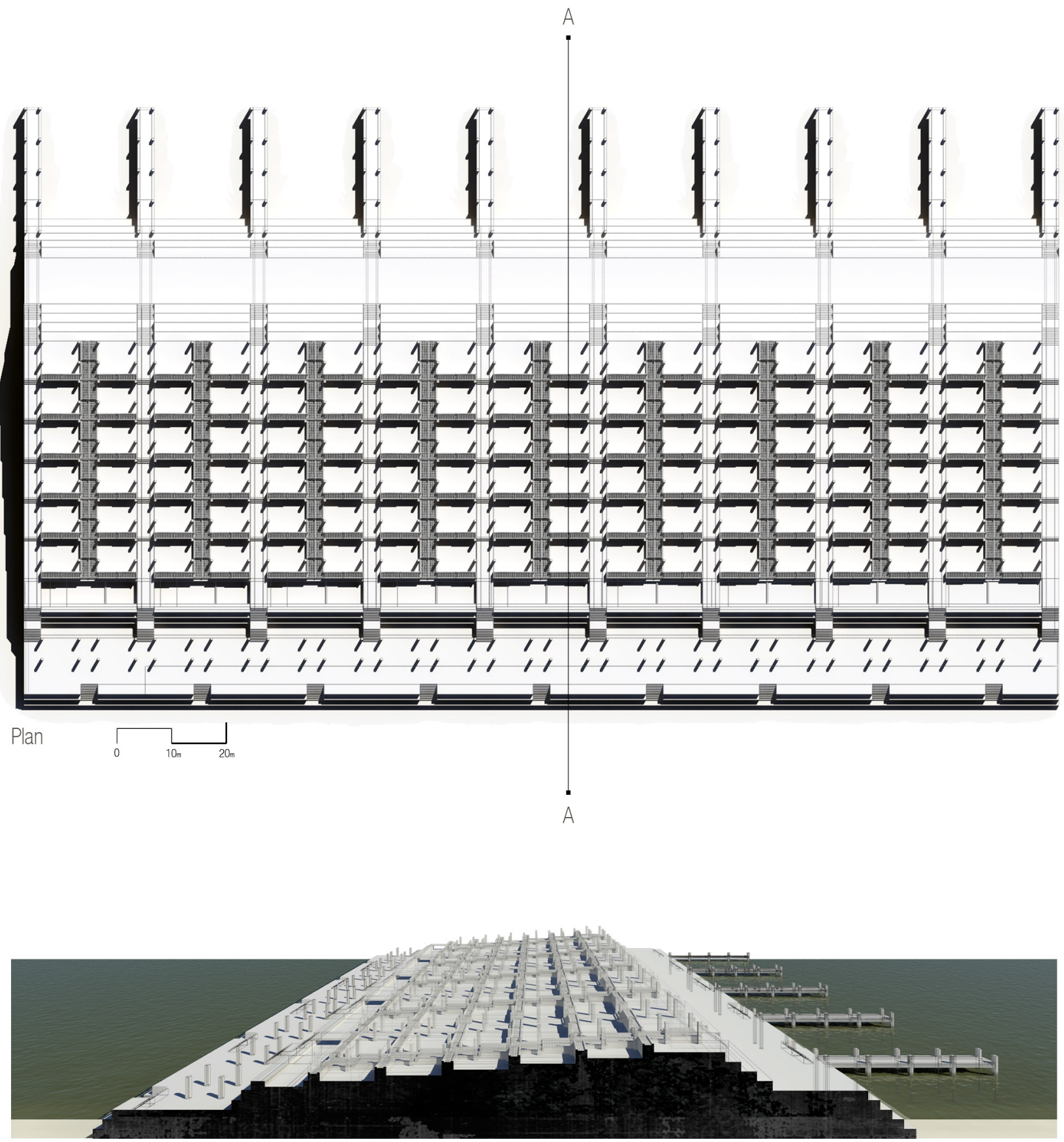

Section AA 
Figures 162-163 show examples of ancient Indian architecture designed with terraced and elevated foundation platforms to mitigate monsoon flooding within temple complexes. The design response (Figure 161) reflects a contemporary translation of this vocabulary to form a series of terraced platforms above the tidal surge mark where slum dwellers are able to maintain their habitats within a safe environment.

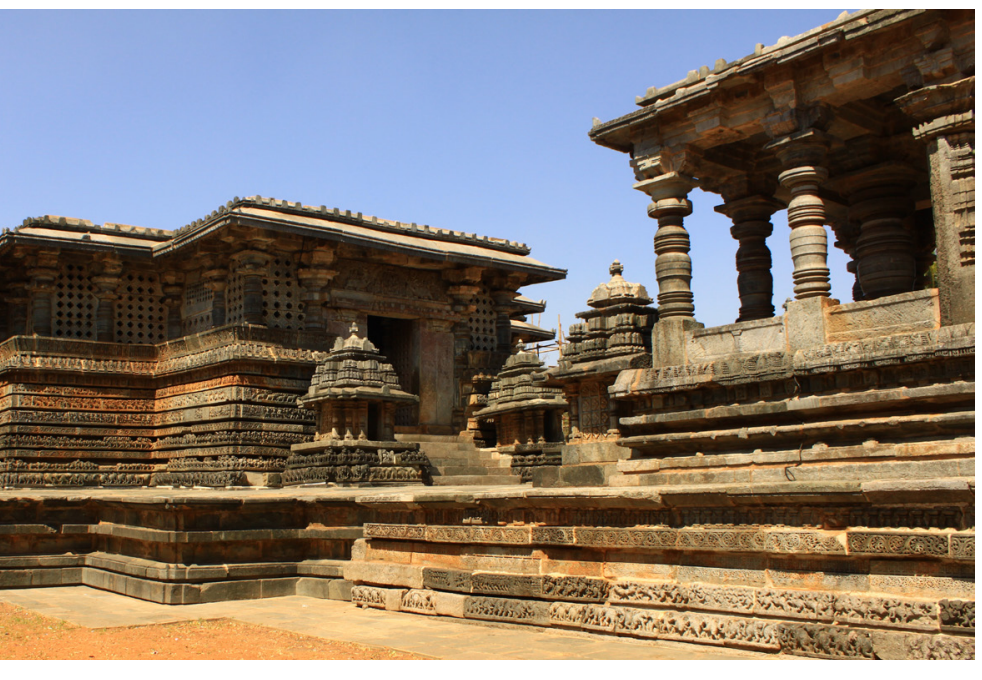

Fig. 162. Hoysaleshwara Hindu Temple, Halebidu.

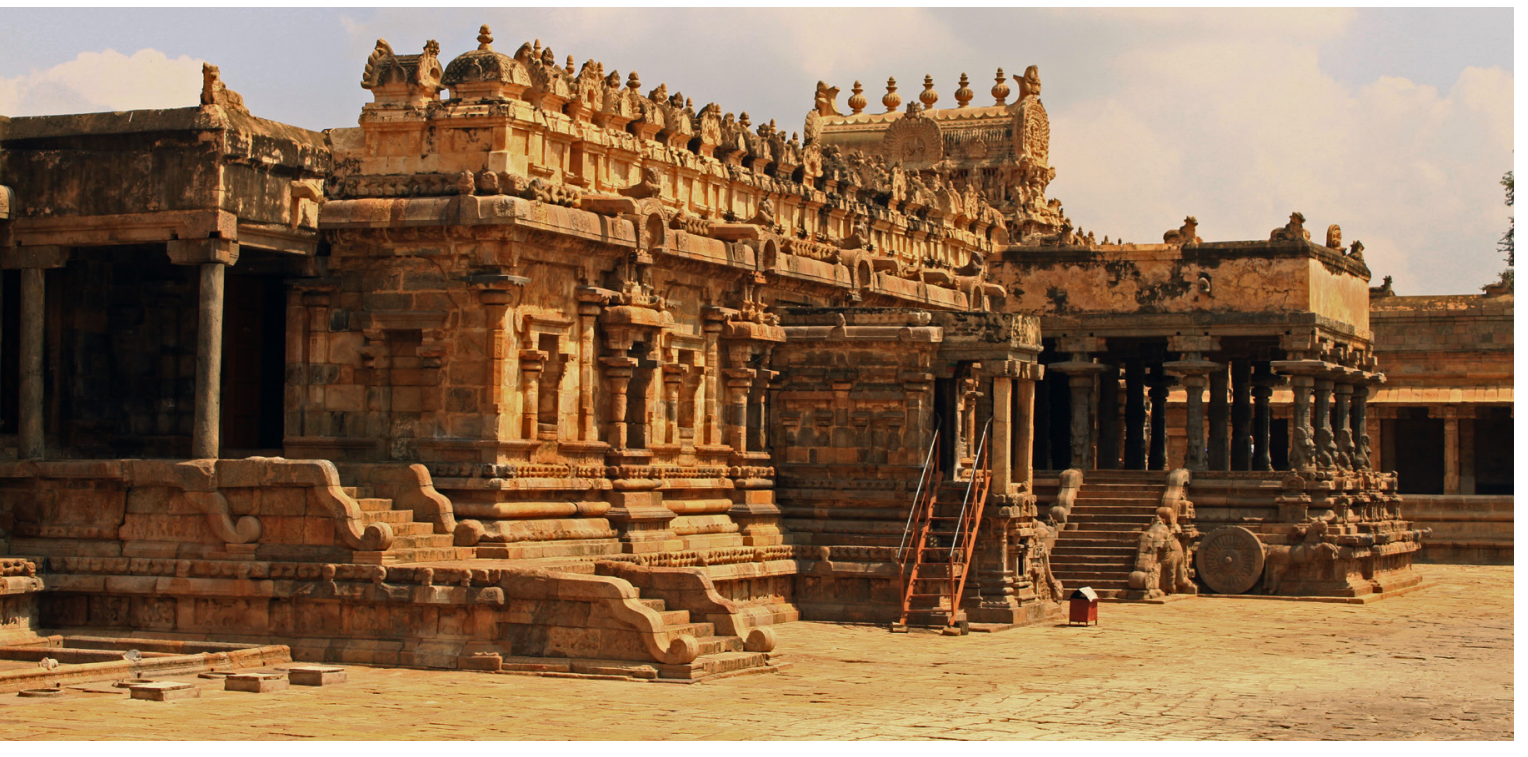

Fig. 163. Airavateswarar Temple, Darasuram. 
Ancient South Indian architecture often used stone hardscapes to divert and channel water (Figures 164-165). As an important means of cleansing the Adyar River, the design response (Figure 166) tests a terraced hardscape that allows the flow rate of the river mouth to increase and decrease with reference to the water level. During the monsoon season when the river is in flood and water levels are high, the wider terracing allows for a greater flow rate, while during dry months when the water levels are low, the river mouth has a narrower structure therefore maintaining an adequate flow rate to cleanse itself.

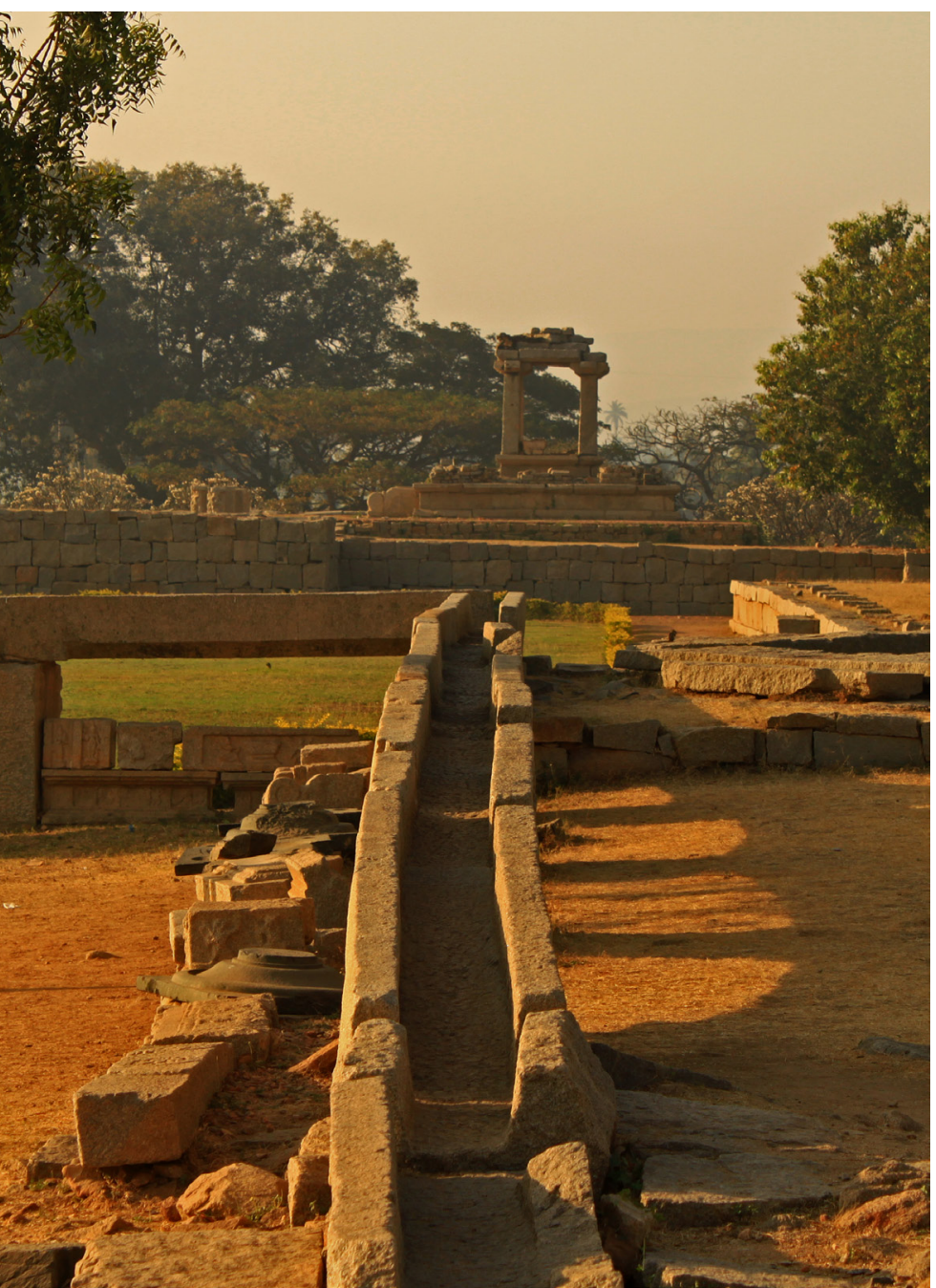

Fig. 164. Stone drainage hardscape, Vijayanagara Empire, Hampi.

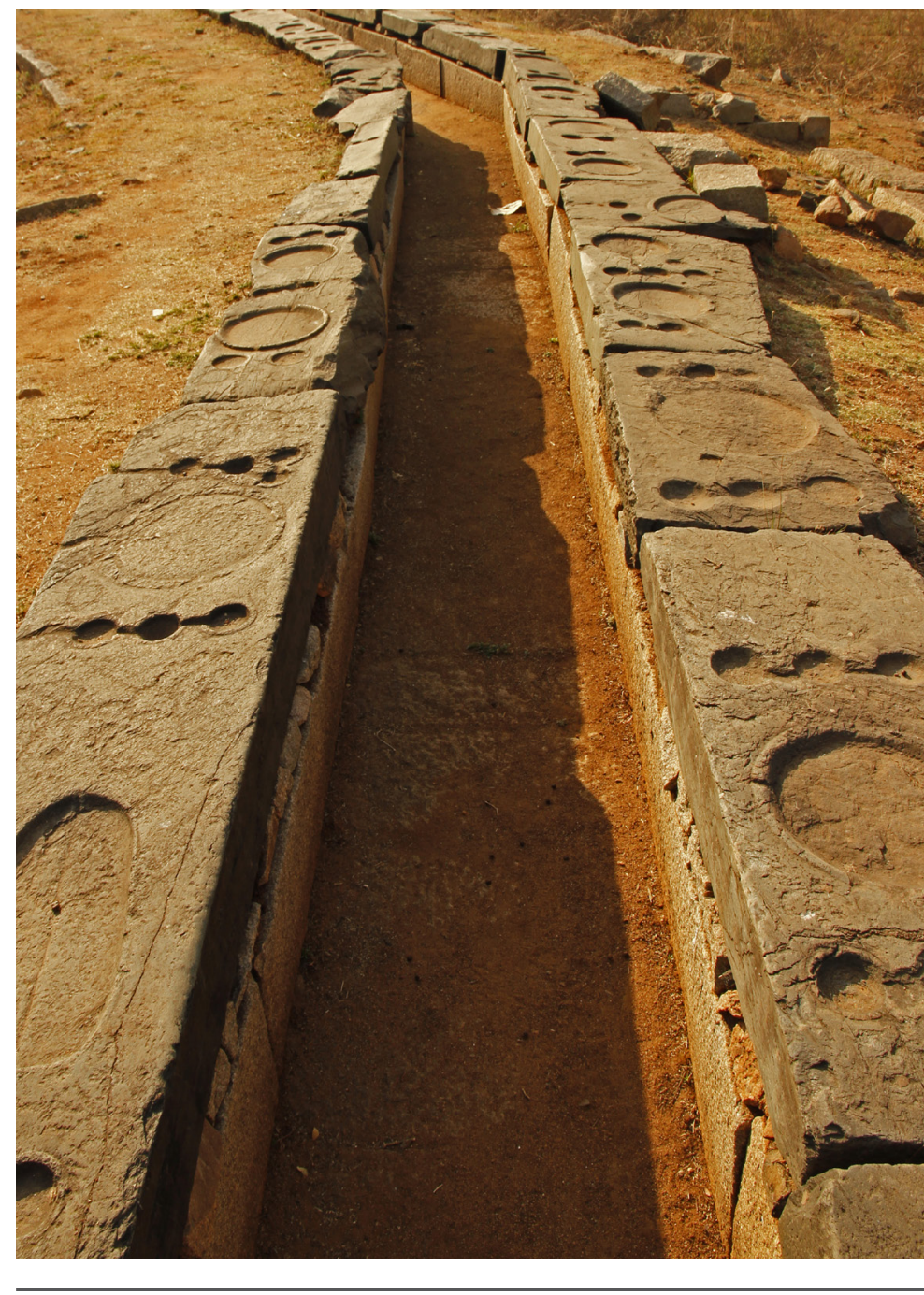

Fig. 165. Stone drainage hardscape, Vijayanagara Empire, Hampi. 


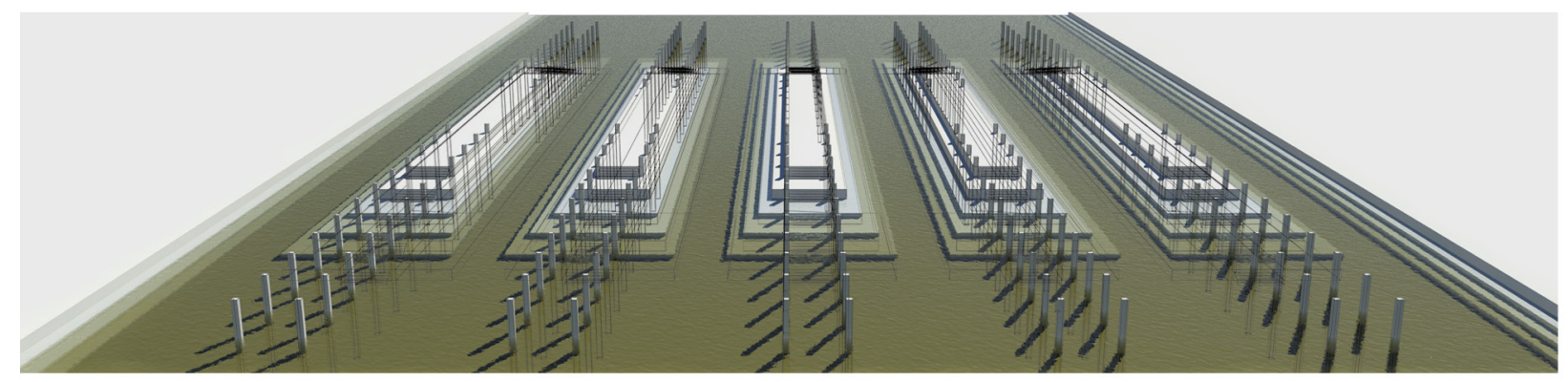

River Mouth Hardscape
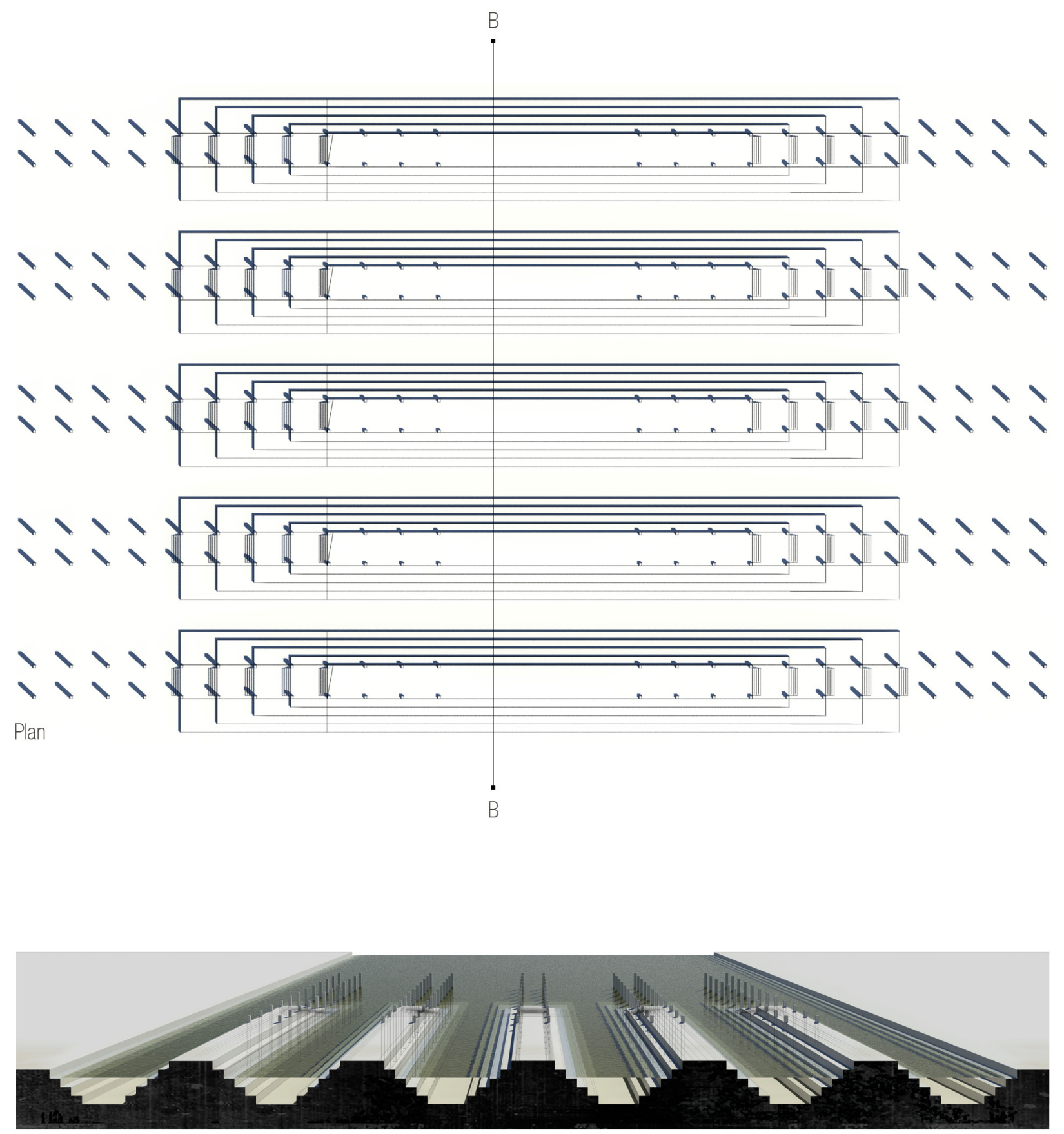

Section BB 


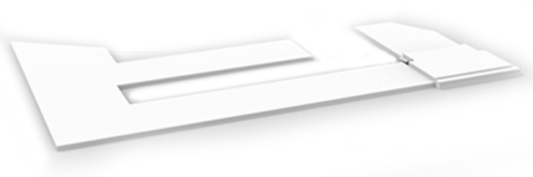

01. Initial Framework

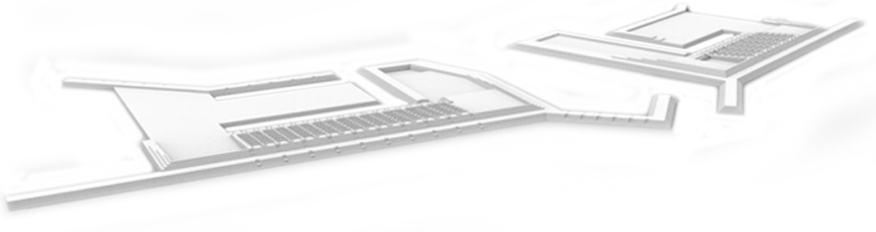

03. Housing Structures

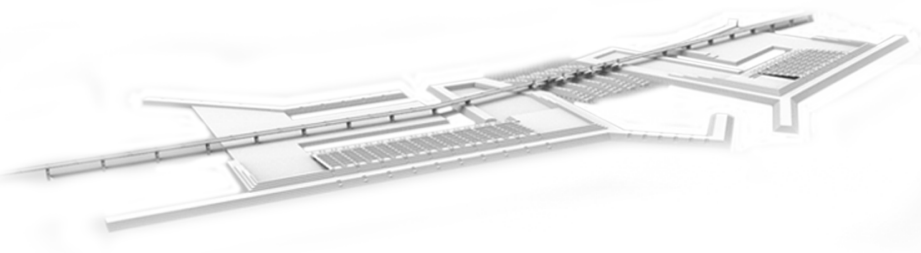

05. Elevated Bridge System

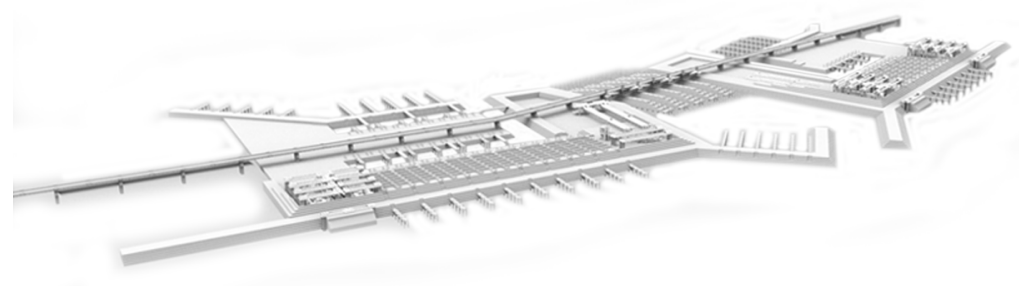

07. Desalination + Wave to Energy Plants

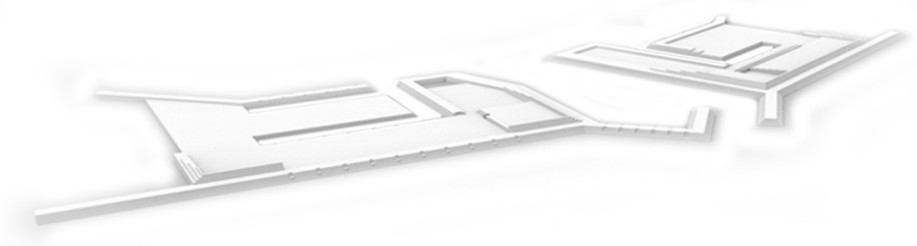

02. Breakwater System

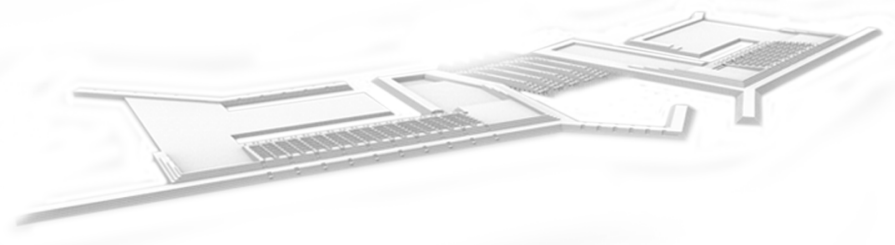

04. Terraced River Mouth Channels

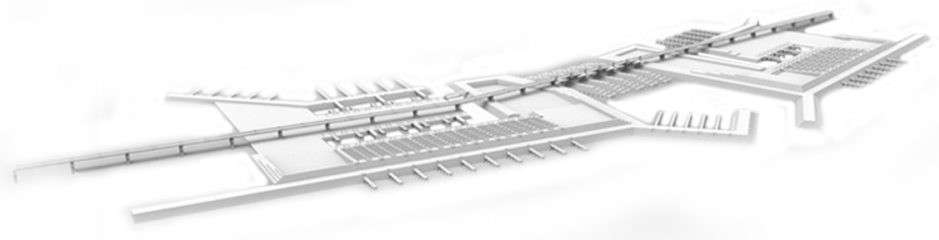

06. Fishing Vessel Mooring Structures

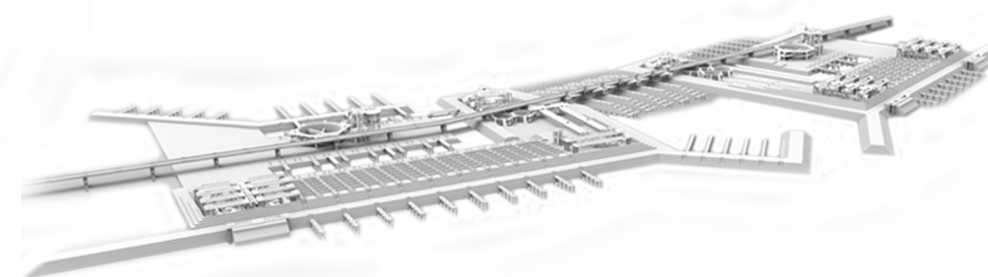

08. Sewage \& Garbage Treatment + Water Storage

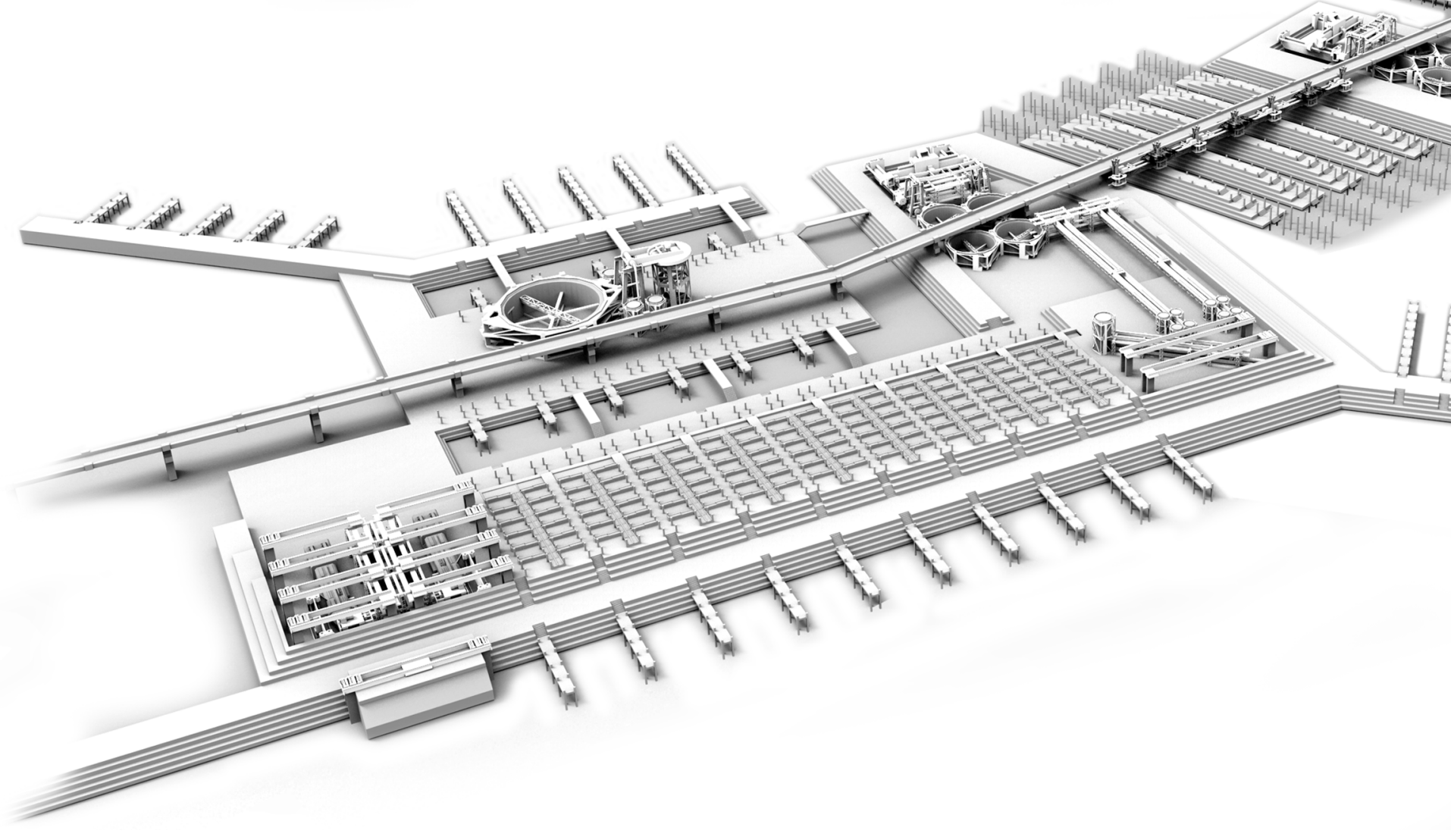




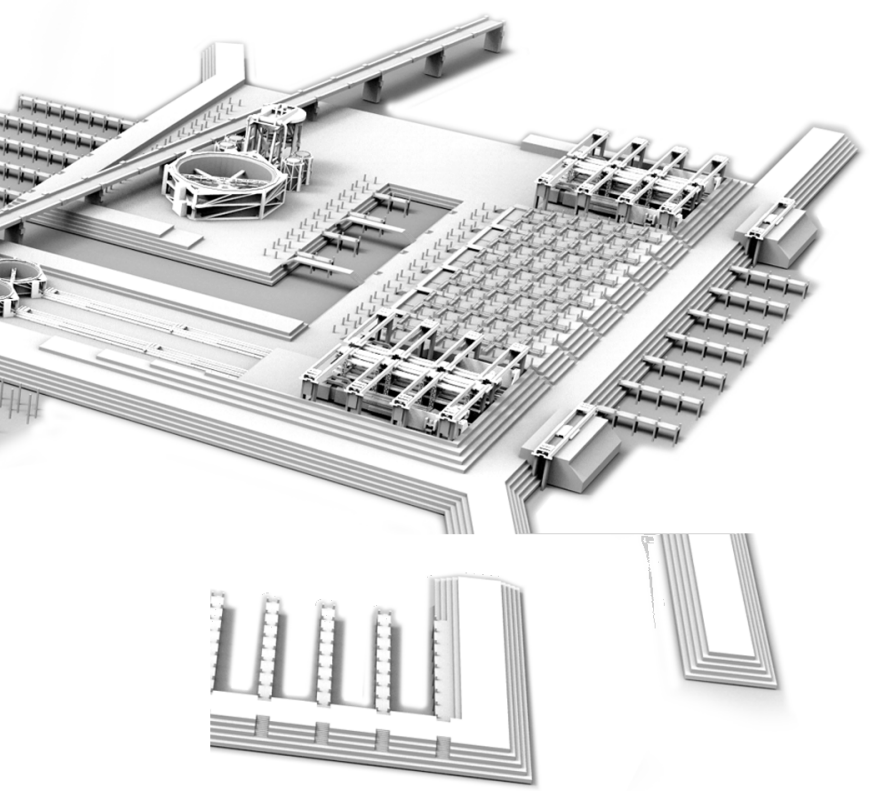

The individual component design tests throughout conceptual scheme three have led to a developed framework responding to site dynamics such as the fluctuating river mouth structure, the directional flow of the river, extended site grids of the urban grain and the northeast storm patterns. The design integrates these underlying site influences with traditional South Indian architecture typologies to form a contemporary structure that helps mitigate the threat of natural disasters to the immediate and extended site. The framework incorporates a series of elevated hardscapes to slow, block and channel inundation caused by surge from both the Bay of Bengal and the Adyar River. The terraced river mouth hardscape flanked by a two tier breakwater system helps prevent the formation of sandbars allowing the river to naturally cleanse itself while providing safe conditions for fishing vessel mooring. The elevated platform allows for all self-sustainable machine components to remain above the tidal surge mark as a means of minimising damages to crucial infrastructure such as fresh water purification systems and storage tanks. 
Figures 168-169 examine dialogues between fishing vessel mooring, market space and housing terraces to help create an integrated community structure that reflects traditional Indian living. The housing terraces are oriented away from the coastline as a means of providing shelter from storms while allowing for a number of social and public sub-centers and open spaces to form along the canal. Each allotment provides a total of $49 \mathrm{~m}^{2}$ per family to encourage diverse typologies to form both indoor and outdoor spaces. Every allotment is supplied with service cores that provide a fresh water supply, electricity, sanitary facilities and integrated grey water and rainwater terraced wetland systems encouraging slum dwellers to grow their own food. Domestic grey water filters through a series of public wetland systems before being stored and recycled. The modular housing framework allows the community to expand with population growth long the coastline.
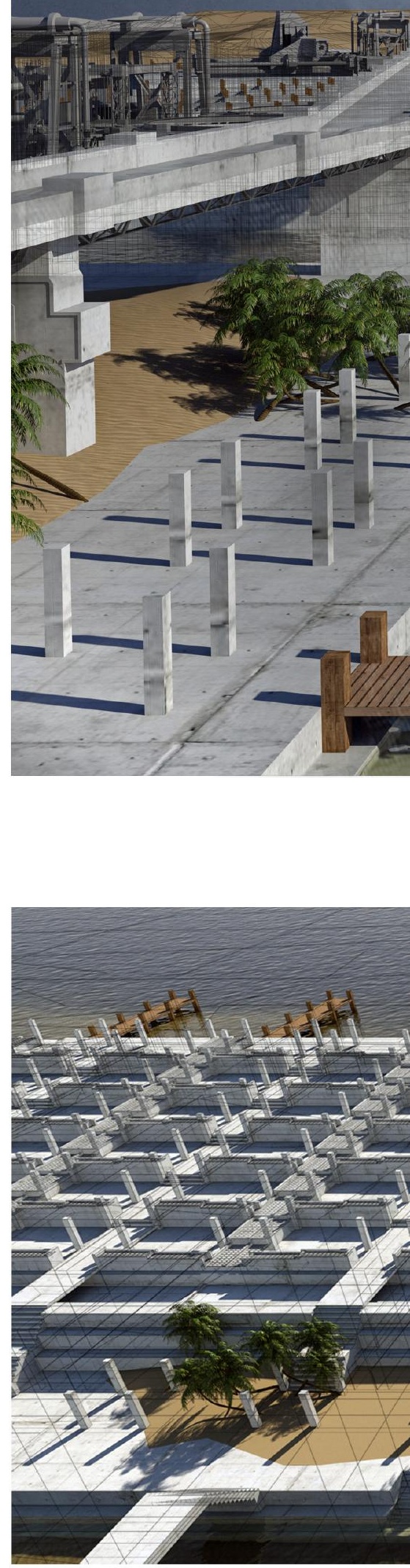


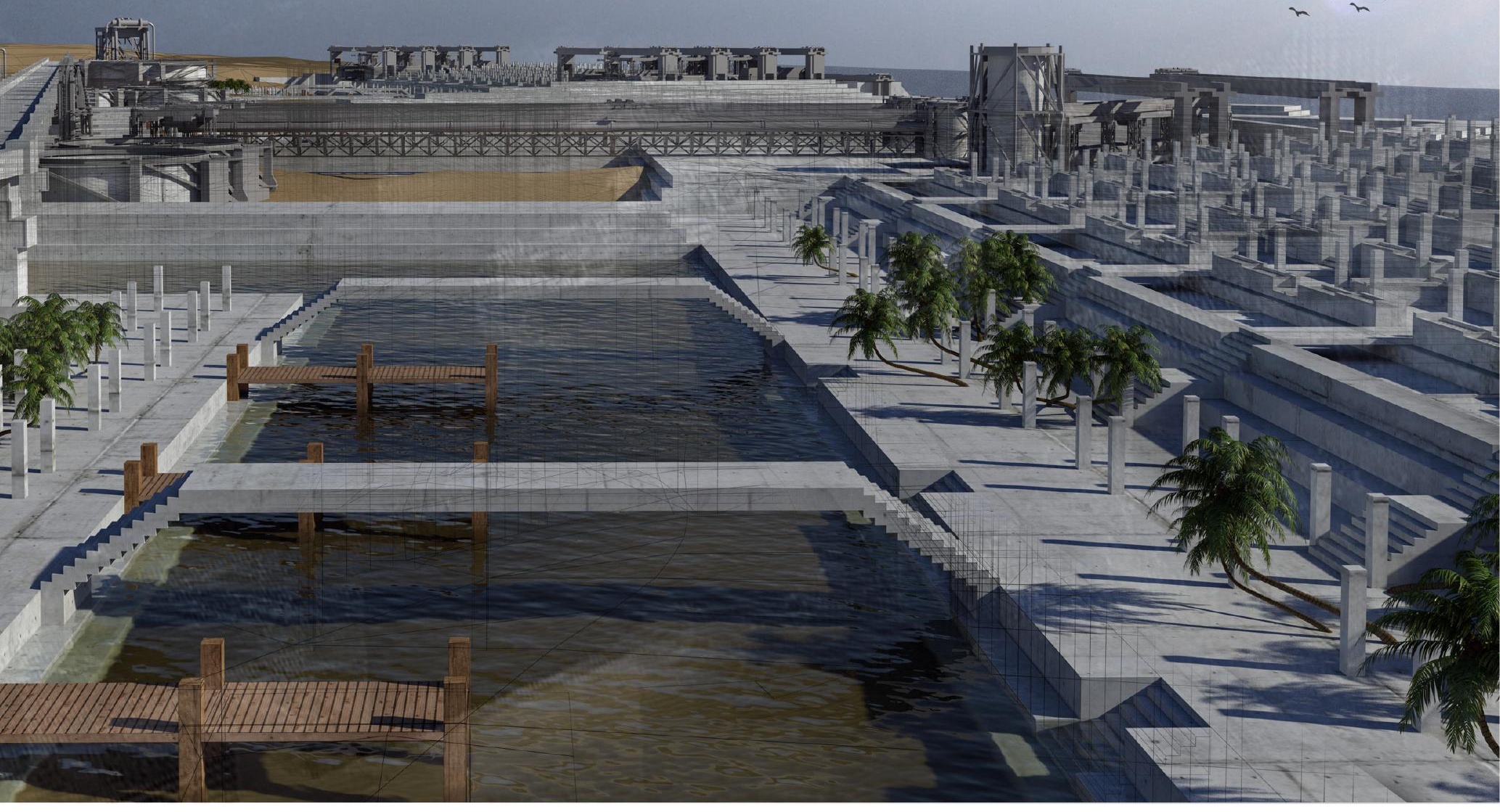

Fig. 168. Perspective sketch illustrating the relationship between fishing vessel mooring, public space and housing terraces.

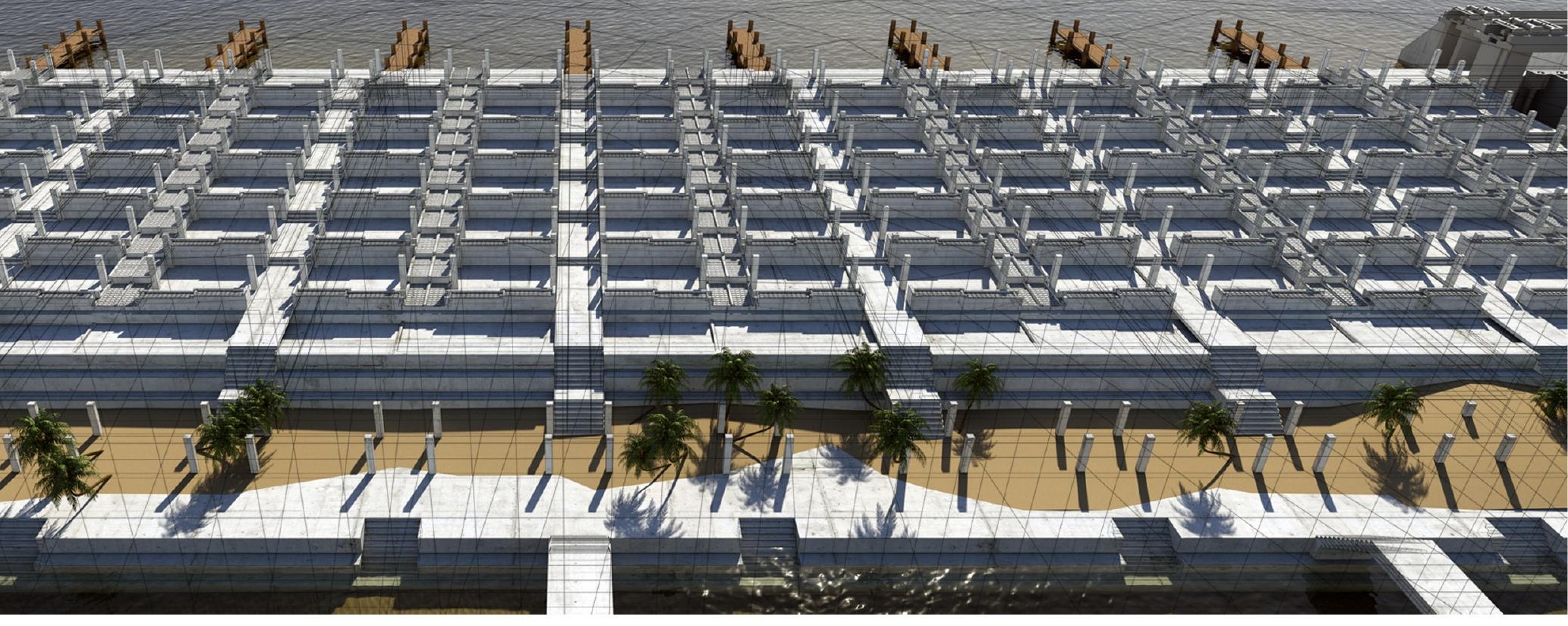

Fig. 169. Perspective sketch of the terraced housing structure. 


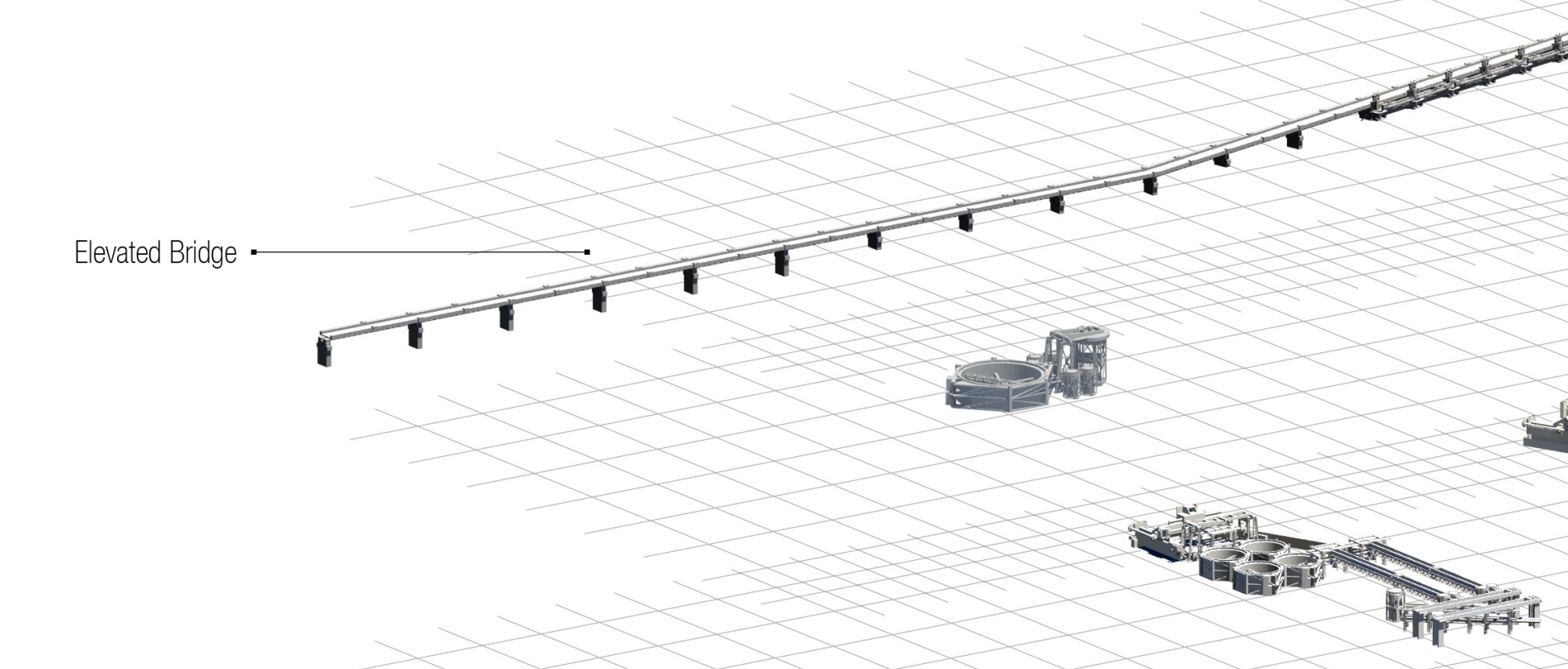

Sewage + Garbage

Treatment

$$
\begin{aligned}
& \text { 1यक्जिता }
\end{aligned}
$$

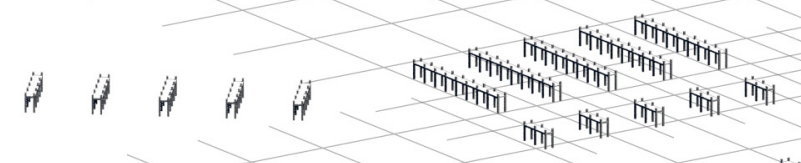

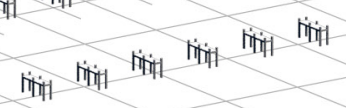

Fishing Vessel

Mooring 


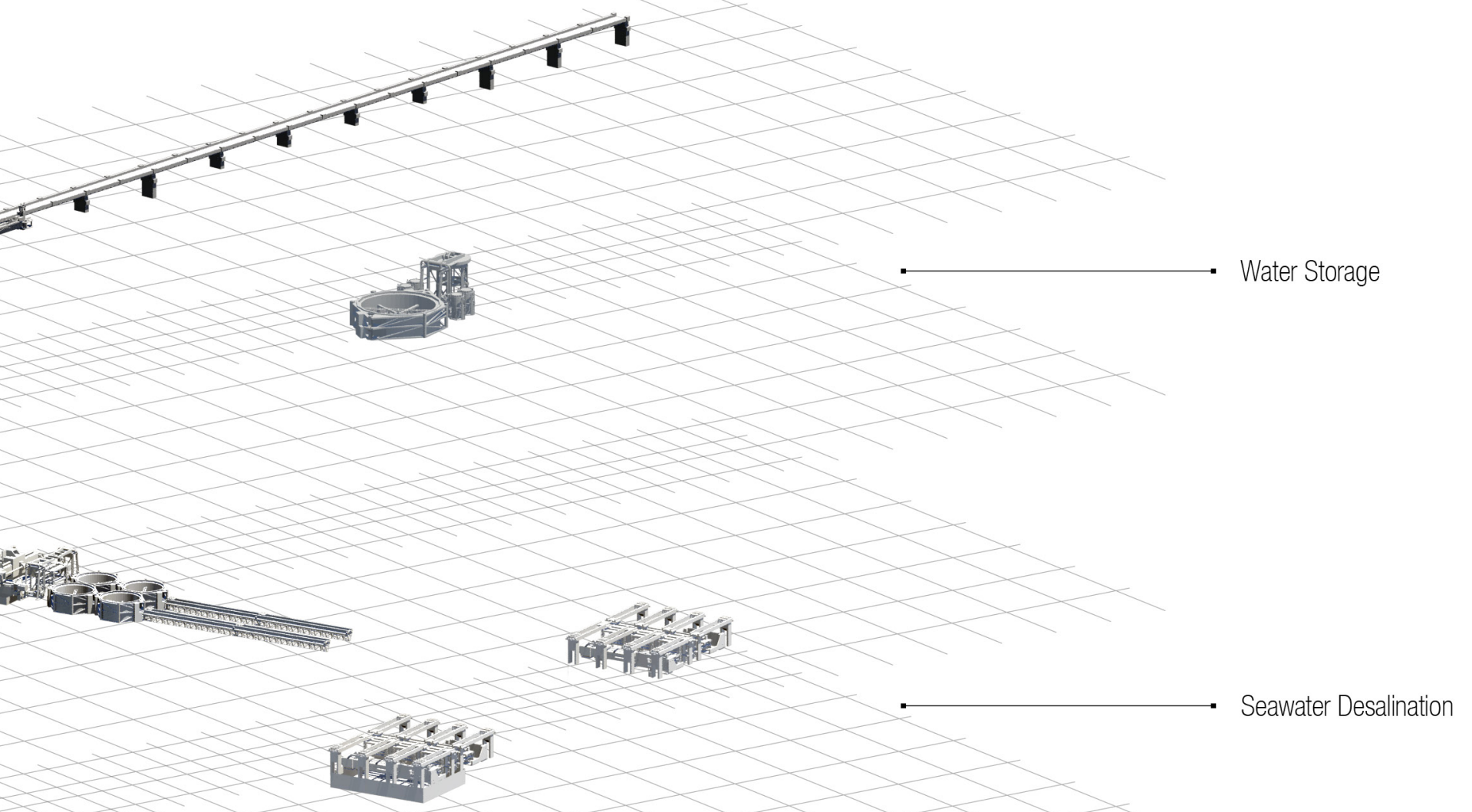

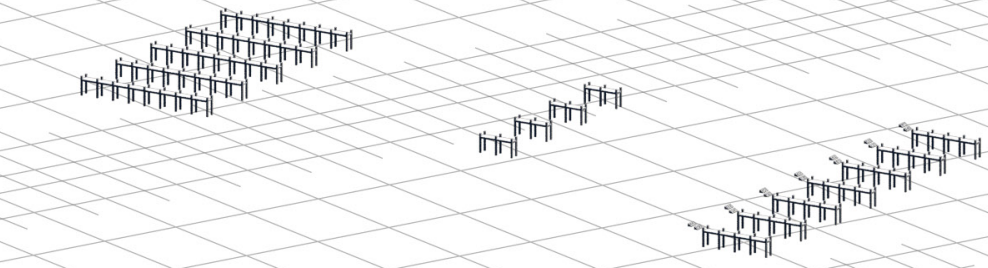
HINAIN
Housing 


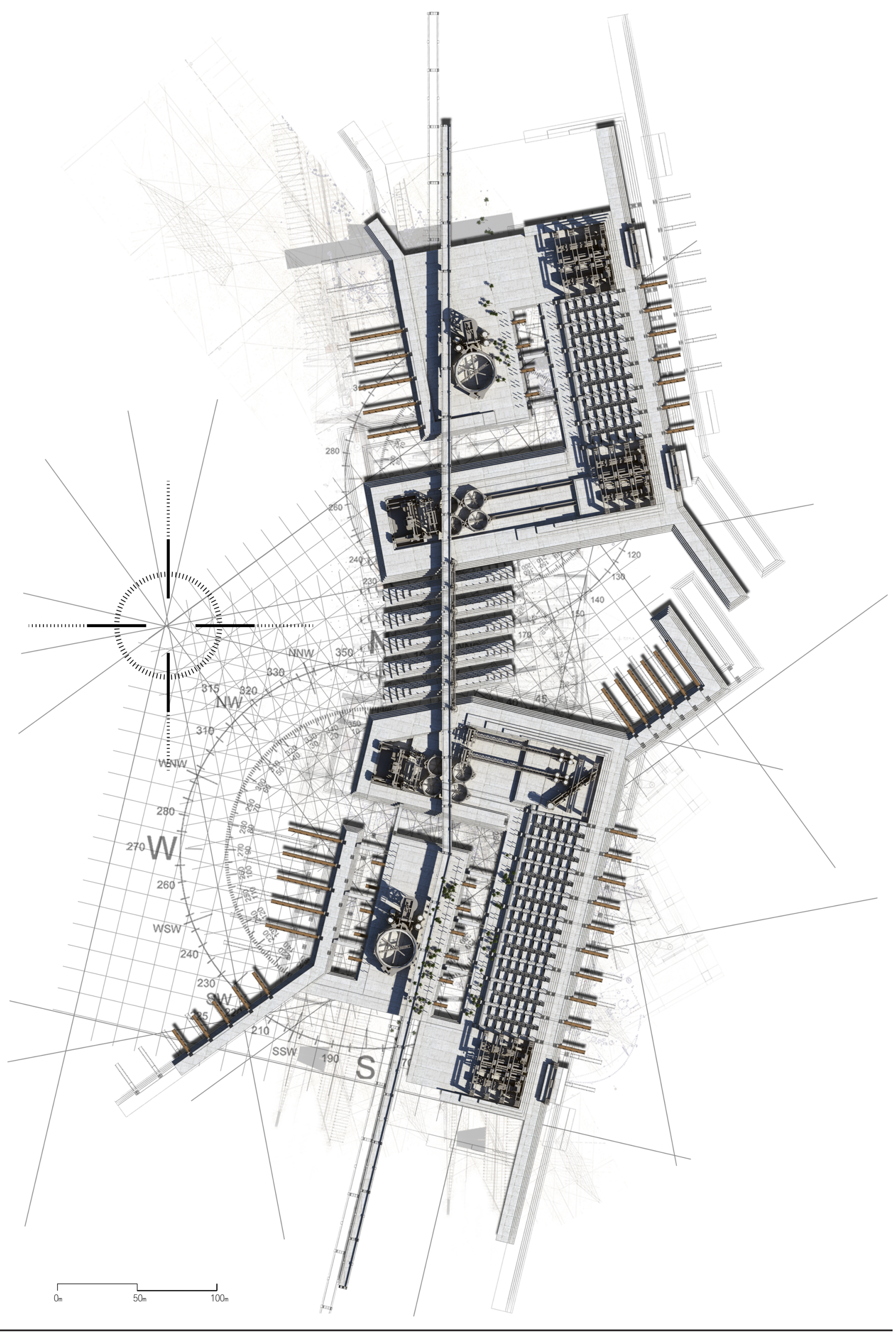

Fig. 171. Conceptual scheme three - Plan. 
PROS:

- The terraced framework creates a vital connection between public/social space and housing platforms giving a sense of communal participation, interaction and belongingness for the inhabitants, reflecting traditional Indian living - public space could be even more generous

- Contemporary translation of terraced ghats meeting the water's edge allows the framework to adapt and evolve with the continual change in tidal water levels

- Expressive of coastal fishing community function and identity

- Breakwater system, river mouth hardscape, as well as fishing vessel and housing structure respond well to framing site dynamics such as the variation in river mouth structure, the directional flow of the river, extended grids of the surrounding urban grain and the prevailing northeast storm patterns

- Modular housing platforms allow for the framework to adapt, evolve and expand with population fluctuation and growth of informal settlements

CONS:

- Vehicular and pedestrian access via the elevated bridge system spanning the river mouth creates isolation from the framework

- Machine and housing components could be even more fully integrated to illustrate a framework representative of a living machine as opposed to separate entities 


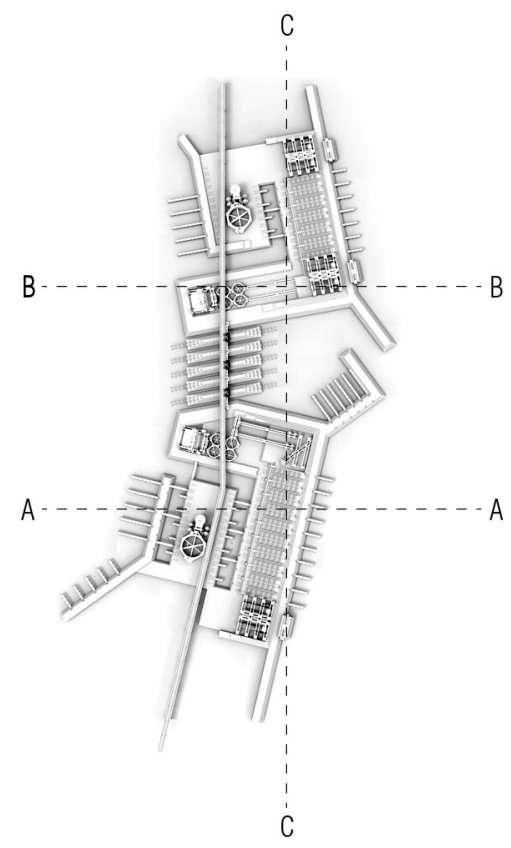

Section AA

Y.

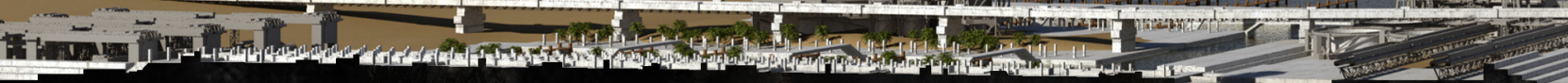
If

Section CC 


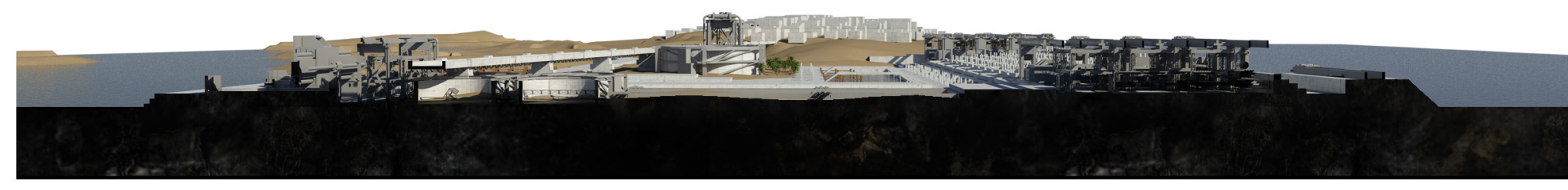

Section BB

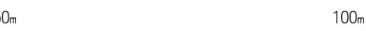

are $x$ -

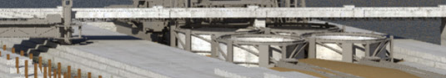


The Preliminary Design Chapter has tested a number of iterative design experiments testing ways to mitigate a range of diverse environmental problems. These experiments illustrated how each design can draw from the extreme conditions of the site to assist the function of the architectural framework, through the use of innovative new environmental technologies. 


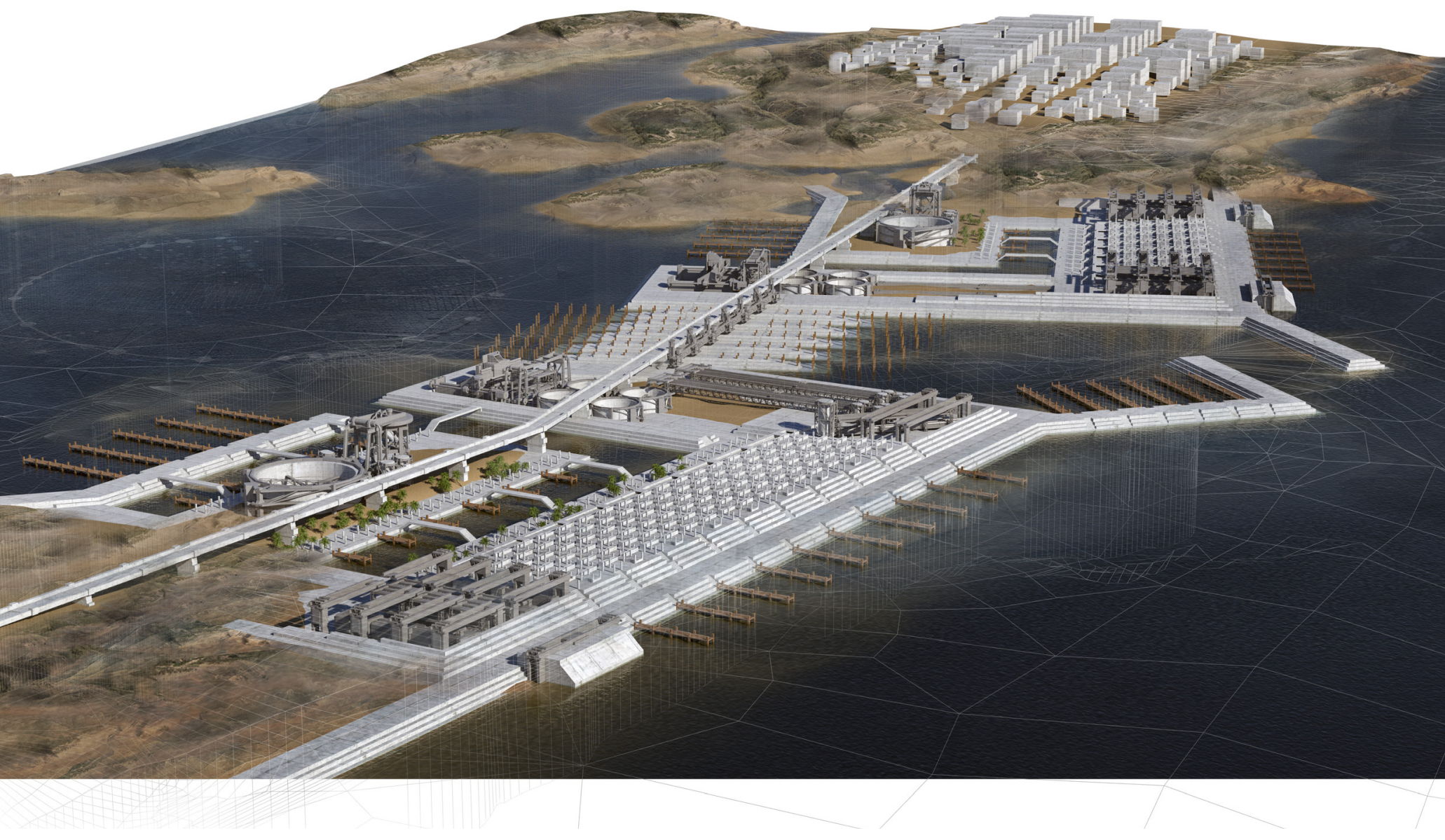

Fig. 173. Conceptual scheme three - Perspective. 


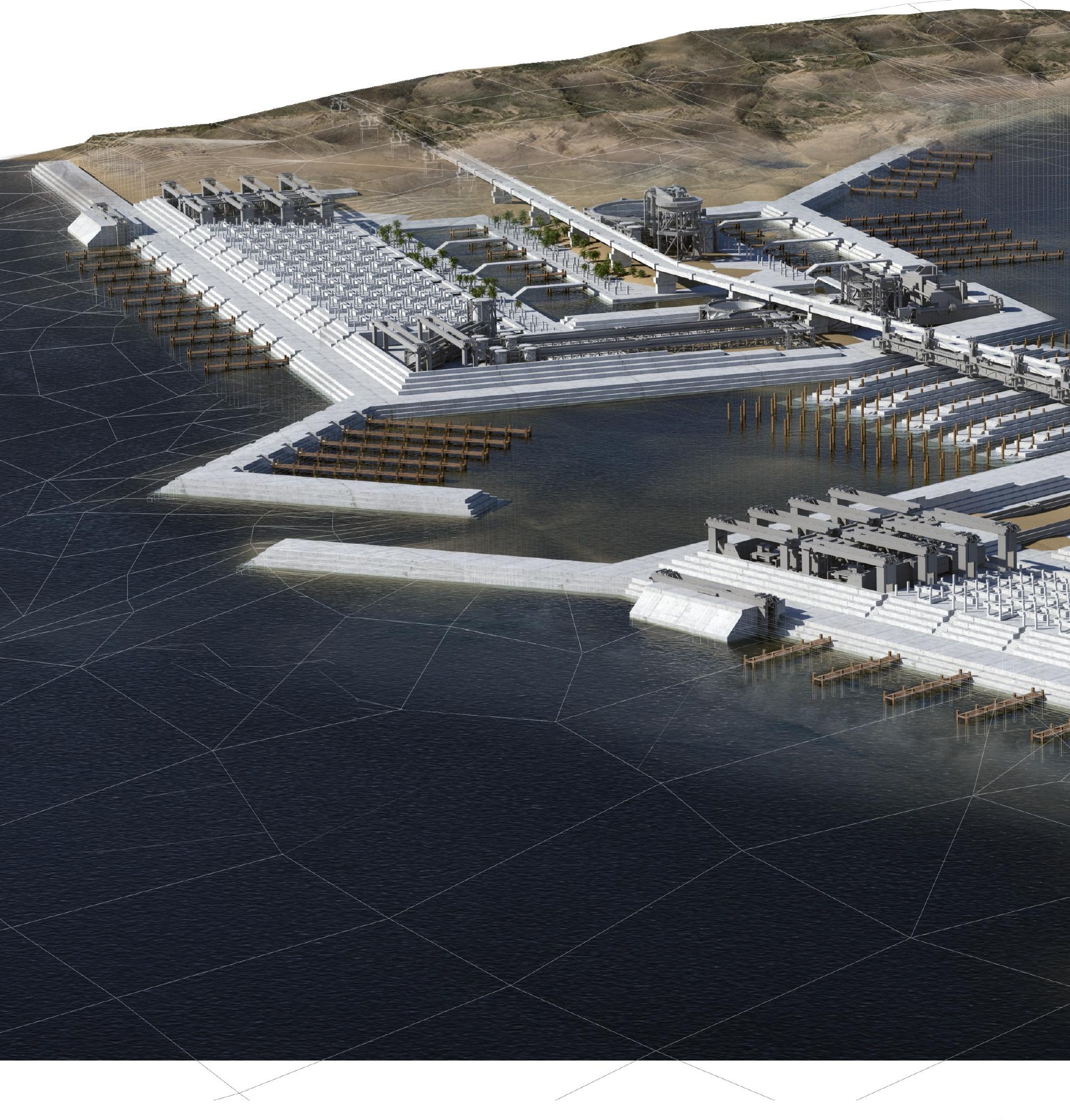

Fig. 174. Conceptual scheme three - Perspective. 


\subsection{DEVELOPED DESIGN}

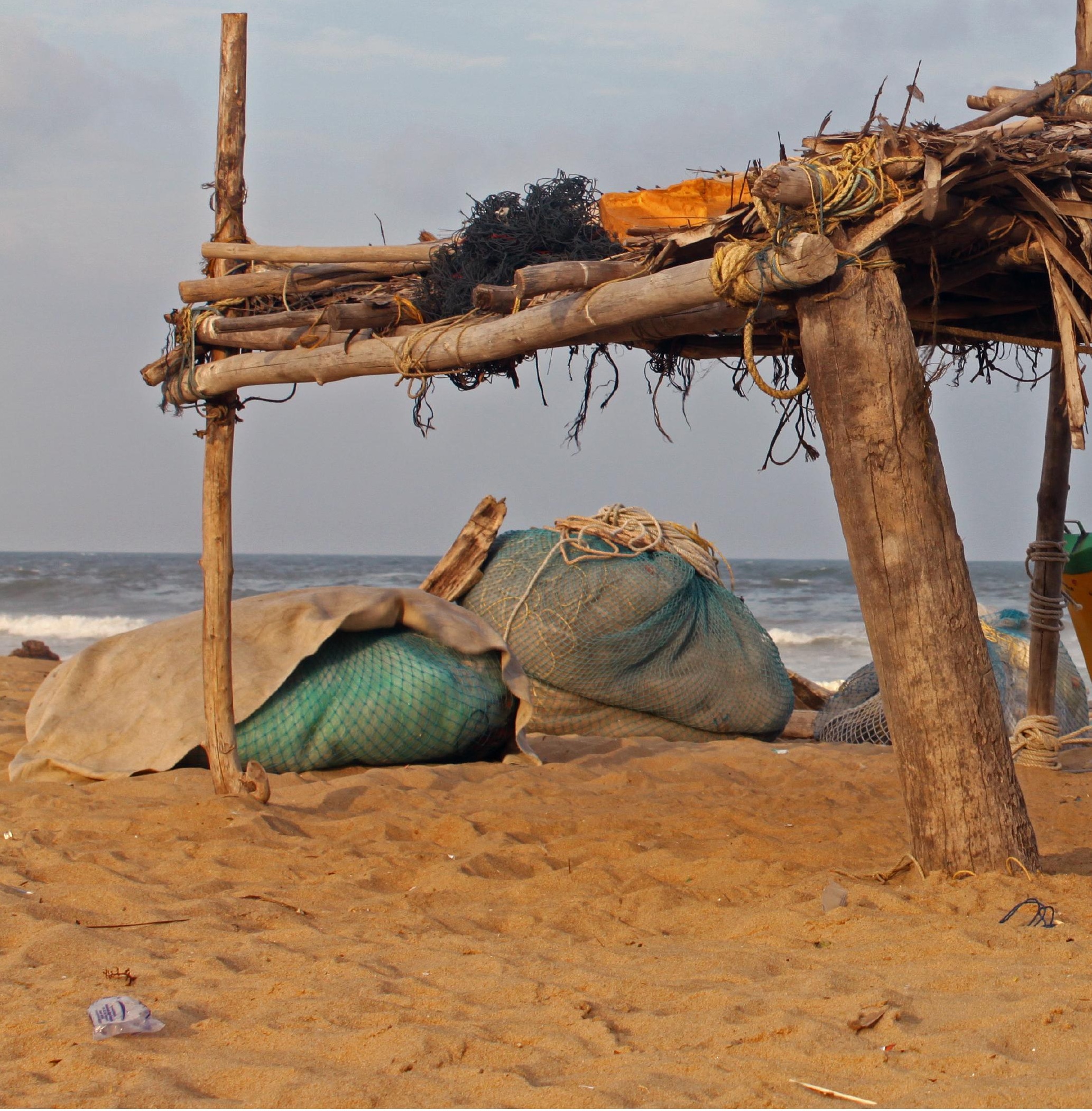




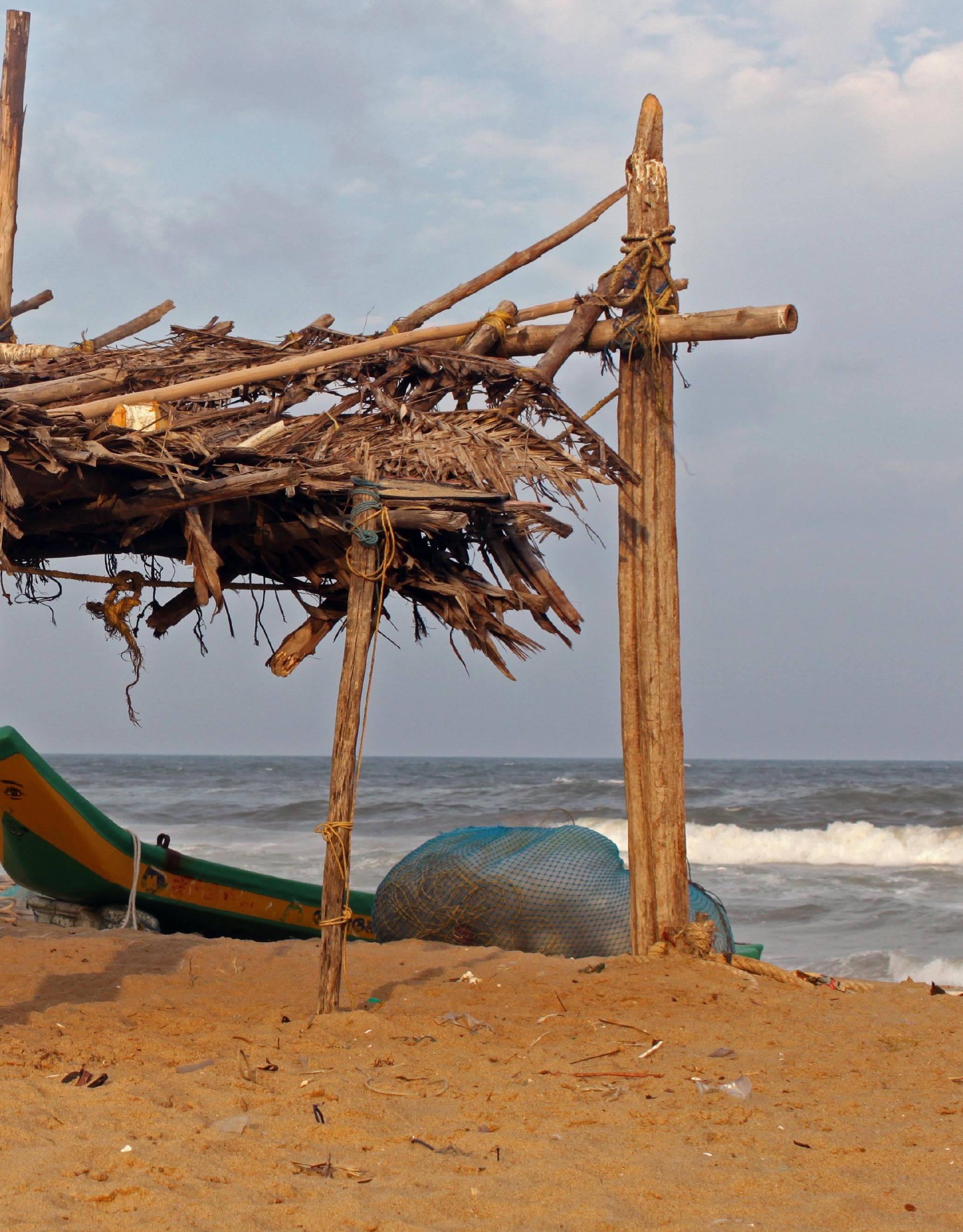




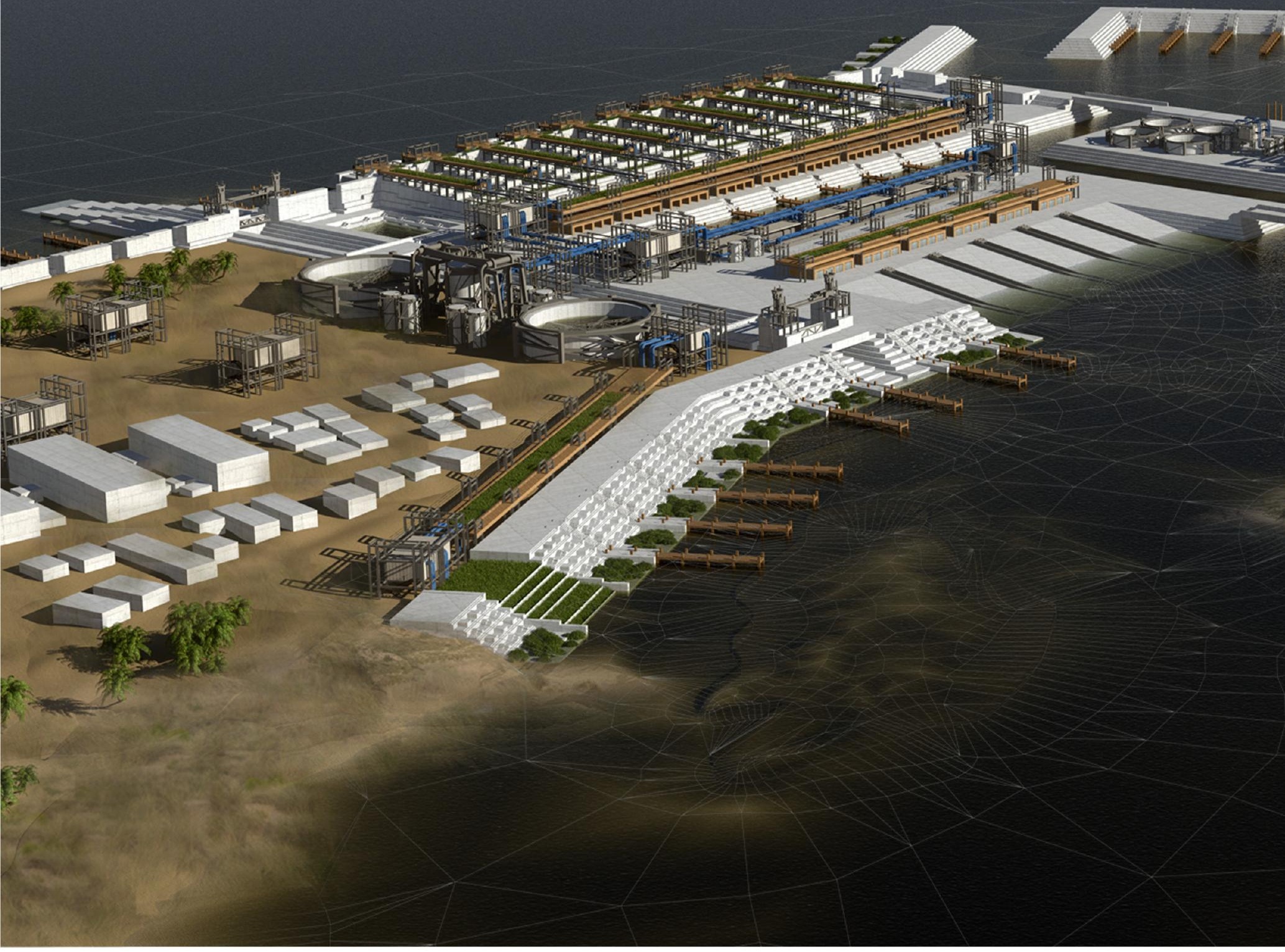

The developed final framework articulates a network of internal systems responding to external conditions to form a unified, self-sustainable and adaptable framework for the community of Srinivasa Puram. Fully incorporated systems such as natural disaster mitigation structures, renewable energy sources as well as fresh water, sewage and garbage treatment plants represent a dynamic model that is the framework for the thesis approach "Inhabiting the Machine".
This chapter critically reflects on how well the developed design has established a self-sustainable architectural framework for coastal slum dwellers while helping mitigate environmental disasters and pollution for the immediate and extended site. 

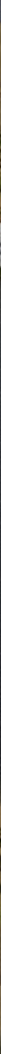

Fig. 176. Developed design-Perspective. 


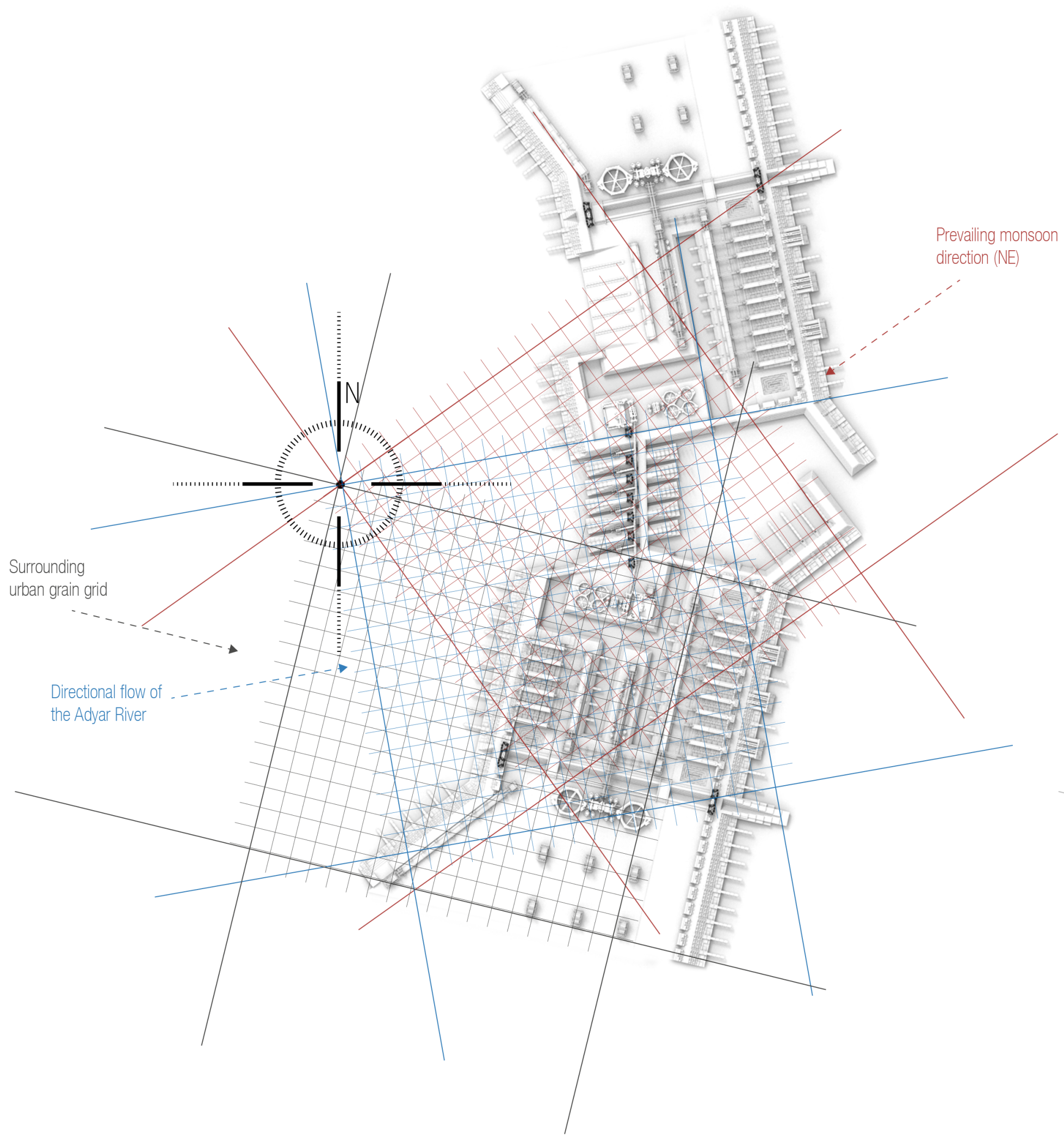




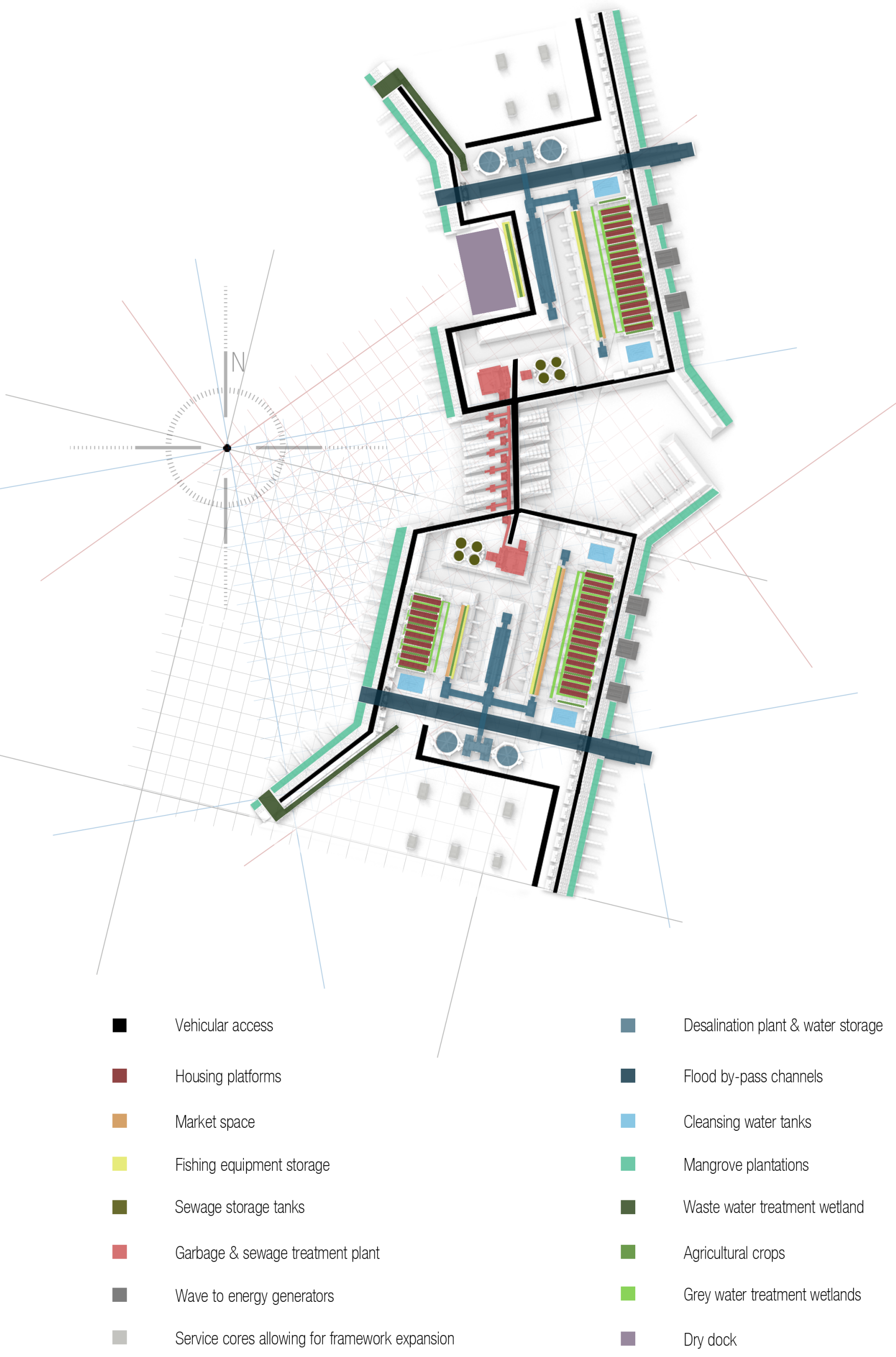

Fig. 178. Program diagram 
Machine

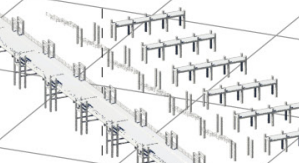

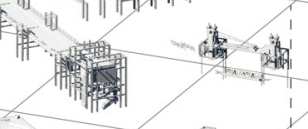
int hines

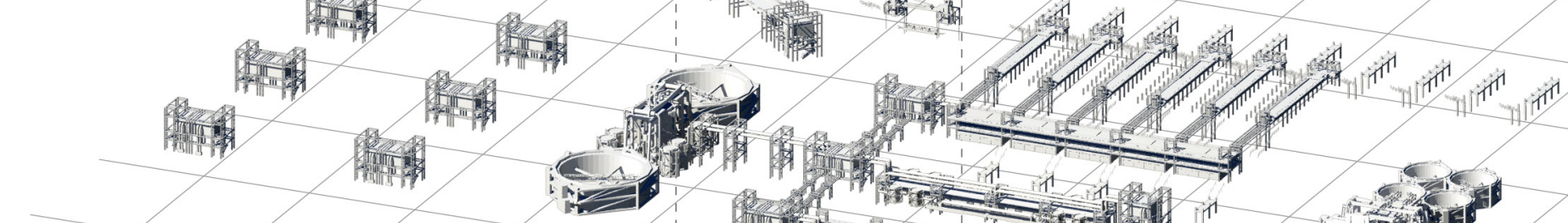
(> 


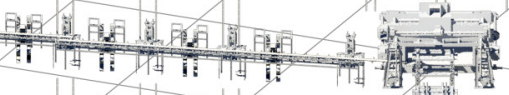

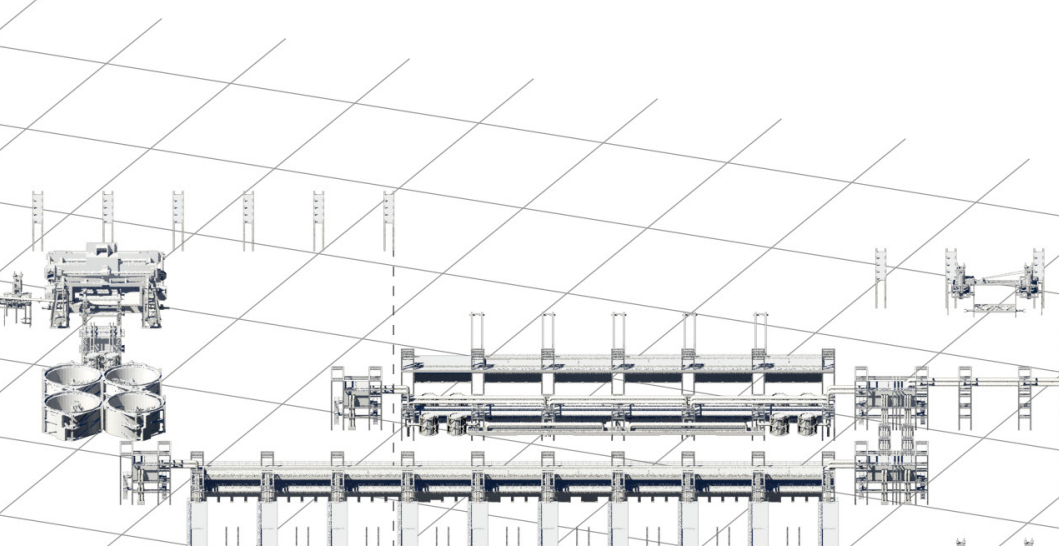

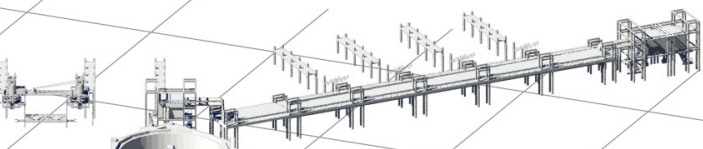

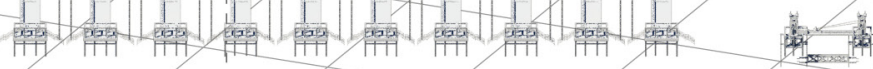

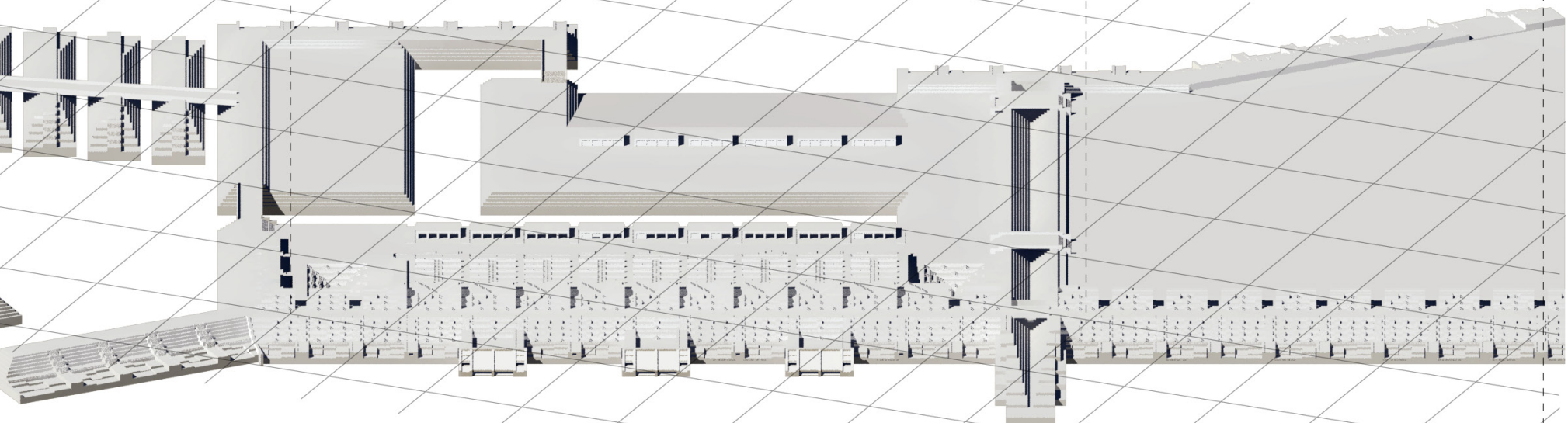


Integrated terraced

wetlands

Agriculture canopies

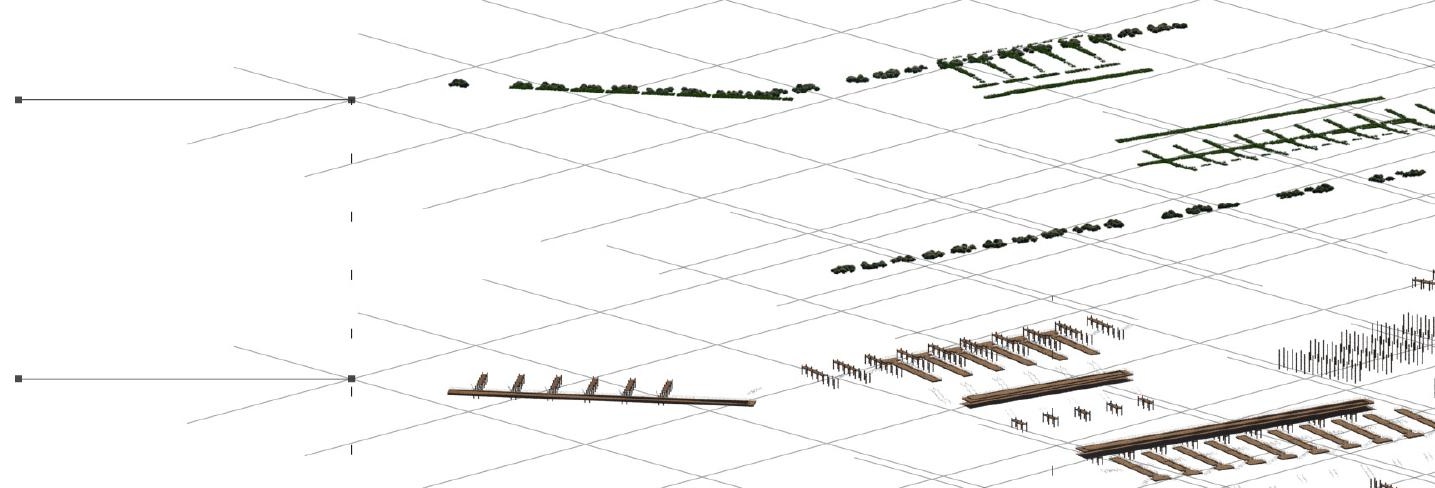

River Mouth infrastructure: Sewage \& garbage treatement,

Flood channel gates,

Wave to energy converters

Service cores,

Water \& Sewage storage tanks

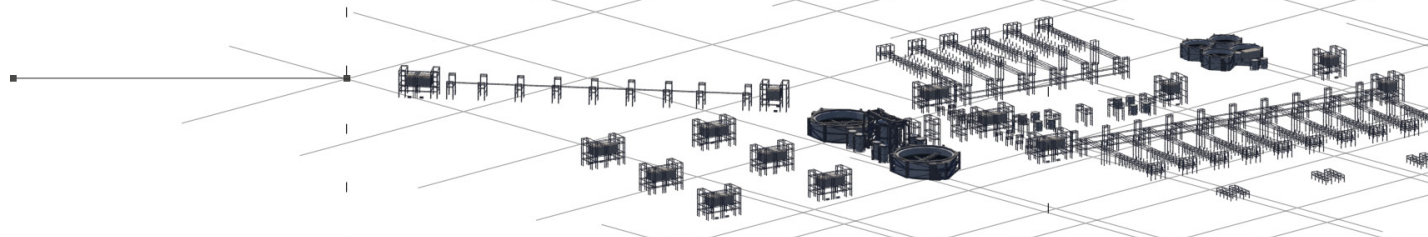

Architectural Hardscape including:

Breakwater system,

River mouth,

Flood channels,

Terraced housing platforms

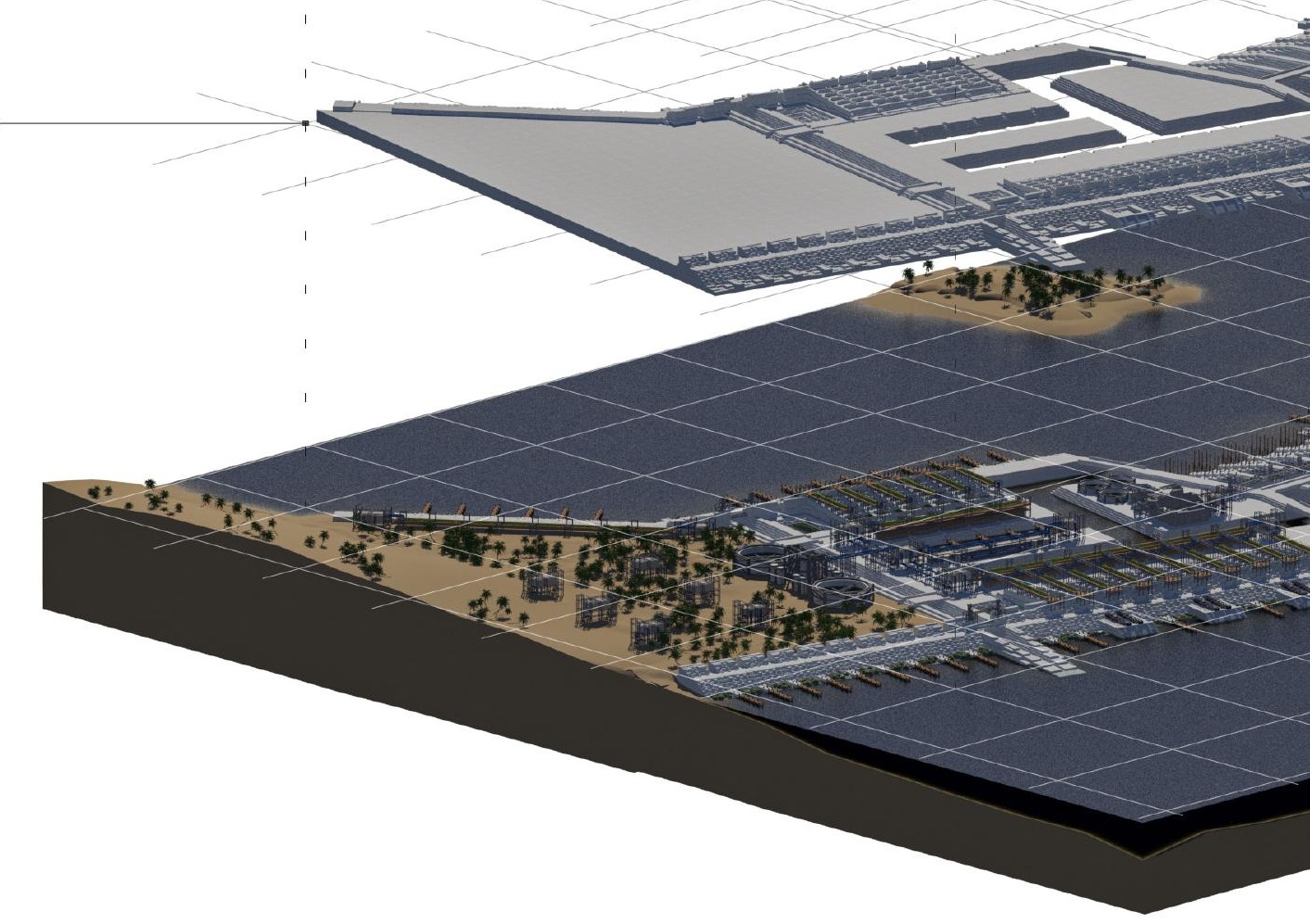




\section{MITIGATING THE STORM}

The proposed breakwater design (Figures 181-184) has been developed as a multi-system structure that responds to dynamic site conditions including rising sea levels, storm surges, tsunamis approaching from the Bay of Bengal in the east and monsoon flooding from the Adyar River in the west. The alignment of the structure provides shelter from the prevailing northeast weather patterns while preventing the formation of future sandbars that are currently causing a buildup of stagnant pollution destroying the surrounding ecosystem and contributing to widespread flooding up stream. The structure reflects a contemporary translation of traditional South Indian ghats to form a terraced barrier system stepping up from the seabed and estuary floor until the low tide line. Here an open hardscape provides a platform to reintroduce mangrove plantations within the littoral zone to help naturally dissipate wave and wind energy generated from storm surges, tsunamis and flooding, as well as mitigating coastal erosion and rejuvenating the surrounding ecosystem by providing a natural habitat for native flora and fauna.
Wharf structures provide fishing vessels with safe mooring conditions that adapt to the change in water levels with buoyancy devices as opposed to the current solution of boats being pulled onto the vulnerable beach. The modular terraced ghat structure provides access to mooring structures and the water's edge while elevating a vehicular and pedestrian platform $6 \mathrm{~m}$ above the high tide line. Six wave-to-energy generators are integrated into the breakwater system as a predictable, daily scheduled and dependable source of renewable energy. With reference to the LIMPET 500 case study in Hebridean Island, Scotland, the proposed wave-toenergy scheme for Srinivasa Puram has the ability to produce 15,000 kilowatts of renewable energy per day.
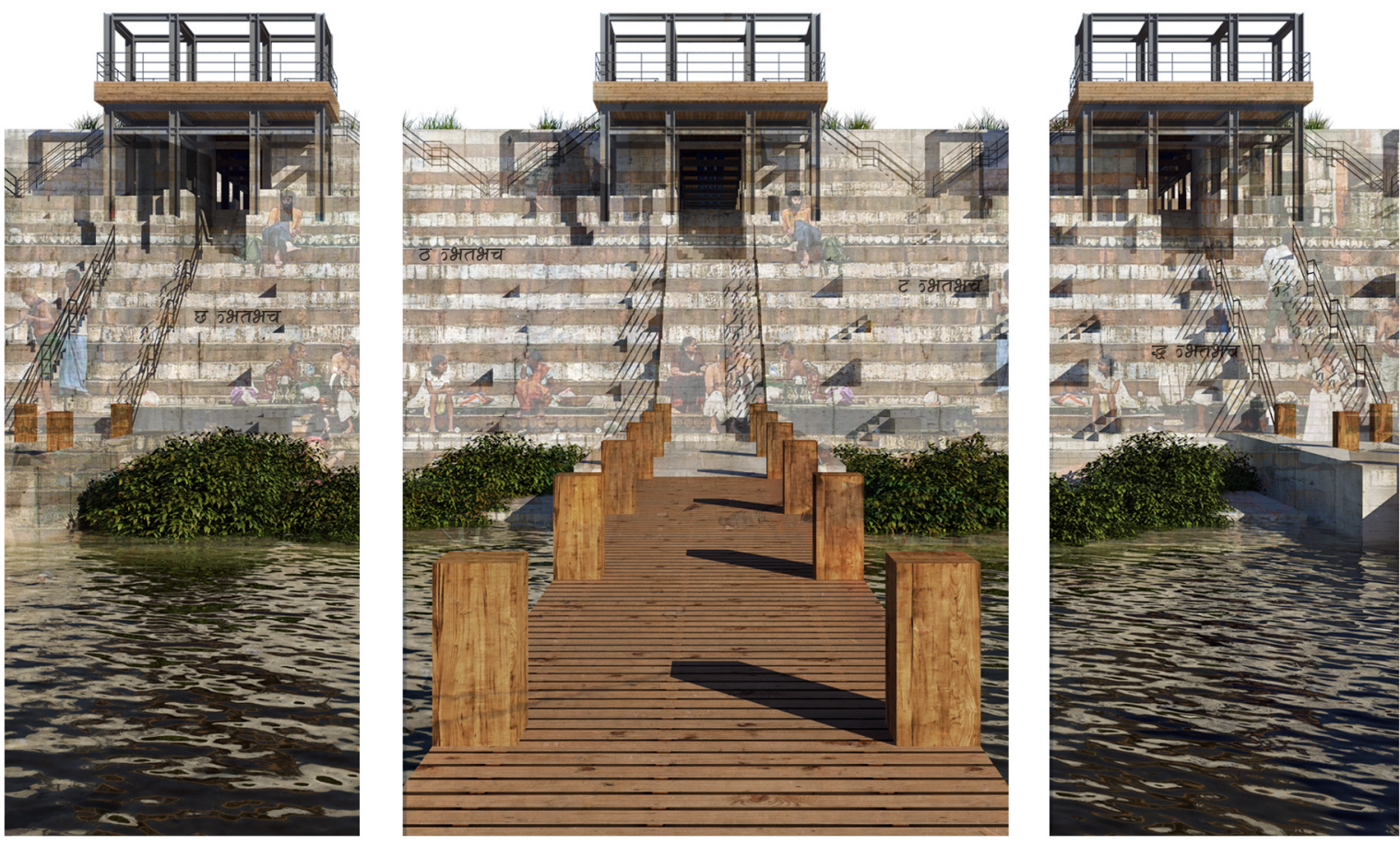

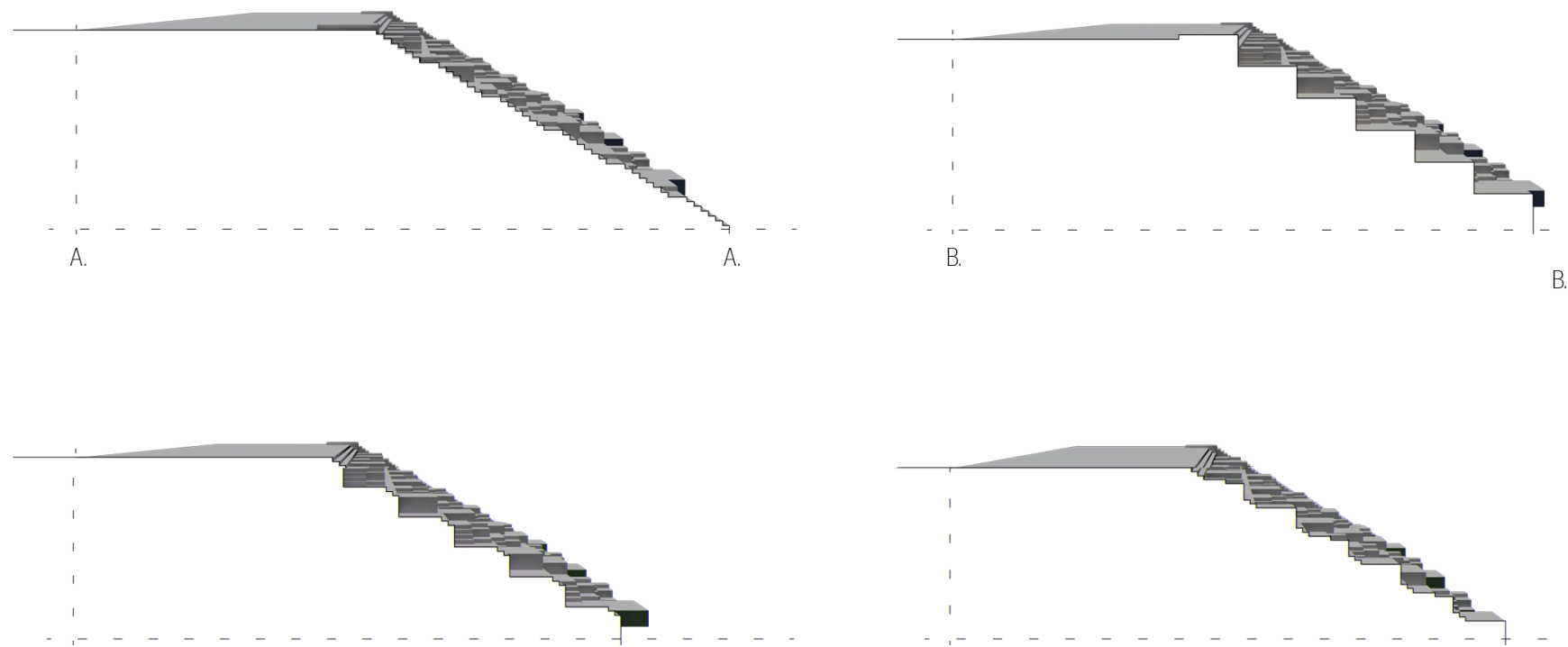

C.

C.

D.

D.
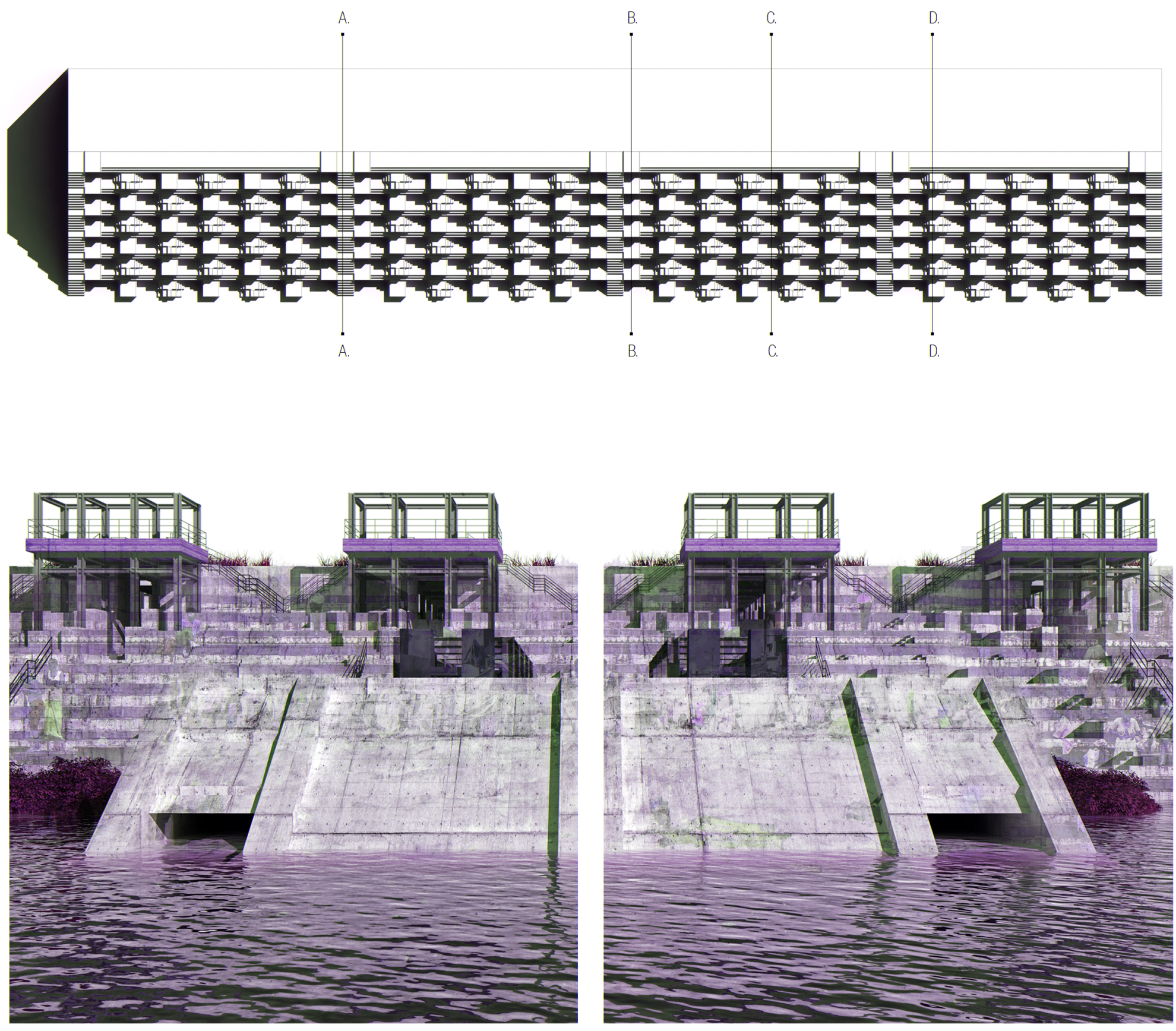
The architectural hardscape is designed to mitigate the effects of a worst case scenario where monsoon flooding meets a high tide or storm surge. The framework integrates two flood bypass channels, increasing the flow rate of the river mouth and minimising flood damage to the immediate and extended site.

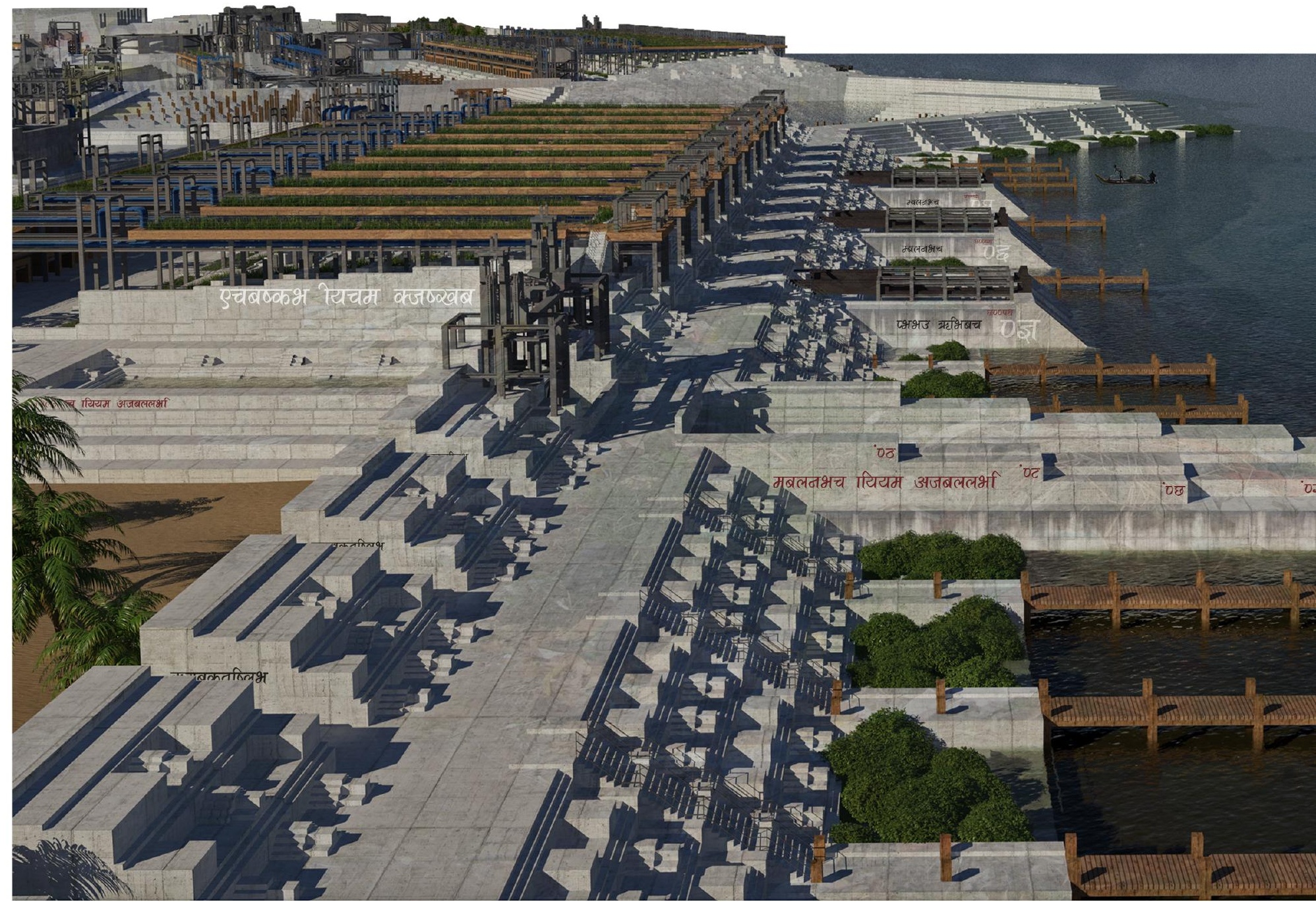

01. 


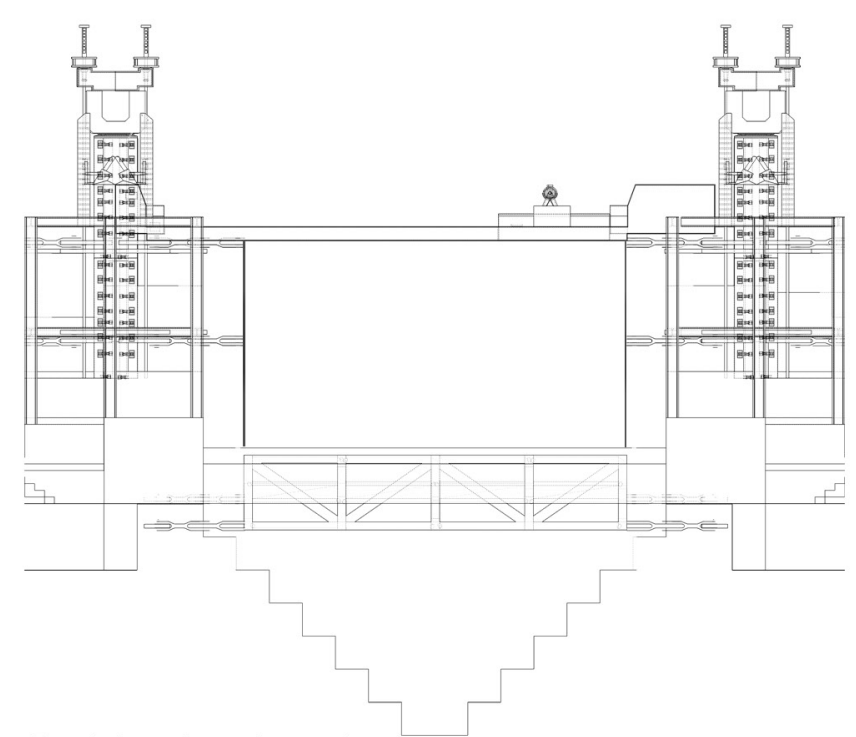

Flood channel gate lowered

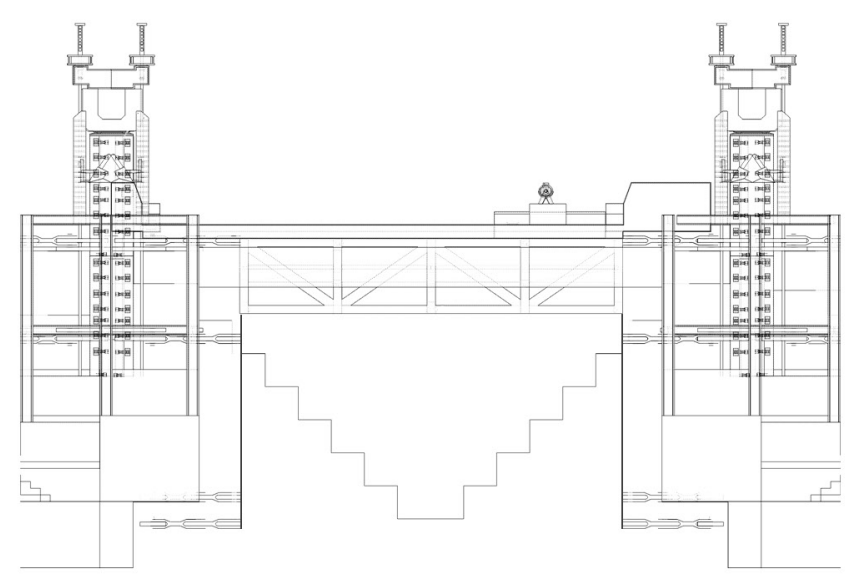

Flood channel gate raised

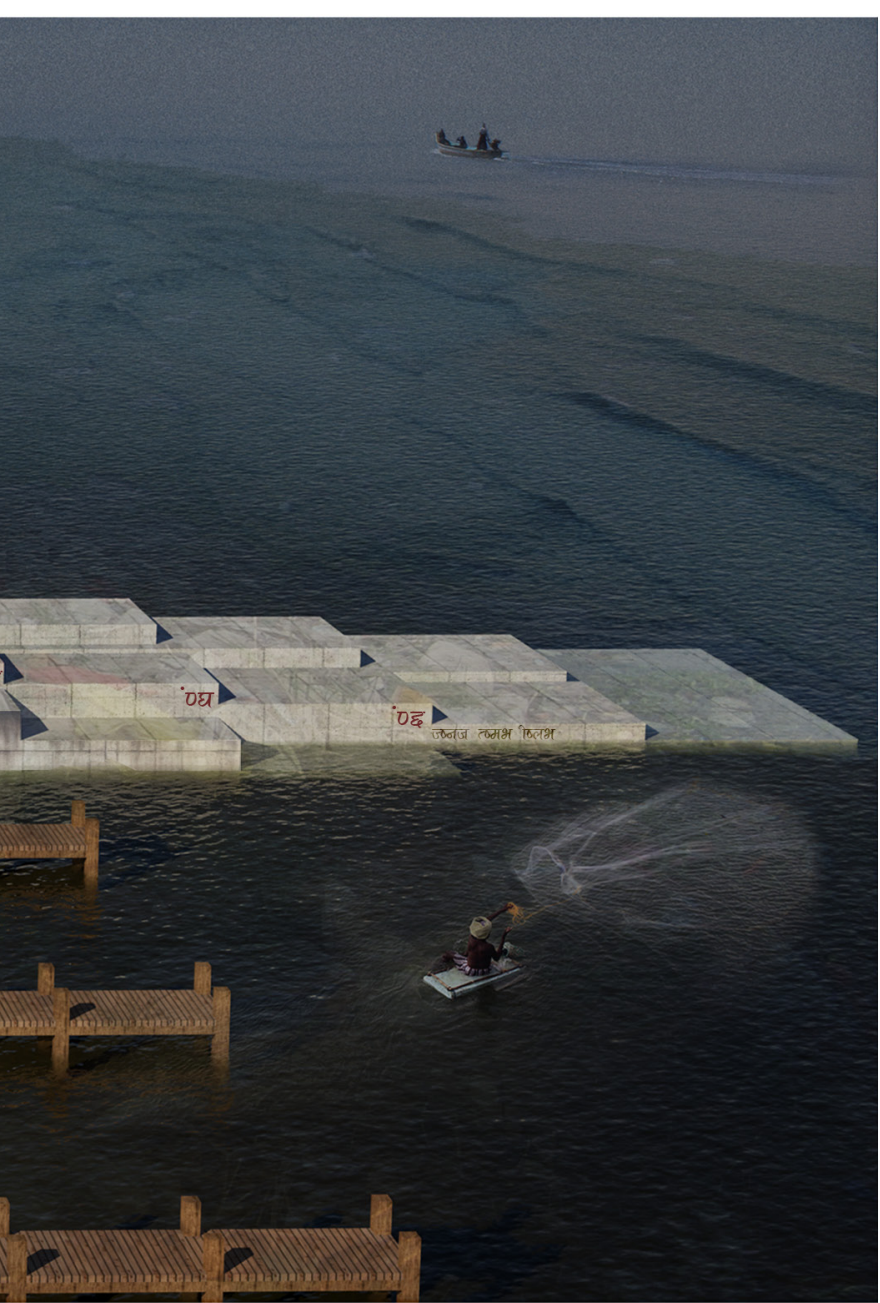

Site Plan

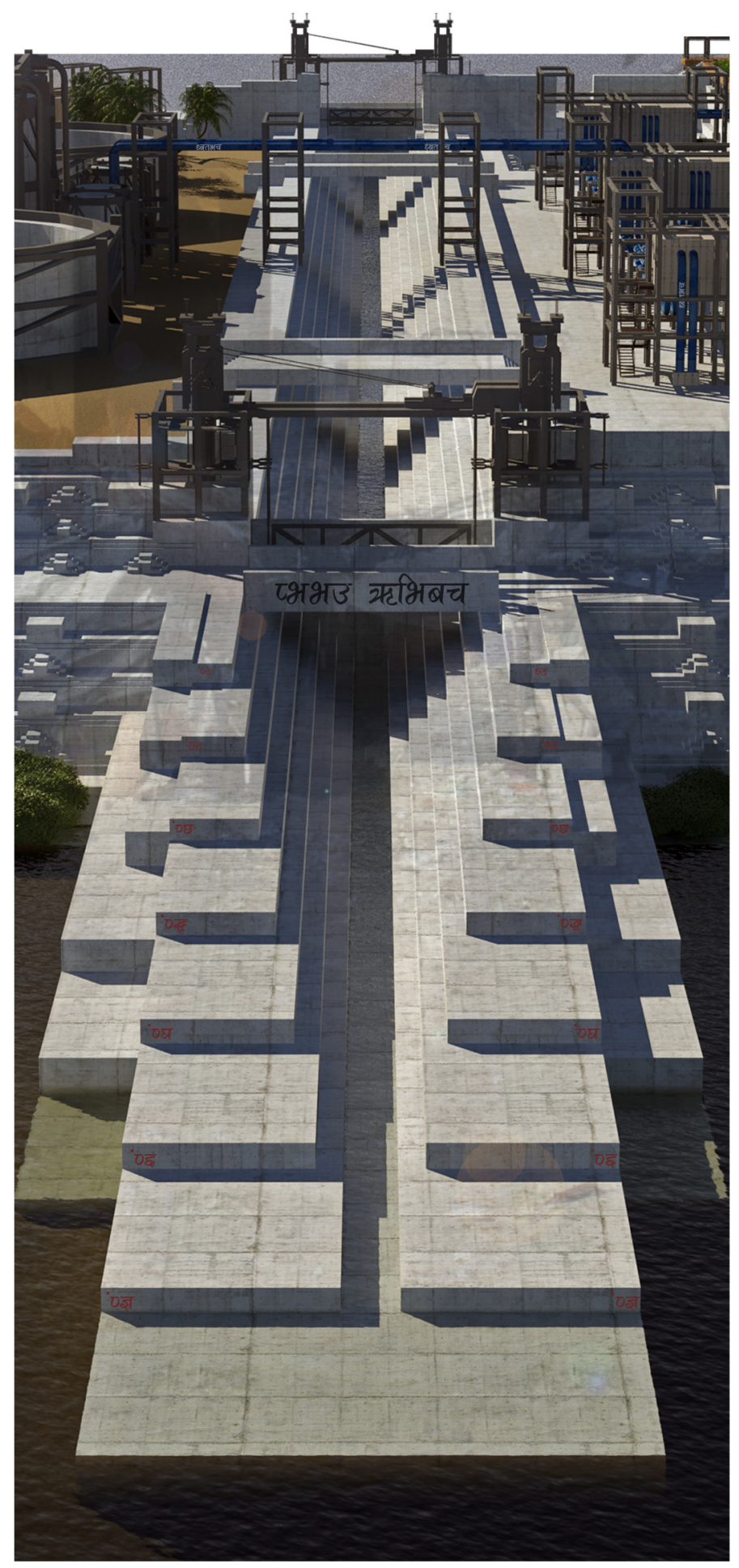




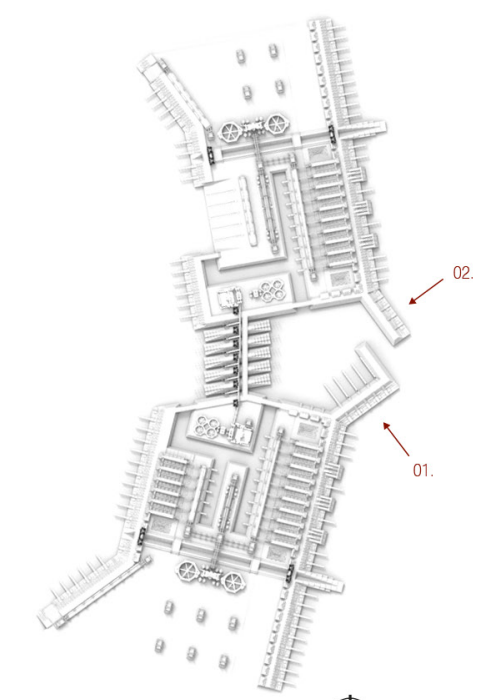

Site Plan

$\oplus_{N}$

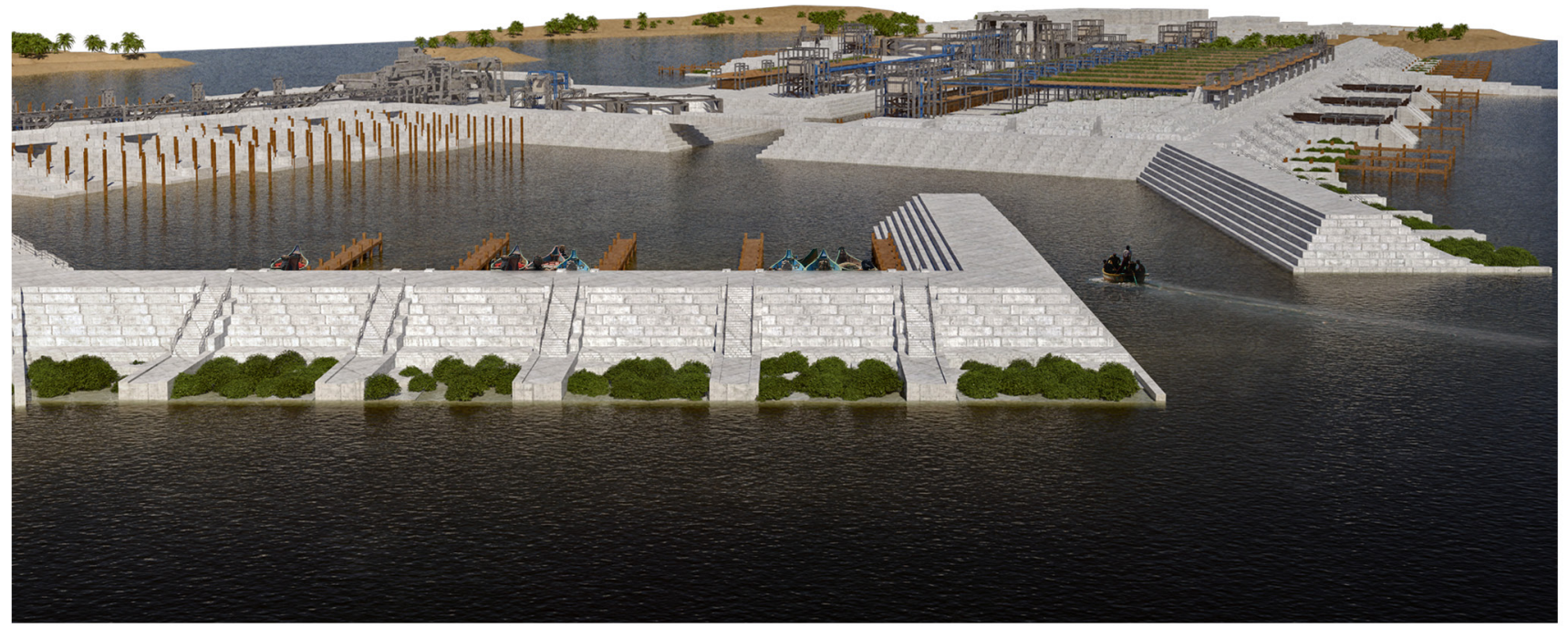

01.

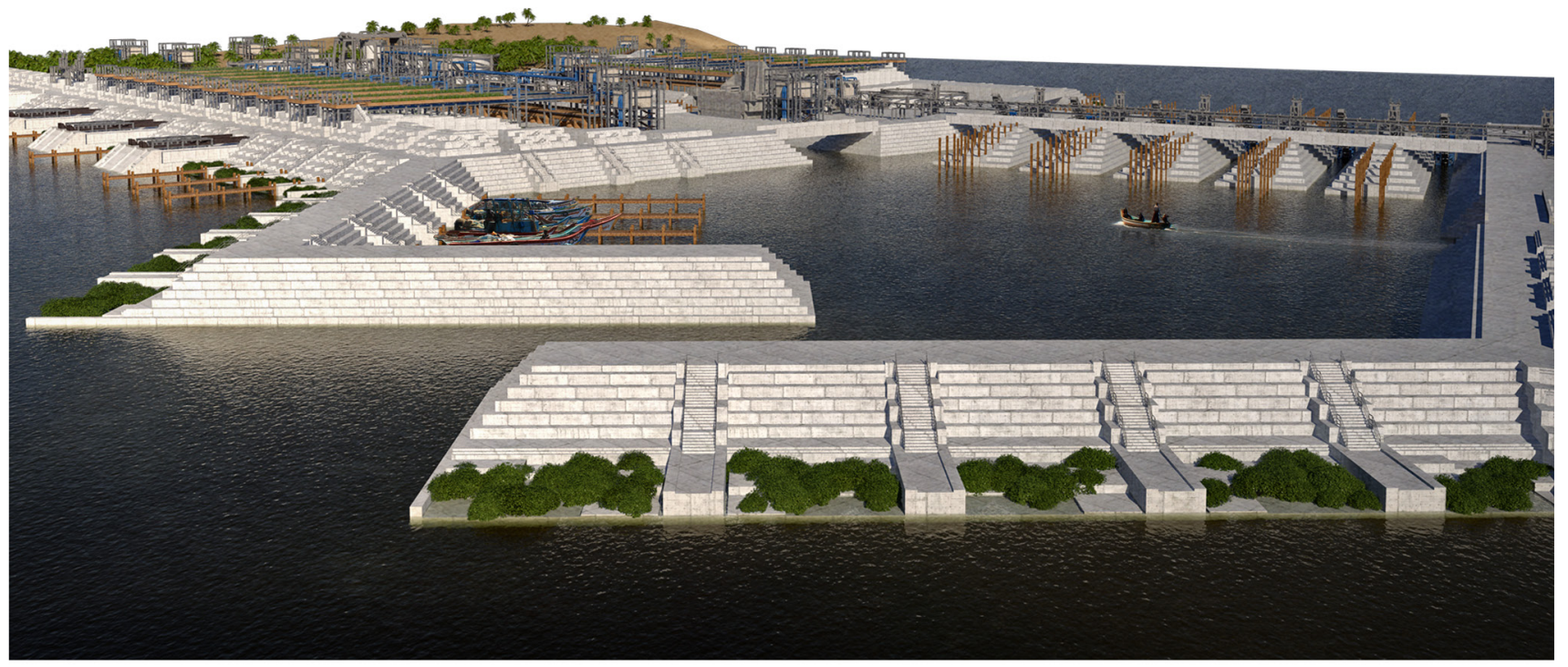

02 


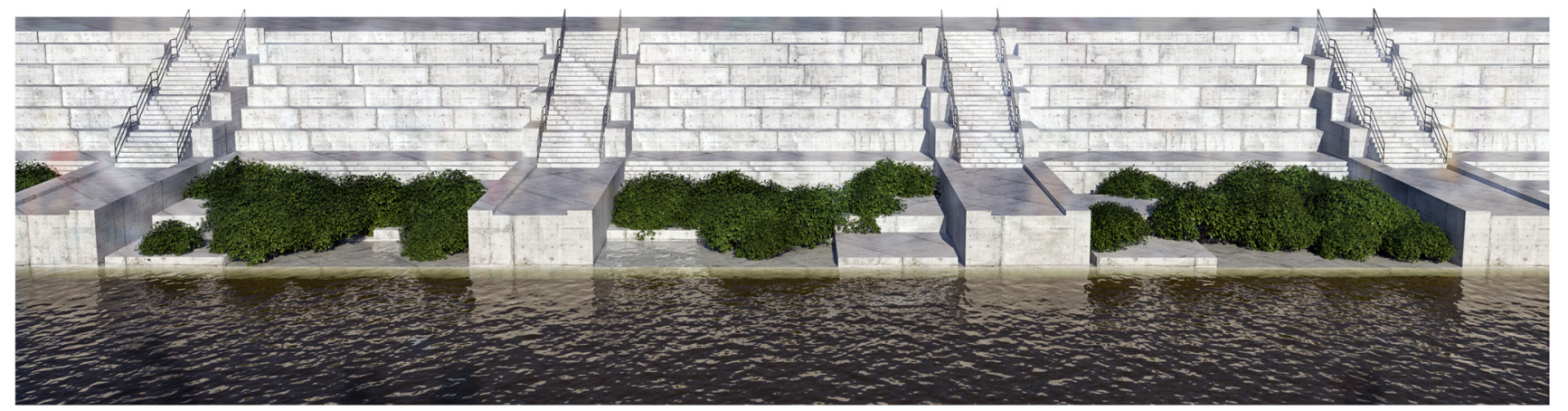

Low tide water level

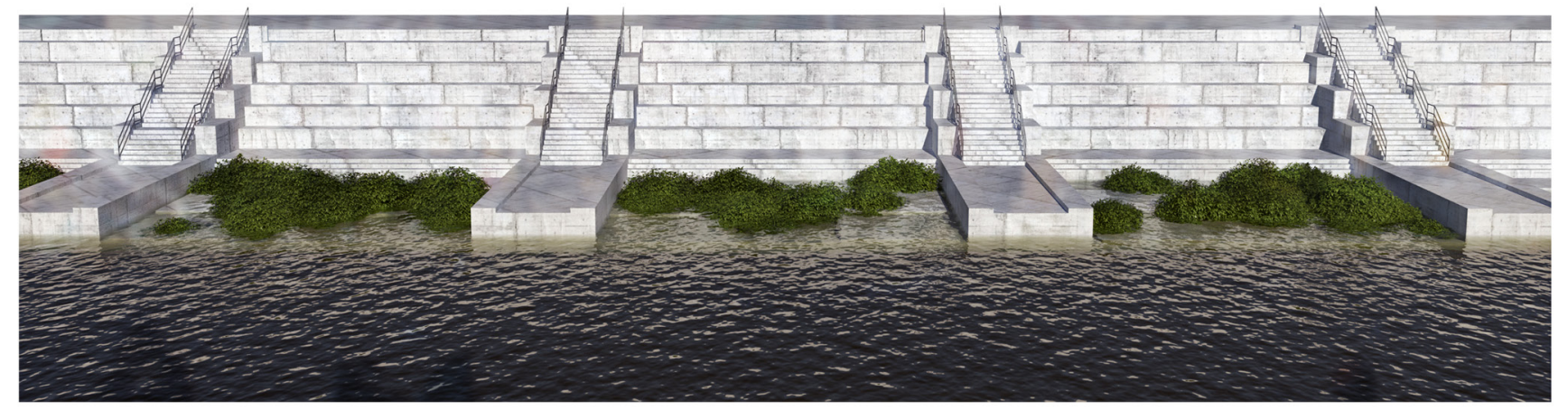

High tide water level

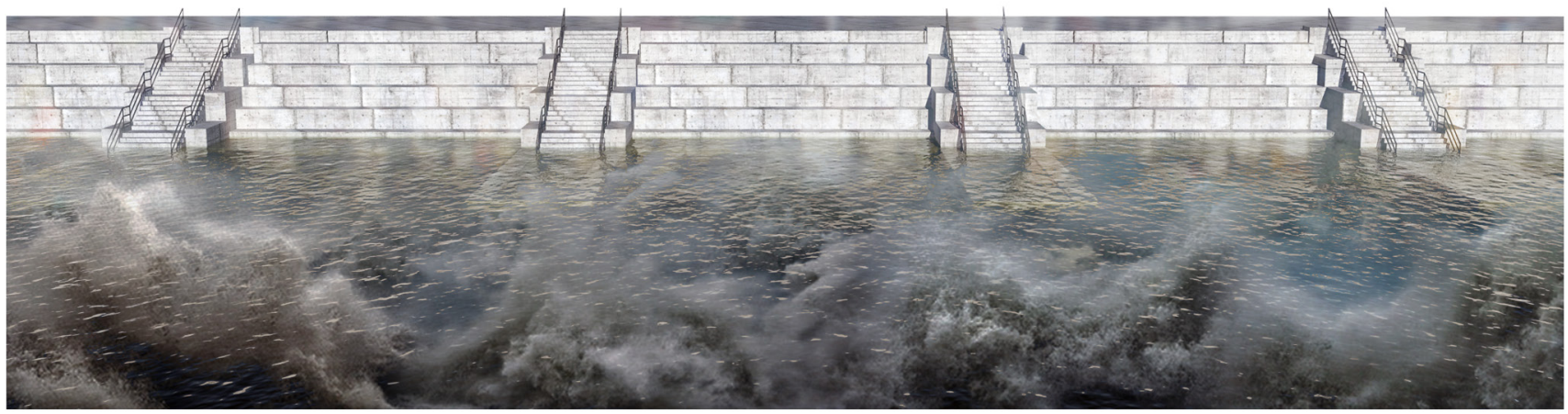

Worst case scenario of $1 \mathrm{~m}$ sea level rise or storm surge

Fig. 184. Effects of water level against the breakwater system. 

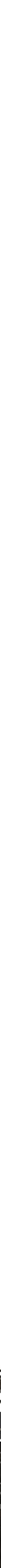
CLEANSING THE ENVIRONMENT

The developed design of the river mouth (Figures 185187) reflects a contemporary translation of traditional South Indian cleansing rituals at an urban scale. The design is configured as a hybrid of both architecture and machine to "cleanse the river" of pollution, while also helping to mitigate environmental disasters and generate renewable energy. The terraced hardscape allows for the Adyar River to benefit from a continual flow rate throughout the year while adapting to changes in water levels. The developed design further remediates environmental pollution and enhances hygiene issues by integrating innovative technology similar to the Baltimore Solar-Powered Water Wheel case study.

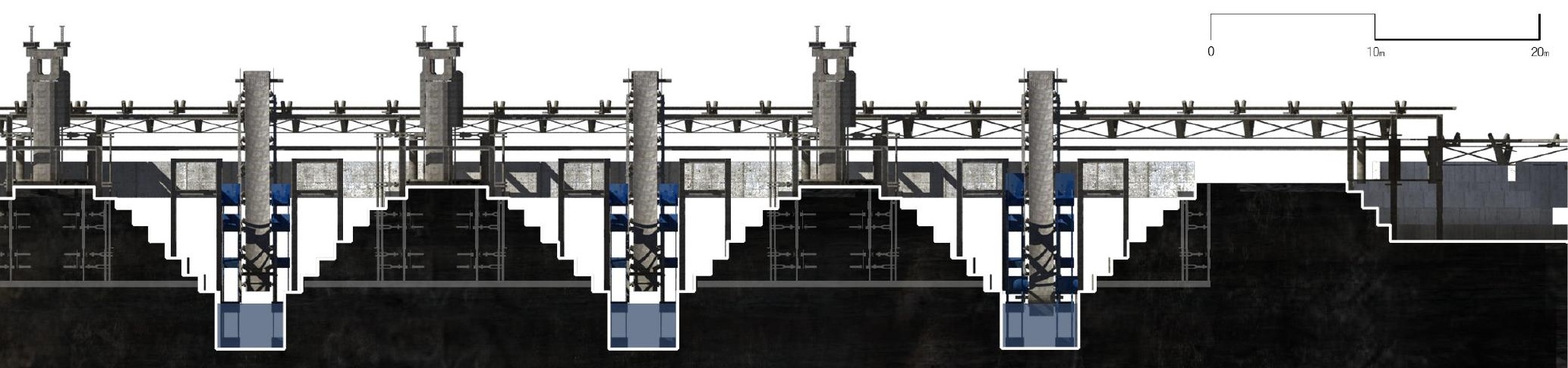


A series of conveyor belts (Figures 186-187) driven by the flow rate of the water removes both garbage and sewage sludge from the river before it enters the Bay of Bengal, essentially cleansing the river of toxic waste buildups, encouraging the rejuvenation of surrounding marine and estuarine ecosystems, and improving hygiene conditions within the framework. The modular terraced hardscape integrated with a series of conveyor belts delivers both garbage and sewage sludge from the river to an onsite waste management sorting facility where hazardous waste is separated and trucked to landfill; recyclable material is sorted and sold, generating an income; and all organic matter is converted from waste to energy onsite using the process of Anaerobic Digestion. The primary outcome of the process produces renewable energy that is then fed back into the system, while a byproduct consisting of a nutrient rich bio-fertiliser can be sold to the agricultural industry, generating further income.

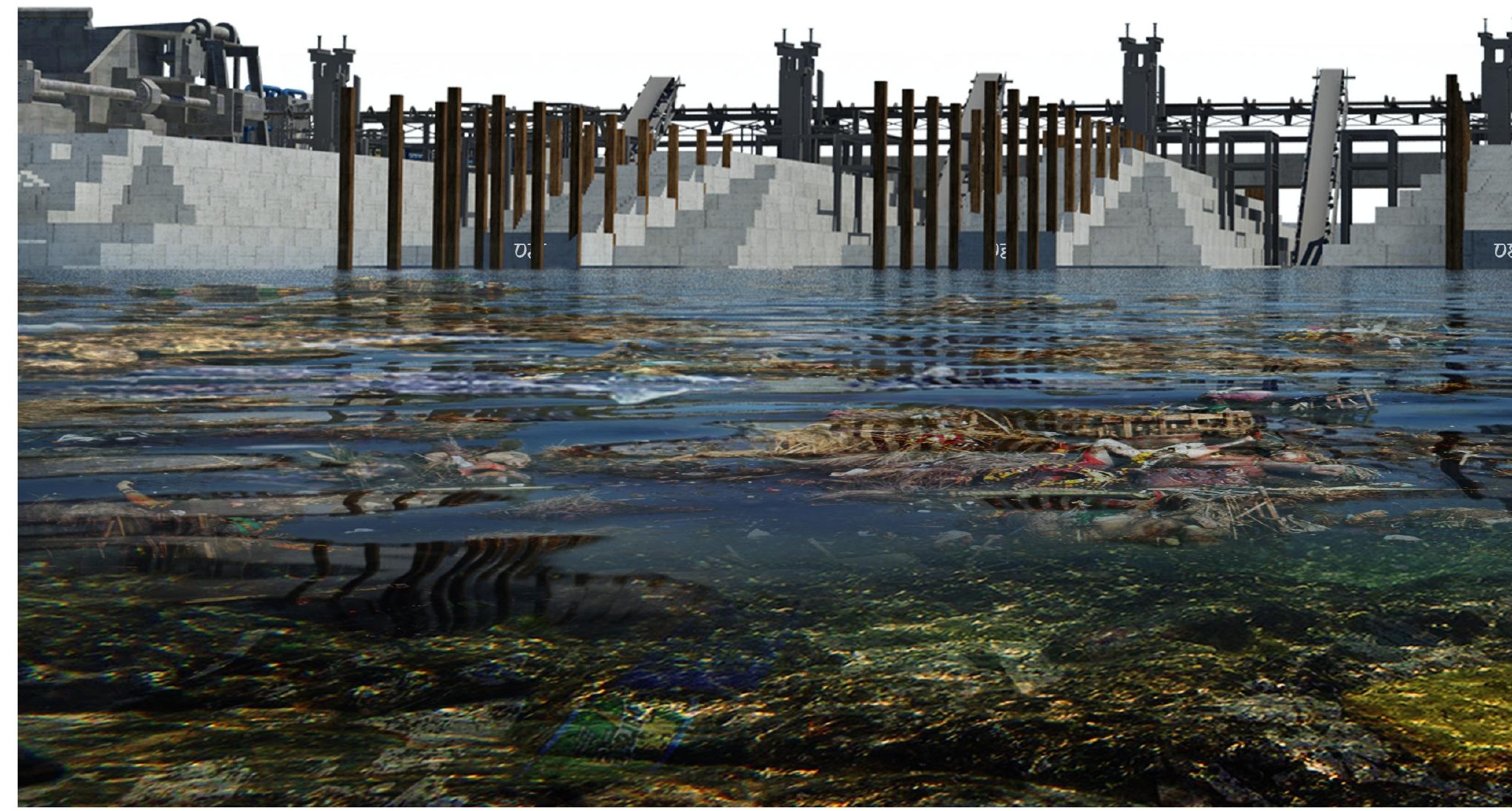



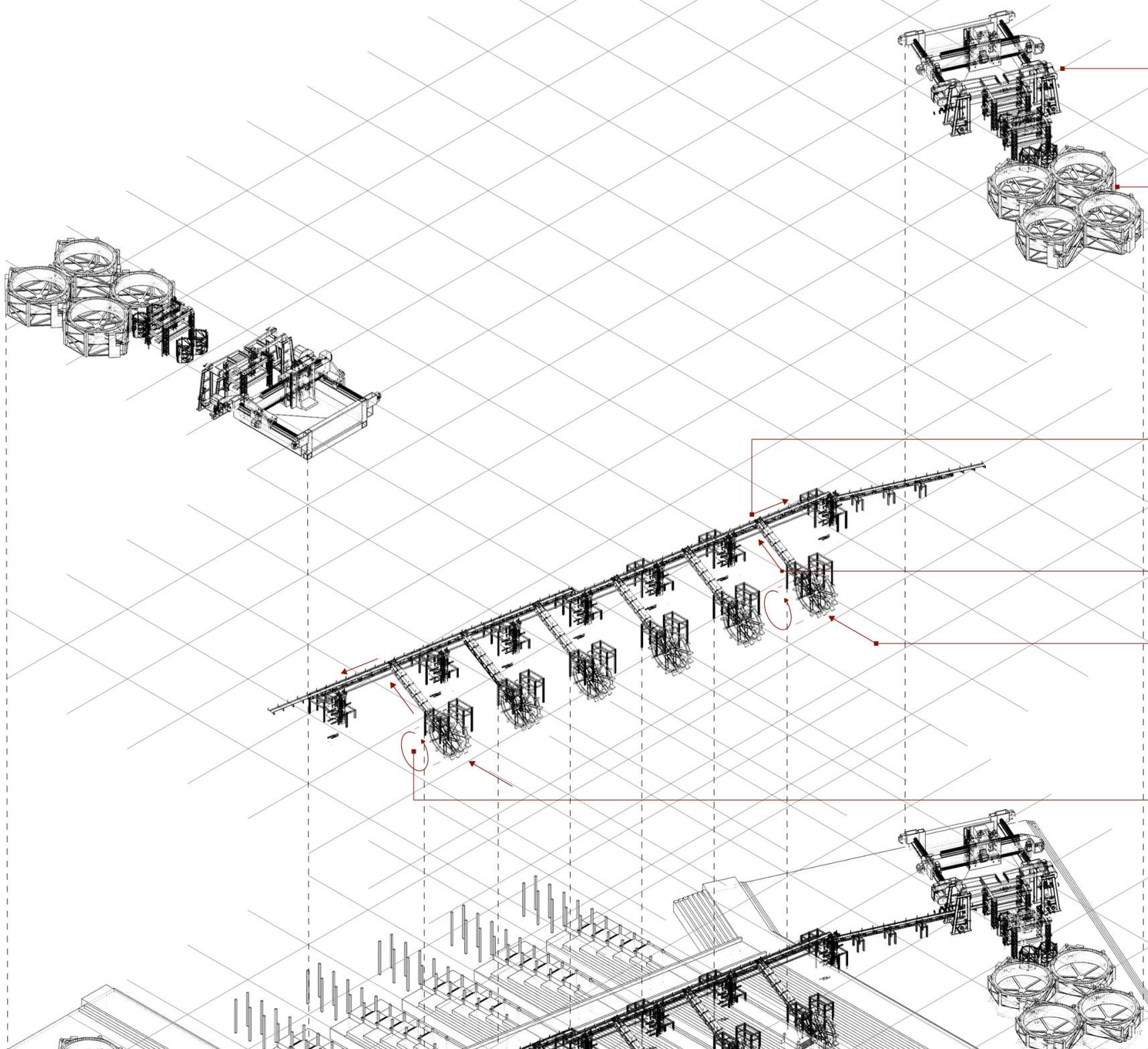

,

r
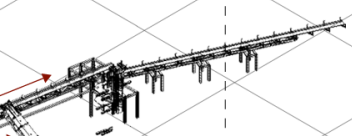

- 
Waste management facility including:

-Sorting

-Converting organic waste to energy

Sewage storage (total 2 week

capacity - $8624 \mathrm{~m}^{3}$ )

Secondary conveyor belt system transferring garbage \& solid waste to the on site waste management system

Primary conveyor belt system removing garbage \& solid waste from the Adyar River

Directional flow of the Adyar River + garbage

Water wheels using the river's flow rate to power each primary conveyor belt system

Terraced river mouth hardscape

Platform hardscapes allowing mangrove plantations to be reintroduced throughout the littoral zone

Terraced breakwater system

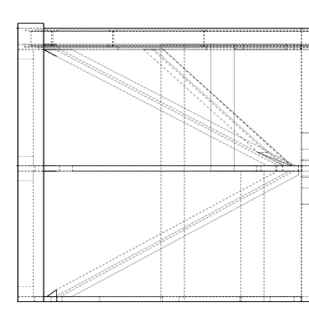

Sewage storage tank elevation

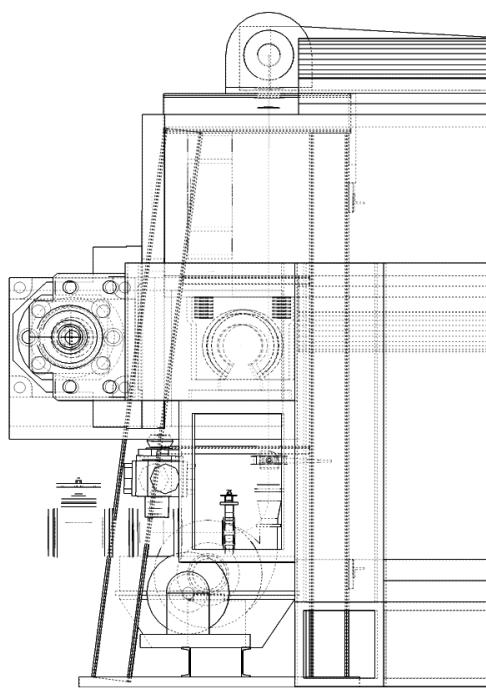

Waste management facility elevation

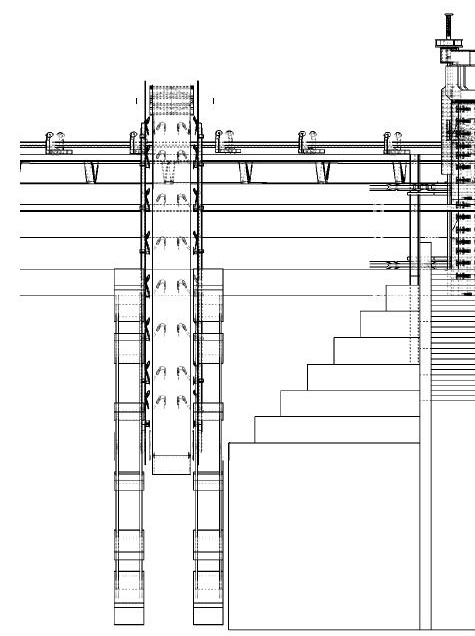

River mouth garbage removal system elevation 

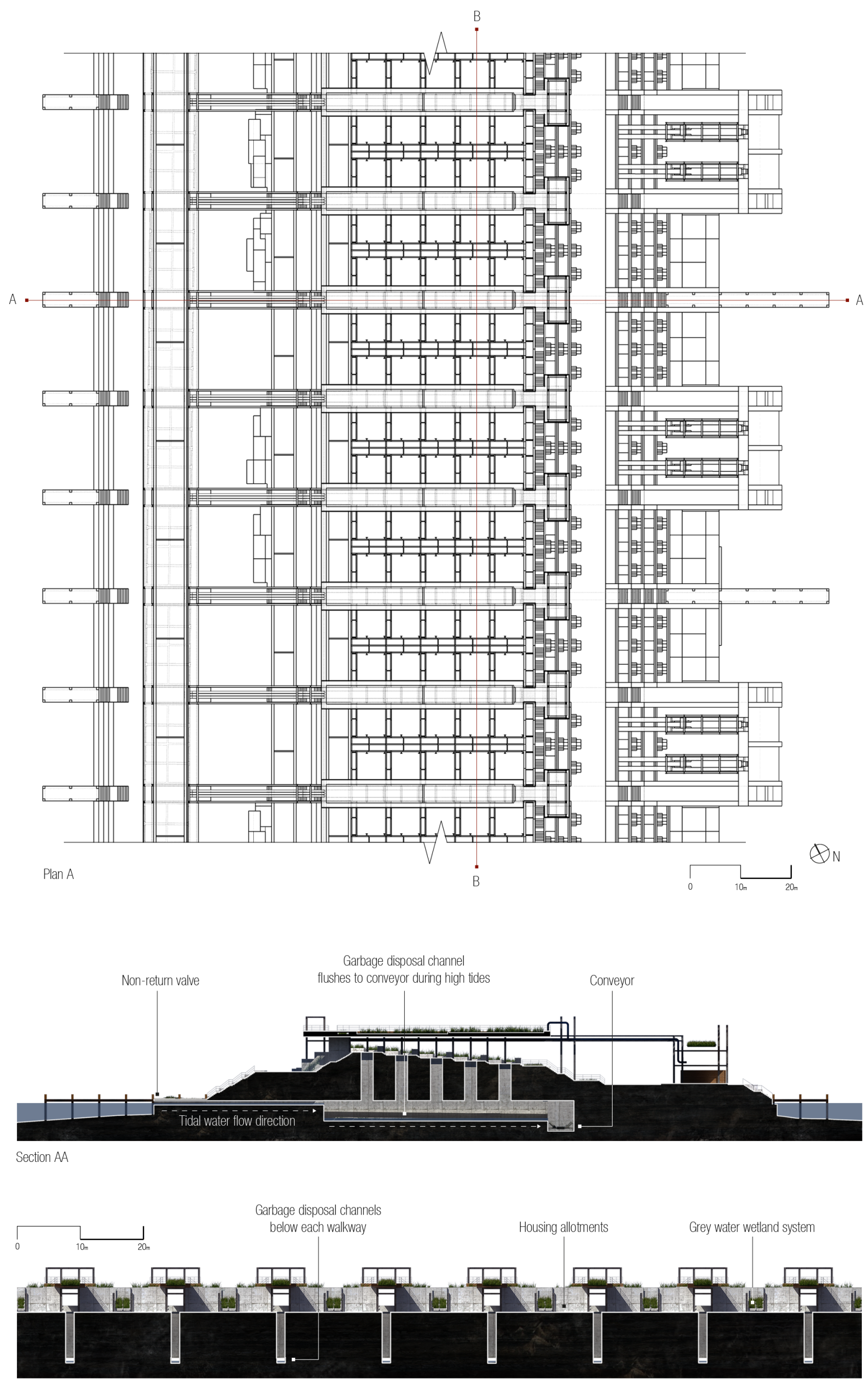


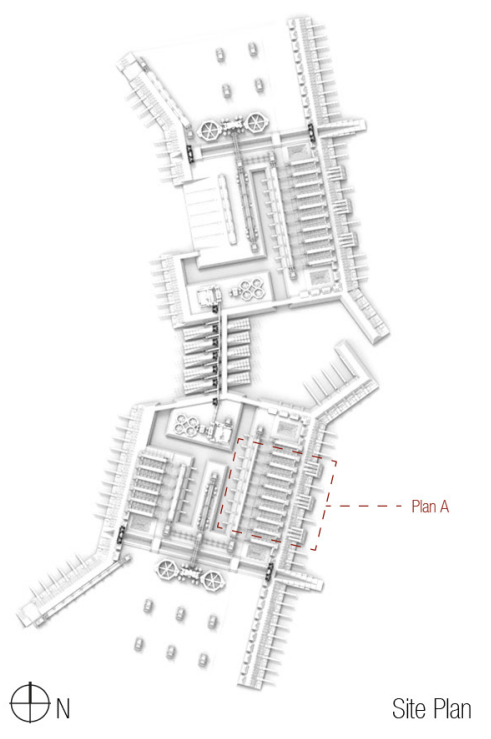

With the complete lack of waste management facilities in Srinivasa Puram causing severe environmental pollution and hygiene issues for the immediate and extended site, the developed design integrates a passive means of garbage collection driven by tidal action. As illustrated in Figure 188, domestic garbage is deposited into concrete channels below each access way. During high tides each channel becomes inundated, essentially flushing garbage to a collection point. A conveyor belt structure further transfers all waste collected to the onsite garbage sorting facility with the opportunity to sell recyclable material generating an income. Organic waste can be converted to electricity through Anaerobic Digestion. The system provides inhabitants with a dependable waste management system that improves hygiene, reduces environmental pollution, generates an income and produces renewable energy. 


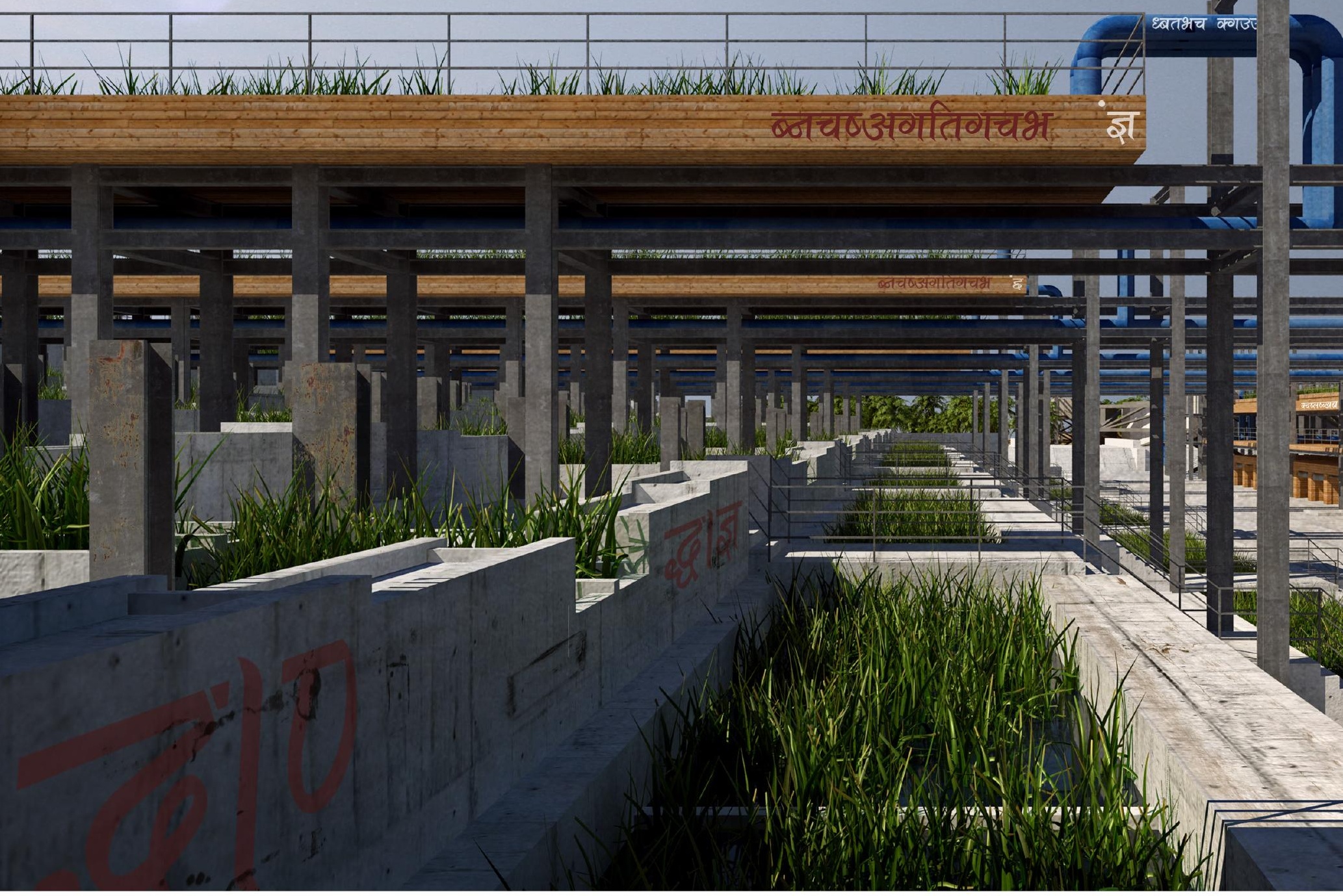

Fig. 189. Terraced grey water wetlands system.

HARVESTING AND PURIFYING

The developed design integrates a three tiered fresh water harvesting and purification system. The primary source of fresh water is delivered to the framework through a preassembled, pre-wired, and pre-piped reverse osmosis seawater desalination system, similar to the Mindelo case study on the island of Sao Vincent in Cape Verde, West Africa. Adapted to the conditions of Chennai's coastline, the system requires seawater to be delivered from a minimum of $600 \mathrm{~m}$ offshore due to the high levels of coastal pollution. The system can supply 150 liters of fresh water per capita daily to the framework and incorporates a contingency plan in the event of a natural disaster damaging infrastructure, providing a continual two week fresh water storage supply of $32340 \mathrm{~m}^{3}$.
The large scale of the scheme and its modular design establishes a systematic ordering device for the framework enabling the number of housing units to increase at regular intervals while providing the opportunity for the seawater desalination system and the number of housing units to expand with population growth simultaneously. The terraced elevation changes and modular repetition of the architectural hardscape integrates domestic and public wetland purification systems (Figures 189190) to form a secondary source of fresh water. The passive water purification systems integrated into each domestic allotment treats both grey water and rainwater while simultaneously providing an irrigation supply for crops, encouraging inhabitants to grow their own food. 

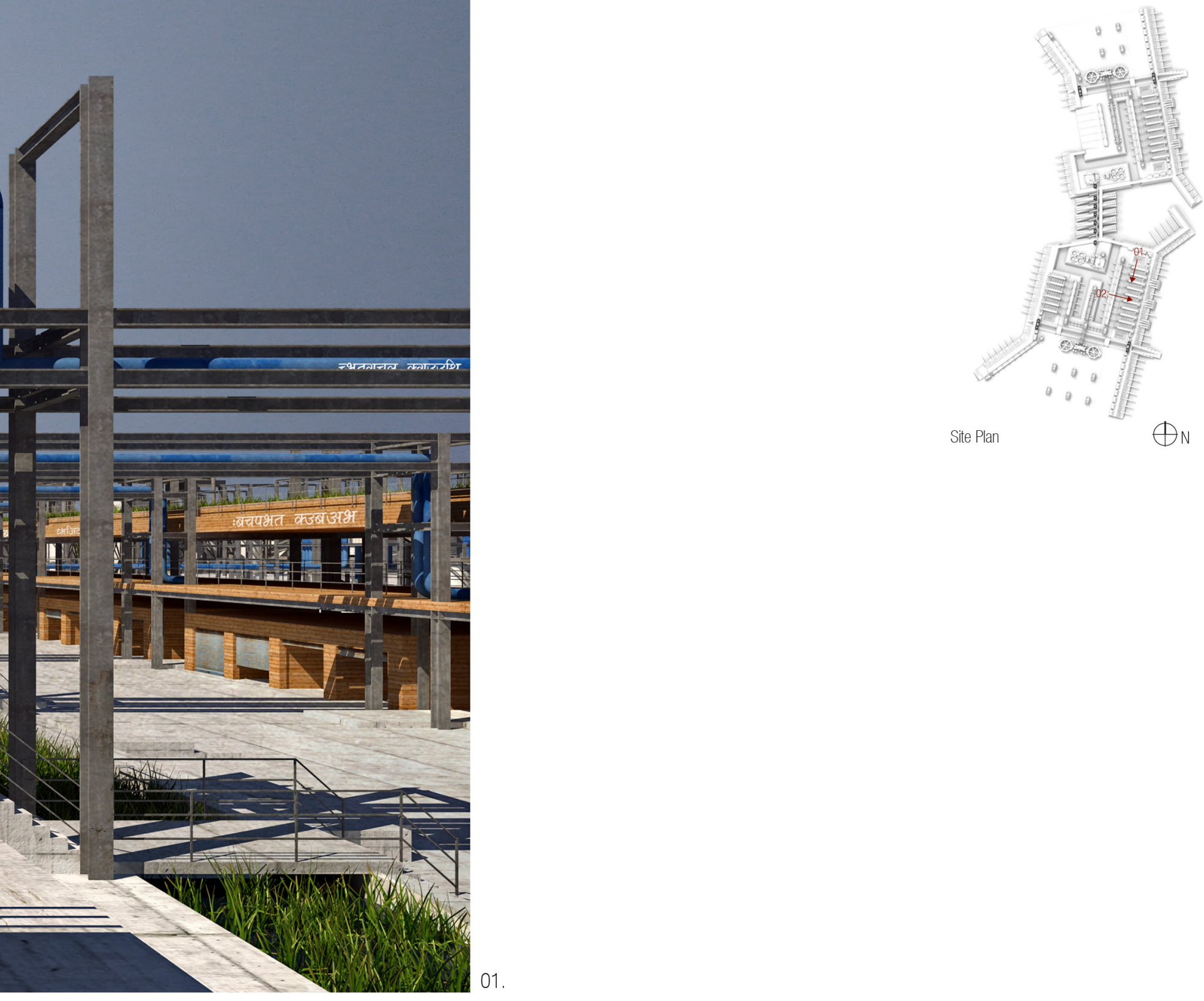

Site Plan

$\oplus_{N}$

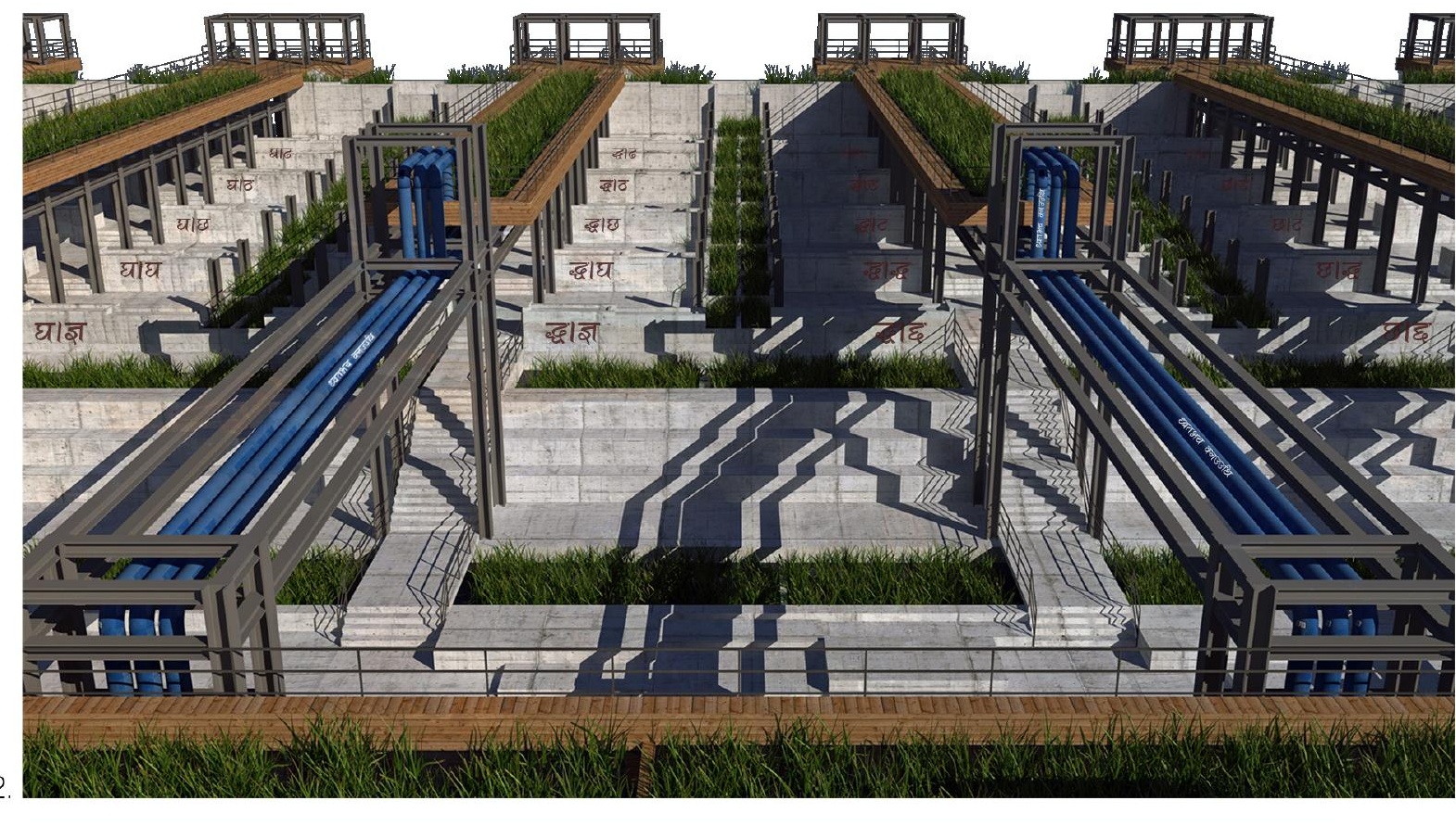




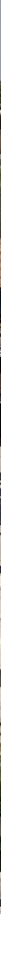

Fig. 191. Agriculture canopies. 


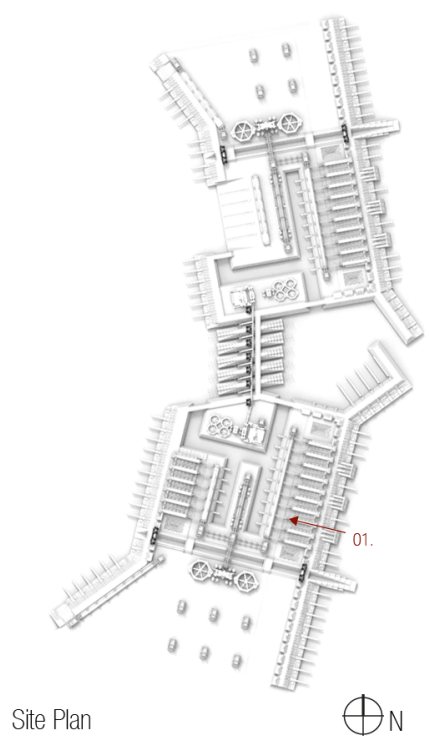

The site and program analysis chapters illustrated fresh water consumption per capita of 150 liters per day. The research highlighted the opportunity to treat and recycle 100 liters of grey water per capita daily, enabling the developed design to reduce the need for seawater desalination and the energy consumption process by $66 \%$. All domestic grey water and rain water is filtered through public wetland gardens before being stored and recycled.

The final design of the framework integrates a separate tertiary wetland system with the capacity to treat all waste water produced on site (Figure 193). The passive waste water purification system delivers treated water back into the Adyar Estuary, helping to reduce levels of environmental pollution, rejuvenating the surrounding ecosystem and improving hygiene conditions. 


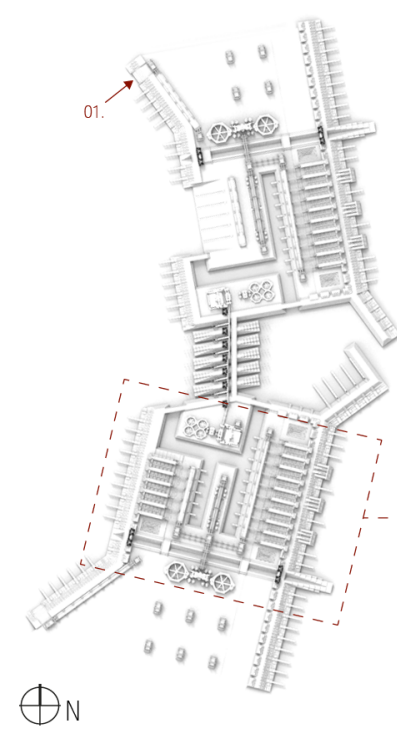

Site Plan
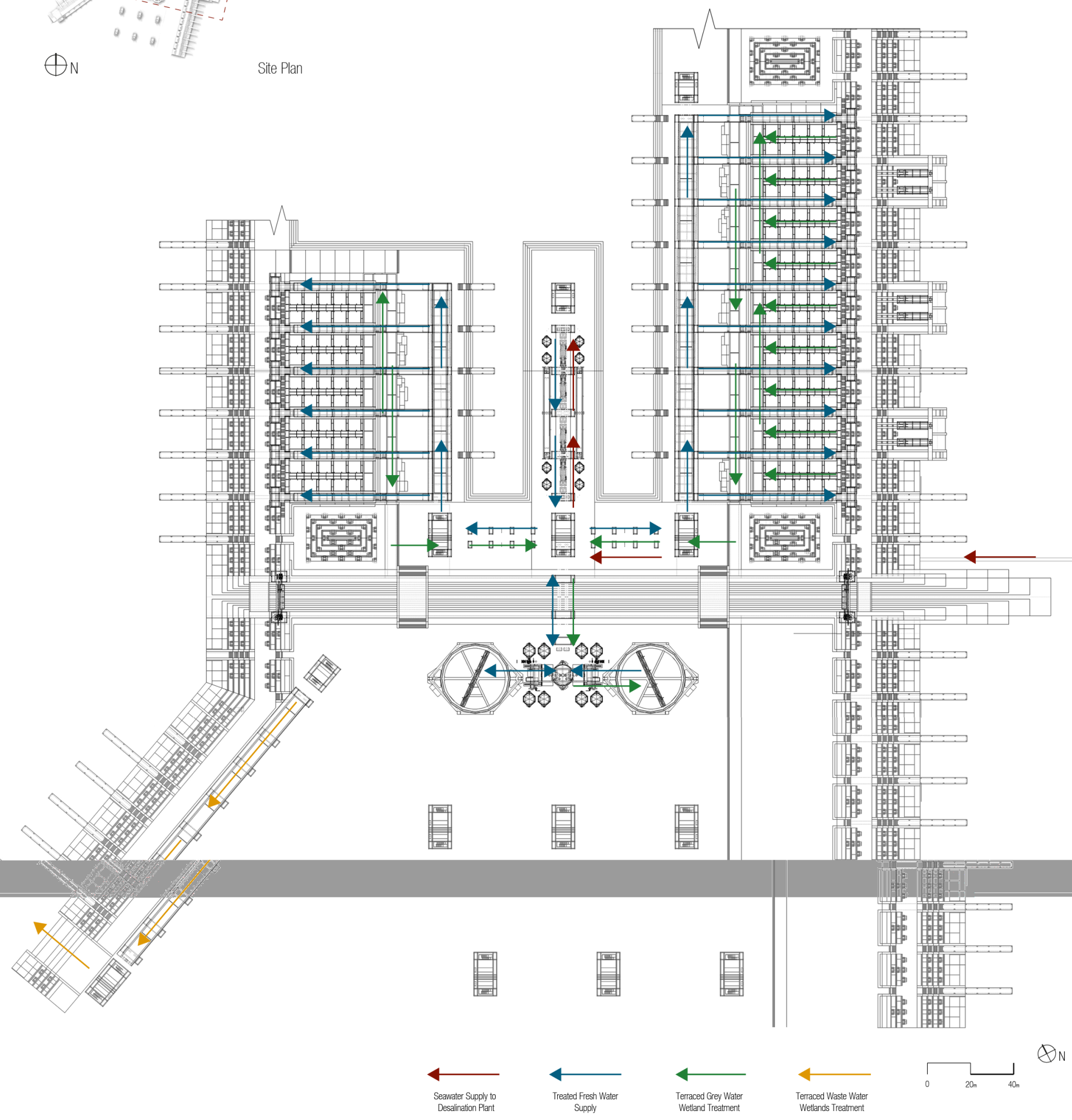

$\otimes_{N}$ 


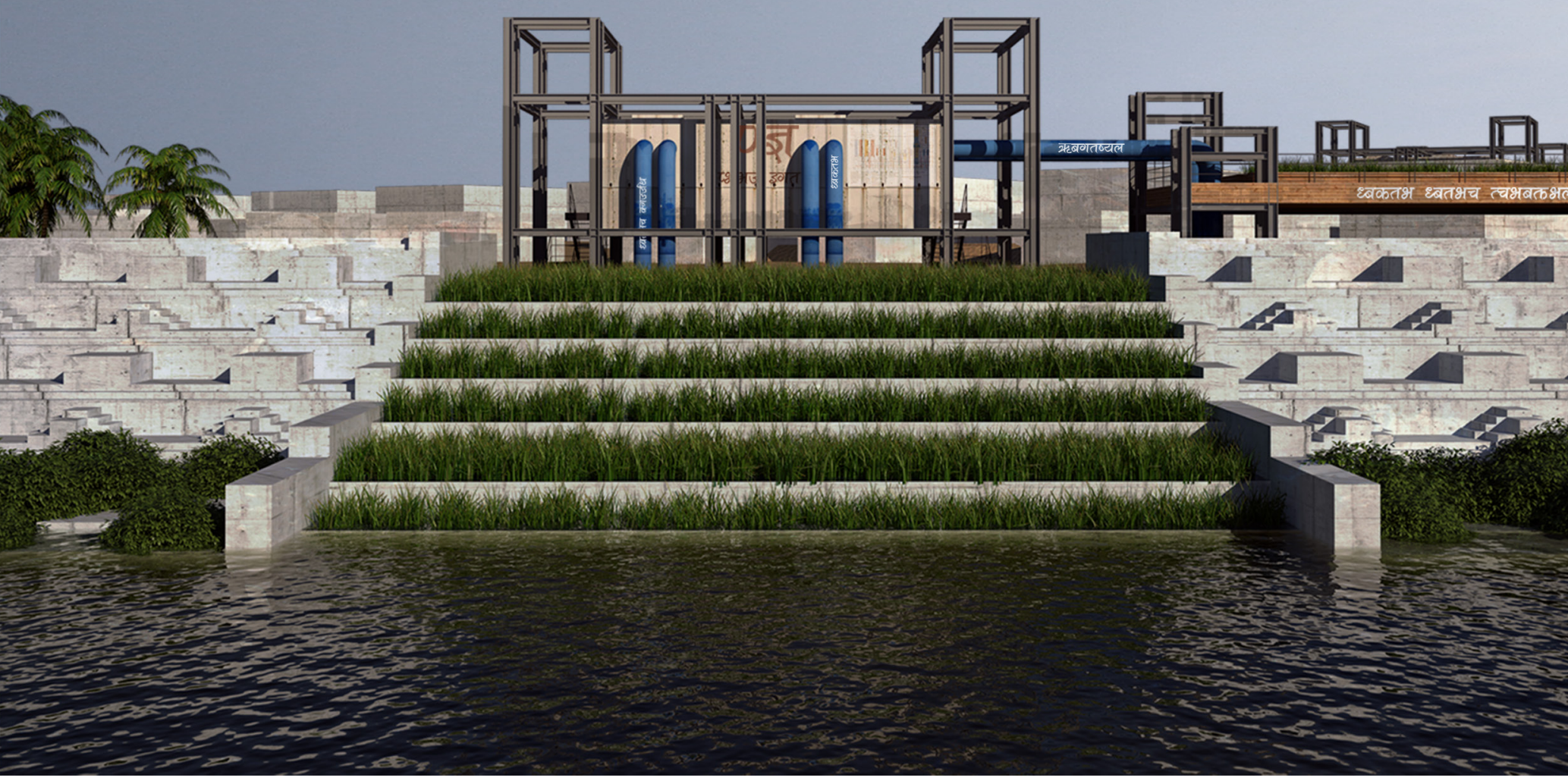

Fig. 193. Treated wastewater returning into the Adyar Estuary. 


\section{RETAINING LIVELIHOODS}

The developed framework is configured with a sequence of elevated hardscape terraces and a modular repetition of horizontal and vertical service cores allowing for a dialogue between fishing vessel mooring, fishing equipment storage, public market and social gathering spaces, bathing and cleansing tanks, agricultural crops, terraced wetlands and housing platforms (Figure 197). These spatial relationships encourage traditional Indian values and rituals of an intimate community to be reinstated into the daily lives of slum dwellers. The integration of stepping stones, platforms, raised platforms, free-standing columns and the stone aesthetic represents a contemporary translation of traditional South Indian architectural typologies with the intention of creating an inspiring experience, evoking communal memory, and establishing a sense of belonging for the inhabitants.
The framework provides a surplus of basic amenities such as fresh water, electricity, sanitary services and waste management systems integrated through a modular system to discourage the mass overcrowding of dwellings built within close proximities of service cores, typical within informal settles. The delivery and availability of these services to every allotment at regular intervals allows for the community to sustain healthy, hygienic and well-structured living conditions.

The open housing hardscape responds to climatic conditions by maximising natural light and ventilation while providing adequate shelter from tropical storms through a series of overhead canopies that deliver services and provide the opportunity to grow agricultural crops.

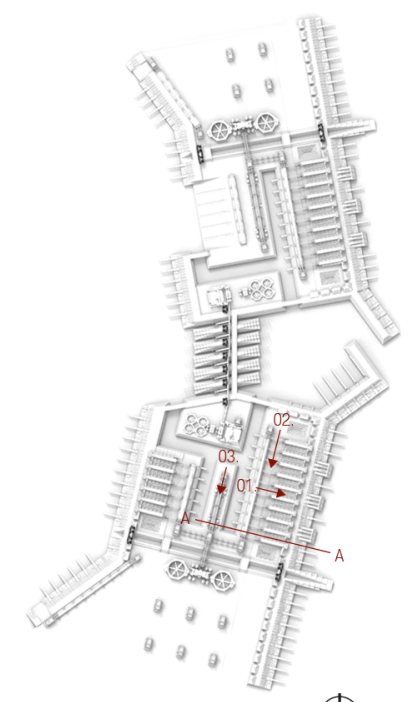

$\oplus_{N}$ 


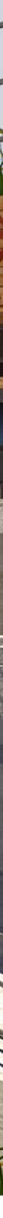

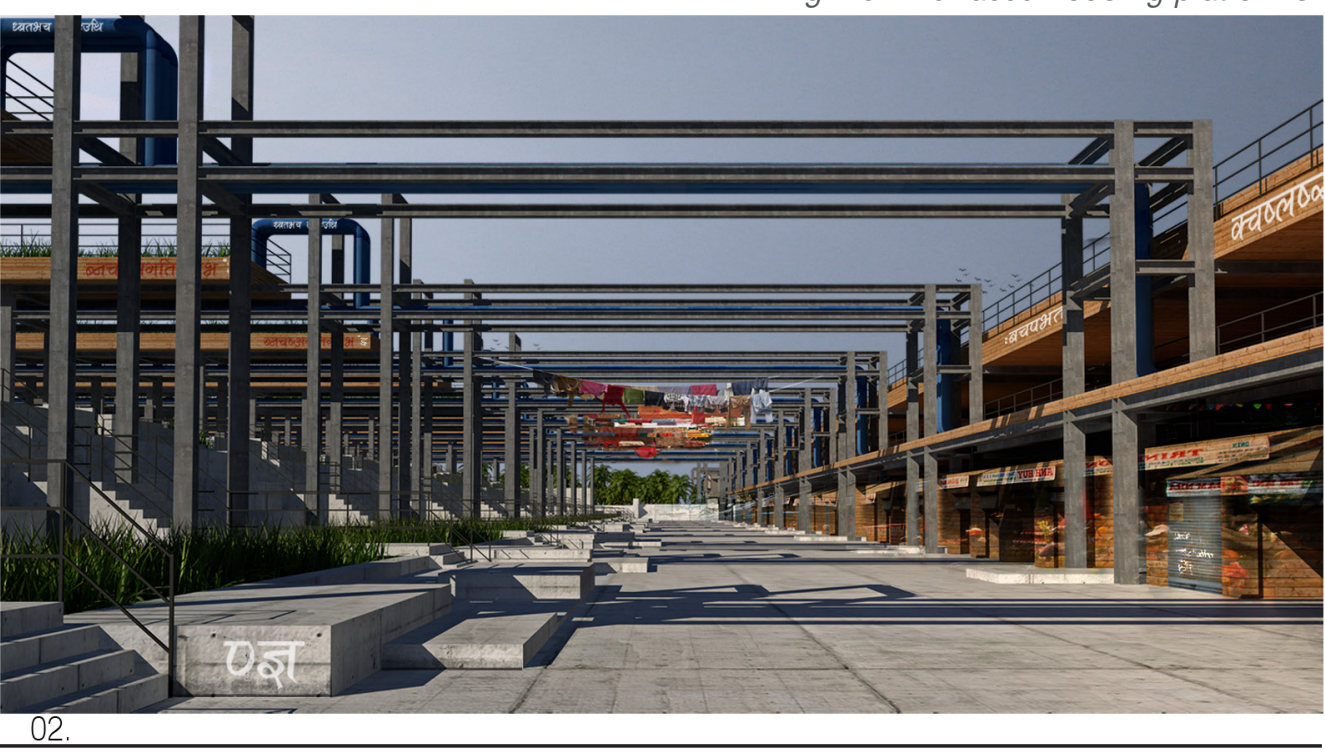

02.

Fig. 195. Public market space.

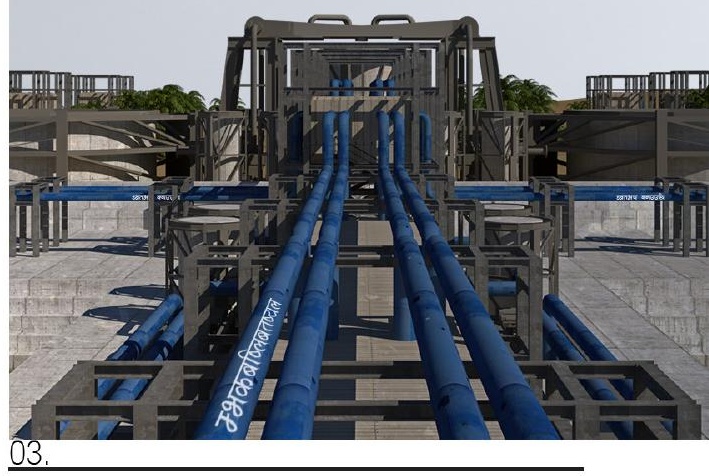

Fig. 196. Desalination plant.

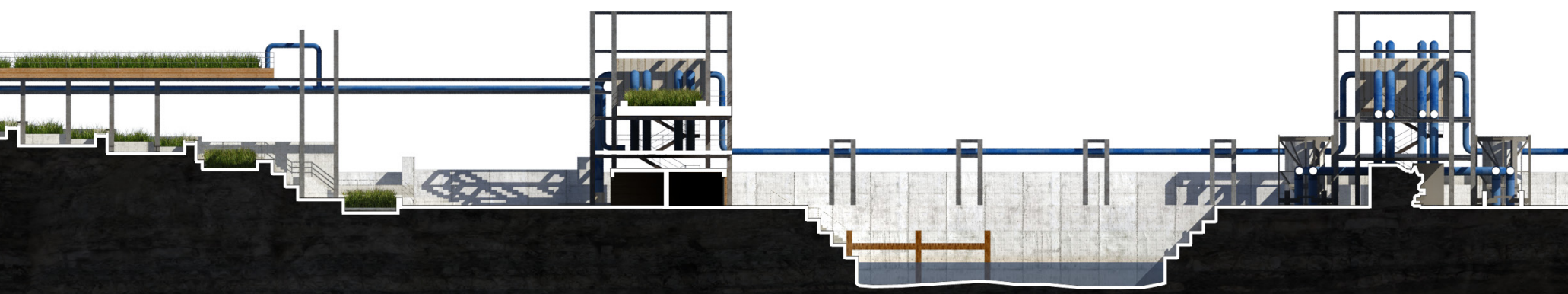


Each allotment is designed as a $7 \mathrm{~m}$ by $7 \mathrm{~m}$ section with four free standing columns provided as a support structure to define a recommended 28m2 interior space. The approach applies similar design principles to Doshi's Aranya Housing project by enabling inhabitants to building their own homes using traditional materials and construction methods within a safe environment. The intention is to encourage the community to grow, adapt, evolve and personalise its own building typologies to suit their living conditions. The gross floor area of $49 \mathrm{~m}^{2}$ per family is designed to enable development of hybrids of indoor and outdoor spaces surrounding internally supplied service cores and externally integrated grey water and rainwater terraced wetland systems.

While the overall 'machine' framework is a substantial size to incorporate needed environmental technologies, the human scale 'habitation' zones of the framework reflect a contemporary translation of traditional South Indian architectural relationships by absorbing, consuming and transforming the surrounding site problems into design solutions. By harnessing the potentials of naturally occurring tide fluctuations, the flow rate of the river and gravity feed systems, the design has strategically configured an architectural framework fused with innovative technology to form a self-sustainable living machine that can help mitigate environmental disasters and pollution while providing slum dwellers with housing in the immediate vicinity of where they have always lived.

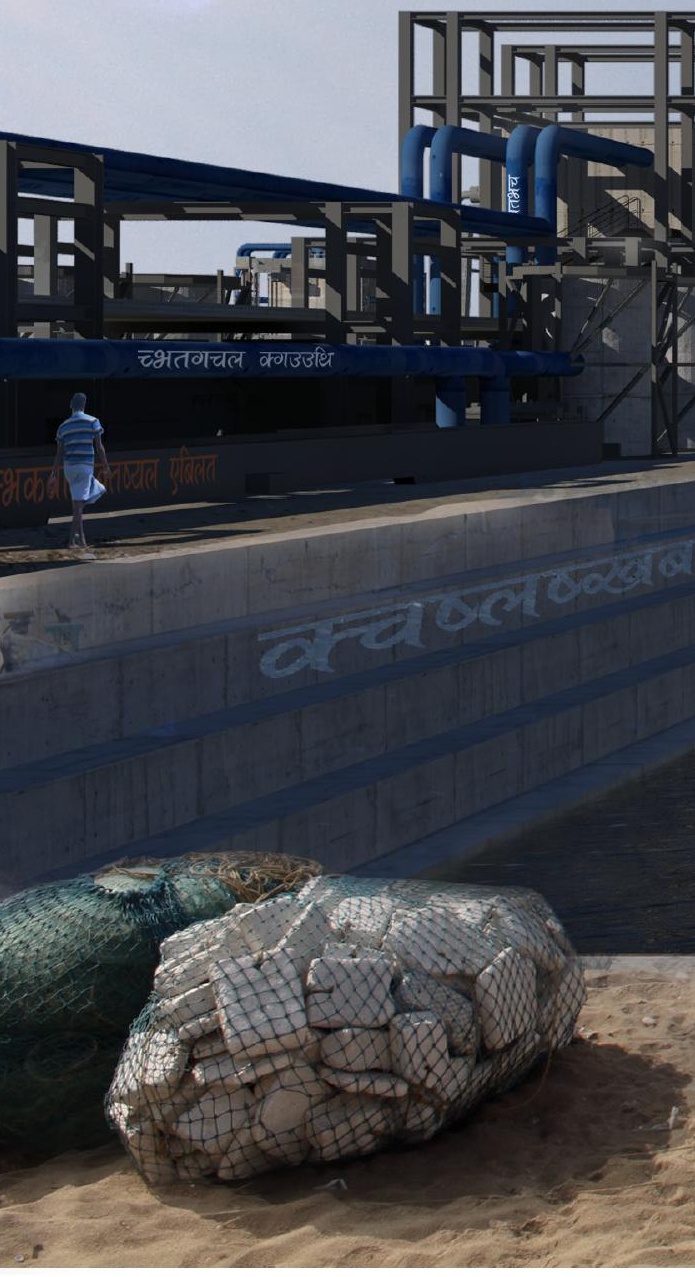




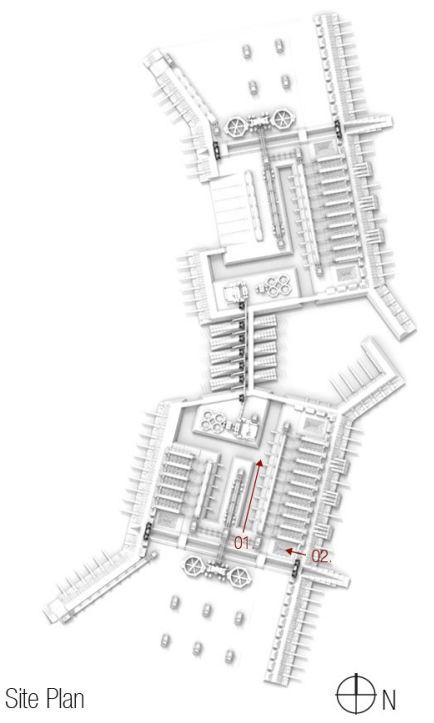

02.

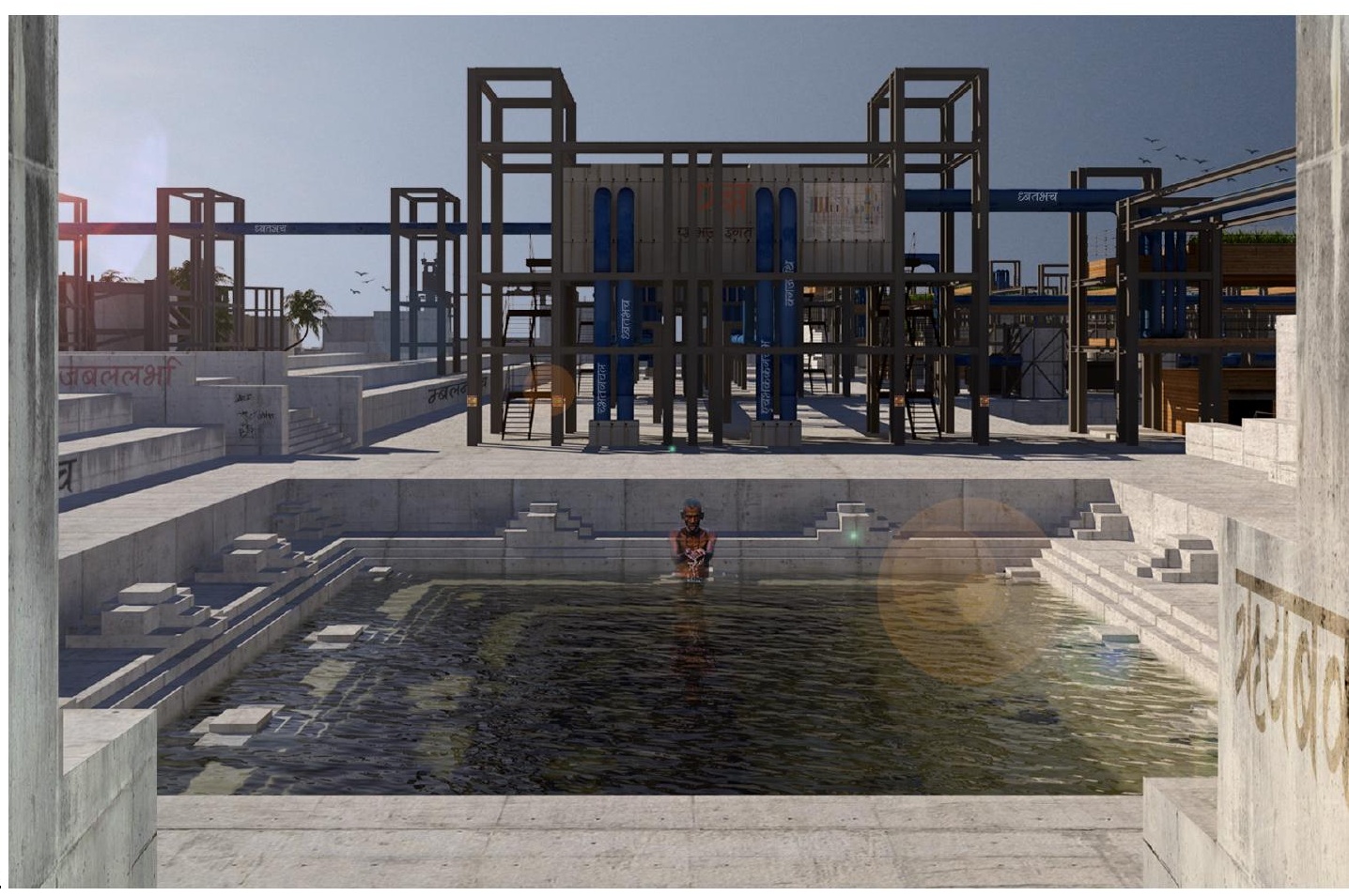




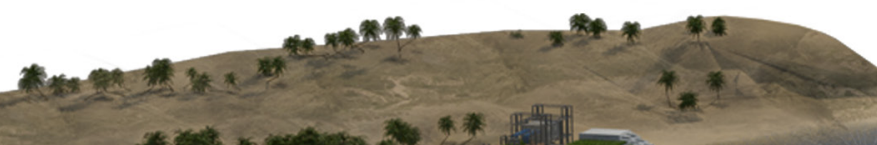

$=4$.

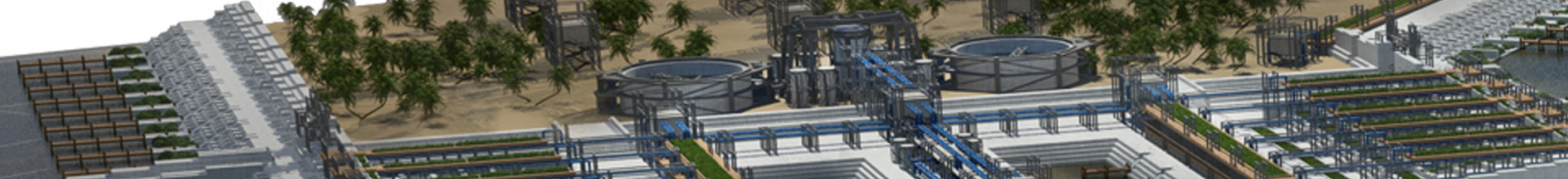

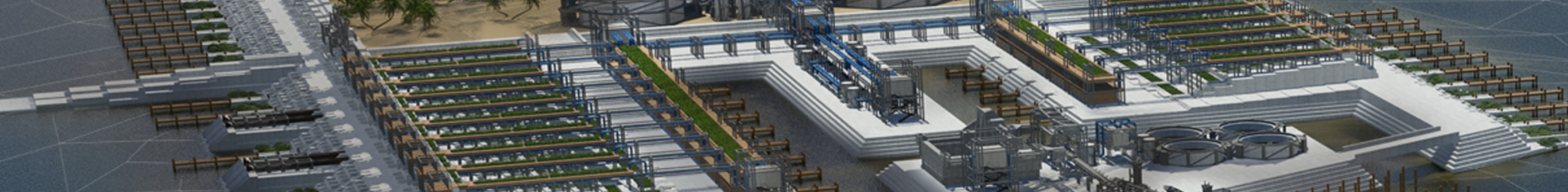

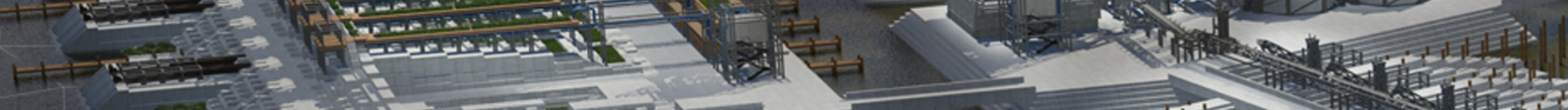

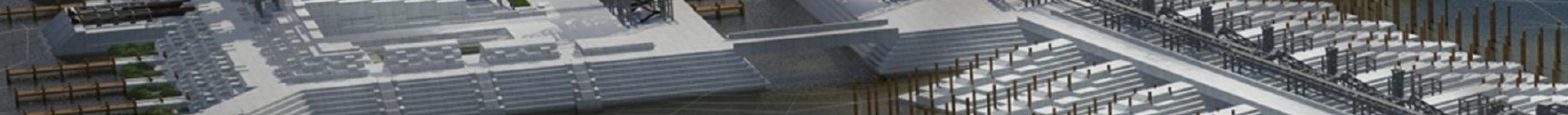

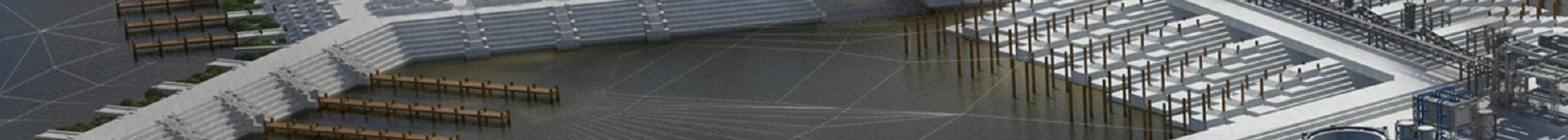

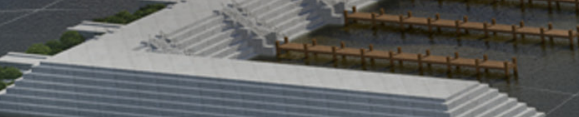
Hifl 16)

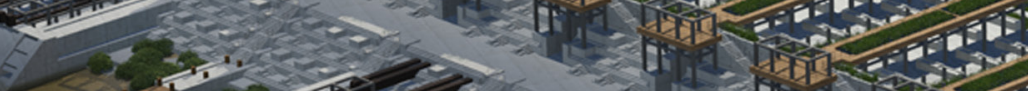

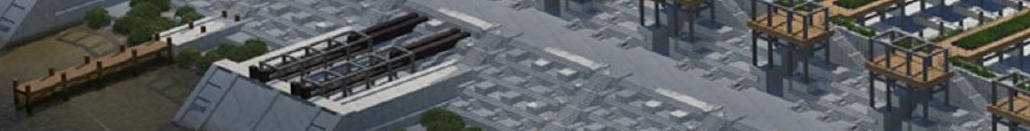
4.

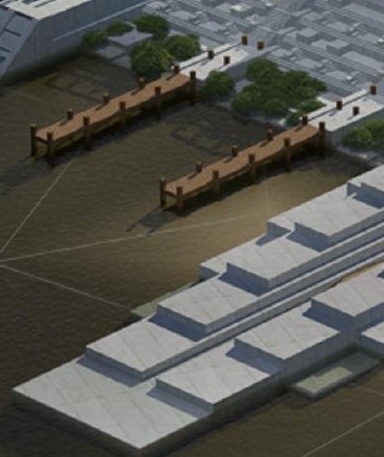



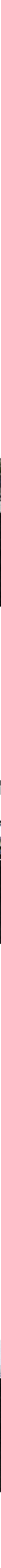


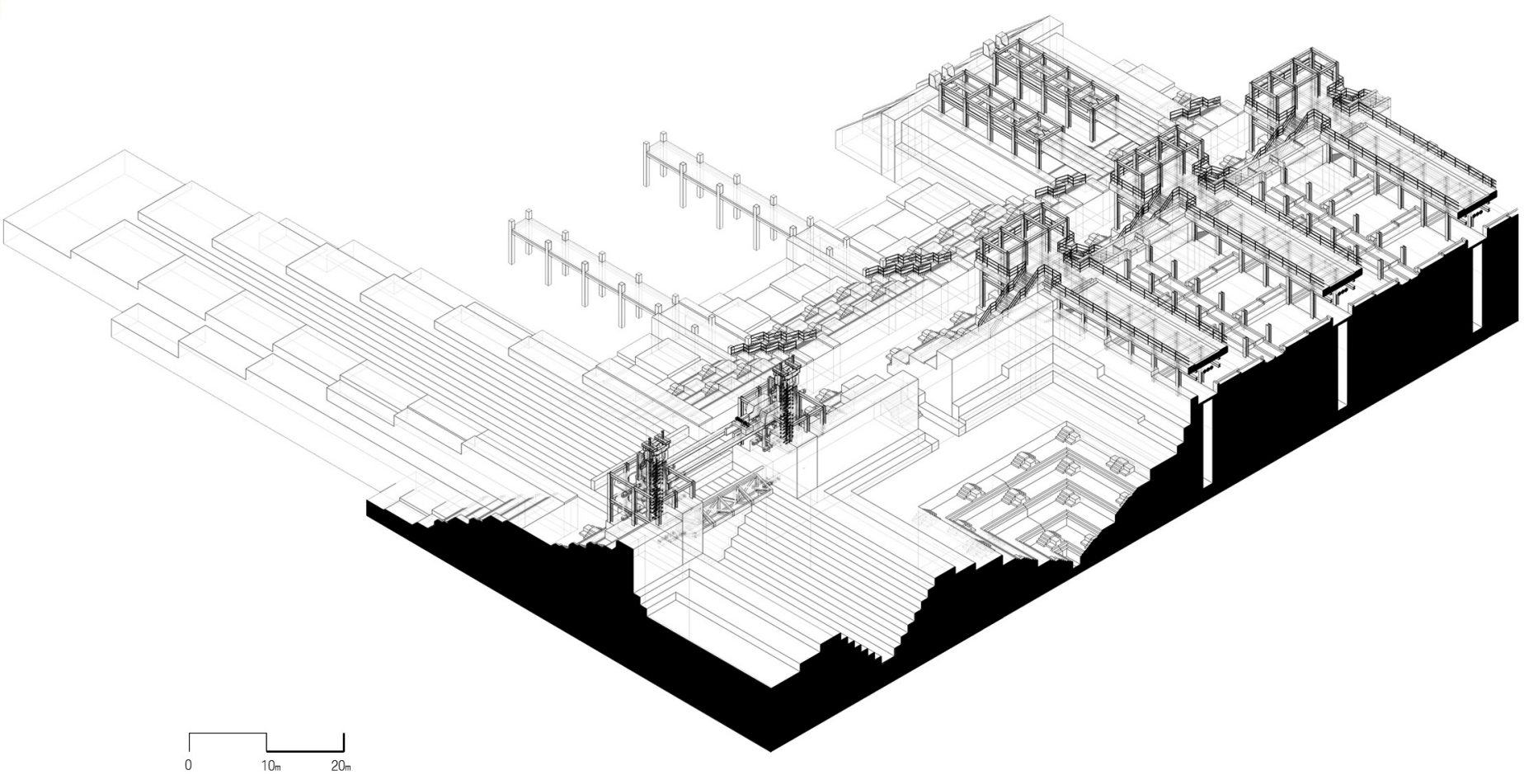

Axonometric Section: Breakwater - Flood Channel - Cleansing Tank - Terraced Wetlands 


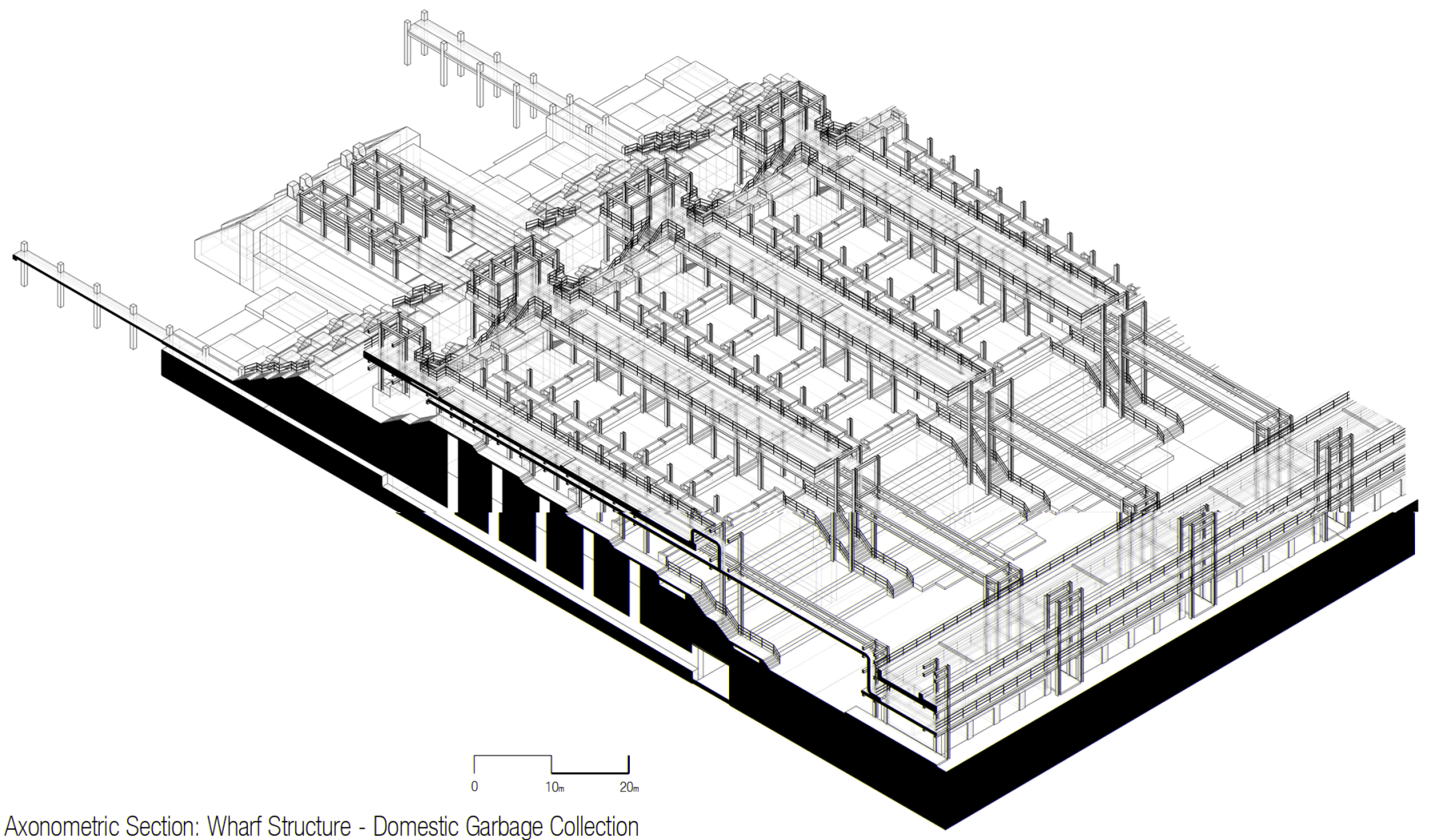

Fig. 203. Developed design - Axonometric sections. 


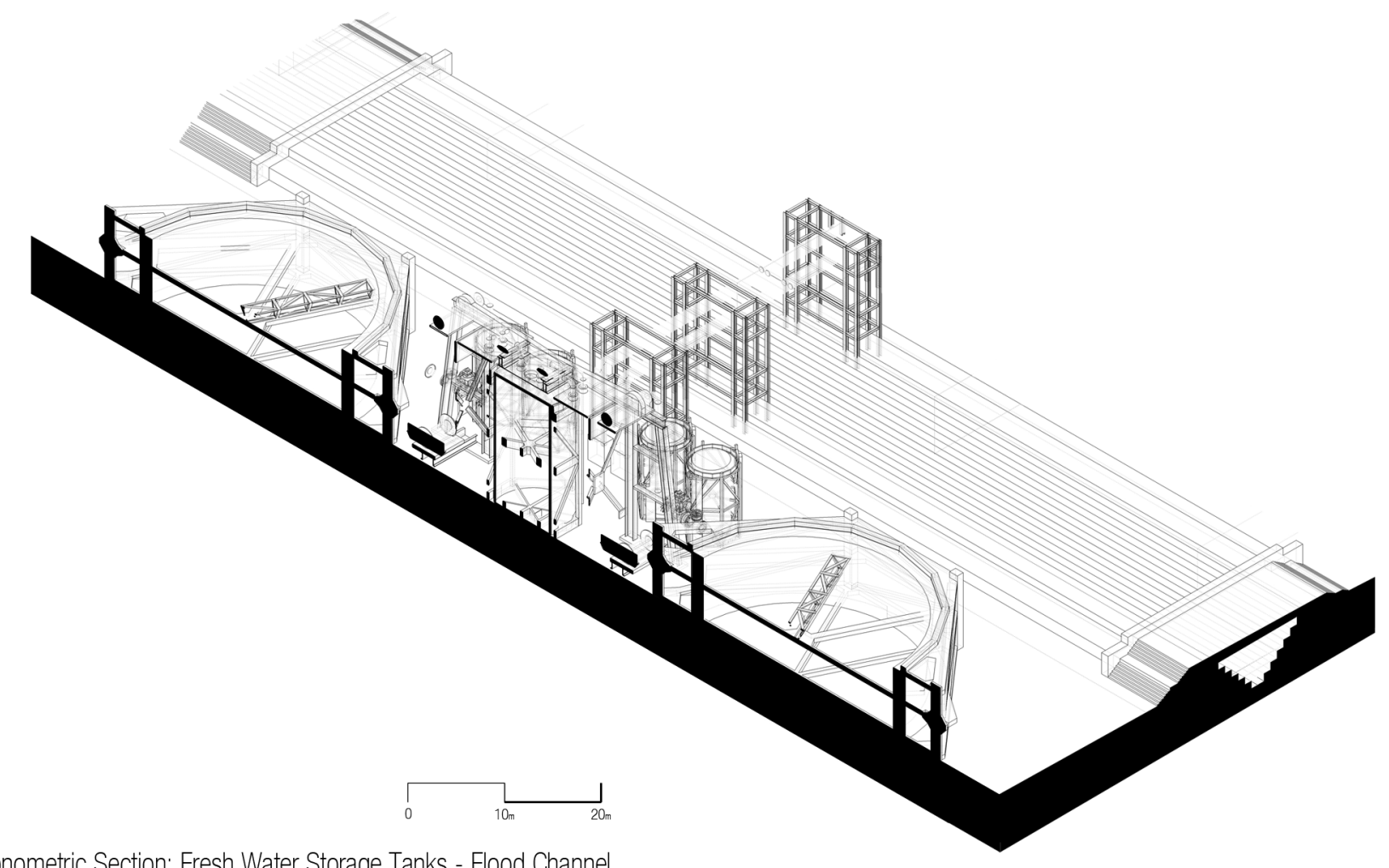

Axonometric Section: Fresh Water Storage Tanks - Flood Channel 


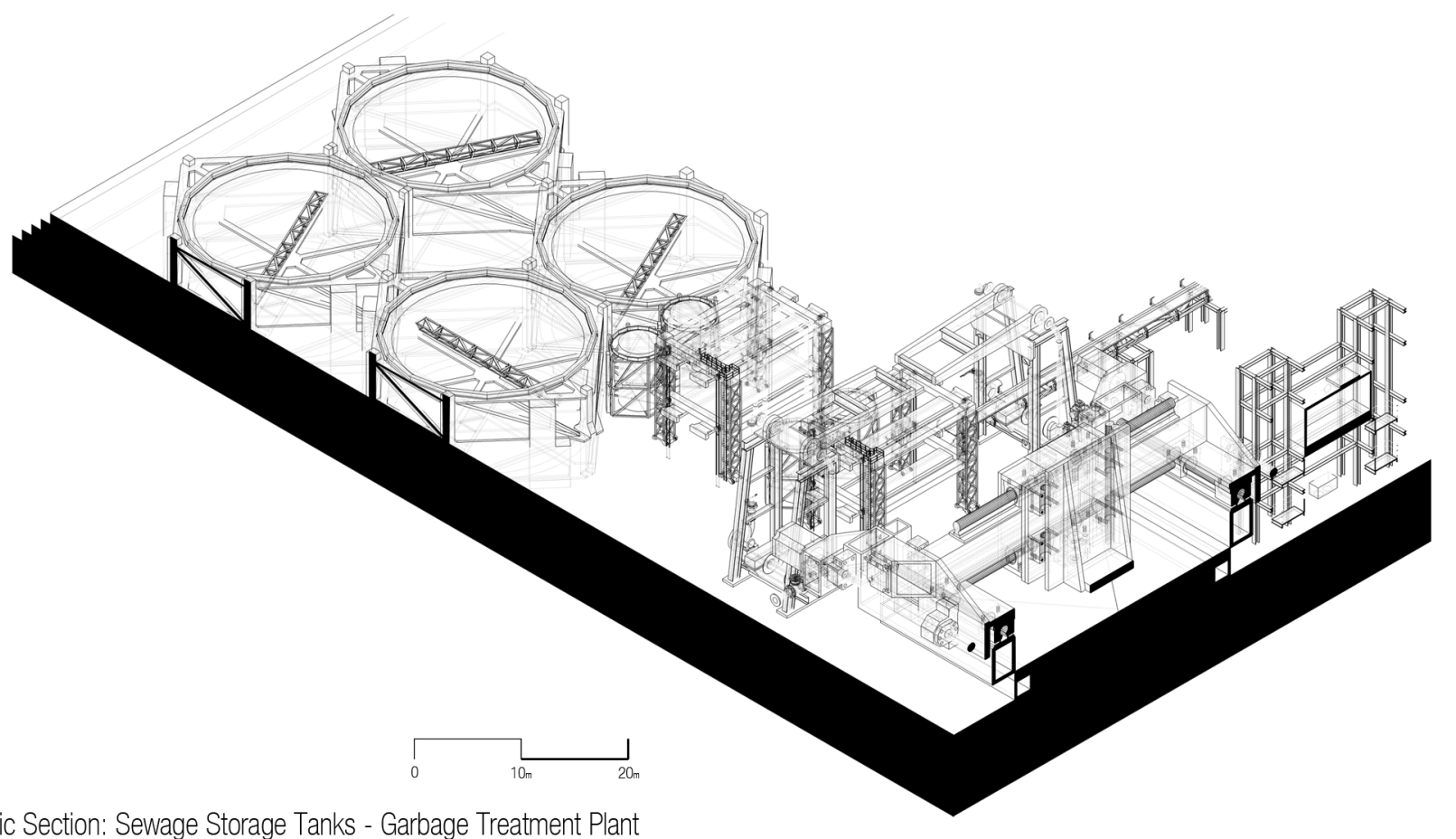

Axonometric Section: Sewage Storage Tanks - Garbage Treatment Plant

Fig. 204. Developed design - Axonometric sections. 


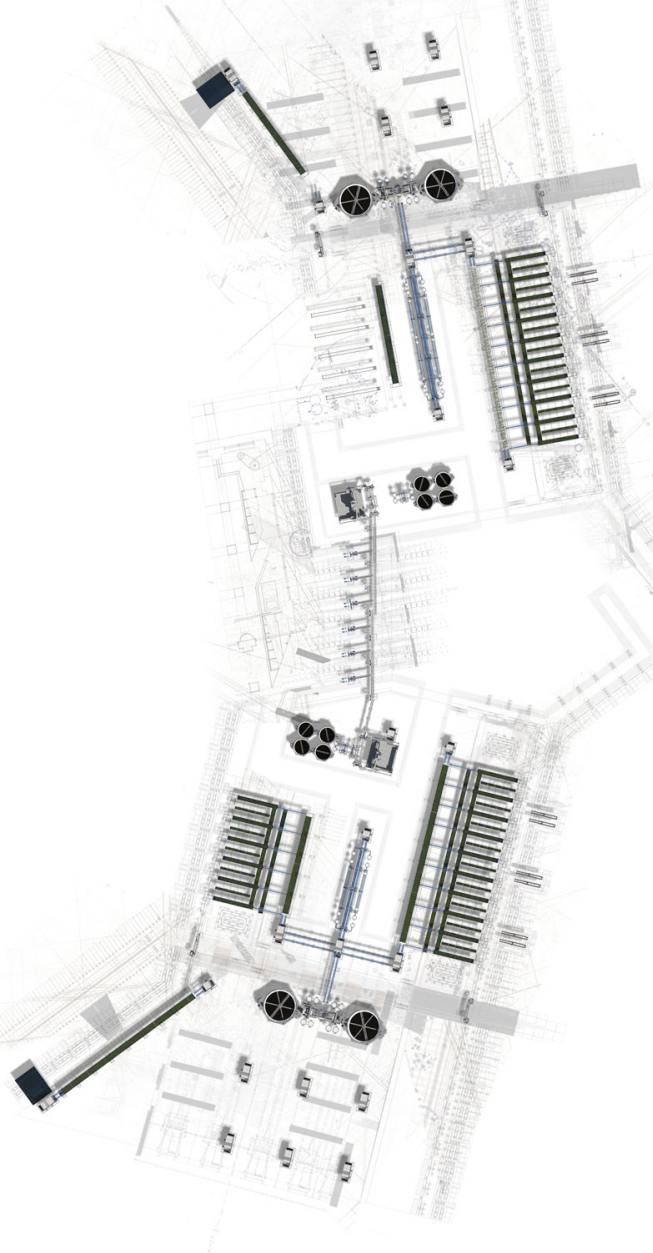

Machine

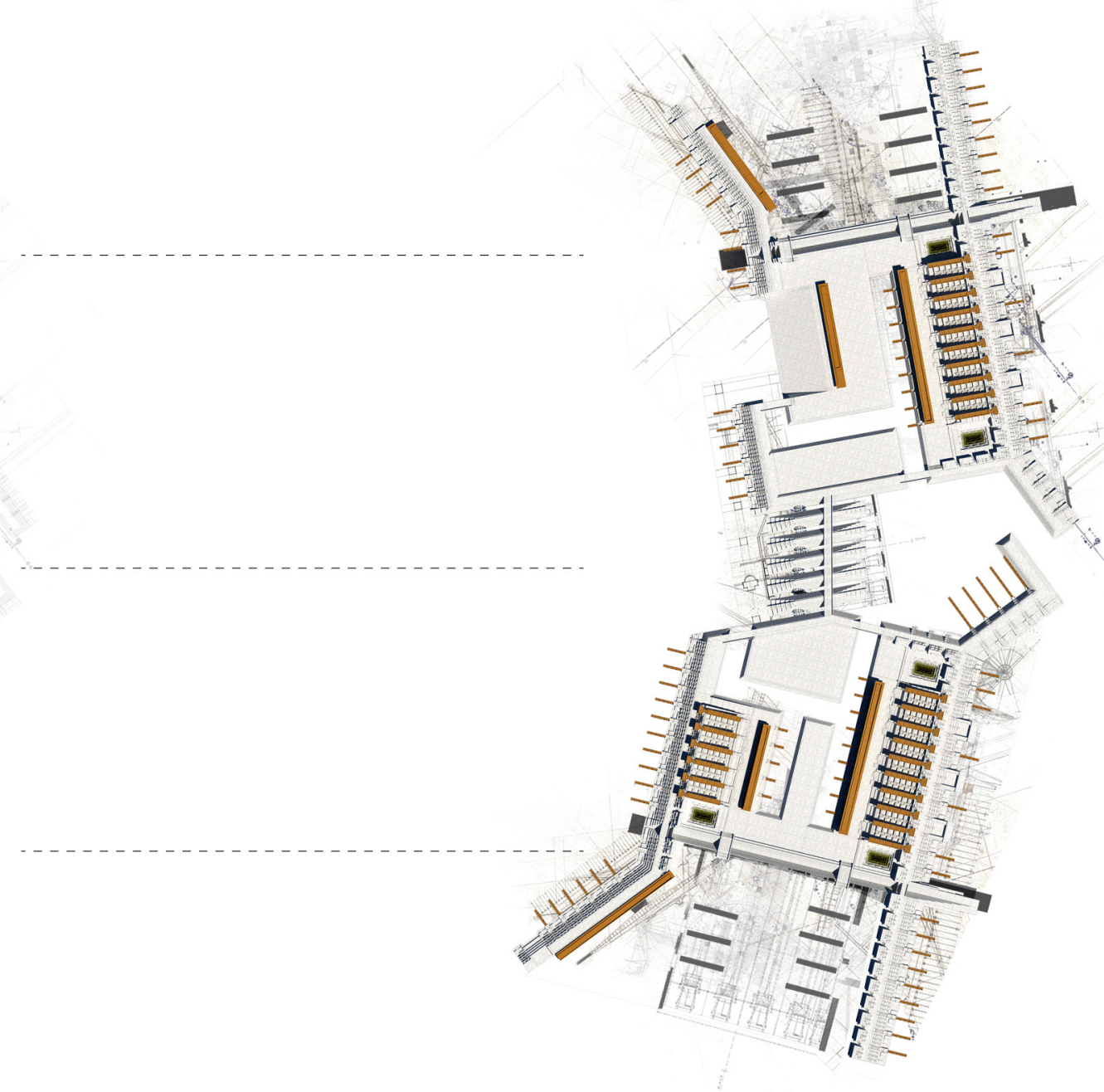

Framework 


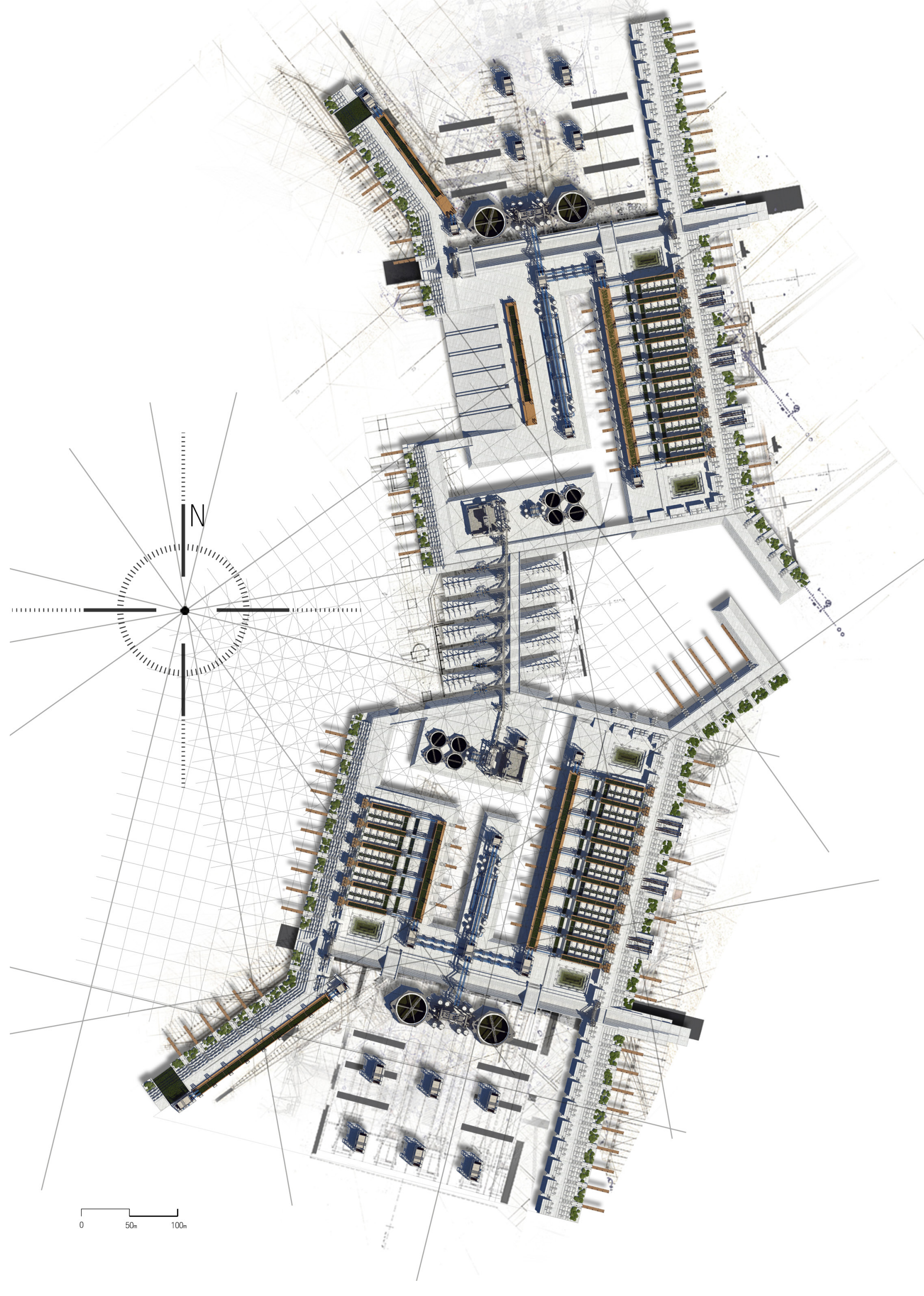




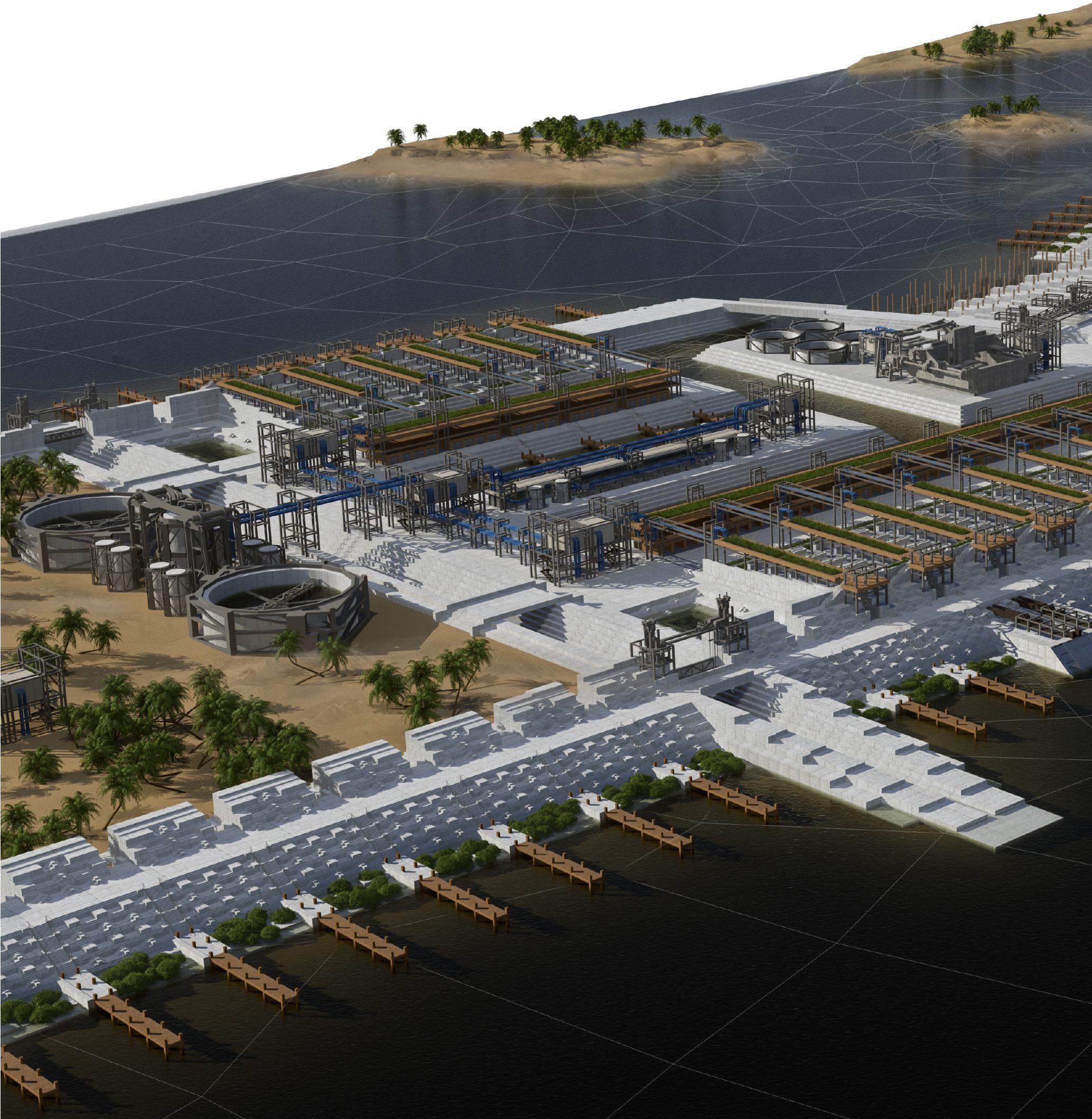




\subsection{CONCLUSION}

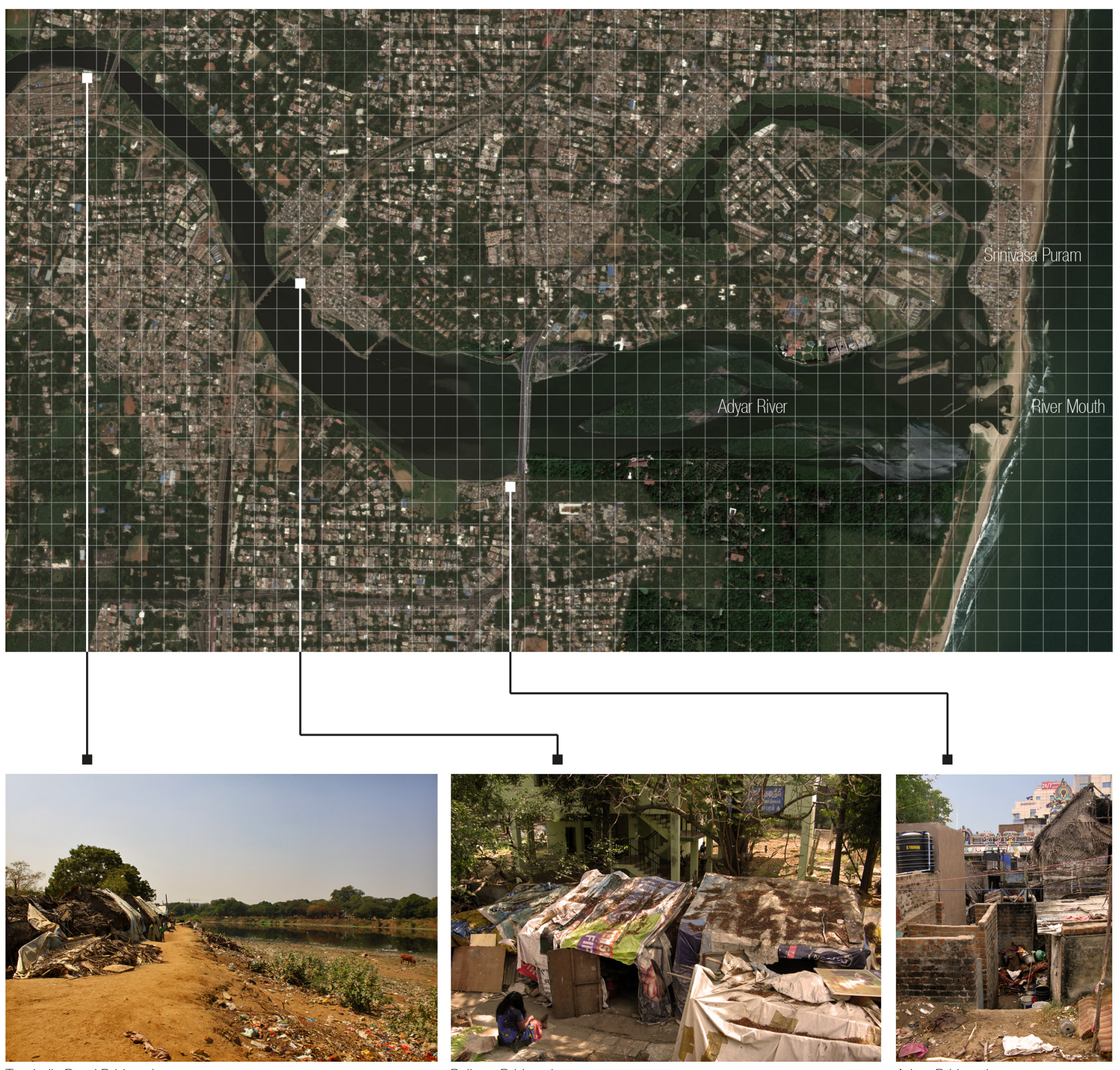


The thesis has tested experimental approaches to expandable design immediately adjacent to Srinivasa Puram without displacing slum dwellers through forcible eviction and relocation. Rather, the developed design invites the residents of Srinivasa Puram to expand into the adjacent framework while maintaining their livelihoods within the coastal environment. Slum dwellers are given the opportunity to rebuild their habitats within a safe environment while not only expanding the current fishing economy but also establishing a number of new economies including agriculture, recyclable waste and renewable energy.

The strategic integration of the architectural framework fused with innovative self-sustainable and environmental remediation technology develops job opportunities that assist and maintain the function of the entire system. This not only generates a dependable income for families allowing them to personalise and develop their own homes, but it also serves as an important tool to educate slum dwellers that environmental remediation and hygienic living conditions are crucial to sustaining healthy development. This further provides inhabitants with a purpose and sense of belonging that would otherwise be stripped from them when forcibly evicted and relocated to one of the city's three high rise settlement colonies on the outskirts of the city.

If the scope of this investigation were to be expanded in future, there are opportunities to develop similar systems along the Adyar River where a number of informal settlements are currently situated (Figure 207). These architectural frameworks at a reduced scale can provide a platform for the integration of additional infrastructure to remediate environmental pollution, generate economic sources of fresh water and renewable energy, while simultaneously providing enhanced housing, without building high rise complexes and causing residents undue suffering due to displacement and utilities not being connected.

The developed design also suggests opportunities for integration into other major infrastructure systems such as hydroelectric dams. These structures are designed to contain water bodies while having the potential for agricultural crops to be grown on site; passive means of water harvesting and purification methods to occur; and access to renewable energy. Governments are already establishing major funding for large-scale technology infrastructures to help prevent environmental disasters, increase fresh water production and waste removal, generate energy, treat sewage, mitigate pollution, etc. These major technological infrastructures can be integrated into collaborative systems. And these systems can be designed as frameworks for housing, rather than simply being built as isolated industrial configurations. By integrating the technology systems they reinforce one another environmentally, economically, and socially. And by "Inhabiting the Machine" costs can actually be reduced, and people's lives be improved. 


\subsection{BIBLIOGRAPHY}

"Access to Electricity." N.p., n.d. Web. 19.07.2014.

Alongi, Daniel M. "Present State and Future of the World's Mangrove Forests." Web. 23.11.2014.

"Anaerobic Digester Plant." N.p., n.d. Web. 20.11.2014.

Ashok, S, and M Lavanya. "For Those Resettled in Semmenchery, New Home Does Not Mean Better Life." The Hindu 7 Apr. 2012. The Hindu. Web. 29.06.2014.

"A Tale of Two Emerging Economies." Ins Quarterly. N.p., n.d. Web. 24.09.2014.

"Beyond Mere Aesthetics, Architecture Is about Life." Designer + Builder. N.p., n.d. Web. 06.12.2014.

Brown, Daniel K. "Research in the Unique Use of Architectural Narrative in the Hindu Architecture of India." 2007: n. pag. Print.

Chennai Metropolitan Water Supply and Sewage Board. "Meeting the Challenges in Water and Sanitation: The Chennai Experience." Web. 21.04.2014.

"Chennai Metropolitan WSSB - 40 MLD Sewage Treatment Plant." Hindustan Dorr-Oliver Limited. N.p., n.d. Web. 23.08.2014.

"Chennai's per Capita Waste at 0.7kg Highest in Country." The Times of India. Web. 23.08.2014.

Childambaram, S. Recent Trends in Water Research: Hydrogeochemical and Hydrological Perspectives. I. K. International Pvt Ltd, 2010. Print.

"Containerized Reverse Osmosis Desalination System in Sao Vincent, Cape Verde." RWL Water. N.p., n.d. Web. 17.07.2014.

Curtis, William J.R., Balkrishna Doshi: An Architecture for India. Rizzoli International, Inc, 1988. Print.

Designing for Tsunamis. National Tsunami Hazard Mitigation Program. Web. 04.05.2014.

"Designing Our Future: Sustainable Landscapes: Sidwell Friends School, Washington, D.C., U.S.A." American Society of Landscape Architects. N.p., n.d. Web. 19.11.2014.

"Energy - State Power Scenario." Web. 24.09.2014.

Gilau, Asmerom M, and Mitchell J Small. "Designing Cost-Effective Sea Water Reverse Osmosis System under Optimal Energy Options for Developing Countries." Web. 24.08.2014. 
Gowri, V. S et al. "Application of GIS in the Study of Mass Transport of Pollutants by Adyar and Cooum Rivers in Chennai, Tamil Nadu." Web. 21.03.2014.

Gupta, Anil K, and Sreeja S Nair. "Urban Floods in Bangalore and Chennai: Risk Management Challenges and Lessons for Sustainable Urban Ecology." N.p., n.d. Web. 23.07.2014.

Gupta, K. R. A Textbook of Agricultural Extension Management. Atlantic Publishers \& Dist, 2008. Print.

Horrison, Ebin, and Lilly Rose. "Urban Climate Mapping For Supporting Urban Planning In Chennai, India." Web. 12.08.2014.

Human Rights Council. "Promotion and Protection of All Human Rights, Civil, Political, Economic, Social and Cultural Rights, Including the Right to Development." Web. 24.05.2014.

“India's First and Largest Sea Water Desalination Project - IVRCL." N.p., n.d. Web. 23.10.2014.

"Information for the Fact Finding Report on the Relocation Settlements of Kannagi Nagar and Semmenchery." Web. 30.06.2014.

Isaly LIMPET Wave Power Plant. N.p. Web. 20.10.2014.

“Islay Limpet Wave Power Plant." Web. 24.10.2014.

Kemp, Robert. "Energy \& Water Benchmark Survey."

"Koyambedu Sewage Treatment Power Plant." Clarke Energy. N.p., n.d. Web. 18.09.2014.

Kultermann, Udo. “Doshi's 'Sangath' in Ahmedabad." N.p., n.d. Web. 07.12.2014.

Kumar, A. Arun, and Pravin D Kunte. "Coastal Vulnerability Assessment for Chennai, East Coast of India Using Geospatial Techniques." 14 July 2012. Web. 10.03.2014.

Lakshmi, K. “Dredging of Cooum, Adyar Mouths Stepped up." The Hindu 25 Jan. 2014. The Hindu. Web. 12.07.2014.

Lakshmi, K. "Fresh Lease of Life Likely for Collapsed Bridge." The Hindu 9 Dec. 2011. The Hindu. Web. 19.03.2014.

Langergraber, Günter. "Modeling of Processes in Subsurface Flow Constructed Wetlands: A Review." Vadose Zone Journal n. pag. Web. 18.11.2014.

Lopez-Gunn, Elena, and Ramón Llamas. "Re-Thinking Water Scarcity: Can Science and Technology Solve the Global Water Crisis?" Web. 18.11.2014. 
"Meeting the Challenges in Water and Sanitation: The Chennai Experience." Web. 23.10.2014.

Menon, Asha S. "The Forgotten People." The New Indian Express 21 Nov. 2008. Web. 29.06.2014.

"Metropolis of Hyderabad, India." Ayala Water And Ecology. N.p., n.d. Web. 23.10.2014.

Mirunalini, V et al. "The Role of Integrated Constructed Wetland for Wastewater Treatment." Asian Journal of Applied Sciences n. pag. Web. 18.12.2014.

Pardue, John. "Mitigating Storm Surge with Vegetation." Web. 04.12.2014.

Pelc, Robin, and Rod M. Fujita. "Renewable Energy from the Ocean." Marine Policy 26.6 (2002): 471-479. ScienceDirect. Web. 20.04.2014.

Philip, Christen Mathew. "Chennai Corporation to Set up Biomethanation Plants." The Times of India. N.p., n.d. Web. 23.04.2014.

"Rain Water Harvesting." N.p., n.d. Web. 18.07.2014.

Rajagopalan, Kavitha. "The Human Cost of Slum Clearance." World Policy Blog. N.p., n.d. Web. 29.06.2014.

Raju, Emmanuel. "Housing Reconstruction in Disaster Recovery: A Study of Fishing Communities Post-Tsunami in Chennai, India." n. pag. Web. 10.03.2014.

Raman, Nithya V, and Priti Narayan. “India's Invisible Population." The Hindu 19 Oct. 2013. The Hindu. Web. 29.06.2014.

Ravindran, Shruti. "India's Push for Renewable Energy: Is It Enough?" N.p., n.d. Web. 19.08.2014.

Rockaway Shoreline Protection. New York City Department of Parks \& Recreation, 2013. Web. 05.11.2015.

Selja, Kumari. "Report of the Committee on Slum Statistics/ Census." Web. 14.03.2014.

"Severe Cyclones That Hit India." Skymet Weather. N.p., n.d. Web. 27.06.2014.

Shivakumar, C. "Chennai: Destruction of Coral Reefs Raises Tsunami Fears." N.p., n.d. Web. 11.09.2014.

Silambarasan, K, P Senthilkumaar, and K Velmurugan. "Studies on the Distribution of Heavy Metal Concentrations in River Adyar, Chennai, Tamil Nadu." Web. 16.08.2014.

Smith, Bardwell L., and Holly Baker Reynolds. The City As a Sacred Center: Essays on Six Asian Contexts. BRILL, 1987. Print.

Srivathsan, A. "Fishermen Oppose Move to Relocate Slum Tenements." The Hindu 12 Jan. 2011. The Hindu. Web. 19.03.2014.

"Structure of Chennai." Web. 15.07.2014.

Tan, Hugh. "Is Rubbish the Solution to Tackling Climate Change?" Global Change Biology: Bioenergy n. pag. Web. 20.10.2014.

Tejonmayam, U. "Broken Bridge: A Haven for Mischief Makers." IBNLive. N.p., n.d. Web. 14.04.2014.

Twin-Wing-Tsunami Barrier. Global Flood Defence Systems. Web. 05.11.2014. 
"Two Major Projects in Fisheries Sanctioned in Chennai." The Hindu 15 Jan. 2014. The Hindu. Web. 24.10.2014.

"Two More Desalination Plants for Chennai in the Pipeline." The Hindu 16 Apr. 2013. The Hindu. Web. 23.09.2014.

Umachandran, Shalini. "Chennai - The Informal City Dialogues." Informal City Dialogues. N.p., n.d. Web. 23.09.2014.

Vasundara, R. "Sea Level Rise Raises Submersion Spectre in Chennai." The Times of India. Web. 17.04.2014.

Vishwanath, S. "How Much Water Does an Urban Citizen Need?" The Hindu 15 Feb. 2013. The Hindu. Web. 23.05.2014.

Voutchkov, Nikolay. "Water 21: California's Plans for Desalination.” International Water Association. Web. 18.09.2014.

Wang, Lucy. "Baltimore's Solar-Powered Water Wheel Can Devour 50,000 Pounds of Harbor Trash Every Day." Inhabitat. N.p., 19 May 2014. Web. 05.11.2014.

Water: A Shared Responsibility; the United Nations World Water Development Report 2. United Nations Educational, Scientific and Cultural Organization. Web. 18.08.2014. 


\subsection{SOURCE OF FIGURES}

All figures not included in this list of sources are Author's Own Image 2014.

Figure 12: $\quad$ Sankar.K. 2011. 7 July 2014. Web < http://www.hindustantimes.com/Images/2011/12/36ffc553-f4c044a4-8769-25f3d2942544WallpAutoWallpaper2.JPG>.

Figure 13: $\quad$ Unknown. 6 July 2014. Web < http://static.ibnlive.in.com/ibnlive/pix/sitepix/12_2011/cyclone-thane. jpg>.

Figure 14: $\quad$ Sankar.K. 2011. 7 July 2014. Web < http://www.hindustantimes.com/lmages/2011/12/5b4505bc-cf5b4d8c-ba57-3321ba6051ecWallpAutoWallpaper2.JPG>.

Figure 50: $\quad$ Sowmiya Ashok, 2011. 12 June 2014. Web. < http://www.thehindu.com/multimedia/dynamic/00873/25 THTSUANAMI_873671g.jpg>.

Figure 51: M. Karunakaran, 2013. 12 June 2014. Web. < http://www.thehindu.com/multimedia/dynamic/01649/11 THGARBAGEKANNAGI_1649453t.jpg>.

Figure 53: $\quad$ Priti Narayan, 2013.11 June 2014. Web < http://www.transparentchennai.com/wp-content/ uploads/2013/10/DSC05640.jpg>.

Figure 54: $\quad$ C Shivakumar, 2013. 11 June 2014. Web < http://media.newindianexpress.com/Perumbakkam-house. jpg/2013/08/29/article1756744.ece/alternates/w620/Perumbakkam-house.jpg>.

Figure 60: $\quad$ <http://www.columbia.edu/itc/mealac/pritchett/00maplinks/colonial/constable1893/xmadrasmap.jpg>.

Figure 77: 2004 Web. <http://heybrian.com/lib/images/travels/nepal/kathmandu_burning_ghats_people.jpg>.

Figure 89: 15 July 2014. Web. < http://mck.gr/wp-content/uploads/2013/08/episkopigallerylargeJPG1.jpg>.

Figure 92: $\quad 23$ September 2014. Web. < http://ad009cdnb.archdaily.net/wp-content/uploads/2009/08/12506144912008av36415.jpg>.

Figure 94: 25 September 2014. Web. < http://www.southernfriedscience.com/wp-content/uploads/2014/07/ IMG_20140711_134322806.jpg>.

Figure 97: $\quad 6$ August 2014. Web. $<$ http://www.thehindu.com/multimedia/dynamic/00892/14THWATER_892470f. jpg>.

Figure 98: 13 August 2014. Web. < http://www.businessgreen.com/IMG/309/202309/mutriku-crop.jpg>.

Figure 99: $\quad 17$ August 2014. Web. <http://www.esru.strath.ac.uk/EandE/Web_sites/01-02/RE_info/tidal1_files/ image003.jpg>. 
Figure 101: $\quad 15$ August 2014. Web. < https://www.groepen.nl/picture/w/wem-1103/x/wem-1103_88.jpg>.

Figure 102: 18 August 2014. Web. < http://www.jayforce.com/wp-content/uploads/2013/06/tech_ innovator2313_01_950.jpg>.

Figure 106: 13 October 2014. Web < http://www.templeindia.in/wp-content/uploads/2014/05/madurai-meenaxhiamman-temple-meenakshi-1046480.jpg>.

Figure 107: 13 October 2014. Web. < http://prafulla.net/graphics/god-and-goddess/in-photos-meenakshi-ammantemple-in-madurai-india/>.

Figure 110: $\quad$ History of Architecture in India. Tadgell, Christopher. London: Phaidon Press Limited, 1990. Page 212.

Figure 111: $\quad 15$ October 2014. Web. < http://myboardmyblog.blogspot.co.nz/2012/10/the-submerged-temple-bathalive-is.html>.

Figure 112: $\quad 15$ October 2014. Web. < https://dome.mit.edu/bitstream/handle/1721.3/42697/129098_ cp.jpg?sequence $=1>$.

Figure 113: 15 October 2014. Web. < http://2.bp.blogspot.com/_FkL7LWnbysQ/S-E_7LYSuol/AAAAAAAAAMY/ MvZ0q_U_JiY/s1600/Mill+Owners+House_LeCorbusier_studioACKT_02.jpg>.

Figure 114: 11 October 2014. Web. < http://identityhousing.files.wordpress.com/2009/12/sas-1.png>.

Figure 115: $\quad$ Balkrishna Doshi: An Architecture for India. Curtis, William J.R. Rizzoli International, Inc, 1988: 89. 
